\title{
THE APPLES OF
}

\section{NEW YORK}

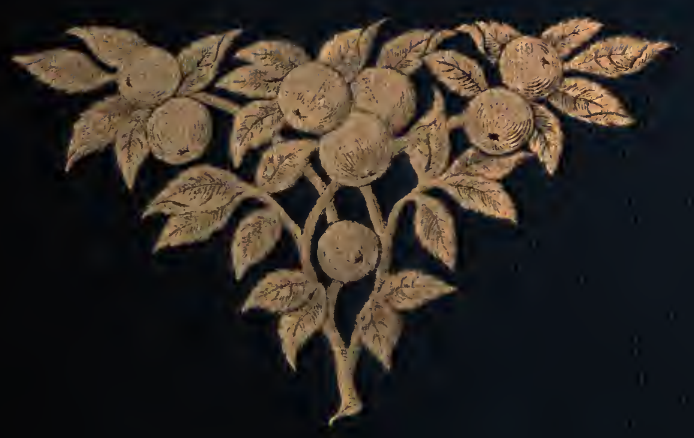

alifornia gional ility 


Bertrond fimitiz. Acres of Peses 149 Pantic, the

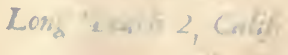




\section{THE APPLES OF NEW YORK.}






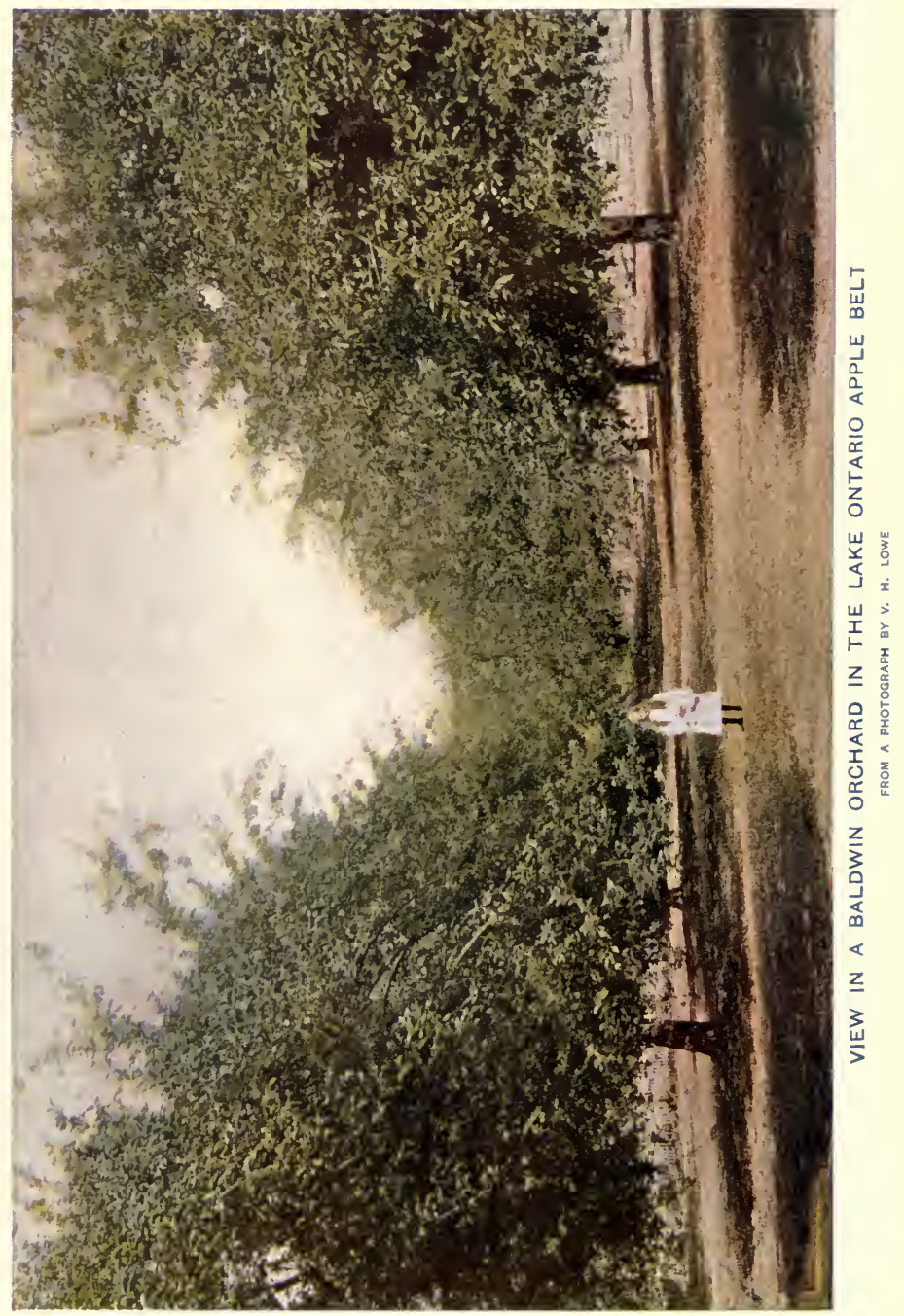


State of New York - Department of Agriculture

\title{
THE
}

\section{APPLES OF NEW YORK}

\section{VOLUME I}

\author{
BY \\ S. A. BEACH \\ Horticulturist \\ ASSISTED BY \\ N. O. BOOTH \\ Assistant Horticulturist \\ AND \\ O. M. TAYLOR \\ Foreman in Horticuiture
}

Report of the New York Agricultural Experiment Station for the Year 1903 II 

New York Agricultural Experiment Station.

Geneva, N. Y., December 31, 1903.

To the Honorable Board of Control of the New York Agricultural Experiment Station:

Gentlemen.-I have the honor to transmit herewith Part II of the Annual Report of the New York Agricultural Experiment Station for 1903, to be known as "The Apples of New York". The period of the collection of the data which form the subject-matter of this publication is coincident with the life of the Station, having been begun over twenty years ago by the late Professor Emmet S. Goff, who was the Station's first horticulturist. In I89I this work passed into the hands of Professor Spencer A. Beach, who is now, fortunately, charged with the presentation to the public of the results of this long-continued and costly effort. In the collection and organization of the information contained in this volume, Professor Beach has had the valued assistance of Professors Wendell Paddock, Charles P. Close, Heinrich Hasselbring and Vinton A. Clark, who have been associated with him in the horticultural department of the Station. Professor Nathaniel O. Booth and Mr. Orrin M. Taylor have not only assisted in the collection of original data, but they have rendered efficient service in the immediate preparation of the text. The publication of this volume, which is confined to the winter varieties of apples, to be followed by a second volume covering the early and fall varieties, is made possible by the generous action of the New York legislature of 1904, and should be regarded as an occasion of justifiable pride on the part of the state, the Station management and the individuals chiefly concerned in the work on its professional side. There is every reason to believe that these two volumes will take their place as a part of the standard literature of pomology, and will be useful and stimulating to one of the most important industries of the state.

W. H. JORDAN,

Director. 



\section{PREFACE.}

This report on the apples of New York is the outgrowth of one of the lines of investigation which from the first has been a distinctive feature of the work carried on at this Experiment Station. During the period when this Station was being established there was an insistent popular demand that the testing of varieties of fruits and vegetables be made a prominent line of work here. Variety testing was accordingly undertaken at once with great thoroughness, as is shown, in part, by the bulletins and reports published by the Station during the first decade of its existence. A collection of apple varieties was begun by Professor Goff as early as $188_{3}$, and since that time it has been continually enlarged by annual additions. For many years it has been one of the most noteworthy collections of its kind in America. By 1900 it had come to include over seven hundred named varieties of apples and crabapples, besides a large number of unnamed seedlings. Professor Goff resigned his position at this Station to become horticulturist in the University of Wiconsin in 1888 , just as the first fruits of the varieties which were grafted into the orchards in 1883 were beginning to appear. He was succeeded here by the writer in the fall of 1891 .

Very many of the varieties herein treated have been collected and grown in the Station orchards. Descriptive notes and other records of these varieties have been made year after year till a mass of firsthand information has accumulated which has been invaluable in the preparation of this report. We have also been favored with the cooperation of fruit growers from all parts of the state. Hundreds of them have assisted by giving information concerning the varieties of apples which are known in their respective localities, and in many cases have supplied samples of the fruit. The leading American and some European pomological works have been constantly referred to in verifying descriptions of varieties; various Experiment Station publications and horticultural reports and periodicals have also been freely consulted. 
For one who is interested in growing apples either for home use or for commercial purposes, or in supplying nursery trees for orchard planting, or in any of the industries accessory to that of apple-growing, such as storing and marketing the fruit or manufacturing fruit products, it is at times a great advantage to have accessible for ready reference full descriptions of the different varieties of apples, each under the name which pomological authorities are accepting as correct, together with the list of synonyms by which the variety has been known. It is for the purpose of making such information more generally available that this report on the apples of New York has been prepared. This, the first volume of the report, treats of winter apples which are in season with Hubbardston and Tompkins King or later. Earlier varieties are treated in the succeeding volume.

The following considerations have generally governed the writer in determining what varieties should be noticed in this report.

First, the comparative value of the variety for planting in any part of the state as determined by its record at this Station, by numerous systematic reports collected especially for this report from New York fruit growers and from men interested in buying and storing fruit in New York and elsewhere, by information published in books, catalogues and periodical literature, and by extensive correspondence.

Second, the probable value in this state of new or comparatively little known varieties. The opinions which the writer has expressed regarding their probable value are based upon the records which these varieties have made in other regions, their general resemblance to other varieties which are better known in this state, and their parentage or origin.

Third, many varieties have been noticed, not because they now are or promise to become valuable in New York, but rather because they are not or do not promise to become valuable here. It is quite as important for the inexperienced prospective planter to know what varieties are unworthy as well as to know what ones are the most worthy of his care and attention. This is particularly true in the case of those varieties which are being urged upon New York fruit growers because they have succeeded elsewhere, but which have as yet been tried only in regions where the conditions are markedly 
different from those which obtain in New York. In such cases an especial effort has been made to give a conservative estimate of the known or probable value of these varieties to New York fruit growers.

Fourth, some varieties are noticed chiefly on account of their historical value. In a report like this it is appropriate to notice old varieties which are becoming obsolete, but which possibly are still in cultivation in this state.

In each full discussion of a variety there is presented first the statement of those matters which seem to be of general interest. With the more important apples this is given in long primer type, while the historica! account and the technical descriptions of the tree and fruit are in brevier. With varieties of less importance the entire text is in brevier.

In addition to the description of the variety, there has been given in many cases some estimate of its known or probable value in this state for either amateur or commercial purposes and the conditions which appear to be best adapted for its successful cultivation are sometimes indicated. In order to make the report more complete and thus add to its value as a book of reference many varieties of little importance, or of only local value, are herein described. Usually in such cases but brief comment is given. More extended notice is commonly given to the more important varieties, and many of them are illustrated either by half-tone or colored photo-engravings made directly from the fruit itself instead of from drawings or paintings. In fact, the illustrations form a unique feature of the work because they have all been made from photographs, thus adding greatly to the fidelity and value of the plates. With but few exceptions the photographing has been done under the personal supervision of the author.

In the immediate preparation of this report the writer has been assisted by Professor N. O. Booth and Mr. O. M. Taylor, whose constant fidelity and active interest in the undertaking it is a pleasure to thankfully acknowledge. The bibliographical work has, for the most part, been done by Professor Booth, to whom very much of the value of this feature of the report is due. Mr. Taylor has assisted in 
various ways, particularly in making technical descriptions of the fruits. John A. Maney, foreman of the orchards, has aided in preparing the technical descriptions of the trees. Assistance in making orchard observations and descriptive notes of varieties has been given in previous years by Wendell Paddock, I893 to I899; C. P. Close, I896 to I899; Heinrich Hasselbring, I900, and V. A. Clark, I902 to I904.

The writer is embarrassed in undertaking to acknowledge properly the many favors which he has received in carrying forward this work. These favors are so various and come from so many different sources that for lack of space the particular personal recognition which he desires to give cannot be made. Fellow workers among professional horticulturists, nurserymen, men interested in buying and storing fruit, apple growers in all parts of the state and particularly members of the State Fruit Growers' Association and of the Western New York Horticultural Society, all have shown a spirit of cordial interest and cooperation which is gratefully recognized. Special acknowledgment is due to Professors L. H. Bailey and S. W. Fletcher of Cornell University for the loan of books and for the use of a collection of numerous references to Experiment Station publications. 


\section{TABLE OF CONTENTS.}

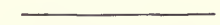

PAGE.

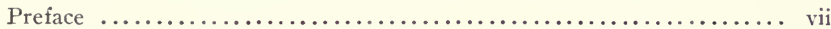

Index to Illustrations......................................

Authorities Cited and Abbreviations Used.................... xvii

Botanical Classification................................... I

The Native Home of the Apple............................ 3

The Origin and Development of Apple Culture in New York......... 4

The Adaptation of Varieties to Particular Regions.............. I 8

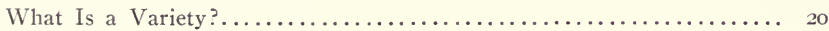

Description of Varieties............................. 27

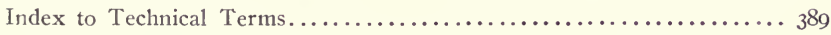

Index to Varieties..................................

$x \mathbf{i}$ 



\section{INDEX TO ILLUSTRATIONS.}

\section{Text Figures.}

Fig. I. Indian Apple Tree Still Standing near the Geneva Experiment

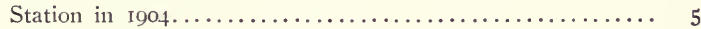

Fig. 2. Collection of Varieties of Wild Apples from a Hill Pasture at

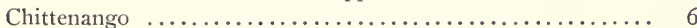

Fig. 2a. The Old Tree Stands as a Reminder of the Days of the Stage Coach and the Paring-Bee...................... 8

Fig. 3. Longitudinal Cross Section of an Apple Showing Internal

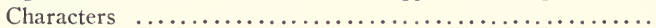

Figs. 4, 5. Longitudinal Sections of the Wild Crabapple Showing Internal

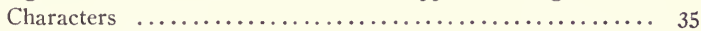

Figs. 6, 7. Transverse Sections of the Wild Crabapple Showing Internal

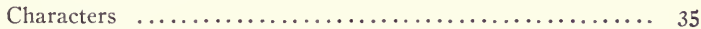

Fig. 8. Transverse Section of an Apple Showing a Closed Axile

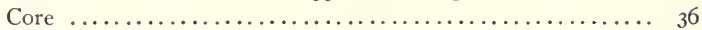

Fig. 9. Transverse Section of an Apple Showing an Open Abaxile

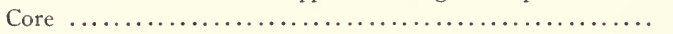

Hal.f-Tone Plates.

FACING PAGE

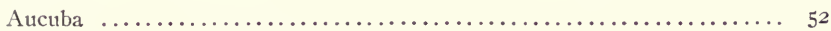

Group of fruit-pickers in the Baldwin orchard of Foster Udell, Brock-

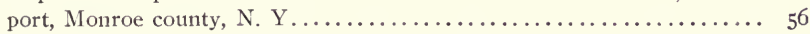

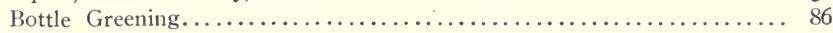

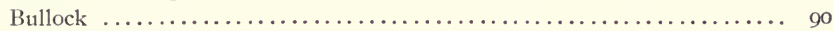

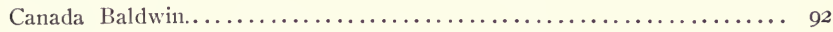

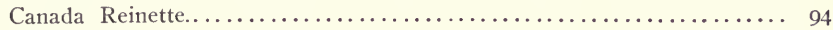

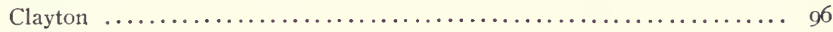

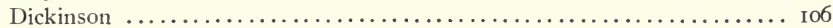

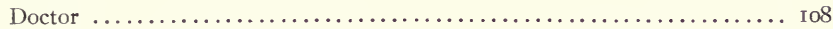

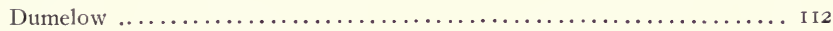

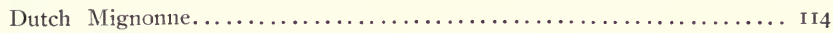

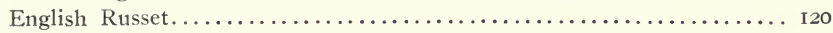

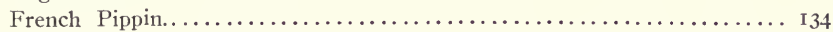

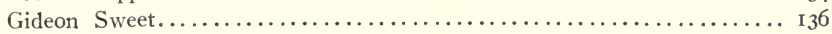

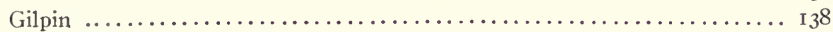

Golden Medal...................................... I40

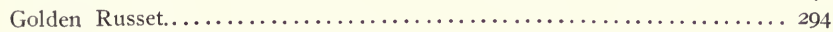

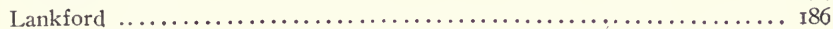


Half-Tone Plates-Concluded.

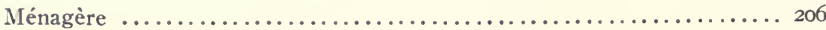

Milden ........................................... 2 I0

Milwaukee ......................................... $2 \mathrm{r} 2$

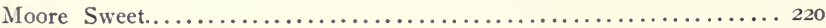

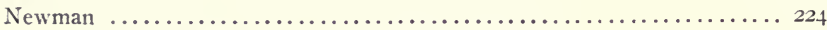

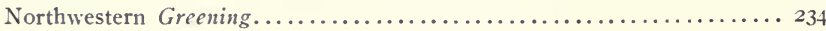

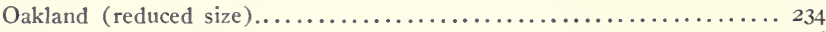

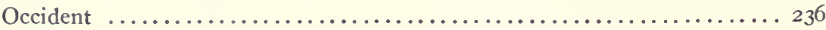

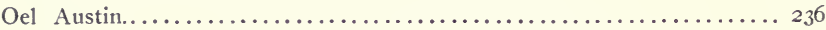

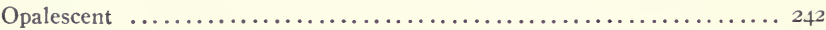

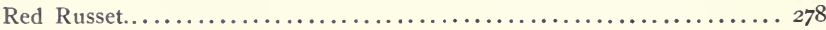

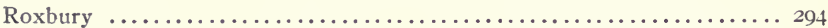

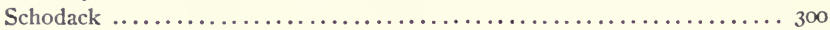

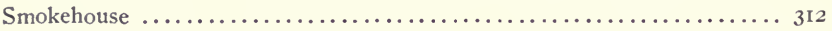

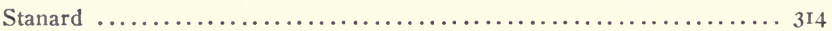

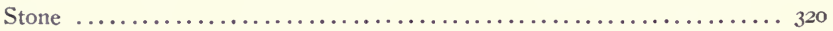

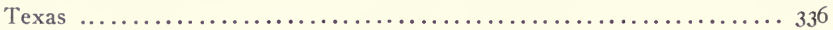

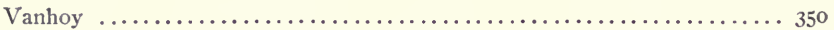

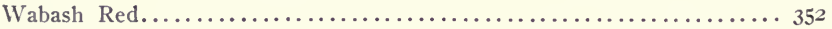

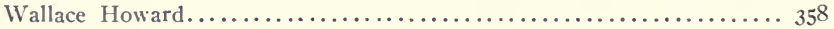

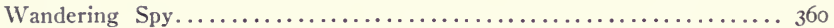

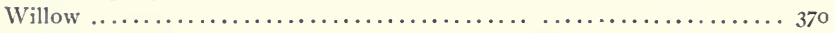

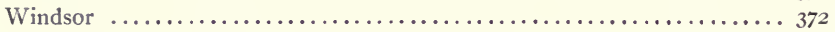

\section{Color Plates.}

View in a Baldwin orchard in the Lake Ontario apple belt....... Frontispiece

FACING PAGB

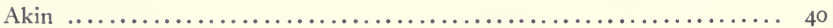

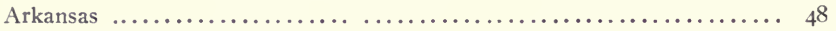

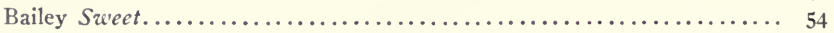

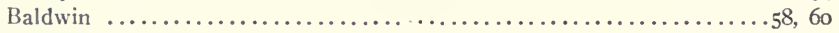

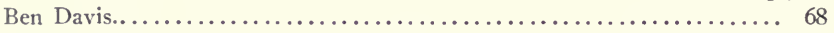

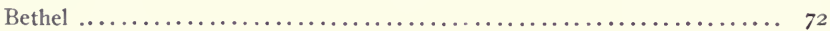

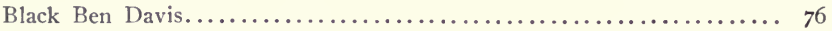

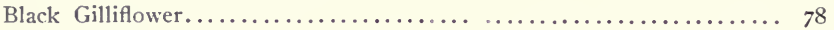

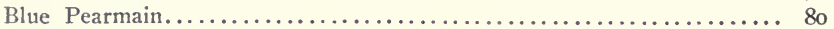

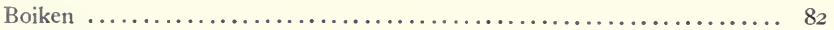

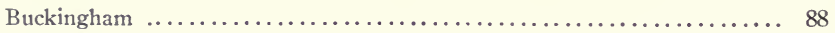

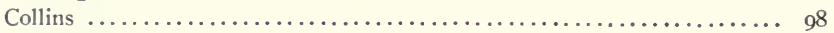

Cooper Market....................................... 100

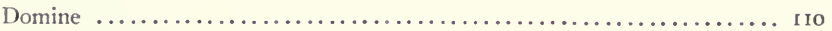

English Russet...................................... I 18

Esopus Spitzenburg................................. I 22

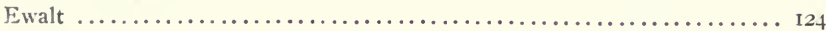

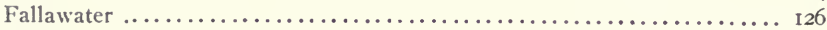

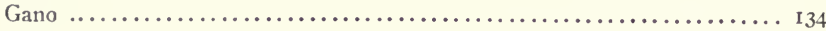

Golden Russet.................................... 144 
Color Plates-Continued.

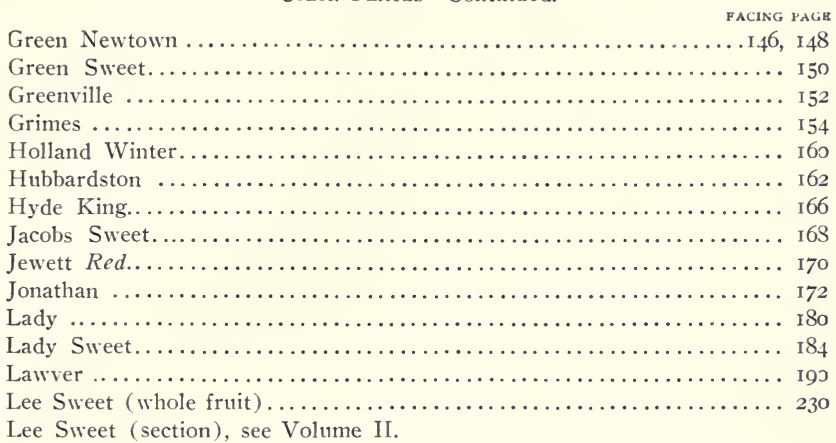

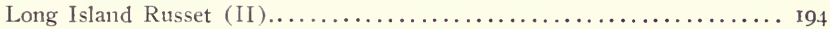

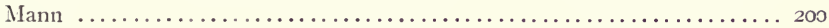

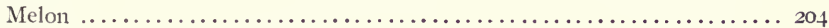

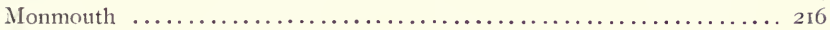

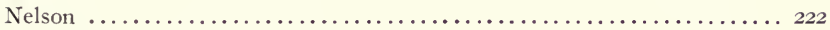

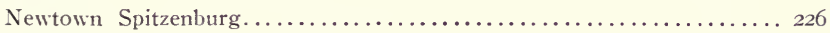

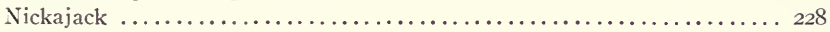

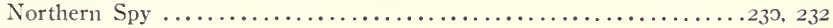

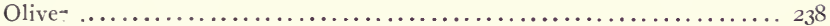

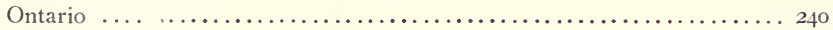

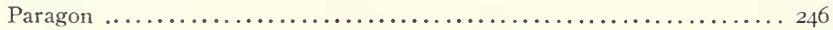

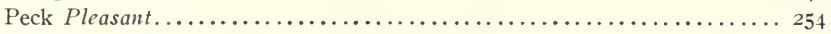

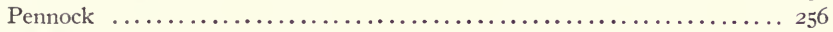

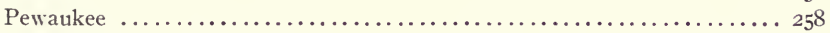

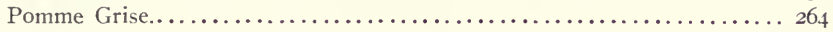

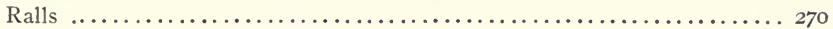

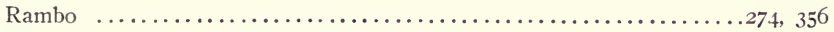

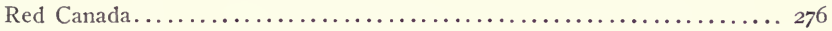

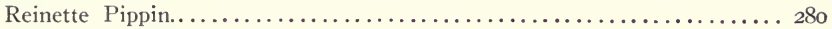

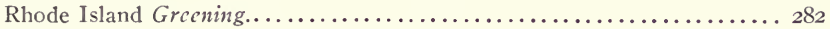

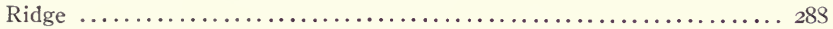

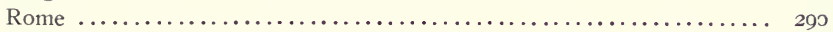

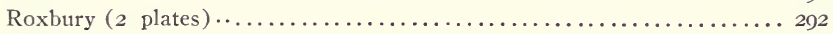

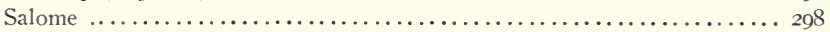

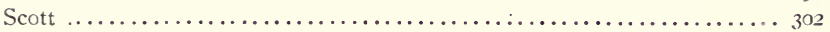

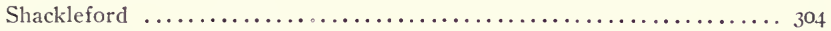

Smith Cider....................................... 310

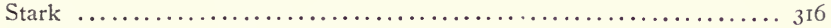

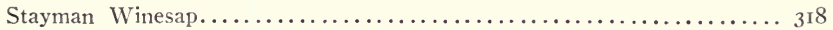

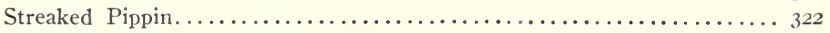

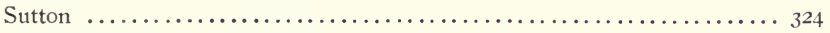

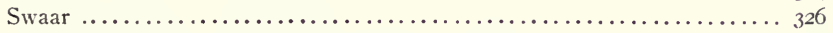

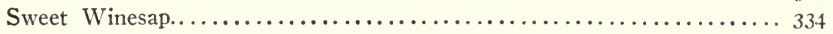


Color Plates-Concluded.

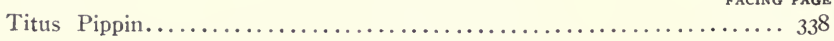

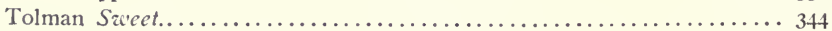

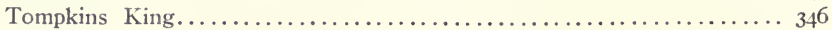

Twenty-Ounce Pippin......................................... 348

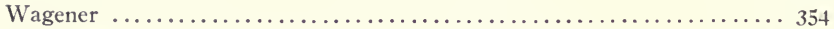

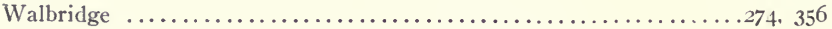

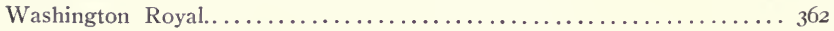

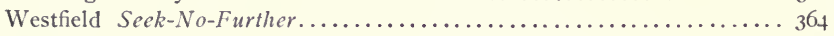

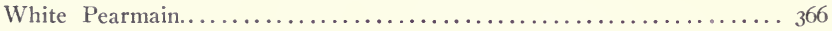

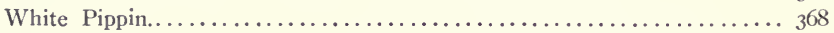

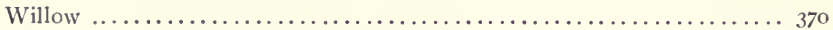

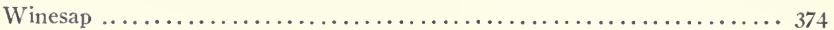

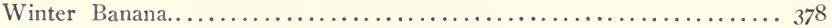

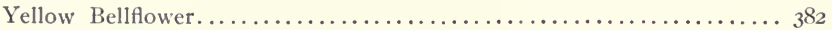

Yellow Newtown................................... I 48

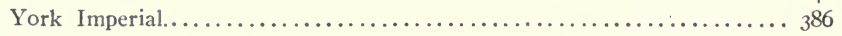




\section{AUTHORITIES CITED AND ABBREVIATIONS USED.}

In the following list of the authorities which have been consulted in preparing this volume the date of publication cited is that of the copyright rather than that of the title page; but where no date for the copyright has been found the date of the title page has been accepted as the date of publication. This has been done for historical reasons, as it appears in most cases that the copyright date is a better index of the time when a book was written than the date given on the title page.

Works issued in series by institutions or by regular organizations, like bulletins and reports of the United States Department of Agriculture, bulletins and reports of experiment stations, reports of horticultural societies and state boards of horticulture and catalogues of nurserymen are not here listed. In referring to surch works the citation in each case has been made sufficiently full for the easy identification of the publication.

Albany Cultivator. See Cultivator.

Amer. Agric. American Agriculturist. New York: 1842 to date.

American Cultivator. 1838 .

American Farmer. Boston.

Am. (or Amer.) Gard. American Gardening. New York: I892-I904. (Before its union with Popular Gardening, in 1892, was known as American Garden. Both Popular Gardening and American Garden resulted from the union or absorption of many other horticultural periodicals.)

Amer. Gard. Cal. American Gardener's Calendar. By Bernard M'Mahon. Philadelphia : I806.

Amer. Gard. Mag. American Gardener's Magazine. See Mag. Hort.

Amer. Jour. Hort. and Florist's Companion. American Journal of Horticulture and Florist's Companion. Boston: I867-I869. Continued as Tilton's Journal of Horticulture and Floral Magazine. I869-I87I.

An. Hort. Annals of Horticulture. See Bailey, L. H.

An. de Pom. Belge. Annales de Pomologie Belge. See Bivort. 
Bailey, L. H. Annals of Horticulture in North America. New York: I889I893. Volume for I 892 contains inventory of apples sold by nurserymen in North America in that year.

Barry. The Fruit Garden. By P. Barry. New York: 1851. Revised edition I883.

Berghuis. De Nederlandsche Boomgaard. S. Berghuis. Erste deel. Appels. Groningen : I868.

Biedenfeld. Handbuch aller bekannten Obstsorten. I854.

Bivort. An. de Pom. Belge. Annales de Pomologie, belge et étrangère. Bruxelles: $1853-1860$.

Boston Cultivator. See American Cultivator.

Bredsted. Haandbog i danske Pomologie. Af H. C. Bredsted. 2 det Bind. Ebler. Odense. I893.

Budd-Hansen. American Horticultural Manual. Part II. Systematic Pomology. By J. L. Budd, assisted by N. E. Hansen. Descriptions of Apples by Hansen. New York: 1903.

Can. Hort. Canadian Horticulturist. Toronto: 1878 to date.

Cat. Cong. Pom. France. Catalogue descriptif des fruits adoptes par le Congres pomologiques de France. I867.

Cat. Hort. Soc. London. A Catalogue of the Fruits Cultivated in the Garden of the Horticultural Society of London. London: 1826. 2d ed. I831; 3d ed. I842. A supplement was published in 1853 .

Cole. The American Fruit Book. By S. W. Cole. Boston: 1849.

Country Gentleman. Albany: 1853-1865. The Cultivator and Country Gentleman. Albany: I866-I897. The Country Gentleman, Albany : I898 to date.

Coxe. A View of the Cultivation of Fruit Trees. By William Coxe. Philadelphia: 1817.

Cultivator. Albany: $1834^{-1865}$. In 1866 united with the Country Gentleman.

Diel. Versuch einer systematischen Beschreibung der Kernobstsorten. Aug. Fried. Ad. Diel. I799-1825.

Dittrich. Systematisches Handbuch der Obstkunde. Vol. III.

Dom. Encyc. Domestic Encyclopedia. Willichs. Edited by Mease. Pliiladelphia: I804.

Downing. The Fruits and Fruit Trees of America. By A. J. Downing. 1845. 2d ed., same text with colored plates, 1847. First revision by Charles Downing, 1857. Second revision, I869. First appendix, I872. Second appendix, 1876. Third appendix, I88t.

Duhamel. Traité des Arbres Fruitiers. Par M. Duhamel du Monceau. Tome premier. Paris : 1768.

Elliott. Elliott's Fruit Book; or the American Fruit Growers' Guide. By F. R. Elliott. New York: 1854. Revised edition, 1859.

Eneroth-Smirnoff. Handbok i svensk pomologi. Af Olof Eneroth and Alexandra Smirnoff. Vol. 2. Applen. Stockholm: 1896.

Fessenden. The New American Gardener. By Thomas G. Fessenden. Boston: 1828 .

Fitz. The Southern Apple and Peach Culturist. James Fitz; edited by J. W. Fitz. Richmond: 1872 .

Flotow. See Ill. Handb. der Obstk. 
Floy-Lindley. A Guide to the Orchard and Fruit Garden. By George Lindley; edited by John Lindley. American edition by Michael Floy. New York: I833. New edition with an appendix, I846.

Forsyth. A Treatise on the Culture and Management of Fruit Trees. By William Forsyth. London: 1802 . Same with Introduction and Notes, by William Cobbett. Albany: 1803. Seventh edition (English) London: 1824 .

Garden. London: 1872 to date.

Gard. and For. Garden and Forest. New York: 1888-1897.

Gardening. Chicago: 1893 to date.

Gartenflora. Berlin: 1852 to date.

Gaucher. Pomologie der Praktischen Obstbaumzüchters. Von N. Gaucher. Stuttgart: 1894 .

Genesee Farmer. Edited by Luther Tucker. Rochester: I83I-I839. Then consolidated with Cultivator. Another periodical of same name was published in Rochester from I845-I865. Also others of this name.

Goodrich. The Northern Fruit Culturist, or Farmers' Guide. By Chauncey Goodrich. Burlington, Vt.: I849.

Gregg. A Handbook of Fruit Culture. By Thomas Gregg. New York: I857.

Hoffy. Hoffy's North American Pomologist. Edited by William D. Brinckle. Book No. I. Philadelphia: 1860.

Hogg. The Fruit Manual. By Robert Hogg. Fifth edition. London: 1884 . Hooper. Hooper's Western Fruit Book. By E. J. Hooper. Cincinnati : 1857. Horticulturist. The Horticulturist and Journal of Rural Art and Rural Taste. Albany, etc. I846-I875. Founded by A. J. Downing. Other editors were Barry, Smith, Mead, Williams and the Woodwards.

Hovey. The Fruits of America. 2 vols. C. M. Hovey. Boston: 1851.

Ill. Handb. Obst. Illustrirtes Handbuch der Obstkunde. (Various authors). Stuttgart: $1858-1865$.

Jour. Roy. Hort. Soc. Journal of the Royal Horticultural Society. London: I846 to date. Vols. I-9, I846-55 bear the title of Journal of the Horticultural Society of London.

Kenrick. The New American Orchardist. By William Kenrick. Boston: 1832. Second edition revised, 1835 .

Knoop. Pomologia. Johann Hermann Knoop. Leeuwarden: 1758.

Langley. Pomona: or the Fruit Garden Illustrated. By Batty Langley. London: 1729.

Lauche. Deutsche Pomologie. W. Laiche. Apfel. Vols. I and II. Berlin: I882-I883.

Le Verger. Par M. [A.] Mas. 5 vols. in 4. Paris: I868-1873.

Leroy. Dictionnaire de Pomologie. Par André Leroy. Paris: I873. Vols. 3 and 4 devoted to the apple.

Lindley. Guide to the Orchard and Kitchen Garden. By George Lindley. London: I83I. (See Floy-Lindley for American editions.)

L.ucas. See Ill. Handb. Obst.

Lucas, Ed. Vollständiges Handbuch der Obstkultur. Von Ed. Lucas. Stuttgart: Ist ed. I880; 2 d ed. I886; 3d ed. I893. Third edition edited by Fr. Lucas.

Lucas, Fr. Die Werthwollsten Tafeläpfel und Tafelbirnen. Von Fr. Lucas. 2 vols. Stuttgart: I893-4. 
Lyon. Mich. Hort. Soc. Rpt. 1890. This catalogue has been quoted rather than the earlier ones because it represents more nearly the final opinion of Mr. Lyon on Michigan fruits.

M'Mahon. Gard. Cal. See Amer. Gard. Cal.

Mag. Hort. Magazine of Horticulture. Boston: 1837-1868. First published under name American Gardener's Magazine 1835-6. Edited by C. M. Hovey with P. B. Hovey, Jr., associate editor during I835-6.

Manning. Book of Fruits. By Robert Manning. Salem: 1838. Second edition with title, New England Fruit Book. Revised by Jolnn M. Ives. Salem: $18+4$.

Mas. See Le Verger.

Nat. Nurseryman. National Nurseryman. Edited by R. T. Olcott and later by John Craig. Rochester: I893 to date.

Nat. Hist. N. Y. Natural History of New York. Part V. Agriculture. By Ebenezer Emmons. Vol. III devoted to fruits. Albany: I85I.

N. E. Farmer. New England Farmer. Boston: I822.

New Genesee Farmer. See Genesee Farmer.

N. Y. Bd. Agr. Mem. Memoirs of the Board of Agriculture of the State of New York. Vol. III. Albany: I826. Article and fruit list by Jonathan Buel.

Oberdieck. See Ill. Handb. Obstk.

Pom. Brit. See Pom. Mag.

Pom. Heref. Pomona Herefordiensis. By Thomas A. Knight. London: I8I I.

Pom. Mag. Pomological Magazine. 3 vols. London : 1828-30. This work has also been publislied under the title Pomona Brittanica.

Pomologie. See Gaucher.

Prairie Farmer. Chicago: 1841. Several periodicals of this name.

Regel. Russkaja Pomologija. E. Regel. St. Petersburg: I868.

Ronalds. Pyrus malus Brentfordiensis. By Hugh Ronalds. Figures by E. Ronalds. London: 183 I.

Rural N. Y. Rural New Yorker. Rochester and New York: I850 to date.

Syst. Handb. der Obstk. See Dittrich.

Thacher. American Orchardist. By James Thacher. Boston: 1822.

Thomas. American Fruit Culturist. By John J. Thomas. Published at various places. Ist ed. I846; 2Ist ed. I903.

Todd. The Apple Culturist. By Sereno E. Todd. New York: I87r.

Trans. Roy. Hort. Soc. Transactions of the Royal Horticultural Society. London: I805-I848.

Verger. See Le Verger.

Warder. American Pomology. Apples. John A. Warder. New York: I867.

Waring. The Fruit Growers' Handbook. By Wm. G. Waring. Boalsburg, $\mathrm{Pa}$ : : $185 \mathrm{I}$.

Western Fruit Grower. Edited by J. M. Irvine. St. Joseph : I896 to date.

Wickson. California Fruits. By Edward J. Wickson. San Francisco: 1889. 2 d ed. 189 I.

IVillichs. See Dom. Encyc.

Wilson. Economy of the Kitchen Garden, etc. By William Wilson. New York: 1828 . 


\section{THE APPLES OF NEW YORK.}

\section{BOTANICAL CLASSIFICATION.}

The apple is classed with a natural group of plants in which the fruit is more or less fleshy and contains seed cells enclosed by either bony or parchment-like carpels. Some botanists still hold to the older classification in which this group of plants is included in the great order Rosacea under the suborder Pomea, but there is a tendency among modern botanists to raise the group to the rank of an order under the name Pomacce. In this suborder or order, whichever it may be called, there are several genera. One includes the mountain ashes, one the Juneberries, one the hawthorns, one the quinces, and one the pears, apples and crabapples. This last genus botanists have called Pyrus. Within this genus there are many species of apples and crabapples, most of which are native to the old world. Sargent, from whom the three following descriptions are largely derived, recognizes in the apples which are indigenous to North America the three species named below. ${ }^{1}$

\section{NATIVE WILD APPLES.}

I. Pyrus coronaria L., the fragrant crab, which is found in glades from Canada, Western New York and the shores of Lake Erie southward along the mountains to Alabama and westward to the Missouri valley and Texas. The flowers are large, showy, on slender pedicels, white or rose-colored and delightfully fragrant. Leaves ovate to triangular ovate and often three lobed. The fruit may reach a diameter of one and onehalf inches. The calyx is persistent. The skin, which is green or becomes yellowish, is waxy and has a peculiar aroma. The fruit ripens late, is sour and almost bitter but has long been valued for making preserves. No varieties of this species are cultivated for the fruit.

In the prairie states this species runs into the variety iowensis Wood, which some regard as a distinct species. There are known in cultivation hybrids between this and the common apple as we shall see later. The fruit of iowensis sometimes reaches a diameter of two inches.

2. Pyrus angustifolia Ait., the native crabapple of the southern states, is much like $P$. coronaria except that its leaves are not lobed but are lanceolate oblong and acute at the base. The flowers are white or rosepink and very fragrant; calyx persistent; fruit about one inch in diameter, pale green or yellowish, ripens in winter and is then very fragrant but

${ }^{1}$ Silva N. A., IV : $70-78$. 
austere. The fruit is used for preserves but no variety of this species is cultivated for its fruit. The spccies is found from Southwestern Pennsylvania to Florida and west to Tennessee and Louisiana.

3. Pyrus rivularis Doug., the Oregon crabapple, has rather small white flowers, and the calyx lobes become deciduous from the mature fruits. The fruit is about three-fourths of an inch long, oblong, yellowish or blushed, and ripens in autumn. It is used by the Indians. No variety of this species is cultivated for its fruit. This species ranges from Northern California northward along the coast to the Aleutian Islands.

\section{CULTIVATED HYBRIDS OF NATIVE APPLES.}

Craig and Hume ${ }^{1}$ describe four hybrids between the common apple and $P$. iowensis, or other indigenous American crabapples, which hybrids are cultivated for their fruit in some locations in the Mississippi valley. These are Soulard, Howard (or Hamilton), Mercer (or Fluke) and Kentucky Mammoth (or Mathews). The fruits of these hybrids are fit only for culinary uses or for cider. They vary in size from medium to large for a crabapple, are green or yellowish and ripen in winter. These hybrids are valued chiefly where superior hardiness is a prime requisite in a variety, but they are practically unknown and unsought in New York state because there are other kinds which are more valuable here.

\section{SPECIES INTRODUCED FROM THE OLD WORLD.}

Ornamentals. Several species of apples or crabapples which are indigenous to the old world are grown in this country for ornamental purposes only, as, for example, the flowering crabs and flowering apples from China and Japan. But we are now particularly concerned with those species which have been brought from the old world to be cultivated here for their fruit, as shown in the common apple and common crabapple.

The Common Apple. The apples which are grown here for their fruit mostly belong to the species which Linnæus called Malus. He placed it in the same genus as the pear and thus its botanical name became Pyrus malus L. Recently Britton has separated it from the pear genus on the ground that it has flesh free from grit cells. He makes its botanical class Malus malus (L.) Britton. ${ }^{2}$ This species is particularly characterized by simple, soft leaves: flowers white or partly tinged with deep rosepink, short-stemmed and borne in a simple umbel; fruit depressed at both ends; calyx persistent. The under side of the young leaves, the young twigs, the buds, calyx lobes and young fruits are commonly fuzzy.

This species is very variable. Under cultivation it has developed innumerable varieties as will be noticed farther on. Some varieties which because their fruit is large are called apples doubtless are hybrids between this species and the one next described.

The Common Crabapple. The crabapples which we cultivate for their fruit are for the most part hybrids between the apple $P$. malus, and the primitive Siberian crab, or berry crab, called by Linnæus Pyrus baccata.

${ }^{1}$ Native Crabapples and Their Cultivated Varieties. Ia. Acad. Sci., VII: 123-141. I899.

${ }^{2}$ Flora Nor. States and Can., II: 236. 
This species, baccata, in its pure forms is readily distinguished from the apple, $P$. malus. The calyx is eventually deciduous, instead of persistent. The leaves are firm, smooth, bright green and are borne on long, slender, hard leaf-stalks. The twigs are smooth and slender. The ripe fruit is brilliant in color, red or yellow, does not get mellow, varies from threeeighths to three-fourths of an inch in diameter and is borne on long slender stalks. The flowers are large and usually pure white. In some of the hybrids, as, for example, Martha and Currant, the calyx is on some fruits deciduous, or partly so, while on other fruits borne on the same tree the entire calyx may be persistent; also the fruit is large and it is clear that other characters which they show are derived wholly or in part from either baccata on the one hand or from malus on the other. ${ }^{1}$

It is well to remark that the name crabapple is not applied exclusively to the Siberian crabs and their hybrids but is popularly used to designate indiscriminately small apples whether of the malus species or of some other species, but the term Siberian crab is properly used to indicate the baccata species and its kin.2

\section{THE NATIVE HOME OF THE APPLE.}

The original home of the apple, P. malus, is not definitely known. After examining the evidence carefully A. DeCandolle came to the conclusion that it is most indigenous to the region south of the Caucasus, from the Persian province Ghilan on the Caspian to Trebizond on the Black Sea, and that from prehistoric times it has existed in Europe, both wild and cultivated, over an area extending from the Caspian Sea to the Atlantic Ocean, except in the extreme north. ${ }^{3}$ He cites it as being found wild in the mountains of Northwest India, but not in Japan, Mongolia or Siberia.

Marlatt says, " The apple industry in Japan is of recent origin, say within the last thirty or forty years. * * * The varieties are our varieties and have been imported from America with the exception of some few European sorts. * * * Prior to the introduction of this fruit from America it was unknown in Japan, the native apple of Japan being a crab, grown more for ornament than for fruit, and a very rare tree, unknown to most Japanese." From the reports of Marlatt and others it appears doubtful whether the Chinese knew this species until cultivated varieties of it were introduced among them from Europe and America.

\footnotetext{
${ }^{1}$ See plate of Martha, in Vol. II of this report.

2 See also Prof. Budd's discussion of this subject in Am. Hort. Man., I: 160. 1902.

SOr. Cult. Plants 233-236. $188_{5}$.

1 Yearbook, U. S. Dept. Agr. 1902: 161 et seq.
} 
It appears that the native apple of North China is quite different from our common apple, $P$. malus, but rather like what we call " crabapples."1

Evidently the Siberian crabapple, $P$. baccata, had its origin farther north and east than $P$. malus. Bailey cites its habitat as Siberia to Manchuria and the Himalayan region. ${ }^{2}$

\section{THE ORIGIN AND DEVELOPMENT OF APPLE CULTURE IN NEW YORK.}

The principal native fruits of New York, in addition to the wild crab already noticed, are the wild strawberries, red raspberries, black raspberries, dewberries, blackberries, elderberries, cranberries, high-bush cranberries, huckleberries, blueberries, the beach plum along the seacoast, the wild red or Canada plum of the St. Lawrence valley, the wild red or yellow plum of Central and Southern New York, the fox grape in eastern and southeastern parts of the state, the summer grape in the southern counties, and the river-bank or frost grape of general distribution. Improved varieties of the native grapes and of many of the small fruits are now extensively grown both for home use and for market, but so far as New York state is concerned this does not hold true for any of the orchard fruits. Some of the native plums are cultivated in the northern counties to a very limited extent, but, generally speaking, New York orchard fruits are all of old world species.

Introduction of the Apple. In view of the primitive character of our native fruits, it was but natural that the Europeans when they began to form settlements on this continent should bring their favorite fruits with them from the old world. This they did. Some few brought trees or scions of choice varieties, but more followed the less expensive plan of bringing seeds of selected fruits to plant about their new homes in America, just as their descendants till recent times have continued to do when leaving the older settlements of the East to take up pioneer life along the frontier of civilization.

${ }^{1}$ Marlatt 1. c. Cf. Leroy Dict. de Pom., 3:5.

${ }^{2}$ Cyc. Am. Hort. III : 1472. 
The introduction of the apple into New York along with other old world fruits was thus begun nearly three hundred years ago. In the following years, at one time or another, very many of the cultivated varieties of apples of Western Europe were brought here, and this importation has been kept up with each succeeding generation till the present time. In the earliest settlements doubtless the varieties which were first brought into New York were mostly from Holland. Later some came from Germany, France and other con-

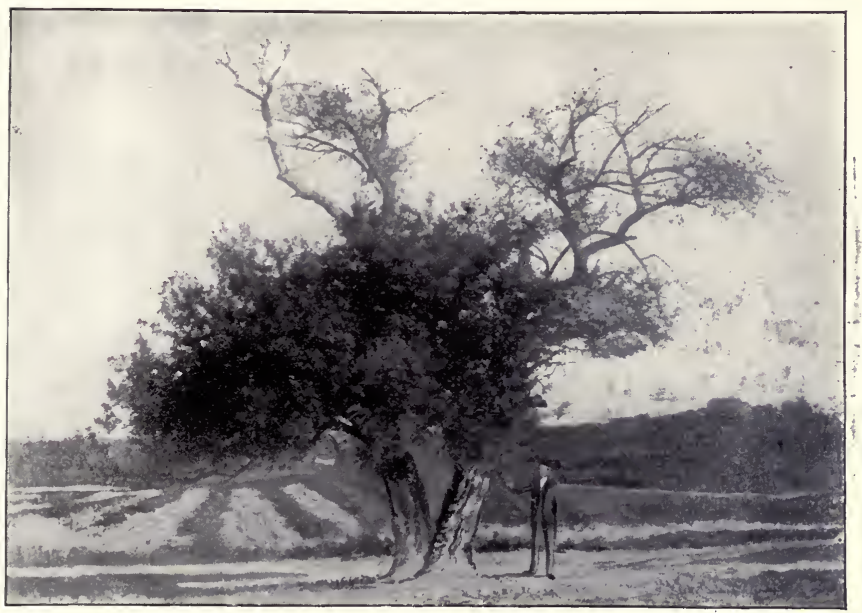

Fig. I. Indian Apple. Tree Still Standing near the Geneva Experiment Station in 1904.

tinental countries, and many from the British Isles, either directly or through neighboring colonies.

The Early Dissemination of the Apple. When once the apple was introduced its dissemination kept pace with the progress of the settlement of the country. In fact, it was carried by Indians, traders and white missionaries far into the wilderness beyond the outermost white settlements. Reports of General Sullivan's expedition, in 1779 , against the Cayugas and Senecas, in describing the Indian villages which were then destroyed, make frequent mention 
of peach and apple orchards that were found bending with fruit. Within sight of the Geneva Experiment Station are two very old Indian apple trees, the only ones in this vicinity now left out of many hundreds which the Indians were growing in the clearings about their town of Kanadesaga, which was located here. The illustration, Fig. 1, shows the present appearance of one of the trees. Both bear winter fruit of medium size. The fruit of one is very good for cooking, that of the other is pleasant flavored, subacid and very good for eating. Neither has been propagated. These trees are interesting as types of the seedling apples which were most common around the homes of the early settlers, and also to some extent in the Indian villages.

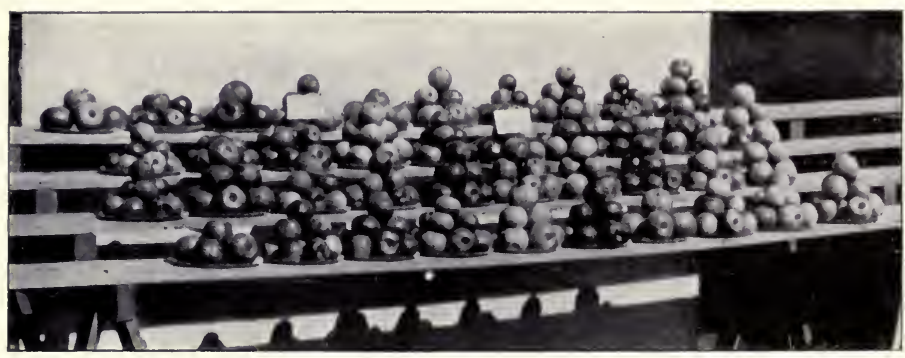

Fig. 2. Collection of Varieties of Wild Apples from a Hill Pasture at Chittenango.

The Apple now Grows Wild in New York. The apple now grows wild in various parts of New York state. It is notably abundant along fence rows and in hill pastures in some places in Southern and Southeastern New York and on the Onondaga limestone formation in Onondaga and Madison counties. Fig. 2 shows the fruit of several wild apples which were found in a hill pasture near Chittenango in Madison county. Some of these are superior to many of the named and cultivated sorts, being more attractive, larger and of better quality.

The Siberian crab has not, to my knowledge, ever been found growing spontaneously either in New York or in any other part of this continent. 
Primitive Orchards. As the early settlements gradually extended back from the Atlantic coast region the pioneers who overspread the interior of New York, hewing farms out of the forests, planted around their new homes apple seeds brought from the older settlements or from Europe. It is commonly known that the cultivated varieties of the apple seldom, if ever, reproduce true from seed. For example, seedlings of large apples may bear very small fruit, seedlings of red apples may bear green or yellow fruit, seedlings of sour apples may bear sweet fruit. In fact, not often does the fruit of a seedling apple resemble the fruit of the parent closely enough to indicate its parentage clearly. The exceptions to this general statement will be considered later. It appears at first thought that it would be better for the fruit grower if the different kinds of apples came true from seed, as garden vegetables do. Then lie could supply himself with as many trees of a kind as he liked by simply growing seedlings of that kind instead of propagating the variety by budding or grafting, as is now done. But from another point of view the great variability of the apple seedlings is a most valuable feature. It has made possible more rapid progress than could otherwise have been made in developing varieties especially well adapted to succeed in the new world. Large numbers of European apples have been tried in America, but the great majority lave failed to maintain themselves alongside of American varieties, and soon have been discarded from American orchards and nurseries. But among the innumerable seedlings of infinite variety which have been grown on this continent during the last three hundred years certain ones have been found from time to time that succeed better in this country than those kinds do which have been brought in from Europe. So also in the region west of the Great Lakes the varieties which are succeeding best are selections from seedlings which have been originated in that region. This is in accordance with what appears to be a general rule, that the varieties originating in any section, probably because they have been selected on account of their capacity to fit the conditions, gradually supersede those brought in from outside. This holds true with regard to different sections of this country, and, as we shall see later, even of different regions within New York state. 
The fruit from the seedling trees would now be called " natural" or "seedling" fruit in distinction from grafted fruit; in the early days, however, and even within the last half century, the fruit of these seedling apples was also called " common" fruit, a designation which might have arisen because of the abundance of such trees at that time. Such apples were then used chiefly for feeding to stock and for cider-making, being on that account often called cider apples. The surplus, if there were any, was usually allowed to rot because there was no profitable way of disposing of it.

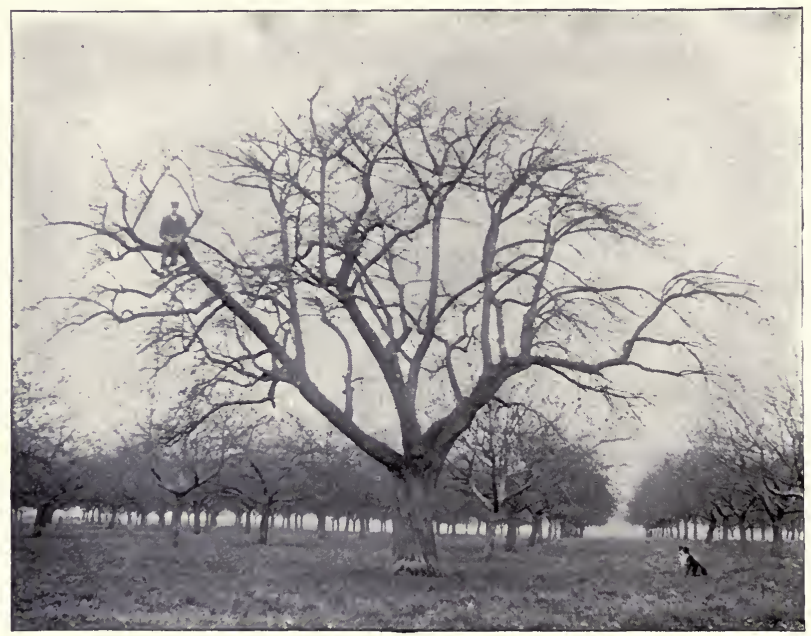

Fig. 2a. The Old Tree Stands as a Reminder of the Days of the StageCoach and the Paring-Bee.

In many parts of New York, especially in the eastern two-thirds of the state, there are still seen portions of the primitive seedling orchards varying in age from fifty to one hundred years, or possibly more. The old trees, having outlived their companions, stand as silent reminders of the days of the stage-coach, the hand-loom, the spinning-wheel, and the paring-bee, and of the time when the farmer generally considered his winter supplies incomplete unless there were several barrels of cider stored in the cellar. 
Mixed Orchards. It is pretty certain that grafted fruit was known in the earliest orchards to a limited extent only. In an appendix to Cobbett's American edition of Forsyth's Fruit Trees, published in Albany, I 803, there is a communication from a member of the State Agricultural Society, Peter W. Yates, in which he remarks concerning the practice of grafting and budding (inoculating) in America:

"The practice of grafting and inoculating in America is but of modern date. It was introduced by Mr. Prince, a native of New York, who erected a nursery in its neighborhood about forty years ago. But since the late American revolution others have been instituted in this and some other parts of the United States. Mr. Livingston has lately established one, not far from the city of New York, which can vie with some of the most celebrated ones in Europe. May he, and others who have undertaken that useful branch of business, meet with encouragement and success."

Although his idea that grafting and budding were introduced in America by Mr. Prince is based upon a misapprehension of the facts, Mr. Yates' statements are of interest because they tend to show that prior to the Revolutionary war the planting of orchards with grafted trees from the nursery was not common in the vicinity of Albany, one of the oldest settlements in the state. But there is reliable evidence that grafting was practiced to some extent by American colonists long before the establishment of the Prince nurseries at Flushing, Long Island. Taylor says: "Certain it is that in 1647 the apple is recorded as grafted upon wild stocks in Virginia; while in I686 William Fitzhugh, in describing his own plantation, mentions 'a large orchard of about 2,500 apple trees, most grafted, well fenced with a locust fence.' By the close of the seventeenth century there were few plantations in Virginia without orchards of apple, peach, pear, plum, apricot and quince. $* * *$ Frequent importations of seeds, scions and grafted trees, together with propagation of those already noticed, both by seeds and grafts, brought the orchards of New England up to such point that Dudley, in $\mathbf{1 7 2 6}$, stated in a paper in the Philosophical Transactions, 'our

${ }^{1}$ U. S. Dept. Ag. Yearbook, $1897: 308$. 
apples are without doubt as good as those of England, and much fairer to look to, and so are the pears, but we have not got all the sorts. *** Our people of late years have run so much upon orchards that in a village near Boston, consisting of about forty families, they made near ten thousand barrels (of cider).'

"Perhaps the earliest recorded grafted tree brought from Europe (that of Governor Endicott is stated to have been a seedling) was the Summer Bonchretien, planted by Governor Stuyvesant, in 1647, in New Amsterdam. It is said to have been brought from Holland, and its trunk remained standing on the corner of Third avenue and Thirteenth street, New York city, until I866, when it was broken down by a dray. Many of the earliest introductions of named varieties of the pear, including White Doyenne, St. Germain, Brown Beurre, Virgouleuse, etc., were made by the French Huguenots, who settled about Boston and New York shortly after the revocation of the Edict of Nantes in I685."

It was at Flushing, Long Island, in one of these Huguenot settlements, that the Prince nurseries above referred to were established, about 1730. Near here the famous Newtown Pippin originated.

While grafted fruit was certainly known in some orchards of the early settlers and sometimes an entire orchard was planted with grafted nursery trees, yet, taking the state as a whole, in the earlier days more often the orchards were of seedling trees, with only a portion of them top-worked to improved kinds, and so the ordinary farm orchard was made up partly of "common" or of "cider" apples and partly of grafted fruit. A great diversity of varieties of grafted fruit was usually included in this class of orchards, because the object was to furnish the home with fruit from the first of the season through the autumn, winter and the spring, and even till early summer. Transportation facilities being crude, there was little encouragement for shipping apples to distant markets. When the farmer went to town he would often take with him a few bushels of apples, to offer in trade for articles which he wished to purchase. The other ways of disposing of surplus apples were in the manufacture of cider, boiled cider, and vinegar, or in drying the fruit. For the latter operation the kitchen stove was 
usually surrounded with festoons of quartered fruit which had been patiently strung on tow strings, or the prepared fruit was spread on racks above or on papers beneath the stove.

Commercial Orchards. The development of domestic and foreign commerce in apples and apple products, such as dried apples, cider, apple brandy and vinegar, naturally first assumed importance in New York in the vicinity of New York city because this was the metropolis and a seaport. Speaking of the beginning of the foreign trade of this country in fruits Taylor remarks:1 "Trade in this fruit with the West Indies probably developed early in the eighteenth century, though we have no record of shipments till I74I, when it is stated apples were exported from New England to the West Indies in considerable abundance. No transatlantic shipment has been disclosed earlier than that of a package of Newtown Pippins of the crop of $175^{8}$ sent to Benjamin Franklin while in London. The sight and taste of these brought to John Bartram, of Philadelphia, an order for grafts of the variety from Franklin's friend Collinson, who said of the fruit he ate: 'What comes from you are delicious fruit-if our sun will ripen them to such perfection.' Subsequently a considerable trade must have resulted, for in 1773 it was stated by the younger Collinson, that while the English apple crop had failed that year, American apples had been found an admirable substitute, some of the merchants having imported great quantities of them. * * * Statistics on the subject are lacking until I82I, when the total export of fruit included in the treasury statement consisted of 68,443 bushels of apples, valued at $\$ 39,966$."

It was not till after the first quarter of the nineteenth century had passed that commercial apple culture began to be developed in New York to any considerable extent above the southern part of the Hudson valley.

According to Mr. W. D. Barns of Middlehope, the planting of commercial apple orchards did not receive much attention in Ulster county till I820 to 1825, although Robert Pell of Esopus had about 20 acres of bearing Newtown Pippin trees from which he exported fruit as early as from 1825 to 1830 . Along the Hudson where the fruit could be easily transported to New York city by boat the trade included a large number of summer and fall apples as well as winter varieties. They were shipped,

11. c., 311. 
says Mr. Barns, in straw-head barrels. Some were contracted for by dealers in New York and some were sold by the captain of the steamboat that carried them to the city. The prices were $\$ \mathrm{I}$ to $\$$ I.50 per barrel, barrel returned. Among the favorite early kinds were Summer Pippin (also called Sour Bough, Champlain and Nyack Pippin), Spice Sweet and Jersey Sweet.

Mr. P. C. Reynolds of Rochester removed in 1836 from the northeast part of Dutchess county to northern Ontario county near Palmyra. He states that in 1830 on their Dutchess county farm were two orchards. The older was planted about 1775 and contained nothing but "natural" or seedling trees. In the younger orchard about 5 per cent were grafted trees. Among the seedlings were some excellent apples. The grafted varieties were Yellow Harvest, Bough Sweet, Fall Pippin, Westfield SeckNo-Further, Black Gilliflower, Rhode Island Greening and Esopus Spitzenburg. The Baldwin was not known there. That portion of the fruit not used by the family was either fed to farm animals or made into cider. There were some large orchards in the neighborhood inside of which no animals were permitted. The fruit of these trees was used for making cider brandy, otherwise called "apple-jack." In that form it became an article of commerce.

This is an interesting account and typical of the orchard conditions in that part of the state in the first quarter of the last century. The view which Mr. Reynolds gives of apple orcharding in northern Ontario county in 1836 is equally interesting because it is typical of the apple orcharding of that time in what is now an important apple-growing region of New York.

He says their farm in Ontario county in 1836 had two orchards with about Io per cent of the trees bearing grafted fruit. A few more varieties were grafted in but no Baldwins. No apples were sold from these orchards till I 843 when some commission men from Palmyra bought the grafted fruit for a New York firm paying about 75 cents per barrel for the fruit, finding the barrels. The fruit was shipped by the Erie Canal. In 1848 he began to graft the seedling trees in one orchard to varieties that were being recommended by Barry, Thomas and Downing and included Northern Spy, Baldwin, Detroit Red, Gravenstein, Porter, Peck Pleasant and a number of other sorts.

Development of Nurseries. Concerning the Prince nursery above mentioned, L. B. Prince says: 1

"The nursery, which was perhaps the first large commercial one in America, was established about 1730 by Robert Prince. The Huguenots who settled at New Rochelle and on the north shore of Long Island brought with them a variety of French fruits, and the interest thus created in horticulture resulted in the establishment of this first nursery. For a number of years attention was confined chiefly to the fruit trees with which to stock the new country, and it was only when more settled con-

\footnotetext{
${ }^{1}$ Cyc. Am. Hort., Bailey, III : 1435.
} 
ditions came that the culture of ornamental trees and shrubs was introduced. *** The catalogues from I8I5 to 1850 ranked among the standard horticultural publications of the country. $* * *$ The catalogue of 1845 which enumerates only the best varieties, contains 350 varities of apples."

At about the middle of the last century the nursery trade began to be more active. Instead of planting seedling orchards, it became a common practice to plant orchards with grafted trees from the nurseries. Large nurseries became more numerous, especially in the interior of the state, where Rochester, Geneva, Dansville and some other places became quite important centers of the nursery trade.

Development of Commercial Orchards. As transportation facilities gradually improved by the opening of canals and railways the farmers in many interior localities found that they could send their fruit to other than local markets and receive profitable returns. Accordingly commercial orcharding began to attract attention, especially in regions which were found to be naturally favorable to the production of good apples. From I 850 to I 860 the number of commercial orchards which were planted increased rapidly, particularly in Western New York, and continued to increase thereafter till commercial apple orcharding assumed the important place which it now holds in the horticultural interests of the state.

With the development of the commercial apple interests the losses from the depredations of the codlin moth and other insects, also from the apple scab and other fungous diseases, became relatively more important. Commonly the causes of the losses which were sustained were not very well understood, and in those cases that were inderstood there appeared no practical remedy. Because of these and other difficulties which faced them some orchardists eventually became so discouraged at the outlook that in the decade from 1880 to 1890 they began to cut down their commercial apple orchards. The practical use in the apple orchard of paris green and other arsenical poisons against the codlin moth, the canker worm and other leaf-eating insects originated for the most part in Western New York in the decade from 1870 to I880. ${ }^{1}$ The use of fungicidal

\footnotetext{
${ }^{1}$ Lodeman, Spraying of Plants: 6r-64.

Hooker, C. M. Spraying Apple Orchards. . Proc, 49 An. Meet. W. N. Y. Hort. Socy., Rochester, 1904: I3I.
} 
sprays was introduced in the decade from 1885 to 1895 . The demonstration that by combined treatment with fungicides and insecticides some of the most destructive enemies of the apple might be profitably kept under control put the business of growing apples upon a more stable basis than ever before. In the decade from I 890 to 1900 notable improvements in the methods of orchard management in matters of tillage and cover crops came into vogue among progressive conmercial orchardists. During the same period the facilities for holding apples both in common storage and in coid storage were greatly increased. ${ }^{1}$ The export trade developed more extensively, giving steadier markets for the better grades of fresh fruit and also of evaporated apples, ${ }^{2}$ and the business of canning apples assumed considerable importance.

${ }_{1}^{1}$ Powell in the Yearbook of U. S. Dept. of Agric. 1903: 228 gives statistics furnished by the International Apple Shippers' Association showing the number of barrels held in cold storage in the United States about December I of each year since 1898 :

Apples in storage about December I of each year from 1898 to 1903 .

\begin{tabular}{|c|c|c|c|c|c|}
\hline & & $\begin{array}{r}\text { Barrels. } \\
800,000\end{array}$ & 1901 & $\cdots \cdots \cdots$ & \\
\hline & $\therefore$. & $1,518,750$ & 1902 & $\ldots \ldots \ldots \ldots \ldots \ldots \ldots \ldots \ldots \ldots \ldots$ & $2,978,050$ \\
\hline & ... & $1,226,900$ & 1903 & $\ldots \ldots \ldots \ldots \ldots \ldots \ldots \ldots \ldots \ldots$ & $2,348,54^{\circ}$ \\
\hline
\end{tabular}

2 The annual export of apples and dried apples from the United States for the years 1891 to 1903 inclusive is shown in the following table:

\begin{tabular}{|c|c|c|c|c|c|}
\hline \multirow{2}{*}{\multicolumn{2}{|c|}{ Year. }} & \multicolumn{2}{|c|}{ APPLES. } & \multicolumn{2}{|c|}{ Dried Apples. } \\
\hline & & Barrels. & Value. & & \\
\hline 1891 & $\ldots \ldots \cdots \cdots \cdots \cdots \cdots \cdots \cdots \cdots \cdots$ & 135,207 & $\$ 476,897$ & $6,973,168$ & $\$ 409,605$ \\
\hline 1892 & $\cdots \cdots \cdots \cdots \cdots \cdots \cdots \cdots \cdots \cdots \cdots$ & 938,743 & $2,407,956$ & $26,042,063$ & $1,288,102$ \\
\hline I 893 & $\cdots \cdots \cdots \cdots \cdots \cdots \cdots \cdots \cdots \cdots \cdots$ & 408,014 & $1,097,967$ & $7,966,819$ & 482,085 \\
\hline 1894 & n.m.n.m.n. & 78,580 & 242,6 I 7 & $2,846,645$ & 168,054 \\
\hline 1895 & $\ldots \ldots \ldots \ldots \ldots \ldots \ldots \ldots \ldots \ldots \ldots$ & 818,711 & $1,954,318$ & $7,085,946$ & 461,214 \\
\hline 1896 & n.w.m.n. & 360,002 & 930,289 & $26,691,963$ & $1,340,507$ \\
\hline 1897 & 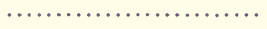 & $\mathrm{I}, 503,98 \mathrm{I}$ & $2,371,143$ & $30,775,401$ & $1,340,159$ \\
\hline 1898 & $\ldots \ldots \ldots \ldots \ldots \ldots \ldots \ldots \ldots \ldots \ldots$ & 605,390 & $1,684,717$ & $31,031,254$ & $1,897,725$ \\
\hline 1899 & n.m.n.m.n. & $3^{80,022}$ & $1,210,459$ & I $9,305,739$ & $1,245,733$ \\
\hline 1900 & n.................... & 526,636 & $1,444,655$ & $34,964,010$ & $2,247,851$ \\
\hline I90I & $\ldots \ldots \ldots \ldots \ldots \ldots \ldots \ldots \ldots \ldots \ldots \ldots \ldots$ & 883,673 & $2,058,964$ & $28,309,023$ & $1,510,581$ \\
\hline 1902 & $\ldots \ldots \ldots \ldots \ldots \ldots \ldots \ldots \ldots \ldots \ldots \ldots$ & 459,719 & $1,628,886$ & I $5,664,468$ & $1,190,593$ \\
\hline 1903 & 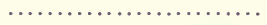 & $1,656,129$ & $4,381,801$ & $39,646,297$ & $2,378,635$ \\
\hline
\end{tabular}

In that section of the Lake Ontario apple belt which is included in Wayne county prob. ably a larger proportion of the apple crop has been made into dried apples than in any other section of the state. Wayne county contains 9 townships. Its total area is 624 square miles. On some farms the entire product of the orchard is put through the evaporator, none of the fruit being sold green. In one township, Sodus, there were in 1896 about 400 evaporators. In 1896 Wayne county marketed about 5,000,000 bushels of green apples. In that year about 1500 carloads of evaporated apples were shipped out of the county, representing about $5,250,000$ bushels of green apples. Mr. E. S. Johnson of Wolcott who supplied the above information also stated that Wolcott for the decade ending in 1896 received an average of $\$ 250$, ooo per annum for its output of evaporated apples. This fruit came from within a radius of 6 to 10 miles of the railroad station. The average price to growers for the same period was estimated at $6 \frac{1}{2}$ cents to 7 cents per pound. The prices were sometimes as low as from 3 to $3 \frac{1}{2}$ cents and sometimes reached as high as 12 cents to 13 cents. 
On the whole the industry of growing apples rests now on a more stable and satisfactory basis than at any previous period in its history.

Lists $1845^{-1903 . ~ T h e ~} 1845$ catalogue of the Prince nursery, as noted above, which claimed to enumerate only the best varieties, contains 350 varieties of the apple. At that time the Baldwin was but little known in New York state, although in the vicinity of Boston it was already highly esteered as a market apple. ${ }^{1}$ In $1845 \mathrm{~A}$. J. Downing made the first attempt to list ail of the varieties of apples known in cultivation in America in his work entitled "The Fruits and Fruit-trees of America." This was revised the second time by his brother Charles Downing in 1869. Bailey finds that in these two lists there are 1,856 varieties named, of which the origin of $\mathrm{I} 72$ is not known, 585 are of foreign origin, and 1,099 are American varieties. ${ }^{2}$

Taylor reports ${ }^{3}$ that the 1852 list of the American Pomological Society consists of 32 varieties, all but one of which, White Seek-No-Further, are still propagated by nurserymen. The list is here given.

"Fruits Worthy of General Cultivation": American Summer Pearmain (Summer Pearmain). Baldwin, Bullock's Pippin, Danvers Winter Sweet, Early Harvest, Early Strawberry, Fall Pippin, Fameuse, Gravenstein, Hubbardston Nonsuch, Large Yellow Bough (Sweet Bough), Lady Apple, Porter, Red Astrachan, Rhode Island Greening, Roxbury Russet, Summer Rose, Swaar, Vandervere (Newtown Spitzenburg), White Seek-No-Further, Wine Apple or Hays, Winesap-(twenty-two varieties). "For Particular LocaliTIEs": Canada Red, Esopus Spitzenburg, Newtown Pippin, Northern Spy, Yellow Belle Fleur-(five varieties). "New Varieties Which Promise Well ": Autumn Bough, Hawley, Melon, Mother, Northern Spy (repeated), Smoke-house-(six varieties). Total 32 varieties.

Additions to this list made from 1852 to 1891 brought the number of names up to 435 of which " 22 were synonyms of others so that but 413 presumably distinct varieties" had then been listed. Many of these had been rejected so that the list of 189 I contained " 339 names, of which at least two are recognized synonyms."

This Society's list for I901 consists of 296 names.

In ${ }^{2} 88_{3}$ Barry made a descriptive list, 4 the main object of which was " to bring to the notice of cultivators the best varieties, those which ample experience has proved to be really valuable, or which upon a partial trial give strong indications of becoming so." The list includes 29 summer apples, 32 fall apples, 102 winter apples, and 21 crabapples.

\footnotetext{
${ }^{1}$ Thacher Amer. Orch., Boston, 1822: 121.

Kenrick New Amer. Orch., Boston, 1832: $4 \mathrm{r}$.

Manning, Book of Fruits, Salem, 1838: 59 .

2An. Hort., 1892: 230.

Am. Pom. Soc., 1895: 192.

4Barry's Fruit Garden: 331-361.

VOL. I -2
} 
The first edition of Thomas' Fruit Culturist was written in 1844 , and subsequently much enlarged through several revised editions. 1 The lists of apples published in the twenty-first edition, 1003, include 954 varieties.

The number of named varieties of the apple now runs into the thousands. Gregory ${ }^{2}$ states that about I,200 varieties of apples were planted in an orchard of the University of Illinois in I869. Bailey ${ }^{3}$ asserts that the varieties of apple trees on sale in the United States in any one year are not far from 1000 kinds. His inventory of the apples sold by nurserymen in 1892 includes 878 entries. ${ }^{4}$

The Old-time Grafted Fruit. As has already been noticed, some of the European settlers brought with them, or afterwards imported, scions or trees of the apples cultivated in Europe. A few nurseries were established at an early day in which these European kinds were propagated. Gradually American varieties found their way into grafted orchards and into nurseries and gained the preeminence which as a class they continue to hold. Among the varieties originating on Long Island or in the Hudson valley, or brought into the state from New England or New Jersey, which were being grafted into the farm orchards in the older settled parts of the state a century or more ago were Green Newtown, Yellow Newtown (the two being often referred to indiscriminately as the Newtown Pippin), Swaar, Esopus Spitzenburg, Fall Pippin, Bough Sweet (also called Large Yellow Bough), Yellow Bellflower, Westfield Seek-No-Further, Rhode Island Greening, Tolman Sweet, Pumpkin Sweet (often called Pound Sweet), and Roxbury Russet. Besides some of these, the Fameuse or Snow was also grown in the Champlain and St. Lawrence valleys, having been introduced from Canada.

Warder $^{5}$ states that grafts taken from the orchard of Israel Putnam, of wolf-killing memory, in Pomfret, Conn., were set in an apple nursery at Marietta, Ohio, by W. Rufus Putnam in 1796 , and most of the early orchards of that region were planted from this nursery. He cites the following authentic list of the varieties propagated as given in the Ohio Cultivator, Aug. I, I846:

1. Putnam Russet (Roxbury).

2. Seek-No-Further (IVestfield).

3. Early Chandler.

4. Gilliflower.

5. Pound Royal (Lowell).

6. Natural (a seedling).

7. Rhode Island Greening.

8. Yellow Greening.

9. Golden Pippin.

ro. Long Island Pippin.

11. Tallman Sweeting.

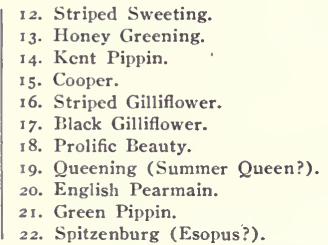

In 1806 Bernard M'Mahon published at Philadelphia in his American Gardener's Calendar a list of apples recommended for planting which, in addition to some of the varieties named above, includes Early Harvest, Early Red Margaret, Vandevere, Newark Pippin, Priestly, Holland Pippin

\footnotetext{
${ }^{1}$ Preface to Nineteenth Edition.

${ }^{2}$ Rep. Univ. Ill., 1870: 44 .

${ }^{3}$ Cyc. Am. Hort., I: 78 .

An. Hort., 1892: 253.

Am. Pom. Apples: 25 .
} 
and Quince. Bailey has republished the complete list, 1 thus making it more widely accessible, together with the list of one hundred selected kinds published by William Coxe in 1817 in his work on Fruit Trees, the two lists of the Downings, 1845 and 1869 , and a survey by himself of the contemporary varieties in 1892 .

Coxe states 2 that his list includes "a selection of one hundred kinds of the most estimable apples cultivated in our country" with "a corresponding engraving of each kind." Besides some of the kinds mentioned above, Coxe describes among others the Maiden Blush, Siberian Crab, Domine, Rambo, Pomme d'Api or Lady Apple, Doctor, Long Island Russet, Ribston Pippin, Newtown Spitzenburg, Roman Stem, Pennock, Winesap and Gilpin.

Varieties now in the Lead. In 1896 the writer, assisted by Prof. C. P. Close, made an inquiry as to what varieties were then grown most extensively throughout the state and their relative hardiness. ${ }^{3}$ During the present year, 1904, many inquiries have been made also among the fruit growers of the state concerning the varieties of apples that are being grown, as to their relative importance and characteristics. From these and other data it appears that Baldwin ranks preeminently above any other kind of apple in importance in the commercial orchards of the state. Probably more Baldwin apples are put upon the market than all other kinds in the state put together. Rhode Island Greening ranks next in importance. It is doubtless speaking within bounds to say that these two varieties supply at least two-thirds of the apples grown for market in New York. Next in reneral importance comes Northern Spy. The relative rank of other varieties is not so readily determined, but in the following list those of more general importance precede those of less importance, although it may be not in exact order. Among other important kinds, besides the three just named, are Tompkins King, Roxbury, Golden Russet, Hubbardston, Esopus Spitzenburg, Black Gilliflower, Ben Davis, Tolman Sweet, Twenty Ounce, Pumpkin Sweet, Swaar, Westfield Seek-No-Further, Fameuse, Fall Pippin, Yellow Bellflower, Yellow Newtown, Green Newtown, Jonathan, Red Astrachan, Oldenburg, Maiden Blush, Wealthy, McIntosh, Gravenstein, Alexander, Early Harvest, Yellow Transparent, St. Lawrence and Blue Pearmain.

\footnotetext{
${ }^{1}$ Annals of Hort. 1892: 209.

${ }^{2}$ Coxe on Fruit Trees: 100. 1817.

Ann. Rep. Geneva Exp. Sta. 1896: $408-418$.
} 


\section{THE ADAPTATION OF VARIETIES TO PARTICULAR REGIONS.}

It is worthy of notice that the apples in the above list which are of dominant importance in the present day commercial orchards of New York are of New York and New England origin. Baldwin, Roxbury and Hubbardston come from Massachusetts; Rhode Island Greening and Tolman Sweet from Rhode Island; Twenty Ounce, Pumpkin Sweet and Westfield Seek-No-Further are from Connecticut. Northern Spy originated in Ontario county, New York, from seed brought by settlers from Connecticut. Fall Pippin is probably from Eastern New York. Tompkins King, though it is said to have originated in New Jersey, was first brought to notice in Central New York. Esopus Spitzenburg, Jonathan and Swaar originated in the Hudson valley; Green Newtown Pippin and Yellow Newtown Pippin on Long Island; Early Harvest in Central New York; Yellow Bellflower and Maiden Blush in New Jersey; Fameuse, McIntosh and St. Lawrence in Canada; Red Astrachan, Alexander, Oldenburg and Gravenstein in Russia or Germany; Blue Pearmain, Black Gilliflower and Golden Russet are of uncertain origin.

Only one of the list, the Ben Davis, comes from south of Mason and Dixon's line, and this one succeeds better in the South and Southwest than it does in New York. While the Newtown Pippin, under the name of Albemarle Pippin, has become a very important commercial variety in some portions of the South, yet, a case like this is rather exceptional. As a rule northern varieties have not succeeded well in the South or Southwest, nor do southern varieties appear prominently among the commercial varieties of the northern states or Canada.

York Imperial, which is an important commercial apple in southern orchards from Virginia westward to Arkansas, does not develop properly in either size or quality even in the best apple districts of Central and Western New York. It does better in Southeastern New York but is not at all adapted to the Lake Champlain region nor to the St. Lawrence valley. Other kinds, too, which are commonly cultivated in the south and southwest as, for example, Buckingham, Grimes, Huntsman, Kinnard, Kittageskee, Lankford, Yopp's Favorite, Missouri Pippin, Nickajack, Ralls Genet, Willow Twig and even varieties which have gained prominence in New Jersey, Pennsylvania and other regions of that latitude as, for example, Fallawater, Lawver, Minkler, Rambo, Roman Stem, Smith Cider, Vandevere and York Imperial, have none of them become leading kinds in New York. The Fameuse and St. Lawrence which have 
been introduced from Canada grow to perfection along Lake Champlain and the St. Lawrence but do not succeed so well in either the central or the southern parts of the state. Blue Pearmain, Bethel, Jewett Red and other kinds which succeed well in Northern New England and in northern counties of New York do not usually develop as good quality nor as high color when grown in the central and southern parts of the state.

This general law as to the adaptability of varieties to regions having about the same latitude as that in which they have originated is verified in the experience of apple growers in other portions of the continent. In the fruit districts of Washington, for example, where the length of the growing season more nearly approximates that of New York and New England the apples which are gaining prominence in the commercial orchards, barring local seedlings, are Baldwin, Rhode Island Greening, Esopus Spitzenburg, Yellow Bellflower and other kinds which are taken from the lists of the New York and New England apples. Moreover in the upland orchards of that state York Imperial cannot be brought up to its best quality, while in the valleys good York Imperials are growr, as well as other kinds which require for their proper development a climate milder and a season longer than that of Central New York. Wealthy in Southern New York becomes a September apple but at Ottawa, Canada, it may often keep well into the winter. The Baldwin, which in New York is a standard winter variety, becomes a fall apple in Virginia and Arkansas. It thus appears that each variety has its own peculiar requirements as to length of season and amount of heat needed to bring it to its best development. Those varieties which, like Ben Davis, Grimes Golden and York Imperial require a warmer and longer season for their proper development than do such apples as Baldwin, Rhode Island Greening and Tompkins King, can never become standard sorts in Central and Western New York, by reason of climatic limitations.

But the adaptability of a variety to a particular region is not altogether a matter of latitude, or length of season, nor prevailing temperature during the growing season. The general character of the soil, the prevailing climatic conditions during the blooming season, and other conditions peculiar to the local environment also enter into the question. Probably there is no region of New York where better Esopus Spitzenburgs are grown than in the Schoharie valley; or better Newtown Pippins than in certain locations on the north shore of Long Island and in the Hudson valley; or better Fameuse than along the St. Lawrence river and Lake Champlain, yet there are other locations having corresponding latitude and altitude where these kinds do not succeed as well as they do in the regions named. Just what are the peculiar local conditions favorable or unfavorable to a particular variety cannot all be definitely stated, but it is beyond question that some localities do afford peculiar advantages for certain varieties and also that some other localities are not particularly favorable or are even unfavorable to these varieties, aside from the factors of the length and warmth of the season. Since these peculiar favorable or unfavorable conditions are not all definitely known it is unwise to plant any variety extensively till it has been first tested and proved satisfactory either in that region or in an apparently similar region. 


\section{WHAT IS A VARIETY?}

It will lead to a clearer understanding of the question as to what a horticultural variety is, if we consider how such varieties originate and how they are perpetuated. With respect to the manner of their origination horticultural varieties fall into two general classes: (a) those which arise by sexual reproduction, that is to say, from seed; (b) those which arise by asexual reproduction, that is to say, from some vegetative portion of the parent plant.

The ways of perpetuating varieties likewise fall into two general divisions:

(a) Sexual propagation, which is propagation by seed.

(b) Asexual propagation, which is propagation by dividing the plant, as by taking from it cuttings, buds, scions, etc.

Some plants which have originated from seed are propagated asexually and vice versa some which have originated asexually are propagated from seed. Some varieties may be propagated either sexually or asexually as suits the convenience.

\section{Reproduction by Seed,}

The normal blossom of the apple species is perfect. In it both sexes are represented. In the case of a seed developed from a self-fertilized blossom the seed-bearing parent, which is the mother, is also at the same time the male parent. But when the apple seed arises from a crossfertilized blossom the seed-bearing parent represents the female line of ancestry only, while the male line is represented by that apple tree which produced the pollen by which the cross-fertilization was effected. Under natural conditions cross-fertilization is a common occurrence among apple blossoms. Multitudes of insect visitors to the flowers carry the pollen from one flower to another. Accordingly, if one should plant the seeds of a particular variety, as Wagener for example, without having protected the Wagener blossoms from the visits of insects, he would be uncertain whether or not the seedling thus produced were a pure seedling of Wagener. If the blossom from which it developed happened to be cross-fertilized by means of pollen from another variety then the seedling would be a cross between the Wagener and that variety which bare the pollen. Since under natural conditions intercrossing occurs abundantly among apple varieties it is not to be wondered at that our common apples are mongrels and almost never reproduce the varieties true from seed. But among a few races, or groups, of apples there is a very marked tendency to reproduce the variety somewhat closely from seed as in the Aport group which includes Alexander and Wolf River and in the Fameuse group which includes McIntosh, Louise and many 
local seedlings of the Snow class, such as are particularly abundant along the St. Lawrence valley.

Nearly all of the cultivated varieties of apples have arisen from seed of unknown parentage. In a few cases the seed-bearing parent of a variety is known or is probably apparent from the evident similarity of the seedling to its supposed parent. Thus Fameuse is credited with being the parent of Louise which resembles it in many ways, and Ben Davis is thought to he the parent of Gano. In very rare instances both parents of a variety are on record. Thus Ontario is a cross of Northern Spy and Wagener.

\section{HYBRIDS.}

Seed Hybrids. Those varieties which originate from the cross-fertilization of distinct varieties or races may be called hybrids or more specifically seed hybrids to distinguish them from the graft hybrids noticed below. Thus have originated very many of the cultivated varieties of garden vegetables. When the new variety that has originated from seed is a kind of plant that is propagated by asexual methods such as budding, grafting and layering, it is an easy matter to perpetuate it by working it upon some other stock, just as Baldwin and other apples, for example, are propagated in nurseries by either budding or grafting them upon seedling stocks, or in the orchard by top-working them upon the orchard trees. But if the new cross or hybrid is a kind of plant that commonly is propagated by seed only, as most garden vegetables are, then it is necessary to "fix" the variety before it may safely be disseminated as a new sort. With the first attempt to propagate a new variety from seed there are usually found among the plants some which are more or less unlike the first, or original, seedling. These must be cast out if the new variety is ever to become so fixed that it will come true from seed. The process of casting out such plants is well known among seedsmen. By them it is called "rogueing." The " rogueing" must be continued faitl1fully, generation after generation, till the variety appears to be sufficiently fixed to permit of its being safely disseminated. It may be necessary to continue the "rogueing" indefinitely in order to hold the variety up to its typical standard.

Graft Hybrids. Hybrids may originate asexually, as when the grafting or budding of one sort upon another produces a new variety unlike either of the original ones represented in the union. A variety thus originated is called a graft hybrid. Graft hybrids are exceedingly rare but well authenticated cases are on record. 1

\section{SPORTS.}

Occasionally new varieties or new strains of a variety originate as sports from the parent variety. Sports are sometimes called "freaks." They may be classed according to their origin into bud sports and seed sports.

Seed Sports. Among varieties that are propagated by seed there is sometimes found a decidedly peculiar plant, unlike the typical plants of the variety, which may prove to be a true seed sport and be capable of

\footnotetext{
${ }^{1}$ Daniel, L., Compt. Rend., Acad. Sci., Paris, 118: 992-955. 1894. Congres. Lyons Soc. Reg. Vit., II: $262-365$. 1902.
} 
reproducing itself by seed. Thus dwarf lima beans have originated from pole lima beans, and dwarf sweet peas from tall-growing varieties. Various other instances of this kind might be cited. If it should seem desirable to perpetuate such a sport by seed it is quite probable that it wouid be necessary to fix the type before introducing it as a new variety.

Bud Sports. Bud sports are well known. They correspond to seed sports in that they appear suddenly. They usually show permanent characters when propagated, entitling the sport to be called a new variety. Moreover, these characters may be transmitted, to a greater or less extent, through the seed produced by such a sport. Numerous instances in which varieties have originated as bud sports are found among ornamental plants and they are not unknown among orchard fruits.

\section{Selected Strains.}

In the case of a sport a variation from the ordinary type arises suddenly. In other cases as great variations have been developed gradually by selecting individuals for breeding purposes which showed a tendency to vary in some particular way which it was desirable to perpetuate and intensify. Selected strains may be developed either sexually or asexually. Many well-known strains of garden vegetables have been originated by gradual selection under propagation by seed. So also under asexual propagation distinct strains have in some cases originated through a gradual process of selection of the propagating wood, or whatever other material is used in propagating the variety. This latter process corresponds to the development of strains by seed selection. By it varieties of the pear which in the original seedling tree were armed with sharp thorny spurs have been changed so that it may be truly said that the thorns have been bred away. In a like manner thorns have been bred away from certain cultivated varieties of the orange. Galloway, 1 who has given much attention to the growing of violets, states that "left to itself the tendency of the violet is to retrograde. By proper selection and right cultural methods the yield may be raised from fifty flowers to one hundred flowers per season in three years."

From all that has been said it appears that new varieties may be produced sexually in seed hybrids, asexually in graft hybrids; sexually in seed sports, asexually in bud sports; sexually in selected seed strains, and asexually in selected bud strains.

\section{Variations Due to Environment.}

It is important to discriminate between those variations that are inherent in the plant and capable of being propagated, as in those cases which have been just considered, and variations which are due to the peculiar influences of local environment and which are not transmitted under propagation.

Many of the differences that different orchard trees show in habits of growth and productiveness; in the size, color and quality of the fruit produced; in resistance to disease, and in other ways, may be satisfactorily accounted for on the ground of differences of environment. For

\footnotetext{
1 Violet Culture: 109-1 16.
} 
example, certain apples are known to develop peculiarly different characters when grown in different regions, as has already been noticed. This occurs regardless of where the plants of the particular variety in question were obtained. The fruit of Yellow Bellflower as grown in Washington is more elongated and more angular than that from New York; Grimes grown in the Missouri valley is a larger, better colored and better flavored fruit than Grimes grown in New York; Fameuse develops deeper and more brilliant red color in the valley of the St. Lawrence than it does in the valley of the Genesee; Roxbury is more russeted when grown in Southeastern Ohio than when grown in New England.1 These differences hold true with so many individual trees and in so many different orchards in the regions named that they are not satisfactorily accounted for on the assumption that they are due to variations in the buds or scions from which the stock was propagated. They must be attributed to peculiar local differences in environment. There are many other differences among orchard varieties in habit of tree, color of fruit and in other particulars, which are known to be due to differences in environment, because they are not transmitted by propagation.

\section{Varieties are Plastic Yet Distinct.}

In view of what has been said above as to the peculiar influence of environment upon both tree and fruit it is clear that a variety must not be regarded as unchangeable. It is not always and everywhere the same. It is plastic. Some are more plastic than others. On the other hand a variety must hold certain peculiar distinguishing characteristics otherwise it is not entitled to be called a variety. Under propagation it must transmit its individuality to such an extent that the different plants thus produced may all bear the same name without confusion.

\section{Apple Varieties Grouped.}

The named varieties of apples together with the unnamed seedlings, as has been already noticed, exhibit infinite variations among themselves in the form, size, color, flavor and season of the fruit, in the characters of foliage, bark and buds, and in the habit of growth of the tree. In fact they vary so greatly that they almost defy any attempt to classify them into groups. But when large numbers of varieties are taken into consideration with the idea of studying their resemblances it is sometimes found that a few more or less definite groups may be formed in which the

${ }^{1}$ Warder Am. Pom.: 492. 
members of each group are on the whole more like each other than they are like the varieties outside of that group. ${ }^{1}$

For example, Baldwin is more like Esopus Spitzenburg than it is like either Rhode Island Greening or Fall Pippin or Ben Davis or Winesap. In fact Baldwin and Esopus Spitzenburg might be taken for the nucleus of a group of apples characterized by certain similarities of the fruits in their form; in the color, dots and other markings, texture and aroma of their skin; also in the flesh as to its texture, flavor, color and quality. In this group would be included Jonathan, Mother, Red Canada, Esopus Spitzenburg, Baldwin, Tufts, Olympia, Arctic and some others. These varieties certainly show decided differences when compared with each other but when contrasted with other groups it is seen that after all they exhibit general resemblances among themselves. Since the Baldwin is the best known of the varieties named in this group and is intermediate in character between the other members it may well be taken as the type and its name be given to the group.

In like manner other groups might be formed. In many cases there is doubt as to what varieties should be grouped together but in other cases the indications are clear and convincing. A few groups are presented below by way of illustration of this idea. These groups are given tentatively because they are evidently incomplete and, moreover, further study would probably lead to modifications of them.

Fall Fippin group.

Fall Pippin,

Holland Pippin (of early autumn),

Lowell,

York Pippin,

French Pippin,

Hawley.

Rhode Island Greening group.

Section A. Holland Pippin (winter), Bottle Greening,

Northwestern Greening, Rhode Island Greening.

Section B. Green Newtown, Yellow Newtown,

Occident,

Newman,

White Pippin,

Peck Pleasant.

IVinesap group.

Winesap,

Arkansas Black,

Arkansas (Mammoth Blacktwig),

Paragon.
Northern Spy group.

Northern Spy,

Wagener,

Melon,

Ontario.

Blue Pearmain group.

Section A. Blue Pearmain,

Oel Austin,

Bethel,

Scarlet Beauty,

Stone.

Section B. Mabie Sweet, Monroe Sweet, Gideon Sweet, Victoria Sweet.

Ralls Genet group.

Ralls,

Salome,

Ingram.

${ }^{1}$ Cf. Hansen, Am. Hort. Man., II: 26. 
Fameuse group.1

Fameuse (Snow),

Canada Fialdwin,

Louise, Princess,

McIntosh,

Scarlet Pippin,

Shiawassee.

Alexander or Aport group.

Alexander,

Wolf River,

Grand Duke Constantine,

Bismark,

Various other Russian kinds.
Wealthy group,

Wealthy,

Peter,

Also several Wealthy seedlings

from Minnesota and adjoining states.

Duchess of Oldenburg group.

Oldenburg,

Late Duchess,

Gladstone,

Pewaukee,

Milwaukee,

Various other Russian kinds.

Groups of Russian Apples. During the last 75 years liundreds of varieties of apples commonly classed as Russian have been brought into the United States. These Russian types of apples have now become established over wide areas in this country. But little of value in the way of winter fruit has as yet been derived from them, but some of the summer and fall kinds are unquestionably desirable additions to the lists of hardy apples for America. As early as 1832 Kenrick, in a select list of foreign varieties which he considered worthy of trial in the United States, includes "two highly celebrated Russian apples," one the Duchess of Oldenburg, the other Emperor Alexander or Alexander or Aporta. ${ }^{2}$

In a list "deserving of trial in Nova Scotia and Canada" he also includes the Astrachan or White Astrachan, the Borovitsky (Oldenburg) and the Red Astrachan. ${ }^{3}$ It appears that about two years after this Alexander, Tetofsky, Oldenburg and Red Astrachan were imported by the Massachusetts Horticultural Society from the London (England) Horticultural Society. 4 One of the best concise accounts of the introduction and present status of these Russian apples is that given by Professor Craig in the Cyclopedia of American Horticulture. 4 After observing that the U. S. Department of Agriculture imported about 300 varieties from Russia in 1870 , he remarks that the Iowa Agricultural College made some importations between 1875 and 1880 and following the trip of Prof. J. L. Budd of that institution with Charles Gibb of Canada to Russia in I882, this college made further large importations of Russian apples and other fruits. After calling attention to the fact that it is difficult to say which

\footnotetext{
${ }^{1}$ See Waugh, Bull. 83 Vt. Sta., 1900.

${ }^{2}$ New Amer. Orch.: 61 .

${ }^{8}$ New Amer. Orch.: 87 .

'Craig, J., in Cyc. Am. Hort., 11I: 1404 .
} 
are Russian and which German, Polish or Swedish apples, 1 Professor Craig discusses the characteristic types of these fruits. He recognizes the Red Astrachan as a type of a small group of Russian apples. Besides this and the Anis type which he supposes is derived from it, "having trees upright, spreading or vase-shaped; leaves medium, veins reddish;" he cites four other types.

I. Hibernal type: trees vigorous growers, with open spreading tops and very large leathery leaves.

2. Oldenburg type: moderate growers, with round-topped heads; leaves of medium size.

3. Longfield type: slow growers; branches horizontal or pendulous; leaves whitish and woolly underneath.

4. Transparent and Tetofsky type: trees pyramidal; bark yellow with numerous spurs; leaves large, light green.

'On the pomological use of thé term "Russian apple," see also W. A. Taylor's views as published by Waugh, Vt. Expt. Sta. Bul. 61, 1897: 24 . 


\section{DESCRIPTION OF VARIETIES.}

This volume of the report on THE Apples of NEw YoRK treats of varieties which are in season with Tompkins King and Hubbardston and all which ripen later. A subsequent volume is planned in which those varieties which come in season earlier than Tompkins King and Hubbardston are to be considered.

Those portions of the descriptive text which are supposed to be of most general or popular interest appear in long primer type, while that which is of less interest to the ordinary reader is given in brevier.

\section{Names and References.}

In the following descriptions, that name which the present writer accepts as the correct one is given first. In this matter the decision of the American Pomological Society and its rules of nomenclature are, with rare exceptions, accepted as authoritative. ${ }^{1}$

${ }^{1}$ The revised code of pomological nomenclature adopted by the American Pomological Society is here given in full. See Proc. Am. Pom. Soc., 1903: 40.

\section{Priority,}

RULE 1. - No two varieties of the same kind of fruit shall bear the same name. The name first published for a variety shall be the accepted and recognized name, except in cases where it has been applied in violation of this code.

A.-The term "kind" as herein used shall be understood to apply to those general classes of fruits that are grouped together in common usage without regard to their exact botanical relationship; as, apple, cherry, grape, peach, plum, raspberry, etc.

B.-The paramount right of the originator, discoverer, or introducer of a new variety to name it, within the limitations of this code, is recognized and emphasized.

C.-Where a variety name tlirough long usage has become thoroughly established in American pomological literature for two or more varieties, it should not be displaced or radically modified for either sort, except in cases where a well-known synonym can be advanced to the position of leading name. The several varieties bearing identical names should be distinguished by adding the name of the author who first described each sort, or by adding some other suitable distinguishing term that will insure their identity in catalogues or discussions.

D.- Existing American names of varieties which conflict with earlier published foreign names of the same, or other varieties, but which have become thoroughly established through long usage shall not be displaced.

\section{FORM OF NAMES.}

RULE 2. - The name of a variety of fruit shall consist of a single word.

A.-No variety shall be named unless distinctly superior to existing varieties in some important characteristic nor until it has been determined to perpetuate it by bud propagation.

B.- In selecting names for varieties the following points should be emphasized: distinc*iveness, simplicity, ease of pronunciation and spelling, indication of origin or parentage.

C.-The spelling and prowunciation of a varietal name derived from a personal or geographical name should be governed by the rules that control the spelling and the pronunciation of the name from which it was derived.

D.-A variety imported from a foreign country slould retain its foreign name subject 


\section{DESCRIPTIONS.}

The present status of the variety, its general adaptability to different regions and its fitness for market or other uses are given briefly together with other observations of popular character. This is followed by historical obscrvations and finally by the technical descriptions of the tree and fruit.

Technical Description. In the treatment of varieties which are given on the following pages the descriptions vary much as to their completeness. Sometimes a description has been made short because the variety is comparatively unimportant in New York; in other cases it is short because the present writer lacks the information necessary to make it more complete.

In a full technical description the tree, its twigs, bark, buds and leaves are first noticed as well as its degree of hardiness and productiveness, its adaptability to locations and the cultural methods suited to its requirements if these have not been given previously. The fruit, as developed under New York conditions, is then described in detail. The suitability of the fruit for home or market or for other special uses is also considered.

Descriptions not Exact. The reader should bear in mind that these descriptions cannot be made so as to fit exactly every specimen of the

only to such modification as is necessary to conform it to this code or to render it intelligible in English.

E.-The name of a person should not be applied to a variety during his life without his expressed consent. The name of a deceased horticulturist shculd not be so aprlied except through formal action by some competent horticultural body, preferably that with which he was most closely connected.

F.-The use of such general terms as seedling, hybrid, pippin, pearmain, beurre, rareripe, damson, etc., is not admissible.

G.-The use of a possessive noun as a name is not admissible.

H. - The use of a number either singly or attaciied to a word should be considered only as temporary expedient while the variety is undergoing preliminary test.

I.-In applying the various provisions of this rule to an existing varietal name that has through long usage become firmly imbedded in American pomological literature no change shall be made which sliall involve loss of identity.

RULE 3. - In the full and formal citation of a variety name, the name of the author who first published it shall also be given.

\section{Fublicatjon.}

RULE 4.-Publication consists ( 1 ) in the distribution of a printed description of the variety named, giving the distinguishing characters of the fruit, tree, etc., or (2) in the publication of a new name for a variety that is properly described elsewhere; such nublication to be made in any book, bulletin, report, trade catalogue, or periodical, providing the issue bears the date of its publication and is generally distributed among nurserymen, fruit growers and horticulturists; or (3) in certain cases the general recognition of a name for a propagated variety in a community for a number of years shall constitute publication of that name.

A.- In determining the name of a variety to which two or more names have been given in the same publication, that which stands first shall have precedence.

\section{ReVISION.}

RULE 5.-No properly published variety name shall be changed for any reason except conflict with this code, nor shall another variety be substituted for that originally described thereunder. 
variety which may be found. Different fruits of the same variety may vary considerably when grown under differing conditions. Some varieties exhibit more irregularities in this way than others do. For example, Northern Spy fruit grown on the topmost branches fully exposed to light and air may be finely colored and highly flavored while on the same tree overshadowed branches may bear fruit poorly colored and decidedly inferior in flavor and quality. Innumerable examples of this kind migit be cited to show that the individual fruits of the same variety may vary noticeably in size, form, color and quality on the same tree even during the same season, and often the general character of the crop differs noticeably in different seasons. Variations are also found in fruit from trees of different ages or under different conditions of growth or from different localities as has been previously stated.1 It should be noticed that normally developed fruits of the same variety may differ not only in the characters above mentioned but also in such features as the calyx (eye) being open or closed; the basin wrinkled or smooth, deep or shallow; the stem long or short, thick or slender, and in other characters of this kind. For example, Baldwin usually has a short thick stem but the smaller fruits of this variety often have long slender stems.

This tendency of different fruits to vary more or less must be recognized if the reader wishes to use technical descriptions of fruits in the most satisfactory and helpful manner. "Of what use then are these exact descriptions?" some may ask. They are of much value if rightly comprehended. While fruits of the same variety may vary in the ways above indicated yet by examining a considerable number of specimens it will often be found that although it may be impossible to identify the variety from descriptions by any single character yet it may be identified by the combination of characters which it exhibits. Thomas aptly remarks 2 "Controlling circumstances will produce changes in all fruits and descriptions are not founded on extreme exceptions but on average characteristics."

Describing the Tree. In the following descriptions when the habit of growth of the tree is referred to the writer has in mind trees of bearing age unless otherwise specified. The descriptions of the bark are made from young twigs of a season's growth.

Top. In describing the top the terms used, which are largely selfexplanatory, designate gradations from strong, very vigorous, moderately z'igorous or medium, to rather slow or weak growth. The form of the head is usually described in the terms used by Downing ${ }^{3}$ upright spreading as in Baldwin, see frontispiece, wide spreading as in Rhode Island G:eening, round-headed as in Early Harvest, or upright as in Red June Carolina, Tetofsky or Benoni. The top is sometimes noticeably close or dense as in Fameuse and other varieties, or it may be open as in Haas, Lady, Gilpin and Canada Reinette.

Twigs. The new growth may be slender as in Rome and Cooper Market or thick and stout as in Sutton. The twigs are said to be longjointed when the internodes, or the spaces from one bud to the next, are long; they are called short-jointed when the internodes are short.

\footnotetext{
1 Page 22.

${ }^{2}$ Amer. Fruit Cult., 1897: 248.

${ }^{3}$ Fruits and Fruit-trees, 1872: 71 .
} 
The color of the bark after the leaves have fallen from the twigs of the current season's growth may assist in identifying the variety, together with appearance of its epidermis, or scarf-skin, the number and shape of the lcnticels, or corky dots which are found on the twigs, and the amount of fuzz, or pubcscencc, present.

Buds. The more sharply pointed buds are called acute; the more blunt ones are obtuse. If they are flattened unusually close to the twig they are called appressed; if not close to the twig they are called free.

Leaves. The leaves vary much in size and form according to the condition of growth of the wood which bears them. The descriptions do not refer to the smaller leaves found on the slow growing spurs but to the leaves which are borne upon the free growing twigs.

\section{DescribiNg the FrUit.}

External Characters. In making a technical description of the fruit of any variety of the apple it is convenient to note first the external characters as seen in the size, form, stem, cavity, calyx, basin, skin and color; next observe the internal characters as seen in calyx-tube, core, carpels, seed, flesh; then state the uses for which the fruit is adapted, its season, general appearance and general desirability. The principal technical terms used in making such a description will now be given.

The stem end is called the base of the apple and the end in which the calyx or the eye is located is called the apex. The diameter passing from the stem through the eye is the vertical or arial diameter; at right angles to this is the transverse or equatorial diameter.

Size. In considering the size it is well to hold the Siberian crabapples in a class apart from the common apples. In popular usage in this country crabapples of the size of Martha and Hyslop are called large, but as compared with common apples they are small.

The gradations in size are expressed by the terms very large, large, above medium, medium, below medium, small, very small.

Uniform signifies that the variety commonly makes a comparatively uniform grade so far as size of fruit is concerned.

Form. Concerning the importance of form as a taxonomic character Van Dieman well says, "Certain characteristics of fruit are more constant than others. *** To my mind, considering all classes of fruit, there is no one character so fixed as the form. **** It is true of the immature as well as of the fully developed specimens. $* * *$ A Chenango the size of a marble is not the shape of a Rambo. * * * Indeed it would not be hard to tell the difference between such marked varieties even before the petals had expanded."

In order that the following remarks concerning the form of the apple may be more clearly understood the reader is referred to particular varicties which illustrate the points mentioned. Plates showing each variety thus cited accompany the description of that variety in the following pages.

In examining the form of an apple let the fruit be held opposite the eye so that it may be observed from a point perpendicular to the axia diameter. As seen thus it may appear round; flattened or oblate; conical;

\footnotetext{
${ }^{1}$ Identification of varieties. Rer. Am. Pom. Soc., 1887:34.
} 
somewhat egg-shaped or ovate; oblong; or it may be intermediate between some of these forms. Then let the fruit be turned at right angles to its former position so as to bring either the base or the apex into full view. From this point the outline of the fruit may appear round, or nearly so, when it is called regular; or its sides may be compressed, elliptical; or, if the fruit be somewhat ribbed, angular or ribbed.

Round, globular, globose are terms which signify that the apple approaches spherical shape. See Tompkins King, Tolman, Hyde King. In McMahon the fruit is roundish inclined to conical; in Fallawater it is roundish conical or a little oblate. Rhode Island Greening and French Pippin are roundish oblate.

Oblate signifies that the apple is flattened as in Canada Reinette, Doctor, Lady and Menagere. The meaning of such terms as oblate conic and roundish oblate is apparent.

Conical is a term applied when the apple narrows noticeably toward the apex. See Bullock, Red Canada, Westfield Seek-No-Further and White Pearmain. The Black Gilliflower is oblong conic. Occident and Opalescent are roundish conic.

Ovate. When the fruit is contracted toward both base and apex it may be ovate, that is, somewhat egg-shaped. Bullock sometimes is this way as also are Dickinson, Magog, Oel, and Stone.

Oblong. When the axial diameter appears long the form may be called oblong. If it narrows toward the apex it becomes oblong conic as in Yellow Bellflower, or oblong inclined to conic as in Gilpin.

Truncate. When the fruit appears as though it were cut squarely across, or in other words is abruptly flattened at the end, it may be called truncate. See Gilpin, Grimes and Jonathan.

Oblique. The form is said to be oblique when the axis slants obliquely as in Yellow Newtown and York Imperial. This form is sometimes called lopsided but that term is more properly applied to indicate the form next mentioned.

Sides unequal or lopsided are terms applied when the fruit under normal conditions has one side noticeably larger and better developed than the cther, as in Milwaukee, Reinette Pippin, Sutton and slightly in Westfield Seck-No-Further.

Symmetrical. When the sides are equally developed the fruit is symmetrical.

Regular. When a section through the equatorial diameter shows a nearly circular outline the apple is called regular.

Irregular is the term used if such outline be elliptical or angular. See Figs. 6 and 7 .

Sides compressed or elliptical are terms also applied when the outline is somewhat flattened instead of round. See Roxbury.

Angular denotes that the sides are more or less ribbed or scalloped. See Figs. 6 and 7 .

Uniform as applied to shape is a term which signifies that the different fruits of the variety show comparatively little variation in form, as, for example, Black Gilliflower and Wealthy. Other varieties like Canada Reinette and Roxbury characteristically show considerable variation in this respect. 
Stem. The character of the stem is of some taxonomic importance notwithstanding that it may vary much in different fruits of the same variety. It may be generally long and slender as in Dutch Mignonne, Rambo, Rome and Westfield Seek-Vo-Further; or short and thick as in Canada Reinette, Fallawater, Sutton and York Imperial; or fleshy as in Peck Pleasant. or clubbed when enlarged at the end.

In general it does not seem to be affected by the environment of the tree as much as other fruit characters and thus it is somewhat a means of recognition with fruit that has so changed, owing to a change of location, that it is otherwise unrecognizable. Unfortunately there are comparatively few varieties which show a stem so characteristic that the fruit may be recognized by this character alone.

Lipped is a term which signifies that the flesh forms a protuberance or lip under which the stem is inserted as often is seen in Pewaukee and Peck Pleasant and sometimes in Sutton and Esopus Spitzenburg.

Cavity. The depression around the stem is technically called the cavity. See Fig. 3a. If it meets the stem at a very sharp angle as in Clayton, McMahon and Magog it is termed acuminate; if the angle is wide as in Rome, Doctor, Tolman and White Pearmain it is called obtuse; if intermediate between the two it is called acute as in Green Sweet, Lady Sweet and Red Canada. In Jonathan and Gilpin it varies from acute to acuminate. The cavity may be wide as in Northern Spy, Tompkins King and York Imperial, or narrow as in Black Gilliflower or medium as in Ribston and Tolman. It may be deep as in Jonathan, Northern Spy and York Imperial; medium in depth as in Baldwin or shallow as in Pewaukee.

Calyx. The lobes of the outer green covering of the flower bud are called calyx lobes. These persist in the common apple and when the fruit is ripe may still be found in what is commonly called the "blowend" of the apple. See Fig. 3b. They fall away, or are deciduous, in the pure Siberian crab species. In some of the hybrid Siberian crabs the calyx is partly deciduous. ${ }^{1}$

The calyx in the mature fruit is open in some varieties, closed in others and partly open in others. In some cases, as for example, in Blenheim the segments of the calyx are noticeably separated at the base. The lobes may be flat and convergent; when upright and the tips inclined towards the axis they may be called connivent; when turned backwards they may be called reflexed or divergent. Very often the different fruits of a variety show considerable variations with respect to the various features above mentioned.

Basin. The depression in which the calyx is set is technically called the basin of the apple. See Fig. 3b. It may be shallow, medium in depth or deep; narrow, medium in width or wide. A basin with sides which show a sudden slope as in Jonathan and Gilpin is termed abrupt, but if, as in Black Gilliflower, Fishkill and Lady, the slope is gradual it is termed obtuse. The basin may be nearly round when it is called symmetrical or it may have the sides compressed. If the sides are smooth it is called regular. When depressed lines extend up the sides as in Winesap, some call it ridged, ribbed or angular, others term it furrowed. When the furrows are less distinct as in Baldwin, it may be called wavy. If wrinkled, plaited or folded about the calyx lobes as in Yellow Bellflower and Black Gilli-

\footnotetext{
Page 3.
} 
flower it is often called corrugated. Peculiar fleshy protuberances about the base of the calyx lobes are sometimes technically called mammiform. These are decidedly marked in some Siberian crabapples.

Skin. Both the color of the fruit and the character of the surface of the skin, as to its being rough or smooth or even russeted, vary more or less with the varying conditions under which the fruit is grown.

The surface of the skin in some varieties as McIntosh and Northern Spy is covered with a delicate whitish bloom which is easily rubbed off. In other cases the skin is waxy or oily as in Lowell (Tallow Pippin), Titus, and to some extent in Sutton and Tompkins King. This character which is determined by the sense of touch must not be confused with that denoted by the term waren which refers only to the appearance of fruit that looks bright, smooth and clear like wax. The surface may be somewhat rough on account of minute capillary russet netted veins as often in Tolman and Hubbardston, or by russet dots, or by both; or it may have more or less of an unbroken russet surface as in various russet apples.

Russet Skin. Sometimes this character is quite variable as in the case of Roxbury which under some conditions becomes nearly or quite smooth. Sometimes the russet is thin as in Bullock; on other varieties it may be dense or heavy. Very often the cavity is somewhat russeted when the surface of the rest of the apple is smooth, as in Pumpkin Sweet. The russet in the cavity may be nearly unbroken or it may spread out in broken rays when it is sometimes spoken of as radiating or stellate.

Dots. The dots are sometimes rough to the touch; in some varieties they may be sunken or depressed; again they are visible under the epidermis. In the latter case they may well be called submerged. If they approach a star form they may be called stellate. If they are surrounded by a halo of a paler or brighter color they may be called areolar. They are in some cases decidedly conspicuous as in Westfield, Blue Pearmain and Red Canada or inconspicuous in others. They may vary from large to very small even on the same fruit; often they are scattering toward the base of the apple, and often smaller and numerous towards its apex. In certain varieties some of the dots are elongated. With Red Canada, Baldwin and Esopus Spitzenburg elongated dots are often seen on the base of the fruit along lines radiating from the carity.

Suture. Sometimes suture lines extend from the base towards or to the apex as is often seen in Tolman.

Pubsscucc. In some varieties there is a noticeable amount of fuzz or pubescence on and about the calyx.

Color. The fruit may be striped with one or more shades of red. If it is not striped it may be called self-colored. A fruit may have a bronzed or blushed cheek and still be classed as self-colored in distinction from striped apples. It has already been remarked that the amount of color will vary on fruits of the same variety in different locations and in different seasons. In some cases trees of certain varieties have been known to bear a crop one season with no trace of red appearing on any of the fruit and in following seasons show a noticeable blush or red stripe on the fruit. When the overlying color is broken it may be designated by the term mottled or by any other suitable expression. The shorter stripes are often spoken of as splashes. The term blush in distinction from 
mottled, striped or splashed, indicates that the surface is overspread with a red tint that is not much broken.

The scarf-shin sometimes gives a characteristic appearance to the fruit. It extends outward from the base in whitish lines or stripes readily distinguished in contrast with the green or yellow color in the Pumpkin Sweet (Pound Sweet of Western New York), the Green Newtown and certain other varieties; or it may give a dull or clouded appearance to a red skin as in Sweet Winesap (called Henrick or Hendrick Sweet in Western New York) and Black Gilliflower.

Internal Characters. When the apple is cut in longitudinal section, as shown in Fig. 3, the internal characters disclosed are very often of great assistance in identifying the variety.

Core Lines. That part of the flesh of the apple which immediately surrounds the seed cavities, and strictly speaking, constitutes a part of

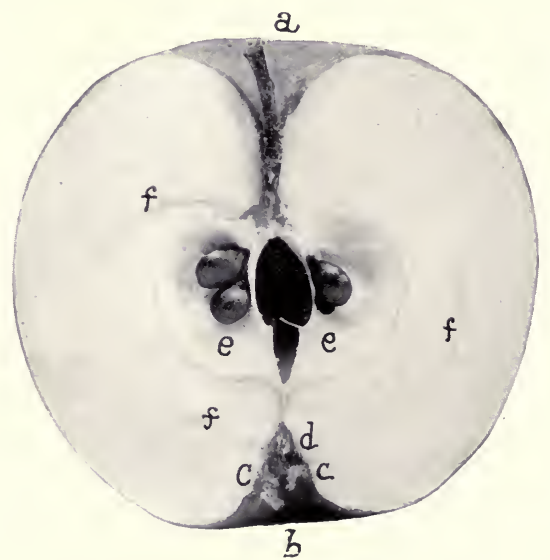

Fig. 3. Longituinal Cross Section of an Apple Showing the Cavity $a$, Basin $b$, Cairyx lobes $c$, Conical Calyx Tube $d$, Abaxile Open Core with Broadly Elliptical Mucronate Carpels $e$, $e$, and a Portion of the Core Lines $f$. $f$.

the core is delimited by visible core lines. Fig. $3 \mathrm{f}$. In the native American species, $P$. coronaria and $P$. iowensis, the separation along the core lines between the core and the outer main flesh of the apple is so complete that by exercising proper care the core may be taken out so as to leave a clearly defined globular cavity within the apple. See Figs. 4 to 7. While in the case of the common apple this natural division of the core from the outer flesh of the fruit is not so complete as it is in the native wild apples referred to, nevertheless such division does exist, as may often be seen in a cross-section of an apple when the flesh of the core proper shows a somewhat different shade of color than does the outer 
flesh. This difference is more clearly shown in the fresh fruit than in a photo-engraving. It is seen in the case of Jones seedling, Fig. 8, as well as in the sections of Ralls Genet, Westfield Seek-No-Further and other fruits which are shown in the accompanying text.

Bundles of fibres or veins called fibrovascular bundles enter the fruit through the stem. Some of them pass directly through the core along

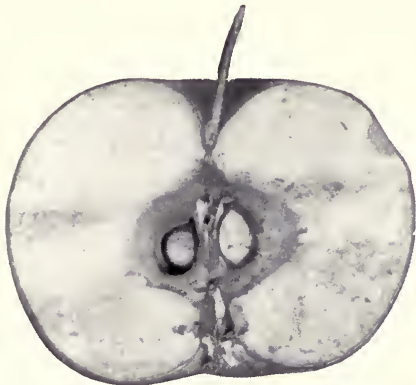

4

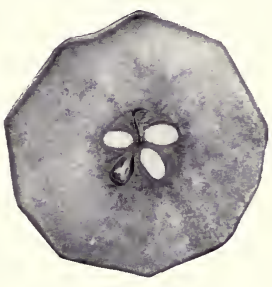

6
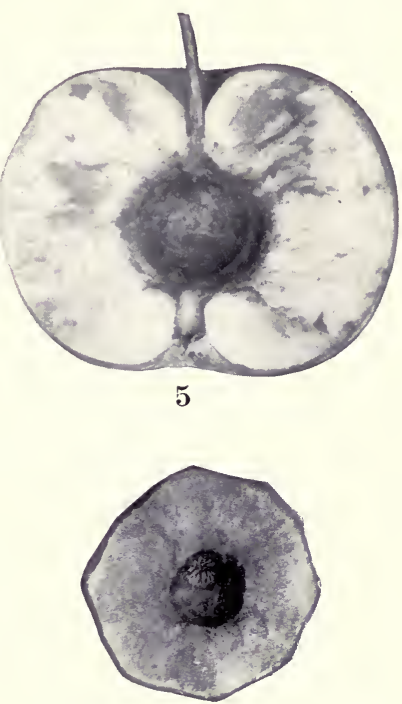

7

Wild Crabapples, $P$. coronaria, L. Shown in Longitudinal Section, Figs. 4 and 5, and in Transverse Section, Figs. 6 and 7. The Core Lines Sharply Delimit the Core from the Flesh, Figs. 4 and 6. When the Core, as Outlined by the Core Lines, is Removed a Rather Globular Cavity is Made as Shown in Figs. 5 and 7. Fig. 5 Shows Plainly a Longitudinal Section of the Cylindrical Calyx Tube which Extends from the Core to the Calyx. In Fig. 7 the Core Cayity is Seen from a Point Perpendicular to the Limb of the Calyx Tube Thus Showing the Stamens from Beneath as They Close the View into the Calyx Tube.

the inner edges of the seed cavities and continue on into the outer parts of the pistils. See plates of McIntosh and Canada Baldwin. Between the seed cavities and the base of the stem other lines of fibrovascular bundles lead off from the stem, inclose a portion of the flesh varying in different varieties from turbinate, as in Canada Reinette, to nearly globular in form, as in Admirable, and terminate principally in that part of 
the calyx tube where the stamens are inserted, though sometimes apparently below the insertion of the stamens. See plates of Ribston and Sharpe. The fibrovascular bundles which may be most easily followed in tracing the core lines are normally ten in number, as shown in Figs. 8 and 9. They occur one opposite each outer angle and alternately one opposite each inner angle of the seed cells. Consequently a longitudinal section through either the outer or the inner angle of a seed cell brings out the core line most clearly.

Clasping core lines is a term which indicates that the core lines appear to join the calyx tube along the side somewhat above the base of the tube, as shown in the plates of Admirable, Ribston and Green Sweet.

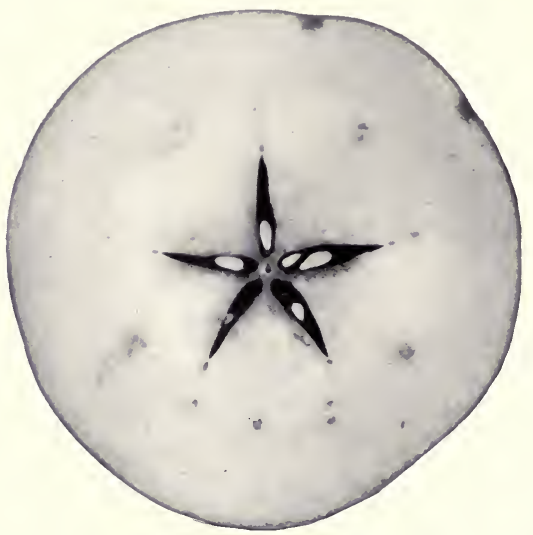

Fig. 8. Transuerse Section of Jones Showing a Closed Core Which is Axile and has Symmetrical Cfilds. The Dark Dots Show Cross Sections of the Principal Fibrovascular Bundles of the Core Lines.

Core lines meeting is the term used when the core lines appear to join the calyx tube at or near its base, as seen in the plates of Bullock and York Imperial.

The point at which the core lines meet the calyx tube does not vary materially in the same variety although different descriptions of it may vary when in the same variety some of the apples show a funnel-form extension of the calyx tube towards the core and others do not, as stated below in discussing the calyx tube.

In some cases before the fibrovascular bundle reaches the calyx tube it sends off a distinct branch to the calyx lobes as seen in the plates of Fallawater, Green Sweet and Newman.

Calyx tube. The hollow just under the calyx lobes is called the caly.x tube, Fig. 3, d. This may be cone-shaped, as in Dickinson and Salome, or when it is extended below in a nearly cylindrical narrow tube it is funnelform, as in English Russet. If instead of assuming either of these forms 
it is comparatively broad and rounded toward the base it may be called urm-shaped. When the calyx tube is funnel-form its broad upper portion is called the $\lim b$; the narrow part extending from the limb towards the core may be called the cylinder.

In some cases as in Northern Spy and Red Canada the tube may vary in the same variety, being cone-shaped in some fruits and funnel-form in others, thus making the core line appear to vary in the character of its meeting or clasping the calyx tube. Such variation is due to the fact that in some fruits and not in others the base of the styles below the

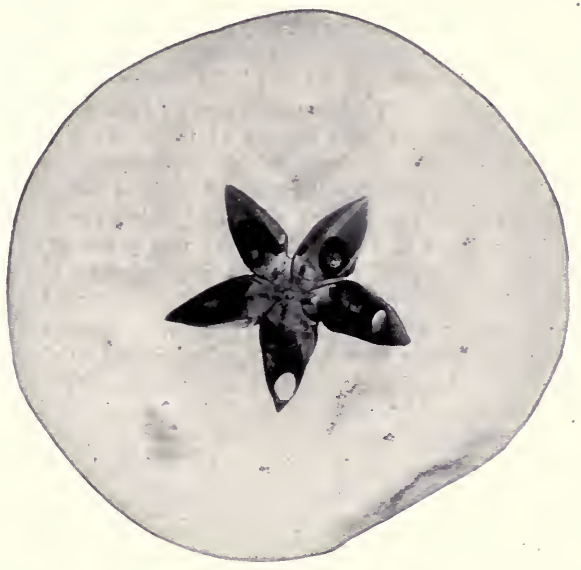

Fig. 9. Transverse Section of Thompson Showing an Open Core Which is Abaxile. The Cells are Symmetrical, or Nearly so, and Wide Open. The Dark Dots Show Cross-sections of the Principal Fibrovascular Bundles of the Core Lines.

limb of the calyx tube develops into a fleshy tissue which fills that part of the tube.

Pistil Point. In some varieties the fleshy base of the styles forms a pistil point which projects into the calyx tube in a way that is characteristic, and of some taxonomic value. An example of this kind is found in Gano.

Stamens. Hogg studied critically the taxonomic value of the position of the stamens, or the remnants of them, 1 in the calyx tube 2 and finally made this character the basis of the primary classes in his analytical key of the apples of Great Britain. He recognizes thus the three following divisions among apples.

A. Marginal Stamens. In this class the stamens are inserted near the outer margin of the calyx tube.

\footnotetext{
${ }^{1}$ The remnants of the stamens appear in the ripe fruit as withered thread-like organs on the side of the calyx tube.

${ }^{2}$ Fruit Manual, London, 1884: xi to xxxix.
} 
B. Median Stamens. In this class the stamens are located about the middle of the calyx tube.

C. Basal Stamens. In this class the stamens are found near the base of the calyx tube.

Core. In describing the core its location in the fruit is noticed, also its size and the character of the carpels and of the seeds.

Core Scssile. The core is sometimes very close to the stem. It may then be called sessile.

Core Median. If the core, as usually is the case, is located at about the center of the apple, it is median.

Core Distant. When the core is comparatively far from the stem it is called distant.

Carpels. The parchment-like walls of the seed cells are called carpels. Fig. 3e. Since they vary in form somewhat as leaves do the terms used in describing leaves may be well applied to them. In noting the form of the carpels the stem of the fruit, which corresponds to the petiole of the leaf, should be held towards the observer. The two sides of the seed cell correspond to the two halves of a leaf, with the axis of the fruit representing the midrib of the leaf. From this point of view it will be noticed that the carpels of some fruits approximate a roundish form; others a heart-shaped or cordate form; others a reversed cordate or $o b$ cordate form; others are so broad as to be well termed elliptical, while others are so narrow that they may be called oblong or elongated; or they may be either ovale or obovate. If the outer edge at the tip is indented it may be termed emarginatc; if long and slender-pointed it may be called mucronate. Fig. 3 .

Hogg, in the classification of apples above referred to, 1 also notes the following characters of carpels: When the walls extend to the axis, best seen in a cross-section of the fruit, as in Fig. 8, the cells are symmctrical and are termed arile, whether they are open or closed. When the walls are distant from the axis, as in McIntosh and English Russet, and the cells are unsymmetrical, they are called abaxile. Fig. 9.

Open Core. The core is called open when the cells are open, or slit, as shown in Figs. 3 and 9.

Closed Corc. When the cells are closed the term closed core is applied. See Jonathan, Red Canada and Fig. 8.

The inner surface of the carpels may be either smooth, or, as in Tompkins King, may have a soft whitish outgrowth. In this case the carpels may be described as tufted.2

Seeds. The number of seeds to each seed cell varies with different varieties. Two is the usual number. Sometimes no seeds develop. In rare cases there are three or more seeds in a cell. The number, size, shape and color of the seeds are all worthy of notice in a technical description of the apple. The seeds like the carpels may be tufted. When the seed has a long sharp point it is termed acuminate; if rather blunt, it is obtusc; if intermediate between acuminate and obtuse, it is acutc.

Flesh. In a description of the flesh its color is noticed; also the firmness and grain of its texture; its juicincss; the acidity and aroma that are found in its favor, and lastly its general rating on all of the above points combined.

\footnotetext{
${ }^{1}$ Fruit Manual, London, 1884 : xiii.

"The "Wollstreifen" of Soraner. See Handb. Planzenkrankheiten, zweite Auflage, 1: 295. 1886 .
} 
Color. The color of the flesh is called white in such apples as McIntosh and Fameuse. In Jonathan, Baldwin and Rhode Island Greening it is somewhat tinged with yellow. In Fallawater, Rambo and Green Sweet it is greenish-white. In some varieties it may be streaked or clouded with red, as it sometimes is in Wealthy and McIntosh. Occasionally seedling apples are seen in which the whole flesh is remarkably tinged with red, but such varieties have not found their way into cultivation, at least not to any considerable extent.

The flesh of apples of the same variety is liable to show some variations under different conditions of growth. This is especially noticeable in varieties adapted to the South when they are grown in northern latitudes where the season is not long enough to bring them up to their highest standard. Thus when Winesap and other southern varieties are grown in Western New York they may have a decidedly greenish tinge to the flesh, whereas if properly developed, the flesh would be tinged with yellow: or those fruits of such a variety which have the most favorable locations on the tree may develop a yellowish flesh while others less favorably located come to the close of the season with the flesh still greenish. In passing upon the color of the flesh, therefore, it is important to have properly developed specimens under examination. With such specimens the color of the flesh will be found pretty constant and characteristic of the variety.

Texture and Flaior. The terms commonly used in describing the texture and flavor are firm, hard, tender, tough, crisp, breaking, dry, juicy, sour, subacid, swect, sprightly, aromatic, astringent. Various intermediate modifications of easily recognized significance are also used.

General Rating. The gradations in the general rating on all points combined are expressed by the terms poor or inferior, fair, good, very good, best. One who is unaccustomed to the technical significance of these words should observe that the word good here signifies a class of apples of medium quality only. Above it are the higher classes very good and best. The quality varies somewhat in a variety so that it is often necessary to use more than one term to indicate its proper rating. Thus Baldwin rates good to very good, and Red Canada from good to best. The quality of the fruit corresponds in a general way with the development of the color of both its skin and its flesh. It has already been observed in speaking of the color of the flesh that under certain conditions it is not normally developed. When the color of either the skin or the flesh is not properly developed, there is a corresponding lack of development of the quality of the fruit. This statement may be easily verified, as already noticed, by testing highly colored Northern Spy apples in comparison with poorly colored fruit of the same variety. It will be found that the poorly colored fruit, even though it may have been produced on the same tree as that which bore the highly colored fruit, is decidedly inferior in quality.

Use. The uses for which the fruit is particularly suitable is indicated by customary terms. Market signifies that it is suitable for general market. Local market indicates either that it does not stand handling well enough or is not appreciated for general market uses but is acceptable for local trade. Dessert or table signifies that the fresh fruit is desirable 
for serving at the table. Culinary, cooking or kitchen are ierms used to indicate that the fruit is suitable for either general or special culinary uses.

Season. The term season is used to indicate the period during which the variety is in good condition for use. This varies with the same variety in different latitudes. Even in the same location the fruit may ripen later and keep later in some years than in others. Unless otherwise stated the season of winter apples as here given refers to the fruit kept in ordinary fruit houses or in cellars. In cold storage the season may be prolonged several weeks beyond its natural limit. The reader should bear in mind that the manner of handling fruit before it goes into storage has an important influence upon the length of the period during which it will keep in good condition.1

${ }^{1}$ Beach and Clark, Bull. N. Y. Exp. Sta., 248:92. 1904. 

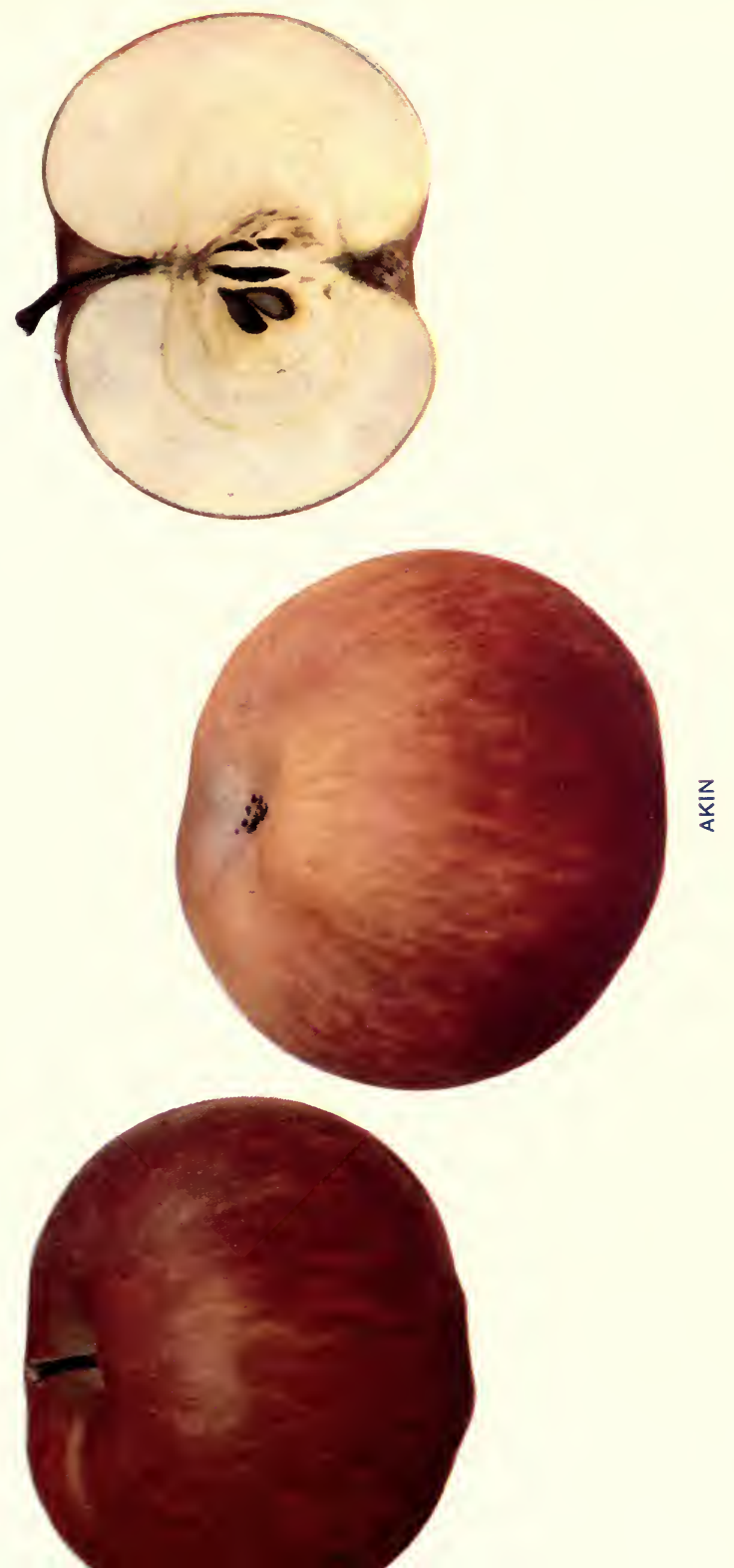



\section{AKIN.}

References. 1. Bailey, An. Hort., I892:234. 2. Riehl, Am. Pom. Soc. Rpt., I897:137. 3. Taylor, U. S. Dept. Agr. Yr. Bk., 1903:268. col. pl. 4. Ill. State Hort. Soc. Rpt., I8go.

Synoxyms.1 Akin Red, Akin Seedling, Akin's Seedling, Aikin's Red, Aiken, Aken-not "Aiken's Winter" of Downing which is a crab of Minnesota origin. (3). Alin's Red. (4).

When the Akin is well developed it is a beautiful, dark red, winter apple of pretty good quality. It appears to be specially adapted for fancy trade and for dessert use. Although it has not been sufficiently tested to determine its value for cultivation in New York, it promises to be hardy, healthy and reliably productive. It seems to be best suited to more southern localities, but it has usually developed well at Geneva, although in occasional seasons its fruit has not attained good color here. With ordinary care the fruit does not average much above medium size. In ordinary storage it keeps well till midwinter and in cold storage till March or later. It is sufficiently promising to be worthy of testing for commercial purposes.

Historical. Taylor gives an excellent accourt of the origin of the Akin (3) from which it appears that the original tree was grown from seed brought from Tennessee and planted in I83 1 near Lawrenceville, Ill., on the farm now owned by W. J. Akin. It was first propagated for sale in I868. Mr. Akin exhibited it in December, I890, at the Cairo meeting of the Illinois State Horticultural Society, where it was awarded first premium both as a "Seedling" and a "New Variety good enough to be recommended." Taylor says (3), "It has now been fruited in several states, and is one of the most promising of the recently introduced sorts for the apple growers who desire a variety well adapted to the needs of the fancy trade in the larger cities. It succeeds well in the Middle West and in the winter apple districts of the Allegheny Mountain region, and is worthy of thorough test on rich, warm soils in the northern apple districts from New York westward."

\section{TreE.}

Trec upright, becoming somewhat spreading, dense, medium in size, moderately vigorous. Branches long, moderately stout. Twigs long, straight, stocky, with thick tips; internodes short to medium in length. Bark olivegreen varying to dull purplish-brown, largely covered with a gray pubescence that becomes thicker and heavier towards the tips. Lenticcls numerous, conspicuous, oblong or roundish, raised. Buds medium size, obtuse, broad appressed, quite pubescent. Leaves large, broad.

\footnotetext{
${ }^{1}$ Numbers in parentheses designate authors or publications cited in the preceding list.
} This plan is followed with all of the formal descriptions given in this report. 
FrUIT.

Fruit usually medium or above, sometimes large. Form oblate to roundish oblate, often irregular, slightly ribbed, sides sometimes unequal. Fairly uniform in size and shape. Stem medium to long, slender. Cavity obtuse, broad, rather shallow to deep, often distinctly furrowed, not often russeted. Calyx small to medium, usually closed. Basin medium in width and depth, usually somewhat abrupt, somewhat furrowed and corrugated.

Skin tough, smooth, rather attractive yellow, blushed and striped with bright dcep red; in well colored specimens almost completely red. Dots small, whitish or with russet point, sometimes conspicuous in contrast with the dark red skin. Prevailing effect attractive bright red with contrasting clear yellow or greenish-yellow:

Calyx tube conical, sometimes approaching funnel-form. Stamens median.

Core abaxile, medium, open or partly closed; core lines meeting. Carpels elliptical or approaching roundish obcordate, slightly emarginate. Seeds moderately dark brown, long, rather narrow, acute, numerous.

Flesh whitish, slightly tinged with yellow, rather crisp, moderately coarse, moderately tender, very juicy, sprightly subacid, aromatic, good to very good for dessert.

Season January to June.

\section{(I) ALLINGTON.}

This is a late winter apple of medium size, yellow with a bronze blush, subacid. It was oŗiginated by S. A. Alling of Homer, Minnesota. As a seedling it was awarded first premium by the Minnesota Horticultural Society in I90I.1 We have received no reports of its being grown in New York State.

\section{(II) ALLINGTON.}

References. I. Bunyard, Jour. Royal Hort. Soc., 2I:356. I898. 2. Jour. Royal Hort. Soc., 27:217. 1903. fig.

Synonym. Allington Pippin $(1,2)$.

This is a new English variety which was awarded a first class certificate by the Royal Horticultural Society in 1894 . (I) Although it is of good size and of good quality it is not attractive enough in color to make it a promising commercial variety for New York. It has not been tested here sufficiently to show how well it is adapted to New York conditions.

\section{TREE.}

Tree vigorous. Form spreading, rather open. Twigs long to below medium, irregular, crooked, rather slender; internodes above medium to below medium in length. Bark rather dull brownish-red and dull green; on older wood rather light green. Lenticels scattering, large, roundish, sometimes raised. Buds large, roundish, rather obtuse, appressed, pubescent. Leaves somewhat narrow.

As grown at the Geneva Station it comes into bearing young and gives promise of being quite productive.

\footnotetext{
${ }^{1}$ Hansen, S. D., Expt. Sta. Bul. 76:22. 1902.
} 


\section{FrUit.}

Fruit medium to large, pretty uniform in size. Form roundish, often somewhat inclined to oblong conic varying to slightly oblate, sides unequal, sometimes slightly ribbed, rather uniform in shape. Stem medium to long. Cavity rather obtuse to acute or slightly acuminate, rather shallow to moderately deep, moderately narrow, usually russeted, sometimes prominently lipped. Calyx medium to large, closed or partly open; lobes very long, acuminate, reflexed. Basin rather obtuse, noderately wide, medium to shallow; often slightly corrugated, nearly symmetrical.

Skin thick, smooth, greenish-yellow almost entirely overspread with somewhat dull red, indistinctly striped and mottled with carmine, sprinkled with gray dots; uccasionally rather large russet dots and flecks are seen. Not particularly, attractive in color.

Calyx tube rather large, rather short and wide to sometimes long, funnelform with short truncate cylinder and fleshy projection of pistil point into its base.

Core medium or below, open or partly closed, nearly axile; core lines meeting or when the tube is funnel-form, clasping the cylinder of the tube. Carpels roundish ovate to pointed ovate, deeply emarginate. Seeds below medium, very numerous, dark, short, obtuse to acute, plump.

Flesh tinged with yellow, moderately coarse, rather crisp, tender, rather firm, very juicy, briskly subacid to nearly acid, pleasantly aromatic, rich in flavor, good in quality.

Season November to midwinter.

Uses. Acceptable for dessert. Particularly suitable for culinary use.

\section{ALLISON.}

References. I. U. S. Pom. Rpt., 1895:19. 2. Watts, Tenn. Sta. Bul., 9:6. 1896. fig. 3. Taylor, Am. Pom. Soc. Rpt., r897:35.

Synoxyu. Jones Seedling $(1,2,3)$.

This is a variety of Tennessee origin. Watts (2) calls it a valuable winter apple for Tennessee. Although it has not been tested here sufficiently to show its adaptability to New York conditions, so far as it has been tested it does not promise to be as valuable as it is in more southern latitudes.

TREE.

Tree rather vigorous, productive; branches long and slender. Form upright spreading, rather dense. Twigs long, slightly curved, medium stout; internodes below medium to short. Bark bright reddish-brown varying to reddish-green with light scarf-skin; pubescent. Lenticels numerous, small, roundish. Buds medium size, broad, obtuse, pubescent. Leaves medium in size, broad.

\section{FrUit.}

Fruit medium to above. Form oblate, rather strongly ribbed, sides unequal, rather uniform. Stem short to medium. Cavity wide, rather shallow, irregular, sometimes russeted. Calyx below medium to large, closed or somewhat open. Basin moderately deep or rather shallow, moderately wide, slightly wrinkled. Skin rather thick, greenish, sometimes faintly blushed and splashed 
with rather dull unattractive red, heavily splashed with large and small russet patches. Dots usually russet, rather large, scattering. General appearance not attractive.

Core rather small to above medium; closed or very slightly open. Seeds medium, ratler broad.

Flesh greenish-white, firm, rather fine-grained, slightly crisp, not tender, moderately juicy, mild subacid, or nearly sweet. As grown at this Station it is not more than fair in flavor and quality.

Season late winter.

\section{AMASSIA.}

References. I. Hogg, r884:6. 2. Bailey, An. Hort., r892:234. 3. Beach and Close, N. Y. Sta. An. Rpt., 15:260. 1896.

Hogg (I) speaks of Amassia as a very beatiful and ornamental apple and states that it is tic apple most generally grown in Asia Minot on the shores of the Mediterranean. When fruited here under favorable conditions Amassia is attractive in form and color, having a bright red blush. It has a pleasant, sweet or nearly sweet flavor and is very good in quality for dessert use. Under less favorable conditions it is not uniformly well colored and is apt to fall below medium size. These characteristics together with the fact that the variety would be classed among the sweet apples, make it doubtful whether it will ever be grown in this state to any considerable extent in commercial orchards.

\section{Tree.}

Tree is a moderately vigorous or slow grower. Form upright spreading. Tiungs vary from short to rather long, straight or nearly so; moderately stout; internodes medium to long. Bark dull dark reddish-brown with light streaks of scarf-skin; slightly pubescent. Lenticels scattering, rather inconspicuous, oblong or roundish in shape, medium size. Buds medium in size, broad, obtuse, rather prominent, pubescent, almost free. Leaves moderately long and narrow.

FRUIT.

Fruit usually medium or below, sometimes nearly large. Form ovate or roundish conic, slightly ribbed; sides sometines compressed; fairly uniform in shape and size. Stem medium to long, rather slender. Cavity acute to acuminate, narrow, medium to rather deep, often compressed, smooth or partly russeted. Calyx small to very small, usually closed. Basin small, varying from obtuse and very shallow to moderately deep and abrupt; often furrowed and corrugated.

Skin smooth, somewhat waxy; clear pale yellow or greenish, in well colored specimens largely covered with a bright deep blush, and somewhat striped with carmine. Dots whitish, small but rather conspicuous. Although the apple is somewhat striped, the general effect when it is well colored is that of a solid deep blush, which in contrast with the pale green or yellow gives a decidedly attractive appearance.

Calyx tube funnel-form, moderately wide and deep, with pistil point projecting into its base. Stamens median or nearly marginal.

Core medium to small, ahaxile, closed or sometimes slightly open: core lines clasping. Carpels roundish ovate to oblong ovate, emarginate. Seeds few, medium to snall, plump, obtuse, light brown. 
Flesh nearly white, firm, moderately fine-grained, rather crisp, tender, juicy, with pleasing aroma, mild subacid, becoming sweet or nearly so; good to very good.

Season December to March or April.

\section{AMERICAN BEAUTY.}

References. I. Downing, I857:I I5. 2. Warder, I867:7II. 3. Downing, 1872:75. 4. Barry, I883:341. 5. Thomas, I903:689.

Synonyms. Beauty of America (4). Sterling Beauty (1, 3, 4, 5).

So far as we can learn the American Beauty is not now grown in New York. It is not listed in Bailey's inventory of apples offered by nurserymen in North America in 1892.1 It is an old variety which originated in Sterling, Mass. Downing describes it as a large red apple, mildly subacid, aromatic, very good in quality. In season from December to April.

\section{AMERICAN BLUSH.}

The Hubbardston has long been known in some portion of Seneca and Tompkins counties under the name American Blush, and has been disseminated from there under that name. It is not surprising that the Hubbardston has been disseminated under other names because it shows such remarkable variations with changes in environment. Whether the variations which have appeared are all due to differences in environment or whether distinct strains of the Hubbardston have arisen under cultivation has not been definitely determined. Some fruit growers are very positive in the opinion that American Blush is different from the Hubbardston. If this be true and if these differences are maintained under propagation it should be regarded as a distinct strain of the Hubbardston.

\section{AMERICAN PIPPIN.}

References. x. Coxe, I8I7:I47. 2. Downing, r845:98. 3. Thomas, 1849: 163. 4. Emmons, Nat. Hist. N. Y., 3:74. I851. 5. Hooper, 1857:42. 6. Elliott, I859:184. 7. Warder, I867:420. 8. Downing, I872:77. 9. Lyon, Mich. Hort. Soc. Rpt., 1890:288. го. Bailey, An. Hort. 1892:234. II. Thomas, 1903:689.

Synonyus. Grindstone (5). Grindstone (3, 7, 8, 9, 10). Stone (8).

The American Pippin is an old variety. Coxe gives it a very high reputation both for cider and for keeping late (I). Lyon says of it (9) "keeps a year, cooks well, but otherwise scarcely eatable."

Coxe describes the tree as very open, remarkably spreading with hanging crooked shoots.

The fruit is medium, regular, oblate, "without any hollow at the ends" (Coxe) ; calyx small, open; skin dull red, shaded and streaked with dull green, the surface being rougl, sometimes with slight russet markings, thickly sprinkled with gray or coarse russet dots; core wide, irregular, closed; seeds numerous, plump, brown; flesh white or yellowish, hard, rather coarse, moderately juicy, mild subacid. Variously rated by pomologists from poor to good in quality.

\footnotetext{
${ }^{1}$ An. Hort., 1892 :234.
} 
There is a variety grown under the name of American Pippin in Northern New York and Canada which is valued on account of its hardiness and late keeping qualities. Macoun 1 describes the fruit of this variety as large, roundish; greenish-yellow with pink or orange blush; dots not prominent; basin rather deep; calyx large, open; cavity deep; flesh yellow, subacid, good.

I have not determined whether this is identical with the American Pippin of Coxe but it does not appear to be that variety.

\section{AMOS.}

References. I. Ill. Sta. Bul., 45:313, 326. I896. 2. Powell and Fulton, U. S. B. P. I. Bul., 48:36. 1903. 3. Beach and Clark, N. Y. Sta. Bul., 248:111. I904.

Synonyms. Jackson (I). Amos Jackson (1, 2, 3).

This variety was received for testing at the Geneva Experiment Station from Benjamin Buckman of Farmingdale, Illinois. It is supposed to be of southern origin. The tree is moderately productive. The fruit is of mediu:n size, attractive deep yellow, subacid, fair to good. Season November to March. It is not recommended for cultivation in New York.

\section{Fruit.}

Fruit averages below medium. Form roundish oblate, almost truncate, usually symmetrical; uniform in form and size. Stem long to very long, slender, sometimes bracted, often reflexed in a characteristic way to one side. Cavity acute, shallow to moderately deep, moderately wide, usually russeted, often lipped. Caly.x large, open; lobes long and reflexed. Basin obtuse, shallow or moderately deep, hroad, sometimes corrugated.

Skin yellow, often with blush, not striped, sprinkled with scattering russet dots. Prevailing effcct attractive yellow.

Calyx tube short, cone-shaped, with tendency to funnel-form. Stamens median to basal.

Core sessile, turbinate, axile, small to medium, closed or slightly open. Carpels elliptical, inclined to obcordate, emarginate, mucronate.

Flesh nearly white, hard, rather coarse, breaking, moderately juicy, sprightly subacid, fair to good in quality.

Season November to March.

\section{ANDREWS.}

References. I. Beach and Close, N. Y. Sta. An. Rpt., I5:270. I896. 2. Beach and Clark, N. Y. Sta. Bul., 248:111. 1904. 3. Not listed by Bailey in An. Hort., 1892:234.

Synonyms. Andrews Winter (1). Andrews Winter (2).

Fruit small to medium, not very attractive in form or color and therefore not desirable for market. It is not recommended for planting in New York state.

TREE.

Tree vigorous. Form upright spreading, rather dense; branches rather small and crooked. Tuigs medium size, curved, stout; internodes medium

${ }^{I}$ Macoun, Can. Dept. Agr. Bul. 37:42. I90I. 
to rather long. Bark clear brownish-red mingled with olive-green, partly covered with streaked scarf-skin; quite pubescent. Lenticels numerous, medium to below, oblong. Buds medium size, plump, acute, appressed, pubescent. Leaves medium size, broad.

\section{FruIT.}

Fruit small. Form roundish conic to oblong conic, often unsymmetrical; sides often compressed. Stem short, thick, often obliquely inserted. Cavity acute, moderately shallow to rather deep, furrowed or compressed, sometimes lipped, usually smooth. Calyx small, closed. Basin abrupt, medium in width and depth, distinctly furrowed.

Skin tough, somewhat waxy, dull yellowish-green partly overlaid with a dull, rather dark red having narrow, indistinct, carmine stripes. Dots numerous, pale, rather conspicuous.

Calyx tube narrow, elongated, cone-shape or funnel-form. Stamens median to marginal.

Core abaxile, closed or partly open; core lines clasping. Carpels decidedly concave, broadly ovate, slightly emarginate, distinctly tufted. Seeds medium to large, rather narrow, long, acute, somewhat tufted.

Flesh greenish-white, firm, moderately fine, somewhat crisp, moderately jiricy, mild subacid, fair to good.

Season March to June.

\section{ARKANSAS.}

Refrerences. 1. Van Deman, Am. Pom. Soc. Rpt., r8gr:123. 2. Babcock, Amer. Gard., 1891: 118. 3. Bailey, An. Hort., 1892:234, 244. 4. Babcock, Am. Pom. Soc. Rpt., 1895:190. 5. Amer. Gard., 1895:419. 6. Stinson, Ark. Sta. Bul., 43:103. 1896. 7. Amer. Gard., 1896:29, 65, 146, I52, 210, 306. 8. Watts, Tenn. Sta. Bul., 9:24. 1896. fig. 9. U. S. Pom. Bul., 6:9. 1897. ro. Stinson, Ark. Sta. Bul., 49:5, 7. I898. figs. of trees and fruit. I1. Powell, Del. Sta. Bul., 38:19. I898. fig. 12. Stinson, Ark. Sta. Bul., 60:124. I899. 13. N. C. Bd. of Agr. Apple Bul., 1900:9. 14. Alwood, Va. Sta. Bul., г30:127. 1901. 1 5. Stinson, Mo. State Fruit Sta. Bul., 3:26. 1902. 16. Budd-Hansen, 1903:39. fig. I7. Thomas, 1903:322, 690, 708 .

Synonyms. Arkansaw (4, io, 12). Arkansaw (16). Mammoth Black Twig (6). Mammoth Black Twig (9, Io, II, I2, I4, I5, I6). Paragon (erroneously) (I). Arkansas Black and Arkansas Black Twig (i7) but erroneously.

The Arkansas is a late keeping winter apple, rather large, of good red color, and good quality. It is not a desirable variety for growing in New York state because it is not sufficiently productive and because in this northern latitude the seasons are not always favorable to the proper development of its fruit. It keeps later than the Baldwin but it is inferior to that variety in productiveness and also in the color and quality of its fruit.

$$
\text { VoL. } \mathrm{I}-3
$$


During the last quarter century Arkansas has been quite extensively planted in the South and Southwest, but even as grown in these regions, the variety has not been satisfactory in commercial orchards because it is a shy bearer.

Arkansas and Paragon resemble each other so closely that at one time many regarded these two varieties as identical, and, in consequence, the stock of the two kinds became badly mixed in nurseries and orchards.

Arkansas Black is decidedly distinct from Arkansas both in tree and fruit. Sometimes these two varieties have been erroneously listed as identical (I7). This mistake doubtless arose because of the similarity of the two names, rather than from any marked resemblance between the varieties.

Historical. Arkansas was grown from seed (4, 10) planted about 1833 near Rhea Mills, Arkansas, where the original tree still stands. It bears a marked resemblance to the Winesap of which it is said to be a seedling (4). Nurserymen began to propagate it about 1868 . In succeeding years it became pretty generally disseminated in Arkansas and surrounding states.

As previously stated, this variety las been confused with the Paragon, an apple of Tennessee origin which it much resembles. It is now conceded that Paragon and.Arkansas are two distinct varieties $(4,7,8,9$, го).

\section{TREE.}

Tree rather large, vigorous; branches large, crooked, stout. Form upright spreading, rather open. Triigs medium to long, sometimes drooping, somewhat curved, thick; internodes short. Bark very dark brownish-red with some dull olive-green, thickly mottled with thin gray scarf-skin; somewhat pubescent toward the tips. Eventually it becomes almost black. Lenticels scattering, rather conspicuous, mostly roundish, medium or sometimes small, often slightly raised. Buds somewhat pubescent; towards the tip and base of the twig they are appressed and often obtuse, but on the intermediate portion they stand out prominently and are large, broad, plump, acute, free. Foliage rather dense; leaves medium to large, often broad.

The mature young twigs of Arkansas much resemble those of Paragon but they are somewhat darker and stockier. The mature Paragon twigs have comparatively more of a reddish-brown tinge.

\section{FrUIT.}

Fruit large to medium, pretty uniform in size. Form roundish inclined to conic, sometimes slightly oblate, broadly ribbed, pretty uniform in shape. Stem laing to almost short, rather stout. Cavity acute, rather wide, medium in depth, green, often much russeted, sometimes indistinctly furrowed. Calyx smáll to medium, usually closed. Basin rather abrupt, rather wide, moderately deep, broadly furrowed or wavy. 


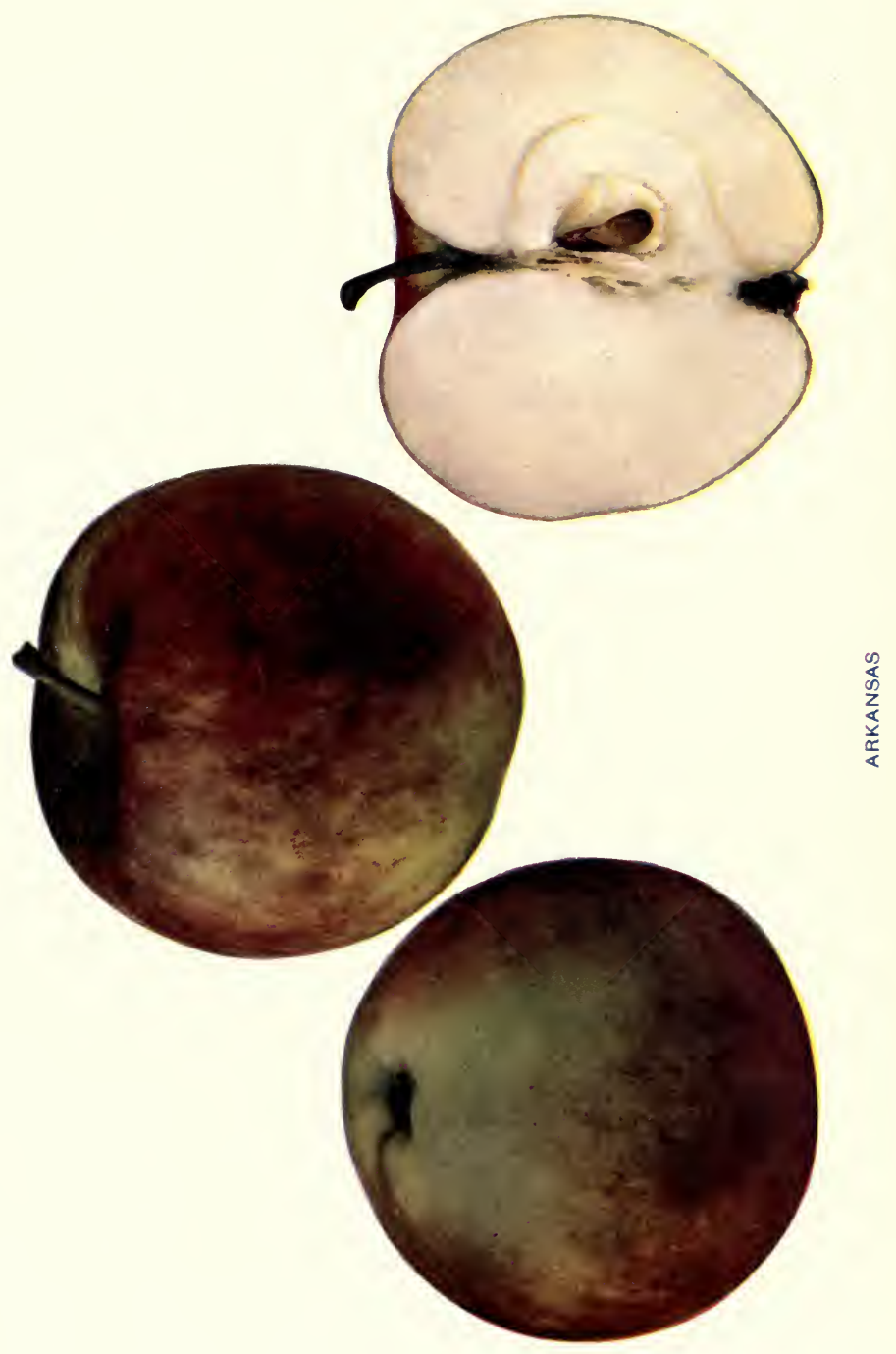



Skin nearly smooth, dull green, often becoming good deep yellow, largely overspread with a di!ll deep red, obscurely striped with darker red. Dots generally small, russet, inconspicuous; sometimes medium and whitish.

Calyx tube medium, conical, sometimes funnel-form. Stamens median to nearly basal.

Core usually axile, ustually closed; core lines slightly clasping. Carpels broadiy ovate, deeply emarginate, tufted; not always well developed. Seeds few and variable, not always well developed; if plump they are long, rather narrow, acute, tufted.

Flesh tinged with yellow, very firm, moderately fine-grained, rather tender, moderately juicy, subacid, crisp. good.

Seascn, Uecember to May.

\section{ARKANSAS BEAUTY.}

References. I. Stinson, Ark. Sta. Bul., 60:124. 1899. 2. Bailey, $A n$. Hort., 1892:234. 3. Budd-Hansen, 1903:40. 4. Powell and Fulton, U. S. B. P. I. Bul., 48:36. I903.

The Arkansas Beauty is a variety of Arkansas origin. Stinson (I) says that it is grown to some extent in a few sections of that state but has not proven valuable. As grown in this latitude the fruit does not always attain good color or good quality.

TREE.

Tree vigorous; branches long, stout, crooked. Form wide spreading with a rather open top. Taigs rather long, moderately stout, often crooked; internodes usually short. Bark olive-green with reddish-brown markings, dull, mottled thickly with scarf-skin; somewhat pubescent. Lenticels rather scattering, roundish or somewhat oblong, medium size to rather small. Buds large to medium, plump, rather obtuse, pubescent. Leaves rather long and narrow.

\section{FrUIT.}

Fruit above medium. Form roundish inclined to conic. Stem long to medium, rather slender. Cavity small, acute, deep, broad, nearly symmetrical, slightly furrowed. Caly.x medium, closed or partly open, pubescent. Basin small, medium in depth and width, rather abrupt, somewhat furrowed.

Skin tough, smooth, rather glossy, pale green or yellow, blushed with pinkishred, and marked with rather faint stripes of carmine.

Caly.x tube long, funnel-shaped.

Core open. Carpels much concave, broadly roundish, emarginate inclined to obcordate, tufted. Secds 1uumerous, dark, medium or below, rather wide, plump, obtuse.

Flesh slightly tinged with yellow, firm, rather fine, moderately crisp, tender, juicy, mild subacid, good.

\section{ARKANSAS BLACK.}

References. I. Van Deman, U. S. Agr. Rpt., I886:268. col. pl. \& fig. 2. Bailey, An. Hort., 1892:234. 3. Stinson, Ark. Sta. Bul., 43:103. 1896. 4. Ib. Bul., 49:7. 1898. 5. Ib. Bul., 60:126. 1899. 6. Kan. Sta. Bul., 106:51. 1902. 7. Budd-Hansen, I903:40. 8. Powell and Fulton, U. S. B. P. I. Bul., 48:36. 1903. 9. Thomas, 1897:272. fig. Ib., 1903:322, 690, 708 . 
Synonyms. Arkansas Black Twig (9). Mammoth Black Twig (9) but erroneously.

The Arkansas Black is one of the most beautiful of apples. It is a good keeper and commands a good price in market. The color is a lively red deepening on the exposed side to purplish-red or nearly black. The tree is unproductive and not desirable for general planting.

Arkansas Black is distinct from the Arkansas or Mamm.oth Blacktwig.

Historical. According to Stinson (4) the Arkansas Black originated in Benton county, Arkansas, and bore its first fruit about I87o. The first description of it which I find, is that given by Van Deman (I) in I 886.

TREE.

Tree moderately vigorous; branches long, slender. Form upright spreading, rather open. Tavigs short, stout; internodes short. Bark dark reddish-brown, mottled with scarf-skin, pubescent. Lenticels scattering, small to below medium, round. Buds large, broad, acute, appressed, pubescent. Learcs medium in size.

\section{Fruit.}

Fruit as grown here is medium or below, rarely large, pretty uniform in size and shape. Form nearly round. Stcm medium. Cacity acute, rather small, sometimes lipped, not deep, partly russeted. Calyx rather small, closed. Basin obtuse, very shallow, slightly furrowed, faintly corrugated.

Skin smooth, somewhat waxy; yellow covered with a lively red deepening to purplish-red or almost black on the exposed side. Dots small, inconspicuous. Prevailing effect bright very dark red.

Calyx tube conical, approaching funnel-form. Stamens marginal.

Core medium to small, abaxile, closed or partly open; core lines clasping. Carpels concave, roundish, emarginate. Seeds plump, rather short, obtuse, moderately dark brown.

- Flesh decidedly tinged with yellow, very firm, rather fine-grained, crisp, moderately juicy, sprightly subacid, good to very good.

Season December to April or later. In cold storage (7) it keeps well through the storage season.

\section{ARNOLD.}

References. I. Downing, 1876: app. 43. 2. Bailey, An. Hort., 1892:234. 3. Thomas, 1897:626. 4. Mich. Sta. Bul., 177:48. 1899. 5. Ib. Bul., 187:85. 1901. 6. Ib. Bul., 194:62. 1901. 7. Ib. Bul., 205:43. 1903. 8. Budd-Hansen, 1903:40.

Synonyms. Arnold's Beauty ( 1,3 ). Arnold's Beauty (8).

The Arnold was raised from seed produced by pollinating Northern Spy with pollen from Wagener and Esopus Spitzenberg by Charles Arnold, Paris, Ontario (I). Fulton reports $(4,5,6)$ 
that "it is too light in color and almost too tender for market, promising for home use." Tree vigorous and productive.

\section{FRUIT.}

Fruit medium in size. Form oblate, slightly ribbed. Stem medium, slender. Cavity broad, deep, usually slightly russeted. Calyx small, closed. Basin deep, slightly corrugated. Skin yellowish-white, netted russet, sometimes with a little bright red. Prevailing effect light yellow. Calyx tube funnel-shape. Core small. Flesh yellowish, firm, mild subacid, juicy, slightly aromatic, very good.

Season November to March.

\section{ARTHUR.}

References. I. Hansen, S. D. Sta. Bul., 76:26. 1902. fig. 2. BuddHansen, I903:4I.

The Arthur originated as a chance seedling in Northern Iowa where hardiness of tree is a prime consideration and where it is reported to have endured for many years better than any other variety except the Oldenburg. ${ }^{1}$ It is not desirable for planting in New York.

\section{TREE.}

Tree is a moderate or rather slow grower with stocky branches and drooping branchlets, forming an upright roundish head. Twigs short, stout; internodes medium. Bark dark reddish-brown covered with light scarf-skin; somewhat pubescent. Lenticels scattering, brownish, small to medium, slightly elongated, raised. Buds small, deeply inserted in the bark, obtuse, pubescent. Leavcs medium size, broad.

\section{FrUit.}

Fruit usually below medium. Form oblong narrowing towards the stem, varying to roundish obovate; hardly symmetrical; sometimes slightly ribbed. Stem medium to long, slender, often bracted. Cavity acuminate, deep, rather narrow, thinly russeted. Caly.x small, closed or nearly so; lobes reflexed. Basin rather abrupt, moderately deep, moderately wide, usually smooth.

Skin rather pale dull yellowish-green, thinly washed with dull red and faintly striped with carmine splashes. Dots numerous, dull russet, inconspicuous. Prevailing effect striped.

Calyx tube narrow, funnel-shaped. Stamens medium to marginal.

Core medium, abaxile, slightly open to wide open, sometimes with four cells instead of five; core lines clasping. Carpels roundish to obcordate, decidedly concave. Seeds thick, rather short to medit:m.

Flesh tinged with yellow, moderately firm, somewhat coarse, not tender, juicy, subacid, somewhat aromatic, fair to good in flavor and quality.

Season October to January.

Uses. Suitable for culinary purposes. It is not desirable for market because it is not particularly attractive in form, size or color, it is not a good keeper and it is inferior to standard varieties in quality.

'Patten, C. G., Charles City, Ia., Cat. 1892. 


\section{AUCUBA.}

References. I. Leroy, 1873:301. fig. 2. Beach, N. Y. Sta. An. Rpt, 14:586. I892. 3. Bailey, An. Hort., I892:234. 4. Thomas, I903:689. 5. Powell and Fulton, U. S. B. P. I. Bul., 48:36. 1903. 6. Beach and Clark, N. Y. Sta. Bul., 248: I II. I904.

Synonyms. Acuba-leaved Reinette (4). Acuba-leaf Reinette (2). Feuilles D'Aucuba (I). Aucubafolia (3). Reinette a feuille d'Acuta (2).

The Aucuba is a moderately attractive apple of medium size and pretty good quality. The tree is hardy, healthy and bears regularly and abundantly. It is in season from October to January. The variety is not recommended for general planting because the fruit is second rate in size, appearance and quality.

Historical. Leroy (I) states that Aucuba was described as early as 1839 in Jardin fruitier p. 216, but that its origin is still unknown. In New York state it has been disseminated but sparingly and is not commonly known.

\section{TREE.}

Tree moderately vigorous; branches moderately long and stout. Form rather open, upright spreading. Twigs long, slightly curved, moderately slender; internodes below medium to short. Bark dark reddish-brown with light scarf-skin, pubescent. Lenticels numerous, small, round. Buds medium, rather long, acute, pubescent, often free. Leaves large and broad.

Aucuba begins bearing rather young and usually bears annual crops. There is some tendency for the fruit to drop before the crop is ready to be gathered.

\section{Fruit.}

Fruit medium to above, pretty uniform in size and shape. Form roundish inclined to conic, sometimes a little oblate, sides occasionally unequal. Stem usually long and slender. Cavity acuminate, sometimes acute, deep, moderately narrow to rather broad, nearly symmetrical, seldom russeted. Calyx small, closed or partly open; lobes long, acuminate. Basin usually narrow and shallow, sometimes moderately wide and moderately deep, obtuse to rather abrupt, often somewhat furrowed and corrugated.

Skin smooth, waxen yellow, rather pale but bright, often nearly covered with bright pinkish-red indistinctly marked with narrow carmine stripes. In well colored fruit the red rather predominates over the yellow. Dots very inconspicuous, gray or russet. General appearance is rather attractive.

Calyx tube either rather short, narrow, cone-shaped, with core lines nearly meeting, or narrowly funnel-form, in which case the core lines clasp the cylinder of the calyx tube. Stamens median.

Core medium to small, axile, partly open or sometimes closed.

Carpels smooth, slightly emarginate, roundish cordate, sometimes distinctly narrowing toward the apex. Seeds numerous, small to medium, narrow, acute or acuminate.

Flesh whitish with yellow tinge, firm, breaking, fine, tender, juicy, sprightly subacid, with distinct aroma, good to very good.

Season October to January; some of the fruit may keep till spring but it is apt to deteriorate in flavor and quality after midwinter. 


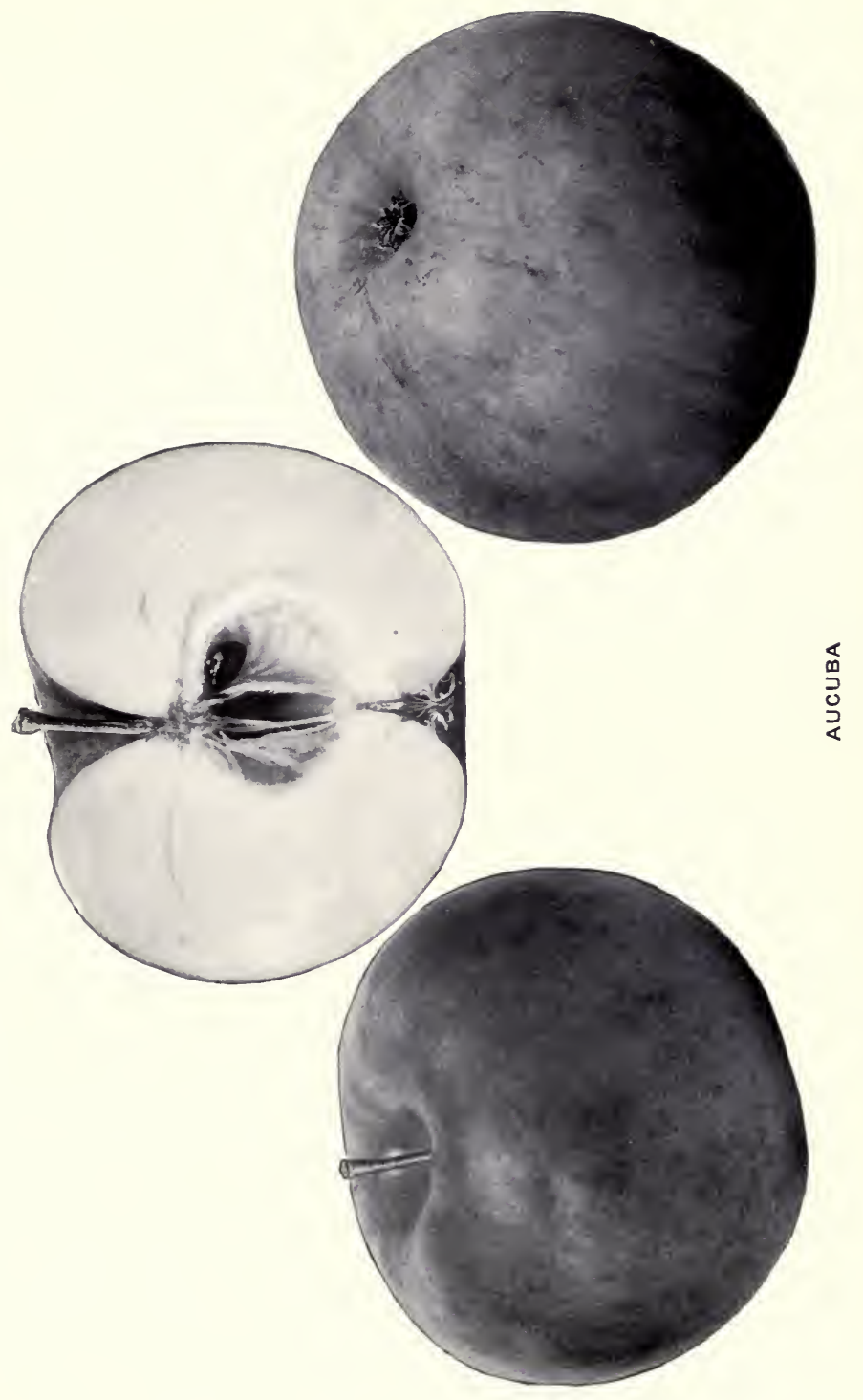





\section{BABBITT.}

References. 1. Gano, Am. Pom. Soc. Rpt., r889: izo. 2. Bailey, An. Hort., 1892:234. 3. U. S. Agr. Rpt., 1893:286. 4. Lyon, Mich. Sta. Bul., I69:18o. I899. 5. Fulton, Ib., 194:62. I90I. 6. Thomas, 1903:322 7. Budd-Hansen, I $903: 4 \mathrm{I}$.

Synonym. Western Baldwin $(3,6,7)$.

Babbitt is a very handsome large apple, red and striped, of about the same season as the Tompkins King. It is excellent for cooking but too sour for dessert. It is hardy, healthy and very vigorous. In Western New York, so far as tested, it appears to be productive, comes into bearing rather young, and bears heavy biennial crops. In fact some report that the fruit sets so abundantly that it is apt to be rather small unless attention be given to pruning and thinning. Further testing is required to determine its merits for this region. It has been found very productive in Michigan ( 5 ), and is reported as generally productive in the central states (3). In Eastern New York, although it blooms abundantly, it has been found to be a shy bearer. On this account and because the fruit is very acid, it is not there considered worthy of cultivation.

Historical. Babbitt originated from seed of Baldwin about $\mathrm{I} 845$ with C. W. Babbitt of Woodford county, Illinois (3).

TREE.

Tree vigorous to very vigorous. Form roundish spreading, rather open; branches stout, often crooked, tough, with strong joints which hold heavy loads without splitting. Twigs moderately long, rather stocky, varying from curved to nearly straight; internodes very short. Bark bright olive-green with dull reddish-brown markings, thickly mottled with scarf-skin; quite pubescent. Lenticels irregularly scattering, medium to small, usually roundish or somewhat elongated. Buds medium to large, broad, obtuse, pubescent. Leaves medium to large, rather broad, dark green, with thick texture.

\section{Fruit.}

Fruit somewhat resembles Wagener in form, being large, roundish oblate, slightly angular and somewhat irregular. Stem short. Cavity obtuse to acute, moderately shallow, medium to broad, slightly russeted. Calyx nearly closed. Basin somewhat abrupt, moderately decp, somewhat furrowed, slightly corrugated.

Skin bright pale yellow with mottled red cheek, striped with bright carmine. When well grown the fruit has good size, bright attractive color and fine general appearance.

Calyx tube conical approaching funnel-form. Stamens median.

Core rather small, axile, closed; core lines clasping. Carpels broad, roundish, nearly truncate. Seeds dark brown, medium or below. 
Flesh whitish, tinged with yellow, moderately fine-grained, moderately crisp, juicy, sprightly subacid or sour; too sour for dessert, excellent for cooking.

Season. It is in season about with Tompkins King but sometimes keeps well till late spring, and is then especially desirable for cooking because it retains well its sprightly subacid flavor.

\section{BAILEY SWEET.}

References. I. Thomas, I849:I59. 2. Emmons, Nat. Hist. N. Y., 3:59. I851. 3. Downing, I857:I16. 4. Elliott, I858:121. 5. Warder, r867:633. fig. 6. Downing, I872:84. 7. Barry, 1883:342. 8. Lyon, Mich. Hort. Soc. Rpt., 1890:288. 9. Bailey, An. Hort., 1892:234. го. Vt. Sta. An. Rpt., 1901:287. I1. Fulton, Mich. Sta. Bul., I87:85. I901. I2. Hansen, S. D. Sta. Bul., 76:27. 1902. I3. Thomas, 1903:319. 14. Budd-Hansen, 1903:42. fig. 15. Beach and Clark, N. Y. Sta. Bul., 248: I I, i904. I6. Cole, 123. I7. Hooper, I2.

Synonyms. Bailey's Golden Sineet (i6). Bailey Sweet ( I, 4, 5, I2, I3, 17). Bailey Swect (8, Io). Bailey's Sweet (2, 3, 7, I6). Bailey's Swect (9). Edgerly Sweet (I, 4, I3). Edgerly's Swect $(3,6)$. Howard's Swect $(3,6)$. Paterson's Sweet $(3,6)$. Patterson Sweet (13). Patterson's Sweet $(\mathrm{I}, 2)$.

This is a very beautiful red apple, distinctly sweet and of very good quality. It is in season from October to January or sometimes later. It is not a very good keeper. In some localities the fruit is apt to be rather scabby and knotty, and unless it is well sprayed the percentage of unmarketable and low-grade fruit runs rather high. The tree is reliably productive but it does not excel either in vigor, health or hardiness. It is not recommended for cultivation.

Historical. Bailey Sweet was introduced under this name from Perry, Wyoming county, New York, more than 60 years ago (I). Whether it originated there or was an old variety brought in from the East is uncertain (3). Although it has long been known and widely disseminated, there is no section of the state where it is grown in large quantities.

TREE.

Tree upright, somewhat spreading, rather open, not dense; branches moderately stout or slender. Trivigs rather slender, nearly straight; internodes medium to short. Bark rather dark brownish-red marked with thin gray scarf-skin ; sparing!y pubescent. Lenticels numerous, medium to below, usually oblong, conspictous, somewhat raised. Buds medium to large, broad, acute to somewhat obtuse, appressed; somewhat pubescent. Lcaves often rather broad and large; foliage not dense.

In the nursery the development of the root system is rather light or weak. In the orchard the tree makes a rather slow or moderately vigorous growth and does not become large. It is a reliable cropper with a tendency to annual bearing. The fruit hangs well to the tree. 


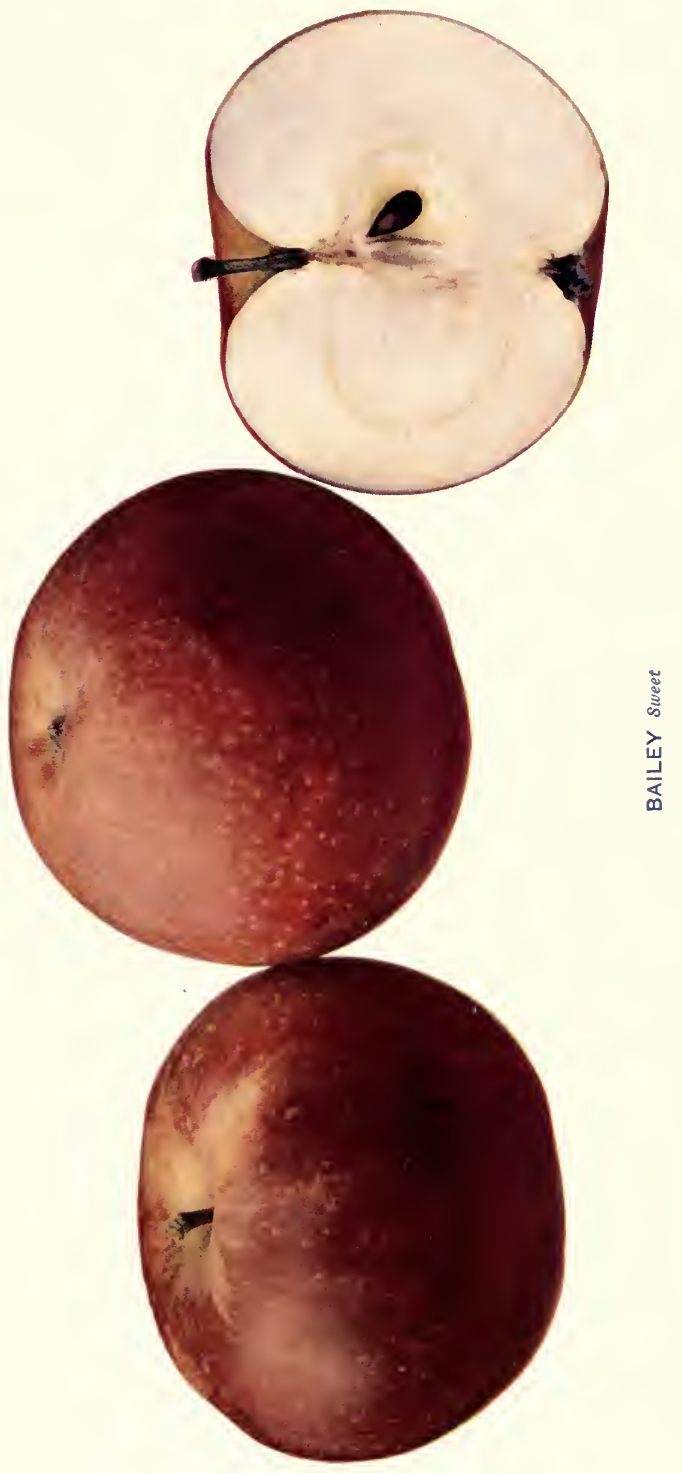





\section{FRUIT.}

Fruit sonetimes as large as Baldwin or larger and averages above medium. Form roundish to roundish conic, or somewhat oblate, ribbed obscurely if at all, rather symmetrical, sides somewhat elliptical; pretty uniform in size and shape. Stem short to medium, rather slender to thick. Cavity acute, usually rather deep, somewliat furrowed, sometimes with sides compressed or lipped, often partly covered with a thin golden-brown russet. Calyx closed or sometimes partly open, small to medium with short obtuse to acute lobes. Basin somewhat shallow to very sinallow, medium to narrow, obtuse to rather abrupt, often slightly furrowed or slightly corrugated, with a tendency to develop mammiform protuberances.

Skin rather tender, nearly smooth, clear bright yellow largely covered with deep red, mottled or obscurely striped with darker red. Often irregularly netted markings and dots of whitish or russet-gray contrast conspicuously with the red surface. Whitish scarf-skin sometimes radiates from the cavity. Prezailing effect attractive bright red.

Calyx tube funnel-shape, medium length with a rather wide limb. Stamens median.

Core axile, medium in size, closed; core lines clasping. Carpels elliptic to roundish cordate, emarginate. Seeds medium to rather large, long, acute.

Flesh tinged with yellow, firm, moderately coarse, moderately crisp, rather tender, moderately juicy to juicy, decidedly sweet, agreeable in flavor, very good in quality.

Season October to January or later.

\section{BAKER.}

REFERENCES. I. Horticulturist, I5:92. I860. 2. Downing, I872:84. 3 . Thomas, 1885:502. 4. Not listed by Bailey, An. Hort., r892:234. 5. Taylor, Am. Pom. Soc. Rpt., I895:193. 6. Budd-Hansen, 1903:43. 7. Powell and Fulton, U. S. B. P. I. Bul., 48:37. 1903 .

Synonym. Scott (2).

This is a red apple of good size, pretty uniform in size and shape and of fairly good quality. It is not so good a keeper as Baldwin and is inferior to it in quality and hardly equal to it in color. The tree is hardy, healthy, vigorous and reliably productive with a tendency to biennial bearing. There is a considerable loss from the dropping of the fruit. Although it has been known in cultivation for more than a century (I), it appears to have practically passed out of the lists offered by the nurserymen in North America (4) and evidently is nearly obsolete.

Historical. It is stated that the original tree was in full bearing in its native place, Richfield, Ct., during the Revolutionary War. Forty years ago it was but little known outside the vicinity of its origin (I).

TREE.

Tree large, vigorous, productive; branches stout, crooked. Form upright spreading, open. Twigs below medium to long, erect, slightly curved, stout, blunt at the tips; internodes medium. Bark rather clear olive-green partly covered with dark brownish-red, with light streaked scarf-skin; quite pubescent. 
Lenticels scattering, roundish, medium sized, raised. Buds prominent, large, broad, plump, obtuse, pubescent, free or nearly so. Leaves large, broad.

\section{Frutt.}

Fruit above medium to sometimes large; pretty uniform in size and shape. Form roundish to roundish conic, sometimes slightly oblate, generally symmetrical. Stcm medium to short, rather thick. Cazity acuminate, rather shallow to moderately deep, broad, often with radiating russet, sometimes lipped. Calyx large, usually open, sometimes closed; lobes often reflexed, acute to obtuse. Basin abrupt, moderately decp, moderately wide to wide, somewhat furrowed.

Skin yellow or greenish-yellow, largely overlaid or mottled with red and striped and splashed with carmine, but not conspicuously so. Dots numerous, russet, mingled with some broken lines or flecks of russet, yet the skin is rather smooth. Prevailing effect when highly colored is bright red, otherwise yellowish.

Calyx tube wide, conical sometimes with short funnel tube extension. Stamens median to basal.

Core comparatively small, axile, closed or sometimes open ; core lines slightly clasping. Carpels flat, elongated ovate approaching cordate, tufted. Secds medium, moderately wide, moderately long, acute, tufted, medium brown.

Flesh whitish or tinged with yellow, moderately firm, moderately coarse, breaking, moderately tender, rather juicy, mild subacid becoming somewhat sweet, agreeable in flavor, good or nearly good in quality.

Season October to February.

Baker's Eastern Pippin Apple is a distinct variety of Canadian origin.1

\section{BALDWIN.}

References. I. Thacher, I822:IzI. 2. Cat. Hort. Soc. London, I83I. 3. Kenrick, 1833:41. 4. Mag. Hort., $1: 360.1835$. 5. Manning, 1838:59. 6. Dittrich, 3:53. 7. Downing, 1845:98. fig. 1847. col. pl. 8. French, Horticulturist, I:315. I846. 9. Thomas, I849:163. Io. Cole, I849:128. Ir. Emmons, Nat. Hist. N. Y., 3:75. 1851. fig. 12. Hovey, I:II. I852. fig. and col. pl. I3. Bivort, An. de Pom. Belge, I855: I47. 14. Hooper, I857:I4. I 5. Elliott, I858: 66. fig. 16. Flotow, Ill. Handb. Obstk., I:427. I859. I7. Mas, Le Verger, 5:163. col. pl. 18. Warder, 1867:42. fig. I9. Downing, I872:85. fig. 20. Leroy, 1873:89. fig. 21. Barry, 1883:342. 22. Hogg, 1884:13. 23. Wickson, 1891:245. 24. Bailey, An. Hort., r892:234. 25. Woolverton, Ont. Fruit Stas. Rpt., 1895:7. fig. 26. Taylor, U. S. Div. Pom. Bul., 7:350. I897. 27. Amer. Gard., 1899:546. 28. Eneroth-Smirnoff, rgor:261. 29. Budd-Hansen, 1903:43. fig. 30. Thomas, 1903:323. fig. 31. Fr. Lucas, 187.

Synonyms. Baldwin Rosenapfel (3i). Baldwin's Rother Pippin (6). Calville Butter (18). Felch (7, 18, 19). Latc Baldwin (12, 18). Pecker (I, 7, 18, 19). Red Baldwin Pippin (18). Steele's Red Winter (7, 12, 18, 19). Woodpecker (7, I8, 19, 2I).

The Baldwin is a bright red winter apple, above medium in size or large, and very good in quality when grown under favor-

${ }^{1}$ Montreal Hort. Soc. Rpt., 3:20. 1877 . 


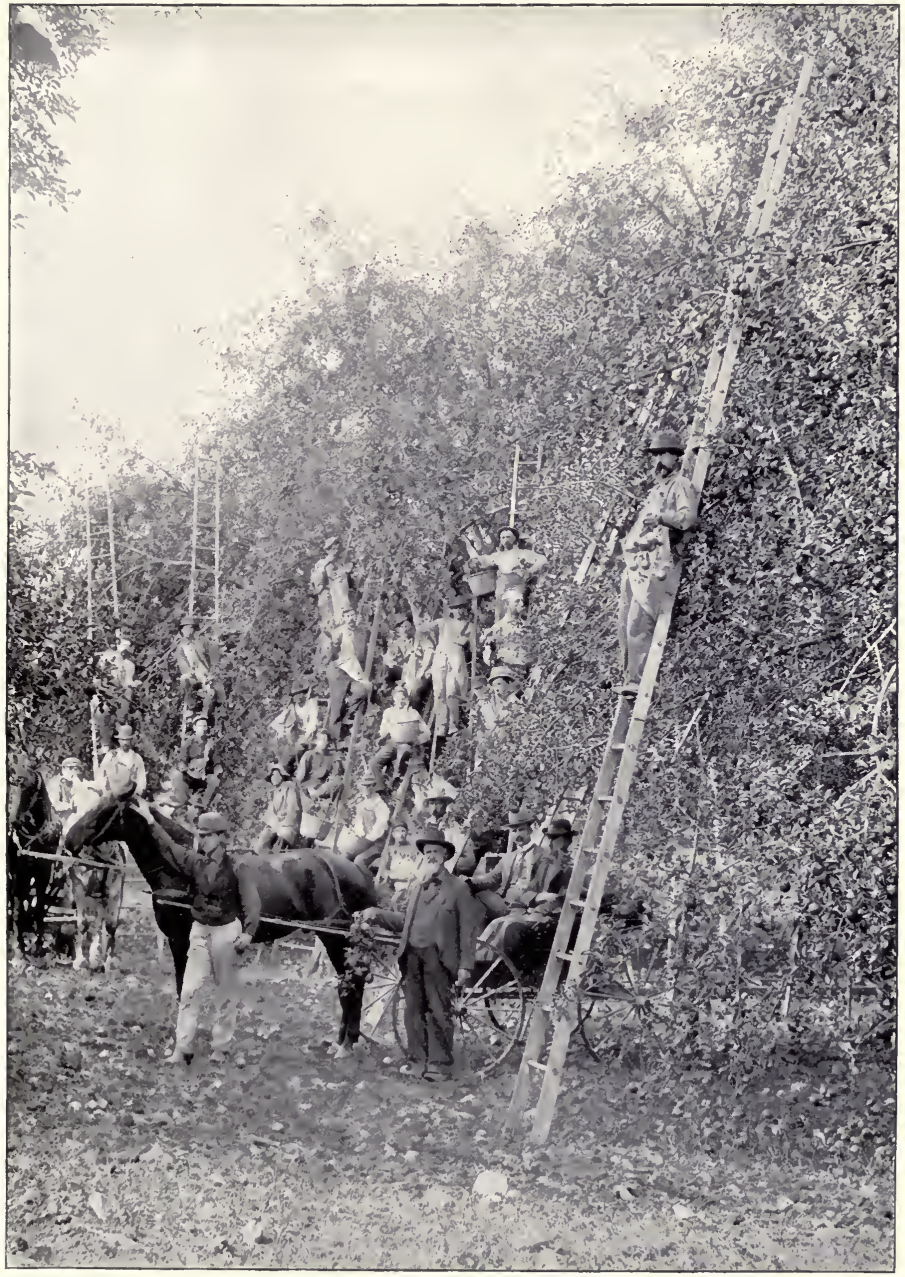

GROUP OF FRUIT PICKERS IN THE BALDWIN ORCHARD OF FOSTER UDELL, BROCKPORT, MONROE COUNTY, N. Y. 

able conditions. It stands handling well because of its firm texture and thick skin. It is a favorite market variety because of its desirable season, good size, attractive red color and good quality.

The Baldwin is preeminently the leading variety in the commercial orchards in New York, New England, certain regions in Southern Canada, in the southern peninsula of Michigan and on the clay soils of Northern Ohio. In many localities in Northern New York it is apt to winter-kill, especially in the higher altitudes. For the same reason it also fails in portions of Michigan and west of the Great Lakes. In the South and Southwest it is not desirable because it there becomes a fall apple and also because it does not attain as good quality as it does in the Baldwin belt. From Colorado to Washington it is more or less grown in many localities.

Not only is the Baldwin a standard fruit in American markets but it is one of the leading apples used for export trade. It is one of the principal varieties handled in cold storage. The apples of this variety which are unsuitable for barrelling supply a large part of the evaporator stock in New York state, and are also used to some extent by canneries.

The tree is a strong grower, long-lived and vigorous. The accompanying view illustrates the rigorous development of mature Baldwin trees, as also does the frontispiece. It is somewhat slow in reaching bearing maturity, but when mature it bears very abundantly. In fact, one of the faults of this variety is its habit of producing an overload of fruit biennially and bearing little or none on alternate years. On rather light, sandy or gravelly soils the fruit is apt to have a better color, or at least to color earlier in the season, than it does when grown on heavy clay lands. Some hold that fruit from the lighter or more gravelly soils ripens earlier and consequently scalds earlier in storage than do the duller colored Baldwins grown on heavier soils. The Baldwin is grown successfully on various soils and under various climatic conditions. Besides the other good points of the Baldwin which have been noticed above, it has the advantage of yield- 
ing a pretty uniform grade of fruit with a low percentage of culls, when kept free from injurious insects and fungous diseases.

The Baldwin foliage and fruit are often much injured by the apple scab fungus. It has often been remarked that the prevention of fungus diseases and of the attacks of insects, by proper spraying, not only increases the yield of marketable fruit but improves the quality as well. The Baldrin Spot is the name given to brown flecks in the flesh of Baldwin apples. This is not caused by either insects or fungi. It is a physiological defect which is more apt to appear in overgrown than in medium-sized fruit. No remedy is known. ${ }^{1}$

Historical. Soon after 1740 the Baldwin came up as a chance seedling on the farm of Mr. Johı Ball, Wilmington, near Lowell, Mass., and for about 40 years thereafter its cultivation was confined to that immediate neighborhood. The farm eventually came into the possession of a Mr. Butters, who gave the name Woodpecker to the apple because the tree was frequented by woodpeckers. The apple was long known locally as the Woodpecker or Pecker. It was also called the Butters. ${ }^{2}$ Deacon Samuel Thompson, a surveyor of Woburn, brought it to the attention of Col. Baldwin of the same town, by whom it was propagated and more widely introduced in Eastern Massachusetts as early as $\mathrm{I} 7 \mathrm{~S}_{4}$. From Col. Baldwin's interest in the variety it came to be called the Baldwin. ${ }^{3}$

In 1817 the original tree was still alive but it perished between 1817 and 1832.4 A monument to the Baldwin apple now marks the location.

Coxe in his work on fruits in 1817 makes no mention of the Baldwin. Thacher's American Orchardisl, published in Boston in 1832, gives it very brief but favorable mention. Floy in his American edition of Lindley, Guide to the Orchard, New York, 1833 , does not mention it, but in the appendix to the 1846 edition he describes the Baldwin and states that "in the Eastern States (New England) it is well known, highly esteemed, and extensively cultivated." Kenrick's New American Orchardist, Boston, 1833, says, "No apple in the vicinity of Boston is so popular as this, at the present day. It is raised in large quantities for the market $* * *$ and is recommended for extensive cultivation."

Hovey in 1852 published an extended description of Baldwin with colored plate (12). He remarks, "The Baldwin is the most popular apple of New England, and is cultivated to a much greater extent than any other variety. Several large and fine orchards are to be found in the vicinity of Boston, some of which produce about one thousand barrels of fruit every bearing year. For exportation it is much sought after; and the large number of fifteen hundred barrels have been sent to the East Indies in one season."

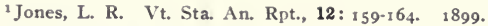

${ }^{2}$ French, B. V. Downing Hort., I: 315.1846.

${ }^{3}$ Mass. Ploughman, cited in Mich. Hort., I: 335 .

-Amer. Gard. Mag. $1835: 360$. New Eng. Homestead, 1885:228.
} 

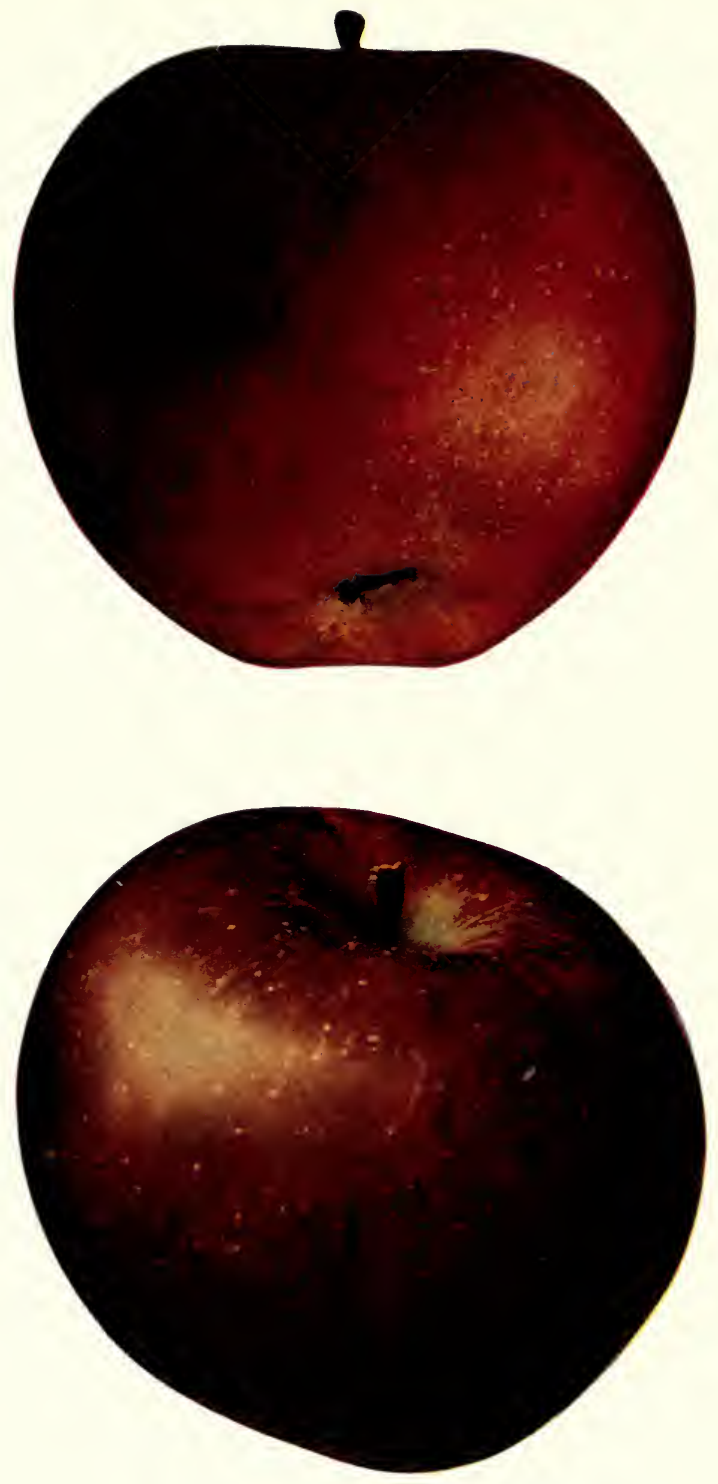

BALDWIN 

Prior to 1850 the Baldwin was but little known in New York state. After that date, with the extension of the planting of commercial orchards, it came rapidly into popularity and gained the supremacy among the commercial apples of New York which it still holds.

\section{TREE.}

Tree large, very vigorous; branches large, strong. Form upright spreading, eventually becoming rather round and somewhat dense. Twigs long, straight, or somewhat crooked, moderately stout; internodes medium to long. Bark dark brownish-red mingled with olive-green and faintly marked with thin scarf-skin; somewhat pubescent. Lenticels numerous, conspicuous, raised, usually oblong, sometimes large. Buds medium to large, broad or roundish, acute, pubescent, free or nearly so. Leaves often broad and large to very large; foliage rather dense.

\section{FrUIT.}

Fruit sometimes large to very large; usually above medium; pretty uniform in size. Form roundish inclined to conic, varying to roundish oblong; often faintly ribbed or somewhat irregular; symmetrical; fairly uniform in shape. Stem usually medium, to long. Cavity acute, medium to rather deep, rather broad, often somewhat furrowed, sometimes compressed, sometimes lipped, often russeted, with outspreading rays of russet or deep green. Caly.x small to rather large; closed or somewhat open; lobes long, acute to acuminate. Basin abrupt, narrow to moderately wide; often distinctly furrowed; slightly corrugated.

Skin tough, smooth, light yellow or greenish, blushed and mottled with bright red, indistinctly striped with deep carmine. Flecks of russet, or even broken russet lines, may occasionally be seen on the base of the fruit. Dots gray or whitish, depressed, small and numerous toward the basin, more scattering, conspicuous, large, irregular, or elongated towards the cavity. Prevailing effect is brigint red.

Calyx tube conical, rather short and wide with projection of fleshy pistil point into its base. Stamens basal.

Core medium or below, nearly axile, closed or partly open; core lines meeting. Carpels roundish ovate, emarginate, somewhat tufted. Seeds variable, often abortive; when normally developed they are large, long, acute, and dark brown.

Flesh yellowish, firm, moderately coarse, crisp, rather tender, juicy to very juicy, agreeably subacid, sprightly, somewhat aromatic, good to very good.

Season November to March or April in common storage; to May or later in cold storage. 1

Uses. Well adapted for general market, dessert and culinary uses.

\section{Other Baldwin TyPes.}

Besides the general type of the Baldwin apple above described, mention should be made of the following:

Russet Balduins. Cases have been reported where the Baldwin has sported and developed fruit with russet skin. Since these apples appear

${ }^{2}$ Beach and Clark. N. Y. Sta. Bul, 248:111-112. 1904. 
to show no advantage over the smooth-skinned Baldwins, they are seldom propagated.

Gray Baldwin, Blue Baldwin, Black Baldwin and Dark Baldwin are indefinite terms sometimes applied to what appears to be a distinct type of the Baldwin. Scattering trees of it are occasionally found mingled in orchards with Baldwins of the ordinary type. The Dark Baldwin as compared with the common type has fruit that is slower in maturing on the tree, and keeps longer. The flesh has more of a greenish tinge and is firmer. The skin also shows dull green where the common type is yellow, and the red is dull and darker than the red of the common Baldwin. So far as we know the Dark Baldwin is not being intentionally propagated.

In speaking of the Dark Baldwin as a distinct type the fact is here recognized that the ordinary Baldwin when grown on sandy or gravelly soil generally gives brighter colored fruit than when grown on heavy clay soil. But the above-mentioned occurrence of a type called Dark Baldwin, mingled as it sometimes is in orchards with Baldwins of the common type, does not seem to be satisfactorily accounted for by attributing its apearance to a difference in soil. It is more probable that a distinct strain has arisen and been disseminated unwittingly in place of the common type.

Olympia is a sport of the Baldwin which differs from the type in having larger and better colored fruit. It is described under "Olympia."

\section{BANANA SWEET.}

References. I. Rural N. Y., I885:278. fig. 2. Hexamer, Am. Pom. Soc. Rpt., $1895: 69$.

This is a sweet winter apple, attractive in appearance. Color greenish-yellow, highly colored specimens are blushed. Season January to March in New Jersey. So far as we know it has not been fruited in New York. This should not be confused with the Winter Banana introduced by Greening Brothers of Monroe, Michigan, in 1890 , which is not a sweet apple.

Historical. Banana originated as a chance seedling with C. E. Blackwell, Titusville, N. J., about 1867 .

TREE.

Tree spreading, upright, vigorous, rather dense. Twigs rather slender; internodes short. Bark reddish-brown. Buds not prominent.

\section{Fruit.}

Fruit large. Form roundish conical, sometimes one-sided. Stem medium to large, long, slender. Cavity rather small, moderately deep, often with outspreading, irregularly broken, russet patches. Calyx rather small, closed. Basin small to medium, somewhat irregularly corrugated, rather deep.

Skin greenish-yellow with a pale blush on the exposed side. Dots minute, scattering. Prez'ailing effect yellow.

Calyx tube conical, approaching funnel-form.

Core medium size, axile. Carpels roundish. Seeds medium size, obtuse.

Flesh white, fine-graired, tender, juicy, sweet, good.

Season, January to March or April. 

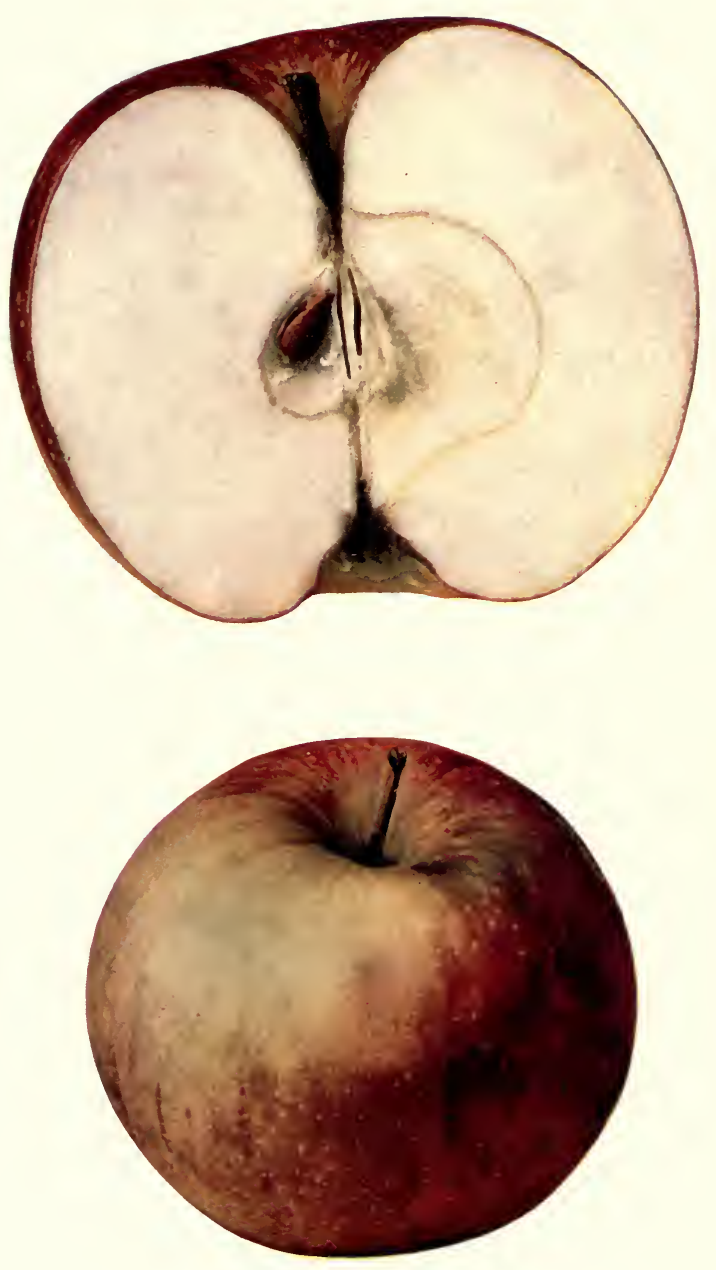

BALDWIN 



\section{BAPTIST.}

References. I. Downing, r876: app. 44. 2. Bailey, An. Hort., 1892:234. 3. U. S. Pom. Rpt., 1895:20. 4. Taylor, Am. Pom. Soc. Rpt., 1897:36.

As fruited at the Geneva Experiment Station, Baptist lacks distinctive character both in appearance and quality. In early winter its prevailing effect is dull dark red overspreading a dull greenish background, but it holds its color well until very late in the season and eventually the yellow tones become brighter making the fruit rather attractive. It is not recommended for cultivation in New York.

Historical. Baptist originated at Clinton, Kentucky (I), and was received for testing at the Geneva Experiment Station from W. M. Samuels of that place.

TREE.

Tree vigorous; branches rather stout. Form roundish, spreading, dense. Twigs rather long to below medium, somewhat curved, moderately thick; internodes medium to short. Bark rather dull, dark reddish-brown; somewhat pubescent. Lenticels numerous, very irregular in size, shape and distribution, generally small, slightly elongated, and very thickly set, but some are large and narrow. Buds medium or below, often rather prominent, generally acute, very pubescent and free. Leaves moderately broad.

\section{Fruit.}

Fruit medium or below; pretty uniform in size and shape. Form oblate to roundish, truncate at base, sides sometimes unequal, often obscurely ribbed. Stem short to medium, thick. Cavity obtuse, moderately shallow to rather deep, broad, sometimes russeted, greenish, occasionally lipped. Calyx closed or sometimes slightly open, medium, or below, pubescent. Basin rather shallow to moderately deep, wide, rather abrupt, somewhat furrowed and corrugated.

Skin thick, tough, smooth, green or yellowish blushed with red, deepening to very dark red in the sun, indistinctly marked with narrow deep crimson stripes. Dots conspicuous, small, pale yellow or russet. Prevailing effect very dark red.

Calyx tube long, conic to funnel-shaped. Stamens median to basal.

Core medium to small, closed or partly open, axile or nearly so, very broadly turbinate; core lines clasp the cylinder. Carpels elliptic or inclined to obcordate, emarginate. Seeds few, about medium size, rather wide, obtuse, somewhat tufted.

Flesh yellowish, very firm, somewhat coarse, not crisp, moderately tender, not very juicy, mild subacid, eventually becoming nearly sweet, hardly good.

Season at Geneva, January to June, in Kentucky, December to February.

\section{BARBEL.}

References. I. Gibb, Ia. Hort. Soc. Rpt., i883. 2. Budd, Ia. Agr. College Bul., 1885:18. 3. Beach and Close, N. Y. Sta. An. Rpt., 1896:275-276. fig. 4 . Beach and Clark, N. Y. Sta. Bul., 248:1 12. I904.

Synonyms. Dept. No. 467 (2). Sugar Barbel (4). Sugar Barbel (3).

This is an attractive, dark red, winter apple of no special value in this region (3). It ranks good for dessert but only fair to good for culinary uses. 
Historical. It was imported from Russia by the U. S. Department of Agriculture under No. 467 about 1870 (2). Stock was received for testing at this Station fron Dr. T. H. Hoskins, Newport, Vt., 1888.

TREE.

Tree vigorous, spreading, rather open. Taigs long to medium, rather slender to moderately stout; internodes short to medium. Bark dark brownish-red mottled with light scarf-skin. Lenticels numerous, small to medium, round or somewhat elongated; pubescent. Buds medium in size, plump, broad, obtuse to acute, appressed; pubescent. Leaves large, broad.

\section{Fruit.}

Fruit medium to large. Form oblate to oblate conic, slightly ribbed, pretty symmetrical. Stem short to medium, often thick. Cazity acute to acuminate, deep, rather wide, with outspreading russet rays. Caly.r rather large, broad, open or partly closed. Basin broad, rather abrupt, moderately deep, corrugated.

Skin dull yellow, overspread with dark red, sparingly marked with yellowish dots and russet flecks. Prez'ailing effect good, dark red.

Calyx tube funnel-form with long cylinder. Stamens median. Core axile, closed. Seed medium size to rather large, tufted, obtuse.

Flesh tinged with yellow, rather coarse, firm, crisp, moderately juicy, moderately subacid, eventually becoming sweet or nearly so, slightly aromatic, good.

Season October to February or later.

\section{BARRINGER.}

References. I. Hexamer, Am. Pom. Soc. Rpt., I899:89. 2. Hexamer, Amer. Agric., 62:569. Dec. 3, 1808. figs. 3. Fancier's Review and Fruit Grower, Chatham, N. Y., Nov., I899:5 4. Johnson, Amer. Agric., 75:79. í95. figs. 5. Beach, West. N. Y. Hort. Soc. Rpt., I901:76.

Synopyas. Pride of the Hudson $(1,2,4)$. Pride of Hudson (5). Coon (locally).

This variety has been known for many years in Clermont, Columbia county, where a few trees of it were in their prime fifty years ago. Mr. Jacob Barringer of Germantown, N. Y., was the first to propagate it from these old trees $(I, 4)$. Columbia county fruit growers report that it is worthy of a place in the commercial orchard, the tree very thrifty, long-lived and productive, the fruit good in size, showy and of excellent quality. At the American Institute in New York in 1898 the fruit was exhibited under the name Pride of the Hudson, but in 1899 this name was changed to Barringer.

\section{TREE.}

Trec vigorous; branches long and moderately stout. Form upright spreading, rather open. Tavigs long, slightly curved, with thick tips; internodes short. Bark reddish-brown, with light streaks of scarf-skin; pubescent. 
Lenticels numerous, small, roundish. Buds of medium size, broad, obtuse, free, pubescent. Leaves medium, broad.

\section{Fruit.}

Fruit above medium to large. Form roundish conical, slightly ribbed, sometimes flattened. Stem long. Cavity acute to acuminate, moderately deep, rather broad, somewhat furrowed and partly russeted, often lipped.

Skin bright red handsomely striped with dark red and slightly dotted, unusually attractive (4). Calyx tube cone-shaped. Core rather large. Core lines clasping. Flesh white, tinged with yellow, very fine, juicy, mild subacid, very good.

Season ordinarily early winter but it may keep till spring $(1,4)$.

\section{BARRY.}

Reference. I. Ellwanger \& Barry, Rochester, N. Y., Catalogue, r895.

Resembles the Greening type of apples in color and in the acidity of the flesh.

The Barry originated about I880, in the nurseries of Ellwanger \& Barry, Rochester, N. Y., and has been recently introduced by that firm after having been thoroughly tested by them. It has their recommendation as a novelty of sterling merit, and one which they believe will prove valuable for commercial orchards (I).

\section{TREE.}

Tree a good grower; well branched with long upright branches. Form upright, becoming spreading and somewhat open. Twigs curved and often crooked, long, medium, stout; internodes long. Bark rather light olive-green shading to reddish-brown and overlaid with thin gray scarf-skin; quite pubescent. Lenticels scattering, usually small, round, slightly raised. Buds large, broad, obtuse, appressed, pubescent. Leaves large or very large, broad.

\section{Fruit.}

Fruit medium, sometimes large. Form roundish oblate to roundish conic, obscurely ribbed, somewhat irregular. Sten medium. Cavity acute, deep, rather broad, usually with some thin greenish russet, broadly furrowed. Calyx small to medium, closed; lobes acute. Basin abrupt, rather shallow to rather deep, narrow to moderately wide, with narrow furrows and wrinkled.

Skin tough, smooth, clear pale yellow or greenish with faint shade of red on the exposed cheek. Dots numerous, minute, pale, submerged, and a few show a brown or russet point. Prevailing effect green or greenish yellow.

Calyx tube medium size, conical or funnel-shaped. Stamens marginal.

Core medium to rather large, abaxile, open; core lines clasping. Carpels elliptical, much concave, emarginate, tufted. Seeds numerous, medium, obtuse, medium to dark brown.

Flesh firm, moderately fine to fine, crisp, tender, juicy, subacid, sprightly, good.

Season. Late. 


\section{BATULLEN.}

References. I. Lucas, Ill. Handb. der Obstk., 4:559. I864. 2. Leroy, 1873:92. fig. 3. Budd, Montreal Hort. Soc. Rpt., 8:49. I88I-2. 4. Budd, Ia. Sta. Bul., 19:542. 1892. 5. Gaucher, Pomologie, 1894. col. pl. 6. Fulton, Mich. Sta. Bul., 187:85. 1901. 7. Hansen, S. D. Sta. Bul., 76:28. 1902. 8. BuddHansen, I903:44.

Synonym. Pomme de Transylvania (2).

An attractive yellow apple sometimes blushed, desirable for market and culinary uses and acceptable for dessert. If productive enough it is doubtless worthy of a place in the commercial orchards. As tested at the Geneva Station it has not yet proved very productive. It has made a similar record at the Michigan Station.

Origin, Transylvania $(1,2)$.

\section{TREE.}

Tree a poor grower in the nursery (4), moderately vigorous; branches short, moderately stout. Form upright spreading or roundish, dense. Taigs long to medium in length, nearly straight, medium stout; internodes rather short. Bark dark reddish-brown, mottled with scarf-skin; slightly pubescent. Lenticcls numerous, small, generally roundish, raised. Buds medium or below medium in size, narrow, acute, appressed, rather pubescent. Leaves large, broad.

\section{FrUit.}

Fruit medium or above; pretty uniform in size and shape. Form roundish to slightly roundish conic, sometimes a little inclined to oblong, rather regular. Stem medium to short, rather slender. Cavity acuminate, moderately broad to rather narrow, wayy, bright green with whitish spots, sometimes russeted. Calyx small, closed. Basin abrupt, moderately deep, rather narrow, sometimes furrowed and wrinkled, sides sometimes compressed.

Skin smooth, clear, bright, almost waxen yellow, often with no shade of red but sometimes having a distinct blush. Dots small and inconspicuous, usually stubmerged. Prevailing effect attractive yellow.

Calyx tube long, rather narrow, conical or approaching funnel-form. Stamens median.

Core small to medium, axile, closed or open; core lines clasping. Carpels roundish, sometimes unsymmetrical, emarginate. Seeds small to medium, plump, obtuse to acute, dark.

Flcsh tinged with yellow, firm, moderately coarse, crisp, rather tender, juicy, subacid, aromatic, sprightly, very good.

Season November to March.

\section{BAXTER.}

References. I. Ont. Fr. Gr. Assn., I881:92. 2. $I b$., I882:83. 3. Bridge, Can. Hort., I884:59. 4. Woolverton, Am. Pom. Soc. Rpt., I889:I55. 5. Nicol, Ont. Fr. Gr. Assn., r891:89. 6. T't. Sta. An. Rpt., 14:287. I90I.

Synonyms. Baxter's Red (3). La Ruc (3). Red Pound (3).

A large red apple decidedly attractive in appearance. Some see in it a resemblance to Tompkins King, but there is more evidence 
of a relationship with the Blue Pearmain group of apples. This is seen in the form and color of the fruit, the bloom, the areolar dots and the character of the flesh. It does not rank high in quality. In the St. Lawrence valley it is said to be a strong grower, hardy, productive and not subject to the scab. It is there regarded as a desirable apple to grow for commercial purposes. At Geneva it has proved vigorous and productive, but because it is inferior in quality to other varieties of its season, such as Tompkins King, McIntosh and Hubbardston, it is doubtful whether Baxter is worthy of a place in the commercial orchards of Western and Southern New York.

Origin. It was known near Brockville, Canada, one hundred years or more ago. It gradually found its way into nurseries and within the last twentyfive years has been quite extensively propagated (3).

\section{TREE.}

Tree productive, very vigorous; branches long, medium stout. Form upright spreading, open. Twigs medium to long, straight, rather stout, thick at the tips; internodes medium to long. Bark clear brownish-red streaked with olive-green; pubescent. Lenticels rather numerous, conspicuous, small, sometimes large, round, raised. Buds moderately prominent, imbedded in the bark, acute, appressed. Leaves large, broad.

\section{FRUIT.}

Fruit large to very large. Form roundish to conic flattened at the base or varying to somewhat oblong, often faintly ribbed, somewhat irregular, sides often unequal and also often compressed; axis sometimes oblique. Stem usually short. Cavity large, deep, acute, broad, usually partly russeted, often somewhat furrowed. Calyx small to above medium, sometimes closed or partly open. Basin often oblique, moderately shallow to rather deep, rather narrow to wide, obtuse to moderately abrupt, slightly furrowed, corrugated, sometimes compressed.

Skin thick, tough, slightly roughened by russet dots; pale yellow or whitish largely mottled and blushed with rather bright red often deepening to purplish shades characteristic of the Blue Pearmain group, distinctly splashed and striped with purplish-red. Dots numerous, conspicuous, areolar, whitish or with russet point. A bluish bloom gives the skin a rather dull appearance but when polished it is bright and glossy. Highly colored specimens show but little of the yellow ground color. Prevailing effect attractive red or striped red.

Calyx tube large, elongated, cone-shape or funnel-form. Stamens medium to marginal.

Core medium, usually abaxile, open; core lines meeting or slightly clasping. Carpels roundish varying to elongated ovate, slightly emarginate, tufted. Seeds numerous, below medium, rather wide, plump, obtuse; tufted, dark brown. 
Flesh yellowish, sometimes stained with red, firm, breaking, rather coarse, tender, moderately juicy, mild subacid, slightly aromatic, fair to good.

Season November to January.

Baxter's Pearmain of Downing, p. 89 and of Hogg, p. I6 is distinct from Baxter above described.

\section{BEACH.}

References. I. Stinson, Ark. Sta. Bul., 49:9. I898. fig. 2. Ib., 60:126. 1899. 3. Am. Pom. Soc. Cat., r899:15. 4. N. C. State Bd. Agr. Bul., rgoo:9. 5. Waugh, Vt. Sta. An. Rpt., I4:287. I901. 6. Budd-Hansen, 1903:44. 7 . Powell and Fulton, U. S. B. P. I. Bul., 48:37. 1903.

Synonyms. Apple of Commerce (1, 2, 3, 4, 5, 6, 7). Lady Pippin (I). Richardson's Red ( I, 2, 3, 4, 6, 7).

A red Arkansas apple, which as yet has been but little tested either in New York or adjacent states. In New York ordinarily the season is not long enough for the proper development of apples of the group to which the Beach belongs. For this reason that variety can hardly be expected to prove valuable here. Waugh reports that, as grown in Vermont, it appears to be superior in all respects to Ben Davis, and is really good in quality (5). It is a very late keeper.

Historical. Stinson reports that this variety has been grown to a considerable extent in Benton and Washington counties, Arkansas, under the names Lady Pippin and Richardson's Red. It has also been introduced under the name Apple of Commerce (I). He has found the variety productive and a good keeper, but because it is only fair in quality he advises against the planting of it in Arkansas (2).

TREE.

Tree rather large, vigorous, productive, comes into bearing rather young, and has a tendency to produce moderate crops annually; branches somewhat stocky. Form round, dense. Twigs moderately stout, with long internodes, somewhat crooked. Bark nearly smooth, clear, bright light reddish-brown, becoming dull dark brown approaching black, thinly mottled with scarf-skin, somewhat pubescent. Lenticels rather numerous, conspicuous, usually roundish, above mediun to very large, raised slightly or not at all. Buds small to medium, deep set, obtuse, pubescent. Leaves large, long, often broad; petioles red at base; foliage rather dense.

\section{FrUIT.}

Fruit as grown in this region appears not to ripen properly. It is about medium in size and pretty uniform in size and shape. Form usually roundish, slightly obovate, or sometimes somewhat oblate, regular, symmetrical. Stem medium, rather slender. Carity acute to acuminate, deep to medium depth, moderately wide, green or with outspreading russet, symmetrical. Calyx medium, closed. Basin rather shallow to moderately deep, obtuse to rather abrupt, moderately wide, furrowed, corrugated, often with some mammiform protuberances.

Skin rather thick, tough, smooth, bright yellow, shaded and mottled with red and striped with dark carmine. Dots inconspicuous, small, gray or whitish. Prevailing effect red or red striped, decidedly attractive.

Caly.x tube rather narrow, deep, conical or funnel-form, with fleshy projection of pistil point into its base. Stamens median to marginal. 
Core axile, medium to rather large, closed; corc lines clasping. Carpels broadly ovate, emarginate. Seeds large, rather narrow, long, acute.

Flesh somewhat tinged with yellow, very firm, moderately coarse, not very juicy, subacid, fair to nearly good in quality.

Season very late; it is one of the latest keeping varieties.

\section{BELLE ET BONNE.}

References. I. Downing, I857:II8. 2. Downing, I872:91. 3. Hogg, (?) I884: 18. 4. Thomas, I885:242. 5. Mich. Hort. Soc. Rept., I890:288. 6. Ill. Sta. Bul., 45:314. I896. 7. Thomas, I903:337. .

Synonyms. Bellyband (?) (3). Rolland (?) (3). Tenon Hills (1, 2). Winter Belle Bonnc (?) (3).

This old Connecticut variety $(I, 2)$ is found occasionally in Southeastern New York. The fruit is large, handsome, smooth, uniform in size and of about the same season as Hubbardston. It is rather too mild in flavor to be desirable for general purposes. Although an old variety it has never become a standard kind in the markets of this state. In hardiness, health and longevity it ranks about with Baldwin. The trees are moderately productive, usually bearing biennially. They are a little slow about coming into bearing. It is not recommended for planting in New York.

Downing regards it as probably identical with the Belle Bonne of Hogg $(\mathrm{I}, 2,3)$ which was first described by Parkinson in 1629 . It is quite distinct from Billy Bond.

\section{TREE.}

Tree large, vigorous. Form roundish, spreading. Twigs rather long, stout, somewhat pubescent. Bark dull reddish-brown.

\section{FRUIT.}

Fruit large to very large. Form roundish oblate. Stem short. Cavity wide, deep, thinly russeted. Calyx closed. Basin medium in width and depth. Skin deep yellow or greenish. Dots small. Flesh tinged with yellow, firm, rather coarse, juicy, mild subacid, good. Season, early winter.

\section{BELMONT.}

References. I. Downing, I845:I42. 2. Thomas, I849:I77. 3. Cole, 1849: I20. 4. Emmons, Nat. Hist. N. Y., 3:80. I85I. 2 figs. and col. pl. No. 76. 5. Hooper, 1857:16. 6. Downing, I857:74. 7. Elliott, 1858:69. fig. 8. Warder, 1867:529. fig. 9. Chamberlain, Country Gentleman, 1885:1054. Io. Lyon, Mich. Hort. Soc. Rpt., I89o:288. Ir. Bailey, An. Hort., I892:235. 12. Barry, 1896:342. 13. Waugh, Vt. Sta. An. Rpt., I4:288. I901. I4. Thomas, 1903: 337. fig. I5. Budd-Hansen, I903:45.

Synonyms. Belmont Late (4). Belmont (i). Gate (I, 6, 7, 8, II, I2). Gait (13). Golden Pippin of some $(6,7)$. Kelley White $(6,7)$. Mamma Beam $(6,7)$. Mamma Bean (8). Waxen Apple (I, 4). Waxen of some $(6,7)$. White (6). White Apple (7).

Fruit waxen, yellow with beautiful bright blush; excellent either for dessert or cooking. It makes a fine appearance on the tree but appears somewhat dull in the barrel or package. It is handled satisfactorily in local markets 
but it is not a good shipper. Because of its tender skin and delicate color it shows bruises readily, so that with ordinary methods of handling it is apt to be damaged in appearance. It has not always kept well. When the trees are overloaded, a gcod deal of the fruit is either too small for market or grades second class in size. For these reasons and because there are other commercial sorts larger in tree and in fruit, more reliable croppers and less subject to scab, Belmont, although it is known in various parts of the state, is grown to a limited extent only in New York commercial orchards. The tree is generally hardy except in the more elevated or more northern portions of the state. In trying locations it is sometimes injured by sunscald or canker. It usually bears biennially and yields good to heavy crops. The fruit hangs well to the tree.

Historical. Downing at first regarded Belınont as identical with Waxen of Coxe (I), but in the first revised edition this error is corrected with the statement that the variety originated in the garden of a Mrs. Beam, near Strasburgh, Lancaster county, Pennsylvania, from whence it was taken to Belmont county, Ohio, where it became very popular and received the name of Belmont.

\section{Tree.}

Tree medium size, usually moderately vigorous, in some places rather dwarfish but on rich soils and in favorable locations it becomes large. Form upright spreading. Tavigs medium in length or rather short, rather slender. Bark light reddish-brown or olive-green becoming rather dark; partly covered with gray pubescence.

\section{Fruit.}

Fruit medium or above, sometimes large; fairly uniform in size and shape. Form varies from rounded oblong to oblate conic but is usually roundish, somewhat broadly and indistinctly ribbed, somewhat irregular. Stem medium to short, often slender. Cavity rather large, acute to acuminate, rather deep, moderately broad, wavy, irregular, usually with thin brown russet, sometimes lipped. Calyx ratler small, usually closed. Basin rather shallow to deep, moderately abrupt to abrupt, furrowed and wrinkled.

Skin thick, tough, smooth, waxen, clear bright yellow with bright orangered blush. Dots whitish with minute russet point, often submerged, on the blushed portion becoming red areolar. Prevailing color yellow, not striped.

Calyx tube long, elongated cone-shape or funnel-form. Stamens marginal.

Core medium to rather large, axile, sometimes closed; core lines clasping.

Carpels roundish, pointed cordate, tufted. Seeds rather long, acute, tufted.

Flesh tinged with yellow, firm, moderately fine, crisp, tender, moderately juicy, mild subacid, very good.

Season October to February.

Uses. Cooking, dessert and local market.

\section{BEN DAVIS.}

References. I. Downing, r857:I19. fig. 2. Elliott, 1859:124. 3. Adair, Hortıculturist, 15:226. 1860. 2 figs. 4. Downing, Horticulturist, 16:40. I86I. 5. Am. Pom. Soc. Cat., 1852. 6. Warder, 1867:585. fig. 7. Am. Pom. Soc. Rpt., 1869:40. 8. Downing, 1872:93. fig. 9. Leroy, 1873:126. fig. Io. Barry, 1883:343. 11. Thomas, 1885:230. I2. Lyon, Mich. Hort. Soc. Rpt., r89o:288. 

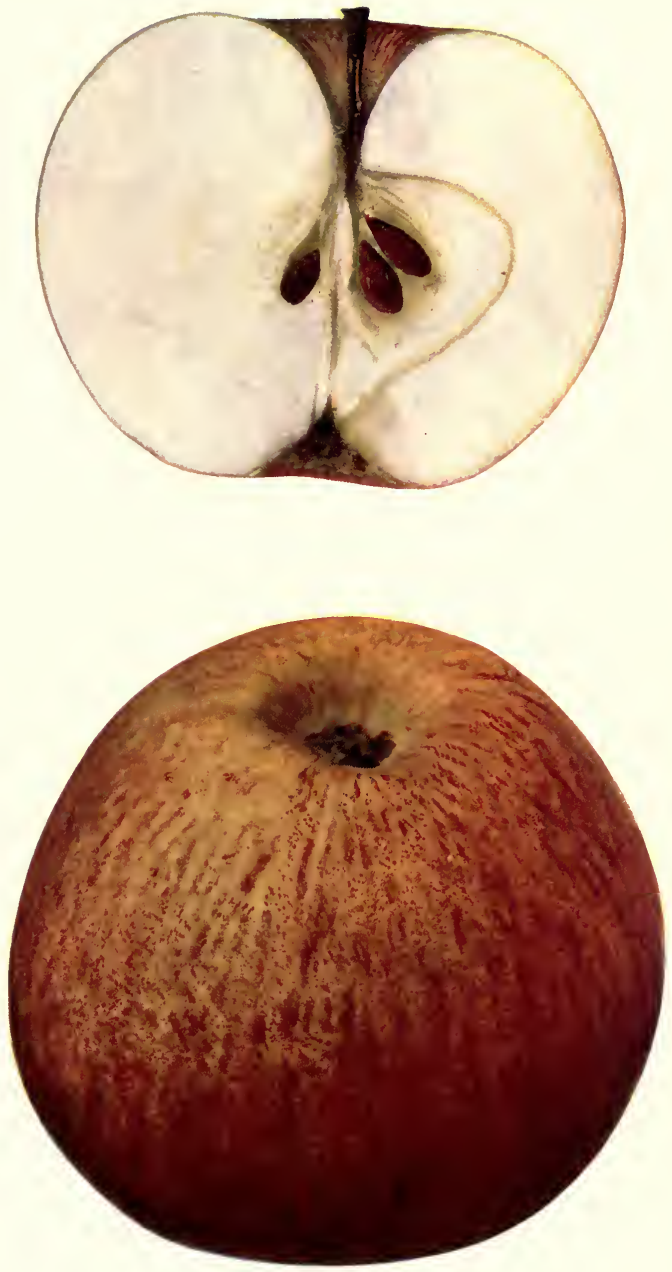

BEN DAVIS 

13. Bailey, An. Hort., 1892:235. 14. Woolverton, Ont. Fr. Gr. Assn., 26:170. 1894. 15. Woolverton, Ont. Fr. Stas. An. Rpt., 3:4. I896. fig. I6. Watts, Tenn. Sta. Bul., I896:7. 17. Amer. Gard., 18:746. 1897. 18. Waugh, Vt. Sta. Bul., 61:30. I897. I9. Taylor, U. S. Div. Pom. Bul., 7:351. 1898. 20. Woolverton, Ont. Fr. Stas. An. Rpt., 6:36. I899. 21. Waugh, Gardening, 7:278. I899. 22. Alwood, Va. Sta. Bul., I30:130. I901. fig. of tree. 23. Waugh, Vt. Sta. An. Rpt., 14:288. I901. 24. Hansen, S. D. Sta. Bul., 76:29. 1902. fig. 25. Stinson, Mo. State Fruit Sta. Bul., 3:24. 1902. 26. Ont. Fr. Gr. Assn. An. Rpt., 34:I08. 1902. 27. Powell and Fulton, U. S. B. P. I. Bul., 48:38. I903. 28. Budd-Hansen, 1903:45. fig. 29. Beach and Clark, N. Y. Sta. Bul., 248:112. 1904.

Synonyms. Baltimore Pippin $(8,9)$. Baltimore Red $(8,9)$. Baltinore Red Streak $(8,9)$. Carolina Red Streak (8, 9, II). Funkhouser (8). Kentucky Pippin (8). Kentucky Streak (II). New $\operatorname{YoRK} \operatorname{PippiN}(3,4,5)$. New York Pippin (6, 8, 8, 9, 10, I I). Pepin de New-York (9). Red Pippin (8). Victoria Pippin $(8,9)$. Victoria $\operatorname{Red}(8$, I I).

The Ben Davis reigns over a much greater extent of country than does the Baldwin. It is unquestionably the leading commercial sort and the most popular apple grown south of the Baldwin region. Generally speaking, it is the most important variety known in the apple districts of the vast territory which stretches from the Atlantic to the Pacific between parallels 32 and 42 . It is preeminently successful in the Virginias, Kentucky, Tennessee, Illinois, Missouri, Arkansas and portions of adjoining states.

In the more elevated and more northern portions of New York it is not usually regarded with favor, but in Southeastern New York the planting of it for commercial purposes has extended until, in many sections, it now ranks in importance next to Baldwin and Rhode Island Greening. It is grown to a considerable extent in various other parts of the state, but in many cases less successfully because too often the seasons are less favorable to the best development of the fruit. Some find it acceptable for home use after the Baldwin season has closed, but here it is generally regarded as not good enough in quality for home use. It is often criticised disparagingly on the point of quality. When grown in the South or Southwest, at its best it is but of second rate quality, and unquestionably in most portions of New York state the seasons are usually too short to mature the variety properly. When grown in the South, the period when it is at its best is comparatively short. As fruited in New York, it ripens later and keeps later than when 
grown farther south. It often keeps here in ordinary storage till May, and in cold storage till June, or often till July. In the Ben Davis belt the fruit becomes large and handsomely colored, but in many portions of New York state it does not range much above medium in size and color. The fruit is thick-skinned, does not show bruises easily, and presents a good appearance in the package after being handled and shipped in the ordinary way.

Nurserymen like it because of its free-growing habit and the ease and rapidity with which trees of marketable size can be grown. In the orchard the tree is very hardy, healthy and vigorous. Although it does not appear to be as long-lived as Baldwin, it comes into bearing at an early age, and usually bears annually and abundantly. Often it makes a good growth, even while bearing good crops. The top is rather dense, and in pruning, particularly in the case of young trees, especial care should be taken to keep it open and spreading so as to give the best possible opportunity for the fruit to color well. Its habit of blossoming late in the spring is an advantage in some regions because the weather is then more apt to be favorable during the pollinating period, and the result is that Ben Davis in such cases often bears good crops, when with other varieties there is more or less of a crop failure.

Histirical. The origin of this apple will probably never be definitely known. It has been variously credited to Tennessee (I6, I9), Kentucky (I), and Virginia $(7,16,19)$. It is supposed to have originated about the beginning of the last century. This view is supported by the fact that before the Civil War it had spread throughout the states just mentioned, and following the routes of migration had been carried into Southern Indiana, Illinois and pretty generally disseminated throughout Missouri and Arkansas. Downing does not mention it in his first edition, but it is described in the first revision (I) of his book on The Fruits and Fruit Trees of America. Warder (6) refers to it as a comparatively new sort in Ohio and the Northwest but common in the South and Southwest. During the last quarter century it has been disseminated extensively through all the apple-growing portions of the United States.

\section{TREE.}

Tree medium in size, rather rank-growing, especially when young, forming coarse strons wood which seldom breaks under heavy crops; branches strong, with nunicrous rather short laterals and spurs, often inclined to bend or droop. Form upright becoming roundish, and in old trees rather spreading. Twigs long or very long, straight or slightly curved, moderately stout; internodes long. Bark bright, rather dark brownish-red, continuously mottled with fine, thin scarf-skin, pubescent. Lenticels scattering, round, sometimes oblong, 
raised, of a clear straw color, moderately conspicuous. Buds medium to large or broad, obtuse, appressed, sunken in the bark, very sparingly pubescent. Leaves large, long, rather broad.

\section{Fruit.}

Fruit usually above medium to large. Form roundish, varying from somewhat conic to somewhat oblong, broad, rounded at the base, often somewhat elliptical or slightly irregular, sides sometimes unequal; pretty uniform in shape and in size. Stem medium to long, rather slender. Cavity acute, moderately deep to deep, of medium width, nearly symmetrical, often partly russeted or with outspreading rays of thin greenish russet. Calyx medium, elosed or sometimes partly open; lobes rather short, of medium width, acute. Basin abrupt, medium in width and depth, varying to shallow and narrow and rather obtuse, sometimes furrowed, usually oblique.

Skin tough, waxy, bright, smooth, usually glossy, clear yellow or greenish, mottled and washed with bright red, striped and splashed with bright dark carmine. Dots inconspicuous, small, scattering, light, whitish or brown. Prevailing effect bright deep red or red striped.

Calyx tube varies from short and cone-shaped to rather wide and funnelform with rather long cylinder and frequently with fleshy projection of pistil point into its base. Stamens median to marginal.

Core medium, axile, closed or partly open; core lines clasping when the tube is funnel-form, meeting or slightly clasping when it is cone-shaped. Carpels rather flat, roundish or inclined to obovate, very emarginate, mucronate. Sceds large, long, irregular, rather wide, plump, acute, dark brown.

Flesh whitish, slightly tinged with yellow, firm, moderately coarse, not very crisp, somewhat aromatic, juicy, mildly subacid, good.

Season January to June.

\section{Different Types of Ben Davis.}

Some assert that it is possible to recognize as many as four distinct types or strains of Ben Davis. So far as we know none of these types, if such exist, is being kept separate under propagation. It is certain that Ben Davis shows great variations in fruit in different parts of the country, in some cases so much so that those unfamiliar with it would not recognize fruit of it from different regions as being of the same variety.

Various seedlings of Ben Davis which have been introduced into cultivation show more or less resemblance to the parent and to each other. In the case of Gano and Black Ben Davis a notable controversy has arisen among nurserymen and fruit growers as to whether these are distinct varieties or identical. The Gano is known to some extent in New York. It resembles its parent Ben Davis very closely in the nursery, but it is unmistakably distinct from it in fruit. So far as we have tested it, it seems to be better adapted to New York conditions than is the Ben Davis.

Rutledge, Arkansas Belle, Etris and Eicke also belong in the Ben Davis group.

\section{BENTLEY.}

References. I. Emmons, Nat. Hist. N. Y., 3:10o. I851. fig. 2. Downing, 1857:I2I. 3. Elliott, 1858:122. 4. Warder, I867:558. 5. Thomas, 1885:227. 6. Lyon, Mich. Hort. Soc. Rpt., I890:288. 7. Budd-Hansen, I903:47. Synonyms. Bentley Sweet (4). Bentley's Sweet $(\mathrm{I}, 2,3,5)$. 
Tree hardy, varies from moderately productive to very productive and comes into bearing rather young. The fruit is very sweet and keeps very late but is not attractive in color and ranks second rate in size and quality. It is not recommended for planting.

Historical. It is supposed to have originated in Virginia. It is but little known in New York.

TREE.

Tree medium size, spreading, a rather slow grower.

\section{Fruit.}

Fruit variable, sometimes above medium to large, averages below medium. Form roundish to oblong, often inclined to conic, sometimes irregular and obscurely ribbed, sides often unequal; fairly uniform in shape. Stem short to medium. Cavity deep, wide, often slightly furrowed or compressed, sometimes with greenish russet rays. Calyx large, closed or partly open. Basin abrupt, often oblique, moderately wide, moderately deep, often furrowed and somewhat wrinkled.

Skin smooth, rather clear pale yellow, mottled with red and striped with bright carmine. Dots numerous, conspicuous, dark brown. Prevailing color thin striped red.

Calyx tube rather large, sometimes long and funnel-shaped with core lines clasping, but sometimes short with core lines meeting. Stamens medium to marginal.

Core medium to small, axile, closed or partly open. Carpels roundish to obovate, emarginate. Seeds large, rather wide, plump, obtuse, black.

Flesh whitish slightly tinged with yellow, firm, rather fine, moderately juicy, sweet, crisp, good.

Season. December to May or June.

\section{BERGEN.}

References. I. Downing, r876:44 of app.

But little known in New York. Originated on the farm of Jessie Griswold, Bergen, N. Y. Fruit medium sized, partly red, mild subacid, good either for dessert or culinary use (I).

\section{BESS POOL.}

REFERENCEs. I. Downing, I872:95. 2. Hogg, I884:21.

Synonym: Best Pool (I).

An old English apple but little known in this country. Above medium size; clear yellow, washed and striped with red; attractive in appearance. Flesh white, juicy, subacid. Season November to March. Not a reliable cropper. Esteemed in England both for culinary and dessert uses (2).

\section{BETHEL.}

References. I. Hoskins, U. S. Agr. Rpt., 1886:274. 2. Hoskins, Rural N. Y., 47:249. 1888. figs. 3. Bailey, An. Hort., 1892:235. 4. An. Pom. Soc. Cat., I899:15. 5. Waugh, Vt. Sta. An. Rept., 14:288. 1901, 6. Munson, Me. Sta. Bul., 82:83. 1902. 7. Budd-Hansen, 1903:48. 

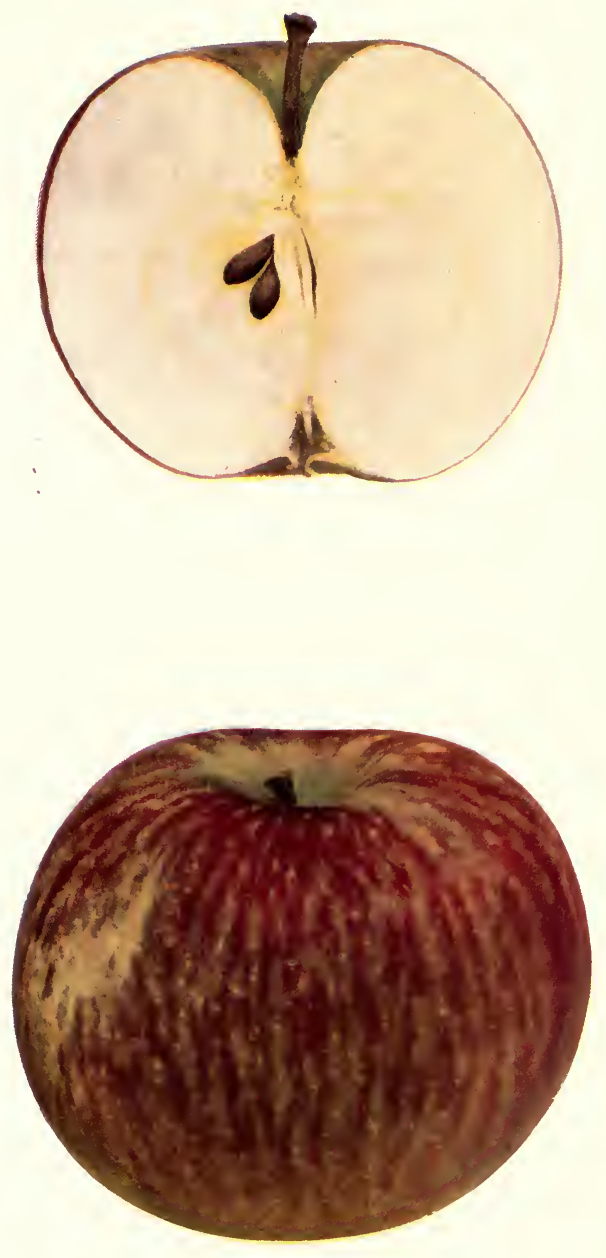

BETHEL 

This shows its kinship to the Blue Pearmain in the quality, texture, form, conspicuous dots and color of its fruit. Sometimes it has a rather dull appearance, but it may attain a bright and attractive, though dark red, color. The quality is fairly good. It will not bear rough handling, and is suitable rather for local markets than for shipping long distances. The tree shows a rather weak development of roots in the nursery, but in the orchard becomes moderately vigorous and generally quite productive. It has proved very hardy in Northern New York, and is recommended for planting for home use and local markets in that section and in the more elevated regions of the state, where varieties of the grade of hardiness of Baldwin are apt to show winter injury. In such localities some prefer to grow it on warm soil or sod, to favor the development of better color. It is locally profitable. It is healthy, long-lived and a reliable cropper, usually comes into bearing rather young and bears annually. There is apt to be considerable loss from dropping of the fruit.

Some have thought that it is identical with an apple grown in Northern New York under the name Stone. The two varieties, as we have received them, are certainly distinct, but both belong to the Blue Pearmain group.

Historical. It originated in Bethel, Vermont (I). During the last twentyfive years it has become scattered throughout Northern New York, Northern New England and portions of Canada.

TREe.

Tree medium to rather large, moderately vigorous or vigorous. Form round, spreading. Twigs spreading, below medium in length, usually curved, somewhat slender; internodes medium. Bark brownish-red, exceptionally mingled with olive-green, blotched with gray; sparingly pubescent. Lenticels not very conspicuous, moderately abundant, rather small, roundish. Buds rather small, obtuse, appressed, pubescent.

\section{Fruit.}

Fruit large. Form roundish, slightly conic, somewhat angular or irregularly elliptical. Stem short, rather slender. Cavity acute to acuminate, deep, rather broad, rather symmetrical, with red russet often outspreading. Calyx pubescent, medium to rather large, partly open or closed; lobes rather narrow, acute. Basin rather shallow to moderately deep, moderately wide, slightly furrowed and wrinkled.

Skin thick, tough, smooth; good deep yellow, washed and mottled with red and striped with purplish carmine, becoming very dark red in highly colored 
specimens. Dots numerous, conspicutous, russet or light, many small, many large and areolar. Prevailing effect somewhat striped.

Calyx tube very large, wide, somewhat funnel-shaped with a short cylinder. Stamens median to basal.

Core large, somewhat abaxile, open or sometimes closed; core lines somewhat clasping. Carpels broad, roundish ovate, emarginate, tufted. Seeds large, rather wide, long, acute to acuninate, tufted, medium brown.

Flesh yellowish, firm, coarse, crisp, moderately tender, moderately juicy, mild subacid, fair to good.

Season November to midwinter or possibly March.

Uses. Baking, dessert and local market.

\section{BETHLEHEMITE.}

References. 1. Elliott, 1858:69. fig. 2. Warder, 1867:423. fig. 3. Am. Pom. Soc. Cat., 1871:6. 4. Downing, 1872:96. fig. 5. Thomas, 1885:231.

Synonym. Bethlemite $(2,4)$.

This is an apple of the Newtown Spitzenburg type but it is inferior to that variety in size and color and is not better in quality. When well grown it ranks good to very good for either dessert or culinary uses, but it does not always develop good quality. It is not recommended for planting in New York.

Origin. It was first brought to notice in Bethlehem, Ohio (I) from which town it takes its name. Its origin is obscure. It is but little known in New York state.

\section{TREE.}

Tree moderately vigorous. Form upright spreading, somewhat open. Twigs short, stout; internodes short. Bark olive-green, mingled with dark red, covered with light scarf-skin, very pubescent. Lenticels numerous, large, oblong, raised, conspicuous. Buds large, brcad, obtuse, appressed, pubescent. Leaves large, broad.

\section{FRUIT.}

Fruit medium or below, rarely above medium size. Form oblate to roundish conic, often obscurely ribbed, sides sometimes unequal; fairly uniform in shape and size. Stem medium to rather long, rather thick. Cavity acute to acuminate, wide, deep, often symmetrical, sometimes appressed or lipped and covered with thin greenish, outspreading russet. Calyx rather large, closed or partly open; lobes often separated at the base, often erect, wide, long, acute, conspicuous. Basin rather shallow to moderately deep, moderately wide, somewhat abrupt, furrowed and wrinkled.

Skin rather smooth, pale yellow or greenish, washed, mottled and striped with red. Color rather dull and unattractive. Dots distinct, large to very small, gray or russet and near the basin very numerous and often submerged.

Caly.x tube wide, large, cone-shaped, or approaching funnel-form. Stamens median to basal.

Core small, somewhat abaxile; cells usually symmetrical and partly open; core lines meeting. Carpels short, concave, sometimes slightly tufted, wide Seeds short, plump, obtuse, dark reddish-brown, sometimes tufted, numerous.

Flesh whitish with slight green or yellow tinge, firm, fine-grained, tender, crisp, juicy, mild subacid, aromatic, good to very good.

Season November to March. 


\section{BILLY BOND.}

References. I. Downing, $1872: 90$. 2. Thomas, $1885: 503$. 3. Not listed by Bailey, An. Hort., r892:234.

Synoxyus. Belle Bonde (1). Belle Bonne (2). Billy Bond (1, 2).

Fruit rather attractive, being mottled, shaded and splashed with red over a yellow background. It is quite uniform in size and shape. It is desirable for cooking and evaporating, but is not much esteemed for dessert because it ranks but second rate in quality. In Wayne county it is regarded by many as a profitable commercial variety. It comes into bearing young and is a reliable cropper with a marked tendency to bear annually. The tree is a good grower, both in orchard and nursery.

Historical. Downing mentions a report that this apple had its origin in France in 1790 , but in Wayne county where it was first brought to notice, it is claimed by some that it originated in the town of Lyons with a man whose name, Billy Bond, became attached to the variety. After it was disseminated this name evidently became confused with that of Belle et Bonne or Belle Bonne a very different apple, and so it came to be called variously Belle Bonde, the name which Downing accepted as correct (I), Belle Bonne, which Thomas sanctioned (2), Belle Bend, Billy Bend, etc. It has been grown to a limited extent in Wayne county, and scattering trees of it are occasionally found in other parts of Western New York. Bailey does not list it in his inventory of North American Apples in 1892 (3). It has never received much attention from nurserymen nor has it gained a prominent place in commercial orchards.

TREE.

Tree large, rather vigorous. Form upright or somewhat spreading. Twigs medium in length, rather erect, thick. Bark reddish-brown mingled with olive-green; internodes short, pubescent. Lenticels numerous to medium size, usually roundish, conspicuous. Buds medium to large, broad, plump, obtuse, slightly pubescent. Foliage moderately dense; leaves medium to large, often broad.

Fruit.

Fruit usually above medium to rather large. Form roundish inclined to oblong, or sometimes to conic, somewhat elliptical or irregular; sides sometimes unequal, often broadly or obscurely ribbed, axis often oblique. Stem medium to rather long, rather slender. Cavity acute, deep, moderately wide, compressed or furrowed, often partly russeted or with outspreading rays of thin russet, sometimes lipped. Caly.r small to medium, closed or partly open. Basin often oblique, moderately wide, rather abrupt, indistinctly furrowed, varying from rather shallow to moderately deep.

Skin smooth, somewhat waxy, bright yellow, mottled and shaded with red, splashed with lively deep purplish-red. Dots whitish, or russet, rather numerous. Prevailing effect striped red, attractive.

Calyx tube long, rather narrow, funnel-form. Stamens median to marginal.

Core medium to rather small, axile, closed or partly open; core lines claspVOL. I -4 
ing the cylinder of the calyx tube. Carpels roundish to roundish ovate, slightly emarginate. Seeds rather broad, acute to ohtuse, light brown, medium size, plump.

Flesh nearly white, with slight yellow tinge, sometimes stained with red, firm, moderately coarse-grained, rather tender, rather crisp, juicy, with a peculiar rather pleasant but not high flavor, subacid, becoming mild subacid when fully ripe, good.

Season October to January. The fruit is sometimes kept till March but after midwinter it deteriorates in quality and color.

\section{BLACK ANNETTE.}

References. I. Hansen, S. D. Sta. Bul., 76:30. 1902.

A variety which in 1886 was introduced under this name from Marietta, O., into Northern lowa has proved very hardy there. Because of its hardiness it is considered worthy of attention in the Northwest (I). Its season extends into the spring. Possibly it is distinct from the Black Annette formerly grown in some parts of New York, which is a late fall apple.

\section{BLACK BEN DAVIS.}

Referexces. I. Amer. Gard., 23:403. 1902. 2. Van Deman, Rural N. Y., 61:717. 1902. 3. Van Deman, Rural N. Y., 62:500. 1903. 4. Budd-Hansen, 1903:50. 5. Ark. Hort. Soc. Rpt., 1904. 6. Nat. Nurseryman, $12: 18,19.1904$. 7. Wickson, Hestern Fruit Grower, 1904:124.

This is a variety of the Ben Davis type, very brilliant in color and decidedly attractive in appearance. In size and color it is intermediate between Jonathan and Ben Davis. It is sometimes obscurely striped, but more often it shows a solid, deep red color somewhat like that of the Jonathan. As grown in this state it is but little better than Ben Davis in quality. It appears to be as good a keeper as Ben Davis. It has not yet been sufficiently tested in New York state to demonstrate whether or not it will be valuable in this region, but it appears sufficiently promising for commercial purposes to merit attention in those parts of the state where Ben Davis succeeds best.

Historical. It is said to have originated about $\mathrm{I} 880$ on the farm of M. Black in Washington county, Arkansas $(5,7)$. It has been claimed by some that it is identical with Gano. It certainly resembles Gano very closely, but the preponderance of evidence scems to favor the opinion that these two varieties are of distinct origin (7).

\section{TREE.}

Young trees are upright and vigorous, becoming somewhat spreading, rather dense; branches moderately stout, curved. Does not resemble Ben Davis so closely in tree as Gano does, being more upright and having less willow-like 

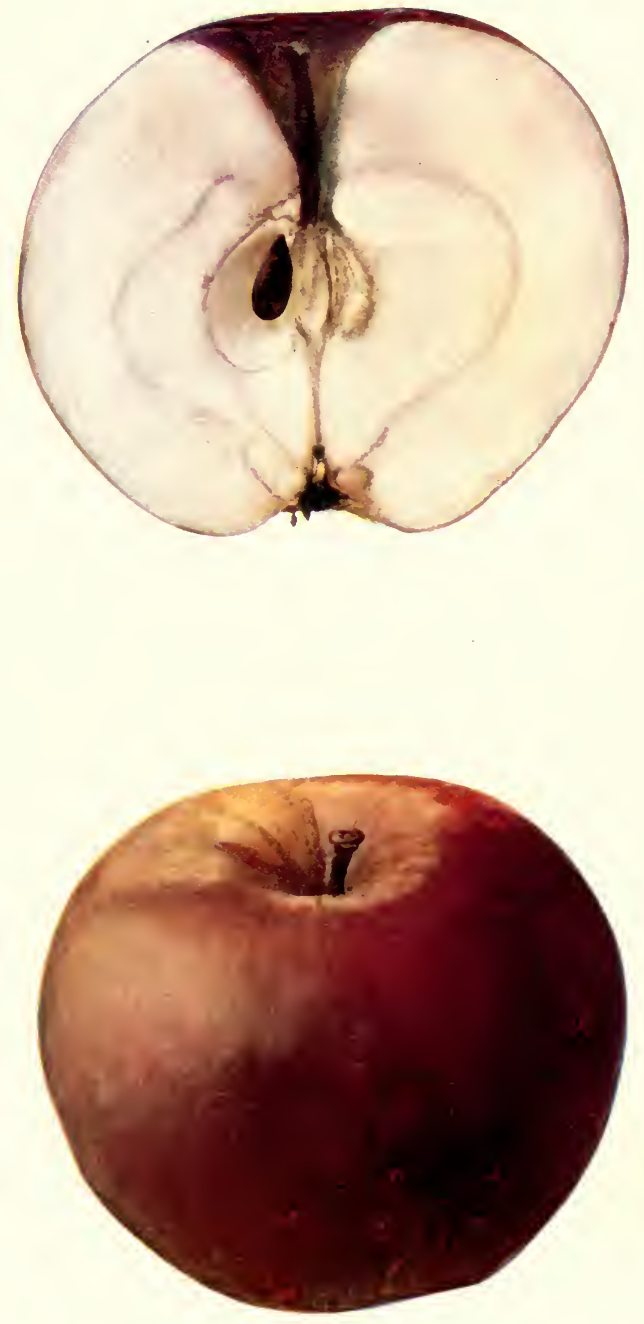

BLACK BEN DAVIS 

lateral twigs. Twigs medium in length, straight, stout; internodes medium. Bark dark brown, tinged with olive-green, mottled with scarf-skin; pubescent. As grown here is darker than Gano. Lenticels scattering, large, round, raised, conspicuous. Buds large, broad, obtuse, appressed, set deep in bark, pubescent. Lear'es medium, broad.

\section{Fruit.}

Fruit medium to above, sometimes large, averaging marketable size. Form roundish ovate to roundish conic, pretty regular. Stcm medium to rather long and slender. Cazity acute, moderately deep to deep, of medium width, nearly symmetrical, usually with some greenish or orange-red russet which often spreads beyond the cavity in broken rays. Calyx rather large, usually open or partly so; lobes rather broad, obtuse. Basin often somewhat oblique, rather shallow and obtuse to moderately deep and abrupt, often slightly furrowed and somewhat wrinkled.

Skin thin, tough, smooth, somewhat glossy, brilliant red almost completely overspreading a clear pale yellow ground color, becoming dark purplish-red on the exposed cheek. Dots numerous, very small, red or gray, sometimes with russet point. Prevailing effect brilliant red, often with some contrasting clear pale yellow.

Calyx tube varies from short cone-shape to somewhat funnel-form, with fleshy pistil point projecting into the base. Stamens median to marginal.

Core medium to rather small, axile or nearly so, closed; core lines clasping the funnel cylinder, or when the calyx tube is cone-shaped, nearly meeting. Carpels roundish, elongated, emarginate. Seeds rather long, obtuse to acute, dark brown.

Flesh whitish, firm, somewhat coarse, moderately crisp, not tender, moderately juicy, mild subacid, a little aromatic, good in quality.

Season January to April or May.

\section{BLACK GILLIFLOWER.}

References. I. Manning, Mag. Hort., 7:49. I841. 2. Mag. Hort., 13:106. 1847. 3. Thomas, I849:I64. 4. Cole, 1849:126. 5. Hovey, Mag. Hort., 16:64, 198. 1850. fig. 6. Emmons, Nat. Hist. N. Y., 3:61. 1851. col. pl. \& fig. 7 . Downing, I857:208. 8. Hooper, 1857:18, 76. 9. Elliott, 1858:167. Iо. Warder, 1867:662. fig. II. Lyon, Mich. Hort. Soc. Rpt., 1890:288. 12. Bailey, An. Hort., 1892:235. 13. Waugh, Vt. Sta. An. Rpt., 14:289. 1901. 14. Powell and Fulton, U.S. B. P. I. Bul., 48:38. 1903. 15. Beach and Clark, N. Y. Sta. Bul., 248:113. I904.

Synonyms. Black Gilliflower (5). Black Spitz (13). Gilliflower (14, 15). Red Gilliflower ( 1,5 ).

A dessert apple which is very distinct in color, form and flavor. The color is yellowish or greenish, sometimes almost completely covered with red, which in highly colored specimens becomes dull purplish and very dark, as recognized in the name "Black" Gilliflower. The color of the fruit is often much darker than it appears in the accompanying plate. The flesh at its best is but moderately 
juicy and soon becomes dry, but it has a peculiar aroma which is pleasing to many. It is not sour enough to be very valuable for cooking, but it is sometimes used for baking. It is fast becoming obsolete in most parts of the state, but in some sections the planting of it in commercial orchards is being extended because it is found profitable to grow it in limited quantities for southern markets. On good soil the tree is a good, vigorous grower and a reliable cropper. The apples grow fair and smooth and there is little loss from unmarketable fruit.

Historical. Black Gilliflower is supposed to be an American variety. It was brought into the central and western portions of the state more than a hundred years ago by the early settlers. It is evident that it was known in Connecticut as early as the latter part of the eighteenth century (2).1 Manning (I) mentions it in $184 \mathrm{I}$ under the name Red Gilliflower and Hovey (5) described it in I850 under the same name, giving Black Gilliflower as a synonym. It has generally been known under the simple name Gilliflower, which name usually appears in the market quotations of this variety.

\section{TREE.}

Tree large, moderately vigorous. Form rather upright spreading with moderately open top. Twigs long, slender, pubescent; internodes short to medium. Bark dark olive-green and reddish-brown with thin gray scarf-skin. Lenticels rather numerous, small to medium, roundish or elongated, raised. Buds medium, obtuse or acute, quite pubescent, appressed. Leaves rather long, medium to above medium in size.

\section{FrUIT.}

Fruit medium to large, seldom very large; very uniform in size and shape. Form long ovate to oblong conic, somewhat ribbed; axis sometimes a little oblique. Stem medium to long, moderately thick. Cavity usually acuminate, rather wide, moderately deep to deep, sometimes lipped but usually symmetrical with red russet or greenish outspreading rays. Calyx medium or below, closed. Basin often oblique, usually very shallow and obtuse, varying sometimes to moderately deep and abrupt, furrowed and much wrinkled.

Skin thick, tough, nearly smooth; yellow or greenish-yellow, striped or mostly covered with red, deepening to dark purplish-red or almost black, obscurely striped with darker crimson, and with streaks of bluish-gray scarfskin, especially toward the cavity, giving almost the effect of a dull bloom. Dots numerous, gray, rather small, not conspicuous, somewhat rough. Prez'ailing effect in highly colored specimens dull dark purplish.

Calyx tube large, wide, cone-shape or funnel-form. Stamens median or above.

Core large, decidedly axile, closed; core lines somewhat clasping. Carpels very long ovate, tapering both ways, emarginate, much tufted. Seeds often

\footnotetext{
${ }^{1}$ Cited from Bateman, Ohio Cultivator, Aug. 1, 1846 . Warder gives same citation, $1847: 25$.
} 

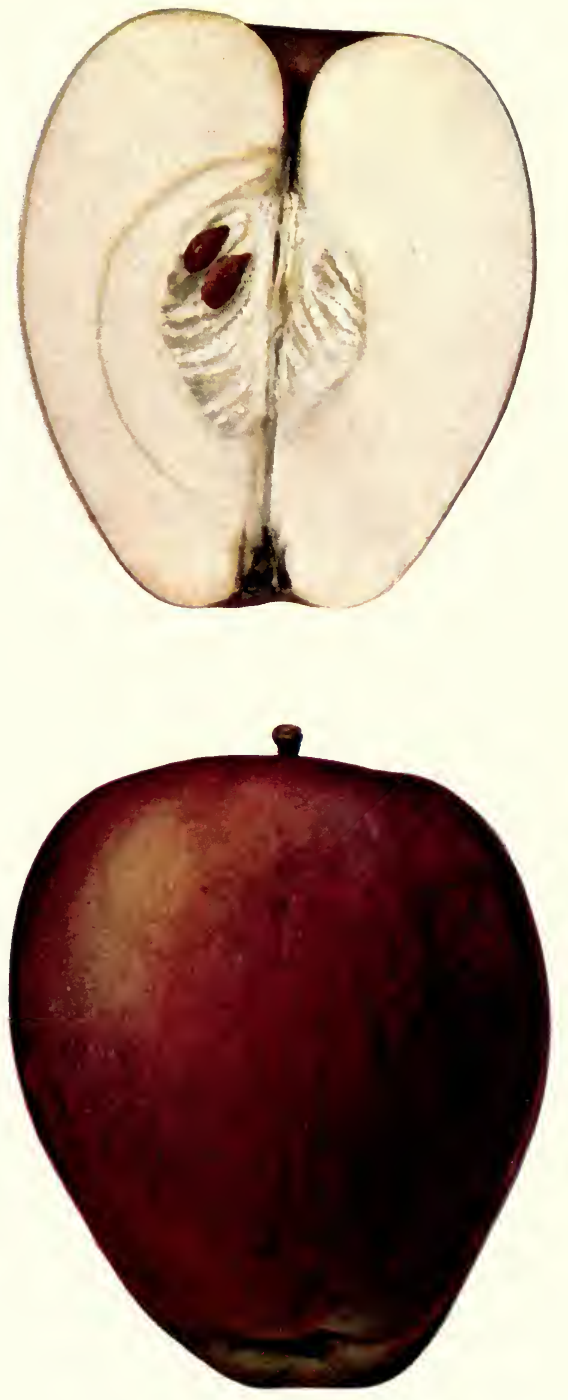

BLACK GILLIFLOWER 

abortive; when well developed they are above medium, acute to acuminate, somewhat tufted.

Flesh whitish or slightly tinged with yellow, firm, rather tender, rather coarse, moderately juicy eventually becoming dry, mild subacid, rich, peculiarly aromatic, good for dessert and special markets.

Season October to January or February.

\section{BLACK JERSEY.}

References. I. Coxe, I8I7:139. fig. 2. Thacher, 1822:121. 3. Downing, I845:99. 4. Horticulturist, 4:470. 1849. 5. Thomas, I851:63. 6. Hooper, 1857:18. 7. Elliott, 1858:123. 8. Warder, 1867:653. fig. 9. Am. Pom. Soc. Cat., 1873. го. Ill. Sta. Bul., 45:327. 1896. I1. Budd-Hansen, 1903:49.

Synonyms. Black Apple $(1,2,3,5,6,7)$. Black American (7). Dodge's Black (7). Jersey Black (4, Io). Warder (8) describes a Jersey Black which he believes is not the Black Apple of Coxe and Downing. Jersey Black (7).

Fruit medium, dark red, almost black. A pleasant flavored, dessert apple.

Origin. There are several varieties which have been disseminated under the name Black Apple and more or less confusion exists with regard to their correct names. Black Jersey is generally believed to be identical with the Black Apple described and disseminated by Coxe (I), although Warder differs from this view (8). It is an old variety now practically obsolete.

\section{Tree.}

Tree moderately vigorous, productive, with slender branches eventually becoming drooping. Trvigs rather slender to rather stout, rather pubescent, clear olive-green mingled with red, irregularly overlaid with grayish scarfskin; internodes long. Lenticels conspicuous, numerous, raised, mostly below medium, elongated. Buds medium, not very prominent, broadly acute to obtuse, adhering and slightly pubescent.

\section{Fruit.}

Fruit medium. Form roundish, somewhat irregular; sides somewhat unequal; pretty uniform in size and shape. Stem variable, sometimes knobbed, often inserted under a lip. Cazity irregular, moderately deep to deep, acute. Calyx rather small, closed or partly open. Basin rather wide, somewhat abrupt, furrowed and wrinkled, shallow.

Skin very dark red, almost black, shading to a wine red over yellow, and somewhat streaked in the lighter portions; sometimes it shows a whitish bloom; attractive. Dots many, whitish or light, rather large, showing through the red skin.

Caly.x tube conical.

Core medium or above, usually axile, closed or somewhat open; core lines clasping. Carpels elongated ovate to obcordate, concave, slightly tufted. Seeds acute, plump, dark.

Flesh yellowish-white often tinged with red, juicy, crisp, a little coarse, subacid becoming mildly sweet, aromatic, agreeable in flavor but not high in quality.

Season November to January or February. 


\section{BLUE PEARMAIN.}

REFERENCES, 1. Kenrick, I833:42. 2. Manning, 1838:55. 3. Manning, Mag. Hort., 6:172. I840. 4. Downing, 1845:122. 5. Phoenix, Horticulturist, r:361. 1846. 6. Cole, I849:120. 7. Thomas, 1849:164. 8. Emmons, Nat. Hist. N. Y., 3:69. 1851. col. pl. No. 54. 9. Hooper, 1857:19. 1o. Elliott, 1858:122. Ir. Am. Pom. Soc. Cat., 1862. 12. Barry, 1883:3+3. 13. Lyon, Mich. Hort. Soc. Rpt., I89o:288. 14. Bailey, An. Hort., I892:235. I 5. Waugh, I't. Sta. An. Rpt., 14:289. 1901. 16. Can. Hort., 25:49. 1902. 17. BuddHansen, 1903:52. fig. 18. Beach and Clark, N. Y. Sta. Bul., 248:113. 1904.

Synoxym. Prolific Bcauty (I8) incorrectly.

- Occasional trees are found in the oldest home orchards of the state. It is rarely planted now. In some localities it bears well, but more often it is not a reliable cropper. It is apt to have a pretty high percentage of unmarketable fruit. The fruit is of mild flavor and does not rank high in quality. The skin is thick. When well colored it is beautiful, though not brilliant, being overcast with a dull bluish bloom. In common storage it does not keep late, and by January it often becomes shriveled ( 18 ). It is not a good market fruit and is not recommended for commercial planting.

Historical. This is an old variety of uncertain origin but it is supposed to be an American variety (13). On account of its hardiness it has often been planted in the home orchards of the more elevated regions of New York and New England during the last 75 years. Probably it has been in cultivation for a century or more. Kenrick ( 1 ) mentions it as common in the vicinity of Boston in the early part of the I9th century.

\section{TREe.}

Tree becomes moderately large to large, moderately vigorous or on rich soil sometimes vigorous. Form spreading. In the nursery it is a slow, stiff grower (5). Tivigs below medium, rather stout, nearly straight, rather blunt at tips, with large terminal buds; internodes medium to long. Bark very dark, being of a dull brownish-red; scarf-skin varies from thin to rather heavy; quite pubescent. Lenticels inconspicuous, scattering, below medium, roundish, raised. Buds above medium, moderately projecting, roundish, slightly pubescent, free. Leaz'es broad, coarsely serrated.

\section{FruIT.}

Fruit above medium to very large; pretty uniform in size and shape. Form roundish or inclined to oblate, sometimes a little inclined to conic, irregular, often obscurcly ribbed, sometimes distinctly furrowed from the cavity nearly to the basin. Stem medium length to rather short, rather thick. Cavity moderately deep, obscurely furrowed, usually covered with orange-russet or greenish-russet. Caly.r partly open; lobes acute. Basin medium in depth and width, with concentric gray or russet lines, obscurely furrowed.

Skin a little rough; yellow, washed and mottled with red, often deepening on one side to nearly solid red, splashed and striped with deep purplish-car- 

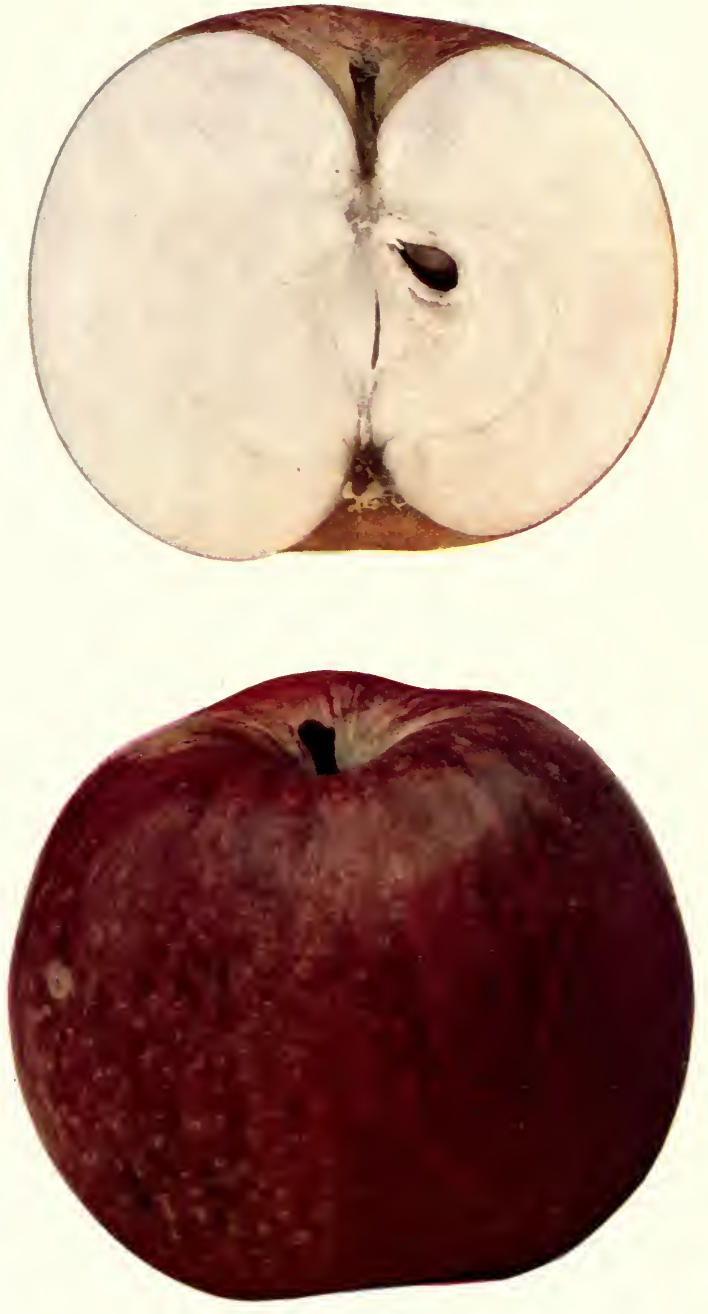

BLUE PEARMAIN 

mine and overspread with an abundant blue bloom from which the variety takes its name. Dots numerous, small, pale, mingled with others which are conspicuous, very large, gray with russet center and often also mingled with irregular lines or flecks of dull green or russet. The large dots are characteristic of this variety as also of other varieties of the Blue Pearmain group.

Calyx tube elongated conical approaching funnel-form. Stamens basal to median.

Core rather large, nearly axile, closed or somewhat open; core lines clasping or, with modified calyx tube, nearly meeting. Carpels broad, elongated or roundish, slightly tufted. Seeds medium or rather long, acuminate, rather light brown.

Filesh yellowish, moderately firm, rather coarse, moderately juicy, mild subacid, decidedly and agreeably aromatic, good.

Season. Comes into season in October. It may keep till March but often begins to shrivel after January.

Use. Home and local market.

\section{BOGDANOFF GLASS.}

References. I. Budd, Ia. Agr. Coll. Bul., I885:39. 2. Lyon, U. S. Div. Pom. Bul., 2:40. I888. 3. Hoskins, Rural N. Y., 49:742. I89o. figs. 4. Budd, Ia. Agr. Coll. Bul., 1892:5. 5. Budd, Ia. Sta. Bul., 19:539. I892. 6. Ibid, 31:332. 1895. 7. Hansen. S. D. Sta. Bul., 76:33. 1902. 8. Budd-Hansen, 1903:53. fig. 9. Can. Hort., 26:12. I903.

Synonyms. Bogdanoff $(3,7,8,9)$. Bogdanoff's Glass (2). Sklanka (6). Sklanka Bogdanoff $(4,5)$. Steklianka Bogdanoff $(1,2)$.

A green or yellow apple sometimes with a faint blush, desirable in size and attractive in appearance, but not ranking high in quality. On account of its hardiness it may have some value in the northern portions of the apple belt.

Professor Budd attached the name Bogdanoff to several varieties which he obtained from the Bogdanoff estates in Russia. The name Sklanka is used in Russia as a class name. The adoption of either name alone is open to objection. We prefer, therefore, to follow Lyon (2) in assigning to this variety the name Bogdanoff Glass.

Historical. Imported from Russia for the Iowa Agricultural College by Prof. J. L. Budd about 25 years ago and disseminated by him from that institution.

\section{TREE.}

Tree moderately vigorous; branches long, curved and moderately stout. Form upright spreading and rather open. Twigs medium to long, moderately thick; internodes pretty long. Bark clear dark reddish-brown or nearly black, scarcely pubescent but with noticeable scarf-skin. Lenticels numerous, medium in size to small, elongated, raised. Buds large to medium, broad, plump, obtuse, slightly pubescent, free. Scales often parted. Leaves large, broad. 


\section{FRUIT.}

Fruit large; uniform in size and shape. Form roundish conic sometimes approaching roundish oblate, obscurely ribbed, usually symmetrical, sometimes elliptical or irregular. Stem short, thick, often swollen at the base, sometimes knobbed. Cazity acuminate, moderately shallow to deep, rather broad, somewhat furrowed or compressed, often somewhat russeted, with narrow broken outspreading russet rays. Caly'x medium, usually closed; lobes acute to acuminate. Basin variable; often abrupt, medium in width and depth, somewhat furrowed, wrinkled.

Skin thin, tough, smooth, waxy, somewhat glossy, green becoming bright pale yellow, occasionally with faint bronze blush. Dots numerous, inconspicuous, mostly submerged, white or green.

Calyx tube rather large, long, cone-shape or funnel-form. Stamens median.

Core medium or below, axile, closed or partly open; cells often unsymmetrical ; core lines meeting or somewhat clasping. Carpels smooth, very broadly obovate, somewhat emarginate. Seeds moderately light reddish-brown, smooth, above medium, wide, plump, obtuse to acute.

Flesh nearly white, rather firm, moderately fine, crisp, moderately tender, juicy, brisk subacid, fair to possibly good.

Season November to February.

\section{BOIKEN.}

References. I. Oberdieck, Ill. Handb. der Obstk., I:212. 1859. 2. Berghuis, r868: col. pl. No. 8o. 3. Leroy, 1873:144. 4. Lauche, r: col. pl. No. 5. I882. 5. Budd, Ia. Sta. Bul., 19:542. I892. 6. Bailey, An. Hort., I892:235. 7. Bredsted, 1893:205. 8. Bronson, W. N. Y. Hort. Soc., 1893:113. 9. Troop, Ind. Sta. Bul., 53:124. I894. Io. Buckman, Rural N. Y., 54:806. I895. II. Willard, Rural N. Y., 55:751. I896. 12. Thomas, 1897:288. fig. 13. Rural N. Y., 57:285. 1898. 14. Ia. Sta. Bul., 41:70, 85. 1899. 15. Rural $N . Y$., 60:342. I901. 16. Eneroth-Smirnoff, Igor:274. 17. Hansen, S. D. Sta. Bul., 76:33. 1902. 18. Munson, Me. Sta. Bul., 82:89. I902. I9. Budd-Hansen, 1903:53. 20. Beach and Clark, N. Y. Sta. Bul., 248:1 I3. I904.

Synonyms. Boiken Apfel $(2,4)$. Boikenapple (i6).

This is a very attractive, bright yellow apple, usually with a beautiful blush. It is justly regarded as one of the most valuable of the recent introductions for growing in commercial orchards, on account of the vigor and health of the foliage, hardiness and productiveness of the tree, and the desirable size, attractive appearance and fairly good quality of the fruit. Its flavor is a rather brisk subacid. It is hardly rich enough in quality or mild enough in flavor to excel as a dessert fruit, but it is desirable for culinary use and for market. It appears to be better adapted than Rhode Island Greening for storage (20). It makes very light colored evaporated stock. The tree comes into bearing rather young and is a good, reliable cropper. 

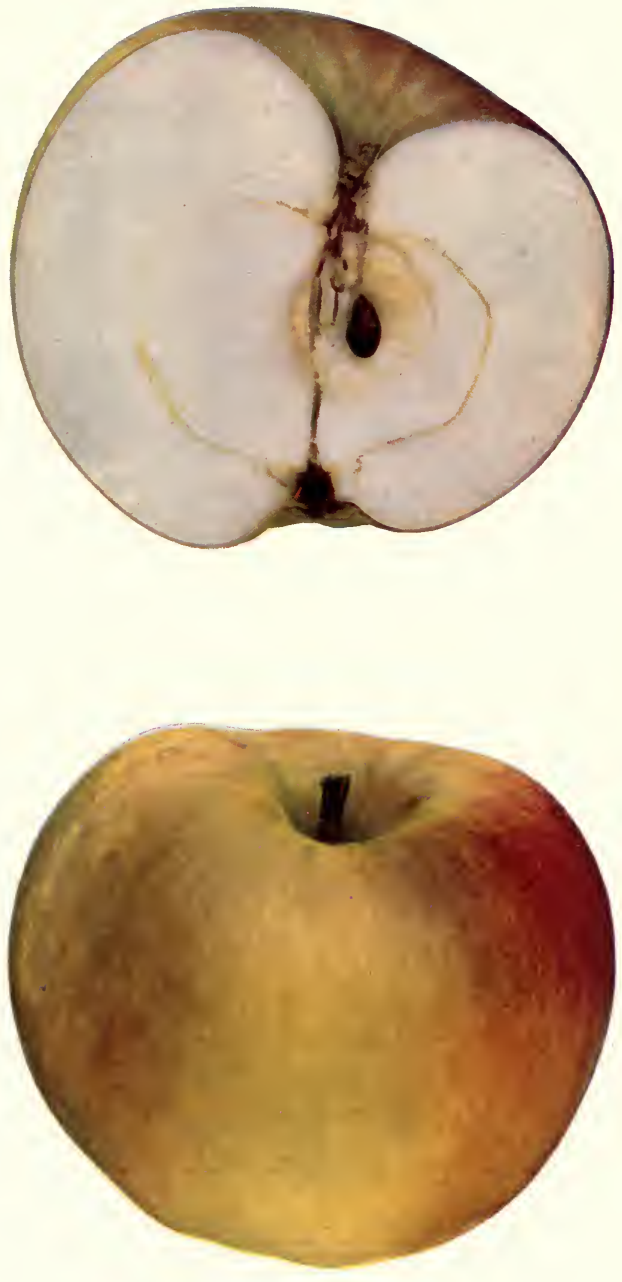

BOIKEN 

The foliage is remarkably healthy and the fruit is pretty resistant to the scab.

Historical. This is a German variety which has long been known under cultivation in Prussia ( 1,2 ). It is said to have been named after a former dike warden (4). It has been quite extensively disseminated in this country within the last decade, having been introduced some years earlier (8). In New York commercial orchards the plantings of it are now being gradually extended.

\section{TREE.}

Tree moderately vigorous; branches short, stout and crooked. Form somewhat spreading, rather dense. Twigs medium in length or rather long, curved, pretty stout, especially at the tips; internodes short to medium. Bark brownish-red, streaked and conspicuously blotched with grayish scarf-skin; pubescent. Lenticels scattering, rather conspicuous, moderately abundant, irregular in shape and size, often large, oblong, sometimes roundish. Buds large or above medium size, broad, rather plump, obtuse to nearly acute, projecting, free, pubescent. Leaves large, broad.

\section{Fruit.}

Fruit above medium to very large; fairly uniform in shape but rather uneven in size. Form somewhat oblate, being broad at the base, conical, often somewhat ribbed, pretty symmetrical. Stem long to medium. Cavity obtuse to acute, very broad, furrowed, sometimes compressed, partly colored with thin brownish-russet. Calyx large, closed or somewhat open; lobes acute. Basin sometimes oblique, moderately wide to rather narrow, abrupt, moderately deep, furrowed and wrinkled.

Skin tough, smooth, waxy, clear bright pale yellow, often with sharply contrasting brilliant pinkish-red blush. Dots numerous, rather small, often red areolar, with whitish or russet center, not very conspicuous, often submerged. Prevailing effect yellow relieved more or less by pinkish-red, not striped. The fruit is decidedly attractive in appearance for a yellow apple.

Calyx tube large, funnel-form, or approaching cone-shape, often extending to the core. Stamens median.

Core rather large, open or partly so, abaxile; cells usually symmetrical; core lines clasping. Carpels decidedly concave, very broad, elliptical, slightly emarginate, tufted. Seeds medium, plump, obtuse to acute, dark.

Flesh white, firm, crisp, tender, fine-grained, very juicy, sprightly, brisk subacid, not high in quality, good.

Season November to February or March. In cold storage its season extends to May or later (20).

\section{BORSDORF.}

References. I. Ronalds, $1831: 26$. 2. Cat. Hort. Soc. London, 1831. 3. Kenrick, I833:72. 4. Downing, I845:99. 5. Thomas, r849:178. 6. Emmons, Nat. Hist. N. Y., 3:72. I851. 7. Elliott, 1858:167. 8. Berghuis, r868: col. pl. No. 73. 9. Downing, 1872:103. ro. Leroy, 1873:150. Ir. Montreal Hort. Soc., 7:156. I881. I2. Hogg, 1884:26. I3. Hoskins, U. S. Pom. Rpt., I886: 279. 14. Hoskins, Garden and Forest, 3:516. I890. I5. Budd, Ia. Sta. Bul., I9:541. I892. I6. Bailey, An. Hort., I892:235. I7. Bredsted, I893:301. I8. Ill. Sta. Bul., 45:315. I896. 19. Munson, Me. Sta. An. Rept., 12:73. 1896. 
20. Can. Hort., 20:412. 1897. 21. Eneroth-Smirnoff, rgor:173. 22. Munson, Me. Sta. An. Rpt., 18:83, 86. I902 (also Bul. 82). 23. Powell and Fulton, U. S. B. P. I. Bul., 48:38. 1903. 24. Beach and Clark, N. Y. Sta. Bul., 248: I13. 1904 .

SyNoNyms. Borsdorf (6). Borsdorfer (3, 8, 14, 21). Borsdörfer (12). Borsdorff (7). BorsdorfF (5). BorsdörfFer (2). Borsdorffer ( $1,6,7$, 18). Borsdorffer (5). EDELBORSDORFER (8). King George the Third (7). King GeORge the ThiRd (I). Queen's (7).

A German variety, which is valued in many parts of Europe as a dessert fruit of first quality. The tree is very hardy and very productive. Although it was introduced into this country many years ago, it has not won recognition either in the home orchards or in commercial orchards. It is not recommended for planting in New York state because it is less desirable here than other wellknown varieties.

Histurical. Hogg states (12) that, "It is believed to have originated either at a village of Misnia, called Borsdörf or at a place of the same name near Leipsic. According to Forsyth it was such a favorite with Queen Charlotte that she had a considerable quantity of them annually imported from Germany for her own private use. It is one of the earliest recorded varieties of the continental authors. but does not seem to have been known in this comntry before the close of the last century. It was first grown in the Brompton Park Nursery in 1785 . It is mentioned by Cordus, in 1561 , as being cultivated in Misnia, which circumstance has no doubt given rise to the synonym 'Reinette de Misnie."

\section{TREE.}

Trec moderately vigorous; branches long, rather slender, with numerous small laterals. Form ronndish, dense. Taigs short, straight, slender; internodes short. Bark dull reddish-brown, quite pubescent. Lenticels inconspicuons, scattering, very small, oblong. Buds small, narrow, acute, free, quite pubescent. Leaves medium in size, rather broad.

\section{Friti.}

Fruit below medium to small. Form oblate, somewhat ribbed, sides slightly unequal, pretty uniform in size and shape. Stem long to very long, slender, often inclined obliquely. Cazify moderately shallow to rather deep, wide, obtuse, often a little furrowed and somewhat russeted. Caly $x$ rather large. usually partly open. Basin usually rather shallow, wide, and obtuse, somewhat ridged and slightly wrinkled.

Skin yellow, partly washed with rather dull light scarlet and often marked with streaks of russet and inconspicuous capillary netted russet lines. Dots scattering, often large and irregular, gray or russet.

Caly.x tube short, wide, cone-shape or urn-shape, with a fleshy projection of the pistil into its base. Stamens marginal to median.

Corc medim to rather small, axile, closed or nearly so: core lines meeting. Carpels broad, narrowing sharply towards the apex, nearly truncate at base. 
slightly emarginate. Seeds numerous, medium to small, plump, acute, compactly filling the cells.

Flesh whitish, tinged slightly with yellow, rather coarse, moderately crisp, rather tender, moderately juicy, mild subacid, becoming nearly sweet, aromatic.

Season November to February.

\section{BOSTON RUSSET.}

This name is one of the old synonyms for Roxbury Russet but in the vicinity of Albion it has been applied to another variety which, so far as we can discover, has not been described in any publication. The fruit is roundish conic, regular, with medium cavity and basin. Skin pale yellowish-green, irregularly overspread with thin russet. Dots numerous, small. Flesh tinged slightiy with yellow, moderately tender, mild subacid, not more than good in quality. Not considered desirable for commercial purposes.

\section{BOT'TLE GREENING.}

References. 1. Amer. Jour. Hort. and Florists' Companion, x:357. 1866-67. 2. Downing, 1872:103. 3. Bailey, An. Hort., 1892:235. 4. Lyon, Mich. Sta. Bul., I52:220. I898. 5. Ibid., I69:I79. 1899. 6. Lyon, Mich. Hort. Soc. Rpt., 1890:290. 7. Waugh, Vt. Sta. An. Rpt., 14:290. I90I.

Much esteemed by a few growers because the tree is healthy, hardy and productive, and the fruit is excellent for culinary use and good for dessert. It is rather attractive in color for an apple of the Greening class. Because of its tender skin and light color it shows the least bruise plainly. For this reason it requires very careful handling. It is even more apt to scald in storage than Rhode Island Greening. Most growers and buyers find it unsatisfactory as a commercial apple. It is said to succeed particularly well on sandy or gravelly loam, usually bearing annually. The fruit usually hangs well to the tree.

Historical. It originated as a chance seedling on a farm on the dividing line of New York and Vermont where the original tree was still standing about a half century ago. Its name is derived from the fact that workmen found the hollow in this old tree a convenient place for the "bottle" (I). It is still handled by nurserymen (3) but is not being much planted in this state.

\section{TREE.}

Tree medium in size, moderately vigorous; branches moderately long, stout, crooked, with yellowish bark. Form rather round and open. Twigs medium in length, straight, rather stout; internodes short to medium. Bark olive-green mingled with reddish-brown, pubescent and covered with thin scarf-skin. Lenticels scattering, very small to medium, round, inconspicuous. Buds large to medium, broad, acute, appressed, heavily pubescent. Leaves medium, broad. 


\section{Fruit.}

Fruit medium to large. Form roundish oblate to ovate, inclined to conic, pretty regular, sometimes obscurely ribbed, fairly symmetrical, sides sometimes unequal. Stcm rather short. Cavity acuminate, moderately deep, rather broad, sometimes lipped, sometimes indistinctly furrowed or compressed. Calyx rather large, closed or somewhat open. Basin abrupt, medium in depth, rather narrow to moderately wide, often slightly furrowed, sometimes wrinkled.

Skin thin, tough, smooth, grass-green, or yellowish, thinly washed or often deeply blushed with dull pinkish-crimson, not striped. Dots few, usually submerged, pale and inconspicuous; a few scattering ones are russet. Prevailing color green but more blushed than Rhode Island Greening.

Calyx tube rather large, conical. Stamens median.

Core rather small, somewhat abaxile; cells often closed towards apex and open at base; core lines slightly clasping. Carpels broad, roundish to obcordate. Seeds medium, acute.

Flesh nearly white, moderately firm, very tender, very juicy, peculiarly aromatic, pleasant subacid, good to very good.

Season October to March or later. Commercial season October to January.

\section{BOUCKEN.}

Known locally for many years in the vicinity of Buffalo. We have not seen this variety. The following statement concerning it is furnished by C. D. Zimmerman, Buffalo, N. Y.: "Resembles Maiden Blush very much in size and color; keeps till June; flavor good; an enormous bearer. Often a large apple is borne at the extreme end of the branch."

\section{BOYS DELIGHT.}

An excellent dessert apple in season from October to midwinter. It is not equal to either Fameuse or McIntosh in appearance and is apparently desirable only for the home orchard. Fruit medium or below, pale greenishyellow, partly overlaid with a light shade of "Fameuse" red. Flesh white, of Fameuse character but more nearly sweet. It originated from Fameuse seed with S. P. Morse, Lowville, Ontario.

\section{BRISTOL.}

The variety known in Western Connecticut and in Eastern New York by this name appears to be identical with Red Canada.

\section{BROWNLEES.}

References. I. Downing, 1872:108. 2. Mas, Le Verger, 4:93. col. pl. 3. Hogg, 1884:33. 4. Bailey, An. Hort., $1892: 235$. 5. Beach and Clark, N. Y. Sta. Bul., 248:113. 1904.

Synonym. Brownlees' Russet $(1,4)$. Brownlees's Russet (3). Broz'nlecs' Russet (5). Brozonlees' Secdling Russet (I). REINETte GRISE BRownLEES' (2). Reinette Grise Brownlees' (I). 

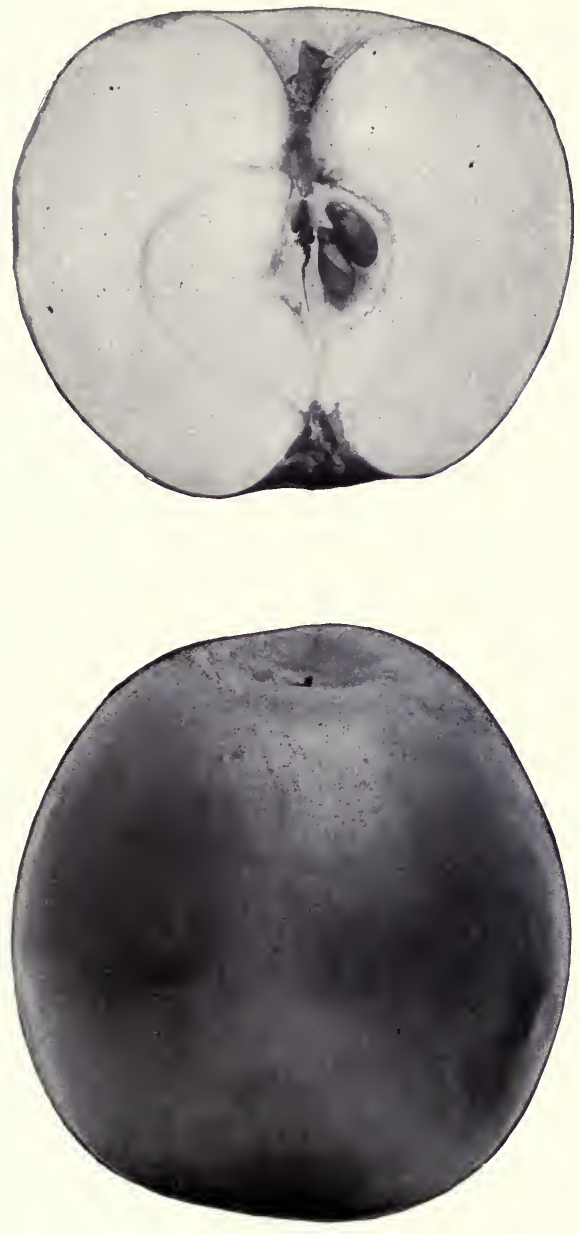

BOTTLE GREENING 

Fruit excellent in quality, desirable in size, and of good appearance for a russet apple, but not sufficiently productive here to make it profitable for commercial planting.

Historical. An English variety introduced by Mr. William Brownlees, a nurseryman at Hemel, Hempsted, Herts, about the year 1848 (3). It appears on the lists of sonic nurserymen but is but little known in New York and is not being planted here to any considerable extent.

\section{TrEe.}

Tree vigorous, moderately productive. Form upright. Twigs numerous, rather short or sometimes long, generally slender, straight or slightly curved at hase; internodes long. Bark smooth, clear reddish-brown somewhat shaded with olive-green and dull brownish-red, often overlaid with heavy scarf-skin; quite pubescent. Lenticels inconspicuous, not raised, moderately numerous, of medium size or small, roundish or elongated. Buds medium, more or less projecting, obtuse, somewhat pubescent.

\section{Fruit.}

Fruit medium to large; fairly uniform in size, rather variable in shape. Form oblate, often oblique, sometimes ribbed, irregular often bulging or with sides compressed, flattened at the base, rounded toward the basin. Stem usually short and thick, often swollen. Cavity large, variable in form, usually acute, deep, broad, furrowed, sometimes compressed or lipped. Calyx small, closed. Basin usually rather small, shallow, abrupt to obtuse, often somewhat furrowed and finely wrinkled.

Skin rather tender, entirely covered with russet or sometimes with patches of smooth yellow. Dots often conspicuous, scattering, pale gray or whitish.

Calyx tube small, varying from fumnel-shape to conical. Stamens median to marginal.

Core nearly axile; cells symmetrical, closed or slightly open; core lines clasping. Carpels rather flat, rather pointed ovate, broad and almost truncate at the base, mucronate, somewhat tufted.

Seeds often abortive, rather dark reddish-brown, rather small to above medium, narrow to rather wide, plump, acute to acuminate, somewhat tufted.

Flesh more or less tinged with yellow, moderately firm, fine, moderately crisp, juicy, sprightly, with a rich subacid aromatic flavor which is found only in some russet apples, very good quality.

Season October to January or later $(3,5)$.

\section{BROWN SWEET.}

Known locally in Oswego county. The following statement concerning it is furnished by D. D. Stone of Oswego: "Tree healthy, and a good but not a rampant grower. In alternate years it bears heavily, yielding smooth fruit of large size which is excellent for baking or boiling. It withers or shrivels quickly in a dry cellar."

\section{FRUIT.}

Fruit large. Form ovate to oblong conic, often narrowing sharply towards the apex, more or less ribbed and irregular. Stem medium. Cavity medium to large, acute to acuminate, usually deep and somewhat russeted. Calyx 
closed or open, medium to small; lobes acuminate. Basin often oblique, shallow to moderately deep, rather narrow, abrupt, somewhat furrowed and wrinkled.

Skin moderately thick, tongh, green or yellow, sometimes with a red cheek, and often much russeted.

Calyx tube small to medium, conical. Stamens median to basal.

Core large, axile to usually decidedly abaxile; cells often unsymmetrical, open; core lines meeting to slightly clasping. Carpels roundish obovate, somewhat tufted. Seeds medium or below, medium brown, plump, obtuse to acute.

Flesh tinged witl yellow, fine, rather tender becoming tough when shriveled, juicy, very sweet, good to very good.

Season September to midwinter.

\section{BUCKINGHAM.}

References. I. Coxe, I8I 7:I47. fig. 2. Downing, I845:I44. 3. Van Buren, Mag. Hort., 23:256. I857. 4. Elliott, 1858:180. 5. Am. Pom. Soc. Cat., 1858. 6. Mag. Hort., 27:98, г52. I86r. 7. Warder, 1867:537. fig. 8. Downing, 1872:109. 9. Leroy, 1873:87. I0. Barry, I883:343. II. Thomas, I885:217. 12. Lyon, Mich. Hort. Soc. Rpt., I890:290. 13. Wickson, 1891:246. I4. Bailey, An. Hort., 1892:236. I 5. Massey, N. C. Sta. Bul., 92:42. 1893. 16. Hoskins, Rural N. Y., 53:278. 1894. 17. Stinson, Ark. Sta. An. Rpt., 1894:45. 18. Beach, N. Y. Sta. An. Rpt., 13:579. I894. 19. Taylor, Am. Pom. Soc. Rpt., I895:195. 20. Powell and Fulton, U.S.B. P. I. Bul., 48:38. igo3. 2 I. Budd-Hansen, I903:57. fig. 22. Beach and Clark, N. Y. Sta. Bul., 248:1 13. I904.

Synonyms. Bachelor (9). Bachelor (8, I I). Batchellor (9). Blackburn (8). Blackburn, erroneously (7). Buckingham (9). Byer's (8). Byer's Red $(7,8)$. EQuinetely (3). Equinetely (8, Iо, I I, I3, I7). Fall Queen (7, 8, 10, 15, 17, 21). Fall Queen of Kentucky (II, I6). Frankfort Queen (8). Henshaw $(7,8)$. Kentucky Queen $(8,9$, I I, I7). King (8, 9). Ladies' Favorite of Tenn. (8). Lexington Queen (8). Merit $(8,9)$. Ne Plus Ultra $(8,9)$. Ox-Eye of some in Kentucky $(8)$. Queen $(8,9,17)$. Red Gloria Mundi of some $(8,9)$. Red Horse $(8,17)$. Sol Carter (3, 8). Winter Queen $(1,2,4)$. Winter Queen $(8,9,17,18)$. Winter Queen of Kentucky, incorrectly (8). Winter Quecning $(2,4)$.

This variety has long been favorably known in the southern states. When well grown it is decidedly attractive in appearance, but, as grown here, it is not especially attractive and not desirable. This location is too far north for the variety to develop its best color and quality. While it occasionally gives heavy crops, we find it an irregular bearer and often unproductive.

Historical. Origin unknown (8), by some said to have come originally from Louisa county, Va. (7), by others, from North Carolina (3). It has long been known from Southern New Jersey southward through Virginia and westward through the Ohio valley. 

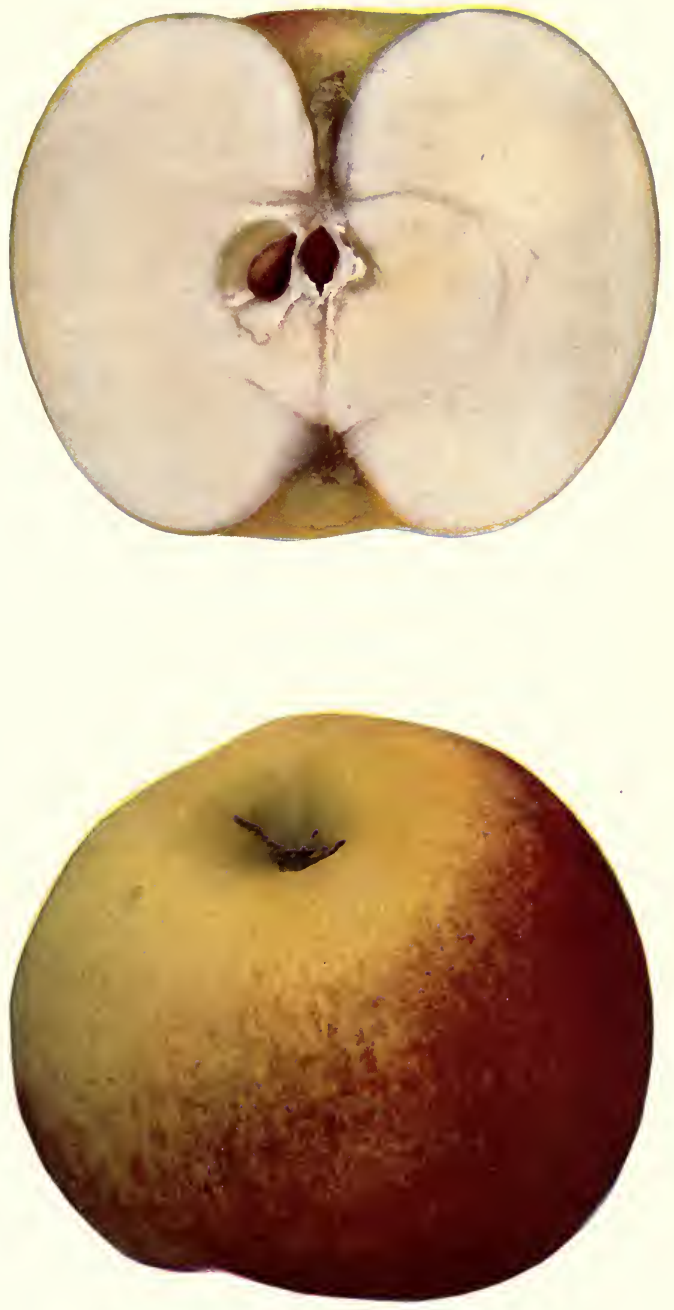

BUCKINGHAM 

TREE.

Tree a moderate grower. Twigs short, rather slender, rather crooked considering the length; internodes short. Bark smooth, clear light reddish-brown mingled with olive-green, not pubescent. Lenticcls rather scattering, below medium, generally elongated, raised. Buds medium or below, rather prominent, rather acute, slightly pubescent, lightly attached to the bark.

\section{Fruit.}

Fruit large. Form oblate to roundish oblate, somewhat irregular, usually broadly and obscurely ribbed; sides sometimes unequal. Stem rather stout, short to medium. Cavity large, acute to acuminate, wide, deep, usually with heavy outspreading russet. Calyx medium to large, closed or open. Basin large, abrupt, wide, moderately deep, obscurely furrowed, wrinkled.

Skin thick, tough, pale yellow or pale green washed and mottled with red, striped and blushed with bright carmine. Dots numerous, small, light or russet, mingled with others which are large, gray and areolar. Prevailing effect in well colored specimens, beautiful red striped.

Calyx tube medium, varying from conical to funnel-form. Stamens median or approaching basal.

Core below medium to small, varying from decidedly abaxile to nearly axile; cells usually symmetrical and open or sometimes closed; core lines clasping. Carpels much concave, elliptical to roundish, emarginate, usually smooth. Sceds rather dark, medium to rather large, plump, wide and obtuse.

Flesh tinged with yellow, moderately firm, moderately coarse, rather tender, crisp, juicy with distinct aroma, mild subacid, fair to good.

Season November to April $(20,22)$.

\section{BULLOCK.}

References. I. Coxe, I8I7:125. 2. Thacher, 1822:122. 3. Buel, N. $Y$. State Bd. of Agr. Memoirs, 3:476. Cat. No. 34. 1826. 4. Cat. Hort. Soc. London, I831:35. 5. Kenrick, 1833:33. 6. Manning, 1838:54. 7. Dittrich, Syst. Handb. der Obstk., I:504. 1839. 8. Downing, 1845:131. 1847. col. pl. 9. Thomas, 1849:178. fig. ro. Mag. Hort., 15:250. I849. II. Emmons, Nat. Hist. N. Y., 3:94. I851. fig., col. pl. No. 52. 12. Am. Pom. Soc. Cat., 1852. 13. Mag. Hort., I9:I26. I853. 14. Biedenfeld, 1854:223. 15. Mag. Hort., $2 \mathrm{I}: 300,398$. I855. I6. Hooper, 1857:II, 20. I7. Elliott, 1853:7I. fig. I8. Flotow, Ill. Handb. der Obstk., I:337. I859. r9. Warder, 1857:521. 20. Regel, I:440. I8C8. 2I. Mas, Le Vergcr, 4:33. col. pl. 22. Lauche, I: col. pl. No. 73. I882, 23. Barry, 1883:341. 24. Hogg, 1884:7. 25. Lyon, Mich. Hort. Soc. Rpt., I890:288. 26. Bailey, An. Hort., 1892:236. 27. Munson, Me. Sta. An. Rpt., r893:132. 28. Ont. Fr. Stas. An. Rpt., 2:32. 1895. 29. N. C. Bd. of Agr. Bul., 1900:6. 30. Waugh, Vt. Sta. An. Rpt., 14:286. 1901. 31. Macoun, Can. Dept. Agr. Bul., 37 :42. I901. 32. Budd-Hansen, 1903:57. fig.

Synonyms. American Golden Russet (9, I6, 19, 20, 21, 23, 24, 25, 26, 28, 30, 31). American Golden Russet (17, 27, 29, 32). Bullock (30). BuLlock's Pepping (i8, 22). Bullock's Pippin (8). Bullock's Pippin ( I, 2, 9, 10, 13, I5, 16, I7, 21). Fall Winesap (I7), erroneously. Golden Russet (5, 6). Golden Russet $(8,9$, I7). Golden Russet, American (8). Little Peamain (i7). Pippin Bullok (7, I4). Sheepnose (I). Sheepnose (8, 9, 17). Sheep's Nose (4). Sheep's Snout (2). 
Early in the last century Coxe described this as one of the finest apples in New Jersey in autumn and early winter (I). In 1826 Buel characterized it as "tender, juicy and high flavored; among the best fruit for table" (3). A. J. Downing called it " one of the most delicious and tender apples" (8). Thomas remarks that it is too small to become popular (9).

The fruit is below medium size, light yellow, marbled with thin russet. Flesh yellowish, very tender, with a mild, rich, spicy, slightly subacid flavor. It is still grown to a limited extent in some portions of the state, particularly in the Hudson and Champlain valleys. It may be recommencled for the home orchard, but it has not been found profitable as a commercial sort. Some have found that it succeeds best on sandy or gravelly soil. Some nurserymen have reported that when grown on clay soil the bark of the trees is apt to split at the collar, and for this reason they prefer not to grow the trees in the nursery on their own trunks.

Historical. Originated in Burlington county, New Jersey, more than a century ago (1). It has been favorably known in the West and the South (19) and as far north as Ontario and Quebec (3I). In New England and the West it has been known as Golden Russet $(5,6,8)$. To distinguish it from the English Golden Russet, Downing called it American Golden Russet (8). There are so many Golden Russets ve prefer to follow the Catalogue of the Anerican Pomological Society (I2) and Hovey (IO) and retain Coxe's name Bullock, believing this will be less liable to lead to confusion.

\section{TREE.}

Tree not large but a fairly strong grower. Form upright or reundish. Twigs short to medium, moderately stout, rather blunt at tip, nearly straight; internodes mediuns. Bark dull brownish-red or olive-green with a grayish hue due to the rather heavy scarf-skin; slightly pubescent. Lenticels only moderately numerous, inconspicnous, raised, below medium, elongated. Buds small to medium, moderately projecting, acute, sparingly pubescent, free.

\section{FrUIT.}

Fruit below medium. Form roundish conic to ovate, pretty regular in outline, uniform. Stem long. slender. Carity acuminate to acute, moderately deep to deep. rather narrow, fumnel-shape or compressed. Caly $x$ rather small, closed. Basin small, often oblique, rather shallow, narrow, wrinkled, not ridged.

Skin attractive, pale yellow or greenish-yellow, more or less overspread and splashed with thin russet. Dots numerous, small, obscure, russet. General appearance attractive.

Core medium to rather large, axile, slightly open; core lines nearly meeting. Carpels roundisl. Seeds rather large, plump. 


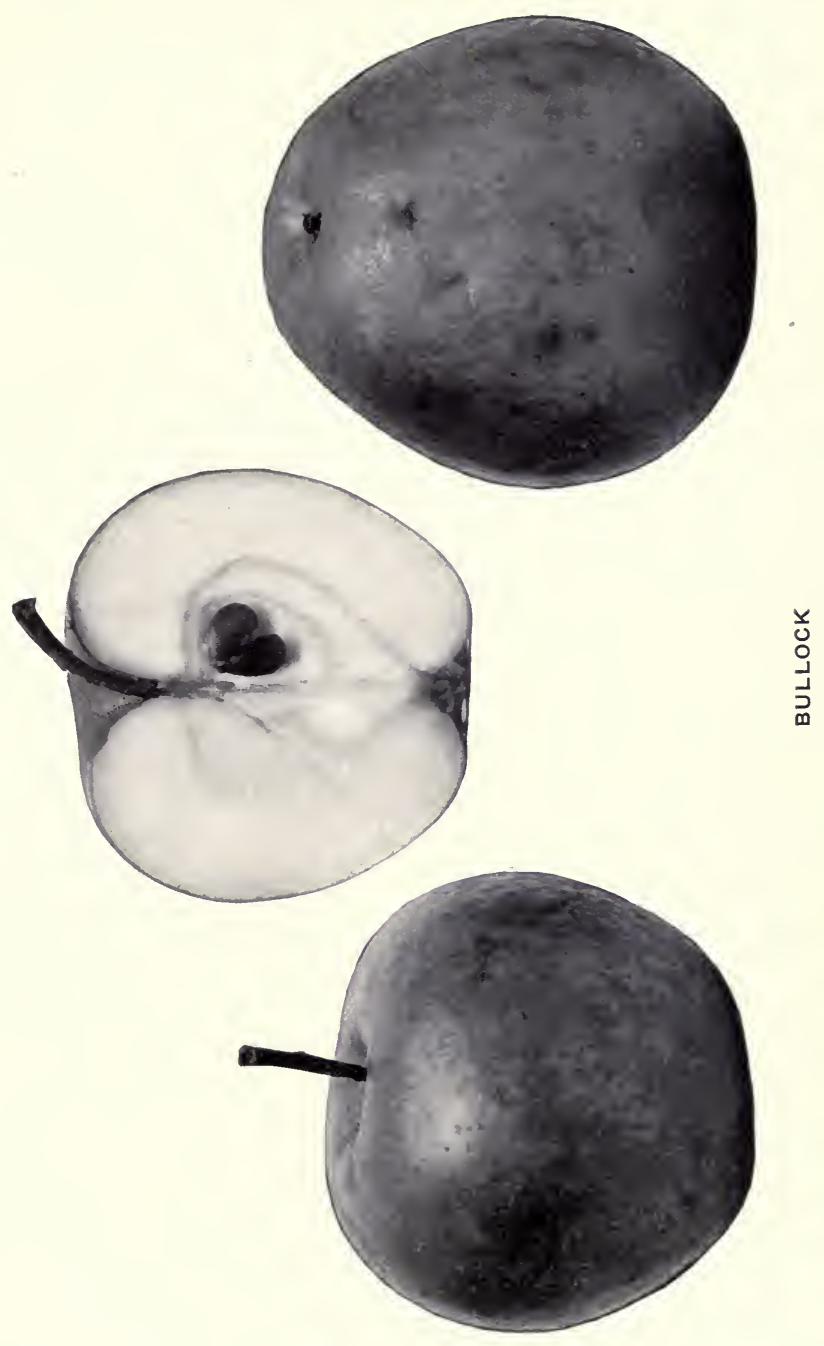



Flesh slightly tinged with yellow, firm, fine, crisp, very tender, juicy with an agreeable rich, aromatic, mild subacid flavor; very good to best.

Season October to January.

\section{CABASHEA (WINTER).}

The variety recognized by Downing, Lyon, Woolverton and some other pomologists as Cabashea, so far as we can learn, is not known to New York fruit growers and fruit dealers under that name but by them is commonly called Twenty Ounce Pippin. It is in season with Tompkins King and a little later. Sometimes it is called King. The variety which is generally called Cabashea in Western New York is a large, flat apple somewhat marked with dull red. It comes in season about with the true Twenty Ounce but is not so good a keeper.

We prefer to follow Thomas, Warder and Emmons in retaining the name Cabashea for the fall apple above mentioned and in recognizing Twenty Ounce Pippin as the correct name for the later variety. The Twenty Ounce Pippin should not be confused with the true Twenty Ounce nor with the Tompkins King.

For more extended notice of these varieties the reader is referred to Cabashea (fall) in the succeeding volume and to Twenty Ounce Pippin in this volume.

\section{CAMPFIELD.}

ReFERENCES. I. Coxe, I8I7:I49. fig. 2. Thacher, I822:122. 3. FloyLindley, 1833:88. 4. Downing, 1845:I44. 5. Emmons, Nat. Hist. N. Y., $3: 64$. I851. fig. 6. Downing, I857:226. 7. Elliott, I858:126. 8. Warder, 1867:382. fig. 9. Am. Pom. Soc. Cat., 1871:6. го. Barry, 1883:336. II. Rural N. Y., 49:251. I890.

Synonyms. Canfield (II). Newark Sweeting ( I, 2, 3, 4, 5, 6, 7, 8, 10). Sweet Maiden's Blush (6).

An old variety recommended by Coxe (I) for cider. Downing (6) calls it good for baking and stock feeding. Warder (8), who gives a very good description of the variety, ranks it poor in quality. The tree is very hardy, healthy, a biennial bearer. It is apt to overbear causing the fruit to be small. It has the merit of being a good keeper but as there is not much demand for fruit of this character it is fast becoming obsolete.

Historical. Originated in Eastern New Jersey and named after a family by the name of Campfield (I).

TREE.

Tree large, very vigorous. Form spreading. Twigs long, rather slender, light colored.

\section{Fruit.}

Fruit medium to large; uniform in size. Form roundish oblate to roundish ovate or roundish conic. Stem below medium. Cavity acute, rather narrow, deep, regular. Calyx closed or somewhat open. Basin somewhat abrupt, shallow to moderately deep, narrow, slightly wrinkled.

Skin smooth, yellow, blushed and striped with red. Dots small, white or russet.

Calyx tube long funnel-form. 
Core closed; core lines clasping. Carpels broad, emarginate, somewhat tufted. Seeds numerous, short, plump, dark.

Flesh whitish, slightly tinged with yellow, firm, rather dry, tender, moderately fine, not crisp, decidedly sweet, good.

Season November to July.

\section{CANADA BALDWIN.}

References. I, Montreal Hort. Soc. An. Rpt, 2:28. I876. 2. Ib., 4:120. I878. 3. Amer. Pom. Soc. Cat., 1881:6. 4. Downing, r881:79. app. 5. Thomas, 1885:505. 6. Can. Hort., 12:337. 1889. 7. Ib., 15:337. 1892. 8. Rural N. Y., 52:51. 1893. 9. Munson, Me. Sta. An. Rpt., 1893:132. ro. Amer. Gard., I5:288. I894. Ir. Taylor, Am. Pom. Soc. Rpt., I895:I93. I2. Lyon, Mich. Sta. Bul., 169:179. I899. 13. Waugh, Vt. Sta. Bul., 83:90. 1900. I4. Macoun, Can. Dept. Agr. Bul., 37:43. I901. 15. Rural N. Y., 61 :800. 1902. 16. Stone and Wellington, Rural N. Y., 62:36. 1903. I7. Budd-Hansen, 1903: 59. 18. Beach and Clark, N. Y. Sta. Bul., 248:II4. I904.

The name is an unfortunate selection, since this variety does not resemble Baldwin, but belongs in the Fameuse group. It yields moderately heavy crops, and under favorable conditions tends to become an annual bearer. It is a better keeper than Fameuse, but is less attractive; yet highly colored specimens are beautiful and attractive. It is not recommended for planting, except in those regions where a hardy variety of the Fameuse type is desired to extend the Fameuse season.

Historical. "Said to have originated from seed of Pomme de Fer on the farm of Alexis Dery, St. Hilaire, Que. It was given its name by N. C. Fisk, Abbotsford, Que., who propagated it in $1855 . "$ (14).

TREE.

Tree in the nursery is a moderate grower, with good hard wood and strong deep roots. In the orchard it is a moderate grower, upright, becoming rather open and spreading with age; branches long, moderately stout. Twigs medium to short, somewhat curved, moderately stout; internodes short to above medium in length. Bark dull dark brown, tinged with reddish-brown, mingled with olive-green, and lightly streaked with gray scarf-skin; slightly pubescent near tips. Lenticels rather numerous, medium to small, roundish or oblong, raiscd. Buds of medium size, plump, acute, free, quite pubescent. Leaves medium in size, broad.

\section{Fruit.}

Fruit averages below medium. Form roundish inclined to conic, or sometimes slightly oblate, obscurely ribbed, usually symmetrical, regular, sides sometimes unequal; pretty uniform in size and shape. Stem pubescent, sometimes long, moderately slender and bracted, but more often short and thick. Cavity rather large, acute to somewhat obtuse, moderately deep to deep, moderately broad, smooth or partly covered with thin greenish russet, often slightly furrowed or compressed; pubescent near base of stem. Calyx closed or partly 


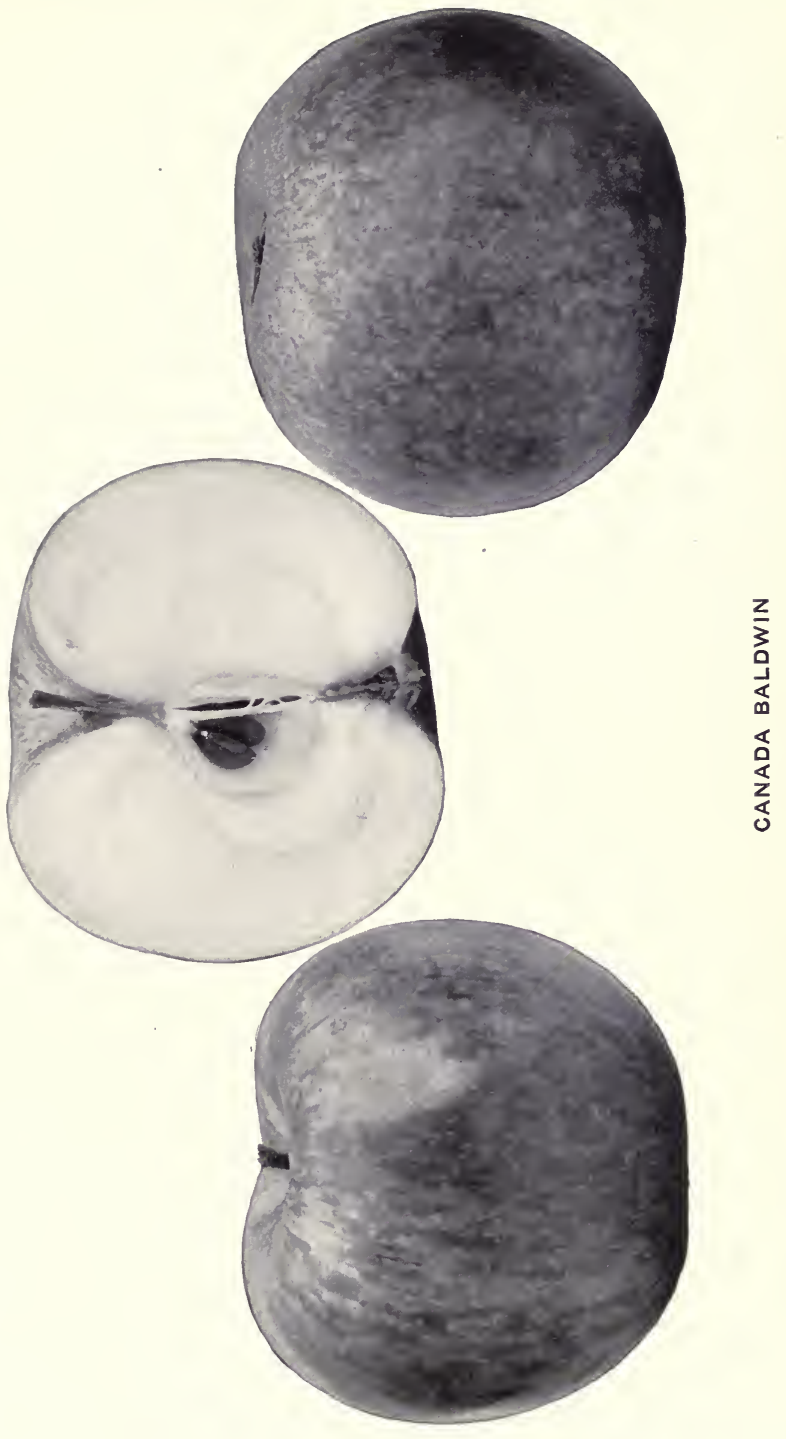



open, pubescent; lobes often long and acuminate, reflexed. Basin shallow to moderately deep, medium in width, obtuse or somewhat abrupt, often furrowed or compressed, irregularly wrinkled, often with a tendency to mammiform protuberances.

Skin thick, tough, smooth, pale yellow or greenish, mottled and blushed with bright red, splashed and striped with purplish-carmine, conspicuously marked with areolar dots and covered with a thin whitish bloom which makes the fruit somewhat dull in color. Dots large, numerous, whitish, areolar with russet or gray center. Prevailing effect in highly colored specimens beautiful and attractive, the color being a deep dark red, but as grown in Western New York the color effect is that of pale yellow striped with red. The skin takes a brilliant polish.

Caly $x$ tube generally tends toward funnel-shape but is sometimes conical. Stamens marginal to median.

Core medium or above, closed or partly open; core lines clasping; often part of the cells are not well developed because of abortive seeds. Carpels smooth, ovate to roundish, or obovate, slightly emarginate, mucronate. Seeds medium to large, plump, acute, numerous, rather narrow, long, smooth or sometimes slightly tufted, variable in color.

Flesh white, often tinged with red, firm, moderately coarse, crisp, moderately tender, juicy, mild subacid, sometimes slightly astringent, with a Fameuse-like aroma, pleasant, good or possibly very good in quality.

Season November to January but often some portion of the fruit may keep till April.

Use similar to Fameuse, suitable for dessert. Cooks quickly but the color and texture of the cooked fruit are not good.

\section{CANADA REINETTE.}

References. I. Duhamel, 2:299. 1768. 2. Andrieux, Catalogue raisonnée des meilleures sortes d'arbres fruitiers, I771:56. 3. Diel, I:133. I799. 4. Ib., 1800:64. 5. Ib., 9:8I. I807. 6. Ib., 10:86. I809. 7. Lindley, 1841:40. 8. Cat. Hort. Soc. London, 1831:30. 9. Ronalds, 1831:21. fig. ro. Kenrick, 1833:73. I I. Pom. Mag. 2:77. I841. col. pl. 12. Mag. Hort., 7:44. I841. 13. Downing, 1845:129. 14. Cole, I849:134. I5. Thomas, 1849:178. I6. Emmons, Nat. IIist. N. Y., 3:82. I851. I7. Biedenfeld, 1854:193. 18. Elliott, 1858:72. fig. r9. Ib., 1859:69. 20. Lucas, I:I19. 21. Am. Pom. Soc. Cat., 1862. 22. Warder, 1867:479. fig. 23. Regel, I868:470. 24. Mas, Le Verger, 4:31. 25. Leroy, 1873:637. 26. Lauche, 1882:260. col. pl. 27. Barry, 1883:344. 28. Hogg, r884:191. 29. Cat. Cong. Pom. France, 1887:329. 30. Lyon, Mich. Hort. Soc. Rpt., I89o:290. 31. Bailey, An. Hort., I892:236. 32. Can. Hort., I6:I7, I15. I893. 33. Bredsted, 1893:86. 34. Gaucher, Pomologie, I894: col. pl. No. I5. 35. Taft, Mich. Sta. Bul., 105:108. 1894. 36. Eneroth-Smirnoff, Igor:23I. 27. Budd-Hansen, I903:59. fig. 38. Powell and Fulton, U. S. B. P. I. Bul., 48:39. 1903. 39. Beach and Clark, N. Y. Sta. Bul., 248:114. I904.

Synonyms. Canada Pippin (i8). Canadian Reinette (7, io, II, 12, 32 ). Canadian Reinette (I3, I5, I8). CanAdisk Reinet (33). Canada Reinette $($ I8, 28). De Bretagne (I3, I8). Die Haarlemer Reinette (4). Die Weiberreinette (3). German Green (i8). Grosse Reinette D'Angleterre (i). Grosse Reinette d'Angleterre ( $10,13,18)$. Januarea ( 13, I8). KanadA- 
renett (36). Kanada Reinette (34). Mela Januera (io). Pariser Rambour Reinette $(6,20,26)$. Pariser Rambour Reinet (33). Pariser Rambourrenett (36). Pomme de Caen (13, 18). Portugal (10, 13, 18, 28). Reinette De Canada (9, 28). Renette Grosse De Angleterre (17). Reinette Monstreuse De Canada (2). Reinette Du Canada $(8,24,25,29)$. Reinette Von CANAda (23). Reinette du Canada (10, 15, I8). Reinette Grosse du Canada (10, 13, 18). Reinette du Canada Blanche (10, 13, 18). Reinette du Canada a'Cortes (13, 18). Reinette Canada (27). Reinette de Caen (ro). Reinette de Canada a Cotes (10). St. Helena Russet (28). Wahr Reinette (13, i8). Wesse Antillische Winterreinette (5). White Pippin (18). Yellow Newtoz'n Pippin (18), erroneously.

An irregular bearer, in some years very productive, but more often only moderately productive or unproductive. It appears to be much esteemed in Europe, where it has been grown under numerous synonyms. It is not much in demand in America because it is easily excelled by other varieties, both for home use and for market.

Historical. Origin unknown. It was listed in France as the Canada Reinette at least as early as $177 \mathrm{I}(2)$.

TREE.

Tree moderately yigorous; branches long, stout, crooked. Form spreading and drooping. Tavigs medium to long, straight, rather stout; internodes medium or below. Bark dull brown, tinged with dark olive-green, irregularly mottled with scarf-skin; very pubescent. Lenticels rather numerous, conspicuous, large, roundish to oblong, raised. Buds large, broad, plump, obtuse, appressed, rather deeply set, pubescent. Lcaves large, broad.

\section{Fruit.}

Fruit variable in size, averages above medium and is frequently very large. Form oblate or roundish, inclined to conic, often irregular, broadly angular, sometimes with furrows extending from base to apex; not uniform in shape. Stem short. Cavity rather acute, moderately broad, wavy, sometimes russeted. Caly, medium to large, closed or partly open. Basin abrupt, usually rather deep, moderately wide, furrowed and wrinkled.

Skin yellow, sometimes with decided blush but not striped, marked more or less with dots, f.ecks or irregular patches of russet.

Calyx tube medium, rather wide, cone-shaped. Stamens median or approaching basal.

Core medium or below; abaxile to nearly axile, open or partly open; core lines mecting. Carpcls romdish inclined to obovate, somewhat tufted. Secds few, large, long, tufted, dark.

Flesh has a decided yellow tinge and is firm, moderately tender, coarse, breaking, not crisp, juicy, subacid, very good.

Season. Early winter till March or April or perhaps later (39). Late in the season the fruit begins to lose in flavor although it may apparently be still in good condition. 

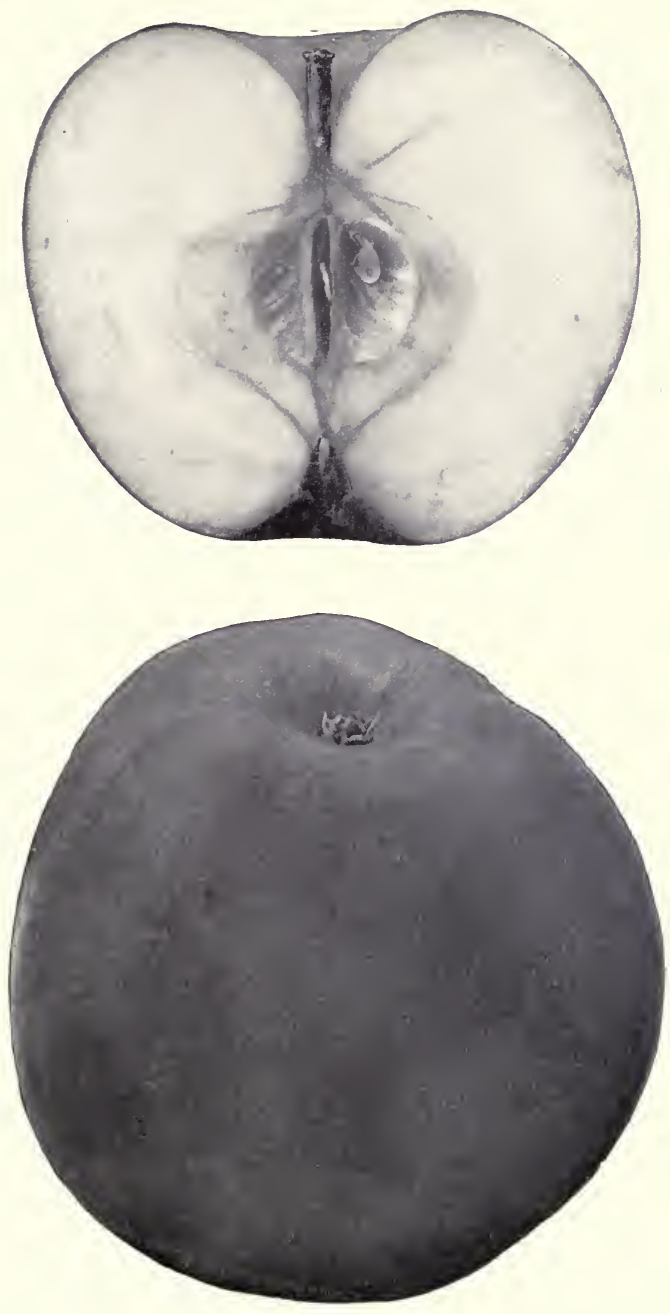

CANADA REINETTE 



\section{CANNON PEARMAIN.}

References. 1. Emmons, Nat. Hist. N. Y., 3:102. I851. fig. 2. Downing, 1857:126. 3. Elliott, 1858:126. 4. Am. Pom. Soc. Cat., 186o. 5. Mag. Hort., 27:99. г861. 6. Warder, 1867:676. fig. 7. Am. Pom. Soc. Rpt., 1871:38. 8. Barry, 1883:344. 9. Bailey, An. Hort., r892:236. 1о. Ala. Sta. Bul., 47:7. 1893. Ir. Powell and Fulton, U. S. B. P. I. Bul., 48:39. Ioo3.

Synonym. Cannon Pearmain (8).

Valued in the South as a long keeping apple of fairly good quality. Not adapted to New York conditions.

Historical. Originated in Virginia or North Carolina $(2,3,6,7)$.

TREE.

Tree healthy, vigorous, spreading.

Fruit.

Fruit medium to nearly large, ovate varying to roundish, regular, symmetrical; pretty uniform. Skin greenish-yellow, mottled and washed with bright red faintly striped with carmine. Dots yellowish, often areolar with russet point. Core medium, axile, closed; core lines somewhat clasping. Flesh tinged with yellow, very firm, somewhat coarse, crisp, juicy, aromatic, subacid, good.

Season January to April.

\section{CARLOUGH.}

References. I. Fulton, Mich. Sta. Bul., I77:49. I899. 2. Farrand, Ib., 205:44. 1903. 3. Budd-Hansen, 1903:60. 4. Powell and Fulton, U. S. B. P. I. Bul., 48:39. 1903.

Said to have originated in New York (2) but it is practically unknown in this state. It is being grown to a limited extent in some portions of the West and South. Its general appearance is good for a green apple.

TREE.

Tree vigorous. Form roundish spreading. Twigs reddish-brown.

FrUIT.

Fruit above medium to very large. Form roundish conic to oblong conic, often truncate at base; axis oblique. Stem short and slender. Cavity acute to nearly acuminate, very deep, moderately broad, russeted, often somewhat furrowed or compressed. Calyx small to medium, closed or partly open. Basin small to medium, medium in depth and width, abrupt, slightly furrowed.

Skin rather thick, tough, smooth, glossy, rather pale greenish-yellow, often with faint brownish-pink blush. Dots russet or submerged and whitish.

Calyx tube medium in width and length, conical or funnel-shape.

Core axile, closed; core lines clasping. Carpels large, obovate, much tufted. Seeds dark, large, rather narrow, long, acute, tufted.

Flesh whitish, somewhat coarse, crisp, tender, juicy, agreeable, mild subacid, sprightly, good.

Season November to April. 


\section{CARPENTIN.}

References. I. Downing, I872:120. 2. Leroy, 1873:205. fig. 3. Hogg, 1834 : 190 .

Synonyms. Carnation Apple. Carpentin Reinette (I). Der Carpentin (I). Klein Grane Reinette (I). Petite-Reinette Grise (2). ReInette Carpentin (3). Reinette Carpentin (2).

A little dessert fruit of about the size of the Lady apple, with red-russet skin and highly aromatic flavor. The following description is made from fruit furnished by C. D. Zimmerman, Buffalo, N. Y., who states that the variety has been marketed locally under the name Carnation apple.

TREE.

Tree vigorous, with long, slender shoots (3).

Fruit.

Fruit small to very small; uniform in size and shape. Form roundish conic to somewhat oblate, regular and symmetrical; occasionally sides unequal. Stem very long, slender. Cavity large, acute to acuminate, deep, broad, symmetrical, often with concentric broken russet lines. Calyx small, closed; lobes short, broad, nearly obtuse. Basin abrupt, shallow to moderately deep, narrow to moderately wide, nearly smooth or sometimes very lightly furrowed, symmetrical, marked with concentric broken lines of russet.

Skin thick, rather tough, dull yellow or with bright red blush, partly smooth but more or less netted or covered with cinnamon-russet. Dots scattering, gray.

Calyx tube small, short, narrow to rather wide, conical or funnel-shape. Stamens nearly basal.

Core axile, medium, often closed; core lines meeting or slightly clasping. Carpels elliptic to round or broadly obovate, emarginate. Seeds dark, medium to below, moderately wide, rather short, obtuse to broadly acute.

Flesh nearly white, sometimes with reddish tinge next the skin, very firm, fine, crisp, tender, very juicy, acid until fully ripe when it becomes subacid, brisk, strongly aromatic, with high flavor and very good quality.

Season December to April (3).

\section{CAYWOOD.}

References. I. Downing, 1857:128. 2. Thomas, 1885:506.

A long kecping, medium-sized, flat apple; color, bright yellow with tinge of red on the cheek. Flesh firm, mild flavored. The variety originated in Ulster county (I). It is now practically obsolete.

\section{CLAYTON.}

References, I. Warder, 1867:512. fig. 2. Downing, 1872:128. 3. Ib., 1872:6 of app. 4. Am. Pom. Soc. Rpt., 1875:36, 134. 5. Bailey, An. Hort., 1892:236. 6. Mich. Sta. Bul., I05:108. I894. 7. Thomas, 1897:632. 8. Lyon, Mich. Sta. Bul., 169:180. 1899. 9. Budd-Hansen, 1903:64. 

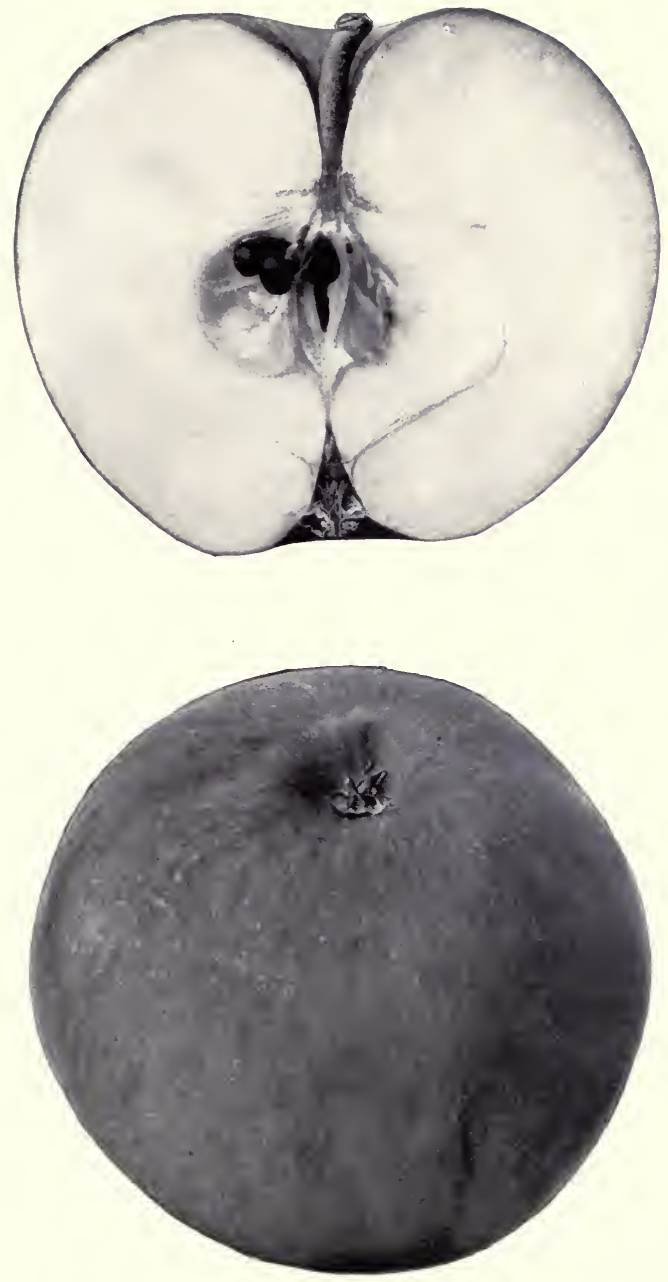

CLAYTON 

Tree hardy, a good grower and fairly productive. Fruit of good size, good quality and fairly good, red color, but not brilliant enough to be especially attractive. As grown at the Geneva Station it has come into bearing young and been very productive. According to L. A. Goodman, it is being planted in the Ozark region of Southwestern Missouri, especially where a late keeping fruit is desired for export trade. It originated in Indiana ( $I, 4)$.

TREE.

Tree vigorous; branches long, moderately stout. Form upright spreading, open. Twigs medium in length, curved, generally stout; internodes short to medium. Bark brown or reddish-brown mingled with olive-green, partly mottled with scarf-skin; pubescent. Lenticels vary from moderately numerous to scattering, medium to large, roundish or oval, raised, conspicuous. Buds medium to large, broad, obtuse, free, somewhat pubescent. Leaves large, broad.

\section{Fruit.}

Fruit above medium to large. Form roundish oblate to roundish inclined to conic. Stem medium, often obliquely set under a very prominent, fleshy lip. Cavity acute to sometimes obtuse, rather deep, broad, sometimes symmetrical but often furrowed, usually with conspicuous outspreading russet. Calyx small to medium, partly open or closed. Basin abrupt, medium in width and depth, usually symmetrical, often wrinkled.

Skin rather thick, tough, smooth, yellow blushed and mottled with a dark, usually rather dull red, with splashes and stripes of carmine, often marked with grayish scarf-skin near the cavity. Well colored specimens are nearly covered with red. Dots medium, pale or russet, scattering.

Calyx tube rather long, narrow, funnel-shape. Stamens marginal.

Core abaxile, medium; cells usually unsymmetrical, open; core lines clasping. Carpcls much concave, elliptical, emarginate. Seeds numerous, dark, medium or below, plump, roundish, obtuse.

Flesh tinged with greenish-yellow, firm, rather coarse, crisp, neither tender nor very juicy, mild subacid, good for either cooking or market.

Season January to May or June.

\section{COFFELT.}

References. I. Bailey, An. Hort., 1892:236. 2. Stinson, Ark. Stc. Bul., 60:127. 1899. 3. Powell and Fulton, U. S. B. P. I. Bul., 48:39. 1903.

Synonym. Coffelt Beauty (3).

As grown at this Station the fruit is too small to be valuable for an apple of the Ben Davis class, to which this apparently belongs. Like Ben Davis, it is quite liable to be roughened by spray. It is a little superior to Ben Davis for eating. Some nursery catalogues state that it is a seedling of Ben Davis.

YOL. I -5 
TREE.

Trce moderately vigorous; branches long, slender and drooping. Form somewhat spreading, rather dense. Tavigs medium in length, curved, slender; internodes long. Bark brown, lightly streaked with scarf-skin; pubescent. Lenticels numerous, small, oblong. Buds small, acute, deeply set in the bark, appressed, pubescent. Leaves medium, broad.

\section{FrUit.}

Fruit medium or above; pretty uniform in size and shape. Form roundish oblate. Stcm variable. Cazity acute, deep, rather broad, slightly furrowed, often with outspreading russet rays. Caly:x medium to large, closed or partly open. Basin moderately shallow to rather deep, medium to rather wide, distinctly abrupt, often sonsewhat furrowed, wrinkled.

Skin nearly smooth, yellow overlaid with bright, dark red and with distinct narrow stripes of carmine. Color decidedly attractive. Dots variable, small to rather large, often russet.

Caly'x tube funnel-shape. Stamens medium to nearly marginal.

Corc medium to rather small, axile; cells usually symmetrical, closed; core lines clasping. Carpcls rather concave, broadly roundish, deeply emarginate approaching broad obcordate, usually smooth. Seeds numerous, medium to rather large, rather wide, obtuse, dark.

Flesh whitisl, firm, rather fine, rather tender, moderately juicy, subacid becoming mild subacid, rather sprightly, slightly aromatic, not high in flavor, good.

Season January to May.

\section{COGSWELL.}

References. I. Hovey, Mag. Hort., I5:252. I849. fig. 2. Hovey, 2:31. 1851. col. pl. 3. Cabot, Mag. Hort., 17:69. 1851. 4. Am. Pom. Soc. Cat., 1854. 5. Clift, Mag. Hort., $22: 76$. I856. 6. Downing, I857:75. fig. 7. Elliott, I858: 469. 8. Downing, Mag. Hort., 27:59. 186r. 9. Warder, 1867:589. Io. Downing, 1872:130. fig. II. Barry, 1883:344. I2. Thomas, I885:232. I3. Lyon, Mich. Hort. Soc. Rpt., I8go:29o. I4. Bailey, An. Hort., I892:237. r5. Lyon, Mich. Sta. Bul., г69:179. I899. I6. Budd-Hansen, 1903:65. fig. I7. Beach and Clark, N. Y. Sta. Bul., 248:I 15. 1904.

Synonyms. Coggeswei. (9). Cogiswell (3). Cogsiocll Pearmain (2, 6, ro). Cogszicll's Pcarmain (7). Not identical with Ohio Nonpareil (8).

Tree hardy and rather vigorous, but not reliably productive, although sometimes it bears heavy crops. Fruit about medium size, yellowish-green more or less overlaid with red; in well colored specimens, nearly covered with red. It is not equal to standard varieties of its season in quality and general appearance. Not recommended for planting.

Historical. Introduced into cultivation in Connecticut about one hundred years ago (5). It has been widely disseminated but in no section of the country has it come to occupy a prominent position as a commercial variety. 

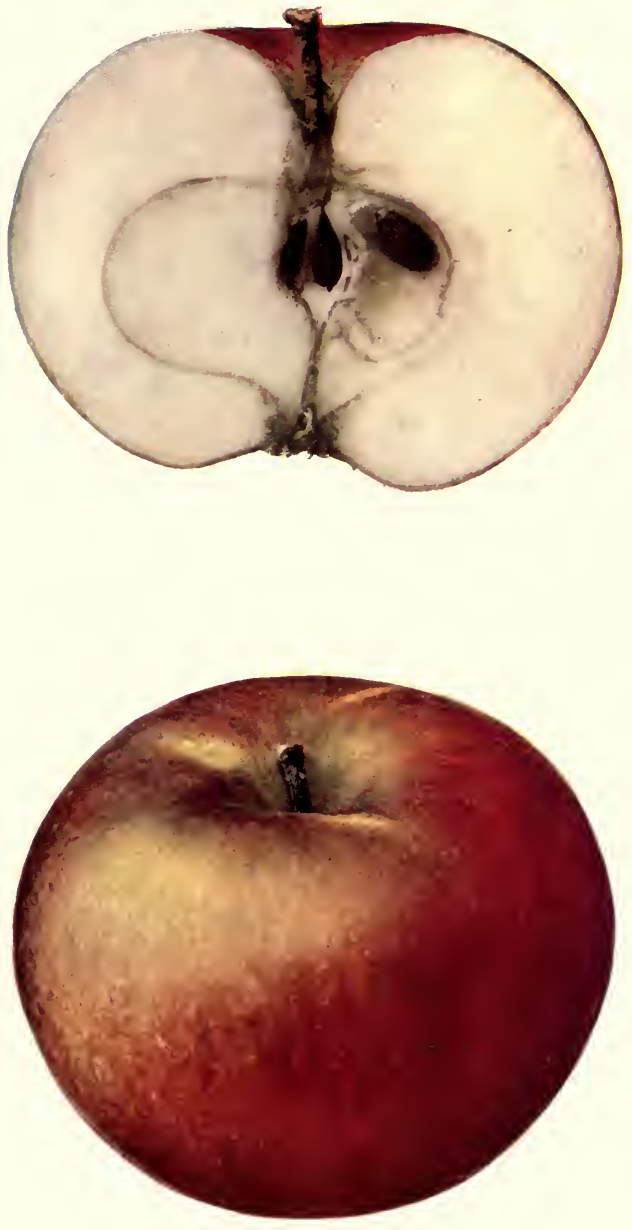

COLLINS 

TREE.

Tree small, moderately vigorous. Form rather open, wide-spreading and drooping. Taigs short to medium in length, rather slender, a little crooked; internodes medium to short. Bark reddish-brown tinged with olive-green, rather heavily streaked with scarf-skin, pubescent near tips. Lenticels rather numerois, medium to large, oblong or roundish, sometimes raised. Buds medium in size, plump, acute, free, slightly pubescent. Leaves large, broad.

\section{FRUIT.}

Fruit medium to above; rather uniform in size and shape. Form roundish conic, occasionally slightly oblate conic, rather symmetrical. Stem short, moderately thick. Casity acuminate to acutc, medium in width and depth, heavily russeted, sometimes lipped. Calyx medium to rather small, usually slightly open. Basin nearly obtuse, shallow to medium in depth, medium in width to rather narrow, smooth or slightly wrinkled.

Skin yellow mottled or covered with red, marked with narrow splashes and stripes of carmine. Dots very numerous, russet, small, prominent. Prevailing effect striped red; rather attractive.

Caly $x$ tube medium in size, funnel-shape. Stamens medium to marginal.

Core medium, axile or nearly so, slightly open; core lines meeting or nearly so. Carpcls nearly round, emarginate. Sceds numerous, medium size, plump, nearly obtuse.

Flesh tinged with yellow or greenish, very firm, moderately fine, moderately tender, juicy, mild subacid, slightly aromatic, fair to good.

Scason December to March.

\section{COLLINS.}

References. I. U. S. Pom. Rpt., r895:21. 2. Thomas, r897:468. 3. Van Deman, Amer. Gard., I9:823. I898. 4. Stinson, Ark. Sta. Bul., 49:10. I898. 5. Ib., 60:127. I899. 6. Brackett, Amer. Gard., 22:190. I901. 7. Budd-Hansen, $1903: 65$.

Synoxyms. Champion $(3,4,5,6,7)$. Champion Red $(3,4,5,6)$. Collins' Red (3, 4, 5, 6). Coss Champion (6). Coss's Champion $(4,5)$.

An Arkansas variety of recent introduction. It has not yet been sufficiently tested in New York to determine whether it is desirable for planting in this region. As fruited here it is of good size and form but decidedly inferior to Baldwin in color and quality, in these respects ranking even below Rome (Beauty) and sometimes below Ben Davis and Cooper Market. When well grown the color is attractive, being yellow, contrasting sharply with the bright red with which it is more or less overspread and sometimes nearly covered. In many cases the cavity shows some resemblance to that of Rome. The tree is a good grower, hardy, and has the reputation of being very productive. Evidently it requires a longer season than Bald- 
win to bring it to perfect development, but it may prove profitable in those sections of the state where Ben Davis does well.

Historical. Originated about 1865 near Fayetteville, Arkansas $(\mathrm{I}, 4,6)$. It has been much planted in the Southwest and is there especially valued on account of the productiveness of the tree and the excellent keeping quality of the fruit.

TREE.

Tree large, tall, very vigorous; branches long, moderately thick, crooked. Form rather upright and dense, eventually becoming more open and outspreading. Trwigs moderately long, rather slender, pubescent; fruit often borne on the ends of the twigs; internodes medium to long. Bark very bright dark reddish-brow11, somewhat mottled with thin, gray scarf-skin. Lenticels numerous, conspicuous, usually small but sometimes large, roundish or oblong, not raised. Buds medium to large, rather flat, appressed, somewhat acute or tending to obtuse, quite pubescent. Foliage rather dense; leaves medium to large, rather long.

\section{FRUIT.}

Fruit large or above medium. Form globular or a little oblate inclined to conic, pretty symmetrical. Stem above medium to short. Cavity acute, sometimes acuminate, medium to rather broad, symmetrical or obscurely furrowed, smooth or with radiating russet rays. Calyx medium to rather small, partly open or sometimes closed; lobes slightly separated at the base, short, obtuse. Basin round, moderately shallow to rather deep, somewhat abrupt to rather obtuse, symmetrical or somewhat furrowed.

Skin thick, tough, slightly waxy, and partly covered with a faint bloom. Highly colored specimens are bright dark red, sparingly and indistinctly striped with purplish-carmine and occasionally showing contrasting clear yellow ground color. Less highly colored specimens are yellow, more or less washed and striped with red. Dots inconspicuous, small, russet or pale gray. Sometimes a suture line extends from cavity to basin.

Calyx tube small, varying from long, narrow funnel-shape to short, approaching conic. Stamens median or below.

Core medium to rather small, abaxile; cells symmetrical, closed or somewhat open; core lines clasp the funnel cylinder. Carpels much concave, elliptical to obcordate, somewhat tufted and deeply emarginate. Seeds dark, large, rather narrow to moderately wide, long, rather flat, acute.

Flesh nearly white, very firm, rather coarse, crisp, moderately tender, moderately juicy, rather sprightly subacid, slightly aromatic, fair to good.

Season January to June.

\section{COOPER MARKET.}

References. I. Mease, Willichs Dom. Encyc., 1804. (cited by 15). 2. M'Mahon, Amer. Gard. Cal., 1806. (cited by 13). 3. Coxe, 1817:137. fig. 4. Horticulturist, 9:291. 1854. col. pl. 5. Downing, 1857:130. 6. Mag. Hort., 25:53. 1859. 7. Am. Pom. Soc. Cat., 1862. 8. Warder, 1867:513. 9. Barry, 1883:344. 10. Thomas, $1885: 232$. 11. Lyon, Mich. Hort. Soc. Rpt., 1890:290. 12. Wickson, 1891:247. 13. Bailey, An. Hort., 1892:237. 14. Can. Hort., 16: 33. 1893. 15. Ragan, Am. Pom. Soc. Rpt., Igor:49. 16. Waugh, Vt. Sta. An. 

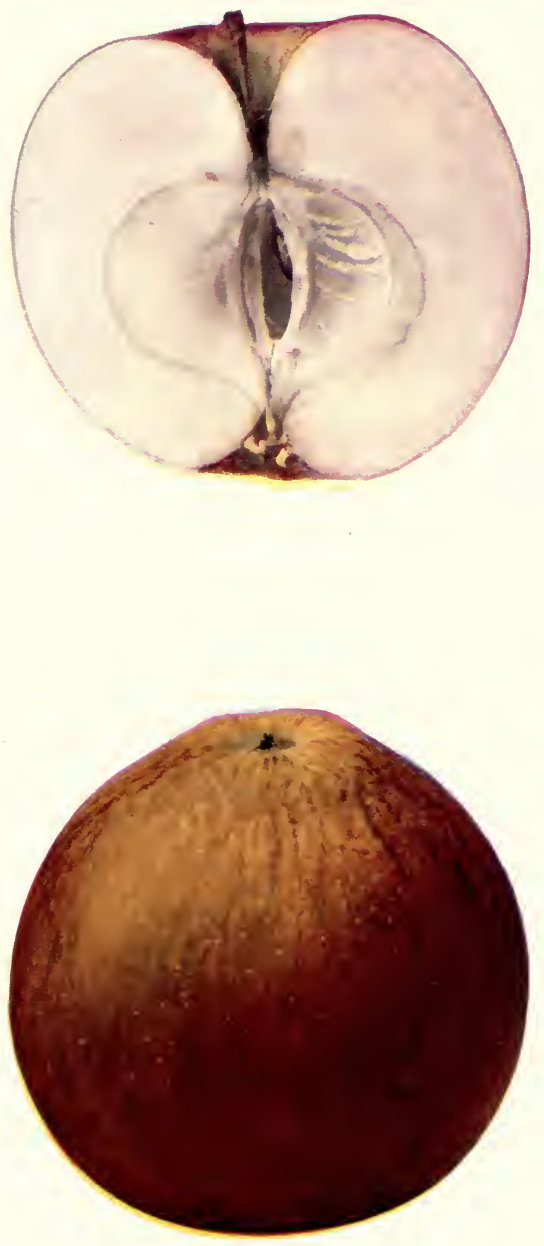

COOPER MARKET 

Rpt., 14:291. I90I. I7. Budd-Hansen, 1903:67. 18. Thomas, 1903:325. I9. Beach and Clark, N. Y., Sta. Bul., 248:1 I5. I904.

Synonyms. Cooper's Market (4, 5, 8, 9, I2, I3). Cooper's Market (10, 18). CoOper's Red (IO). COOPER's ReD incorrectly (I8). CoOper's Redling (6). Cooper's Redling (5,8, Io). Etowah, incorrectly ( I8). RedLING ( I, 2, 3). Redling (9).

Attractive in color and form but not of high quality, often somewhat deficient in size. Especially esteemed for its keeping qualities and for holding a bright color late in the season. Grown to a limited extent in commercial orchards. Desirable for supplying the general trade after the Baldwin season has closed. It may be held very late in common storage. It improves in color in the package when held in common storage, but does not show as great improvement of this kind in cold storage (19).

The tree is hardy, one of the most reliable croppers, and not slow in coming into bearing. In fact, it bears such heavy crops that it requires more than ordinary attention in pruning to make the fruit uniformly of marketable size. The fruit hangs to the tree remarkably well.

Evidently the fact that Cooper's Red is a synonym for Etowah has led some to confuse that variety with Cooper Market (18). The two are quite distinct.

Historical. This is now believed to be of Pennsylvania origin and identical with the Redling of Coxe and others (I, 2, 3, I5).

TREE.

Tree moderately vigorous to vigorous; lateral branches long, slender and rather drooping. Form upright. Twigs below medium to above, rather slender, nearly straight; internodes short to medium. Bark dull, dark brownish-red with considerable olive-green in some specimens, uniformly overlaid with a moderately heavy scarf-skin, heavily pubescent. Lenticels moderately conspicuous, slightly raised, numerous, usually large but varying to small, roundish or elliptical. Buds small, almost sunk in the bark, obtuse, rather pubescent. Sca!es sometimes divided.

FRUIT.

Fruit medium or below, sometimes nearly large. Form roundish ovate varying to roundish conic, flattened at the base and often narrowing sharply towards the apex, pretty symmetrical. Stem medium to long, slender. Cavity acute to acuminate, deep, rather narrow, sometimes slightly furrowed, often russeted. Calyx small, closed, pubescent. Basin small, often oblique, shallow, narrow, obtuse to abrupt, somewhat furrowed, wrinkled.

Skin tough, smooth, glossy, greenish-yellow, mottled and blushed with red, conspicuously splashed and striped with bright carmine and partly covered 
with a light bloom. Dots whitish or with russet point, numerous and small towards the cavity, scattering, large and often irregular towards the basin. Ii fall the color is rather dull but in ordinary storage it improves noticeably as the season advances, becoming bright red with a yellowish-green background.

Calyx tube small, short, cone-shape. Stamens median to nearly marginal.

Core distant, truncate, abaxile, medium; cells closed or open; often part of them are unsymmetrical; core lines slightly clasping. Carpels roundish, slightly emarginate, somewhat tufted. Sceds numerous, dark, medium to short, plump, acute.

Flesh whitish tinged with yellow, very firm, a little coarse, moderately tender, juicy, brisk subacid, fair to good. Although not of high quality it is fairly good when compared with other very late keeping varieties.

Season January to June.

\section{CROTTS.}

References. I. Powell and Fulton, U. S. B. P. I. Bul., 48:39. I903. 2. Beach and Clark, N. Y. Sta. Bul., 248:116. I904.

As grown here the general appearance of the fruit is not attractive. The prevailing color at first is grass-green with faint and dull shades of red. Later the green changes, becoming pale or whitish by spring or early summer. The tree is a good grower and commonly bears well in alternate years. The fruit does not appear desirable for any use and the variety is not recommended even for testing.

Historical. Said to be a seedling of Rambo. Received here for testing from J. J. Measner, Hutchinson, Kansas.

\section{TREE.}

Tree vigorous, upright spreading, rather dense.

FrUIT.

Fruit medium to large. Form usually roundish oblong, sometimes roundish oblate or slightly ovate, sometimes irregular, sides often unequal; uniform in size and shape. Stem short. Cazity deep, acuminate, usually russeted; often russet rays extend out from cavity. Calyx often large, closed. Basin shallow to rather deep, abrupt, somewhat furrowed and wrinkled.

Skin grass-green or at length becoming whitish, faintly mottled and striped with red. Dots scattering, gray or russet, but whitish and numerous tcwards the calyx.

Core small; core lines nearly meeting. Carpels roundish, tufted. Seeds broad, obtuse, tufted, dark brown.

Flesh greenish-white, rather coarse, tender, juicy, with a peculiar aroma, very mild subacid, fair to good.

Season variable; may extend to June in common storage but it often scalds badly as early as March or April $(1,2)$.

\section{CROWNS.}

Fruit of the class of the fall Holland Pippin and Fall Pippin. Uniformly large, green or yellowish, often a little blushed with bright red, too acid for dessert but excellent for cooking and evaporating. It makes very white stock 
when evaporated. It is not a good keeper, is apt to scald in storage, and is not in favor with apple buyers. The tree is very vigorous and reliably productive, bearing regularly and abundantly.

This variety appears to be distinct from the Crown which Hovey describes as a large red apple. 1

Historical. It was formerly planted to a limited extent in portions of Western New York bnt it is now becoming obsolete. In some localities it is known under the name Royal Crown.

\section{TREE.}

Tree large, vigorous. Form roundish spreading. It is a good grower in the nursery.

\section{FRUIT.}

Fruit large. Form conical to roundish, sometimes obscurely ribbed, often somewhat irregular, symmetrical; pretty uniform in size and shape. Stem short to medium, slender. Cazity acuminate, rather deep, broad, smooth, green with whitish dots or sometimes russeted, gently furrowed, sometimes lipped. Calyx open or sometimes closed, medium; lobes leafy, long, acute. Basin medium to shallow, rather narrow, moderately abrupt, a little furrowed.

Skin moderately thin, tough, smooth, bright green changing to pale yellow, with faint blush which in highly colored specimens becomes clear, bright pinkish-red. Dots numerous, conspicuous, russet, often red areolar on the exposed cheek. Prevailing effect green or yellow.

Calyx tube rather long, moderately wide, truncate conical or somewhat funnel-shape. Stamens basal to median.

Core axile, medium to rather large, closed or partly open; core lines meeting; cells pretty symmetrical. Carpels thin, roundish to somewhat ovate, emarginate, somewhat tufted. Sceds large, long, acute, somewhat tufted, light brown.

Flesh whitish, lightly tinged with yellow, rather coarse, crisp, moderately tender, juicy, too sprightly subacid for eating, good.

Season November to January or February.

Use, cooking, evaporating.

\section{DANVERS SWEET.}

References. I. Kenrick, 1833:43. 2. Mag. Hort., I:I54. I835. 3. Manning, 1838:60. 4. Downing, 1845:108. 5. Thomas, I849:16r. 6. Emmons, Nat. Hist. N. Y., 3:86. 1851. 7. Am. Pom. Soc. Cat., 1852. 8. Elliott, 1858:74. 9. Mag. Hort., 26:Ior. I860. Io. Warder, 1867:550. I I. Barry, I883:344. I 2. Lyon, Mich. Hort. Soc. Rpt., 1890:290. 13. Bailey, An. Hort., 1892:237. I4. Munson, Me. Sta. Rpt., 1893:132. 1ј. Budd-Hansen, 1903:69.

Synonyms. Daxvers Sweet (12). Danvers IVinter (14). Danvers Winter Sweet (I, 2, 3, 4, 5, 7, 8, 9, I0, II, I3). Eppes'Swcet (I, 2). Epse's Saceet $(4,8)$.

Tree a good grower and very productive. Fruit is of good marketable size and very good in quality, but rather dull green and not particularly attractive in color. It is no longer recommended for planting.

\footnotetext{
${ }^{1}$ Mag. Hort., 10:210. 1844 .
} 
Historical. About 75 years ago this was being recommended by Kenrick (I) and Manning (3) as a profitable market apple, very productive and worthy of extensive cultivation. Danvers Sweet was included in the American Pomological Society's first list of varieties worthy of being recommended (6). In New York state it is now nearly obsolete. It originated at Dawvers, Mass., where the original tree was still standing in 1832 (I).

\section{TREE.}

Tree a rapid grower. Twigs dark brown with grayish scarf-skin, pubescent.

\section{FrUit.}

Fruit medium to sometimes large; pretty uniform in size and shape. Form roundish inclined to conic, sometimes a little oblate. Stem short to medium, pubescent, knobby. Caz'nty rather large, acute to acuminate, rather deep, broad, sometimes partly russeted, often distinctly furrowed. Caly $x$ small to medium, usually closed; lobes pubescent, sometimes separated at the base. $B$ asin varies from large and wide to rather small and narrow, moderately abrupt, furrowed and wrinkled.

Skin moderately thin, tongh, smooth, grass-green somewhat shaded with yellow, sometimes with faint bronze blush. Dots conspicuous, many submerged and whitisl, others areolar with russet center.

Calyx tube funnel-shape with rather narrow limb. Stamens median or above.

Core axile, medium; cells symmetrical, closed; core lines clasping. Carpels rather flat, roundish to roundish obovate, slightly emarginate, mucronate, smooth. Seeds dark, medium or below, narrow, acute to obtuse.

Flesh greenish with decided yellow tinge, breaking, moderately fine, very tender, rather juicy, very sweet, good to very good.

Season November to April.

\section{DEACON JONES.}

References. I. Powell and Fulton, U. S. B. P. I. Bul., 48:40. I903. Beach and Clark, N. Y. Sta. Bul., 248: i 6. I904.

Fruit showy and of good marketable size, averaging larger than Baldwin. When well colored it is handsome, the yellow ground color being mostly overlaid with good red, relieved with dots of a contrasting color. The tree is a fine grower in the nursery and "delivers" well. In the orchard it is thrifty, comes into bearing young, is almost an annual bearer and very productive. The fruit hangs well to the tree. There is little waste from drops and culls. The flesh is rather coarse; the flavor is mild and the quality is not high, but probably it would generally be rated superior to Ben Davis for dessert. It has a tough skin and firm texture, and stands handling well. In ordinary storage its season for home use extends from 
November to March. So far as tested in cold storage, the commercial limit for barrel stock appears to be March first, but the fruit has kept free from scald and rot till May (I). It is not good enough in quality to be recommended for home use, but it may possibly be of value as a commercial variety.

Historical. Originated in Pennsylvania as a chance seedling. Received here in 1892 for testing from J. S. Ford, Pittsford, N. Y., by whom it is being introduced. The form of the fruit and the character of the core indicate that this variety may be a seedling of the Yellow Bellflower.

\section{TrEe.}

Tree moderately vigorous; branchlets willowy, long, slender, drooping. Form dense, upright spreading. Truigs long, nearly straight, moderately stout, with large terminal buds; internodes long to below medium. Bark clear brownish-red, lightly streaked with scarf-skin; pubescent. Lenticels numerous, generally medium in size, roundish or oval, raised, conspicuous. Buds small to medium, projecting, obtuse to somewhat acute, appressed, quite pubescent, deeply set in bark.

\section{FRUIT.}

Fruit large to very large; pretty uniform in size, somewhat variable in shape. Form roundish conic varying to oblong conic, ribbed; axis sometimes oblique. Stem short. Cavity obtuse to acute or sometimes slightly acuminate, shallow to moderately deep, usually smooth, often prominently lipped. Calyx small to above medium, closed or partly open, often leafy; lobes sometimes separated at the base. Basin shallow to moderately deep, usually rather narrow, distinctly furrowed and wrinkled.

Skin thick, tough, smooth or slightly rough, waxen yellow, mottled and blushed with red and with irregular dashes of carmine, in highly colored specimens being almost completely covered with an attractive deep red. It is covered with a whitish bloom which gives the fruit a somewhat dull appearance. Dots conspicuous, mingled small and large, whitish, many areolar with russet point; numerous toward the eye.

Calyx tube variable in size, urn-shape to conic. Stamens median or below.

Core abaxile; cells symmetrical, wide open, very large; core lines nearly meeting. Seeds numerous, medium to small, rather dark brown, plump, obtuse, somewhat irregular. Carpels much tufted, emarginate, mucronate, elongated and rather broadly ovate.

Flesh whitish, somewhat tinged with yellow, rather firm, coarse, somewhat crisp, tender, moderately juicy, mild subacid, slightly aromatic, not high in quality, fair to possibly good.

Season November to March or later (I, 2).

\section{DEMOCRAT.}

References, I. Warder, 1867:505. 2. Downing, I872:I43, I44. fig. 3. Thomas, 1885:508.

Synonym. V'arick (2). 
An early winter apple of medium size, yellow, blushed and striped with red, handsome and of very good quality, formerly grown to some extent in Western New York $(2,3)$, but now practically obsolete. We have not bren able to determine whether the variety given by IVarder under this name (I) is identical with the Democrat described by Downing and Thomas.

\section{DICKINSON.}

References. I. Pa. Dept. Agr., Rpt. Hort. Assu., r884:49. col. pl. 2. Chase, Am. Pom. Soc. Rpt., r885:25. 3. Bailey, An. Hort., r8g2:237. 4. Beach, N. Y. Sta. An. Rpt., 12:600. 1893. 5. Richman, Utah Sta. Bul., 45:15. 1896. 6. Beach. Western N. Y. Hort. Soc. Rpt., r896:52. 7. Powell and Fulton, U. S. B. P. I. Bul., 48:-0. 1903. 8. Beach and Clark, N. Y. Sta. Bul., 248:116. 1904 .

Sinonym. Dickenson $(5,7)$, but incorrectly.

Tree not a good grower, but very productive. Fruit resembles Yellow Bellflawer in shape, but the color is red. It is of good size and attractive enough in appearance to make a good market apple, but it is not above second rate in quality.

Historical. Grown from seed of the Yellow Bellflower by Sarah Dickinson, Westchester, Pennsylvania $(1,2)$.

TREE.

Tree not large, not very vigorous; branches short, stout, crooked. Form roundish, spreading, rather dense. Tivigs small to medium, crooked, moderately stout; internodes short to above medium. Bark clear, light olive-green tinged with reddish-brown, streaked with scarf-skin, slightly pubescent. Lenticels rather inconspicuous, rather numerous, small or below medium, usually roundish, not raised. Buds medium in size or below, broad, plump, obtuse, free or nearly so, pubescent. Leaves medium in size, moderately broad.

Frit.

Fruit medium to large, somewhat variable in size. Form oblong-conic, sometimes compressed or broadly angular; sides sometimes unequal. Stem medium to long. Carity moderately broad, moderately deep, acute to acuminate, symmetrical or sometimes compressed, usually smooth. Calyx medium, closed or sometimes open. Basin shallow to moderately deep and abrupt, often oblique, somewhat furrowed and wrinkled.

Skin smooth, light yellow or green, blushed and mottled with bright red, striped with larker red, sprinkled with inconspicuous, small, green and whitish dots. Pres'ailing effect red with well-colored fruit.

Caly.r tube fummel-form. Stamens median to basal.

Core large, abaxile; cells not always symmetrical, usually open; core lines ustrally somewhat clasning. Carpels roundish oblong. Seeds numerous, medium or above, plump, ohtuse.

Flesh yellowish, juicy to very juicy, moderately fine-grained, slightly aromatic, sthacid, moderately firm, tender, fair to good.

Season November to April. 


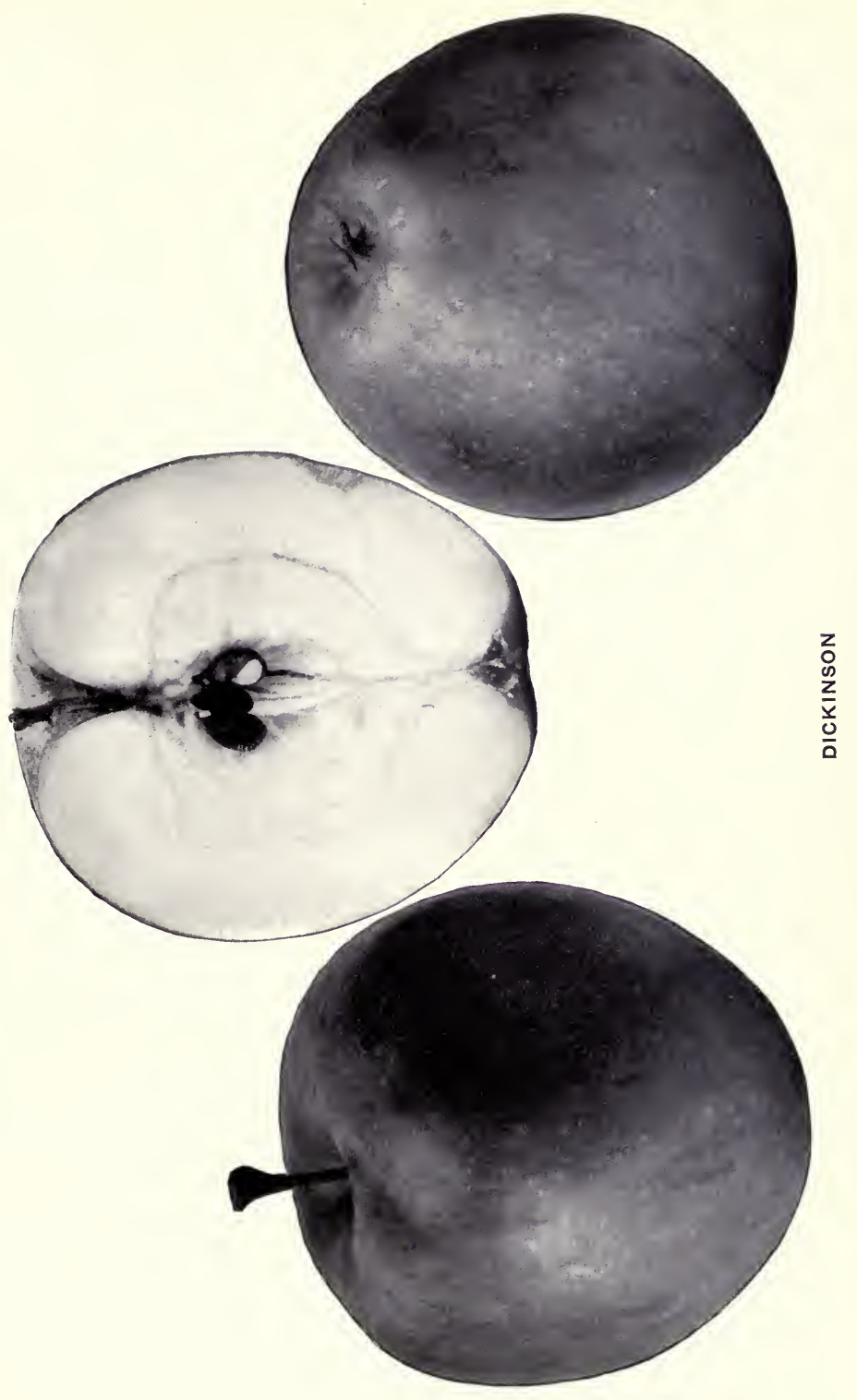





\section{DISHAROON.}

REFEREACES. I. Downing, I857:135. 2. Elliott, 1859:73. 3. Warder, I867: 717. 4. Leroy, 1873:260. fig. 5. Am. Pom. Soc. Cat., 1873. 6. Barry, 1883: 344. 7. Thomas, 1885:223. 8. Bailey, An. Hort., 1892:237.

A yellowish-green apple, rather large, subacid with an aromatic flavor somewhat like that of the Green Newtown. It is a southern apple which is but little known in this region. It is not recommended for planting in New York state.

\section{DOCTOR.}

Referexces. I. Coxe, 1817:119. fig. 2. Wilson, 1828:136. 3. Cat. Hort. Soc. London, 1831. 4. Downing, 1845:107. 5. Thomas, 1849:147. 6. Emmons, Nat. Hist. N. Y., 3:62. 1851. 7. Hooper, 1857:29. 8. Elliott, 1858:130. 9. Warder, 1867:717. I0. Livingston, Amer. Gard., 21:204. 1900. II. Munson, Me. Sta. An. Rpt., 18:89. 1902. 12. Powell and Fulton, U. S. B. P. I. Bul., 48:40. 1903. 13. Heach and Clark. N. Y. Sta. Bul., 248:115. 1904.

Sysoxyms. Coos (13). Coon Red (13). Dewit Apple (1). De Witt $(3,4,5,8)$. Doctor Dewitt (9). Neriby (12). Red Doctor $(4,8)$.

Fruit attractive because of its good color, desirable size and uniformity in size and shape. In texture, flavor and general quality it is inferior to Baldwin. It is of value chiefly for market, although acceptable for either dessert or culinary uses. The tree is vigorous, or moderately so, and has the reputation of being generally a regular and abundant bearer. It is not slow in coming into bearing. Not recommended for planting in New York.

Historical. An old variety which originated at Germantown, Pa. Named in honor of a physician who brought it into notice $(1,4)$. It has been grown to a considerable extent in Pennsylvania, Ohio and other portions of the Central West, but it has gained only slight recognition in New York. It has been reintroduced in Indiana under the name Newby. It has also been disseminated under the name Coon Red, or Coon.

TREe.

Tree moderately vigorous. Form very open and spreading. Twigs long to medium, straight, moderately stout; internodes medium or above. Bark clear reddish-brown with some olive-green, streaked with scarf-skin, but slightly pubescent. Lenticels scattering, medium or below medium size, roundish or oblong, raised. Buds medium size, broad, plump, obtuse, free or nearly so; somewhat pubescent. Leaves medium size, broad.

\section{FrUit.}

Fruit medium to large; pretty uniform in size and shape. Form oblate, symmetrical, angular. Stem short or medium. Cavity acute, deep, wary, not russeted, sometimes lipped. Caly:r large, somewhat open; lobes long, acute. Basin variable, somewhat obtuse to abrupt, often wide, deep, ridged and wrinkled. 
Skin smooth, waxen yellow, overspread with a bright light red blush, indistinctly marked with narrow carmine splashes. Dots green or grayish. Prevailing effect attractive red and yellow.

Caly:x tube rather large, rather short urn-shape to truncate funnel-form. Stamens basal to above median.

Core medium to sinall, abaxile: cells usually symmetrical, open or sometimes closed; core lines meeting or somewhat clasping. Carpels smooth, broadly elliptical, quite concave. Seeds medium in size, wide, obtuse.

Flesh a little tinged with yellow, firm, moderately coarse, crisp, rather tender, juicy, mild subacid, slightly aromatic, good to nearly very good.

Season December to April or later.

\section{DOCTOR WALKER.}

References. I. Downing, I881:83. app. 2. Bailey, An. Hort., I892:237.

3. Thomas, $1897: 633$.

Synonym. Litsey (I).

As grown here the fruit is only moderately attractive, being dull in color and scarcely medium in size. The tree does not come into bearing very early, but is quite productive, and the fruit keeps very late. It is not recommended for planting in New York.

Historical. A seedling of Ralls which originated on the farm of John Litsey near Springfield, Ky., in which locality it is said to be superior to its parent, being hardy, productive and blooming late in the season (I).

TREE.

Tree vigorous or moderately vigorous; branches short, moderately stout. Form upright spreading and rather open. Tavigs below medium or short, straight, rather stout with large terminal buds; internodes below medium or short. Bark clear dark olive-green somewhat tinged with reddish-brown, little or no scarf-skin, decidedly pubescent. Lenticels numerous, medium to small, roundish to oblong, not raised. Buds often large, broad, plump, obtuse, free, pubescent.

\section{FRUIT.}

Fruit medium or below. Form roundish inclined to conic, sometimes roundish oblate. Stem short to medium. Cacity acute to acuminate, rather dcep, moderately broad, somewhat furrowed, sometimes russeted. Calyx mediun to large, closed or partly open; lobes often leafy, long, acuminate. Basin abrupt, medium in width and depth, somewhat furrowed, wrinkled.

Skin tough, smooth, somewhat glossy, pale green or yellowish, deeply blushed or mottled with purplish-red, with distinct narrow dull carmine stripes. Dots numerous, conspicuons, pale yellow or grayish.

Calyx tube cone-shape.

Core medium to small, closed or partly open; core lines meeting or slightly clasping. Carpels roundish inclined to obcordate, emarginate, slightly tufted. Seeds medium or above, dark, wide, obtuse, slightly tufted. 


Flesh whitish, firm, rather fine, crisp, tender, juicy, mild subacid, becoming nearly sweet, somewhat aromatic, good.

Season January to May.

\section{DOMINE.}

References. 1. Cat. Hort. Soc. London, 1831. 2. Downing, 1845:107. 3. Kirkland, Horticulturist, $2: 545$. 1847. 4. Thomas, 1849:165, 173. 5. Humrickhouse, Mag. Hort., I5:27. I849. fig. 6. Phoenix, Horticulturist, 4:470. I850. 7. Emmons, Nat. Hist. N. Y., 3:68. 1851. fig. 8. Hooper, 1857:96. 9. Elliott, 1858:130, 161. го. An. Pom. Soc. Cat., 1862. II. Warder, 1867:430. fig. I 2. Downing, 1872:147. fig. 13. Barry, 1883:345. 14. Lyon, Mich. Hort. Soc. Rpt., 1890:290. 15. Bailey, An. Hort., 1892:237. r6. Rural N. Y., 54:744. 1895. I7. Ill. Sta. Bul., 45:319. 1896. 18. Richman, Utah Sta. Bul., 45:16. 1806. I9. Waugh, $\mathrm{Vl}$. Sta. An. Rpt., 14:292. I901. 20. Budd-Hansen, r9o3: 7o. fig. 21. Beach and Clark, N. Y. Sta. Bul., 248:117. I904.

Synoxyms. Cheat (12). Cling Tight (12). Domini (6). Dominie (4, 10, 16, 17, 18, 19). English Beauty of Pa. (12). English Rambo of some (12). English Red Streak (12, I3, 2I). English Winter Red Streak of some (9). Hogan (9, 12). Holland Pippin, incorrectly (19). Ramboulrette (3). Striped R. I. Grcening (9, 12). Well Apple (9). Wells (4, 7, 8, 9). Wells (12, 2I). Williamson (7).

A striped apple of the Rambo class which much resembles Rambo in appearance. While it does not rank as high in quality it is a much better keeper, its season extending till March; commercial limit, February. When well grown it is large and of good color, but too often the fruit sets so abundantly that it does not average much above medium size. In western New York, although in some seasons it is very productive, it is not as reliable a bearer as are some of the kinds which outrank it in the commercial orchards, and often the color is not well developed. It has been more extensively planted along the Hudson than in any other part of the state, but it is not now grown so much there as it was formerly. It is chiefly valued for dessert, being generally considered inferior for culinary uses, except possibly for baking.

It is evidently not identical with the Domine described by Coxe. ${ }^{1}$

Historical. Origin uncertain. Supposed to be a native of this country (II, 12). Elliott states that it probably came originally from Maryland (9).

TREE,

Tree is vigorous to moderately vigorous, "with long, stout, spreading branches which are very liable to be broken by the heavy crops of fruit" (I4).

${ }^{1}$ Fruit Trees, 1817:115. 
Form upright spreading "with a straggling, open head and bearing its fruit crowded along the smaller branches" (II). Twigs above medium to long, moderately stout; internodes long. Bark smooth, clear reddish-brown, sometimes with a slight undertone of yellowish-green uniformly overlaid with a thin scarf-skin, rather pubescent. Lenticels rather inconspicuous, raised, moderately numerous, above medium, generally roundish. Buds above medium, roundish to acute, free or nearly so, quite pubescent. Leaves long, drooping and characteristically twisted.

\section{FruIT.}

Fruit usually about medium in size, sometimes large or very large. Form usually oblate, sometimes inclined to oblong and distinctly flattened at the base, sides often somewhat unequal, ribbed. Stem medium to long, slender at the base. Cazity obtuse, wide, deep, often distinctly furrowed, usually with outspreading brown russet rays. Caly $x$ below medium to large, closed or slightly open; lobes long, acute. Basin pubescent, rather shallow to moderately deep, wide or compressed, abrupt, usually distinctly furrowed.

Skin thick, tough, smooth, bright, whitish-yellow or green mottled and splashed with deep pinkish-red, striped with bright carmine and overlaid with thin whitish bloom. Dots pale or yellow, numerous toward the basin, but toward the cavity they are scattering, large, often irregular and with russet center.

Calyx tube funnel-shape with a wide limb and short truncate cylinder. Stamens median to marginal.

Core small, somewhat abaxile; cells usually symmetrical, closed or partly open; core lines nearly meeting or clasping. Carpels broadly elliptical, slightly emarginate. Seeds numerous, large, plump, moderately narrow, long, acute, dark.

Flesh whitish or tinged with light yellow, very firm, breaking, somewhat coarse, tender, juicy, mild subacid with a peculiar aromatic flavor, good to very good.

Season November to March.

\section{DOUBLE ROSE.}

The tree is exceedingly productive and comes into bearing young. The fruit is beautiful, being almost wholly overspread with a bright deep red but it is too small to be valuable for ordinary market uses and it does not rank high enough in quality to be classed with fruit suitable for fancy trade. It is not recommended for planting in New York.

Received from Jaroslav Niemetz, Winnitza, Podolia, Russia, in I898, for testing at this Station.

\section{Fruit.}

Fruit small, roundish or oblong conic. Stem long to medium, set in a deep, rather wide, russeted cavity. Caly. closed or partly open. Basin abrupt, moderately deep. Skin smooth yellow overspread with light red sometimes deepening to dark red. Core medium, nearly closed. Flesh tinged with yellow, moderately coarse, mild subacid, fair to possibly good.

Season November to February. 

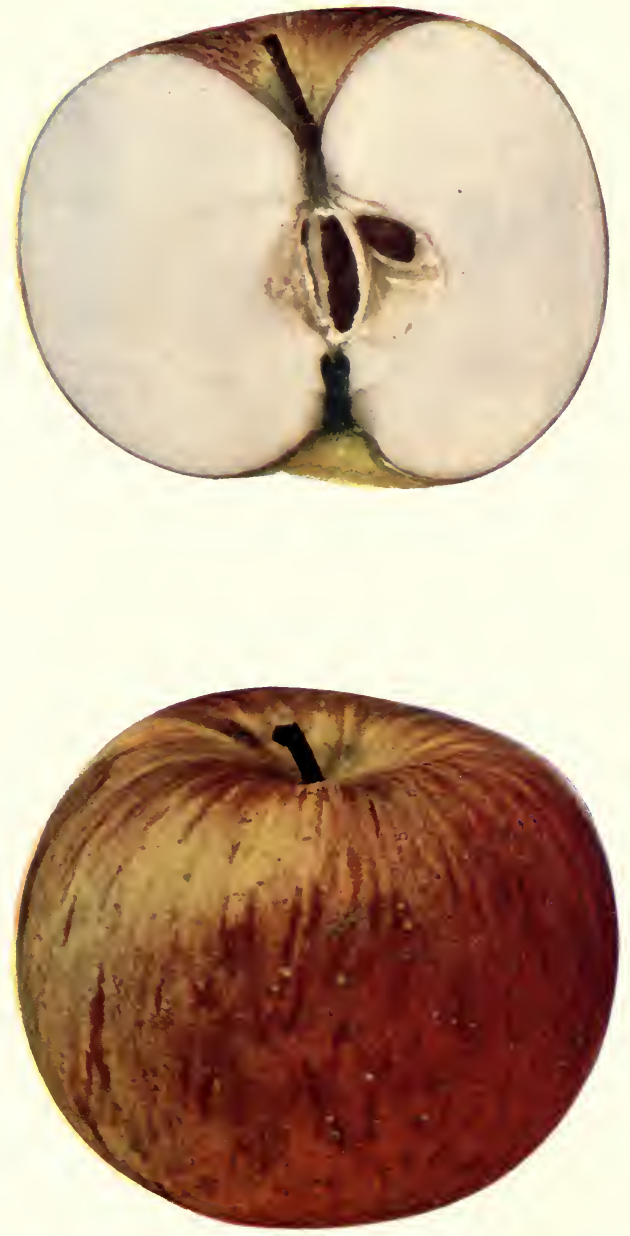

DOMINE 



\section{DU BOIS.}

Reference. r. Heiges, U. S. Pom. Rpt., I894:I9.

A red-striped winter apple described by Heiges (I) in I 894 from specimens received from Columbia county, N. Y., as above medium size, oblate, yellow washed with mixed red and striped with crimson; flesh yellowish-white, stained with red, mild subacid, good. Mr. F. P. Studley, who furnished Heiges with the fruit from which the above description was made reports further concerning this variety that it originated as a chance seedling in the town of Claverack, and that it is a very showy apple of the Blue Pearmain type although the fruit is not so large as that of Blue Pearmain. It apparently would stand shipping well for the skin is tough and the fruit is firm. It is a very late keeper sometimes being kept till July. The tree is very hardy, a good grower, forming a round compact head. It is productive in alternate years.

\section{DUKE OF DEVONSHIRE.}

References. I. Downing, I872:150. 2. Hogg, r884:65. 3. Bailey, $A n$. Hort., I892:237. 4. N. Y. Sta. Rpt., I892:588, 592. 5. Bunyard, Jour. R. H. S., 21:356. 1898. 6. Beach and Clark, N. Y. Sta. Bul., 248:117. I904.

A yellow apple, partly russeted, medium in size, desirable either for dessert or culinary use. The tree does not come into bearing very young, but when mature is quite productive. The fruit is apt to drop badly. It cannot be recommended as superior to other wellknown varieties of its class.

Historical. Originated in England and introduced to commerce there about I875 (5). It is there esteemed as an excellent dessert apple and a good keeper (2). It is but little known in New York.

Tree.

Tree large, vigorous. Form spreading.

FRUIT.

Fruit medium to small. Form oblate to roundish conic, sometimes obscurely ribbed; pretty uniform in shape and size. Stem very short to medium, sometimes swollen. Cavity rather narrow to moderately broad, shallow to moderately deep, acute, often nearly acuminate, often lipped, usually covered with green russet. Caly $x$ rather large, flat, partly open. Basin variable, usually shallow and obtuse, somewhat furrowed and wrinkled.

Skin thin, tough, partly smooth, dull yellow, often with a faint orange or bronze blush, more or less covered with russet, roughened with large russet dots. Dots gray or russet, conspicuous. Prevailing effect greenish-yellow mingled with russet.

Calyx tube small, short, rather wide, conical or urn-shape. Stamens marginal.

Core axile or nearly so, medium in size; cells usually symmetrical, closed; core lines meeting or clasping. Carpels roundish to somewhat oblong, slightly 
emarginate, mucronate, sometimes slightly tufted. Seeds rather light brown, medium to small, wide, plump, obtuse.

Flcsh yellowish or tinged with green, moderately juicy, moderately crisp, firm, somewhat coarse, with a pleasant subacid flavor characteristic of certain russet apples, good to very good.

Season December to April or later.

\section{DUMELOW.}

References. 1. Lindley, 1831:8г. 2. Ronalds, 1831:37. fig. 3. Cat. Hort. Soc.,London, 1831. 4. Diel, 27:55. 1832. 5. Kenrick, 1833:101. 6. Floy-Lindley, 1833:32. 7. Thomas, 1849:165. 8. Rivers, Horticulturist, 4:40. I849. 9. Emmons, Nat. Hist. N. Y., 3:85. I851. 10. Downing, 1857:212. I1. Elliott, 1858:ı́́9. I2. Lucas, E., Ill. Handb. der Obstk., I:187. I859. I3. Warder, 1867:717. 14. Leroy, 1873:864. figs. 15. Hogg, 1884:65. 16. Bredsted, 1893: 274. I7. Bailey, An. Hort., 1892:237. 18. Ill. Sta. Bul., 45:320. I896. I9. Eneroth-Smirnoff, I90I:480. 20. Beach and Clark, N. Y. Sta. Bul., 248:I I7. I904.

Synonyms. Duke of Wellington $(2,5)$. Dumelow's Crab (6, io, il, I4, I5). Dumelozi's Pippin (i4). Dumelow's Seedling (I, 2, 3, 6, 7, 9, io, I I, I5, 16). Dumelow's Secdling (5, I4, I7, I8). Normanton Wonder (3, I4, 15). Sutton Beauty (14), but erroneously. Wellingtox (12, I4, 16, 19, 20). IVcllington (6, IO, II, I5). Wellington's Reinette (4).

Fruit of good marketable size, rather attractive for a yellow apple, and a good keeper ( $\mathrm{I}_{5}, 20$ ). It is excellent for culinary use, but too acid to be agreeable for dessert. The tree is a very strong grower and quite productive in alternate years. Possibly it is worthy of growing to a limited extent for market, but it is inferior to good red apples like Baldwin and Sutton both in appearance and for dessert uses. In England it is esteemed as one of the most valuable culinary apples ( I5).

Historical. First exhibited to the Royal Horticultural Society, London, in I820 under the name Wellington, but prior to that it had been extensively cultivated under the name of Dumelow's Crab, taking its name from the farmer with whom it originated (I5).

\section{TreE.}

Tree very vigorous. Form upright becoming rather round with spreading and somewhat drooping branches. Twigs medium or rather long, nearly straight, somewhat stocky, somewhat pubescent; internodes medium or above. Bark rather clear light brownish-red over olive-green with slight scarf-skin. Lenticels characteristically conspicuous, very numerous, medium to very large, usually elongated, raised. Buds large to below medium, plump, rather acute, somewhat appressed, decidedly pubescent. Leaves medium to large, long and rather broad. Petioles red at base. 


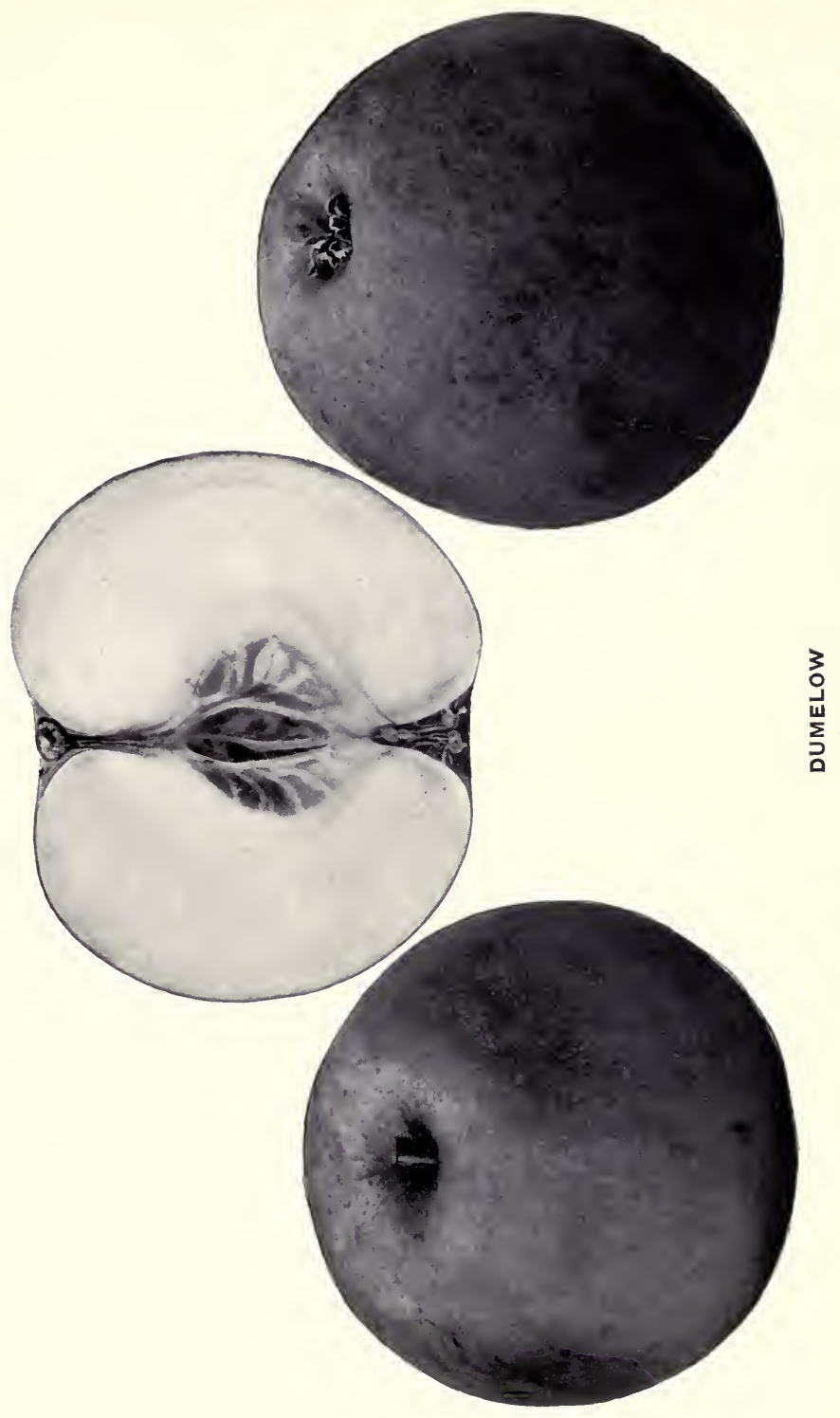





\section{FrUIT.}

Fruit above medium to large; pretty uniform in size and shape. Form roundisl, somewhat oblate, sometimes obscurely ribbed. Stem medium to rather short. Cavity rather narrow, acute to acuminate, moderately shallow to deep, symmetrical, sonietimes russeted. Calyx large, open; lobes separated at the base. Basin variable, obtuse to abrupt, shallow to moderately deep, irregularly furrowed and somewhat wrinkled.

Skin tough, rather pale bright yellow, sometimes blushed with light red and striped with thin carmine. Dots often submerged, dark gray or with russet point. Prevailing color yellow.

Calyx tube conical or funnel-form with broad limb and short truncate cylinder. Stamens basal.

Core below medium to rather small, usually more or less abaxile; cells not always symmetrical, partly closed particularly toward the apex, or open; core lines meeting or somewhat clasping. Carpels roundish cordate, emarginate. Seeds small to medium, wide, plump, acute to obtuse, dark.

Flesh whitish with slight yellow tinge, firm, crisp, moderately fine, tender, very juicy, brisk subacid, slightly aromatic, good for cooking.

Season November to March or April.

\section{DUNCAN.}

References. 1. Cat. Hort. Soc. London, 1831. 2. Downing, 1872:151. 3. Bailey, An. Hort., 1892:238. 4. Beach and Clark, N. Y. Sta. Bul., 248:1 I7. I904.

An apple of the Newtown Spitzenburg class which closely resembles that variety in the appearance and quality of its fruit. When well developed it is rather attractive in color and very good in quality for dessert use. It is an excellent keeper, but as grown at this Station it averages too small for a good commercial apple. The tree comes into bearing young and is almost an annual bearer, but yields heavier crops in alternate years. It is not recommended for planting in New York.

Historical. Received for testing here from B. Buckman, Farmingdale, Ill. It has been disseminated to some extent in portions of the Ohio valley (3). We have not determined whether or not it is identical with the English variety of this name $(1,2)$.

TREE.

Tree small, moderately vigorous; branches short, stout, crooked; laterals willowy and small, slender. Form upright spreading to roundish, dense. Twigs short to above medium, rather slender, straight, moderately stout; internodes short. Bark dull reddish-brown, mingled with olive-green, with thin coat of scarf-skin; slightly pubescent. Lenticels scattering, small, round, not raised. Buds small, plump, obtuse, appressed, deeply set in bark; somewhat pubescent.

\section{FRUIT.}

Fruit below medium or small, pretty uniform in size and shape. Form roundish, pretty symmetrical, sides sometimes unequal. Stem medium. Cavity acuminate to acute, symmetrical, moderately deep, sometimes furrowed, rarely 
russeted. Caly.x closed or partly open; lobes long, acute. Basin obtuse, shallow, irregularly furrowed and wrinkled.

Skin green or pale yellow, striped with carmine over a thin dull blush and conspicuously marked with large, irregular, whitish dots. Often the color is not well developed and not particularly attractive.

Calyx tube short to long, moderately wide, cone-shape or somewhat funnelform. Stamens median to marginal.

Core medium, axile or somewhat abaxile; core lines meeting or clasping; cells sometines unsymmetrical, closed or partly open. Carpels broad, roundish, smooth, emarginate. Seeds medium or below, broad, dark, acute to obtuse.

Flesh whitish, with yellow tinge, moderately firm, fine-grained, tender, crisp. very juicy, agreeable mild subacid mingled with sweet, good to very good when well grown.

Scason January to May.

\section{DUTCH MIGNONNE.}

References. I. Diel, 4:I40. I80I. 2. Ronalds, I83i:5i. 3. Cat. Hort. Soc. London, 1831:30. 4. Floy-Lindley, 1833:33. 5. Dittrich, 1839:429. 6. Lindley, Pom. Mag., I839:84. col. pl. 7. Emmons, Nat. Hist. N. Y., 3:72. I851. 8. Bivort, An. de Pomol. Belge, 1853:83. 9. Elliott, 1858:74. Iо. Lucas, Ed., Ill. Handb. der Obstk., I:I63. I859. Ir. Berghuis, I868: col. pl. No. II. I2. Regel, I868:466. I3. Downing, I872:I5I, 33I. Ib., I876:3. app. 14. Leroy, 1873:644. 2 figs. I 5. Lauche, I:257. I882. I6. Hogg, 1834:66. I7. Cat. Cong. Pom. France, 1887:322. 18. Bailey, An. Hort. 1892:238, 248. I9. Bredsted, I893:182. 20. Beach and Close, N. Y. Sta. An. Rpt., I 5:275. I896. 2 figs. 2r. Eneroth-Smirnoff, rgor:r95. 22. Beach and Clark, N. Y. Sta. Bul., 248:1 I4. I904.

Synonyms. Caux (22). Christ's Golden Reinette (16). Copmanthorpe Crab (i3, I4, 16). Duitsch Mignonne (8). Dutch Mignome (7). Dutch Mignonne (14). Dutch Minion (2). Grosse Casseler Reinette (io, i2, 15). Grosser Casselar Reinette (13). Grosse Oder Doppelte Casseler Reinette ( I, 5). Paternoster Apple (4, I3, I4). Pomme de Laak (4, 13. I4). Reinette de Caux (3, I4, I7, 20). Reinette de Caux (16, 22). Reinette D'or (II). Reinette Dorée (2). Reinette Dorée (4, I3). Stettin Pippin (13, 14, 16). Stor Casseler Reinet (i9). Stor Kasselrenett (2i).

Tree vigorous and very productive on alternate years. Fruit medium or above, not very attractive in color but excellent for cooking, good for dessert and a good keeper. It is recommended for the home orchard, but because the color of the fruit lacks decided character it is not a good commercial variety, except for canning or evaporating.

Historical. This apple has been known in Holland for more than a century. It was introduced from that country into England about I77I (4, I4). Although it was brought into New York state many years ago and has been imported at various times both under the name Dutch Mignonne and that of Reinette de Caux it has not won favorable recognition among commercial 

orchardists and has nowhere been planted to any considerable extent. Leroy (I4) states that Grosse Reinette de Cassel and Reinette Dorée are distinct from this variety although they have been listed by some as identical.

\section{TREE.}

Tree moderately vigorous. Form rather wide-spreading, inclined to droop, pretty dense; branches short, stout, curved. Twigs medium in length, nearly straight, moderately stout to rather slender; internodes medium or above. Bark clear reddish-brown, mostly overlaid or mottled with rather heavy scarfskin, pubescent near tips. Lenticels moderately numerous, small to medium, round or somewhat oblong, sometimes raised. Buds moderately prominent, medium in size, plump, acute, free, somewhat pubescent. Leaves medium in size, broad.

\section{Fruit.}

Fruit above medium, pretty uniform in size. Form roundish oblate to roundish, sometimes inclined to conic, often somewhat elliptical and broadly ribbed. Stem often characteristically long and slender and obliquely inserted. Cazity acute, moderately deep to deep, rather broad, often with outspreading russet rays and faint lines and flecks of dull grayish scarf-skin, furrowed or sonetimes compressed, occasionally lipped. Calyx small to medium, closed or open. Basin usually rather shallow, moderately narrow to rather wide, often somewhat furrowed and wrinkled.

Skin yellow with thin orange blush, in highly colored specimens deepening to orange-red, mottled and sparingly splashed or striped with carmine. Dots numerous, whitish or russet, often areolar. Prevailing effect dull orangeyellow partly covered with thin dull red; not particularly attractive.

Calyx tube rather large, long, conical or sometimes approaching urn-shape. Stamens marginal.

Core axile, medium to small, closed; core lines clasping. Carpels broadly roundish, rather flat, slightly emarginate. Seeds few, often some are abortive, rather long, irregular, flat, obtuse or somewhat acute.

Flesh tinged with yellow, firm, nearly fine, crisp, rather tender, juicy, subacid, sprightly, good for dessert, excellent for cooking.

Season somewhat variable; often extending till May. Commercial limit usually March $(20,22)$.

\section{DUZENBURY.}

RefERENCE. I. Downing, I872:I52.

A medium sized, late winter apple, described by Downing (I) as greenish overspread with dull red, very mild subacid, almost sweet, very good in quality. It originated at Phillipstown, Putnam county, N. Y. It appears to be but little known outside of the locality where it originated.

\section{EDWARDS.}

References. I. Downing, 1872:159. 2. Beach and Close, N. Y. Sta. Rpt., 15:271. 1896. 3. Massey, N.C. Sta. Bul., I49:317. I898. 4. Powell and Fulton, U.S. B. P. I. Bul., 48:40. 1903. 5. Beach and Clark, N. Y. Sta. Bul., 248:1 I8. 1904 .

Synonym. Edwards Favorite (2). 
Fruit good in quality and one of the latest keepers, but as grown here it barely reaches medium size at its best and often is small, and the color is usually rather dull. It is not well adapted for growing as far north as New York state.

Historical. Edwards is said to have originated in Chatham county, N. C., as a seedling of the Hall.

TREE.

Tree not vigorous, small, stunted. Form flat, open, spreading and inclined to droop. Twigs short to medium, straight, slender; internodes medium. Bark olive-green tinged with brownish-red, mottled with scarf-skin; only pubescent near the tips. Lenticels conspicuous, numerous, medium to large, roundish, raised. Buds medium in size, broad, plump, acute, free, not pubescent.

\section{FrUit.}

Fruit medium or below, uniform in size and shape. Form oblate to roundish oblate inclined to conic, often slightly ribbed. Stem long, slender. Cavity obtuse to acute, medium, sometimes russeted. Calyx small, closed. Basin variable, rather shallow to moderately deep, moderately narrow to rather wide, often abrupt, nearly smooth.

Skin smooth, thick, tough, yellowish-green, blushed with dull brownish-red, faintly striped with carmine, in highly colored specimens becoming deep, bright red. Dots large and small, pale and russet. Prevailing effect rather dull green, blushed with dull dark red.

Calyx tube cone-shape or somewhat funnel-form. Stamens median to marginal.

Core below medium, abaxile; cells sometimes unsymmetrical, partly open; core lines meeting or slightly clasping. Carpels rather flat, roundish obovate to roundish obcordate. Seeds few, dark, medium to large, plump, acute; often some are abortive.

Flesh tinged with yellow, firm, rather coarse, tender, breaking, moderately juicy, somewhat astringent, sprightly subacid, aromatic, good.

Season February to May or later; sometimes keeps through the summer.

\section{EISER.}

References. I. Diel, Kernobstsorten, 5:175. 1802. (cited by 3). 2. Oberdieck, Ill. Handb. der Obst., 4:353. I865. (cited by 3). 3. Leroy, 1873:285. fig. 4. Lauche, I: col. pl. No. Io. I882. 5. Eneroth-Smirnoff, Igor:izo. 6 . Kan. Sta. Bul., 106:54. 1902.

Synonyms. Arsäpple (5). Eiser Rouge (3). Durable Trois ans (3). Red Eisen (6). Rother Fiser (2). Rother Eiser (3). Rother EiseiAPFEL (4). Rouge Rayée ( $\mathrm{I}, 3)$.

Fruit very attractive, of good size, very beautiful color and good quality; suitable for general uses. It has a tough skin which does not readily show bruises. It stands shipping well and is an excellent keeper, being much superior to Baldwin in this respect. At the Kansas Station it has not been a good cropper (6), but Leroy states 
that it is satisfactorily productive (3). As tested at this Station the tree is a good grower and almost an annual bearer, but only moderately productive. There is comparatively little loss from drops and culls. It has not been tried here long enough to justify an unqualified recommendation, but it shows merit enough to make it worthy of further testing.

Historical. A German variety which has been in cultivation more than a century $(I, 2,3)$. Our stock came from Prof. Budd who imported the variety from Austria for the Iowa Agricultural college, in I884 and 1885 .

TREE.

Tree moderately vigorous; branches long, moderately stout. Form upright spreading, or roundish, open. Twigs long, moderately stout, nearly straight; internodes long. Bark olive-brown, tinged with red, streaked with grayish scarf-skin; heavily pubescent. Lenticels scattering, small, round, raised. Buds large, broad, obtuse, free, pubescent. Foliage dense, dark green.

\section{Fruit.}

Fruit medium to nearly large. Form conical, broad at the base, often elliptical, sides unequal, somewhat ribbed. Stem short and thick to long and rather slender. Cazity very large to large, acute, deep, broad, sometimes symmetrical, often compressed or furrowed, with outspreading green russet. Calyx medium to large, closed or partly open; lobes acute to acuminate. Basin often oblique, irregular, rather shallow to moderately deep, narrow, abrupt, roughly furrowed and wrinkled.

Skin thick, tough, smooth, slightly waxy, yellow mottled with orange-red and almost covered with bright pinkish-red, sometimes deepening to purplish, inconspicuously striped with deep carmine, covered with a thin whitish bloom. Dots conspicuous, numerous toward the eye, larger, more irregular and more scattering towards the cavity, grayish-white or yellow, sometimes russet areolar. Prevailing effect attractive bright red.

Calyx tube long, funnel-shape or approaching conical. Stamens median to basal.

Core medium or above with hollow cylinder, nearly axile; cells symmetrical, closed or partly open; core lines clasping the funnel cylinder. Carpels roundish or elongated, not emarginate or but slightly so, tufted. Seeds medium to above, rather wide, long, somewhat acute, tufted, often somewhat abortive.

Flesh whitish, slightly tinged with yellow, very firm, moderately fine, crisp, breaking, moderately juicy, mild subacid, good.

Season January to June or later.

\section{ELLSWORTH.}

REFERENCE. I. Downing, 1872:160.

Described by Downing as medium in size, yellow netted with russet. Flesh tender, juicy, rich, sprightly subacid, very good to best in quality. In season from January to March. Origin, Columbia county.

We have not seen this variety. 


\section{ENGLISH RUSSET.}

References. I. Downing, I845:132. fig. 2. Thomas, I849:180, I90. fig. 3. Phoenix, Horticulturist, 1850:470. 4. Emmons, Nat. Hist. N. Y., 3:99. 1851. fig. 5. Elliott, 1858:98. 6. Am. Pom. Soc. Cat., 1862. 7. Downing, 1872: 162. fig. 8. Downing, C., Am. Pom. Soc. Rpt., I875:36. 9. Barry, 1883:345. г. Bailey, An. Hort., I892:238. II. Munson, Me. Sta. Rpt., I893:132. I2. Budd-Hansen, I903:75. I3. Beach and Clark, N. Y. Sta. Bul., 248:1 I8. igo4.

Synonyms. English Russet (5). Poughreepsie Russet (5). Poughkeepsie Russet (2, 7, 9, II). Winter Russet (3, 5).

A greenish-yellow russet of medium size or rather small, pretty uniform in size, not especially attractive in color nor high in quality, but one of the best keeping apples known. In ordinary cellar storage it has often been kept till the next crop has ripened. Late in the season it is apt to shrivel some. Fruit-dealers report that the fruit from Southern and Southwestern New York is larger and has poorer keeping quality, while that from Northern and Western New York is smaller and keeps better.

Within recent years it has been in good demand for export trade, bringing relatively better prices in Europe than in America. It is not very good for cooking, but has the reputation of making exceptionally good cider. It is acceptable for dessert following the season of Esopus Spitzenburg and Baldwin. The fruit hangs well to the tree, but there is apt to be considerable loss because a relatively large percentage of the apples are too small for market. Where insects are not controlled the fruit is often knotty. The trees commonly bear biennially and only moderately, heavy crops being rare.

\section{English Russet and Golden Russet Compared.}

It may be distinguished from the Golden Russet, which is also called by some English Golden Russet, by its straight-growing habit, with erect shoots forming an upright or round top. The Golden Russet trees are more vigorous. spreading, irregular and bushy. The English Russet twigs of one season's growth have more of a clear reddish-brown color, and the lenticels, being comparatively dull in color and only moderately numerous, are not very conspicuous, although they are sometimes large, while the Golden Russet twigs when highly colored are darker brown, varying towards olive-green where the color is less strongly developed. They are finely mottled 


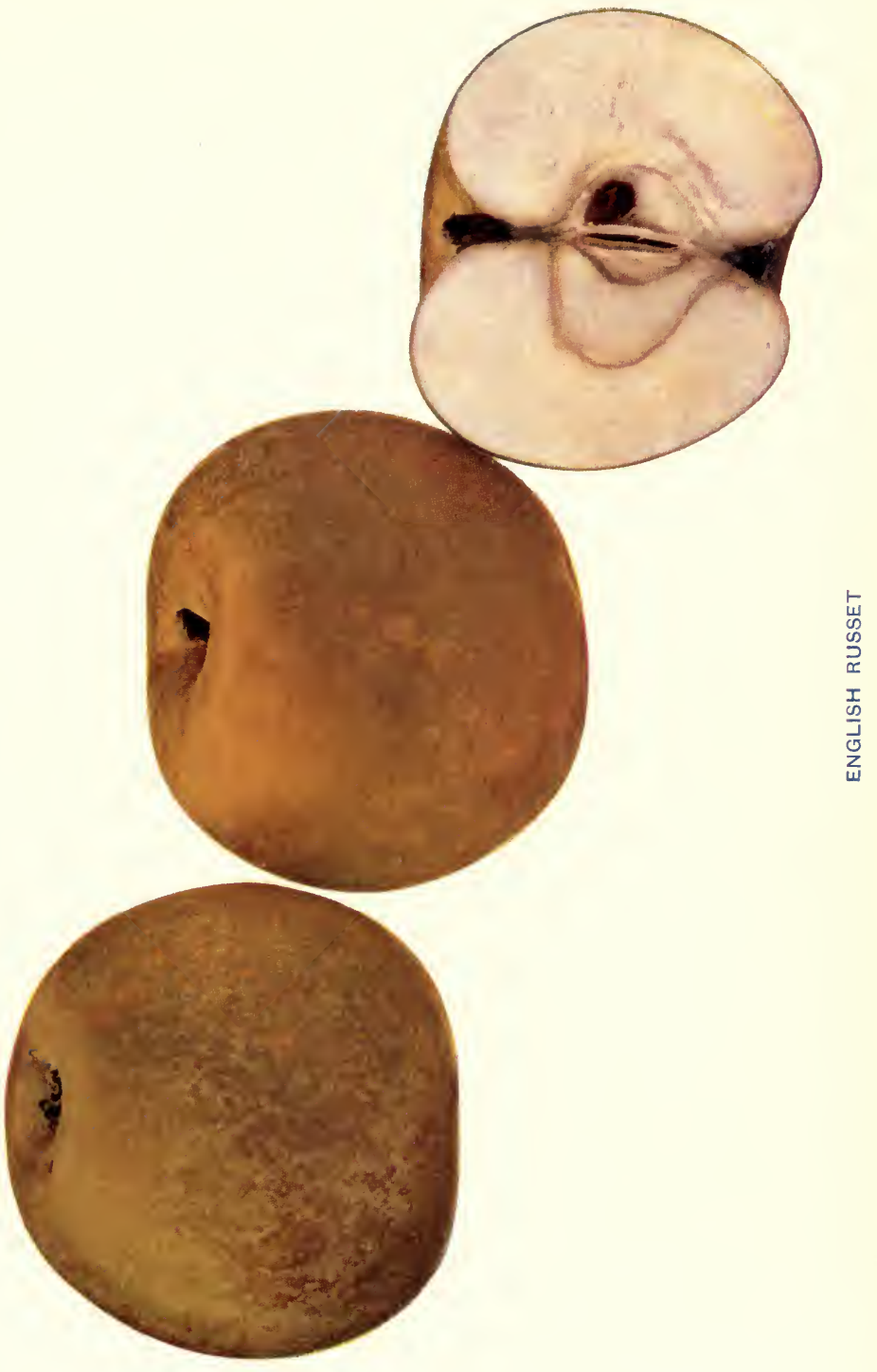



with grayish scarf-skin, and the roundish lenticels, although they are usually small, are numerous and conspicuous, having a clear, pale color. On the bark of the second season's growth the lenticels are elongated transversely, still numerous and decidedly conspicuous.

In the English Russet the tendency of the fruit to become narrow towards the eye is more marked than in the Golden Russet, and its calyx is more often open, with the lobes reflexed. The Golden Russet basin is often the wider and markedly saucer-shaped, with the calyx set in a narrow, green or yellowish circle which contrasts sharply with the surrounding russet. The stem of the Golden Russet is usually the shorter and stouter, while that of the English Russet often has a brownish-red streak not found on the other. The cavity of the Golden Russet is somewhat larger and wider, but on the average is hardly as deep as that of the English Russet. It is often marked with grayish dots, while that of the English Russet is not. The skin of the Golden Russet varies from a dull greenish russet to golden russet; and when grown under favorable conditions sometimes has a bronze blush, but it does not take a polish. The skin of the English Russet shows no sign of a blush, but it is somewhat the smoother, paler and brighter in color, and takes a good polish. The flesh of the Golden Russet is richer in flavor, more tender, and of higher quality than that of the English Russet; its seeds have a more marked red tinge; its core is more distinctly abaxile; its cells are more often unsymmetrical; its carpels are more concave and its seeds are broader, more irregular in form and size, less acute and more distinctly tufted.

Historical. Although this has long been extensively grown under the name English Russet it has not been identified with any European variety and its origin is unknown. It is much grown in Westchester and Putnam counties and is found in old orchards throughout the State. It is distinct from the English Russet of Warder, 1 also from that described by Burrill and $\mathrm{McCluer}^{2}$ as the "English Russet of England."

\section{TREE.}

Tree medium in size to rather large, moderately vigorous to vigorous. Form upright. Trigs erect, medium or above medium in length, moderately stout to rather slender, often with large terminal bud; internodes short. Bark rather dark clear brownish-red or, on the shaded side, brownish-green, covered

${ }^{1}$ Amer. Pom. 1867:625. ${ }^{2}$ Ill. Sta. Bul., 45:320. 1896. 
sparingly with gray scarf-skin: somewhat pubescent. Lenticels moderately abundant, not particularly conspicuous but rather dull colored, often roundish, sometimes large. Buds often short, plump, obtuse to acute, moderately pubescent, rather deeply set in the bark, free.

\section{FRUIT.}

Fruit medium to rather small; pretty uniform in size and shape. Form roundish, more or less inclined to conic, pretty regular and symmetrical, sometimes faintly ribbed, occasionally sides unequal. Stem moderately thick to rather slender, medium in length to short, often streaked on one side with brownish-red, usually not exserted. Cavity acute to somewhat acuminate, rather narrow to medium in width, moderately deep to deep, symmetrical or slightly compressed, occasionally lipped, furrowed obscurely if at all. Calyx small to medium, ustrally open, sometimes closed; segments often long, acute and reflexed. Basin rather abrupt, moderately deep, moderately wide to rather narrow, symmetrical.

Skin tough, takes a good polish, varies from pale green to yellow more or less covered with russet, the base often being entirely russeted. Highly colored specime' 1 become clear golden russet but have no perceptible shade of red. Dots inconspicuous, round or irregular, dark russet.

Calyx tube rather narrow, cone-shape, sometimes funnel-form. Stamens basal to median.

Core rather small, abaxile; cells pretty symmetrical, open, sometimes closed; core lines usually meeting, but with a funnel-form calyx tube they are clasping. Carpels rather flat, roundish to broadly ovate, slightly tufted, but slightly emarginate if at all. Sceds numerous, medium in size, plump, rather narrow, acute to acuminate, rather light brown, sometimes slightly tufted.

Flesh yellowish-white, firm, rather crisp, moderately tender, fine-grained, not very juicy, somewhat aromatic, pleasant, rather mild subacid, good.

Season January to May or later.

\section{ESOPUS SPITZENBURG.}

References. 1. Coxe, I8I7:127. 2. Thacher, I822:137. 3. N. Y. Bd. of Agr. Men., I826:477. 4. Wilson, 1828:136. 5. Cat. Hort. Soc. London, 1831: 368. 6. Kenrick, 1832:40. 7. Floy-Lindley, 1833:45. 8. Downing, r845:1 38 . 9. Thomas, I849:17I, I72. fig. I0. Hovey, Mag. Hort., I6:62. I850. fig. I1. Emmons, Nat. Hist. N. Y., 3: col. pl. No. 23. i851. 12. Am. Pom. Soc. Cat., 1852. 13. Elliott, 1858:76. fig. 14. Bivort, An. Pont de Belge, 1859:75. I 5. Flotow, Ill. Handb. der Obstk., I:525. I859. I6. Warder, 1867:539. fig. I 7. Mas, Le Verger, 4:I4I. col. pl. I8. Leroy, 3:54. I873. I9. Barry, 1883:345. 20. Hogg, 1884:73. 21. Wickson, r889:247. 22. Lyon, Mich. Hort. Soc. Rpt., 1890:290. 23. Bailey, An. Hort., 1892:238. 24. Woolverton, Ont. Fr. Stas. An. Rpt., 3:14. 1896. fig. 25. Eneroth-Smirnoff, rgor:452. 26. Budd-Hansen, 1903:76. fig. 27. Massey, N. C. Sta. Bul., r82:20. I903. 28. Powell and Fulton, U. S. B. P. I. Bul., 48:40. 1903. 29. Beach and Clark, N. Y. Sta. Bul., 248:1 18. I904.

Synonyms. Esopus Spitzemberg (7). Esopus Spitzemberg (8, 10, 18). Esopus Spitzenberg (6). Asopus Spitzenberg (20). Esopus Spitzenburg (8). Esopus Spitzenburgh (I8). Esopus Spitzenburgh (Io). Esopus 


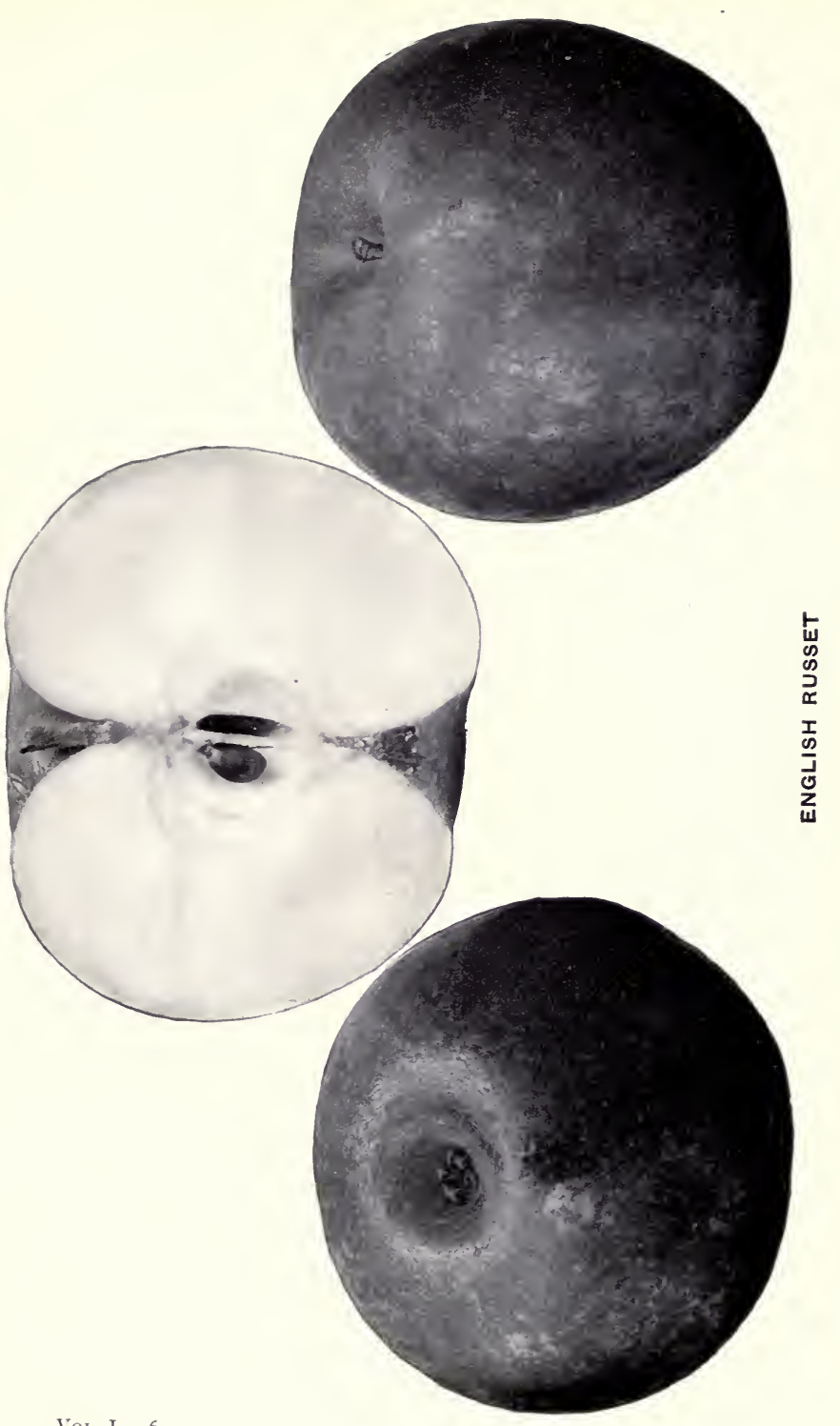

Vol. I -6 

(28). Esopus Spitzemberg (1). Esopus Spitzenberg (3, 10, 16, 21). Esopus Spitzenburg $(13,22,23)$. Esopus Spitzenburg (28). Esopus Spitzenburgh (II, 19, 20). Esopus Spitzenburgh (24). Spitszenburgh (2). Spitzenberg (4). Spitzenburg (29). Spitzenburgh (24). Spitzenburgh, Esopus $(8,9)$. True Spitzenburgh $(8,18,20)$.

The Esopus Spitzenburg, commonly known as the Spitzenburg, is the standard of excellence for apples of the Baldwin class, to which it naturally belongs. When well grown it is handsomely colored and unexcelled in flavor and quality. It is a choice dessert fruit and also one of the best apples known either for canning or for general culinary uses. It is well adapted for handling in cold storage, ships well, has long had a well-established reputation in market, always sells well, is well suited for marketing in boxes or fancy packages and often brings fancy prices. It is in season between Rhode Island Greening and Baldwin. It is quite variable in keeping quality in different seasons and in different localities (29). The fruit is quite susceptible to the attacks of the scab fungus, as also are the blossoms and the foliage. It is often injured by the apple-canker, and therefore it is advisable to graft or bud it upon a healthier variety. Special attention needs to be given to protecting both the tree and the fruit from the diseases just mentioned. ${ }^{1}$ As one means for accomplishing this result and also for the purpose of increasing the yield of high-grade fruit, it is wise to prune regularly but moderately, and to give the trees enough room in the orchard so that they do not crowd each other, thus permitting free movement of air and access of ample light around and among all of the branches. Especial care should be taken to favor a free and vigorous growth of the tree by keeping the soil highly fertile, well supplied with humus, well drained and yet well supplied with moisture throughout the growing season.

Under favorable conditions Esopus Spitzenburg bears pretty regularly, but it is commonly rated as being, on the average, a rather moderate cropper. For this reason and because of its susceptibility to the diseases above mentioned it is not largely planted in commercial orchards, being found less profitable than Baldwin, Rhode

\footnotetext{
${ }^{1}$ Descriptions of these diseases and approved methods of dealing with them are set forth in bulletins of this Station $163: 1899,170: 1900,185: 1900,243: 1903$, and in the Station's corresponding annual reports.
} 
Island Greening and certain other standard commercial sorts. The fruit develops good color and quality in most of the apple-growing regions of the State but it does particularly well in favorable localities in Schoharie and Greene counties and along Lake Champlain.

Historical. Originated at Esopus, Ulster county. We find no authentic accomnt of the date of its origin but it is scattered throughout the State in the oldest orchards and was well known in cultivation in this and adjoining states more than a century ago. It is known in cultivation in Europe, and is one of the recognized comnercial varieties in certain apple-growing districts of the Rocky Mountain region, Washington and Oregon.

\section{TREE.}

Tree in the nursery makes a rather slow root development, and in the orchard is a moderately slow grower; the lateral branches are rather slender and eventually somewhat drooping. Form rather open and spreading, moderately upright. Twigs rather long and slender. Bark dark, rather clear, reddish-brown, and dark green, finely mottled with thin gray scarf-skin; but sligintly pubescent if at all. Lenticels medium size or below, numerous, irregular, elongated, conspicuous. Buds medium size, appressed, obtuse, pubescent. Leaves inclined to be narrow; foliage not dense.

\section{Fruit.}

Fruit below medium to large; pretty uniform in size and shape. Form rather broad and flat at the base, varying from oblong rounding towards the cavity to roundish ovate or to roundish inclined to conic; somewhat irregular and obscurely ribbed. Stem medium. Cazity acute or somewhat acuminate, deep, wide, red or yellow or with outspreading rays of thin yellowish-russet. Calyx medium to small, closed or somewhat open. Basin not large, often oblique at brim, abrupt, moderately narrow, shallow to medium in depth, sometimes compressed, usually furrowed and wrinkled.

Skin tongh, sometimes waxy, slightly roughened by the russet dots, deep rich yellow often almost completely covered with bright red inconspicuously striped with darker red, in the sun deepening to a very dark, almost purplish blush, marked with pale yellow and russet dots which are small and numerous toward the basin, but are apt to be larger and much elongated toward the cavity.

Calyx tube not very large, often elongated, cone-shape. Stamens below nedium to above.

Core medium to rather large, abaxile; cells often unsymmetrical and open but sometimes closed; core lines slightly clasping. Carpels large, roundish ovate, mucronate, tufted. Seeds large, long, wide, acute, dark shaded with light brown.

Flesh tinged with yellow, firm, moderately fine, crisp, rather tender, juicy, aromatic, sprightly subacid, very good to best. June.

Season November to February or later. In cold storage may be held till 

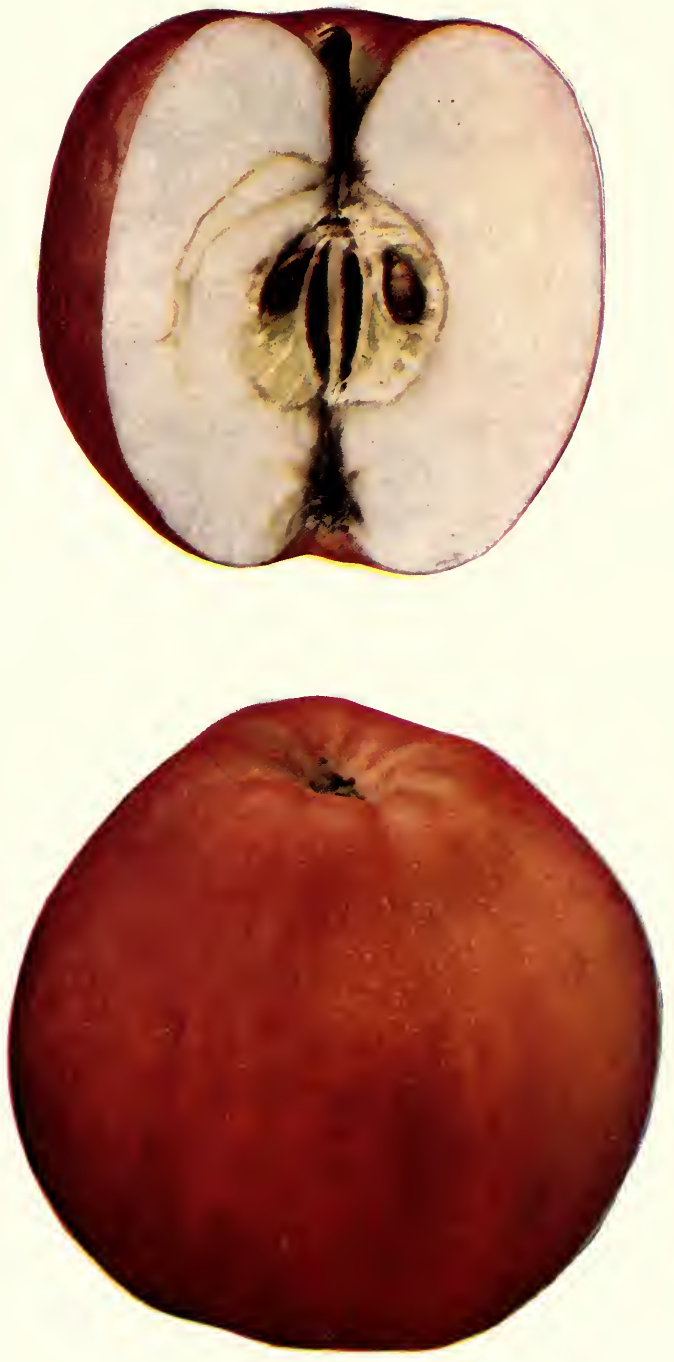

ESOPUS SPITZENBURG 



\section{ETOWAH.}

References. 1. Downing, 1876:51. app. 2. Am. Pom. Soc. Cat., 1881. 3. Bailey, An. Hort., 1892:238. 4. Beach and Clark, N. Y. Sta. Bul., 248:118. I904.
Synonym. Cooper's Red
(3). Cooper's Red (1).

This is a variety of Georgia origin which is regarded with favor in some parts of the South $(1,2,3)$. So far as we know it is not being grown in New York. The variety described under the name Etowah in Bulletin 248 of this Station is not true to name.

\section{ETRIS.}

References. I. Stinson, Ark. Sta. Bul., 49:1 i, 1898. 2. Ib., 6o:128. 1899. 3. Budd-Hansen, r9o3:77.

The variety which has been propagated under this name in Arkansas may be a new variety but it appears to be identical with $\operatorname{Gano}(I, 2)$.

\section{EVENING PARTY.}

References. I. Brinckle, Horticulturist, 10:539. I855. col. pl. 2. Downing, 1857:77. fig. 3. Elliott, 1859:137. 4. Warder, 1867:433. fig. 5. Am. Pom. Soc. Cat., 1873. 6. Mich. Hort. Soc. Rpt., I881:310. 7. Thomas, 1885:233. 8. Bailey, An. Hort., 1892:238. 9. Buckman, Rural N. Y., 54:806. 1895. 10. Budd-Hansen, r903:78. fig.

A pleasant flavored dessert fruit which is in season at Christmas. Some find the tree unproductive but others report that it is a biennial bearer producing so abundantly that the fruit is small if it is not thinned and the tree well pruned. When highly colored it is decidedly attractive but often it does not color well and usually is below medium in size. It is not recommended for commercial planting.

Historical. Origin, Berks çunty, $\mathrm{Pa}$. (4). It has been known in cultivation for fifty years but it is but little grown in New York and its cultivation is not being extended.

\section{TREE.}

Tree medium in size, moderately vigorous. Form roundish with long spreading branches. Twigs dark reddish-brown, slender to rather stout, curved at base; internodes long to very long. Bark generally dull brownishred with a rather strong undertone of olive-green in places; scarf-skin uni form, moderately light. Lenticels inconspicuous, raised, numerous, above medium to rather small, roundish. Buds medium size, moderately obtuse, quite pubescent.

\section{FRUIT.}

Fruit above medium to rather small. Form oblate to roundish, pretty symmetrical, uniform. Stem short, medium in thickness, seldom exserted. Cavity acute to acuminate, deep, moderately broad, usually smooth, occasionally with outspreading russet rays, symmetrical. Calyx medium to large: 
open or partly closed; lobes long, acuminate, somewhat separated at the base. Basin abrupt, moderately deep to deep, moderately wide, slightly wrinkled.

Skin moderately thin, rather tough, smooth, glossy, greenish or pale yellow mottled and blushed with red and indistinctly and sparingly striped with carmine becoming a dark, almost purplish, red in the sun; the deep red color is apt to overspread the basin while the yellow ground color is conspicuous around the cavity. Dots large, pale, mingled with many that are small, whitish and submerged or with minute russet point.

Calyx tube short, broad, conical. Stamens median to marginal.

Core medium to small, somewhat abaxile to axile; cells usually pretty symmetrical, partly open; core lines meeting or slightly clasping. Carpels roundish to elliptical, slightly tufted. Seeds medium in size, moderately wide, plump, obtuse to acute.

Flesh tinged with yellow, moderately firm, fine, rather crisp, tender, very juicy, mild subacid mingled with sweet, somewhat aromatic, very good to best.

Season December and January.

\section{EWALT.}

References. I. Downing, 1857:141. 2. Am. Pom. Soc. Cat., 1862. 3. Warder, $1867: 640$. 4. Downing, 1872:166. 5. Thomas, $1885: 509$. 6. Pa. Hort. Assoc. Rpt., I885:25. 7. Bailey, An. Hort., 1892:238. 8. Powell and Fulton, U. S. B. P. I. Bul., 48:40. 1903. 9. Budd-Hansen, 1903:78. 10. Beach and Clark, N. Y. Sta. Bul., 248:118. 1904.

Synonym. Bullocks Pippin of some (4).

Fruit of good marketable size and attractive, having a clear yellow skin usually somewhat blushed with bright red. It is not a first-class dessert apple, being rather too acid and not high in quality, but it is good for culinary use. The tree occasionally bears good crops but commonly it is a moderate or rather shy bearer.

Historical. Origin, Bedford county, Pa. $(3,4)$. Although it has been known in cultivation for many years it has not gained recognition as a commercial variety.

\section{TREE.}

Tree vigorous; branches long, moderately stout, curved. Form upright spreading, round, rather dense. Twigs medium or above, straight, stout; internodes medium to long. Bark clear dark brownish-red or tinged with olive-green, heavily pubescent; scarf-skin rather thin or none. Lenticels conspicuous, rather numerous, small to medium, oblong, or roundish, not raised. $B u d s$ small to medium, flat, obtuse, free, imbedded in the bark, pubescent.

\section{FRUIT.}

Fruit large. Form varies from roundish conic to roundish oblate, sometimes irregularly elliptical with sides unequal or compressed, usually pretty symmetrical. Stem short to medium, rather slender. Cavity not large, acute to acuminate, deep, rather narrow to broad, sometimes partly russeted with narrow broken outspreading russet rays, often furrowed or compressed. Calyx usually large and leafy, sometimes rather small, closed or partly open; 

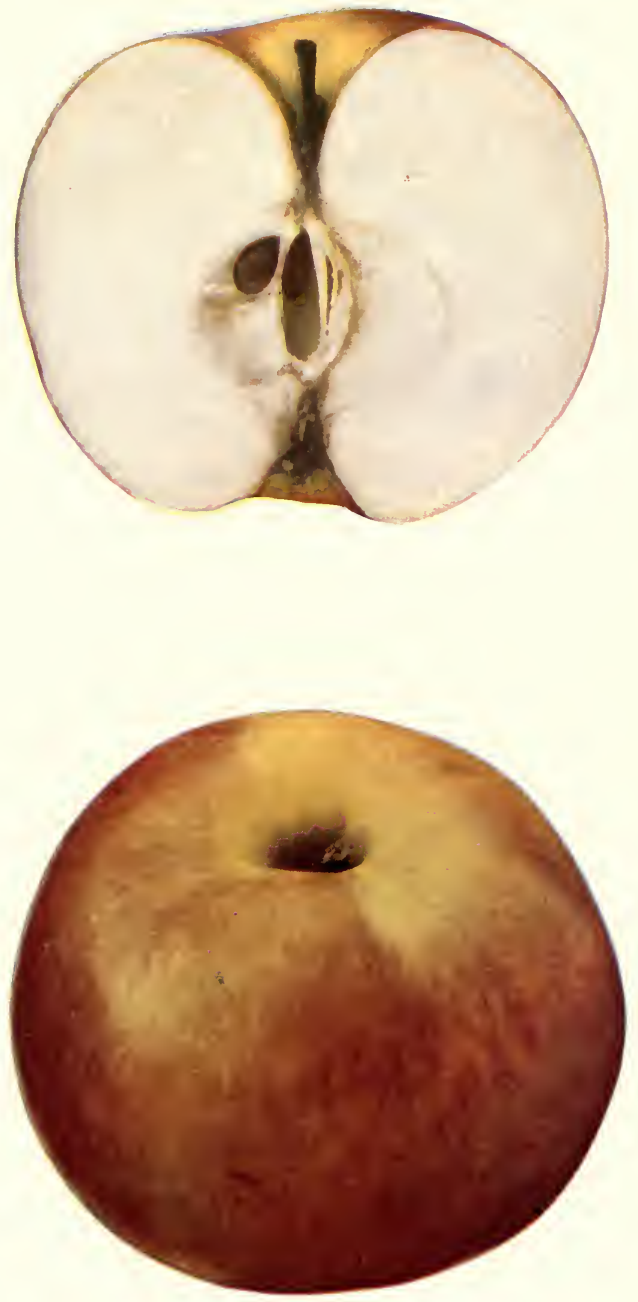

EWALT 

lobes long, acute. Basin not large, sometimes oblique, rather shallow to moderately deep, rather narrow, abrupt, often somewhat furrowed and wrinkled.

Skin tough, waxy, but not glossy, clear yellow usually with a thin brownish blush which sometimes deepens to bright red with a slight tendency to become striped, often marked with suture lines extending from cavity toward the basin. Dots numerous, small, inconspicuous, whitish or with minute russet point, usually submerged.

Caly $x$ tube cone-shape to funnel-form. Stamens median.

Core abaxile, medium or below; cells often unsymmetrical, closed or open; core lines clasping the funnel cylinder. Carpels variable, roundish to roundish ovate or obovate. Seeds numerous, medium to large, rather long, moderately wide, obtuse to acute.

Flesh tinged with yellow, rather firm, moderately fine, crisp, rather tender, juicy, brisk subacid, slightly aromatic, good.

Season November to April. Commercial limit February or March (I0).

\section{FALIX.}

Reference. I. Beach and Clark, N. Y. Sta. Bul., 248:119. I904.

Fruit of medium size with tender flesh, sprightly mild subacid, good but not excellent in quality. In form and also in the ground color and striping it reminds one of the St. Lawrence, being oblate conic and dull green or light yellow mottled and striped with light and dark red. It is less attractive than St. Lawrence. Season November to April. Received for testing here from Benjamin Buckman, Farmingdale, Ills. It does not excel as a dessert fruit and is not attractive enough to be a good market apple. It is not recommended even for trial.

\section{FALLAWATER.}

References. I. Downing, I845:109. 2. Horticulturist, 2:482, 570.1848 . 3. Thomas, 1849:180. 4. Emmons, Nat. Hist. N. Y., 3:44. 1851. col. pl. 5. James, Horticulturist, 8:247. 1853. 6. Hovey, Mag. Hort., 22:556. 1856. fig. 7. Am. Pom. Soc. Cat., 1856. 8. Elliott, 1858:79. fig. 9. Norris, Horticulturist, 15:183. 1860. I0. Warder, 1867:495. fig. I1. Downing, 1872:167. 12. Barry, 1883:345. 13. Lyon, Mich. Hort. Soc. Rpt., 1890:290. 14. Wickson, I891:248. I5. Bailey, An. Hort., I892:238, 251. 16. Dempsey, Ont. Fr. Stas. An. Rpt., I:24. 1894. 17. N. C. Bd. of Agr. Bul., 1900:10. col. pl. 18. Waugh, Vt. Sta. An. Rpt., 14:293. 1901. 19. Budd-Hansen, r903:78. fig. 20. Beach and Clark, N. Y. Sta. Bul., 248:119. 1904.

Synonyms. Faldwalder (6). Fallawater $(2,5,8)$. Fall de Waldes (9). Fallenwalder $(5,8)$. Fallenwalder (6). Fornzualder (5). Green Mountain Pippin (6, 8, I I). Mountain Pippin (8, II). Pim's Beauty of the West (8). Pine's Beauty of the West (6). Pound (2, II). Tulpahocken $(6,8)$. TUlpehocken (2). Tulpehocken (10, 11, 12, 14, 18, 19, 20). Winter Blush (II).

Fruit large or very large, globular, attractive in size and form, but as grown in Western New York it is often rather dull in color. The accompanying colored plate was made from a highly colored 
specimen grown in the Hudson valley. In favorable localities on Long Island it colors well and develops better quality than it commonly does north of Orange county. The flesh is coarse and at best but second rate in quality. It is well known in market, and is often handled at satisfactory prices in domestic and also in export trade.

The tree is usually a good, regular bearer, producing biennially or in some localities almost annually. Sometimes the larger branches break under their load of fruit. The fruit being large, there is apt to be a coisiderable loss from dropping, but considering its size it generally hangs to the tree pretty well. It is variable in season, ranking as a keeper sometimes with Hubbardston and sometimes with Rhode Island Greening. Although it has long been disseminated throughout New York, it has not generally been regarded with favor by New York orchardists, except possibly in some parts of Long Island.

Historical. Origin Bucks county, Pennsylvania. Hovey referred to it in $\mathrm{s} 856$ as having been known and cultivated for many years under the name Fallawater (6). Warder in 1867 remarked that it was then a great favorite in Pennsylvania and "extensively cultivated through the West."

\section{TREE.}

Tree makes a moderately light root growth in the nursery. In the orchard it becomes large and vigorous. Form upright to roundish. Twigs medium in length to short, moderately stout, thick at the tips, erect; internodes medium. Bark smooth, bright brownish-red mingled with olive-green, finely mottled with scarf-skin; slightly pubescent. Lenticels moderately conspicuous, rather abundant, medium in size, usually roundish. Buds medium or above, roundish, obtuse, sparingly pubescent, free.

\section{FRUIT.}

Fruit large to very large. Form globular, sometimes a little oblate, usually symmetrical, sometimes slightly irregular, and faintly ribbed, but it is pretty uniform in size and shape. Stem very short. Cavity distinctly acuminate, deep, rather narrow to broad, usually somewhat furrowed. Calyx medium to large, closed or partly open; lobes variable. Basin shallow to moderately deep, moderately abrupt to abrupt, often nearly symmetrical, sometimes distinctly furrowed, wrinkled.

Skin tough, smooth, a little waxy, often dull grass-green with dull blush, but highly colored specimens eventually become distinctly yellow and largely blushed with bright deep pinkish-red, often considerably streaked with thin grayish scarf-skin. Dots conspicuous, whitish, often large areolar with russet point. 

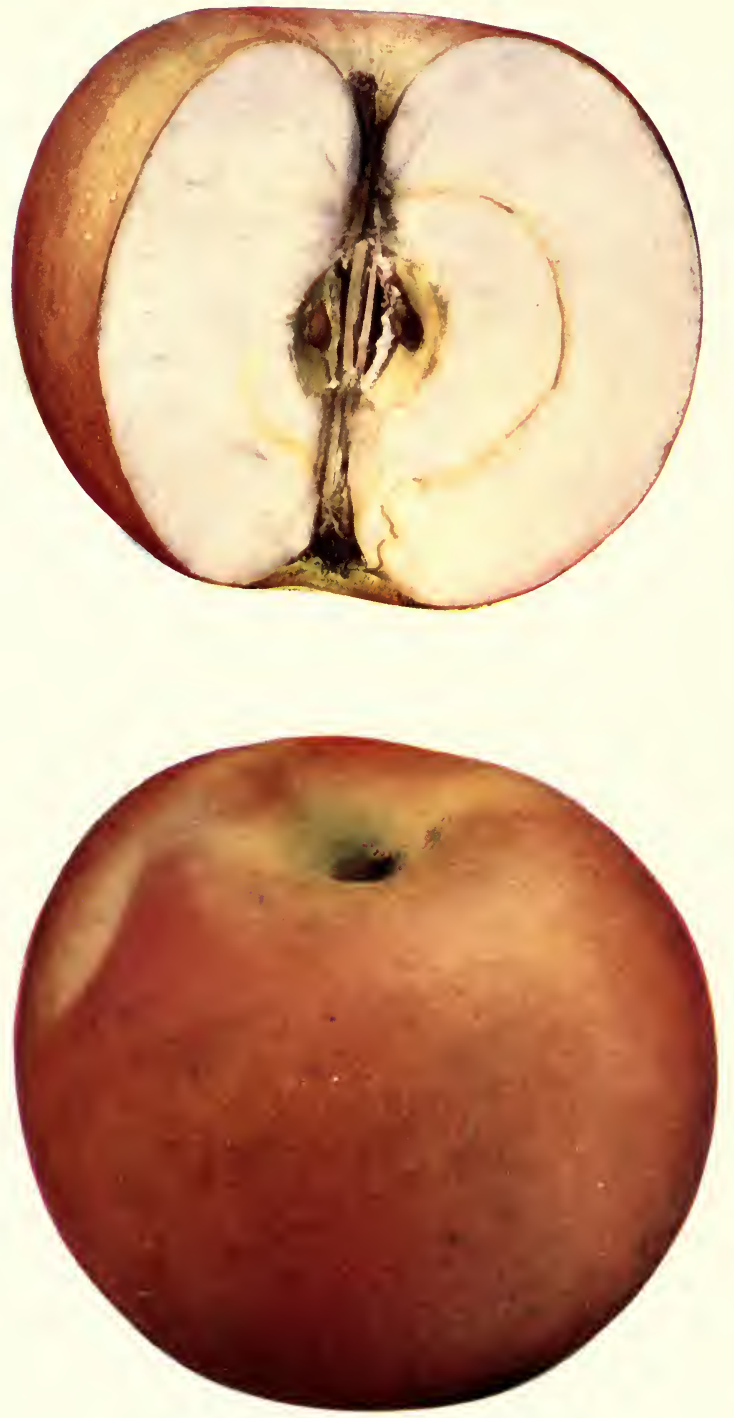

FALLAWATER 

Calyx tube wide, rather short, cone-shape or approaching funnel-form. Stamens basal to median.

Core decidedly abaxile to nearly axile, medium to large, cells unsymmetrical, upen or closed; core lines meeting or somewhat clasping. Carpels distinctly tufted, long, narrowly ovate, mucronate, but slightly emarginate if at all. Secds often are very few, long, narrow, acute to acuminate, tufted.

Flesh tinged with yellow or green, firm, coarse, crisp, moderately tender, juicy, subacid to mildly sweet, without distinct or high flavor, quality good or nearly so.

Season November to March or April, being quite variable in different localities and in different seasons. On Long Island it is commonly in season in October and out of season in January.

Use. Desirable only for cooking and narket.

\section{FAMILY.}

References. I. Warder, r867:515. 2. Downing, 1872:172. fig. 3. Am. Pom. Soc. Cat., 1873. 4. Barry, 1883:333. 5. Thomas, 1885:509. 6. Bailey, $A n$. Hort., 1892:239. 7. Clayton, Ala. Sta. Bul., 47:8. 1893. 8. Budd-Hansen, I903:83.

Synonyms. McCrouds Family (I). McLouds Family $(2,4)$.

As grown at this Station the Family does not agree closely with the descriptions of this variety given by various pomologists $(2,4,5,8)$, particularly in regard to its season of ripening. Nevertheless we believe that we have the variety true to name. We have traced our stock back to W. M. Samuels, Clinton, Kentucky, a careful nurseryman. In Georgia, where it originated, Family is a summer apple and according to some nursery catalogue descriptions "keeps ripening for six weeks." In Central Illinois it is in season in September. Here at Geneva some of the fruit may keep through the winter although its season would best be described as extending from October to January. It is not a desirable variety for planting in New York.

\section{TREE.}

Tree vigorous, with short, moderately stout branches; does not come into bearing young but is an annual bearer and a moderately good cropper. There is a considerable loss from the dropping of the fruit. Form upright spreading, rather dense. Tivigs short, straight, moderately stout; internodes below medium to short. Bark olive-green, tinged with red, covered with a light coat of grayish scarf-skin, quite pubescent near tips. Lenticels not clear in color, inconspicuous, scattering, medium in size, roundish. Buds medium, flat, obtuse, very pubescent, deeply set in bark.

\section{FrUIT.}

Fruit small to medium. Form roundish ovate to roundish conic, faintly ribbed, rather symmetrical, sides often unequal; pretty uniform in shape and size. Stem long to medium, usually rather slender. Cavity acute to acuminate, medium in depth to deep, narrow, usually symmetrical, sometimes lipped, often smooth but sometimes overspread with russet. Calyx medium, usually 
slightly open; lobes rather long and reflexed. Basin shallow to very shallow, narrow, abrupt, narrowly furrowed.

Skin thin, tough, smooth, mottled and washed with red over a rather pale yellow ground, shading to deep dark red in the sun, marked with many narrow and broken stripes of dull purplish-carmine, sprinkled with rather conspicuous pale yellowish or russet dots and overspread with whitish bloom.

Calyx tube long, rather wide, funnel-form or conical, often extending to the core. Stamens median to nearly basal.

Core abaxile, large; cells usually symmetrical and wide open; core lines somewhat clasping. Carpels rather concave, round to broadly elliptical. Seeds numerous, medium to rather large, acute to obtuse, plump.

Flesh yellowish sometimes tinged witl red near the skin, firm, rather crisp, fine-grained, tender, juicy, sprightly subacid becoming mild, pleasant in flavor, good.

\section{FARRIS.}

References. 1. Churchill, N. Y. Sta. An. Rpt., 8:355. I889. 2. Beach, N. Y. Sta. An. Rpt., 14:259. 1895. 3. Beach and Clark, N. Y. Sta. Bul., 248: I20. 1904 .

Fruit resembles Rambo somewhat. As grown at this Station its quality is good bnt not as high as it is rated in Kentucky where it was first introduced into cultivation. The tree does not come into bearing very young. It is usually moderately productive and sometimes very productive, but it is too unattractive in color and too small to be desirable for commercial purposes.

Historical. Farris was introduced by a Mr. Reeves of Allen county, Kentucky, and afterwards brought more prominently into notice by W. M. Samuels, Clinton, Ky. It was granted first premium as the best fall apple at a fruit exhibition in St. Louis in 1876.

\section{Tree.}

Tree moderately vigorous, rather small, with short stout branches. Form spreading, flat, open. Taigs medium in length to rather short, straight, moderately stout; internodes short. Bark clear, reddish-brown, with some olivegreen and streaked with gray scarf-skin; slightly pubescent. Lenticels clear in color, scattering, small, or very small, generally round, not raised. Buds deeply set in bark, medium in size, flat, obtuse or acute, appressed, slightly pubescent.

\section{FRUIT.}

Fruit medium or below. Form roundish oblate to roundish conic, faintly ribbed. Stem rather stout. Cavity acute, sometimes nearly obtuse, shallow to moderately deep, narrow, sometimes lipped, sometimes slightly russeted. Caly.r often flat, small to above medium, closed or partly open. Basin shallow to moderately deep, narrow to moderately wide, often somewhat furrowed and wrinkled.

Skin smooth, waxy, somewhat glossy, yellow, largely overspread with rather dull, deep red, in highly colored specimens becoming purplish, sometimes obscurely striped with purplish-carmine Dots yellowish, sometimes witl russet point, numerous, small to large, often conspicuous. 
Calyx tube usually rather narrow and cone-shape, sometimes funnel-shape. Stamens median to basal.

Core axile, medium, closed; core lines meeting or clasping. Carpels roundish or roundish obcordate, tufted. Seeds large to below medium, narrow, long, acuminate to acute, tufted, often some are abortive.

Flesh tinged with yellow, firm, rather coarse, crisp, tender, juicy, pleasant subacid, good.

Siason variable, usually extending from December to March or April, sometimes later.

\section{FERDINAND.}

REFERENCES. I. Summer, Horticulturist, 4:275. 1849. fig. 2. Elliott, 1858: 133. 3. Warder, I867:533. 4. Downing, I872:175. 5. Leroy, I873:300. 6. Am. Pom. Soc. Cat., 1873. 7. Thomas, 1885:510. 8. Taylor, Am. Pom. Soc. Rpt., $1895: 193$.

Fruit of good form and size and rather attractive in color for a yellow apple. It is a fine dessert fruit and a good keeper. As grown at this Station it is rather slow in coming into bearing and at best is only moderately productive but it bears some fruit nearly every year. It is not recommended for commercial planting. Because it is excellent in quality and a good keeper it may be worthy of a place in the home orchards in the lower Hudson valley and on Long Island.

Historical. Ferdinand originated with Mr. Adam Minnick near Pomaria, S. C. It bore its first fruit in I848. In that locality it is a late autumn variety. In 1873 it was given a place in the American Pomological Society's Catalogue of recommended apples but was dropped from that list in I899.

\section{TreE.}

Tree a strong upright grower in the nursery. In the orchard at this Station it is a rather slow grower with short, moderately stout branches. Form spreading and open, flat at the top. Twigs upright, small to medium, straight, stout; internodes vary from long to short. Bark olive-green tinged with brownish-red, in part mottled with scarf-skin, somewhat pubescent near tips. Lenticcls scattering, medium to large, oblong to roundish, raised. Buds medium to large, broad, obtuse, appressed, slightly pubescent.

\section{FirUIT.}

Fruit above medium to nearly large. Form flattened at the base, roundish conic to oblate conic, often somewhat ribbed, somewhat irregular. Stem short, often with a fleshy protuberance. Cavity acute, moderately shallow to rather deep, rather narrow, often obscurely furrowed or compressed, often overspread with russet, sometimes lipped. Calyx above medium to small, partly open or closed; lobes acuminate. Basin often oblique, usually narrow and shallow but varies to moderately wide and deep.

Skin rather thin, moderately tender, deep yellow or greenish with an orange blush which sometimes deepens to red, sometimes partly covered with russet. Dots numerous, sometimes whitish, but usually rough russet, variable in size and irregular in form. Prevailing effect greenish-yellow. 
Calyx tube wide, cone-shape or sonetimes rather funnel-form. Stamens median.

Core small to above medium, abaxile; cells fairly symmetrical, closed or somewhat open; core lines meeting or clasping. Carpels roundish, emarginate, slightly tufted. Seeds numerous, above medium to below, flat, obtuse, dark.

Flesh tinged with yellow, firm, rather fine, crisp, tender, moderately juicy, aromatic with a rich agreeable flavor similar to that of some russet apples, sprightly becoming mild subacid, good to very good.

Season December to May.

\section{FERRIS.}

REFERENCEs. I. Elliott, I854:170. 2. Downing, I857:165. 3. Warder, 1867:517. 4. Downing, $1872: 175$. 5. Thomas, $1885: 220$.

Synonyms. Ferris $(2,5)$. Long Island Seek-No-Further $(2,3,5)$. Rhode Island Seek-No-Further (5). Westchester Seek-No-Further (2, 3, 5).

A large, red striped apple, formerly grown in Westchester county, and there considered profitable for market (4). The tree is described as vigorous and an annual bearer, producing alternately light and heavy crops $(3,4)$. Its season extends from October to December or later $(1,2,5)$. The variety is not now listed by nurserymen, but another variety of the same name which originated in Delaware is still offered in some southern nurseries. ${ }^{1}$ Neither of these varieties is recommended for growing in New York.

\section{FLORENCE.}

Reference. I. Stinson, Ark. Sta. Bul., 60:129. 1899.

As grown at this Station from stock received from M. Butterfield, Lee Summit, Missouri, the fruit is of the Ben Davis type, strongly resembling Gano, very attractive in size and appearance and a good keeper. As compared with Gano it is more angular, and more conspicuously striped with purplishcarmine; the basin is more often oblique; and the pistils do not persist in the form of a fleshy projection into the base of the calyx tube. As tested at this Station it is a moderately vigorous grower, comes into bearing young, bears annually and is only moderately productive, but it has been grown here under rather unfavorable conditions. Stinson (I) observes that it is in season with Jonathan, but we find it keeps much better than Jonathan. It has not been tested here sufficientlv to indicate whether or not it promises to be a valuable variety in New York. Should it prove to be sufficiently productive it may prove valuable in those portions of the state where Ben Davis does well.

Historical. Originated in Benton county, Ark.

\section{TREE.}

Tree moderately vigorous; branches short, rather slender. Form roundish, upright, rather dense. Tzuigs rather short, straight, slender; internodes rather short to medium. Bark bright, rather dark brownish-red; scarf-skin hardly noticeable; pubescence scarce or none. Lenticels not numerous, clear and

\footnotetext{
'Bailey, An. Hort., 1892:239. Ragan, U. S. B. P. I. Bul., 56:109. 1905. Am. Pom.
} Soc. Cat., 1875:8. 
bright in color, small, rourdish to elongated. Buds medium, rather flat, acute to obtuse, pubescent, free, appressed, point often deflected.

\section{Fruit.}

Fruit medium, sometimes large. Form roundish ovate to roundish conic, flattened at the base, irregular, often broadly ribbed or angular, sides unequal, sometimes compressed; pretty uniform in size but somewhat variable in shape. Stem medium. Cavity acute or obtuse, deep, wide, often furrowed, sometimes lipped, seldom symmetrical, usually with outspreading rays of yellow russet. Calyx medium to small, partly open or sometimes closed; lobes rather narrow, acuminate. Basin very abrupt, usually deep, moderately narrow to moderately broad, often somewhat furrowed, sometimes compressed, usually oblique.

Skin tough, smooth, clear, pale or whitish-yellow, washed and blushed with a bright deep pinkish-red, in well colored specimens becoming solid red, mottled and striped with purplish-carnine, overspread with a thin bluish bloom which gives it a slightly dull appearance, but when polished the prevailing effect is glossy bright red. Dots whitish, scattering.

Caly'x tube large, cone-shape.

Core rather sniall, closed or slightly open; core lines meeting or slightly clasping. Carpels concave, roundish inclined to obcordate. Seeds few, below medium to above, rather dark, irregular, obtuse or sometimes acute.

Flesh tinged with yellow, rather firm, crisp, not very tender, moderately fine-grained, juicy, subacid, aromatic, pleasant, good to very good.

Season December to May.

\section{FLORY.}

References. I. Downing, I872:179. 2. Bailey, An. Hort., r892:239. 3 . Farrand, Mich. Sta. Bul., 205:42. I903. 4. Beach and Clark, N. Y. Sta. Bul., 248: 120 . I904.

Sinonyms. FloRy Bellflower (3). Flory's Bellflower (I). Sheep Shire (I).

An attractive deep yellow apple of good size and good quality. The tree does not come into bearing very early and is but moderately productive. It is not recommended for planting in New York.

Historical. Origin, Montgomery county, Ohio.

TREe.

Tree rather vigorous. Form upright spreading. Twigs below medium to above, rather slender, irregularly curved, very slightly pubescent; internodes short to nearly long. Bark dull brownish-red, mostly overlaid with thick scarf-skin. Lenticels very numerous, raised, not very conspicuous, medium, narrow, elongated. Buds medium, slightly acute, lightly attached or partly free from the bark.

\section{FrUIT.}

Fruit medium or above. Form ovate to roundish conic, often faintly ribbed, pretty symmetrical. Stem medium in length, rather slender. Cavity acuminate, variable in depth, rather narrow, pretty symmetrical, sometimes lipped. Basin medium in width, moderately deep to shallow, abrupt, somewhat furrowed. Calyx closed or partly open; lobes rather narrow and acute. 
Skin tough, beautiful clear yellow, becoming deeper yellow as the ripening season advances, roughened with capillary netted russet lines and russet dots.

Caly.x tube not large, conical to elongated funnel-form, sometimes meeting the core. Stamens median or below.

Core medium to very large, abaxile; cells fairly symmetrical, partly open to wide open; core lines meeting when the calyx tube is conical, clasping when it is funnel-form. Carpels long, ovate. Seeds very numerous, often irregular in form, small to rather large, rather wide, obtuse, dark brown.

Flesh yellowish, firm, hard, moderately coarse, juicy, agreeably subacid, good in flavor and quality.

Scason October and November in Southern Ohio (1); in Western New York it extends to February, and often some portion of the fruit may be kept till spring (4).

\section{FLUSHING SPITZENBURG.}

REFERENCES. I. Thacher, I822:137. 2. Kenrick, 1832:44. 3. Downing, 1845:139. 4. Thomas, 1849:173. 5. Emmons, Nat. Hist. N. Y., 3:71. 1851. 6. Elliott, 1858:133. fig. 7. Warder, 1867:515. 8. Downing, I88I:II. app. index. 9. Hogg, 1884:78. Io. Lyon, Mich. Hort. Soc. Rpt., I890:292. I I. Bailey, An. Hort., 1892:239. I2. Budd-Hansen, 1903:85.

Synonyms. Black Spitzenberg (8). Flushing (10). Flushing Spitzenberg $(2,6,7)$. Flushing Spitzendurgit ( I, 3, 4, 5, 9).

Fruit of good color but not very good in quality. There is considerable loss from the dropping of the fruit before it is fully mature. The tree generally has the reputation of being a shy bearer.

Historical. This variety probably originated in America. Although it has long been known in cultivation $(1,2)$ it is not regarded favorably by commercial orchardists and is now seldom planted.

TREE.

Tree large, vigorous. Form round-headed or spreading. Taigs stout, reddish-brown, quite distinct from the small yellowish gray shoots of Esopus Spitzenburg with which, on account of the similarity of the names, this variety has sometimes been confounded.

\section{FRUIT.}

Fruit medium to nearly large. Form roundish conic or sometimes oblate conic, obscurely ribbed, pretty symmetrical. Stem short to medium. Cavity acuminate, moderately deep to deep, narrow to rather broad, smooth and red or greenish, sometimes more or less overspread with greenish or red russet. Calyx medium to rather small, closed or partly open; lobes broad, obtuse. Basin varying from narrow and shallow to medium in width and depth, obtuse to abrupt, sometimes somewhat furrowed and wrinkled.

Skin tough, yellow or greenish overspread with orange-red, becoming a bright deep red on the exposed side, coated with a light bloom. Dots conspicuous, whitish, scattered over the base but very numerous around the basin.

Calyx twbe long, funnel-form, extending to the core. Stamens median.

Core distant, abaxile with a wide hollow cylinder at the center, varying to nearly axile; cells pretty symmetrical, partly open or closed; core lines clasping 
the funnel cylinder. Carpels roundish, wide, mucronate, slightly emarginate, somewhat tufted. Seeds dark, medium to large, wide, plump, acute to obtuse, sometimes tufted.

Flesh whitish tinged with yellow, sometimes streaked with red, firm, moderately coarse, crisp, not very tender, moderately juicy, mild subacid, not high in flavor, good in quality.

Season October to February.

\section{FOREST.}

References. I. Downing, 1872:I8o. 2. Goff, Wis. Sta. Rpt., I896:212.

Synonym. Red Codlin (I).

Fruit above medium, yellow mostly overspread with faint crimson; aromatic, mild subacid, toward the last becoming sweet or nearly so. Tree an upright grower, an annual bearer, very hardy and very productive. In season from December to March $(1,2)$.

Historical. This is supposed to be a chance seedling from Oneida county, N. Y., which originated about a half century ago. We do not find that it has been grown in New York to any considerable extent, but it appears to have gained a favorable record in Southeastern Wisconsin (2).

\section{FRAKER.}

References. r. Brackett, Am. Pom. Soc. Rpt., r885:157. 2. Kansas Hort. Soc. Rpt., r886:70.

Synonym. Fraker's Seedling (2).

As grown at this Station the fruit is medium to large and when well colored has an attractive deep red blush, but too often it does not develop proper color in this climate. The tree has not come into bearing very early and thus far has been but moderately productive. The fruit is of mild, pleasant flavor and keeps well into the spring. It does not equal the standard commercial varieties of this region either in general appearance or in quality and is not recommended for planting in New York.

Historical. Originated near Garnet, Anderson county, Kansas. Described in the report of the Kansas Horticultural Society for I886 as promising for commercial purposes (2).

\section{TREE.}

Tree moderately vigorous; branches rather short and moderately stout. Form upright spreading with open top. Trvigs medium in length, stout, blunt at the tips; internodes medium or below. Bark bright brownish-red tinged with olive-green. streaked with gray scarf-skin; heavily pubescent. Lenticels numcrous, medium, oblong, raised, conspicuous. Buds medium, plump, broad, obtuse, free, pubescent.

\section{Fruit.}

Fruit above medium to large; pretty uniform in size and shape. Form roundish conic or sometimes roundish oblate, nearly truncate at the base, often obscurely ribbed, rather symmetrical. Stem medium to rather short. Cavity acute, deep, rather broad, often distinctly furrowed. Calyx medium to large, somewhat open or closed. Basin often oblique, shallow, narrow to rather wide, obtuse to rather abrupt, furrowed, wrinkled. 
Skin thick, tough, smooth, yellow with orange-red blush, in highly colored specimens deepening to a tright deep red mottled and striped with dull carmine. Dots pale or russet, not conspicuous.

Calyx tube long, narrow, funnel-form, often extending to the core. Stamens median.

Core somewhat abaxile, medium or below; cells often unsymmetrical, closed or partly open; core lines clasping. Carpels broadly roundish to obcordate, somewhat emarginate, mucronate. Seeds numerous, medium or above, plump, obtuse, rather light brown.

Flesh yellowish, firm, moderately coarse, rather crisp, rather tender, juicy, mild subacid becoming nearly sweet, slightly aromatic, good.

Season Deceniber to April.

\section{FRENCH PIPPIN.}

The name French Pippin has been applied to several varieties of the Fall Pippin group. These vary in season from autumn till late spring or early summer and are characterized by rather large, roundish or oblong fruit which at first is green but later assumes more or less of a yellowish tone. It is sometimes slightly blushed and has yellowish subacid flesh.

An apple of this class is described on a following page as the Lehigh Greening, the name under which it has been disseminated within recent years from Allentown, Pennsylvania. Some believe that the Lehigh Greening is identical with an old variety grown in portions of Southeastern Pennsylvania under the name French Pippin.

An apple which is grown in some parts of New York under the name French Pippin is described below. It is a very late keeper being in season from January to May or June. The fruit is large, brightly colored and attractive for a yellow apple. It bears a very close resemblance to Lehigh (ireening and possibly is identical with it. Comparisons of the fruit from various locaitities have been made but as yet we have been unable to decide whether or not these two are identical. We have not determined definitely whether the variety described below is the French Pippin of Southeastern Pennsylvania above mentioned, nor whether it is the variety referred to by Warder ${ }^{1}$ and Downing ${ }^{2}$ as the French Pippin of Pennsylvania.

\section{TREE.}

Tree medium in size to rather large, modcrately vigorous, a biennial or in some cases an anmual bearer, a reliable cropper and productive. Form upright, somewhat spreading. Tavigs medium in length; erect, moderately stout; bark rather dark.

\section{FruIT.}

Fruit large to very large, pretty uniform in size and shape. Form roundish to roundish oblate, faintly ribbed, pretty regular, sides sometimes slightly unequal. Stem short, moderately thick. Cavity acute to acuminate, moderately deep to deep, narrow to rather wide, thinly russeted, sometimes compressed or lipped. Caly.x medium in size, somewhat open; lobes acuminate. 

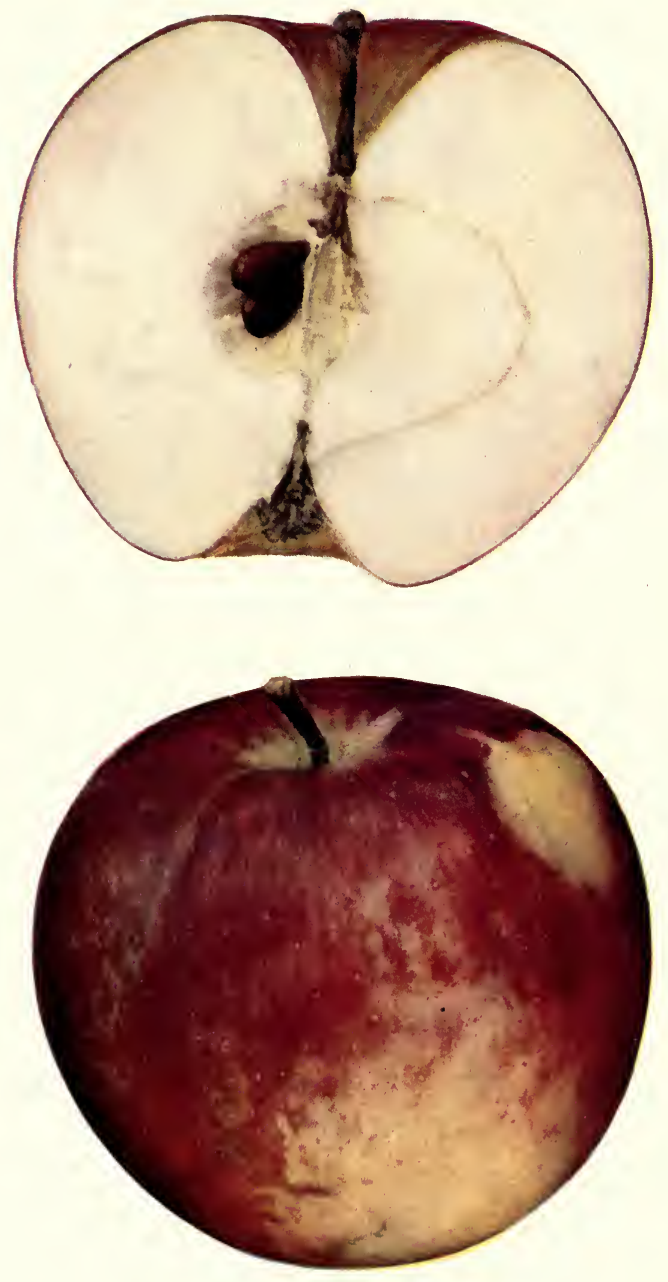

GANO 


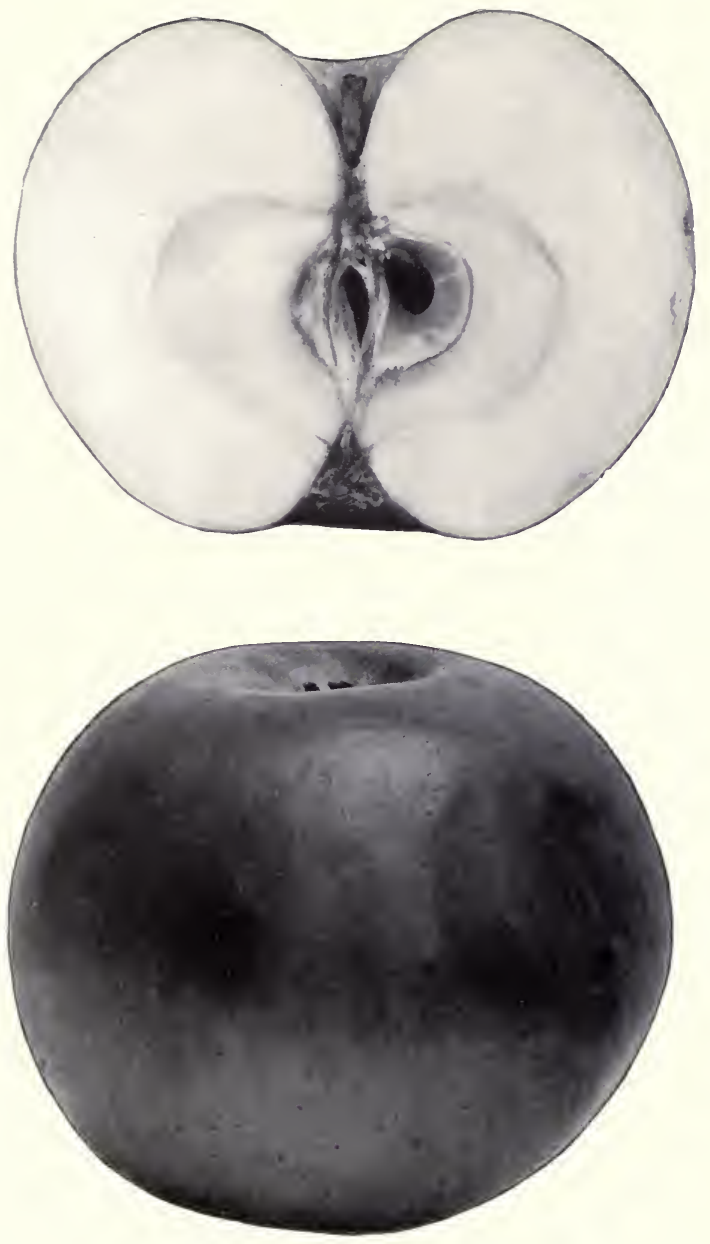

FRENCH PIPPIN 

Basin abrupt, shallow to moderately deep, medium in width to rather wide, smooth or gently furrowed and slightly wrinkled.

Skin tough, thin, smooth, bright pale yellow or greenish-yellow with numerous, conspicuous russet or green dots, often with thin brownish blush.

Caly.x tubc long, funnel-form, sometimes approaching cone-shape, with very wide limb. Stamens median.

Core rather small, slightly abaxile; cells fairly symmetrical, closed or partly open; core lines clasping. Carpels roundish, slightly emarginate. Seeds broad, obtuse.

Flesh nearly as yellow as that of Fall Pippin, firm, rather fine-grained, tender, crisp, juicy, sprightly with an agreeable subacid flavor, good to very good in quality.

Season January to May or June.

\section{GANO.}

References. I. Am. Pom. Soc. Rpt., 1885:156. 2. Am. Pom.Soc. Cat., 1889:6. 3. Stayman, Am. Gard., I I :272. I89o. 4. Bailey, An. Hort., I892:239. 5. Van Deman, Am. Gard., 20:8I. 1899. 6. Mo. Hort. Soc. Rpt., 43:187, 270, 271. 1900. 7. Caston, Ont. Fr. Stas. An. Rpt., 8:40. 1901. 8. Va. Sta. Bul., 130:132. r9or. fig. of tree. 9. Macoun, Can. Dept. Agr. Bul., 37:43, 44. I901. 10. Stinson, Mo. Fr. Sta. Bul., 3:24. 1902. I1. Kan. Sta. Bul., 106:53. 1902. I2. Budd-Hansen, I903:86. fig. I3. Thomas, 1903:326. I4. Powell and Fulton, U. S. B. P. I. Bul., 48:42. 1903. I5. Beach and Clark, N. Y. Sta. Bul., 248:121. 1904. I6. Wickson, Western Fruit Grower, 1904:124. I7. Ragan, U. S. B. P. I. Bul., 56:116. 1905.

Synonyms. Black Ben Davis (17). Jacks Red (5). Ozark (13). Payton (I7). Reagan (13). Red Ben Davis (т7).

This is a variety of the Ben Davis type. In the nursery the tree resembles Ben Davis very closely. As grown in Western New York the fruit is more highly colored but on the average is somewhat smaller than that of Ben Davis. It is less striped in appearance and more of a solid, deep red color, often with a contrasting spot of clear yellow where it has been closely covered by a leaf or twig. In this respect and in its deep, abrupt basin it suggests Jonathan, as at times it also does by its brilliant, deep red or purplish color. It is very attractive in appearance, stands handling well and is a good keeper. In quality it is perhaps a little superior to Ben Davis. The tree comes into bearing young and is an excellent cropper, bearing regularly and abundantly. It has not been tested very many years in New York, but it appears to be adapted to about the same region as Ben Davis.

Historical. Origin obscure. Brought to notice in Missouri about twentyfive years ago and disseminated under the name Gano $(1,5,6)$. It is supposed by some that the original stock came from Kentucky (5). Some 
believe that Gano is the same as Black Ben Davis. It certainly resembles Black Ben Davis very closely but the preponderance of evidence at present seems to favor the opinion that it is of distinct origin (I6).

\section{TREE.}

Tree moderately vigorous; branches long, moderately stout and inclined to droop; laterals willowy, short, slender. Form like that of Ben Davis, upright spreading becoming somewhat drooping, rather dense. Twigs short to rather long, slightly curved, markedly geniculate, moderately stout; internodes short to rather long. Bark bright brownish-red mingled with olive-green, lightly overcast with mottled and streaked gray scarf-skin; pubescent. Lenticels not conspicuous, scattering, medium, round to ovate or often elongated, slightly raised. Buds small to medium with prominent shoulder, plump, obtuse, appressed, decidedly pubescent, deeply set in bark.

\section{FRUIT.}

Fruit medium to sometimes large. Form roundish conic, usually regular, symmetrical; uniform in size and shape. Stem medium to long and slender. Cazity acute, deep, rather broad, symmetrical, sometimes slightly furrowed or compressed, usually with radiating green russet or red russet. Calyx medium or above, closed or partly open; pubescent; lobes rather broad, acute to acuminate. Basin abrupt, moderately narrow to rather wide, often deep.

Skin smooth, waxy, clear light yellow, mottled and blushed with bright light pinkish-red often deepening to a purplish-red, more or less obscurely striped. Dots numerous, small, inconspicuous. Prevailing color fine red.

Caly.x tube short, cone-shape with fleshy pistil point projecting into its base, or sometimes elongated funnel-form. Stamens median to marginal.

Core below medium to large, somewhat abaxile with a comparatively rather wide hollow cylinder at the axis; cells closed, or partly open, usually symmetrical but often not uniformly developed; core lines meeting when the calyx tube is cone-shape but clasping the funnel cylinder when it is funnel-form. Curpels broadly roundish or elongated, slightly tufted, emarginate. Seeds numerous, broad, obtuse. large, dark, sometimes tufted.

Flesh whitish slightly tinged with yellow, firm, moderately tender, rather coarse, moderately crisp, juicy, mild subacid, good or nearly good in quality.

Season abont the same as that of Ben Davis, extending from December to May in Western New York. Commercial limit in common storage March, in cold storage April.

\section{GENEVA PIPPIN.}

References. I. Downing, I857:III. 2. Ib., 1872:189. fig. 3. Thomas, I885:250. (2).

Synonym. Winter Pippin of Geneva $(\mathrm{I}, 3)$. Winter Pippin of Geneva

Resembles Fall Pippin in tree and fruit but a much better keeper, being in season from January to May. Found growing in the garden of Mrs. Crittenden, Geneva, many years ago (I). Evidently it is no longer listed by nurserymen ${ }^{1}$ and so far as we can discover has become obsolete.

${ }^{1}$ Not listed by Bailey in An. Hort., $1892: 239$. 


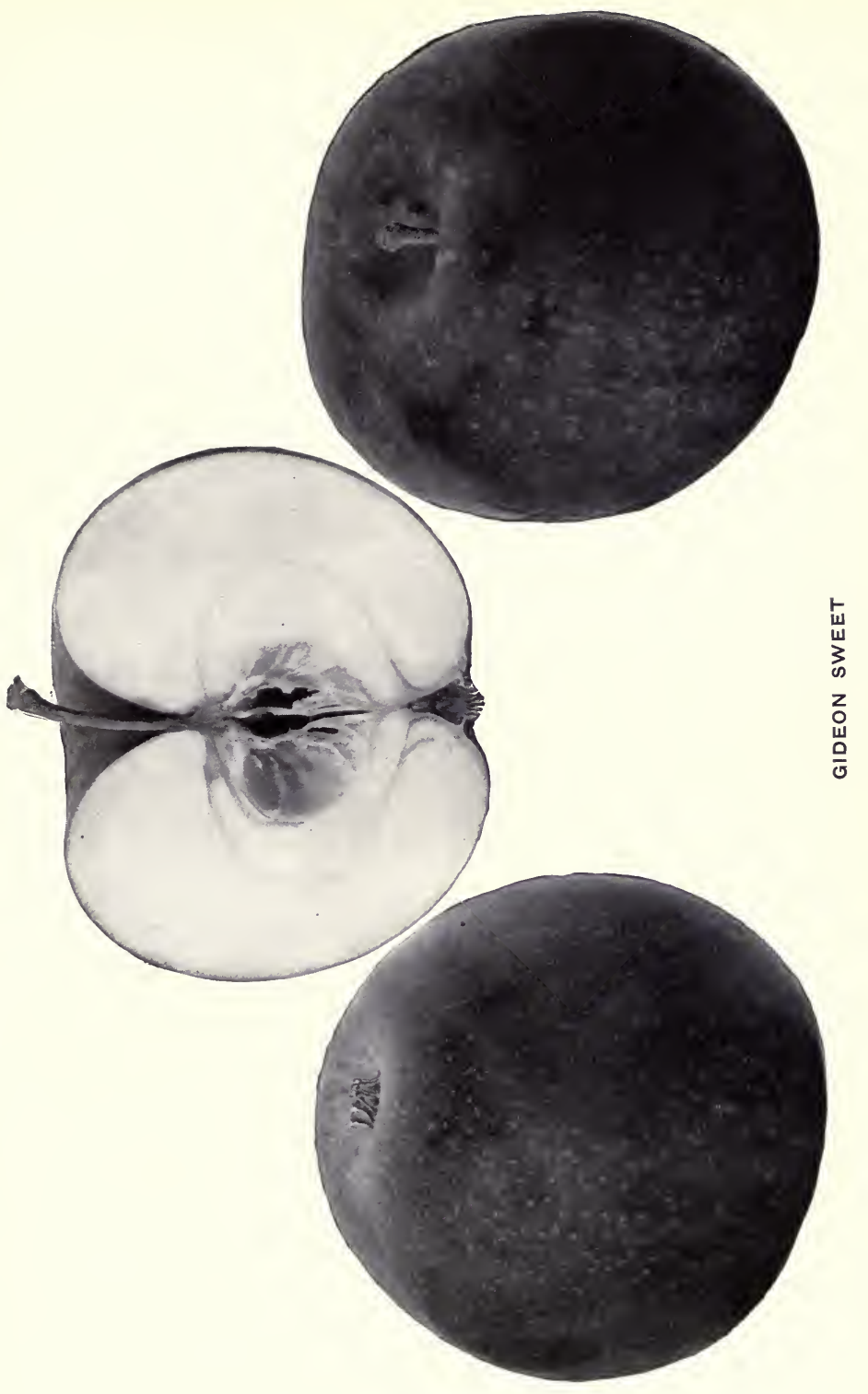





\section{GIDEON SWEET.}

References. I. Farrand, Mich. Sta. Bul., 205:42. 1903. 2. Beach and Clark, N. Y. Sta. Bul., 248:121. 1904.

Received for testing at this Station in I 888 from Peter M. Gideon, Excelsior, Minn. It is clearly of the Blue Pearmain class. This is shown by the form and colors of the fruit, the characteristic large dots, the blue bloom, the color, texture and quality of the flesh, and the tendency of the fruit to shrivel when held too long in storage.

It has been fruited at the Geneva Station for several years, and appears to be worthy of planting for trial where a sweet apple of the Blue Pearmain type is desired. It colors well, is quite attractive in appearance, desirable in size, good in quality, and a good keèper. The flesh is yellowish, juicy, aromatic, mild subacid mingled with sweet, eventually becoming sweet; good to very good. It is in season from November to April. The tree is vigorous, widespreading or roundish, almost an annual bearer, alternating lighter with heavier crops. On the average it is satisfactorily productive.

The fruit resembles that of Bethel very closely, but we have not yet been able to determine definitely whether or not the two are identical, not having had the privilege of comparing them when grown under similar conditions. Bethel from Northern New York and Northern New England, as compared with fruit of Gideon Sweet from the orchard at this Station, shows no constant differences from Gideon Sweet in the form of the fruit or in the characteristics of either the cavity or the basin, but the skin is redder and the flesh is sometimes tinged with red while the Gideon Sweet has a yellower skin, its flesh is not tinged with red, is sweeter and better in quality and the core is more widely abaxile. In both the Gideon Sweet and the Bethel the stem is characteristically curved to one side.

\section{TREE.}

Tree vigorous; branches short, moderately stout, crooked. Form roundish to wide-spreading, rather dense. Twigs short to below medium length, straight, rather slender to moderately stout; quite pubescent towards the tips; internodes short to medium. Bark clear reddish-brown over olive-green, very lightly coated with gray scarf-skin; slightly pubescent. Lenticels moderately numerous, scattering, small, roundish or elongated; the elongated ones are raised. Buds small to medium, broad, obtuse, appressed, quite pubescent, deeply set in bark. 
Fruit.

Fruit above medium to large. Form roundish sometimes inclined to conic, often slightly oblate, elliptical or broadly and obscurely ribbed; sides sometimes unequal, uniform in size and shape. Stem medium to rather long, curved towards one side. Cavity moderately broad to broad, acuminate or acute, deep, indistinctly furrowed, often with greenish or red russet spreading out upon the base of the fruit. Calyx small or medium, closed or slightly open; lobes long, acuminate or acute. Basin shallow to moderately deep, broad, obtuse to somewhat abrupt, slightly furrowed, wrinkled.

Skin tough, nearly smooth at base except where the russet spreads out from the cavity but somewhat rough towards the apex, attractive deep yellow or greenish mottled and blushed with orange-red sometimes deepening to a purplish hue, irregularly splashed and striped with deep carmine and overspread with a thin bloom which produces a rather dull effect. When polished the colors become clear yellow and bright dark red and carmine. Dots conspicuous, yellow or russet, small and very numerous toward the calyx, more scattering, larger, irregular and nore often grayish areolar toward the base.

Calyx tube rather large, broad, conical or sometimes inclined to funnelform. Stamens median to basal.

Core irregular, abaxile, medium to large; cells often unsymmetrical, open or partly closed; core lines meeting or somewhat clasping. Carpels roundish or inclined to cordate, slightly tufted. Seeds below medium to large, light brown, rather narrow, actite, tufted.

Flesh yellowish, moderately firm, crisp, somewhat coarse, juicy, aromatic, mild subacid mingled with sweet eventually becoming sweet, good to very good.

Season November to April.

\section{GILLIFLOWER.}

The old variety which is correctly known among pomologists as the Black Gilliflower is commonly known to fruit growers by the simple name Gilliflower. For an account of this variety the reader is referred to Black Gilliflower.

The Cornish Gilliflower is a very old English variety quite distinct from the Black Gilliflower. It was formerly somewhat grown bit it is now practically obsolete in New York.

\section{GILPIN.}

RfFerences. I. Coxe, I8I7:I55. fig. 2. Thacher, I822:122. 3. Wilson, I828:136. 4. Kenrick, I832:42. 5. Downing, I845:I44. 6. Thomas, I849:164, I89. fig. 7. Cole, r849:I35. 8. Emmons, Nat. Hist. N. Y., 3:66. г851. 9. Hooper, 1857:39. Io. Elliott, I858:135. II. Am. Pom. Soc. Cat., I862. I2. Warder, 1867:559. fig. 13. Lyon, Mich. Hort. Soc. Rpt., I89o:292. I4. Bailey, An. Hort., I892:2.39. I5. Budd-Hansen, I903:89. I6. Powell and Fulton, U. S. B. P. I. Bul., 48:42. 1903. I7. Beach and Clark, N. Y. Sta. Bul., 248: I2I. 1904 .

Synonyms. Carthouse $(1,2,3,4,6,8)$. Carthouse $(5,7,9$, 10, I2, I3, I5, 16). Gilpin (6). Little Red Romanite (12, 15, I7). Red Romanite of Ohio (6). Romanite (7). Romanite of the West (9, 10). 


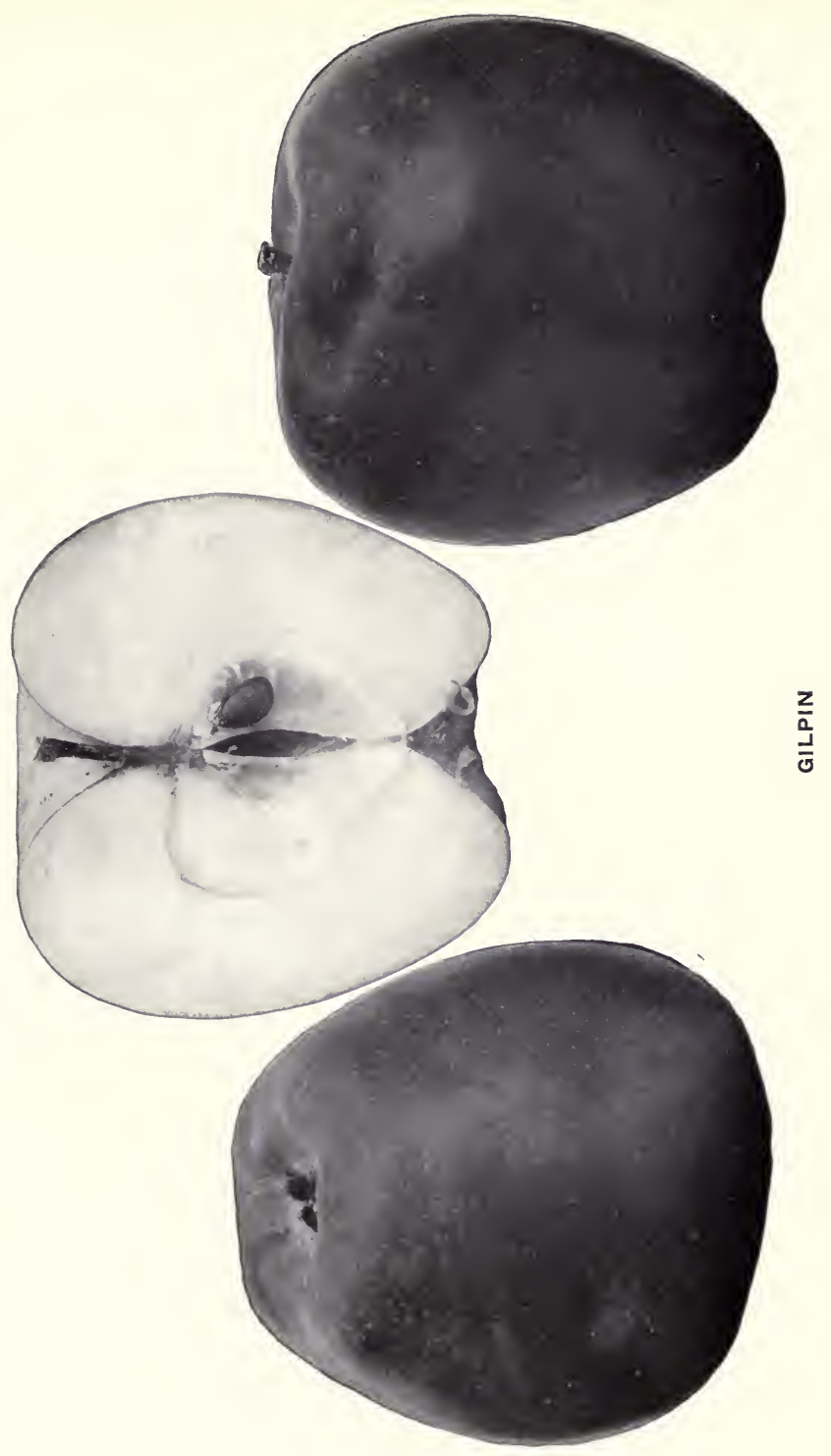



As grown in New York Gilpin is not a good commercial variety because it is rather small and does not rank high in quality. Its color is rather dark red over a clear yellow background. In ordinary cellar storage it usually keeps till June or later and is then acceptable for dessert and very good for certain culinary uses, particularly for boiling. It makes excellent cider. The tree is hardy, healthy, moderately productive and a biennial bearer. The fruit hangs firmly to the tree till loosened by the frost.

Historical. "This apple is said to have been brought from Virginia. It obtained its name from a family in the Delaware state" (I). "It was cultivated and distributed by Coxe and has found its way into the orchards and into favor all over the country on account of its productiveness and early bearing" (12).

\section{TREE.}

Tree moderately vigorous or slow growing. Form round, open, spreading with rather short and somewhat drooping laterals. Twigs short, slender, straight; internodes medium. Bark rather dull reddish-brown overlaid with thin to rather thick scarf-skin; somewhat pubescent. Lenticels moderately numerous, snall, elongated, raised, of clear color, conspicuous. Buds rather small, prominent, heavily pubescent, adhering. Foliage not very dense, somewhat curled.

\section{FRUIT.}

Fruit above medium to rather small; uniform in size and shape. Form roundish to ovate truncate, sometimes nearly cylindrical, often obscurely ribbed, symmetrical or sides slightly unequal, sometimes oblique. Stem short. Cazity acute to acuminate, sometimes shallow but usually deep, rather broad, obscurely furrowed or compressed, sometimes lipped, often partly russeted. Caly $x$ large, open, rarely closed ; lobes leafy, reflexed, long, acute or acuminate, sometimes separated at base. Basin often oblique, usually deep, wide, abrupt and prominently furrowed but sometimes rather shallow and moderately narrow or compressed, often distinctly wrinkled.

Skin tough, smooth, rather glossy, greenish-yellow becoming clear deep yellow, with brownish-red cheek often deepening to an attractive clear dark red. Prevailing effect dark red mingled with good yellow.

Caly.x tube wide varying from short truncate funnel-shape to urn-shape. Stamens basal.

Core axile, bclow medium to above; cells pretty symmetrical, usually closed or sometimes partly open; core lines meeting or sometimes slightly clasping. Carpels round to ovate, narrowing towards apex, mucronate, slightly emarginate. Seeds numerous, dark brown, large to medium or below, plump, acute, slightly tufted.

Flesh yellowish, very firm, rather coarse, at first hard but becoming somewhat crisp and tender as the season advances, moderately juicy, nearly sweet or mild subacid, pleasant, good.

Season February to June. 


\section{GIVENS.}

Rfferences. I. Stinson, Ark. Sta. Bul., 49:12. 1898. fig. 2. Ib., 60:129. I899.

Synonym. Arkansas Baptist (2).

A late keeping red winter apple fully equal to Ben Davis in quality. At the Geneva Station it has come into bearing very young and so far as tested has been quite productive. The tree is a moderate grower. In the nursery it is a poor grower being "crooked and willowy something after the style of the Willow Twig." 1 It may be worthy of testing for commercial purposes in regions where Ben Davis succeeds.

Historical. Originated on the farm of Mr. Givens, Benton county, Ark. Noticed by Professor Stinson in 1898 as one of the promising new Arkansas seedlings (I).

TREE.

Tree moderately vigorous; branches rather long, moderately stout. Form upright spreading, rather open. Twigs long, straight, stout; internodes medium. Bark dark reddish-brown, streaked lightly with grayish scarf-skin; pubescent. Lenticels scattering, large, oval, raised. Buds medium, broad, obtuse, appressed, pubescent, deeply set in bark.

FRU1T.

Fruit above medium to rather small. Form oblate or truncate to roundish conic, ribbed broadly and faintly if at all, sides often slightly unequal. Stem long to very long. Cavity somewhat furrowed, wide, deep, acute, with green or thin russet outspreading rays. Calyx large to very large, closed or partly open; lobes leafy, long, wide, acute. Basin moderately deep to deep, medium in width to wide, somewhat obtuse to very abrupt, wrinkled, symmetrical.

Skin tough, smooth, yellow or greenish nearly covered with dark red inconspicuously mottled and striped with deeper red. Sometimes a suture extends from cavity to basin. Dots small, whitish or with russet points, inconspicuous. Prez'ailing effect red.

Calyx tube funnel-form, often meeting the cylinder of the core. Stamens median or below.

Core medium to large, slightly abaxile with a rather wide hollow cylinder in the axis; cells somewhat unsymmetrical, closed or slightly open; core lines clasping the funnel cylinder. Carpels broadly roundish. Seeds numerous, medium to large, wide, dark, obtuse.

Flesh whitish tinged with yellow, firm, rather fine-grained, not very crisp nor very tender, moderately juicy, mild subacid, good.

Season January to May or June.

\section{GLENLOCH.}

Reference. I. Watts, Tcmn. Sta. Bul, I:I2. I896. fig.

Fruit large, closely resembling York Imperial. Tree very productive. A variety of Tennessee origin which probably is not well adapted for growing in New York except possibly in the southeastern part of the state (I).

\footnotetext{
${ }^{1}$ Letter Stark Bros., Louisiana, Mo.
} 


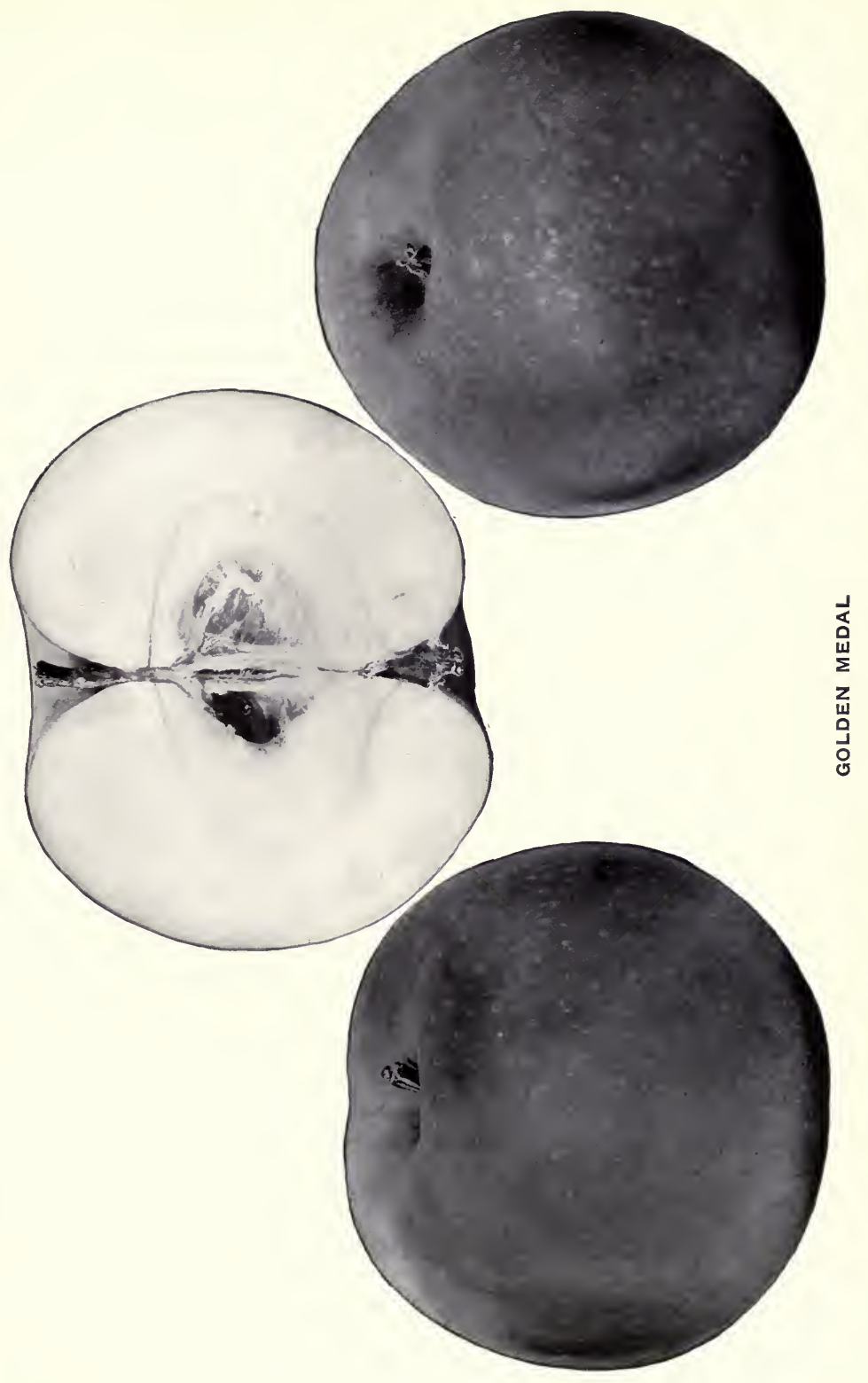





\section{GOLDEN MEDAL.}

References. 1. Goff, N. Y. Sta. An. Rpt., 7:90. 1888. 2. Beach, N. Y. Sta. An. Rpt., 15:280. I896. 3. Powell and Fulton, U. S. B. P. I. Bul., 48:42. 1903. 4. Beach and Clark, N. Y. Sta. Bul., 248:121. 1904. 5. Ragan, U.S. B. P. I. Bul., 56:124. 1905.

Synonym. Gold Medal $(3,5)$.

Fruit attractive for a green or yellow apple and a remarkably good keeper. The tree comes into bearing moderately early, is an annual bearer, bears regularly and is satisfactorily productive. It is worthy of planting for trial where a late keeping sweet apple is desired (4).

Historical. Received here for testing from J. R. and A. Murdock, Pittsburg, Pa., I888.

\section{TREE.}

Tree vigorous. Form upright. Twigs short to medium, of average thickness, bowed and irregular; rather pubescent. Bark brownish-red overlaid with rather thin scarf-skin; internodes medium. Lenticels inconspicuous, rather scattering, small, round. Buds medium, roundish, pubescent, adhering to bark.

\section{FRUIT.}

Fruit above medium to large. Form roundish to roundish oblate, somewhat ribbed. Sicm rather sliort. Cazity acute, deep, rather broad, usually distinctly furrowed, sometimes compressed, sometimes slightly russeted. Culyx small, sometimes medium, usially closed. Basin often somewhat oblique, round, shallow and narrow varying to rather wide and moderately deep, usually rather abrupt, obscurely furrowed, wrinkled.

Skin thin, tough, smooth, attractive pale yellow marbled with green, or greenish, sometimes faintly blushed. Dots numerous, conspicuous, whitish or sometimes with russet point.

Caly $x$ tube funnel-shape.

Core rather large; cells open or partly closed; core lines clasping. Carpels roundish obcordate, somewhat tufted. Seeds numerous, large to very large, wide, obtuse, somewhat tufted, dark.

Flesh tinged with yellow, slightly astringent, firm, moderately fine, somewhat crisp, tender, moderately juicy, sweet, fair to good.

Season December to May or June.

\section{GOLDEN PIPPIN.}

References. I. Forsyth, I803:52. 2. Coxe, I8I 7:138. fig. 3. Thacher,

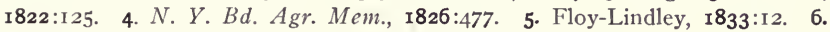
Mag. Hort., I:265. I835. 7. Downing, I845:I12. fig. 8. Thomas, I849:18I, I89. fig. 9. Cole, 1849:128. Io. Emmons, Nat. Hist. N. Y., 3:82. I85 I. II. Hooper, I857:4I. I2. Elliott, I858:I7I. I3. Warder, I867:720. I4. Leroy, 1873:510. 15. Hogg, 1884:91. 16. Bailey, An. Hort., I892:240.

Synonyms. D'Or d’Angleterre (i4). English Golden Pippin (8). English Golden Pippin (7, 12, I4). Old Golden Pippin (7, 12, 14). Pepin d'Or $(5,7)$.

A rather small, smooth, white or yellowish apple with a shade of red towards the base. In season from November to March. In England it has 
long been esteemed as a very valuable dessert and culinary apple ( $7,14,15)$. It does not succeed well here $(7)$. There are many varieties of the English Golden Pippin, the fruit of which differs but little from that of the old variety but the trees are more vigorous (7). None of these appear to have gained favorable recognition in this country. Floy says, "The English Golden Pippin grows with delicate small shoots and is not calculated for an orchard; but if properly managed it makes a beautiful espalier tree and is an abundant bearer. * * * The apple is not much known in this country; the kind called here Golden Pippin is a very different fruit" (5).

The Golden Pippins of New York and New England are fall apples. For an account of them the reader is referred to the succeeding volume.

\section{GOLDEN RED.}

References. I. Downing, 1872:195. 2. Ccnn. Bd. Agr., 1889:356.

A variety formerly grown on Long Island but now apparently obsolete. Downing describes it as medium or below, yellow nearly overspread with red, subacid. Season December and January. Fruit liable to rot on the tree (I).

\section{GOLDEN REINETTE.}

References. I. Forsyth, I803:5 $\mathrm{I}$. 2. Coxe, I8I7:I52. fig. 3. Thacher, 1822:125. 4. Floy-Lindley, 1833:37. 5. Pom. Mag., 2:69. r84r. col. pl. 6. Downing, 1845:129. 7. Thomas, 1849:167. 8. Emmons, Nat. Hist. N. Y., 3:63. 185r. 9. Warder, 1857:720. 10. Leroy, 1873:59r. fig. II. Hogg, I884:92.

Synonyas. English Pippin (4, 5, 6, ro, ir). Goloen Reinette, of all English writers on Gardening. Hort. Soc. Fruit Cat. No. 905 (5). Golden Rennet ( $1,2,3)$. Kirke's Golden Reinette (6, I I). Princesse Noble (10). Yellow German Reinctie (4, 5, 6, 10, II).

An excellent dessert apple but rather small. In season from October to midwinter. It has long been highly estcemed in England (4, 5, Ir) but is little known in New York.

The Russian varieties which have been imported under the name Golden Reinette ripen in autumn. They will be considered in Volume II.

\section{TrEe.}

Tree rather slow growing, below medium in size, spreading, bears annually and is productive. The fruit hangs well to the tree.

\section{Fruit.}

Fruit small. Form roundish, somewhat oblate; pretty uniform in size and shape. Stem medium in length, moderately thick. Cavity regular, deep Calyx large, open. Basin broad, shallow.

Skin usually smooth with a few minute, triangular, russet spots; greenishyellow on the shaded side but golden-yellow in the sun, with a dull blush lightly streaked with brighter red.

Calyx tube funnel-shape. Stamens marginal.

Core axile. Carpels obovate.

Flesh yellow, juicy, crisp, brisk, rich, subacid, excellent $(5,6$, I I $)$. 


\section{GOLDEN RUSSET.}

References. I. Downing, I845:132. 2. Thomas, 1849:179. 3. Emmons, Nat. Hist. N. Y., 3:96. г851. 4. Elliott, I858:131. 5. Am. Pom. Soc. Cat., 1862. 6. Warder, 1867:624. 7. Thompson, Mich. Pom. Soc. Rpt., 1871:30-34. 8. Waring, Ib., I871:41. 9. Downing, Am. Pom. Soc. Rpt., 1875:36. Iо. Downing, 1876:196, 54 app. Ir. Barry, 1883:346. 12. Lyon, Mich. Hort. Soc. Rpt., I890:292. 13. Bailey, An. Hort., 1892:238, 240. 14. Budd-Hansen, 1903:90. I5. Powell and Fulton, U. S. B. P. I. Bul., 48:42. 1903. 16. Beach and Clark, N. Y. Sta. Bul., 248:122. 1904.

Synonyms. English Golden (6). English Golden (10). English Golden Russet (I, 2, 4, 13). English Golden Russet (10, I4). GoldeN Russet of N. Y. (3, 5, 10). Golden Russet of N. Y. (2,4). Golden Russet of Western N. Y. (10, II). Russet Golden $(6,10)$.

Among the russets which are grown in Central and Western New York the Golden Russet ranks second only to Roxbury in commercial importance. In other portions of the state it has been less extensively planted. In recent years the season of good red winter apples has been extended by means of cold storage with the result that long keeping russet apples are less profitable than they were formerly. This is undoubtedly one reason why Golden Russet is now grown less extensively than it formerly was. It is an excellent storage variety, sells well in the general market and is particularly in demand for shipment to Northwestern and Southern markets and for export. The fruit is not large but is pretty smooth and uniform. When grown in favorable locations and properly treated for the control of injurious insects and diseases there is comparatively little loss from culls. The fruit hangs well to the tree till loosened by frost. It is borne on the ends of the branches making it hard to pick. This habit and the smallness of the fruit make the picking and packing comparatively expensive.

The fruit is particularly desirable for home use during the spring months before small fruits ripen, being then excellent for dessert and culinary uses. It makes good evaporated stock and is excellent for cider and stock food. The tree is hardy. In favorable locations it is a reliable cropper, bearing regularly after it reaches maturity. It is usually classed as a biennial bearer, but in some cases it is nearly an annual bearer.

The notable points of distinction between this variety and the English Russet are set forth in the description of English Russet. Vol. $\mathrm{I}-7$ 
Thompson compares these two varieties with each other and with the Roxbury Russet in an excellent article presented to the Michigan Horticultural Society in 1870 (7).

Historical. Downing calls this identical with the old English variety described by Ronalds and Lindley as Golden Russet (9). It has sometimes been catalogued under the name English Golden Russet and has been confused with the English Russet, a distinct variety. It has also been called Golden Russet of New York or of Western New York in distinction from the Golden Russet of Massachusetts, or Hunt Russet, and from the various other apples which have been disseminated under the name Golden Russet.

\section{TREE.}

Tree varies from medium to large and from moderately vigorous to vigorous; branches long, moderately stout, with rather long, slender laterals which after bearing heavily become rather drooping, but the young growth is more upright. Form upright roundish becoming rather spreading, rather dense. Tacigs erect, rather slender to moderately stout, often with large, blunt terminal bud; internodes short. Bark on the younger branches smootl, yellowish or olive; on the new growth olive-green or rather dull reddish-brown lightly mottled with grayish scarf-skin; pubescent toward the tips. Lenticels conspicuous, becoming more so on the two-year-old wood, of a clear pale color, quite numerous, seldom large, usually below medium, roundish, sometimes raised. "It is distinguished among other russets by its peculiar, light colored, speckled shoots" (I0). Buds medium in size or below, deeply set, free, obtuse, pubescent.

It develops but a moderately strong root system in the nursery.

\section{FRUIT.}

Fruit below medium to above. Form roundish, varying from a little oblate to somewhat conic, sometimes rather elliptical, sometimes obscurely angular, usually smooth; uniform in shape and size. Stem short to very short, rather stout, not often exserted. Cavity wide to medium, medium in depth to rather deep, somewhat acuminate to acute, usually not furrowed, often deep green with numerous paler green or grayish dots. Calyx usually rather large to medium, closed or sometimes partly open; lobes long, rather acute, often reflexed, sometimes separated at the base. Basin sometimes oblique or irregular, often saucer-shaped, round, rather abrupt, rather shallow to moderately deep, sometimes plaited or slightly ribbed.

Skin thick, moderately tender, sometimes only partly covered with patches and flecks of russet but more often almost entirely covered with green or yellowish russet, in highly colored specimens becoming golden russet with bronze cheek. Dots grayish or russet, rather inconspicuous on the smooth skin but on the russet skin often clear pale gray and conspicuously scattered over the base. Often decidedly attractive for a russet apple.

Calyx tube rather short, wide, conical or sometimes funnel-form. Stamens basal or nearly so.

Core medium to below, distinctly abaxile, or, at least, having a rather wide hollow cylinder for the axis; cells often unsymmetrical, usually open; core 


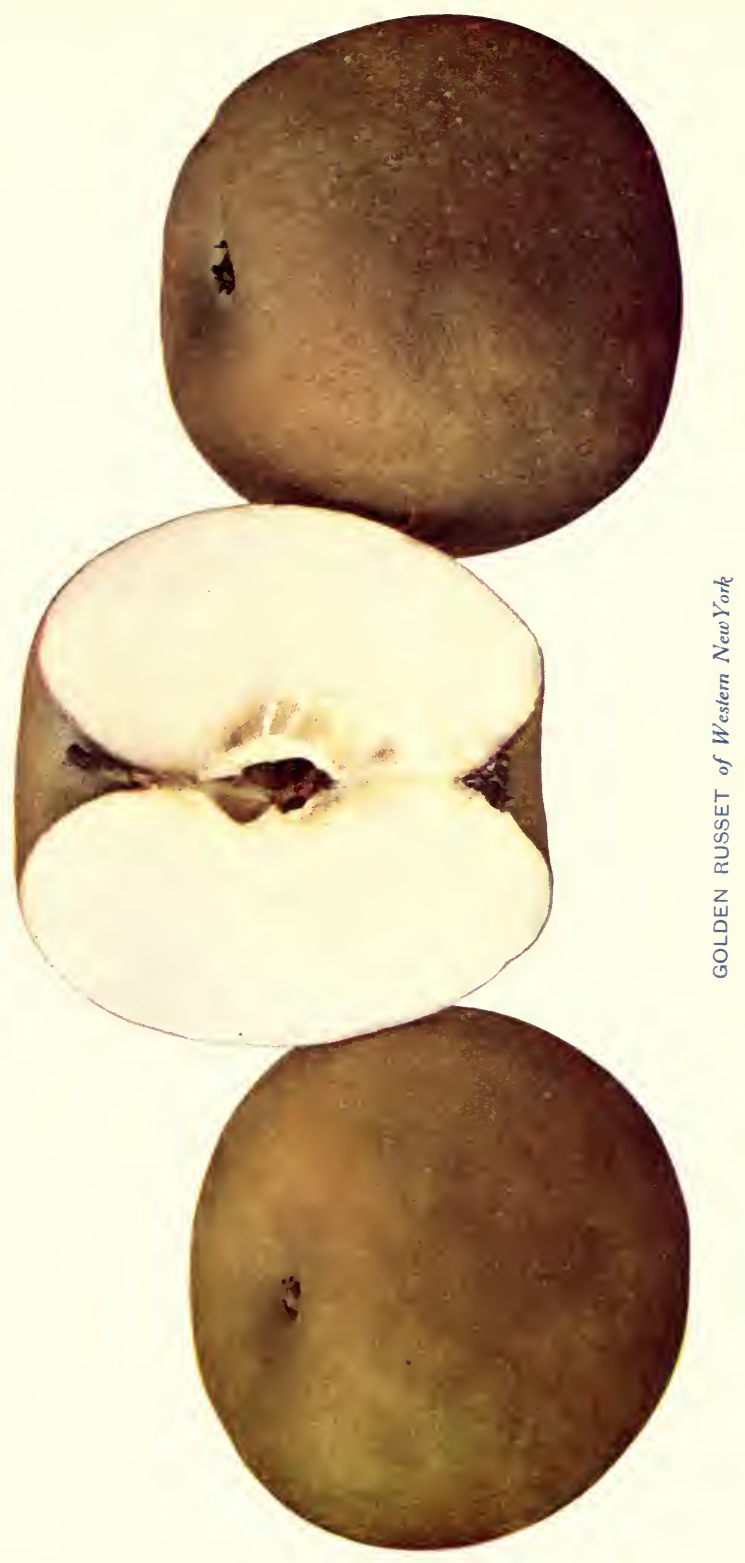





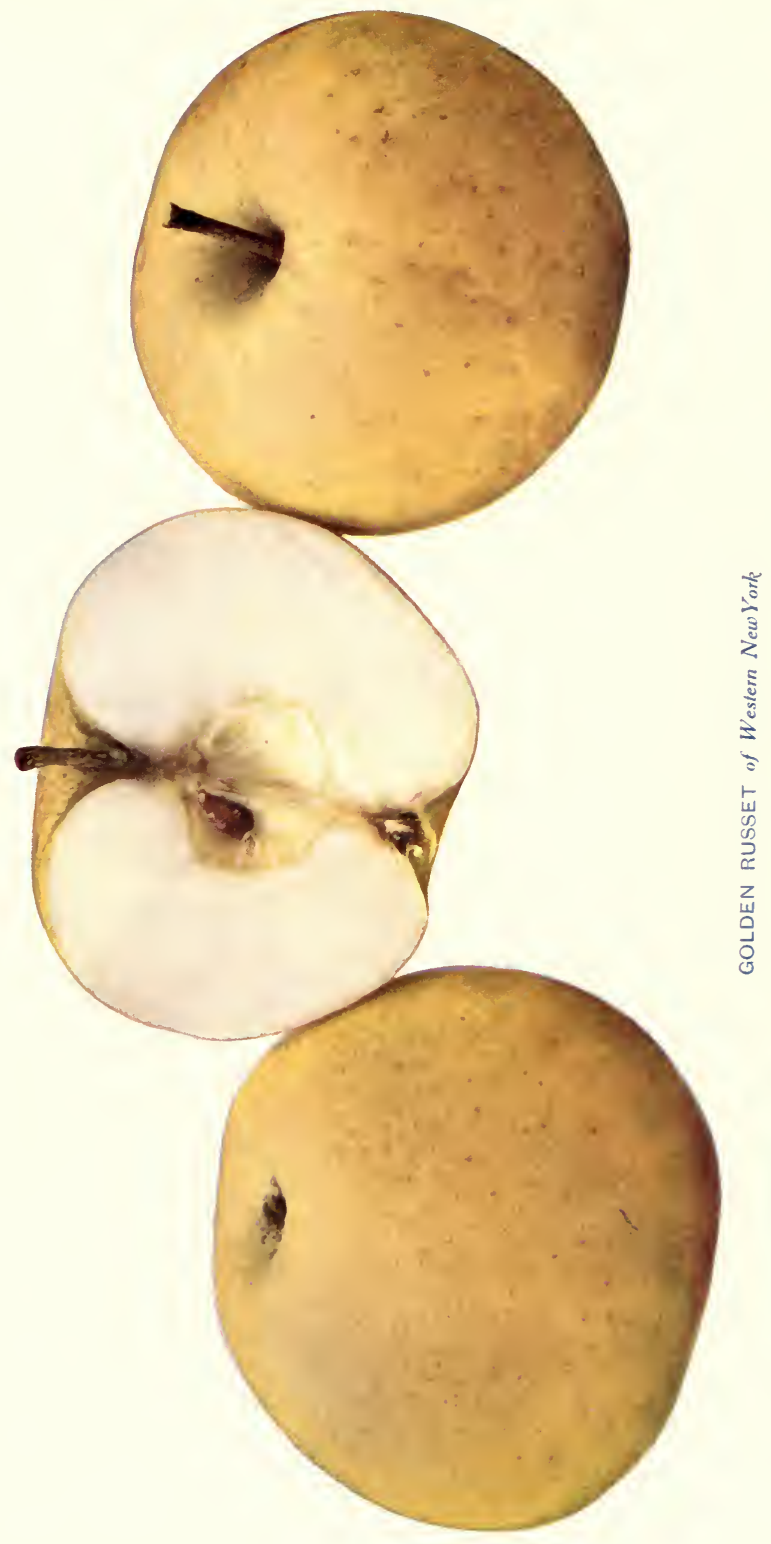



lines meeting or slightly clasping. Carpels broadly ovate, elongated, sometimes tufted, but slightly emarginate if at all. Seeds rather light brown with decided red tone, medium to small, plump, obtuse to acute, sometimes tufted.

Flesh yellowish, rather fine-grained, moderately crisp, tender, juicy, rich, agreeably subacid, aromatic, very good.

Season December to April or later.

\section{GRANITE BEAUTY,}

References. I. Hovey, Mag. Hort., 26:65, I49. 1860. fig. 2. Mead, Horticulturist, 18:83. 1863. fig. 3. Lothrop, Mag. Hort., 32:362. 1866. 4. Warder, 1867:720. 5. Downing, 1872:199. 6. Am. Pom. Soc. Cat., 1873. 7. Barry, 1883:346. 8. Thomas, 1885:233. 9. Munson, Me. Sta. Rpt., 1893:132. 10. Hoskins, Amer. Gard., 1 $5: 299$. 1894 .

Synonyms. Aunt Dorcas (5). Clothes-yard Apple (5). Grandmother's Apple (5).

Fruit about the size of Baldwin, yellow mostly overspread with red, mild subacid, good to very good in quality. In season from November to February. Tree hardy and a good bearer.

Historical. A local variety brought to notice in 1860 by $Z$. Breed, Weare, N. H. (I). In some portions of New England it is still much esteemed, both for home use and for market (9), but it is little known in New York.

\section{GREAT BARBE.}

Fruit uniform, symmetrical, red and yellow, of good size, attractive, but ranking only fair to good in quality. Season midwinter. The tree comes into bearing early, is vigorous and apparently productive. So far as tested at this Station it does not appear to be worthy of introduction into New York.

Historical. A Russian variety received here for testing in 1898 from J. Niemetz, Podolia, Russia.

\section{GREENING.}

The apple commonly known by the name Greening among New York fruit growers and fruit dealers is the Rhode Island Greening to which the reader is referred for an account of this variety. The name Greening has also been used to some extent as a class name for certain types of green or yellowishgreen winter apples and it enters into the names of several well recognized pomological varieties prominent among which are Bottle Greening, Northwestern Greening and Patten, or Patten Greening.

\section{GREEN NEWTOWN AND YELLOW NEWTOWN.}

References. I. Forsyth, 1803:53. 2. Coxe, 1817:I42, I43. figs. 3. Thacher, 1822:125. 4. N. $Y$. Bd. Agr. Mem., 1826:477. 5. Wilson, 1828:136. 6. Ronalds, I831:33. 7. Cat. Hort. Soc. London, 1831:22. 8. Kenrick, I832:45, 55. 9. Floy-Lindley, $1833: 37$, 40. . rett, Horticulturist, 3:240. I848. I2. Cole, 1849:I33. fig. I3. Thomas, 1849: 172, 177, I82, 187. fig. 14. Emmons, Nat. Hist. N. $Y ., 3: 83.1851 . \mathrm{col} . \mathrm{pls}$. 
Nos. 23 and 53. 15. Am. Pom. Soc. Cat., 1852. 16. Mag. Hort., I9:I71. 1853. I 7. Hooper, 1857:64, 102. 18. Elliott, 1858:93, 118, 120. figs. 19. Oberdieck, Ill. Handb. der Obstk., 4:99. 20. Am. Pom. Soc. Cat., 1862. 2I. Warder, 1867:637, 649, 7II, 720. fig. 22. Regel, 1868:463, 464. 23. Downing, 1872: 201. fig. 24. Leroy, 1873:486, 871. figs. 25. Barry, 1883:350, 358. 26. Hogg, 1884:155, 252. 27. Lyon, Mich. Hort. Soc. Rpt., 1890:292, 300. 28. Wickson, I891:249. 29. Bailey, An. Hort., 1892:240, 253. 30. Massey, Rural N. Y., 51:462. I892. 31. Hicks, Ib., 53:205. 1894. 32. Taylor, U. S. Pom. Bul., 7: 358. 1898. 33. Alwood, Va. Sta. Bul., г зо:126, 140. 1901. figs. of trees. 34. Eneroth-Smirnoff, I901:392. 35. Budd-Hansen, 1903:94, 21 r. figs. 36. Powell and Fulton, U.S. B. P. I. Bul., 48:43, 62. 1903. 37. Beach and Clark, N. Y. Sta. Bul., 248:123, 152. 1904. 38. Ragan, U. S. B. P. I. Bul., 56:23, 55, 129, 2 I0, 346. 1905 .

Nomenclature. Albemarle (21, 38). Albemarle $(36,38)$. Albemarle Pippin (13, 18, 33). Albemarle Pippin $(30,32,35,37,38)$. American Newtown Pippin (9, 10, 18, 23, 24, 26, 38). Back Creck (38). Brooke Pippin (38). Brooke Pippin (20). Brookes Pippin (16, 21). Brooke's Pippin (? 23, 38). Green Newton Pippin (2, 3, 4). Green Newtown (27, 35, 36, 37). Green Newtown Pippin (8, I4, I7, 21, 23, 28, 29, probably incorrectly 9). Green Newtozon Pippin (10, 13, 18, 24, 25, 26, 37, 38). Green Winter Pippin (10, 18, 23, 24, 26, 38). Hunt's Fine Green Pippin (23, 38). Hunt's Green Newtown Pippin (?23,38). Large Newtown Pippin $(24,38)$. Large Yellow Newton Pippin (2). Large Yellow Newton Pippin (26). Large Yellow Neztozon Pippin $(8,26,38)$. Mountain Pippin (38). Neustadt's gelber Pepping (19). Newton's Pippin (22). Newton Yellow Pippin (3.4). Newtown Pippin (1, 5, 6, 7, 9, 10, I1, 12, 13, 15, 18, 23, 24, 25, 26, 30, 31). Newtor'n Pippin (36, 37, 38). New York Greening (38). New York Pippin (38). Petersburgh Pippin (10, 18, 23, 24, 26, 38). Pippin (13). Reinette de New-York (24). Virginia Pippin (38). Yellow Newton's Pippin (22). Yellow Newtown (21, 27, 32, 35, 36, 37). Yellow Newtown Pippin (4, 7, 8, I0, I3, I4, I7, I8, 20, 25, 26, 28, 29). Yellow Newtown Pippin $(24,36,38)$. Yopp's Favorite (24), but incorrectly.

The Green Newtown and the Yellow Newtown are here discussed together because they are so much alike that it is highly probable that one is but a sport or strain of the other. At this time it is impossible to determine which of the two was the original Newtown Pippin. It is now believed that Albemarle is Yellow Newtown and Brooke Pippin is possibly identical with Green Newtown. In pomological literature the name Newtown Pippin has often been used in such a way that it is uncertain whether the writer had in mind the Yellow Newtown or the Green Newtown, and the correct synonymy cannot be accurately determined in all cases. On this account, the names as given by the different writers are stated in the above nomenclatural list without indicating whether or not they are used correctly except in the case of Leroy (24). Both the Green Newtown 

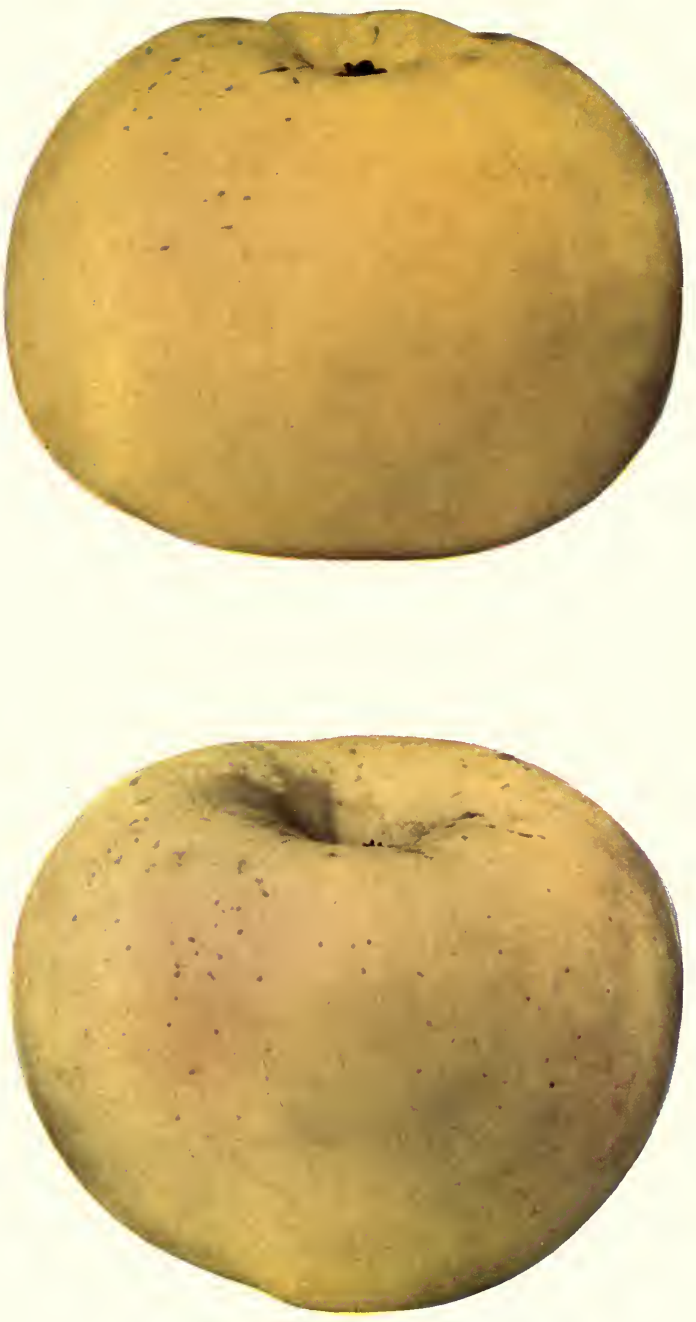

GREEN NEWTOWN 

and the Yellow Newtown differ markedly in size, color and quality in different locations and their successful cultivation is probably more limited by local conditions than is the case with any other standard commercial variety grown in this state. They are successfully and extensively grown in certain localities in the Hudson valley and along the north shore of Long Island, but usually neither of them is regarded as desirable for commercial planting west of the Hudson valley.

Under favorable conditions the trees come into bearing young and are reliable croppers yielding good crops biennially or sometimes oftener. The fruit hangs well to the tree. It is quite susceptible to the scab and requires thorough treatment to hold this disease in check particularly when grown on heavy clay soils. Unless grown on fertile soils and under good cultivation with insect pests and fungous diseases kept well under control there is often a comparatively high percentage of ill-shaped, uneven and low-grade fruit. Under favorable conditions the fruit grows large or sometimes very large and is fairly uniform in size although somewhat variable in form and coloring. It has a long established reputation in Europe and commands the best prices paid there for American apples. It is firm, keeps very late and ships well. The crop is largely exported. In ordinary storage its commercial season is February to March; in cold storage March to May. The fruit is of the highest quality for dessert and excellent for culinary uses. Cider made from it is very clear and of high quality, and in the early days large quantities of the fruit were used for this purpose.

Historical. The excellent historical account of the Yellow Newtown and the Green Newtown given by Taylor (32) is reproduced here:

The "Newtown Pippin" was the first American apple which attracted attention in Europe. After the receipt of specimens by Franklin while in London in 1759 , and the subsequent sending of grafts to Collinson by John Bartram, numerous attempts were made to grow the variety in England. As early as I768 it was cultivated in the Brompton Park nursery under the name "Newtown Pippin of New York."1

It is probable that the large apple exports of 1773 included considerable quantities of the Newtown, for it was at that time quite generally distributed through the apple-growing districts of the Atlantic slope. Thomas Jefferson recorded in his "Garden Book" that in March, I773, grafts of "Newtown

\footnotetext{
${ }^{1} \mathrm{Hogg}$, The Apple and Its Varieties, $1859: 143$.
} 
Pippin," received from Mordecai Debnam, at Sandy Point, were "ingrafted by P. Morton," and in March, 1778, he noted that the grafted trees were planted out at Monticello.

Prior to 1803 Forsyth said of the variety in England,1 "The New-Town Pippin is a fine apple in good season, but seldom ripens with us. It is held in grcat esteem in America." McMahon, 2 in 1806 included Newtown Pippin in his select list of "Long-keeping apples" and also in a list of "Cyder apples."

Previous to 1817 we have no record that more than one type of the Newtown was recognized, but Coxe, ${ }^{3}$ whose work appeared in that year, described as distinct varieties the "Large Yellow Newtown Pippin" and the "Green Newtown Pippin," characterizing the latter as "a variety of the preceding kind." Since the time of Coxe the two types have been recognized as distinct by our leading American pomologists, though fruit growers are by no means unanimous on this point.

The original seedling tree of Newtown Pippin is alleged to have stood near a swamp on the estate of Gershom Moore, in Newtown, Long Island, until about $\mathrm{I}_{805}$, when it died from excessive cutting of cions and exhaustion. Its origin is credited to the early part of the eighteenth century. It is not clear at this time whether the original tree was of the "green" or the "yellow" type, nor has any record of a distinct origin of the two been discovered.

The Yellow Newtown has for many years been considered the better apple for exportation, however, and in commercial orchards has almost superseded the Green Newtown on account of its larger size, brighter color, and better keeping quality.

Both sorts are exceedingly variable and susceptible to the influence of soil, climate, elevation above sea level, etc. They are successfully grown in but few portions of the apple-producing area of the United States at the present time, the principal localities being the lower portion of the Hudson River valley in New York, the Piedmont and mountain regions of Virginia and North Carolina, and portions of California, Oregon and Washington.

Though first grown in commercial orchards in New York, New Jersey and Pennsylvania, the excellent quality of the fruit from "some of the Patowmack counties of Virginia" was noted as early as the time of Coxe.4

In Albemarle county, Va., where it reached a high degree of perfection, it became known as the "Albemarle Pippin" at an early day, and was for many years considered a distinct variety, of local origin, and was so propagated.

An export trade in the fruit from Albemarle county was inaugurated under favorable auspices by a happy circumstance which occurred in the first year of the reign of Queen Victoria. The account below ${ }^{5}$ is kindly furnished by Mr. Samuel B. Woods, president of the Virginia Horticultural Society.

\footnotetext{
${ }^{1}$ Cobbett, A Treatise on the Culture and Management of Fruit Trees, Edition with American Notes, $1803: 58$.

2MeMahon, B., The American Gardener's Calendar, 1806:585.

${ }^{3}$ Coxe, 1817:142, 143 .

Coxe, 1817:143.

'Letter April 30, $\$ 898$. The true history of the matter is that in the first year of Queen Victoria's reign Andrew Stevenson, whose home was on a mountain side in Albemarle, was minister to the Court of St. James. He had Albemarle Pippins sent over for his own use and presented the Queen with several barrels. She was delighted with the perfect flavor and excellence of the fruit, and, as a graceful acknowledgment of the courtesy of Mr. Stevenson, removed from Albemarle Pippins a small tax which then
} 

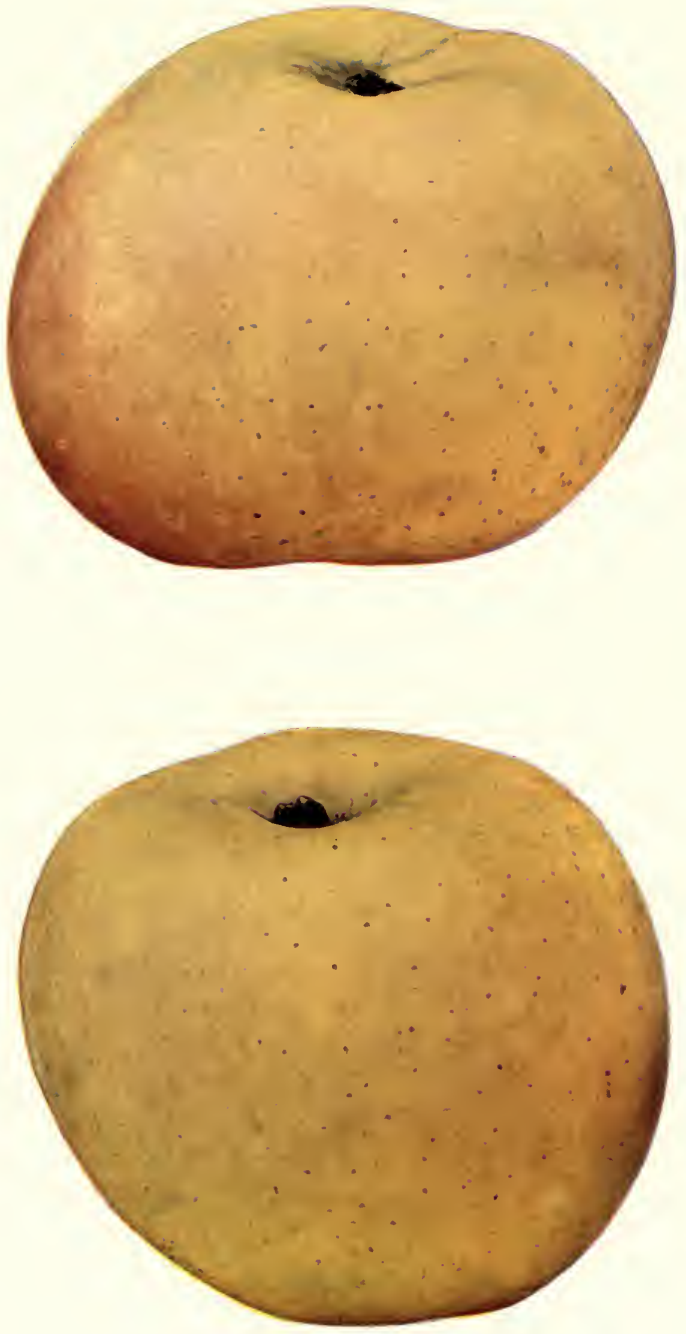

YELLOW NEWTOWN 



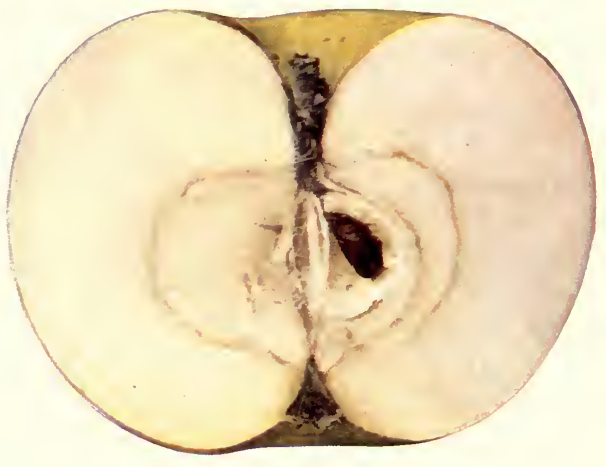

YELLOW NEWTOWN

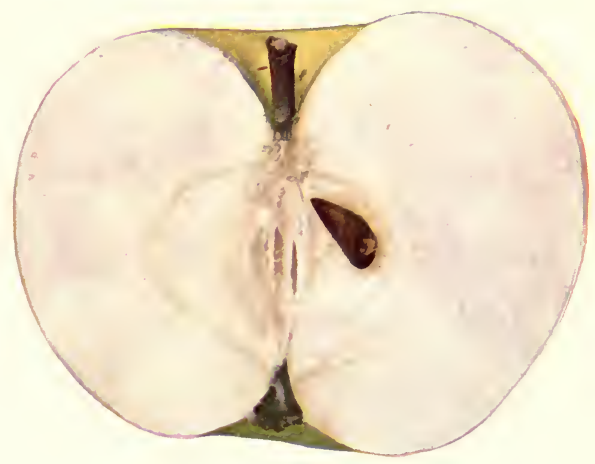

GREEN NEWTOWN 

The identity of Albemarle and Yellow Newtown seems to have been recorded first by the late Franklin Davis in a letter from Staunton, Va., which was published in the Horticulturist in 1857.1 Since that time most pomologists have accepted their identity, ascribing the slight variations which are observable to local soil or climatic conditions. But in the absence of an authentic record of the introduction of Yellow Newtown to Albemarle county, many orchardists in the Piedmont and mountain regions have continued to believe the Albemarle a distinct variety of local origin. Recent investigation by Messrs. H. L. Lyman and Samuel B. Woods, ${ }^{2}$ prominent citizens and fruit growers of Charlottesville, Va., have resulted in an apparent clearing up of the historical uncertainty and establishing a clear connction between the supposed original Albemarle tree and the older variety.

\section{Green Newtown.}

\section{TREe.}

Tree a rather slow grower ar moderately vigorous, of medium size or sometimes becoming large. Laterals shorter, twisted, spreading and drooping more than those of the Yellow Newtown. Form spreading or roundish, rather dense. Tzvigs medium in length and thickness, pubescent near tips; internodes medium to rather long. Bark clear dark brownish-red, lightly streaked with scarf-skin. Lenticels quite numerous, medium or below, somewhat elongated, raised, rather conspicuous. Buds medium, broad, plump, obtuse, free, slightly pubescent.

\section{FRUIT.}

Fruit medium to very large, pretty uniform in size but rather variable in form and coloring. Form usually roundish oblate and more or less angular. As grown in Southeastern New York it often has an oblique axis and is sometimes decidedly elliptical, but in Western New York the tendency of the fruit

existed for the benefit of the Crown on all imported apples. From this time the Albemarle Pippin has grown steadily in favor in the English markets. It is not unusual to see them selling in the wholesale markets at Liverpool for two or three times the price other American apples are bringing. A neighbor last fall sold his entire crop for \$ro per barrel, and Mr. Whately, an English gentleman who recently returned from abroad, told me that he saw Albemarle Pippins retailing at 36 cents a pound.

${ }^{1}$ Horticulturist, $7: 288$. 1857 .

${ }^{2}$ Letter of April 30, 1898 . As far back as 1765 there was a tree noted for its fine fruit standing in a mountain hollow on what is now Mr. William Sutherland's land, in the North Garden neighborhood. How this tree came here no one knows, but tradition has it that it was a seedling, and from its stock came all Alhemarle Pippins.

The other account, and the most authentic one, is that which fixes the earliest introduction at the time of Braddock's defeat. Dr. Thomas Walker, of Castle Hill, Albemarle county, was the commissary officer of the Virginia troops with Braddock, and after the disastrous defeat, when the remnant of the troops went into winter quarters in Philadelphia, he returned home, carrying in his saddle-bags cuttings of apple trees. These were grafted at Castle $H$ ill and became the famous Albemarle Pippin.

These two accounts I find connected in this rather curious way. The land on which the tree in the North Garden neighborhood stood was entered in the land office in $174 \mathrm{I}$ in the name of Mildred Meriwether, in whose lifetime parts of the tract were improved. Mildred Meriwether was the stepdaughter of Dr. Thomas Walker, and what is more natural than that the old tree on her land, supposed to be a seedling, was one of the Walker grafts? There is little doubt that the first appearance of the Albemarle Pippin was at Castle Hill from the grafts brought home from Pennsylvania by Dr. Walker after Braddock's defeat in 1755 . 
to gro: with an oblique axis is less marked and the fruit is less often elliptical and more nearly symmetrical. Stem mediun or short. Cavity deep, acuminate to acute, broad or compressed, often sending out rays of russet. Calyx rather small to medium, closed or nearly so; lobes rather small, acute. Basin medium in width and depth, furrowed and often somewhat wrinkled.

Skin rather tough, smooth or slightly roughened with brownish-russet dots, grass-green at fruit harvest but sometimes pretty yellow later, and often showing some brownish or brownish-pink color, especially near the base. White submerged dots are especially numerous toward the eye and whitish scarf-skin stripes extend over the base.

Calyx tube long, funnel-shape to nearly conical. Stamens median to basal.

Core small to medium, somewhat abaxile; cells fairly symmetrical, closed or nearly so; core lines clasping. Carpels broadly roundish or roundish obcordate, enrarginate, tufted. Seeds tufted, medium or above, dark, narrow, acuminate.

Flesh yellowish or tinged with green according to the color of the fruit, firm, crisp, tender, moderately fine-grained, juicy, sprightly, with a fine aromatic subacid flavor, best.

Season February to May.

\section{Yellow Newtown.}

\section{TREE.}

Trce more vigorous and more erect than that of Green Newtown the branches growing more freely, the laterals showing less tendency to droop and the twigs averaging somewhat longer than is the case with the Green Newtown, otherwise we find that the two varieties, as Downing says (ro) "grow alike."

\section{Fruit.}

The technical description of the fruit of the Green Newtown applies well to the Yellow Newtown in all points excepting the color of the fruit and the color and flavor of the flesh. At fruit harvest the Yellow Newtown is distinguishable from the Green Newtown because both the yellow and the pink tones are more highly developed. When they are fully mature the more highly colored apples are bright yellow often with distinct pinkish blush, especially about the base. Less highly colored fruit is greenish-yellow shaded more or less with duller brownish-pink through which narrow streaks of the ground color often appear, combining with the streaks of whitish scarf-skin to give a somewhat striped effect. In general appearance it is decidedly more attractive than the Green Newtown, and its flesh is apt to be more distinctly tinged with yellow, milder, less sprightly and more highly aromatic.

\section{GREEN SWEET.}

References. I. Manning, 1838:63. 2. Manning, Mag. Hort., 7:45. I84I. 3. Thomas, 1849:162. 4. Emmons, Nat. Hist. N. Y., 3:90. 1851. 5. Horticulturist, 9:192. 1854. 6. Hooper, 1857:45. 7. Downing, 1857:81. 8. Elliott, 1858:83. fig. 9. Mag. Hort., 27:152. 186r. ro. Am. Pom. Soc. Cat., r862. I1. Warder, 1867:385. 12. Barry, 1883:347. 13. Bailey, An. Hort., 1892:240. 14. Budd-Hansen, 1903:95. 15. Powell and Fulton, U. S. B. P. I. Bul., 48: 42. 1903 . 


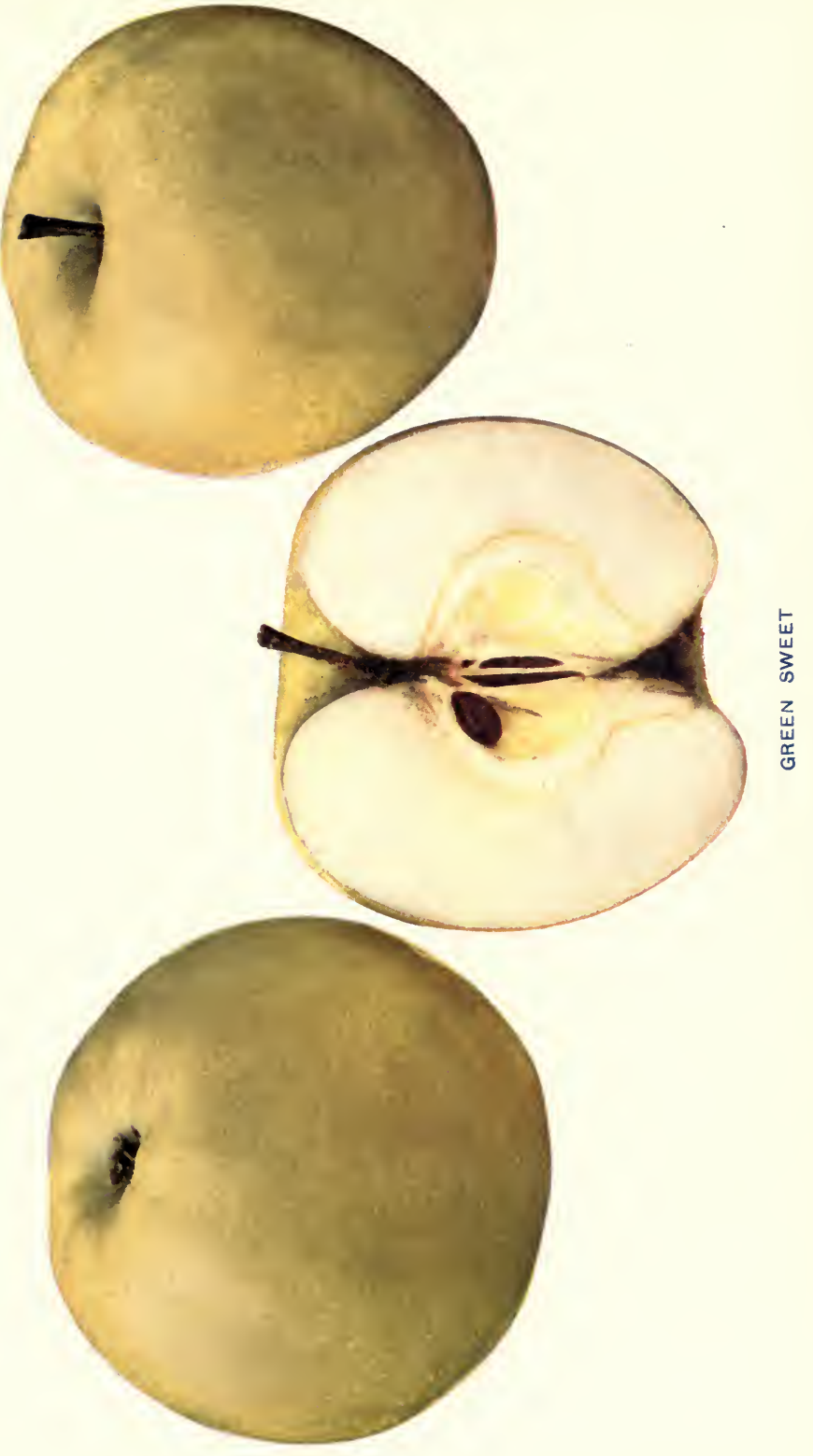



Synonyms. Green Sweet (6). Green Sweeting (5). Green Sweeting (4). Honey Greening (6). Honey Greening (7, 8, II, I2).

A desirable late keeping apple excellent for either dessert or culinary use. It holds its flavor and remains crisp, brittle and juicy till spring. Often it is kept in common cellar storage till April or May. It is undoubtedly one of the best late keeping sweet apples in cultivation in this state. It is grown with profit for selling in local markets wherever it is well known, but it does not sell so readily in the general market because it is not large and not well known and because the trade demands chiefly red, subacid apples. The tree is a good reliable cropper, bears biennially and yields so abundantly that the fruit commonly averages below medium or rather small, but it is perfect, smooth, bright, regular and uniform in size and shape with little loss from drops and culls. The apples are easily picked because the habit of the tree is upright and rather compact and it usually bears its fruit close to the branches or on short laterals or spurs. Green Sweet may be set more closely in the orchard than either Baldwin or Rhode Island Greening because it does not grow so large as either of these varieties and is decidedly more upright in habit.

The Sweet Greening of Thacher ${ }^{1}$ or Green Sweeting of Kenrick ${ }^{2}$ is said to be distinct from this variety.

A fall apple has been introduced from Russia under the name Green Sweet. This will be noticed in the succeeding volume.

Historical. An old variety of uncertain origin. It was already well known and much cultivated in Northeastern Massachusetts in the first half of the last century (I). It has long been highly esteemed in Central and Western New York $(3,4,5,9)$.

TREE.

Tree medium or sometimes large, vigorous or moderately vigorous; branches moderately stout; young branches dark green. Form erect or roundish, rather compact. Taigs short, straight, stout; internodes short. Bark very dark brown, mingled with reddish-brown, lightly streaked with scarf-skin; pubescent near tips. Lenticels numerous, medium, oblong, slightly raised, rather conspicuous. Buds large, plump, broad, obtuse, free, slightly pubescent.

Fruit.

Fruit medium or often below medium, sometimes large. Form ovate to roundish inclined to conic, sometimes obscurely ribbed; pretty regular and 
uniform in size. Stem medium to rather long, slender to moderately thick. Cavity somewhat furrowed, deep, acuminate, moderately broad, smooth or with some radiating russet rays. Calyx medium to rather large, closed or somewhat open; lobes rather leafy, long, acute. Basin variable, usually medium in width and depth, abrupt, slightly wrinkled and more or less obscurely furrowed.

Skin grass-green eventually becoming pretty yellow with a thin brownishred blush in highly colored specimens. Dots green or with fine russet point, often submerged and whitish. Prevailing color green.

Caly $x$ tube wide, cone-shape. Stamens median.

Core rather large, abaxile, open; core lines somewhat clasping or nearly meeting. Carpels roundish ovate. Secds numerous, medium or below, rather narrow, acute.

Flesh greenish-white, tender, fine-grained, juicy, very sweet, good.

Season December to April or May.

\section{GREENVILLE.}

References. I. Beach, N. Y. Sta. An. Rpt., 13:587. 1894. 2. Buechly, E. M., Greenville, Ohio, Cat., 1895. fig. 3. Amer. Gard., I7:162. I896. fig. 4. Can. Hort., 19:86. 1896. fig. 5. Beach, N. Y. Sta. An. Rpt., 15:280. 1896. 6. Ib., Western N. Y. Hort. Soc. Rpt., rgoo:35. 7. Powell and Fulton, U. S. B. P. I. Bul., 48:43. 1903. 8. Farrand, Mich. Sta. Bul., 205:42. 1903. 9. Beach and Clark, N. Y. Sta. Bul., 248:123. I904.

Synonym. Downing Winter Maiden Blush ( $1,2,3,4)$. Downing Winter Maiden Blush $(5,6,7,9)$.

Fruit attractive on account of its desirable size and clear bright color. The skin is tough and withstands rough handling pretty well for a yellow apple. Suitable for general market and culinary purposes but it does not excel in quality. The tree is satisfactorily productive, being usually an annual bearer alternating light with heavier crops.

Historical. Originated from seed of Maiden Blush in 1874 by Jason Downing, Darke comnty, Ohio. E. M. Buechly, Greenville, Ohio, introduced it under the name Downing's Winter Maiden Blush but afterwards changed the name to Greenville. It has not yet become generally disseminated in New York.

TREE.

Tree vigorous, upright becoming rather spreading. Twigs below medium, rather slender to moderately stout, nearly straight; internodes medium or below. Bark clear reddish-brown or olive-green, somewhat pubescent. Lenticels rather conspicnous, moderately numerous, small to medium, usually elongated, raised. Buds below medium, generally roundish, slightly pubescent, acute, appressed.

\section{Fruit.}

Fruit large to medium. Form roundish oblate to roundish oblong, usually symmetrical but sometimes slightly irregular or obscurely ribbed, uniform in shape. Stem short. Carity acute to acuminate, rather deep, moderately 

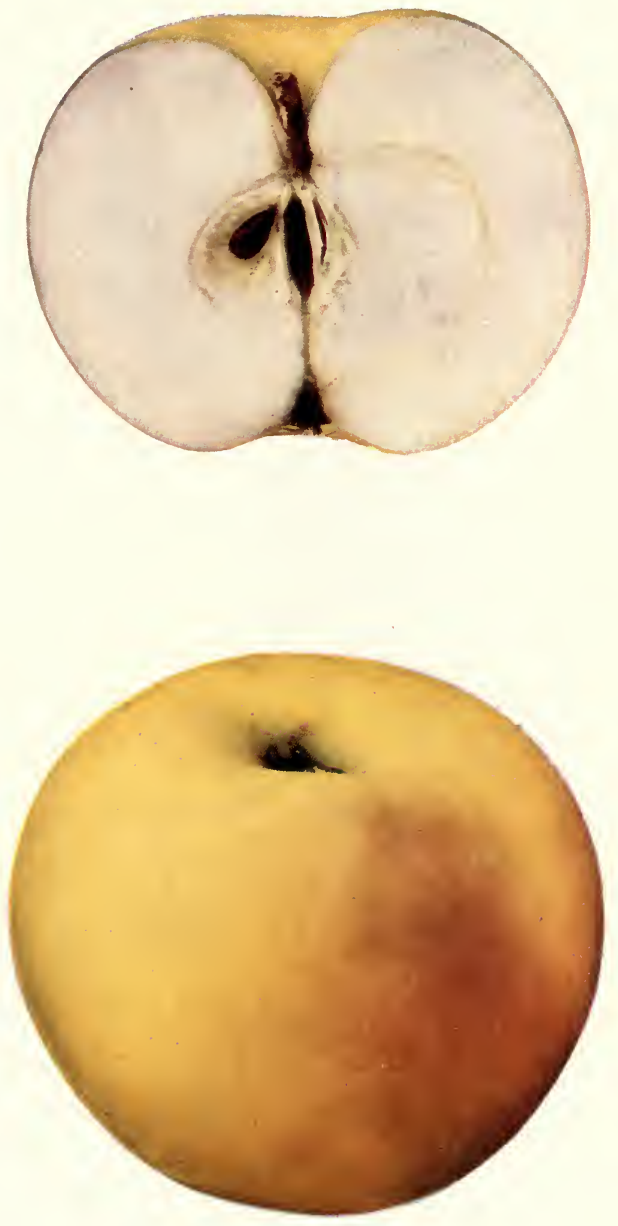

GREENVILLE 

wide, symmetrical or nearly so, sometimes slightly furrowed, sometimes lipped, often a little russeted. Calyx medium, closed or somewhat open; lobes often long, acuminate. Basin shallow, to moderately deep, usually furrowed and wrinkled.

Skin tough, waxen, clear pale yellow with handsome red or pinkish blush, in appearance somewhat resembling the Maiden Blush.

Calyx tube rather narrow, funnel-form. Stamens median.

Core medium, abaxile; cells closed or partly open; core lines clasping. Carpels broadly roundish. Seeds medium or above, rather light brown, rather narrow, acute.

Flesh whitish slightly tinged with yellow, firm, crisp, moderately fine, moderately tender, juicy, pleasant, mild subacid, sometimes a little astringent, good.

Season November to February, sometimes extending into April. Commercial limit January or, in cold storage, February.

\section{GREYHOUSE.}

References. I. Coxe, I8I7:154. fig. 2. Elliott, 1854:174. 3. Downing, 1857:214. 4. Warder, $1867: 720,722$. 5. Downing, 1872:204, 270. 6. Downing, Am. Pom. Soc. Rpt., I875:68. 7. Downing, r876:57 app. 8. Lyon, Mich. Hort. Soc. Rpt., I890:294. 9. Bailey, An. Hort., I892:24I. Io. Burrill and McCluer, Ill. Sta. Bul., 45:323, 326. I896. Ir. Beach and Clark, N. Y. Sta. Bul., 248:131. 1904. I2. Ragan, U. S. B. P. I. Bul., 56:131. 1905.

Synonyms. Big Romanite (incorrectly 6, 7, II, of some 12). Black Jack (6, 7, 12). Black Pennock (6, 7, 12). Black Vandervere (7, 12). Black Vandevere (6). Filliken (6). German Spitzenberg (6, 7, 12). Grayhouse (12). Gray Romanite (6, 12). Hard Red (7, 12). Hoop (12). Hoopes $(4,9)$. Hoopes $(5,6,7,12)$. Hoopes' Pearmain $(6,7,12)$. Hoops (10). Hoops (12). Hopsey (5, 6, 7, 12). Hopson (6, 7, 12). House (1). Keystone $(6,7,12)$. Lopside $(6,7,12)$. Lop-sided Pearmain (5, 12). Lopside Pcarmain (6). May, erroneously (5, 6, 12). May Apple (2). May SeekNo-Farther (7, il ). May Seek-No-Further $(2,6)$. May Seek-NoFurther (12). May Seek-No-Further (8). Pilliken (5, 12). Red Everlasting $(6,7,12)$. Romanite (8, incorrectly 6 and 12).

Fruit medium in size, dull colored, green and red; skin thick; flesh dry, coarse, subacid; not suitable for dessert and valued only as a long keeper ( $I$, 2, 5, 8). Season February to May (5, I I). Tree vigorous, spreading; not a reliable bearer.

Historical. Greyhouse probably originated either in New Jersey (5) or Pennsylvania (4). It has been grown under various names in different parts of the country and there has been much uncertainty with regard to its synonymy. May Seek-No-Farther and Hoops are now considered identical with Grayhouse (12). It is still offered by some nurserymen (9), but it is not now generally cultivated (II).

\section{GRIMES.}

References. I. Hovey, Mag. Hort., 22:131. I856. 2. Downing, 1857:149. 3. Hooper, 1857:42. 4. Hanford, Horticulturist, 18:206. 1863. fig. 5. Warder, 1867:670. fig. 6. Grimes, Horticulturist, 24:5 I. 1869. 7. Am. Pom. Soc. Cat., 
1869. 8. Barry, 1883:347. 9. Thomas, 1885:245. Io. Lyon, Mich. Hort. Soc. Rpt., 1890:292. I1. Wickson, 1891:247. I2. Bailey, An. Hort., 1892:240. I3. Amer. Gard., 19:131. I898, fig. I4. Brackett, Ib., 22:I91. I90I. I5. Alwood, Va. Sta. Bul., 130:133. I901. 16. Stinson, Mo. Fr. Sta. Bul., 3:25. 1902. I7. Hansen, S. D. Sta. Bul., 76:55. 1902. fig. 18. Budd-Hansen, 1903:95. fig. 19. Powell and Fulton, U.S. B. P. I. Bul., 48:43. 1903. 20. Beach and Clark, N. Y. Sta. Bul., 248:123. 1904.

Synonyms. Grimes' Golden $(5,6,7,8,10,12,13,14,15,16,17,18)$. Grimes Golden (19, 20). Grimes Goldex Pippin (I, 2, 3, 4, 9, 1 I, 12).

Fruit beautiful rich golden-yellow, attractive in form and excellent either for dessert or culinary use. It can hardly be called a standard market variety but in some markets it sells well. It is not a good keeper and is apt to scald in storage. It is in season about with Hubbardston. The tree is a biennial or sometimes an annual bearer and a good cropper. Favorable reports on it have been received from certain localities in New York but generally as grown in this state it does not develop in size, color or quality as well as it does in more southern latitudes, and there is a high percentage of loss from drops and culls. Some few New York fruit growers consider it a fairly profitable variety but generally it is regarded less favorably and it has failed to become a standard apple either in the home orchards or in the commercial orchards af the State. The indications are that it will never be grown in New York to any considerable extent.

Historical. Originated in West Virginia. Fruit from the original tree was sold to the New Orleans traders as long ago as I8o4 (6). It has become generally disseminated throughout the Ben Davis regions of the South, West and Southwest, where it is often planted for home use and is highly esteemed as a dessert apple, but it is not grown extensively in many localities in the commercial orchards. It has long been known in scattering localities in New York and old trees of it are found in some orchards but it has not been generally planted.

\section{TREE.}

Tree moderately vigorous; branches short, stout, curved, crooked. Form upright spreading or roundish, inclined to droop; rather dense. Taigs short to long, straight, moderately stout; internodes short. Bark dull brownish, rather lightly mottled with scarf-skin; pubescent in spots and at tips. Lenti-. cels scattering, small to large, roundish or oblong, not raised, rather inconspictous. Buds medium, broad, obtuse to acute, free, varying from slightly pubescent to quite pubescent.

\section{FrUIT.}

Fruit medium to large. Form roundish oblong, often flattened at the ends, sometimes inclined to conic, pretty regular, sometimes obscurely ribbed, some- 


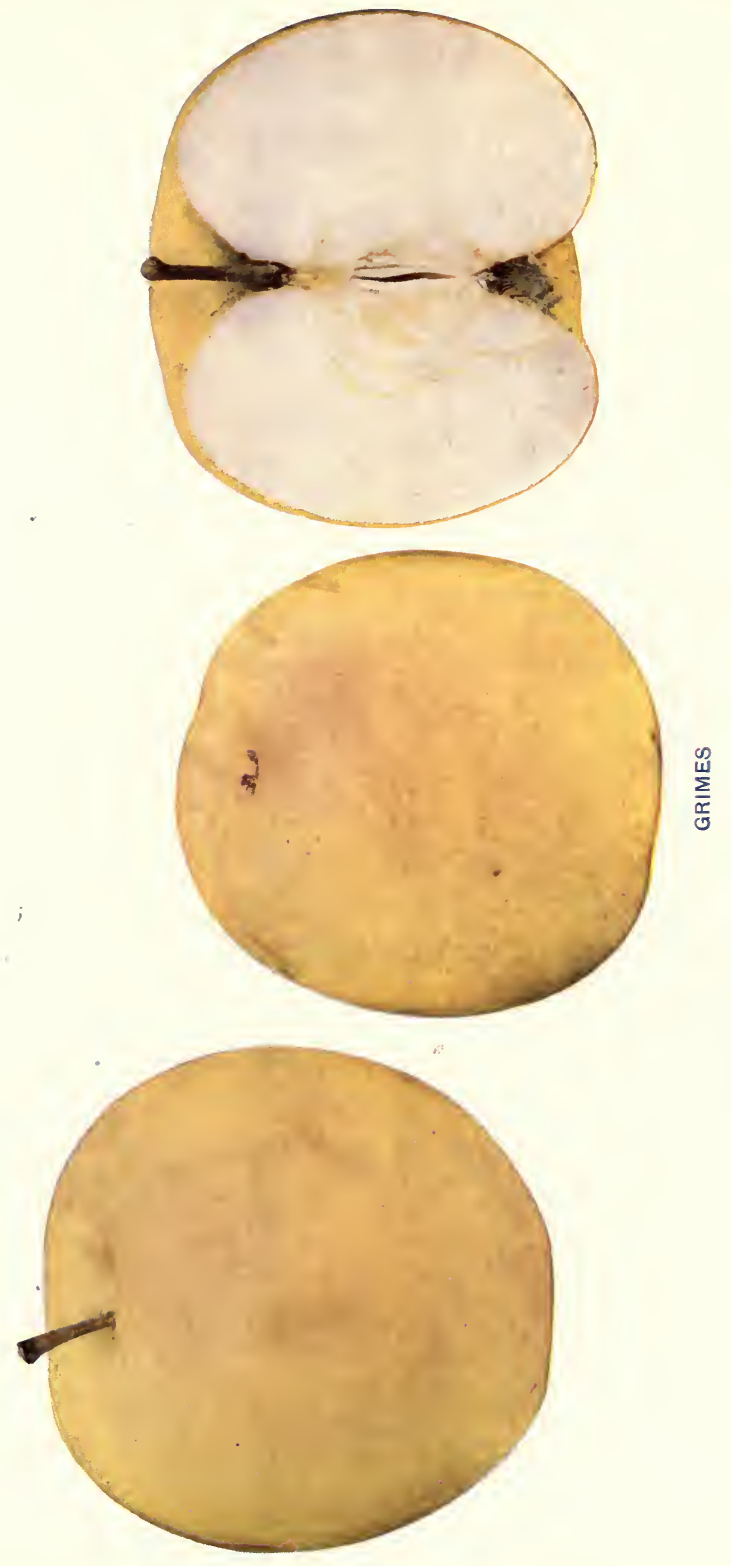



times oblique, symmetrical, uniform; sides often unequal. Stem short to medium. Cavity broad, deep, acute to acuminate, often russeted. Calyx rather large, closed; lobes long, reflexed, often separated at base. Basin abrupt, deep or moderately deep, rather wide, somewhat furrowed.

Skin tough, somewhat rough, clear deep yellow with scattering pale yellow or russet dots.

Calyx tube yellow, very broad at the top, conical, deep. Stamens basal.

Core medium to rather small, somewhat abaxile; cells usually pretty symmetrical, closed or somewhat open; core lines meeting or somewhat clasping. Carpels roundish, emarginate, concave. Seeds numerous, medium or below, somewhat tufted, plump, acute to obtuse.

Flesh yellow, very firm, tender, crisp, moderately coarse, moderately juicy, subacid, rich, aromatic, sprightly, very good to best.

Season November to January or February. Commercial limit, December or January.

\section{HARGROVE.}

References. 1. Amer. Agric., I891:70I. fig. 2. Bailey, An. Hort., r892: 240. 3. Berckmans, Cat., 1892. 4. U. S. Pom. Rpt., 1895:24. 5. Thomas, 1897:638. 6. Taylor, Am. Pom. Soc. Rpt., 1897:38.

A yellow apple of mild flavor and good quality. Received for testing at this Station from P. J. Berckmans, Augusta, Ga. It does not appear to be worthy of trial in New York state. The fruit is pale yellow, sometimes blushed, averages below medium size, is mild in flavor and good in quality. Its season here extends from November to Narch but in the southern states it is classed as an autumn variety.

\section{FRUIT.}

Fruit small to nearly medium. Form roundish conic, sometimes roundish oblate; pretty uniform in size and shape. Stem medium to rather short and thick. Cavity obtuse, shallow to moderately deep, sometimes symmetrical but often compressed or furrowed or lipped, often russeted. Calyx medium, open or sonetimes partly closed; lobes broad, reflexed. Basin shallow or moderately shallow, furrowed, often wrinkled.

Skin tough, somewhat waxen, glossy, bright yellow, sometimes with bright blush. Dots small to large, often irregular, russet.

Calyx tube urn-shape.

Core medium or below, closed; core lines clasping. Carpels broadly roundish, emarginate, tufted. Seeds long, acuminate, tufted.

Flesh a little yellowish, firm, rather crisp, moderately fine-grained, juicy, mild subacid mingled with sweet, slightly aromatic, good.

\section{HAYWOOD.}

References. I. Berckmans, Cat., I892. 2. Bailey, An. Hort., I892:24I. Synonym. Queen of Hayzwood (I).

A southern apple received from P. J. Berckmans, Augusta, Ga., I892, for testing here. The fruit is dull red, striped over yellow background, hardly medium in size, not very attractive, mild subacid, and only fair in quality. Not desirable for planting in New York. 


\section{HAZEN.}

A yellow or greenish apple of good size, mild flavor, nearly sweet, good or nearly good in quality. The tree comes into bearing young, is a raiher strong grower and so far as tested here is productive. It is not recommended for planting in New York.

Historical. Hazen was originated by J. Erwin Lord, Pompanoosuc, Vt., who says that it was produced by crossing some fine cultivated variety, record of name now lost, upon an unnamed seedling red winter apple.

\section{TREE.}

Twigs very short, slender, straight or nearly so; internodes medium. Bark slightly dull reddish, somewhat pubescent. Lenticels not very conspicuous, small to nearly medium, generally quite elongated. Buds rather small, prominent, fleshy, acute, moderately pubescent, slightly adhering to the bark.

\section{FrUIT.}

Fruit medium or above, uniform in size and shape. Form roundish inclined to conic, varying to somewhat oblate, symmetrical. Stem medium to long, rather slender. Cavity obtuse to acute, medium in depth and width, usually symmetrical, sometimes russeted. Caly $x$ small to medium, closed or partly open. Basin often oblique, shallow, moderately wide, obtuse, slightly furrowed, wrinkled.

Skin yellow, marbled with green. Dots small, numerous, greenish and russet.

Calyx tube rather small, short, usually cone-shape, sometimes varying to funnel-form.

Core medium, varying to rather large, open; core lines usually meeting. Carpels broadly roundish, mucronate. Sceds numerous, small to medium, rather narrow, acute, moderately light brown.

Flesh yellowish, rather coarse, somewhat crisp, not tender, moderately juicy, sweet or nearly so, slightly aromatic, fair to good.

Season December to April.

\section{HENNIKER.}

References. I. Downing, 1876:5t app. 2. Hogg, 1884:126. 3. Gartenflora, 39:265. 1890. col. pl. 4. Bailey, An. Hort., 1892:243. 5. Beach, N. Y. Sta. An. Rpt., II:593. 1892. 6. Jour. Royal Hort. Soc., 1898:356. 7. Powell and Fulton, U. S. B. P. I. Bul., 48:44. I903. 8. Beach and Clark, N. Y. Sta. Bul., 248:124. 1904.

Synonym. Lady Henniker $(I, 2,4,5,6)$.

Fruit of good size and excellent quality but not attractive enough in form and color to rank as a first-class commercial variety. The tree is a strong grower. It does not come into bearing very young but is quite productive in alternate years. There is apt to be considerable loss from the dropping of the fruit. It is not recommended for planting in New York. 
Historical. Originated between 1840 and 1850 in Suffolk, England (2). Awarded first-class certificate by the Royal Horticultural Society in I873 (6). It has not been disseminated much in this country and is but little known in New York.

\section{TREE.}

Tree vigorous; branches short, moderately stout, curved, crooked. Form roundish or spreading, rather dense. Tavigs long to short, stout; internodes medium or below. Bark dark brown tinged with red or partly olive-green, distinctly mottled with gray scarf-skin, slightly pubescent. Lenticels rather numerous, scattering, medium to small, roundish, raised, moderately conspicuous. Buds medium, rather prominent, broad, plump, obtuse to acute, free, slightly pubescent.

\section{FrUit.}

Fruit above medium to very large, fairly uniform in size. Form oblate to roundish, rather obscurely ribbed, often elliptical, not very uniform in shape. Stem short to medium, moderately thick. Cavity acuminate or somewhat acute, deep, wide, gently furrowed, often covered with outspreading russet. Calyx medium to rather large; lobes partly open, broad, acute. Basin moderately deep to rather shallow, medium to rather wide, somewhat furrowed and wrinkled.

Skin rather tough, decidedly roughened with capillary netted russet lines and rather large russet dots, and sometimes with broken patches of russet; color rather deep yellow, blushed and mottled with red and sparingly striped with carmine. Prevailing effect rather dull red somewhat mingled with yellow.

Calyx tube rather long, funnel-shape. Stamens median or below.

Core medium to small, axile; cells unsymmetrical, often seedless, irregularly developed; core lines clasping the funnel cylinder. Carpels broadly roundish or approaching obcordate, emarginate, tufted. Seeds few, medium or above, obtuse to acute, tufted.

Flesh tinged with yellow, moderately coarse, somewhat crisp, rather tender, juicy, rich, brisk subacid with something of the flavor characteristic of certain russets, becoming rather mild late in the season; good to very good in quality. Excellent for cooking but at first rather too briskly acid to be desirable for a dessert apple.

Season November to March or April.

\section{HEREFORDSHIRE.}

References. I. Hogg, 1884:106. 2. Lyon, Mich. Hort. Soc. Rpt., I89o: 292. 3. Bailey, An. Hort., 1892:24I.

Synonym. Herefordshire Beefing $(\mathrm{I}, 3$ ).

A dark red subacid apple adapted for kitchen use. As fruited at the Geneva Station it is rather attractive but falls below standard commercial varieties in size, quality and appearance. The tree comes into bearing early and is productive. It does not appear to be worthy of trial in New York state.

Historical. Known in Herefordshire for more than one hundred years (I). It is but little known in New York. 
TREE.

Tree not a very good grower; branches short, slender; laterals willowy and slender. Form roundish or spreading, very dense. Twigs below medium to very short, straight, slender, somewhat pubescent; internodes short. Bark clear brownish-red with some olive-green, lightly mottled with scarf-skin. Lenticels moderately numerous, scattering, small to medium, elongated, slightly raised. Buds below medium to small, broad, very obtuse, appressed, deeply set in the bark, pubescent.

\section{FrUIT.}

Fruit medium in size but with a full crop it varies from below medium to small. Form usually roundish oblate, sometimes oblate conic, symmetrical; uniform in size and shape. Stem short and thick. Carity obtuse, broad, deep, often russeted, usually symmetrical, sometimes furrowed. Calyx medium to rather large, usually open; tips of lobes divergent. Basin varies from shallow to moderately deep, rather wide, slightly wrinkled, ridged.

Skin thin, tough, clear greenish-yellow largely blushed with rather bright dark red, sometimes almost covered with red. Dots medium in size, numerous, usually russet, sometimes submerged. Prevailing effect red with more or less contrasting yellow.

Calyx tube very short, rather wide, broadly conical, sometimes approaching funnel-form. Stamens median or slightly marginal.

Core large, abaxile; cells symmetrical, open; core lines clasping. Carpels usually elliptical sometimes broadly obovate, emarginate, sometimes a little tufted. Seeds small, rather short, plump, broadly acute, rather light colored.

Flesh yellowish, moderately firm and tender, moderately fine, juicy, aromatic, brisk subacid, fair to good in flavor and quality.

Season October to January or February.

\section{HIESTER.}

References, 1. Downing, 1872:215. 2. Boyer, Pa. Fr. Gr. Soc. Rpt., 188r: 34. 3. Ill. Sta. Bul., 45:324. 1896.

Synonyms. Baer (I). Heaster (1). Heister (1). Michel Miller (2). Miller (I). Stehly (I).

A pleasant subacid apple in season here during winter, but where it originated it is classed as a late fall and early winter variety. Tree vigorous and productive (I). It is considered a desirable apple in some parts of Pennsylvania (2). Not recommended for planting in New York.

Historical. Origin, Reading, Berks county, $\mathrm{Pa}$. (1). But little known in New York.

\section{FRUIT.}

Fruit medium. Form roundish oblate, sometimes faintly ribbed. Stem very short and slender. Cavity acute, rather broad and deep. Calyx small, partly open. Basin rather abrupt to somewhat obtuse, broad, deep, slightly wrinkled.

Skin pale yellow mottled with thin bright red on shady side and washed with deeper red and narrowly streaked with deep carmine in the sun. Dots gray or russet, conspicuous about the cavity.

Calyx tube rather small, cone-shape, approaching funnel-form. Stamens median. 
Core small, somewhat abaxile; cells open or partly open; core lines meeting or clasping. Carpels broadly roundish. Seeds medium or below, rather narrow, short, plump.

Flesh yellowish-white, crisp, moderately juicy, rather tender, mild subacid to somewhat sweet, fair to good in flavor and quality.

\section{HIGHLAND BEAUTY.}

References. 1. Manning, Mass. Hort. Soc. Rpt., r881:232. 2. Downing, 1881 :88 app. fig. 3. Dempsey, Ont. Fr. Stas. An. Rpt., 2:32. I895.

A seedling of the Lady exhibited before the Massachusetts Horticultural Society in I88I as a new variety. "In size it surpasses its parent but not in quality" (I). The fruit is of the Lady type. Skin clear, smooth yellow or almost waxen white, blushed with brilliant carmine. Flesh white, crisp, tender, juicy, mild subacid, very good.

Season January to March $(1,2,3)$. It does not appear to be known in cultivation to any considerable extent.

\section{HOLLAND WINTER.}

References. I. Langley, Pomona, I729. (cited by 3). 2. Knoop, Pomol., 1758. (cited by 3). 3. Forsyth, I824:107. 4. Hogg, 1884:110. 5. Powell and Fulton, U. S. B. P. I. Bul., 48:44, par. 2. I903. 6. Beach and Clark, N. Y. Sta. Bul., 248:124. 1904.

The variety here described as Holland Winter was received for testing at this Station from Western Pennsylvania under the name of Holland Pippin. United States Pomologist Heiges identified it for us as the Holland Pippin of Hogg, Langley and Miller, and stated that it is the variety which is generally grown in Pennsylvania under the name of Holland Pippin. We have not yet been able to confirm with certainty the identification made by Heiges.

Forsyth's complete description of the Holland Pippin of Langley (3) is here given.

"This is a middle-sized apple, of a flattish shape. Its colour is yellow, in some places inclining to green, with sometimes a little red towards the sun. This is a pretty good apple, and keeps till the middle of April."

The following is Hogg's description (4).

"Fruit large, three inches wide, and two inches and a half high; roundish and flattened with ribs on the sides. Skin, greenish-yellow, with a slight tinge of pale brown where exposed to the sun, and strewed with large green dots. Eye, 
small and closed, set in a round, narrow, and plaited basin. Stalk, very short, imbedded in a wide and deep cavity. Flesh, yellowish-white, firm, tender, juicy, sweet, and briskly acid.

"A valuable apple of first-rate quality for culinary purposes; it is in use from November to March. The tree is a strong grower, vigorous, healthy, and a good bearer."

This variety is surely distinct from the one described by Downing ${ }^{1}$ and commonly grown in the Hudson valley and to some extent in other portions of the state under the name of Holland Pippin. The Holland Pippin of Downing begins to ripen somewhat earlier than the Fall Pippin, while the variety here described keeps till spring. Since both of these varieties are known in cultivation in this country under the name of Holland Pippin it is well to distinguish between the two by calling the late keeping one Holland Winter.

It is a green apple of the Reinette Pippin class, not equal to Rhode Island Grcening in flavor or quality for dessert or culinary uses but it is a better keeper and less liable to scald. It is attractive for a green apple in both size and color. The tree is a strong grower, healthy and productive, and usually is an annual bearer alternating heavy with rather light crops. It appears to be of sufficient value to be worthy of planting for trial as a commercial variety where a late keeping apple of this type is desired.

Historical. If this is in fact the Holland Pippin of Langley and Miller it is an old variety "native of the Holland district of Lincolnshire, hence its name" (4).

TREE.

Tree vigorous; branches long, moderately stout. Form spreading or roundish, rather open. Twigs moderately long, straight, stout; internodes short to medium. Bark clear reddish-brown with some olive-green, streaked lightly with scarf-skin, heavily pubescent near the tips. Lcnticels numerous, small, roundish, sometimes raised, rather conspicuous. Buds large to above medium, broad, obtuse, free near the old wood but quite appressed near the tips; heavily pubescent.

Fruit.

Fruit medium to large. Form roundish conic, symmetrical, regular or sometimes faintly ribbed. Stem medium or short and rather thick. Cavity acute or approaching acuminate, rather large and slightly furrowed, occas-

${ }^{1}$ Downing, 1872:219. 

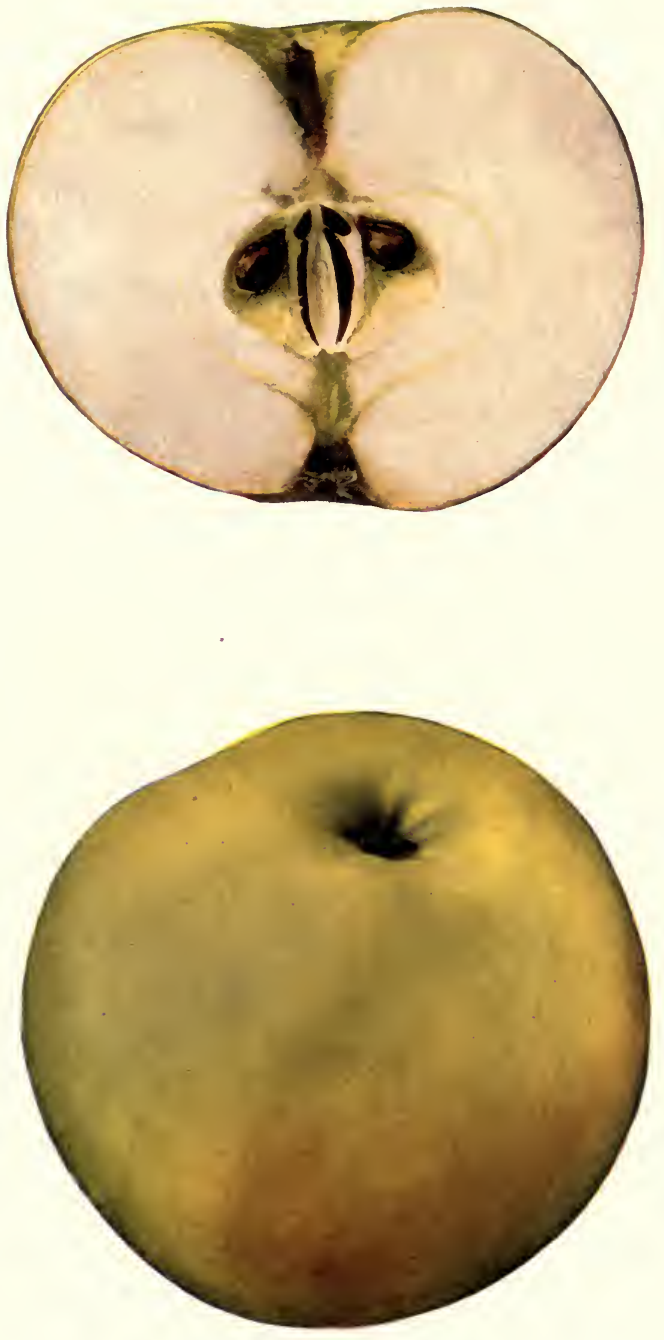

HOLLAND WINTER 

ionally with thin outspreading russet rays. Calyx small to medium, closed or partly open. Basin shallow, occasionally moderately deep and abrupt, somewhat furrowed, wrinkled.

Skin tough, slightly waxy, smooth, pale green or whitish often with a faint, dull blush. Dots numerous, rather large, conspicuous, submerged, whitish, mingled with a few fine russet points.

Calyx tube long, narrow, funnel-shape. Stamens median or below.

Corc medium or below, somewhat abaxile; cells pretty symmetrical, open or partly closed; core lines clasping. Carpels roundish to somewhat elliptical, broad, slightly tufted. Seeds rather short, plump, obtuse.

Flesh nearly white, firm, rather crisp, moderately fine-grained, juicy, subacid with mild, pleasing aroma, good.

Scason December to May.

\section{HOLMES SWEET.}

REFERENCE. I. Downing, I872:220.

Described by Downing as a medium sized yellow apple with red cheek. Flesh tender, sweet, mingled with subacid. Season November to February. Origin, Niagara county, N. Y. (I). Now practically obsolete.

Not the Holmes of Thacher.

\section{HUBBARDSTON.}

References. I. Kenrick, 1832:47. 2. Manning, I838:62. 3. Mag. Hort., 7:45. I84I. 4. Downing, 1845:I13. 5. Mag. Hort., 14:545. 1848. fig. 6. Ib., 15:63. 1849. 7. Thomas, 1849:166, 167. fig. 8. Emmons, Nat. Hist. N. Y., 3:65. 1851. col. pls. 5 I and 74. 9. Hovey, I:67. 1852. col. pl., fig. Io. Am. Pom. Soc. Cat., I852. II. Hooper, I857:46. I2. Oberdieck, Ill. Handb. der Obstk., 8:137. 13. Warder, 1867:600. fig. I4. Mag. Hort, 34:27. 1868. I5. Leroy, 1873:497. fig. I6. Barry, 1883:347. I7. Lyon, Mich. Hort. Soc. Rpt., 1890:292. I8. Wickson, I891:244. I9. Bailey, An. Hort., I892:241. 20. Green, Rural N. Y., 57:802. I898. 21. Eneroth-Smirnoff, I901:363. 22. Budd-Hansen, I903: Iоo. fig. 23. Can. Hort., 26:89. 19c3. fig. 24. Powell and Fulton, U. S. B. P. I. Bul., 48:44. I903. 25. Beach and Clark, N. Y. Sta. Bul., 248:125. 1904.

Synonyms. American Blush (20). American Blush (25). American Nonpareille (I5). Hubbardston (i8). Hubbardston Nonsuch (1, 2, 3, 5 , 6, 7, 8, 9, I I, I3, I4, I6, I9, 21, 22). Hubbardston Nonsuch (15, 23, 24, 25). John May (i5). Nonpareille de Hubbardston (i5). Nonsuch (i8). Nonesuch $(24,25)$. Orleans $(25)$. Sondergleichen von Hubrardston (12). Van Ileet.

Hubbardston is an excellent variety for commercial planting and deserves to be better known among New York fruit growers. It varies remarkably under different conditions of soil and climate not only in vigor of tree but in certain fruit characters also, such as size, color, degree of smoothness or russeting of the skin and in the quality 
and flavor of the flesh. The fact that it has come to have various local names in different parts of the state is doubtless partly due to this variability. It is now generally conceded that American Blush, Van Vleet and Orleans are identical with Hubbardston, or at the most are but selected strains of that variety. In many parts of the state Hubbardston is one of the most profitable varieties of its season, ripening as it does between the perishable early autumn varieties and the late ripening winter apples. It has generally sustained the reputation of coming into bearing at an early age and yielding heavy crops as often as every other year and in many places it is almost an annual bearer. It is apt to be productive to a fault, and for this reason should receive extra attention to keep the soil fertile and the foliage well protected from insects and diseases. When grown upon its own trunk the body is sometimes injured by severe winters. The tree also is somewhat susceptible to attacks of the apple canker. For these reasons it is doubtless best for one who wishes to grow Hubbardston to plant some hardier and more vigorous variety such as the Northern Spy, and the following year topwork the trees to Hubbardston. Under favorable conditions the tree is a vigorous grower and the fruit is fair, smooth, uniform, of good size and pretty good color. The quality is excellent for dessert but less satisfactory for culinary use except very early in the season before the fruit loses acidity.

Its commercial limit in cellar storage does not extend much later than December. It is a very uncertain keeper and in cold storage should go out in late fall or early winter although sometimes it has been held in good condition till spring. Fruit of this variety grown in Central and Western New York usually is somewhat smaller and keeps better than that grown in the lower Hudson valley. It appears that its keeping quality is correlated to some extent with the size of the fruit. If there is only a medium crop on the tree and the fruit is large it goes down quicker than if the crop is heavier and the individual fruits smaller and firmer. Fruit of good color also has good keeping quality, other things being equal, but poorly colored fruit soon deteriorates in flavor and quality (25). When the trees are allowed to become greatly overloaded, as they often do where 

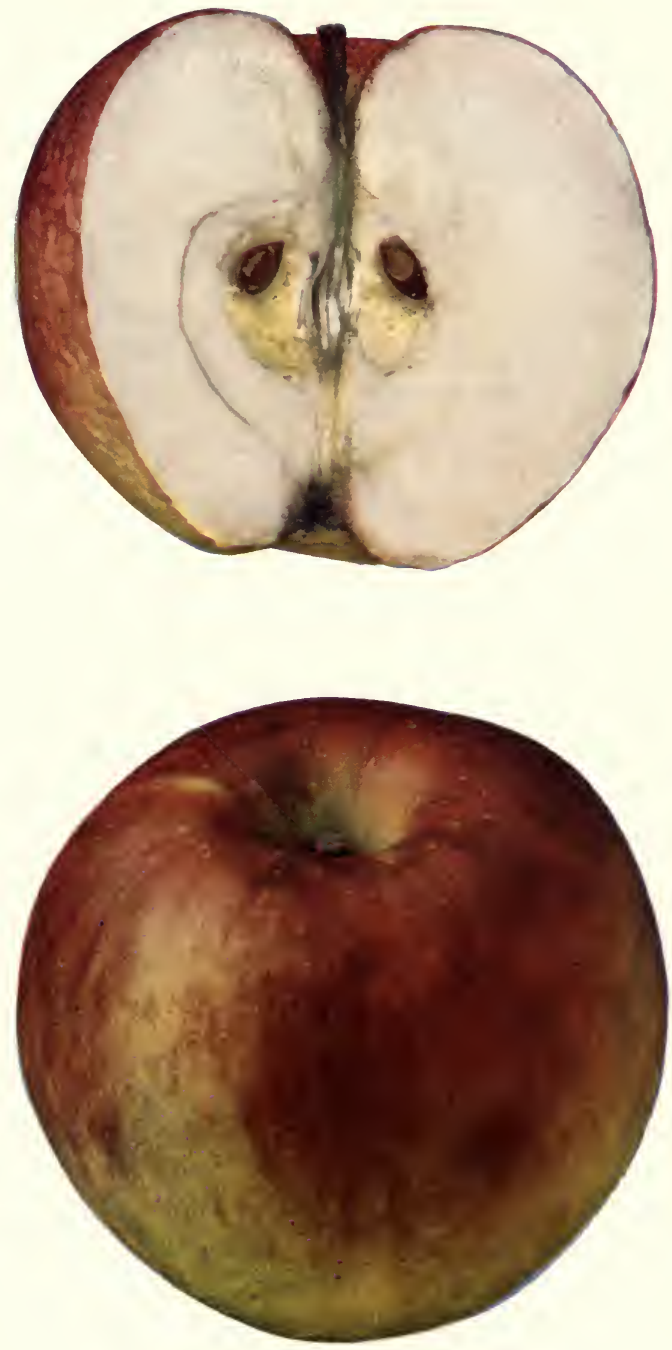

HUBBARDSTON 

the apples are not thinned, there is apt to be a considerable portion of undersized and poorly colored fruit. There is also some loss from the early dropping of the fruit particularly where picking is too long delayed. Hubbardston reaches edible maturity in October and holds its flavor well till December or January, but after that time its quality usually deteriorates rapidly. It may often be kept in edible condition through the winter even in cellar storage but seldom with prime flavor.

Historical. Hubbardston is a native fruit which had its origin in Hubbardston, Massachusetts. As early as 1832 Kenrick referred to it as one of the most desirable varieties known in cultivation in Eastern Massachusetts (I). Although it has long been widely disseminated in New York there are many localities where it is yet unknown and many others where it has been introduced within recent years. The planting of it for commercial purposes is gradually increasing.

TreE.

Tree vigorous, sometimes large, but if it is allowed to overbear and is not properly fed it is more often moderately vigorous and of medium size. Form erect to roundish, somewhat spreading, rather dense. Twvigs medium or rather long, spreading or erect, moderately stout, somewhat crooked, pubescent; internodes below medium to short. Bark dull olive-green with tinge of reddish-brown and mottled with thin gray scarf-skin. Lenticels scattering, conspicuous, medium to small, round or oblong, raised, becoming laterally compressed on the older bark. Buds medium, broad, obtuse, appressed, pubescent. Leaves medium to rather small, rather narrow and inclined to become incurved.

\section{Fruit.}

Fruit above medium to large, sometimes very large. Form roundish ovate or slightly oblong to roundish inclined to conic, characteristically rounded toward the cavity, usually symmetrical, often obscurely ribbed. The crop is usually pretty uniform in size and shape but there is considerable variability in the fruit with crops of different seasons and different localities. Stem short to very short. Cazity rather deep, acute, symmetrical, sometimes slightly furrowed, usually russeted. Calyy small to large, open to nearly closed; when large the lobes are usually reflexed and separated at the base exposing the yellowish calyx tube. Basin moderately narrow to rather wide, shallow and somewhat obtuse to moderately deep and abrupt, distinctly furrowed, often marked with concentric flecks of russet in and about the basin.

Skin sometimes quite smooth but more often roughened with dots, flecks and fine veins of russet and sometimes covered with faint bloom. Color yellow or greenish blushed and mottled with red which varies from dull brownish to clear bright red, and is more or less marked with deep carmine. Dots paie or russet, often large and irregular, especially conspicuous on the red portions of the fruit. Prevailing effect in highly colored specimens attractive red, mingled with more or less of yellow. 
Calyx tube medium in length, broad, cone-shape. Stamens median.

Core medium or rather small, more or less abaxile; cells usually pretty symmetrical, closed or partly open; core lines meeting or somewhat clasping. Carpels broadly roundish, slightly emarginate, tufted. Seeds numerous, medium to rather small, rather short, plump, acute, light brown.

Flesh whitish slightly tinged with yellow, moderately firm, breaking, rather fine-grained, tender, moderately crisp, juicy, aromatic, rich, at first sprightly but becoming mild subacid mingled with sweet, very good to best.

Season October to January.

\section{HUNT RUSSET.}

References. 1. Hovey, Mag. Hort., I9:126. 1853. 2. Ib., 21:300. 1855. 3. Downing, 1857:143, 187. 4. Am. Pom. Soc. Cat., 1862. 5. Warder, 1867:720, 722. 6. Downing, 1872:196. 7. Downing, C., Am. Pom. Soc. Rpt., 1875:36. 8. Downing, I876:53 app. 9. Thomas, 1885:240, 513. 10. Lyon, Mich. Hort. Soc. Rpt., 1890:292. I1. Bailey, An. Hort., 1892:241. I2. Budd-Hansen, 1903:IOI.

Synonyas. American Golden Russet of New England (8). Bullock (I, 2, but incorrectly). FAy's Russet (3). Fay's Russet (8). Golden Russet (not of N.Y.) (8). Golden Russet of Mass. $(4,5,6)$. Golden Russet of Mass. (8). Golden Russet of New England (8). Mass. Golden Russet (8). New England Russet (8). New England Golden Russet (8). Russet Pearmain $(3,9)$. Russet Pearmain (8).

Fruit medium size, golden russet with broken patches of smooth bright red on the cheek. It is quite attractive for a russet apple, excellent in quality and a good keeper. Tree moderately vigorous and productive. It is no longer considered profitable and is not being planted in commercial orchards.

Historical. The following description of the fruit was made from apples grown upon the old Hunt farm, Concord, Mass. Mr. Wm. H. Hunt, to whom we are indebted for these apples, states that the variety originated at least 150 years ago, and adds that it was once considered a profitable market apple but is so no longer. Downing (8) refers to it as an old favorite which is said to have originated in the latter part of the seventeenth century, and which has been widely disseminated under different names. In New England it has by some been called Golden Russet and American Golden Russet. Hovey identified it as Bullock but incorrectly $(1,2,7)$.

TREE.

Tree moderately vigorous, upright spreading. Twigs clear light reddishbrown, slightly grayish (6).

FRUIT.

Fruit medium or below, uniform. Form a little oblate to distinctly conical, often elliptical, pretty uniform in shape. Stem short to medium, slender. Cavity large, acute or approaching acuminate, deep, broad, sometimes furrowed and compressed. Calyx medium, partly open or sometimes closed; lobes 
medium in length, broad, obtuse. Basin moderately deep to shallow, moderately narrow to rather wide, abrupt, slightly furrowed.

Skin thick, rather tender, golden russet or with red russet cheek. Patcines of smooth skin breaking through the russet vary from yellow to bright deep red. Dots numerous, gray or russet.

Calyx tube often long, funnel-shape. Stamens basal.

Core small, axile; cells symmetrical, closed; core lines clasping the funnel cylinder. Carpels roundish to elliptical, slightly emarginate. Seeds dark, medium in size, plump, usually obtuse.

Flesh whitish tinged with yellow, rather fine, tender, juicy, subacid, sprightly becoming mild, not sweet as some have stated, very good to best.

Season January to April or later.

\section{HUNTSMAN.}

References. x. Downing, 1872:14 app. fig. 2. Am. Pom. Soc. Cat., 1875: 10. 3. Thomas, 1885:513. 4. U. S. Pom. Rpt., 1887:631. fig. 5. Mo. Sta. Bul., 6:7. I889. 6. Bailey, An. Hort., I892:241. 7. Stinson, Mo. Fr. Sta. Bul., 3:26. 1902. 8. Kan. Sta. Bul., 106:53. 1902. 9. Budd-Hansen, 1903:103. fig. Io. Powell and Fulton, U.S. B. P. I. Bul., 48:44. I903. II. Beach and Clark, N. Y. Sta. Bull., 248:126. I904.

Synonym. Huntsman's Favorite ( $1,2,3,5,6)$. Huntsman's Favorite $(7,8,10)$.

The Huntsman apple, or as it is more generally known by the growers, the Huntsman Favorite, is a western variety, it having been grown in Missouri and Eastern Kansas for about fifty years. In that section it is quite highly prized on account of its high quality and the good bearing habits of the tree. It is not looked upon with special favor by the commercial growers of the West because of its susceptibility there to bitter rot, sunburn and apple scab. The tree is not an early bearer but after it does begin to fruit is a regular bearer and quite prolific. The fruit is pretty uniformly large or very large, somewhat irregular in form, deep yellow usually somewhat blushed and very attractive. In sections where it is known it is in special demand among apple buyers for the fancy trade.

Historical. This variety originated on the farm of John Huntsman, Fayette, Mo. (I), and up to within very recent years its cultivation seems to have been confined to the Middle West. So far as we can learn it has not been tested to any considerable extent in the East. It is practically unknown in New York.

\section{Tree.}

Tree vigorous; branches long, slender. Form upright varying to roundish or spreading, rather open. Twigs above medium, long, straight, slender; internodes very short. Bark dark reddish-brown, heavily mottled with scarf- 
skin, heavily pubescent. Lenticels numerous, medium to very small, round, not raised. Buds small to nearly medium, broad, obtuse, free near old wood but quite appressed towards the tips, pubescent.

\section{Fruit.}

Fruit above medium to large, usually large. Form roundish oblate, slightly conical, somewhat irregular, obscurely angular. Stem short, rather thick. Cavity acute to slightly obtuse, deep, broad, sometimes russeted, frequently furrowed, sometimes compressed. Calyx small, closed; lobes short, narrow, acute. Basin very abrupt, medium in depth to deep, moderately narrow to narrow, usually deeply furrowed.

Skin rather thick, somewhat tender, deep yellow or greenish, often with an orange-red blush which sometimes deepens to a distinct red. Dots small, inconspicuous, pale, submerged, numerous.

Calyx tube usually extends to the core, cylindrical to slightly funnel-form with broad cylinder. Stamens marginal.

Core medium to small, abaxile; cells often somewhat unsymmetrical, open; core lines clasping. Carpels elliptical to very broadly ovate, deeply emarginate, sometimes slightly tufted. Seeds frequently irregular in shape, moderately dark brown, rather wide and long, usually plump, obtuse.

Flesh tinged with yellow, rather firm, moderately coarse, not very crisp, tender, juicy, mildly subacid with a distinct pleasantly aromatic flavor, good to very good.

Season December to April.

\section{HYDE KING.}

References. I. Bailey, An. Hort., I892:241. 2. Beach, N. Y. Sta. An. Rpt., 13:592. 1894. 3. Ib., 14:265. 1895. 4. Ib., 15:284. 1896. 5. Beach, $W$. N. Y. Hort. Soc. Rpt., 1900:37. 6. Powell and Fulton, U. S. B. P. I. Bul., 48:60. 1903. 7. Beach and Clark, N. Y. Sta. Bul., 248:II4. 1904.

Synonyms. Chase ( 7 ), but incorrectly. Hyde's King (of the West) (1). Western Beauty $(2,3,4,5,6)$, but incorrectly.

Hyde King appears to be one of the most valuable of the newer varieties of apples which have been tested at this Station. The fruit is large or very large, pretty uniform, smooth, glossy, pale green or yellow, often a little shaded with red. It is quite attractive for a green apple. Although not high-flavored it is good in quality, suitable for culinary use and evidently desirable for general market purposes being a good keeper. So far as tested here the tree is vigorous, and almost an annual bearer. It is not a very heavy cropper but the fruit is very uniformly large with a low percentage of culls.

TREE.

Trec vigorous. Twigs medium to long, stout; internodes short. Bark dull brown tinged with olive-green, somewhat streaked with scarf-skin; pubescent. 

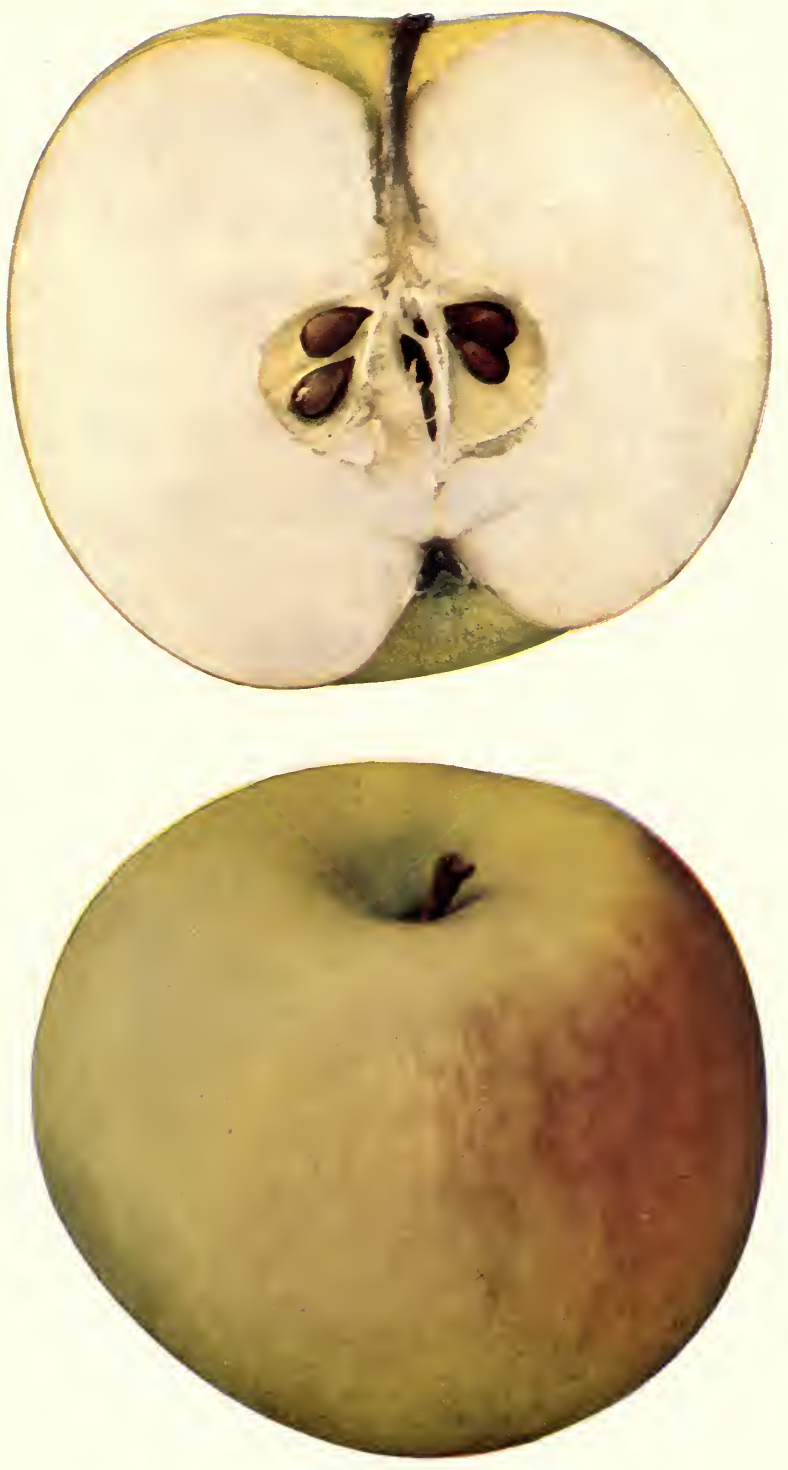

HYDE KING 

Lenticels quite numerous, medium to below, round, raised. Buds medium, plump, obtuse, free, pubescent.

\section{FRUIT.}

Fruit large to very large, pretty uniform in size and shape. Form nearly globular varying to slightly oblate or somewhat conic, often obscurely ribbed, sometimes with sides unequal but usually pretty symmetrical. Stem short, stout. Cazity acute to obtuse, moderately deep to deep, broad, usually smooth and bright green with contrasting large white dots, sometimes partly russeted. Calyx medium to large, closed or somewhat open; lobes short, obtuse. Basin moderately deep, rather narrow, sometimes becoming broad, somewhat furrowed and wrinkled.

Skin thin, tough, smooth, glossy, light green shading to pale or whitish yellow, often with a thin blush and sometimes faintly striped with darker red and marked towards the cavity with broken stripes of whitish scarf-skin. Dots numerous, sometimes with a russet point, usually large about the cavity.

Caly: tube usually short, cone-shape, sometimes approaching funnel-form. Stamens median to basal.

Core medium to rather large, somewhat abaxile; cells open or partly closed; core lines meeting or somewhat clasping. Carpels smooth, concave, roundish or very broadly elliptical. Seeds above medium, wide, obtuse to acute.

Flesh whitish, slightly tinged with yellow, firm, rather coarse, breaking, rather tender, juicy, mild subacid, somewhat aromatic, good but not of high flavor.

Season December to April or May. Commercial limit in ordinary storage February or March; in cold storage, May (7).

\section{INGRAM.}

RfFerences. I. Horticulturist, 23:201. I868 (cited by 5). 2. Downing, 1872:229. 3. Bailey, An. Hort., 1892:241. 4. Rural N. Y., 56:345. 1897. 5. Taylor, U. S. Dept. Agr. Yr. Bk., Igor:382. col. pl. 6. Stinson, Mo. Fr. Sta. Bul., 3:22. 1902. fig. 7. Thomas, 1903:328. 8. Budd-Hansen, 1903:103. 9. Powell and Fulton, U. S. B. P. I. Bul., 48:45. I903.

Synonyms. Ingraham (5). Ingram SeEdiIng (I). Ingram Seedling $(5,7)$.

This variety has attracted attention in the Southwest within recent years on account of its excellent keeping qualities $(4,5,6,9)$. It is said to be exceptionally promising for the Ozark region (6) where it is being largely planted for commercial purposes. Like the Ralls it blooms late in the season and the older trees are apt to bear rather small fruit unless the fruit is thinned. The fruit is of the Ralls type but averages larger and is more highly colored, being nearly red. In quality it ranks about with York Imperial. In flavor it is much like Ralls but less juicy. It has not yet been sufficiently tested in New York to determine whether it is a desirable apple 
for this state but since it is so much like its parent, Ralls, it probably is not so well adapted for this region as it is for more southern localities.

Historical. Originated with Martin Ingram near Springfield, Mo., from seed of the Ralls (Geniton) between 1844 and $1855(5,6)$.

\section{TREE.}

Trec vigorous, with long, moderately stout branches. Form upright or roundish, rather dense. Twigs medium to long, straight, rather stout; internodes medium or below. Bark olive-green partly covered with clear brownishred, lightly mottled with scarf-skin. Lenticels numerous, large, generally round, raised, very conspicuous. Buds medium, broad, flat, obtuse, appressed, pubescent, deeply set in the bark.

Fruit.

Fruit usually about medium, sometimes large. Form roundish conic, to roundish oblate, symmetrical. Stem rather short, varying from thick and swollen to moderately slender. Cazity acuminate, varying from medium in depth and width to deep and broad, sometimes partly russeted, obscurely furrowed. Caly.x large, open. Basin pretty regular, moderately deep, medium in width to rather narrow, moderately abrupt.

Skin rather thick and tough, smooth, bright greenish-yellow or pale yellow, washed, mottled and striped with two shades of red and clouded with whitish scarf-skin over the base. Highly colored specimens are nearly overspread with rather dark red. Dots numerous, whitish or areolar with russet center, rather conspicuous.

Caly $x$ tube conical or somewhat funnel-form. Stamens basal.

Core medium to rather sniall, axile; cells symmetrical, closed or nearly so; core lines meeting or slightly clasping. Carpels roundish, tufted. Seeds medium in size, rather wide, acute, tufted.

Flesh somewhat tinged with yellow, firm and hard but becoming crisp and tender, juicy, very mild subacid, somewhat aromatic, good to very good.

Season February to June or later.

\section{JACKSON.}

References. I. Smith, Horticulturist, II :286. 1856. 2. Brinckle, Ib., I 2 : 520. 1857. fig. 3. Downing, 1857:156. 4. Warder, 1867:723. 5. Thomas, I 885:514.

SyNonym. Jackson Seedling (I).

A greenish-yellow apple of medium size, not particularly attractive. In season from October to February. Not recommended for planting in New York.

Historical. Origin, Bucks county, Pa. (1, 2, 3). Although it has long been known in Pennsylvania it has not been disseminated to any considerable extent in this state. 

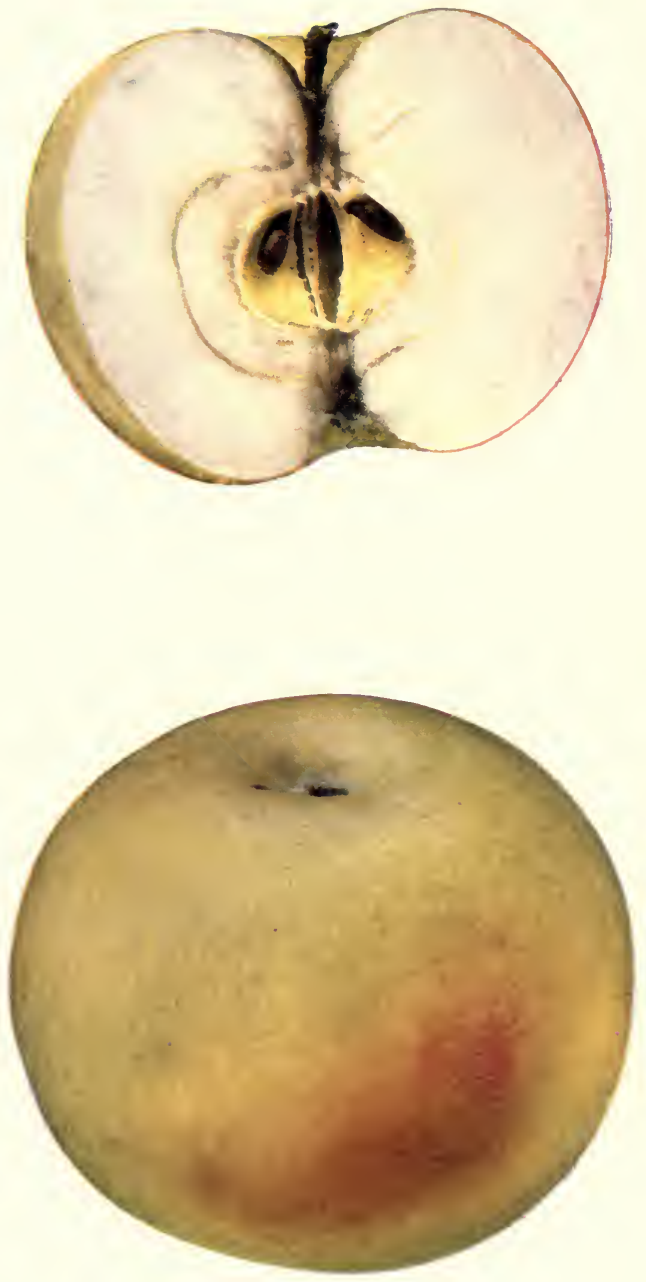

JACOB SWEET 

TREE.

Tree vigorous; branches moderately long, stout, crooked. Form roundish or spreading, rather dense. Twigs long, curved, stout; internodes medium. Bark dark brown lightly streaked with scarf-skin, pubescent near the tips. Lenticels numerous, small, round, not raised. Buds deeply set in bark, of medium size, broad, obtuse, appressed, slightly pubescent.

\section{Fruit.}

Fruit medium, uniform in size and shape. Form roundish to roundish oblate, symmetrical. Stem medium to rather long, slender. Cavity usually acuminate, deep, narrow to rather broad, often heavily russeted and with outspreading irregular rays. Calyx medium in size, closed or sometimes open; lobes long, rather narrow, acute. Basin abrupt, medium in depth to deep, moderately wide, slightly furrowed and wrinkled.

Skin moderately thick, tender, greenish-yellow with many dark green blotches and gray dots, a very few faint red stripes scarcely perceptible, and on the exposed side a warm mottled brown blush, containing numerous white dots with a central gray speck in each (2).

Calyx tube large, long, conical to funnel-form, extending nearly to core. Stamens marginal to median.

Core medium in size, abaxile; cells unsymmetrical, wide open; core lines clasping. Carpels smooth, nearly cordate to broadly ovate. Seeds numerous, dark brown, medium in size, plump, obtuse.

Flesh slightly tinged with yellow, fine, crisp, very tender, juicy, very mild subacid mingled with sweet, good.

\section{JACOBS SWEET.}

References. I. Manning, Mass, Hort. Soc. Rpt., 1880:235. 2. Ib., Am. Pom. Soc. Rpt., 1885:28. 3. Bailey, An. Hort., 1892:242. 4. Beach, N. Y. Sta. An. Rpt., 14:253. 1895. 5. Ib., West. N. Y. Hort. Soc. Rpt., 1896:52. 6. Manning, Am. Pom. Soc. Rpt., 1899:185. 7. Budd-Hansen, r903:105. 8. Rural N. Y., 62:771. 1903. fig. 9. Powell and Fulton, U. S. B. P. I. Bul., 48:45. 1903. Io. Beach and Clark, N. Y. Sta. Bul., 248:126. I904.

Synonyms. Jacobs $(4,5,9)$. Jacob's Sweet $(1,2,3)$. Jacobs Sweet (9). Jacob's Winter Sweet (3). Jacobs' Winter Sweet (4).

A large showy apple, green or yellowish often with bright blush. In form, color and texture it somewhat resembles Bough Sweet. It is one of the best sweet apples of its season for baking. The fruit is very tender and liable to crack and spot. It rots on the tree and also in storage. It is an unreliable keeper and rather variable in season but commonly is in season about with Pumpkin Sweet or Tompkins King. Its commercial limit varies from October to December or later in cellar storage and from January to March in cold storage (9, Io). The tree is not a very satisfactory grower in the nursery 
but in the orchard it is vigorous, comes into bearing moderately young and is almost an annual bearer often yielding rather heavy crops. It is recommended for the home orchard but not for general commercial planting.

Historical. Originated by Charles Sumner Jacobs, Medford, Massachusetts, about $1860(1,2)$. It has been but sparingly disseminated in New York state.

\section{TREE.}

Tree medium to large, vigorous. Form spreading. Twigs short to rather long, rather stout, straight or slightly curved; internodes medium to short. Bark clear light brownish-red with some olive-green, lightly mottled with scarf-skin; rather pubescent. L.enticels rather inconspicuous, rather scattering, small, elongated, sometimes raised. Buds lightly attached to the bark or free, medium or below, very prominent, fleshy, broad, obtuse, pubescent.

\section{FRUIT.}

Fruit above medium to large or very large. Form roundish often inclined to conic, sometimes slightly oblate, pretty symmetrical. Stem medium to short. Cavity rather wide, moderately deep to deep, acute or approaching acuminate, sometimes slightly furrowed or compressed, seldom russeted. Calyx medium, closed or partly open. Basin often abrupt, usually round, medium in width and depth.

Skin tough, somewhat waxen, rather glossy, clear yellow or greenish, often with a bright blush. Dots obscure, whitish or russet.

Calyx tube cone-shape or somewhat funnel-form. Stamens median to basal.

Core rather large, somewhat abaxile; cells pretty symmetrical, open or partly closed; core lines slightly clasping. Carpels large, roundish to broadly obovate. Seeds numerous, medium, acute.

Flesh whitish tinged with yellow, moderately firm, moderately coarse, very tender, crisp, juicy, slightly aromatic, very sweet, good.

Season October to March or April.

\section{JEWETT RED.}

References. I. Hovey, Mag. Hort., 8:250. 1842. 2. Thomas, 1849:149. 3. Cole, 1849:112. 4. Mag. Hort., 21:569. I855. fig. 5. Downing, I857:157. 6. Elliott, 1858:140. fig. 7. Am. Pom. Soc. Cat., 1862. 8. Warder, 1867:723. 9. Barry, 1883:347. ro. Hoskins, U. S. Pom. Rpt., r886:274. II. Lyon. Mich. Hort. Soc. Rpt., 1890:292. 12. Munson, Me. Sta. Rpt., 1893:133. 13. Waugh, V't. Sta. Bul., 6r:30. 1897. I4. Budd-Hansen, I903:106. I5. Beach and Clark, N. Y. Sta. Bul., 248:126. 1904.

Synonyms. JewetT's Fine Red (5, 8, 9, 10, 14). Jezvett's Fine Red (2, 4, 6, 12, I5). JewftT'S RED $(2,3,4,6,7$, I1, I5). Nodhead (3, 4, 5, 6, $9,12,13,14,15)$.

An early winter apple of medium size and of beautiful dark red color overspread with blue bloom. It is highly esteemed as a dessert fruit in portions of New England, particularly in Maine and New 


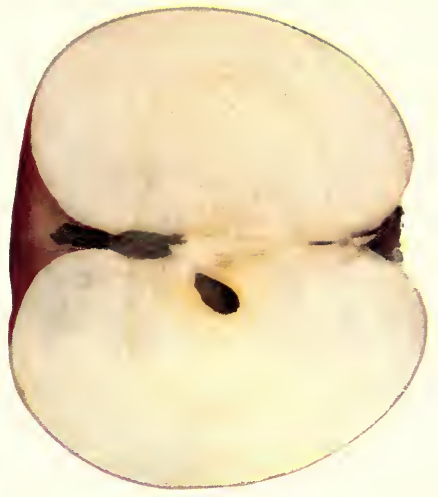

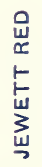



Hampshire where it is grown to some extent commercially. It is of the Blue Pearmain type and one of the best of that group in quality. As fruited at this Station it does not develop as high color nor as good quality as it does in the region where it originated. The tree comes into bearing rather young but is a slow grower and only moderately productive. As compared with standard varieties like Baldwin and Rhode Island Grecning, it evidently requires extra attention in pruning, spraying, fertilizing and tilling in order to secure a good average grade of fruit.

Historical. Origin, Hollis, N. H. (4). It has been known in certaiı local markets in New England for fifty years or more, but has not yet been grown to any considerable extent in New York.

TREE.

Tree makes a very unsatisfactory growth in the nursery and for that reason does best when top-worked on some thriftier stock. In the orchard it is a rather slow grower and hardly attains medium size; branches rather short and stout with comparatively few laterals and numerous spurs. Form spreading or roundish, somewhat open. Twigs very short to moderately long, nearly straight, rather stout; internodes short. Bark dull dark brownish-green varying to brownish-red mottled and streaked with light scarf-skin, slightly pubescent. Lenticels rather scattering, small to medium, roundish, not raised, rather dull in color. Buds rather short, small, plump, obtuse, free, slightly pubescent.

FrutT.

Fruit above medium to less than medium size, pretty uniform in size and shape. Form roundish oblate, sides unequal, obscurely ribbed, often somewhat irregular. Stem short. Cavity variable, acute to acuminate, shallow to medium in depth, moderately wide, furrowed obscurely if at all, green or russeted, sometimes lipped. Caly.t small to medium, open or partly closed; lobes broad, short, obtuse. Basin shallow to medium in depth, moderately wide, obtuse, obscurely furrowed and slightly wrinkled.

Skin rather thin, tough, nearly smooth, dark red over yellow background, often deepening to purplish-red and obscurely marked with broken stripes and splashes of carmine. Dots numerous, often conspicuous, pale yellow or whitish. Characteristic bluish-white scarf-skin often more or less overspreads the base. Prez'ailing effect very attractive, deep red.

Calyx tube moderately narrow, funnel-form or approaching cone-shape. Stamens median.

Core axile or nearly so; cells sometimes unsymmetrical, closed or sometimes open; core lines clasping. Carpels oval, elongated, emarginate. Seeds numerous, clear reddish-brown, below medium or rather small.

Flesh yellowish, moderately fine, tender, juicy, pleasantly aromatic, mild subacid or nearly sweet, good to very good.

Season October to February (15). 


\section{JONATHAN.}

References. I. Buel, N. Y. Bd. Agr. Mem., r826:476, Cat. No. 39. 2. Cat. Hort. Soc. London, I831. 3. Kenrick, 1832:47. 4. Downing, 1845:1 I3. 5. Thomas, 1849:167, I89. fig. 6. Cole, 1849:123. 7. Hovey, Mag. Hort., 16: 6o. I850. fig. 8. Emmons, Nat. Hist. N. Y., 3:60. 1851. col. pl. No. 25. 9. Am. Pom. Soc. Cat., 1856. ro. Hooper, 1857:48. II. Reynolds, Horticulturist. 12:51. 1857. 12. Dewey, Ib., 12:I98. 1857. 13. Elliott, 1858:86. fig. 14. Warder, 1867:679. fig. I5. Barry, I883:348. I6. Hogg, I884:119. I7. Lyon, Mich. Hort. Soc. Rpt., I89o:294. 18. Meehan, Can. Hort., 14:75. I891. fig. 19. Wickson, I89r:246. 20. Bailey, An. Hort., 1892:242. 21. Súinson, Ark. Sta. An. Rpt., 7:46. I894. 22. Lyon, Mich. Sta. Bul., 118:60. I895. 23. Ib., I43:200, 202. I897. 24. Powell, Del. Sta. Bul., 38:18. I898. 25. Van Deman, Rural N. Y., 59:224. 1900. 26. Kan. Sta. Bul., 106:53. 1902. 27. Hansen, S. D. Sta. Bul., 76:61. 1902. 28. Budd-Hansen, 1903:106. fig. 29. Powell and Fulton, U. S. B. P. I. Bul., 48:45. 1903. 30. Beach and Clark, N. Y. Sta. Bul., 248:127. 1904.

Synonyms. Esopus Spitzenberg (New) (i). Johnathan (2I). Jonathan (II). King Philip (4, 7, I0, II, I3). Philip Rick (11). Philip Rick (4, 7, I3). Ulster Scedling (1). Wine (erroneously ro, I3). Winesap (erroneously Io, I3).

This is a fruit of the Esopus Spitzenburg class. It is very beautiful, of a brilliant red color, highly flavored and of excellent quality for either dessert or culinary use. It excels its parent in hardiness, productiveness, health and vigor and is adapted to a wider range of territory, but the fruit is not so large nor does it keep as well as that of Esopus Spitienburg. In New York state it does fairly well in favorable localities if grown on rich soil and given careful attention but even under such circumstances it does not usually attain as good size as it does in certain portions of the valleys of the Ohio, Mississippi and Missouri and in the irrigated districts in the mountain regions farther west. In some localities in these regions it ranks next to Ben Davis in commercial importance. As grown in this state it is ordinarily rather small with a comparatively high percentage of uneven and irregular fruit, and is not at all adlapted to the general trade. At its best it is one of the most desirable varieties for the fancy trade at the holiday season. Its season is about the same as that of Tompkins King. It may be kept through the winter but when held in ordinary storage later than January dark spots are liable to develop in the skin and seriously injure the appearance of the fruit. Handled in this way its commercial limit is December or 

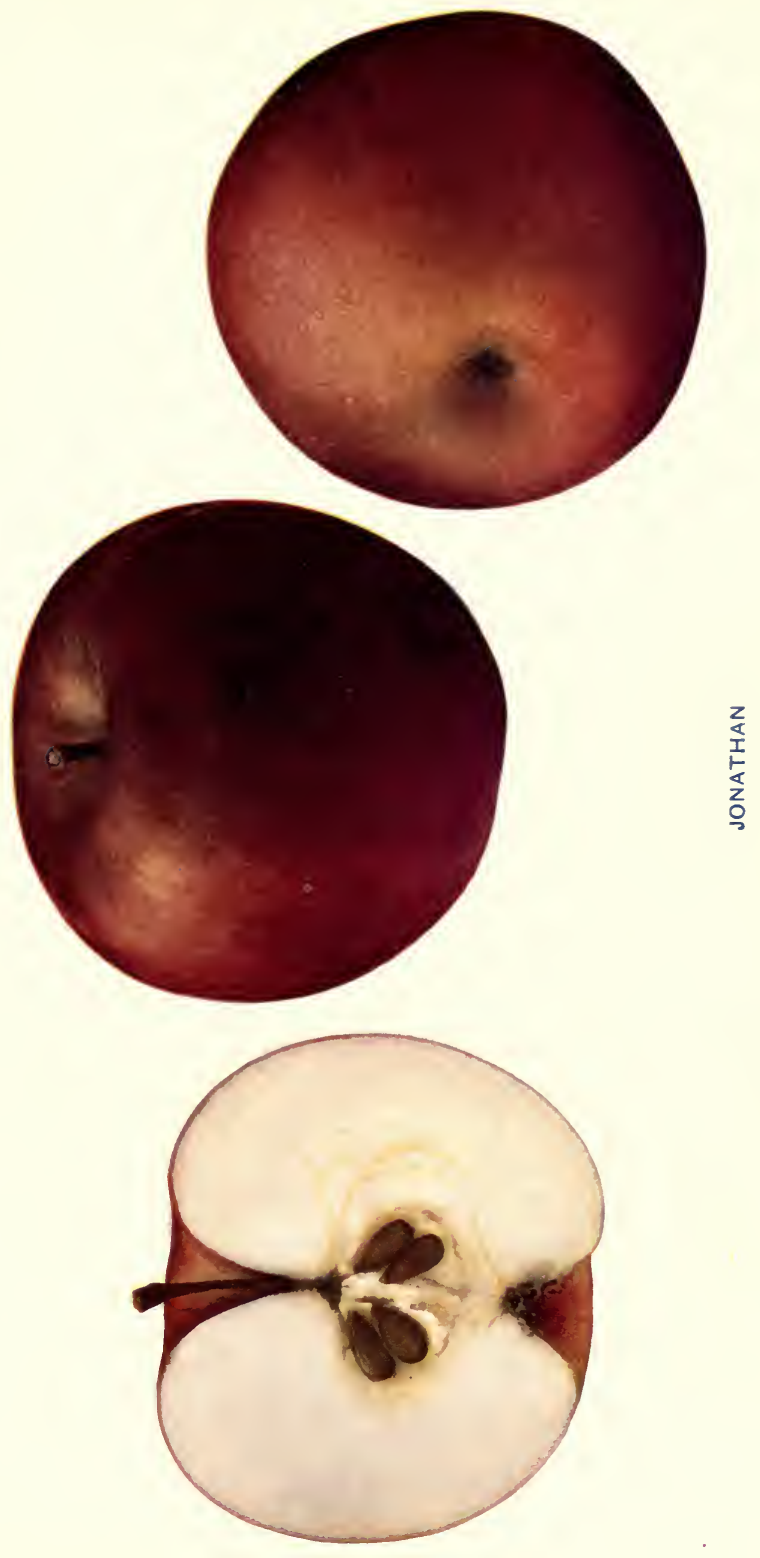

2
$\frac{1}{1}$
$\frac{1}{1}$
$\frac{1}{2}$
0 

early January. In cold storage its commercial limit varies from January to March or sometimes later (30).

As grown in New York the tree is but a moderate grower and for this reason it is well to top-work it upon some stock that is more vigorous such as Northern Spy, Baldwin or Rhode Island Greening. It does not grow much above medium size and may be planted more closely than Baldwin. Particular attention should be given to keeping the soil fertile, well supplied with humus and well tilled, and the trees should be thoroughly protected from injurious insects and fungus-diseases. Under favorable conditions the tree is a reliable cropper bearing good crops biennially or in some cases almost annually. It comes into bearing rather young. Usually the fruit hangs pretty well to the tree. It is not recommended for general commercial planting in New York but in some places under good management it has proved a profitable variety.

Historical. The first published account which we find of the Jonathan is that given by Judge J. Buel, of Albany, in 1826, in an article on "Observations on the utility of a Descriptive Catalogue of Garden and Orchard Fruit," addressed to the members of the New York Horticultural Society, in which he presents "A Descriptive Catalogue of some of the most valuable apples propagated in the nurseries of this state." In this catalogue the Jonathan is listed as the Esopus Spitzenberg (New) with the synonym Ulster Seedling (I). In I829 Judge Buel sent specimens of the fruit to the Massachusetts Horticultural Society with the statement that it was "An Esopus Seedling and sometimes called the New Spitzenberg." It originated on the farm of Mr. Philip Rick of Woodstock, Ulster county, New York (7). According to Downing the original tree was still alive in 1845 . It was at first disseminated under various names, all of which were soon superseded by the name Jonathan which was assigned to it by Judge Buel in honor of Jonathan Hasbrouck by whom his attention was first called to the variety. It has been widely disseminated throughout the apple-growing regions of New York but in none of them is it grown extensively. It is extensively planted in regions farther west and south where, as above stated, it is recognized in many localities as one of the leading commercial varieties.

\section{TREe.}

Tree medium in size, a moderately vigorous or rather slow grower. Form roundish or spreading, somewhat drooping, rather dense. Twigs medium in length, nearly straight, rather slender; internodes short. Bark dark brownishred mingled with dark green, and heavily coated with scarf-skin; pubescent. Lenticels usually very scattering, sometimes moderately numerous, small to medium or sometimes large, roundish to oblong, not raised. Buds medium, plump, rather narrow, acute to obtuse, free, pubescent. Leaves medium or below, rather narrow. 
Fruit.

Fruit medium to rather small, rarely large. Form roundish conic to roundish ovate, often somewhat truncate, regular; pretty uniform in shape and size. Stem medium to long, rather slender. Cavity acute to acuminate, deep to very deep, w:de, symmetrical, sometimes slightly furrowed. Calyx small, closed. Basin deep to very deep, very abrupt, wide to moderately narrow.

Skin thin, tough, smooth, pale bright yellow overlaid with lively red, striped with carmine. When well colored the fruit is almost completely covered with red which deepens to purplish on the sunny side and often shows a beautiful contrasting bit of clear pale yellow about the cavity where a twig or leaf lay in contact with the skin. Less highly colored fruit has more of a striped appearance particularly toward the basin. Dots minute, usually inconspicuous. Prevailing effect attractive lively deep red.

Calyx tube rather small, funnel-shape or sometimes conical. Stamens basal to median.

Core medium or below, axile or nearly so; cells symmetrical but often not uniformly developed, usually closed, sometimes open; core lines clasp the funnel cylinder. Carpels rather concave, roundish to roundish cordate, emarginate, smooth. Seeds rather large, long, acute to acuminate, dark, numerous.

Flesh whitish or somewhat yellow, sometimes with tinge of red, firm, moderately fine, crisp, tender, juicy, very aromatic, sprightly subacid, very good to best.

Season November to January or later.

\section{JONATHAN BULER.}

References. I. Beach, N. Y. Sta. An. Rpt., 14:253. I895. 2. Ill. Sta. Bul., 45:309, 328. I 896. 3. Powell and Fulton, U. S. B. P. I. Bul., 48:38. 1903. 4. Beach and Clark, N. Y. Sta. Bul., 248:127. 1904 .

Synonyms. Buler (3). Buler (4). Jonathan of Buler (2). Jonathan of Buler (3).

Fruit of good size and decidedly attractive being predominantly of a bright red color. It is hardly good enough in quality to take first rank as a commercial variety and it is excelled by others for dessert and culinary purposes. It probably is not worthy of planting for trial in New York. Tree comes into bearing rather young and is an annual bearer. Sometimes it yields heavy crops but usually it is a moderate cropper. There is considerable amount of fruit lost by dropping.

Historical. Origin uncertain. Tested at the Illinois Experiment Station and reported in 1896 as worthy of further trial. We have no knowledge of its being grown anywhere in New York except at this Station.

\section{TREE.}

Tree moderately vigorous: branches long, moderately stout. Form upright spreading or roundish, dense. Twigs medium to short, straight, rather stout with large terminal buds; internodes medium. Bark brown tinged with red, 
mottled with scarf-skin, rather pubescent. Lenticels quite numerous, medium or below, oval or elongated, slightly raised. Buds medium to large, broad, plump, acute, free, slightly pubescent.

Fruit.

Fruit rather large to medium. Form oblate, fairly symmetrical, broadly and obscurely ribbed, sometimes a little onesided. Stem very short. Cavity acute to acuminate, broad, deep, with radiating red stripes, sometimes thinly russeted. Calyx small to rather large, closed or partly open; lobes often erect. Basin usually abrupt, moderately wide to wide, rather deep, sometimes compressed, somewhat furrowed and slightly wrinkled.

Skin smooth, waxen, glossy, whitish-yellow or green largely overspread with bright red being blushed and mottled with light red striped and splashed with deep carmine. Dots whitish or russet, small.

Calyx tube long, meeting the core, varying from slender and funnel-form to wide cone-shape. Stamens basal.

Core small to medium, abaxile; cells often symmetrical and closed, sometimes open and unsymmetrical; core lines somewhat clasping. Carpels broadly roundisl to elliptical and almost truncate. Seeds short, wide, plump, obtuse, dark.

Flesh white, often streaked or stained with red, firm, tender, very crisp, moderately coarse, very juicy, mild subacid with a peculiar aroma which is not altogether pleasing, fair to almost good in quality.

Season November to April but in common storage it is apt to scald after January.

\section{KANSAS GREENING.}

References. I. Beach, N. Y. Sta. An. Rpt., 14:26I. I895. 2. Ib., 15:28I. 1896. 3. Beach and Clark, N. Y. Sta. Bul., 248:127. 1904.

Fruit unattractive, medium to rather small, roundish to roundish conic, grass-green with a dull brownish-red cheek; mild subacid, not high in quality but a good keeper. The tree is not a good grower and does not come into bearing very young. It yields moderate crops biennially. Not worthy of planting in New York.

\section{KANSAS KEEPER.}

Referencrs. x. Stayman, Am. Pom. Soc. Rpt., 1877:44. 2. Powell and Fulton, U. S. B. P. I. Bul., 48:46. 1903. 3. Beach and Clark, N. Y. Sta. Bul., 248: 127 . 1904 .

Synonym. Kansas (2).

Kansas Keeper as grown in Western New York is usually less highly colored than when grown in more southern localities and often is below good marketable size and rather dull and unattractive in color. It is a very late keeper. The tree comes into bearing moderately young, and bears annually, yielding moderate crops.

Historical. Origin unknown (I). We have not had the opportunity of deciding whether it is identical with Keeper. 1

${ }^{1}$ U. S. Pom. Rpt., 1895:27. Taylor, Am. Pom. Soc. Rpt., 1897:39. Ragan, U. S. B. P. I. Bul., 56:161, 162. 1905.

VO1. I -8 
Tree.

Tree moderately vigorous. Form upright. Tarigs short to nearly long, rather slender, generally straight; internodes medium. Bark dull reddish or brownish-red, quite uniformly overlaid with a moderately heavy scarf-skin, somewhat pubescent. Lenticels inconspicuous, generally scattering, but on some twigs numerous, small, elongated or roundish. Buds small, acute, somewhat pubescent, lightly attached to the bark or nearly free.

\section{Fruit.}

Fruit medium to large, sometimes averaging below medium; pretty uniform in size and shape. Form roundish or inclined to conic or somewhat oblate, often obscurely ribbed and with sides unequal. Stem rather short. Cavity acuminate, deep, broad to rather narrow, symmetrical, often with outspreading russet rays. Caly.r small to medium, closed, varying to large and open. Basin often oblique, very abrupt, rather narrow, often somewhat furrowed.

Skin smooth, pale yellow or greenish, thinly overspread with orange-red or pinkish-red, becoming clear red on exposed cheek, abundantly striped with bright carmine, mottled with thin gray scarf-skin towards the cavity. Dots whitish, often conspicuous, sometimes with russet point. Prevailing effect in highly colored specimens striped red, bright and attractive.

Calyx tube long, funnel-form with wide limb. Stamens median to basal.

Core somewhat abaxile, rather small; cells closed or partly open; core lines clasp the funnel cylinder. Carpels broad at base, narrow at apex, emarginate, tufted. Seeds dark, medium in size, moderately wide, somewhat acute, tufted.

Flesh whitish, firm, somewhat coarse, moderately crisp, rather tender, juicy, sprightly subacid, fair to good.

Season December to June.

\section{KING.}

Tompkins King, more often called King of Tompkins County, is usually known among fruit growers and fruit dealers as King. For an account of this variety the reader is referred to Tompkins King.

Twenty Ounce Pippin has also been known to a limited extent locally as King, but it is a very different variety from Tompkins King.

\section{KINNAIRD.}

References. 1. Downing, 1872:18 app. fig. 2. Am. Pom. Soc. Cat., r875. 3. Bailey, An. Hort., $1892: 242$. 4. Watts, Tenn. Sta. Bul., 1:15. 1896. fig. 5. Wright, Am. Gard., I7:33. 1896. 6. Thomas, 1897:291. 7. Ragan, U. S. Pom. Bul., 8:18. 1899. 8. Kan. Sta. Bul., 106:53. 1902. 9. Budd-Hansen, 1903:1 10. fig. 1o. Farrand, Mich. Sta. Bul., 205:45. I903. 11. Bruner, N. C. Sta. Bul., 182:25. 1903 .

Synonyms. Kinnaird's Choice $(\mathrm{I}, 8)$. Kinnaird's Choice $(4,6)$. KinNaIRds Favorite (2). Kinnard $(7,9)$. Kinnard's Choice (9).

This is a dark red winter apple of the Winesap class. When well grown it is of good size, very good quality and attractive in appearance. The tree 
comes into bearing rather young and yields moderate crops biennially. The fruit hangs well to the tree but is not very uniform in grade and does not produce as large a percentage of marketable fruit as either Baldwin or Rhode Island Greening. It is in season about with Baldwin. It is a variety of Tennessee origin which is highly esteemed in some sections of that state and in other portions of the Middle West (4). So far as tested in New York it does not appear to be adapted to regions as far north as this.

Historical. Origin Franklin, Williamson county, Tennessee. It is practically unknown in New York.

\section{TREE.}

Tree medium in size, a moderately vigorous grower; branchlets rather slender. Form rather spreading or roundish, irregular, not dense. Truigs mediun to rather long, moderately slender, often irregularly crooked. Bark brownish-red or some portions olive-green, somewhat pubescent; scarf-skin thin, not conspicuous. Lenticels rather numerous, irregular in size, not often large, usually very small, dull, elongated. Buds considerably sunk in the bark, rather broad, obtuse, appressed, quite pubescent.

\section{Fruit.}

Fruit medium to large. Form oblate inclined to conic, flat at the base, rather obscurely ribbed, nearly regular, sides sometimes unequal. Stem not exserted, short, rather thick. Cavity very wide, deep, acute, sometimes russeted. Calyx small, closed or partly open. Basin moderately wide, deep, abrupt, gently furrowed, often somewhat oblique.

Skin moderately tlick, tough, smooth, yellow, mottled and blushed with red, in the sum becoming a lively deep red shading to purplish-red. Dots numerous, small, whitish, becoming somewhat elongated towards the cavity. Prevailing effect good dark red.

Caly.x tube conical and moderately short varying to almost cylindrical and deep, sometimes extending to the core. Stamens nearly marginal.

Corc small, axile; cells symmetrical, closed; core lines clasping. Carpels obcordate, emarginate, noticeably concave, tufted. Seeds rather short, wide, plump.

Flesh tinged with yellow, crisp, moderately fine or a little coarse, agreeably subacid, somewhat aronatic, good to very good.

\section{KIRKLAND.}

References. x. Downing, 1881:92 app. 2. Lyon, Mich. Sta. Bul., 143:200. 1897.

A fruit of the type of the Yellow Bellflower but with less acidity, valued locally in Central and Eastern New York because it is productive, a good late keeper, fairly acceptable for dessert and good for culinary use. When well grown it is often partly suffused with a lively reddish-pink and late in the spring the ground color becomes a clear rich yellow, giving it a very attractive appearance for a yellow apple. The tree is a vigorous grower and a reliable cropper. The fruit often keeps in ordinary storage till May or June. It is doubtless worthy of more attention from fruit growers in the localities to which it is well adapted. 
Historical. Originated in Oneida county, New York, and named after Domine Kirkland, a missionary to the Oneida Indians. It is but little known outside of the Mohawk valley.

\section{TrEe.}

Tree dwarfish to medium in size, a moderately vigorous grower. Form roundish or spreading. Twigs medium to long, erect or spreading, moderately stout.

\section{FrUIT.}

Fruit above medium to large. Form broadly ovate or slightly oblong varying to roundish conical, ribbed, somewhat irregular, fairly symmetrical; sides sometimes unequal. Stem short, slender to moderately stout, not exserted. Cazity moderately narrow to rather wide, deep, acuminate, often partly russeted and sometimes with outspreading russet rays. Calyx small to medium, closed. Basin small to medium, shallow to moderately deep, narrow to moderately wide, somewhat furrowed and wrinkled.

Skin ratler thin, tough, smooth, clear pale yellow with a thin blush which in highly colored specimens deepens to reddish-pink. Dots whitish areolar with brownish russet center or whitish and submerged.

Caly. $x$ tubc rather wide, elongated conical or approaching funnel-form and extending to the core. Stamens basal to nearly median.

Core decidedly abaxile; cells fairly symmetrical, usually wide open; core lines meeting. Carpels mucronate, nuch concave, broadly rundish to elliptical. Seeds numerous, short, rather small to medium, rather wide, plump, obtuse.

Flesh somewhat tinged with yellow, firm, rather hard, moderately coarse, not very juicy, crisp, subacid, good.

\section{KIT'TAGESKEE.}

References. I. Warder, I867:724. 2. Downing, I872:242. 3. Fitz, I872: 178. 4. Leroy, 1873:4I6. figs. 5. Thomas, 1885:5I5. 6. Bailey, An. Hort., 1892:242. 7. Clayton, Ala. Sta. Bul., 47:6. I893. 8. Beach and Clark, N. Y. Sta. Bul., 248:128. 1904.

Synonym. Kettageska (3).

Fruit too small to be valuable for general market purposes, but its quality is excellent and it is attractive in appearance, being of uniform size, symmetrical form and bright yellow color. It is desirable for dessert use, especially because it retains its texture, flavor, quality and color remarkably well till very late in the season. The tree comes into bearing rather young, is an annual bearer or nearly so, yielding from moderate to heavy crops. The fruit hangs well to the tree. In the South it has the reputation of being vigorous, very prolific and almost free from blight. It is recommended for growing on dwarf stock in that region (3). It is reported as ripening in September in Alabama (7). Leroy (4) gives its season 


\section{in France as December to April. Here at Geneva its season extends} to May or June. It is worthy of planting in those cases where a choice late keeping dessert apple is desired for home use.

Historical. Probably originated with the Cherokee Indians in Western North Carolina. Introduced into Georgia about 185I. It was sent to France in 1860 from the Berckmans Nurseries of Augusta, Georgia, and since that time has been continuously propagated there. It is there regarded as a fruit of first quality and the tree is very productive (4). It is grown to a limited extent in the South but is practically unknown in New York.

Tree.

Tree a moderately vigorous or rather slow grower with rather slender branchlets. Form spreading, somewhat open. Trvigs medium to rather short; internodes rather short. Bark olive-green with some brownish-red, somewhat pubescent. Lenticels dull, rather conspicuous, moderately numerous, small, roundish, somewhat raised. Buds rather long, narrow, flat, appressed, rather acute, pubescent.

\section{FrUit.}

Fruit small to sometimes medium, uniform in size and shape. Form varies from roundish ovate or roundish conic to slightly oblate, regular, pretty symmetrical, often obscurely ribbed. Stem usually long and rather slender. Cavity moderately shallow to rather deep, narrow to rather wide, obtuse to acute; usually it is at least partly russeted and often it has outspreading russet rays. Calyx small to medium, usually closed; lobes acute to acuminate, reflexed. Basin usually very shallow, obtuse, wrinkled and often gently furrowed.

Skin thin, tough, smooth, clear yellow often shaded with a bronze blush. Dots small, russet or submerged and whitish.

Calyx tube cone-shape, sometimes approaching funnel-form. Stamens median to marginal.

Core medium to rather small, somewhat abaxile; cells fairly symmetrical, usually somewhat open; core lines somewhat clasping to meeting. Carpels very broad and pointed with truncate base varying to broad pointed ovate. Seeds numerous, dark, medium or below, rather narrow, plump, acute.

Flesh yellowish, firm, very tender, crisp, rather fine-grained, perfumed and aromatic, sprightly, mild subacid becoming nearly sweet, very good for dessert.

Season December to May or June (8).

\section{LACKER.}

REFERENCES. I. Watts, Horticulturist, I :482, 483. I847. 2. Thomas, 1849: I68. 3. Emmons, Nat. Hist. N. Y., 3:Ior. I851. fig. 4. Elliott, 1854:142. 5. Downing, 1857:163. 6. Hooper, 1857:53. 7. Warder, 1867:443.

Synonyms. Lacker $(2,4)$. Lacquier (I). Laduier $(2,3,6)$. Laquier $(4,5)$. LeCKer (4).

A red-striped winter apple evidently of the Rambo class. Fifty years ago in some sections of Western New York it was held to be one of the most 
desirable apples for that region $(1,2)$, but it has made little headway as a commercial variety and is gradually passing out of cultivation. It keeps rather better than Baldwin but is less attractive in appearance having a rather dull red color as it comes from the tree. It has been valued because of its fine dessert quality particularly in the spring but as it has a rather mild flavor it is less highly esteemed for culinary use. The tree is somewhat subject to canker. It bears biennially or in some cases alnost annually and yields good crops. The fruit hangs well to the tree.

Historical. Disseminated from Lancaster, $\mathrm{Pa}$. (4), and formerly planted to some extent in some portions of New York and the Middle West ( I, 2, $3,4,6,7)$. Occasionally very old trees of the variety are found still growing in New York in old orchards, but we have no knowledge of its being planted within recent years.

\section{TREE.}

Tree medium in size, a moderately vigorous grower. Form erect. Twigs medium in length, rather stout, rather thick at tips, straight or nearly so; internodes short. Bark dull reddish-brown, uniformly overlaid with a thin scarf-skin; heavily pubescent. Lenticels scattering, conspicuous, below medium in size, round, somewhat raised. Buds medium, moderately projecting, roundish, adhering, very pubescent.

\section{FruIt.}

Fruit medium to large. Form varies from oblate to roundish, often tending to elliptical and somewhat ribbed; sides usually a little unequal; fairly uniform in shape and size. Stem short, not exserted. Cavity somewhat furrowed, sometimes compressed, narrow to moderately wide, rather deep, acuminate, green or russet, often lipped. Calyx closed or partly open; lobes pubescent. Basin somewhat variable, usually obtuse but sometimes rather abrupt, medium in width and depth, furrowed and wrinkled.

Skin thick, tough, smooth, light yellow or greenish nearly covered with red, mottled and striped with crimson and conspicuously marked with grayish areolar dots which are mingled with smaller, whitish or russet dots. Prevailing color striped red, sometimes clear and bright but more often dulled by a waxy coating of bluish bloom.

Calyx tubc inclined to funnel-form. Stamens median.

Core medium to rather small, somewhat abaxile; cells usually pretty symmetrical, closed or partly open; core lines somewhat clasping. Carpels broadly roundish, emarginate, somewhat tufted. Seeds tufted, medium or below, obtuse to acute, plump, numerous.

Flesh white or nearly so, firm, tender, crisp, juicy, mild subacid, agreeably aromatic, good to very good for dessert, less desirable for culinary uses.

Season December to May.

\section{LADY.}

References. I. Duhamel, r768:309. 2. Knoop, r77r:68. 3. Forsyth, 1803: 49. 4. Coxe, 1817:117. fig. 5. Thacher, r822:129. 6. Ronalds, 1831:63. 7. Cat. Hort. Soc. London, 183r. 8. Kenrick, 1832:47. 9. Floy-Lindley, I833: 87. 10. Manning, 1838:59. Ir. Downing, 1845:I I 5. fig. I2. Cole, 1849:1 30. 13. Thomas, 1849:18r, 189. fig. 14. Emmons, Nat. Hist. N. Y., 3:89. 1851. 


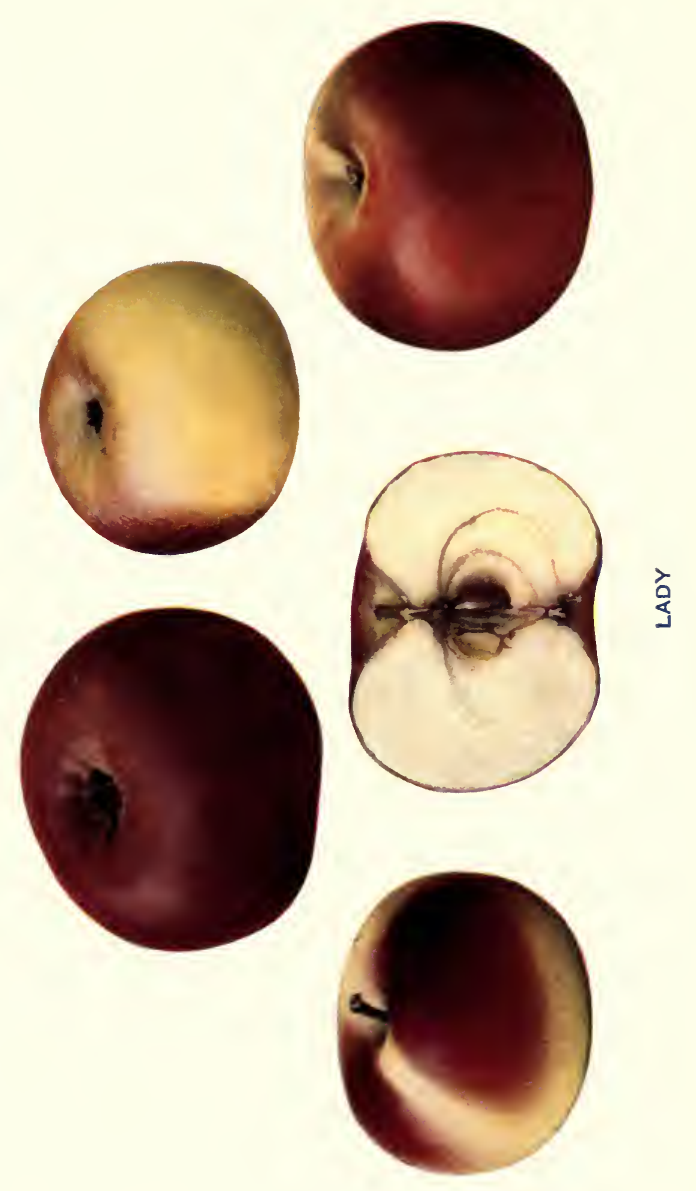



col. pl. No. 47. 15. Am. Pom. Soc. Cat., 1852. 16. Elliott, 1854:87. 17. Hovey, Mag. Hort., 20:29. 1854. 18. Hooper, 1857:52. 19. Lucas, 1859:557. 20. Warder, 1867:4II. 21. Fitz, 1872:166. 22. Downing, 1872:244. 23. Leroy, 1873:65. fig. 24. Barry, 1883:348. 25. Hogg, 1884:8. 25. Lyon, Mich. Hort. Soc. Rpt., 189o:294. 27. Wickson, 1891:248. 28. Bailey, An. Hort., 1892:243. 29. Bredsted, 2:210. 1893. 30. Woolverton, Ont. Fr. Stas. An. Rpt., 3:10. I896. figs. 31. Budd-Hansen, rgo3:III. fig. 32. Beach and Clark, N. Y. Sta. Bul., 248:128. 1904.

Synonyms. Almindelig (29). ApI (1, 23, 25, 29, 30). Api (11, 16, 18, 22, 31). Api eller (29). Api Fin (23). Api Ordinaire (23). Api Petit (11, 12, 20, 22, 25). Api Rose (23). Api Rouge (25). Apy Rouge (23). Cardinale (23). Christmas Apple (32). Gros Api Rouge (1 I, 16, 22). Kleiner Api (19). Lady Apple (5, 8, 9, I1, 12, 13, I4, 16, 17, 18, 21, 22, 24). Lady Apple (4, 10, 23, 25). Lille Api (29). Long Bois (23). Petrt Api $(6,7)$. Petil Api (16, 18). Petit Apis (23). Petit Api Rose (23). Petit Api Rouge (1 I, 16, 22, 23, 25). Pomme D'Api (2, 3). Pomme d'Api (8, 9, 13, I6, 21, 25). Pomme d'Api Ronge (i I, 16, 22). Pomme D'Apis (4). Pomme Rose ( I , 16, 18, 22). Pomone d'Apis (5).

A strikingly beautiful little apple especially suitable for decorative use and for dessert. In New York it is grown to a limited extent only and in restricted localities. It is in some cases grown with profit and often sells at very high prices. It does fairly well on any good apple soil, but a warm, gravelly or sandy loam seems to suit it best, developing to a marked degree the characteristically beautiful color and delicate high flavor of this variety, upon which its value chiefly depends. The upright habit of the limbs, together with the smallness of the apples, makes the picking of the fruit unusually expensive. The branches are full of short spurs upon which the fruit is borne in clusters. The fruit hangs well to the tree. The tree is but a moderate grower and does not come into bearing young, but in favorable locations, after it reaches maturity, it is a reliable cropper, bearing heavy crops biennially or in rare instances nearly annually. In order to grow Lady most successfully, particular pains must be taken to protect it from the attacks of insects and fungi, particularly from the apple scab fungus, by which it is often seriously damaged. When well grown, the crop is pretty uniform in size and shape and satisfactory in color and quality. It does not always color properly, and is then of little value for anything but cider, being too small either for general market purposes or for culinary use. Properly handled, it may be held in cold storage till summer, but there is little demand for it after the holiday season, and as it keeps 
well enough in ordinary storage till midwinter there is but little occasion for holding it in cold storage.

Historical. According to Leroy, who gives an excellent historical account of this variety, the Lady apple, or as it is there known, Api, has been in cultivation in France for at least three hundred years. It has been sparingly disseminated throughout this country from the Atlantic to the Pacific. It has long been recognized in the New York market as one of the most desirable apples for fancy trade at the holiday season.

TREE.

Tree at first moderately vigorous, eventually becomes a rather slow grower; size medium or somewhat dwarfish; branches erect, rather slender. Form rather dense, erect. Twigs long and slender, or on old trees rather short; internodes short. Bark bright brown approaching black, partly overlaid with thin scarf-skin, slightly pubescent towards the tips. Lenticels numerous, conspicuous, round or sometimes elongated, usually medium to small, sometimes large. Buds usually large, rather narrow, acute to acuminate, plump, quite pubescent, free. Leaves not large, rather narrow.

\section{Fruit.}

Fruit small to very small, uniform in size and shape. Form usually oblate but varies to roundish inclined to conic, often obscurely ribbed, symmetrical. Stem medium, slender. Cazity pretty large and wide, obtuse to acute, moderately shallow to deep, gently furrowed, sometimes thinly russeted. Calyx small, closed; lobes small, acute. Basin rather wide, shallow to moderately deep, obtuse, narrowly ridged and wrinkled.

Skin moderately thick, tough, smooth, glossy with a deep red blush which is often irregular and sharply outlined against the clear pale yellow or whitish ground color. Dots whitish or with russet point, inconspicuous. Prevailing effect beautiful bright red and yellow.

Calyx tube conical or somewhat funnel-form with short truncate cylinder. Stamens marginal.

Core small, axile; cells symmetrical, closed; core lines clasping. Carpels smooth, roundish or inclined to elliptical, emarginate, mucronate. Seeds plump, wide, obtuse, completely filling the cells.

Flesh white, firm, fine-grained, crisp, rather tender, juicy, pleasantly aromatic, mild subacid becoming nearly sweet, good to very good for dessert.

Season December to May.

\section{Other Varieties of the Lady Group.}

The Lady often produces seedlings which have a general similarity to the parent. Some of these have found their way into cultivation but up to the present time none of them has superseded the Lady.

Downing (22) mentions besides the Lady four other varieties of the Lady group, namely: the Black Lady Apple (Api Noir), the Star Lady Apple (Api Etoile), the Large Lady Apple (Api Gros), and the Rose-Colored Lady Apple (Api Gros Pomme de Rose). Of these the Large Lady apple appears to be the only one which has been disseminated to any considerable 
extent in this state. It is seldom or never intentionally planted by the fruit grower but sometimes it has been cultivated by mistake in place of the true Lady. It is easily distingtished from the true Lady because the bark of the twigs is not so nearly black, the fruit is more nearly round, has a very shallow basin and is a little larger and less highly colored than the Lady. It is an undesirable variety.

Seedlings. Fruits of different seedlings of the Lady have from time to time been received at this Station. None of these has been sufficiently tested as yet to show whether it is worthy of being introduced into general cultivation. One of the most remarkable lot of Lady seedlings which has come to our attention is that originated by Le Grand M. Smith of Nyack, N. Y., a brief notice of which was published in 1895.1 Some of these may be as desirable as the Lady.

HELEN is an apple of the Lady class much larger than Lady and fully as attractive in color. The flesh is very white, crisp, juicy and of mild agreeable flavor. It is grown by R. N. Lewis of Red Hook, Dutchess county, $\mathrm{N}$. Y., who reports that the tree is productive and that the fruit keeps late and brings good prices.

Highland Beauty, another Lady seedling, is described on a previous page.

\section{LADY FINGER.}

References. I. Coxe, 1817:146. fig. 2. Thacher, I822:129. 3. Elliott, I854:173. 4. Hooper, I857:52. 5. Warder, I867:724. 6. Downing, I869:245, 329. 7. Ib., I876:55 app. 8. Hogg, I884:127. 9. Bailey, An. Hort., I892:243. Io. 'Thomas, 1897:642.

Several different varieties of apples are known in cultivation under the name Lady Finger but none of these is grown to any considerable extent in New York.

Coxe (I) describes Lady Finger or Long Pippin as a variety of very delicate growth with small limbs, fruit remarkably long, skin greenish-yellow, season early winter.

Thacher's (2) description of Lady Finger is that it "is a long, tapering fruit, of a beautiful yellow and red color. It is well flavored, keeps till June. The tree bears ahundantly."

Elliott (3) describes Lady Finger, synonym Sheepnose, " as medium, oblong, pale yellow, often blushed. Flesh firm, watery. Season November, December."

Hooper (4) recognizes Lady Finger as a synonym of Kaighn, but erroneously, according to Downing, who gives Red Winter Pearmain as the correct name for this variety.

Warder (5) gives Red Lady Finger as a synonym of Red Winter Pearmain and Lady Finger Pippin as a synonym of Red Winter Pippin.

Downing $(6,7)$ recognizes the varieties described under the name Lady Finger by Hogg, Coxe, and Elliott as mentioned above and adds the description of still another variety which he received under this name from Maryland, the fruit of which is roundish conical, yellowish, shaded with deep crimson, subacid, good to very good; season August. He also gives Lady

\footnotetext{
${ }^{1}$ Rural N. Y., 54:106. 1895 .
} 
Finger as an erroneous synonym for Kaighn and Red Lady Finger as a synonym for Red Winter Pearmain.

Hogg (8) describes a red cider apple under the name Lady's Finger of Hereford and a greenish-yellow culinary apple in season from November to March under the name Lady's Finger of Lancaster. He also gives Lady's Finger of Kent as a synonym for Smart's Prince Arthur, and Lady's Finger as a synonym for White Paradise.

Thomas (ro) gives Lady Finger as a synonym of White Paradise.

\section{LADY SWEET.}

REFERENCES. I. Downing, 1845:136. fig. 2. Cole, 1849:132. fig. 3. Downing, Horticulturist, 3:578. 1849. 4. Emmons, Nat. Hist. N. Y., 3:75. 1851. 5. Hovey, 2:87. 1851. col. pl. and fig. 6. Am. Pom. Soc. Cat., 1854. 7. Elliott, I854:88. 8. Hovey, Mag. Hort., $21: 566$. 1855. fig. 9. Hooper, 1857:52. 10. Warder, 1867:561. fig. Ix. Fitz, 1872:166. 12. Downing, 1872:246. fig. г3. Barry, 1883:348. I4. Thomas, I885:227. fig. I5. Lyon, Mich. Hort. Soc. Rpt., 1890:294. 16. Bailey, An. Hort., 1892:243. 17. Farrand, Mich. Sta. Bul., 205:42. I903. I8. Budd-Hansen, I903:I12. I9. Powell and Fulton, U. S. B. P. I. Bul., 48:46. I903. 20. Beach and Clark, N. Y. Sta. Bul., 248:128. I904. Synonyms. Ladies Sweet (ii). Ladies Sweeting (i, 2, 3, 4, 5, 6, 7, 8, 9, I0, 14). Lady's Sweet (12, 13). Lady's Sweeting (20). Pommeroy (12, 20). Roa Yon (12).

This is one of the most desirable of the sweet apples for commercial planting. When well grown, the fruit is of good size, fine red color and excellent quality and keeps very late. It has an established reputation in market and is well known to fruit growers in many parts of the state, and often under the synonym Pommeroy. Doubtless it would be grown more extensively were it not for the fact that at present the market demand for sweet apples is quite limited. It ships well, stores well and usually sells well. It is also a good variety for the home orchard because the tree comes into bearing young, is a regular bearer, yields heavy crops, and the fruit is attractive in color and excellent either for dessert or for culinary uses. When grown as far north as Lake Ontario its season for home use extends from late autumn to late spring. Generally the tree is not a remarkably strong grower and is but moderately longlived. In some locations it is not quite hardy, and sometimes it is injured by bark-bursting. These deficiencies are in part overcome by top-working the variety upon some hardier and more vigorous sort. The variety is somewhat susceptible to the attacks of the scab fungus and requires thorough treatment to protect it from this disease. It is a reliable cropper, bearing biennially, or in some cases 

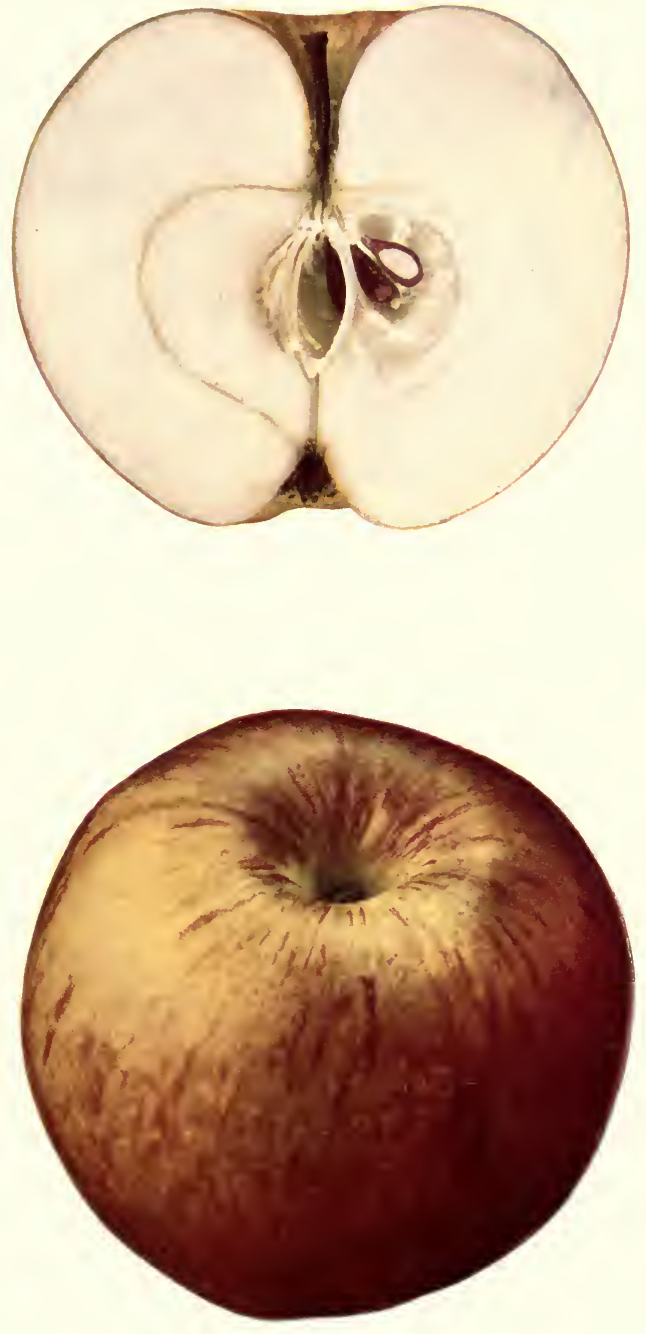

LADY SWEET 

almost annually, and the fruit hangs well to the tree. When it overbears, as it often does, there is apt to be a considerable portion of undersized and poorly colored fruit. This difficulty may be remedied in part by pruning so as to restrict the amount of bearing wood and permit free access of light and air to all parts of the tree.

Historical. This variety originated in the vicinity of Newburg where it established an excellent local reputation. It was first introduced into more general cultivation by the Downing Nurseries of that place $(I, 3,5)$. It is now propagated in the North Atlantic States, the Middle West and the Pacific region (16).

\section{TREE.}

Tree in the nursery is a slim, slow grower with tender foliage and soft wood and should be top-worked. In the orchard under favorable conditions it becomes moderately vigorous or in some cases a rather strong grower. Form rather upright becoming roundish and somewhat spreading. Trvigs medium to rather short, slender; internodes medium to short. Bark dull olive-green or reddish-brown with thin scarf-skin; pubescent particularly toward the tips. Lenticels rather inconspicuous, scattering, very small, elongated or roundish, raised. Buds medium to small, obtuse, closely appressed, slightly pubescent; ends often swollen so that the bud sets on an eminence. Leaves rather narrow, medium to small, ovate.

\section{Fruit.}

Fruit large to medium, pretty uniform in size and shape. Form roundish conic, often approaching oblong conic, irregularly elliptical, often ribbed, nearly symmetrical. Stem short to very short. Cavity acute or approaching acuminate, deep, usually rather narrow, sometimes wide, gently furrowed, often partly russeted, sometimes lipped. Caly.x small, closed, pubescent. Basin small, narrow, rather shallow to moderately deep, abrupt, furrowed.

Skin thin, tough, smooth, yellow or greenish, in highly colored specimens almost entirely overspread with bright red splashed with carmine. It is mottled and striped with whitish scarf-skin about the cavity. Dots rather conspicuous, small to rather large, pale areolar with russet point or submerge 1 , numerous toward the basin.

Calyx tube conical varying to funnel-shape. Stamens basal to median.

Core small to above medium, axile to somewhat abaxile; cells not uniformly developed, closed; core lines meeting or somewhat clasping. Carpels broad, roundish to roundish ovate, mucronate, sometimes slightly emarginate, somewhat tufted. Seeds dark, large, rather narrow, long, acute, slightly tufted, often abortive.

Flesh whitish or with slight yellow tinge, rather firm, moderately fine, crisp, tender, juicy, sweet with a distinct and pleasant aroma, very good to best.

Season November to April or May; in cold storage to May or June.

\section{LANDON.}

References. I. Warder, $1867: 724$. 2. Downing, 1872:248. 3. Thomas, 1885:5I5. 4. Macomber, 4 m. Gard., I I:I4I. I89o. 
Fruit attractive in color, of good marketable size and a good keeper. On account of its mild flavor it is better suited for dessert than for culinary use. The record which it has made at this Station confirms the statement of Macomber (4) that it is a rather shy bearer.

Historical. Brought to notice by Buel Landon, South Hero, Vermont, about forty years ago $(\mathrm{I}, 2,4)$. It appears to be but little known outside of that locality.

\section{TREE.}

Tree moderately vigorous or rather slow-growing; branches slender. Form spreading, dense, dwarfish with rather flat top. Twigs short to medium, nearly straight but somewhat geniculate, moderately slender; internodes short to medium. Bark clear light brown mingled with red, irregularly marked and mottled with scarf-skin; slightly pubescent. Lenticels conspicuous, small to rather large, roundish or elongated, raised. Buds medium or below, plump, roundish, obtuse, free or nearly so, pubescent.

\section{FRUrT.}

Fruit medium to large, averaging above medium, pretty uniform in size and shape. Form roundish oblate to roundish conic, sometimes obscurely ribbed. Stem short. Cazity large, acute, moderately deep to deep, slightly furrowed, sometimes slightly russeted. Calyx small to medium, partly open or sometimes closed. Basin shallow to moderately shallow, rather obtuse, somewhat furrowed, wrinkled.

Skin thin, tough, nearly smooth, yellow mostly washed and mottled with red and distinctly striped with carmine, often becoming deep crimson or purplish on the side exposed to the sum. Dots conspicuous, whitish, large and irregular, especially about the cavity, or areolar with russet point.

Caly.x tube elongated funnel-shape, constricted just below the limb and often extending to the core. Stamens median.

Core medium or above, abaxile; cells open or partly open; core lines clasping. Carpels broad at the base approaching truncate, rounding toward apex, slightly emarginate. Seeds medium or above, rather wide, flat, obtuse.

Flesh yellowish, sometimes tinged with red next the skin, firm, a little coarse, crisp, moderately tender, juicy, aromatic, mild subacid becoming nearly sweet late in season, good to very good.

Season December to May.

\section{LANKFORD.}

References, I. Downing, r881:92 app. 2. Van Deman, U. S. Pom. Rpt., 1891:390. 3. Bailey, An. Hort., 1892:243. 4. Van Deman, Am. Pom. Soc. Rpt., 1895:72. 5. Rural N. Y., 55:1, I22, 195. 1896. fig. 6. Stinson, Ark. Sta. Bul., 43:103. 1896. 7. Powell, Del. Sta. Bul., 38:19. 1898. 8. Am. Pom. Soc. Cat., 1899:18. 9. Alwood, Va. Sta. Bul., r30:133. r9or. fig. ro. Powell and Fulton, U. S. B. P. I. Bul., 48:47. I903. II. Budd-Hansen, I903:113. I 2. Beach and Clark, N. Y. Sta. Bul., 248:128. I904.

Synonyms. Langford (5). Langford (5, 12). Lankford's Seedilng (6). Vickers (1, 12).

Lankford, as fruited at this Station, is a dull red apple of good size and fairly good quality. It is easily excelled by the standard varieties. It is in 


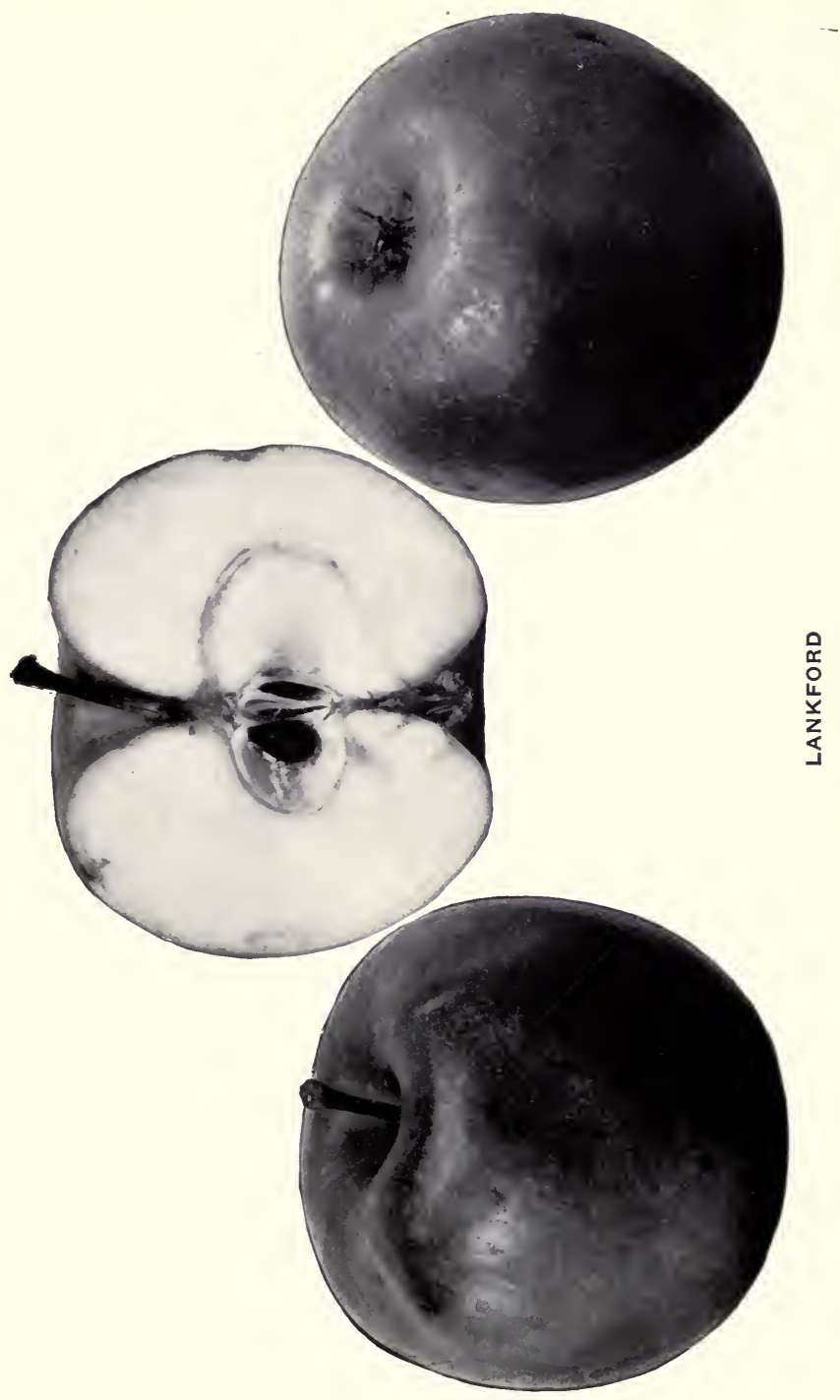



season from December to May but scalds badly after midwinter (IO, I2). The tree makes a tall, slim growth in the nursery. In the orchard it is a strong grower and comes into bearing rather young, but although it occasionally bears a full crop it has not proved a reliable cropper at this Station. Although in some parts of the South fruit growers regard it with favor it does not appear to be well adapted to regions as far north as New York and is not recommended for planting in this state.

Historical. It originated as a chance seedling at Lankford, Kent county, Maryland, about forty years ago $(\mathrm{I}, 4,5,9)$.

\section{Tree.}

Tree vigorous with long, slender branches. Form at first upright but becoming roundish or much spreading, rather dense. Twigs medium in length, rather straight except that they are geniculate, moderately stout; terminal buds large; internodes medium to short. Bark dark brownish-red with some olive-green, partly mottled with thin scarf-skin; pubescent toward the tip. Lenticels conspicuous where the bark is brightly colored, quite numerous, below medium to above, often elongated, raised. Buds medium in size, broad, flat, obtuse, free, slightly pubescent.

\section{FRUIT.}

Fruit usually medium or below, sometimes large. Form roundish oblate to oblong truncate, ribbed but faintly if at all; sides sometimes unequal; axis sometimes oblique; pretty uniform in shape and size. Stem medium to rather long, sometimes very long. Cavity acute to acuminate, deep, broad to medium in width, nearly symmetrical, usually green, sometimes partly russeted. Calyx below medium to large, closed or partly open; lobes usually reflexed. Basin moderately deep and wide, varying sometimes to shallow and narrow, rather abrupt, sometimes wrinkled.

Skin tough, smooth, somewhat waxy, not glossy, grass-green becoming yellowish, washed and striped with red. In highly colored specimens deep, dull red covers nearly the entire surface. Dots whitish or with russet point, numerous and small toward the basin, elongated, large and scattering toward the cavity.

Calyx tube long, cone-shape or somewhat funnel-form. Stamens below median.

Core medium or below, axile or nearly so; cells pretty symmetrical, closed or partly open; core lines clasping. Carpels much concave, broadly roundish or approaching roundish obcordate, mucronate, slightly emarginate, somewhat tufted. Seeds medium in size, rather wide, obtuse to acute, dark; often some are abortive.

Flesh tinged with yellow or greenish, firm, moderately fine, crisp, nearly tender, moderately juicy, mild subacid becoming nearly sweet, fair to good.

Season December to May.

\section{LANSINGBURG.}

References. I. Hooper, 1857:53. 2. Warder, 1867:540. 3. Downing, 1869: 249. 4. Am. Pom. Soc. Cat., 1875:10. 5. Thomas, 1885:515. 6. Bailey, An. 
Hort., 1892:243. 7. Van Deman, Rural N.Y., 58:382. 1899. 8. Budd-Hansen, 1903:I13. 9. Ragan, U. S. B. P. I. Bul., 56:173. 1905.

Synonyms. Lansinburg (I). Lansingburgh $(2,3)$. Lansingburgh (9). Lansingburg Pippin (9). Red Rock. Rock Apple (9).

A late-keeping apple which is grown to some extent in the Middle West (6). Warder speaks of it as an old variety common in Cincinnati and along the Ohio river. Suitable only for culinary use and for market. Color greenish becoming rich yellow with a striped appearance and blushed with carmine. It is coarse in texture, sweetish in flavor and not good in quality $(1,2,7)$. It is sometimes called Rock or Red Rock in New York.

Historical. An old variety which appears to have been first brought to notice in Ohio $(1,2)$. It is but little known in New York and is not recommended for planting in this state.

\section{TREE.}

Tree vigorous or moderately vigorous. Form upright, "brushy and thorny, looking like a wilding" (2). Twigs medium or below, rather stout, nearly straight; internodes short. Bark dull brownish-red overlaid with thick scarfskin, giving a grayish-brown effect, slightly pubescent. Lenticels rather numerous but not conspicuous, small to medium, the larger ones roundish. $B u d s$ medium, acute, somewhat pubescent, appressed.

\section{Fruit.}

Fruit medium or above. Form roundish oblate sometimes a little inclined to conic, obscurely ribbed, nearly symmetrical, often sides unequal, pretty uniform in shape. Stem medium to short. Cavity acute, deep, broad, symmetrical or slightly furrowed, or sometimes compressed, russeted. Calyx medium, open; lobes short, broad, obtuse. Basin shallow to medium in depth, medium to wide, obtuse to somewhat abrupt, furrowed and wrinkled.

Skin thick, very tough, slightly rough, rather dulled with faint bloom, yellow or greenish deeply blushed or mottled with red, striped and splashed with dark carmine. Dots often areolar, green or yellow with gray or russet center, rather conspicuous. Prevailing effect red or striped red.

Calyx tube long, cone-shape or funnel-form with wide limb.

Core medium to small, closed; core lines somewhat clasping. Carpels round approaching round cordate, emarginate, mucronate, slightly tufted. Seeds rather large, wide, flat, obtuse, slightly tufted.

Flesh tinged with green or yellow, very firm, rather coarse, breaking, moderately tender, rather dry, mild subacid, becoming somewhat sweet, fair to good.

Season December to May or June.

\section{LA VICTOIRE.}

References. I. Craig, Can. Dept. Agr. Rpt., I8g6:126. 2. Macoun, Quebec Pom. Soc., 1899:20. 3. Waugh, Vt. Sta. Bul., 83:91. I900. 4. Macoun, Can. Dept. Agr. Bul., 37:44. 1901.

Synonym. La Victoria Seedling (I).

A handsome apple of the Fameuse group, probably a seedling of the Fameuse, but a better keeper. On account of its season and hardiness it may 
be desirable for planting in the northern and more elevated regions of the state.

Historical. Originated near Grenville, Quebec. The first published description of it of which we find any record is that given by Macoun in 1899 (2). It is as yet practically unknown in New York.

\section{TREE.}

Tree hardy and a strong, moderately spreading grower, but so far as tested has not proved very productive (4).

\section{FRUIT.}

Fruit as described by Macoun (4) and Waugh (3) is above medium size to large. Form strongly oblate, slightly conic, smooth and regular. Stem short and stout. Cavity of medium depth, medium in width to wide, slightly russeted. Calyx small to medium, closed or open. Basin abrupt, medium in depth to deep, wide, regular, almost smooth.

Skin tough, greenish-yellow washed and striped and nearly covered with light crimson red, the whole overspread with bloom. Dots fairly numerous, conspicuous, whitish or gray.

Core small to rather large, closed.

Flesh firm, white streaked with red, rather coarse, moderately juicy, aromatic, mild subacid. with a pleasant flavor and aroma distinctly like that of the McIntosh, quality good.

Season winter.

\section{LAWVER.}

References. I. Prairie Farmer, 1868. (cited by 19). 2. Warder, Ill. Hort. Soc. Rpt., 1868:95-97. 3. Am. Pom. Soc. Cat., 1871:8. 4. Downing, 1872: 251. 5. Fitz, r872:I21, I43. 6. Thomas, r885:516. 7. Am. Pom. Soc. Rpt., 1887:92. 8. Mo. Sta. Bul., 6:7. г889. 9. Wickson, r89ı:246. го. Bailey, $A n$. Hort., r892:243. Ir. Beach, Paddock and Close, N. Y. Sta. An. Rpt., r 5:272. I896. I2. Stinson, Ark. Sta. Bul,, 43:103. I896. 13. Mass. Hatch Sta. Bul., 44:4. I897. I4. Macoun, Can. Dept. Agr. Rpt., I899:78. I5. Alwood, Va. Sta. Bul., rзo:ı35. г90г. г6. Powell and Fulton, U. S. B. P. I. Bul., 48:47. I903. I7. Budd-Hansen, I903:I 4. I8. Beach and Clark, N. Y. Sta. Bul., 248:129. 1904. 19. Ragan, U. S. B. P. I. Bul., 56:176. 1905.

Synonyms. Black Spy. Dclaware Red Winter (II, I4, I5, I6, I8, I9). Delaware Winter (7). Delazvare Winter (II, I3).

An attractive bright red apple, pretty uniform in size and shape. It is very firm, ships well and keeps late. It does not rank high in quality and is less suitable for dessert than for market and culinary uses. As grown in this state often a considerable portion of the fruit grades below medium size and lacks proper development in quality and color. It is better adapted to more southern latitudes. In some places the tree is not a good cropper, but usually it comes into bearing rather early and is a reliable biennial bearer, often yielding very heavy crops. The frut and foliage are quite subject to 
the attacks of the apple scab fungus, but this may be readily controlled by proper treatment. This variety is seldom regarded favorably for commercial planting by New York fruit growers, and the quality is not high enough to give it a place among the varieties recommended for the home orchard.

Historical. Origin uncertain. "Introduced by Geo. S. Park, of Parkville, Mo., and said to have been found in an old Indian orchard in Kansas" ( $I$, 4). Reintroduced from Delaware under the name Delaware Winter (7). It has also been disseminated in some portions of New York under the name Black Spy. During the last forty years it has been pretty thoroughly disseminated throughout the country.

\section{TREE.}

Tree medium or above, vigorous or moderately vigorous; branches long, moderately stout, curved. Form roundish or somewhat flat, spreading, rather dense. Truigs short to rather long, curved, moderately stout; internodes medium to rather long. Bark dark brownish-red mingled with olive-green, mottled with rather heavy scarf-skin, slightly pubescent near the tips. Lenticels dull, inconspicuous, rather scattering, medium to large, elongated, raised. $B$ Bds large to medium, broad, plump, obtuse, free, slightly pubescent.

\section{Fruit.}

Fruit medium or above; as fruited here it usually averages no more than medium and often a considerable portion of the crop runs below medium. Form roundish or somewhat oblate, ribbed but slightly if at all, regular and symmetrical. Stem variable, often long and slender. Cavity acute or approaching acuminate, deep, rather large and broad, often compressed or distinctly furrowed, usually more or less russeted and often with outspreading russet rays. Caly.x rather small, closed or partly open, often leafy; lobes sometimes separated at the base. Basin usually rather wide, flat and obtuse, sometimes moderately deep and moderately abrupt, gently furrowed, sometimes wrinkled.

Skin moderately thin, tough, sometimes a little waxy, smooth, occasionally showing some of the yellow ground color but usually completely covered with solid bright red which about the base deepens to purplish and is often mottled and streaked with dull grayish scarf-skin. Toward the apex it has a characteristic ligliter and brighter red tone. Dots whitish or russet, small and numerous about the basin, larger and scattering toward the cavity.

Caly $x$ tube rather long, narrow at top, funnel-form. Stamens median.

Core abaxile, medium or ahove; cells pretty symmetrical, open or partly closed; core lines clasping. Carpels somewhat concave, roundish to broadly obcordate, but slightly emarginate if at all, somewhat tufted. Seeds dark, medium to rather large, wide, obtuse, somewhat tufted.

Flesh slightly tinged with yellow or greenish, rather hard, somewhat breaking, moderately fine, crisp, tender, juicy, rather brisk subacid, somewhat aromatic, not highly flavored, fair to good in quality.

Season January to May or June. Commercial limit March or possibly April. 

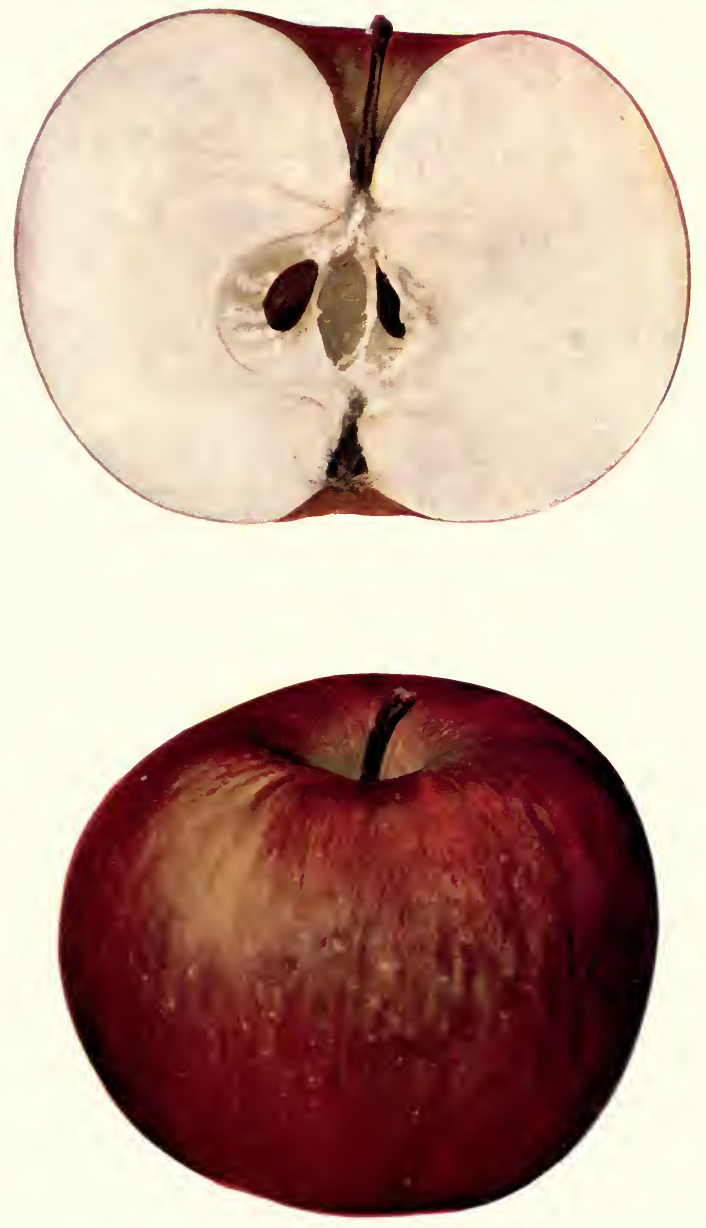

LAWVER 



\section{LEE SWEET.}

Lee Sweet is a handsome deep red apple of good size, acceptable for dessert but especially valuable for market and culinary uses. It is desirable for the home orchard and appears to be worthy of consideration for commercial planting where a sweet apple is desired. The fruit is illustrated on the color plate with Northern Spy, and a section of it is shown on the color plate with McLellan.

The tree does not come into bearing very young, but when mature is a reliable cropper, yielding moderately heavy crops biennially. The fruit hangs fairly well to the tree and is pretty uniform in size and quality, having about as high a percentage of marketable fruit as the Baldwin. It is somewhat subject to scab, but this may be readily controlled by proper treatment. It stores well and, if perfect, keeps well. In ordinary storage it is in season from January to April.

Historical. An old variety of uncertain origin known to some in the vicinity of Geneva under the name of Lee Sweet because it was formerly grown on the White Springs farm then known as the Lee farm. It is here described under its local name because we have been unable to identify it with any other variety.

TREE.

Tree medium in size, moderately vigorous. Form erect. Twigs medium in length to rather short, pretty straight, rather slender; internodes short to medium. Bark olive-green overcast with brownish-red, overlaid with thin scarf-skin, slightly pubescent. Lenticels moderately numerous, raised, generally elongated, small. Buds small, roundish, pubescent, nearly free from bark.

\section{FRUIT.}

Fruit medium to nearly large, fairly uniform in shape and size. Form roundish conic to oblong conic, often somewhat angular or elliptical; sides sometimes unequal. Stem medium to short. Cavity acuminate, deep, moderately wide, sometimes lipped or furrowed, russeted, often with outspreading russet rays. Caly:x rather large, open; lobes long, acuminate, reflexed, often separated at the base. Basin medium to rather small, usually abrupt, usually medium in depth and width, sometimes a little furrowed.

Skin tough, glossy bright red striped with purplish-carmine over a yellow background and sometimes marked with grayish scarf-skin about the base. Highly colored specimens are nearly or quite covered with red but where the color is less strongly developed it has a striped appearance. Dots usually whitish, rather numerous, small, occasionally rather large and dark russet.

Calyx tube conical or funnel-form. Stamens median or below. 
Core medium to small, abaxile; cells pretty symmetrical, open or closed; core lines clasping. Carpcls much concave, roundish ovate, mucronate, tufted. Seeds short, broad, plump, obtusc.

Flesh nearly white, slightly tinged with yellow, firm, somewhat coarse, not very juicy, sweet, good.

\section{LEHIGH GREENING.}

References. r. Van Deman, U. S. Pom. Rpt., 189r:390. 2. Butz, Penn. Sta. An. Rpt., 1892:107. fig. 3. Van Deman, Am. Pom. Soc. Rpt., 1895:72. 4. Am. Pom. Soc. Cat., I899:I8. 5. Johnson, Rural N. Y., 62:19, 370. 1903. figs. 6. Budd-Hansen, 1903:1 I5.

An attractive apple of the French Pippin type, of good size and an excellent keeper. It was mentioned on page I34 as possibly identical with French Pippin. Further comparison leads us to believe that it is distinct. It is desirable rather for market and culinary uses than for dessert.

Historical. It has been grown in Lehigh county, Pennsylvania, for about sixty years (5).

TREE.

Tree moderately vigorous; branches rather stout and crooked. Form widespreading, open. Twigs medium to long, irregularly curved, stout to rather slender; internodes short to above medium. Bark clear dark reddish-brown mingled with olive-green, slightly mottled with scari-skin, slightly pubescent. Lcnticels scattering, rather conspicuous, medium in size, round or slightly elongated, raised but slightly if at all. Buds set deeply in the bark, above medium to rather small, broad, flat, obtuse, appressed, quite pubescent.

\section{Fruit.}

Fruit medium to large, pretty uniform in size and shape. Form roundish oblate to roundish conic, ribbed but faintly if at all; sides sometimes unequal. Stem medium to long, moderately slender. Cavity acute to acuminate, medium in depth to deep, narrow to moderately wide, sometimes lipped, more or less russeted and often with outspreading russet rays. Calyx medium in size, somewhat open; lobes medium to long, rather narrow, acuminate, often somewhat separated at the base. Basin usually rather large, abrupt, moderately deep to rather shallow, moderately wide, gently furrowed.

Skin dark green in the fall but eventually becoming waxen yellow, occasionally with a thin blush of bright red. Dots numerous, submerged or pale areolar with russet point.

Calyx tube rather long and wide, broadly funnel-shape. Stamens median to basal.

Core medium to small, usually abaxile; cells symmetrical, wide open; core lines slightly clasping. Carpels pointed ovate to broadly cordate, tufted. Seeds numerous, medium in size, rather dark brown, somewhat elongated, plump, acute to acuminate.

Flesh yellowish-white, firm, moderately fine or a little coarse, rather crisp, tender, juicy, sprightly, mild subacid, aromatic, good or sometimes very good.

Season January to May. 


\section{LILLY OF KENT.}

References. I. Van Deman, U.S. Pom. Rpt., I89r:390. 2. Wright, Am. Gard., 17:34. I896. 3. Powell, Del. Sta. Bul., 38:19. 1898. 4. Am. Pom. Soc. Cat., 1899:18. 5. Ragan, U. S. Pom. Bul., 8:18. I899. 6. Budd-Hansen, I903: 115 .

Synonym. Lily of Kent $(2,3)$.

Fruit large, globular, green or yellowish-green, subacid, good in quality and a very late keeper. This is a variety of recent introduction (I). It has not yet been stufficiently tested in New York to determine whether or not it is a desirable variety for this region. It originated in Delaware and is being planted to considerable extent in some portions of that state (3).

\section{LIMBERTWIG.}

References. I. Kenrick, I832:59. 2. Thomas, I849:168. 3. Phoenix, Horticulturist, 4:471. I850. 4. Emmons, Nat. Hist. N. Y., 3:67. 1851. 5. Elliott, 1854:I43. 6. Robey, Horticulturist, II :89. I856. 7. Downing, I857: 164. 8. Hooper, 1857:54. 9. Am. Pom. Soc. Cat., 1860. ro. Warder, 1867: 516. fig. I1. Fitz, 1872:143, I49. I2. Leroy, 1873:420. fig. I3. Barry, I883: 348. 14. Lyon, Mich. Hort. Soc. Rpt., 189o:294. I5. Wickson, 1891:248. I6. Bailey, An. Hort., I892:243. I7. Clayton, Ala. Sta. Bul., 47:7. I893. 18. Stinson, Ark. Sta. An. Rpt., 7:47. I894. I9. Ill. Sta. Bul., 45:329. I896. 20. Rural N. Y., 62:822. I903. fig. 21. Budd-Hansen, I903:II5. 22. Bruner, N. C. Sta. Bul., 182:25. I903. figs. 23. Farrand, Mich. Sta. Bul., 205:45. I903. 24. Powell and Fulton, U. S. B. P. I. Bul., 48:47. I903. 25. Beach and Clark, N. Y. Sta. Bul., 248:129. 1904.

Synonyms. James River $(2,5,7)$. Lambertwig (12). Limber Twig (1, 2, 4, 5, 7, 8, 9, I3, I4, 15, 16, 23). Red Limbertwig (22).

There are several different apples which are known locally under the name Limbertwig. Willow Twig is sometimes incorrectly called Limbertwig, as has been noted by some writers $\left(5, \mathrm{I}_{4}\right)$.

There is an apple grown in Northern New York, probably of local origin, which is there known under the name of Limbertwig. This fruit is of the Blue Pearmain class and resembles Bethel in form and color but the flesh is coarser and has more acidity. It is a good keeper.

In some portions of Western New York the Twenty Ounce is called Limbertwig.

The variety described below as the small or red Limbertwig appears to be practically unknown among New York fruit growers except in some localities in the southeastern portions of the state. That described as the large or green Limbertwig, so far as we know, is not grown in New York.

In some of the references above cited the writers appear to have clearly in mind the red Limbertwig (4, 7, I0, I4, 2I); in other cases they evidently describe the green Limbertwig $(2,5)$; occasionally both are mentioned ( 3 , 8 , 19), but in most instances it is not clear which variety is referred to.

\section{LIMBERTWIG (Small or red).}

Fruit attractive in appearance, of good deep red color, pretty uniform in size, well adapted for storage, ships well and keeps late, but the quality is 
only fair to good. The tree is thrifty and an excellent cropper and the fruit hangs well to the tree despite high winds $(8,10,20)$; laterals slender becoming drooping with heavy crops.

\section{Fruit.}

Fruit above medium to below; uniform in size and shape. Form roundish to slightly oblate conic, ribbed but slightly if at all, symmetrical and regular. Stem medium in length and thickness, usually not exserted. Cavity acuminate, deep, rather broad to moderately narrow, sometimes partly russeted, smooth or gently furrowed. Caly.x small to medium, closed or partly open; lobes short, broad, flat or sometimes recurved. Basin small, moderately narrow, varying from shallow and obtuse to moderately deep and somewhat abrupt, often a little furrowed.

Skin slightly roughened with numerous and rather conspicuous russet dots, yellow largely covered with red, deepening in the sun to dark purplish-red, sparingly and obscurely striped with dull carmine, sometimes marked with broken irregular russet veins. Prevailing effect attractive dark red.

Caly.x tube cone-shape to elongated funnel-form. Stamens median or above.

Core sessile, abaxile or nearly so, rather small to medium; cells not uniformly developed, pretty symmetrical, closed or slightly open ; core lines clasping. Carpels concave, elliptical, deeply emarginate, much tufted. Seeds numerous, elongated, medium to small, plump, obtuse to acute, much tufted, clinging to the carpels.

Flesh yellowish, hard, moderately fine, not very crisp, juicy, aromatic, subacid, good.

Season January to March or April; in cold storage February to May or later.

\section{LIMBERTWIG (Large or green).}

As compared with the variety last described the fruit of the large or green Limbertwig is much the larger but it does not keep as well. It is decidedly less attractive being dull green partly overspread with dull brownish-red, marked over the base with ahitish scarf-skin and sometimes with a few irregular patches or streaks of russet. Dots coarse, conspicuous, usually areolar with russet point.

Carity large, acute or approaching acuminate, wide, deep, somewhat furrowed. Caly.r tube cone-shape to somewhat funnel-form. Stamens median. Core medium to rather large, axile; cells symmetrical, closed; core lines meeting or somewhat clasping. Carpels smooth or nearly so, elliptical to broadly obcordate, deeply emarginate. Seeds rather large to medium, rather wide, obtuse, smooth or nearly so, free. Flesh subacid, coarser and more juicy than the other and much inferior in flavor and quality.

\section{(I) LONG ISLAND RUSSET.}

References. I. Coxe, I8I 7:I23. fig. 2. Robey, Horticulturist, Ir:89. I856. 3. Elliott, 1858:173. 4. Warder, 1867:725. 5. Downing, 1869:255. 6. Am. Pom. Soc. Cat., 1875:10. 7. Bailey, An. Hort., 1892:243. 8. Hicks, Rural N. $Y$., 53:205. I894. 9. Thomas, 1897:643.

Syconym. English Russet (8). 


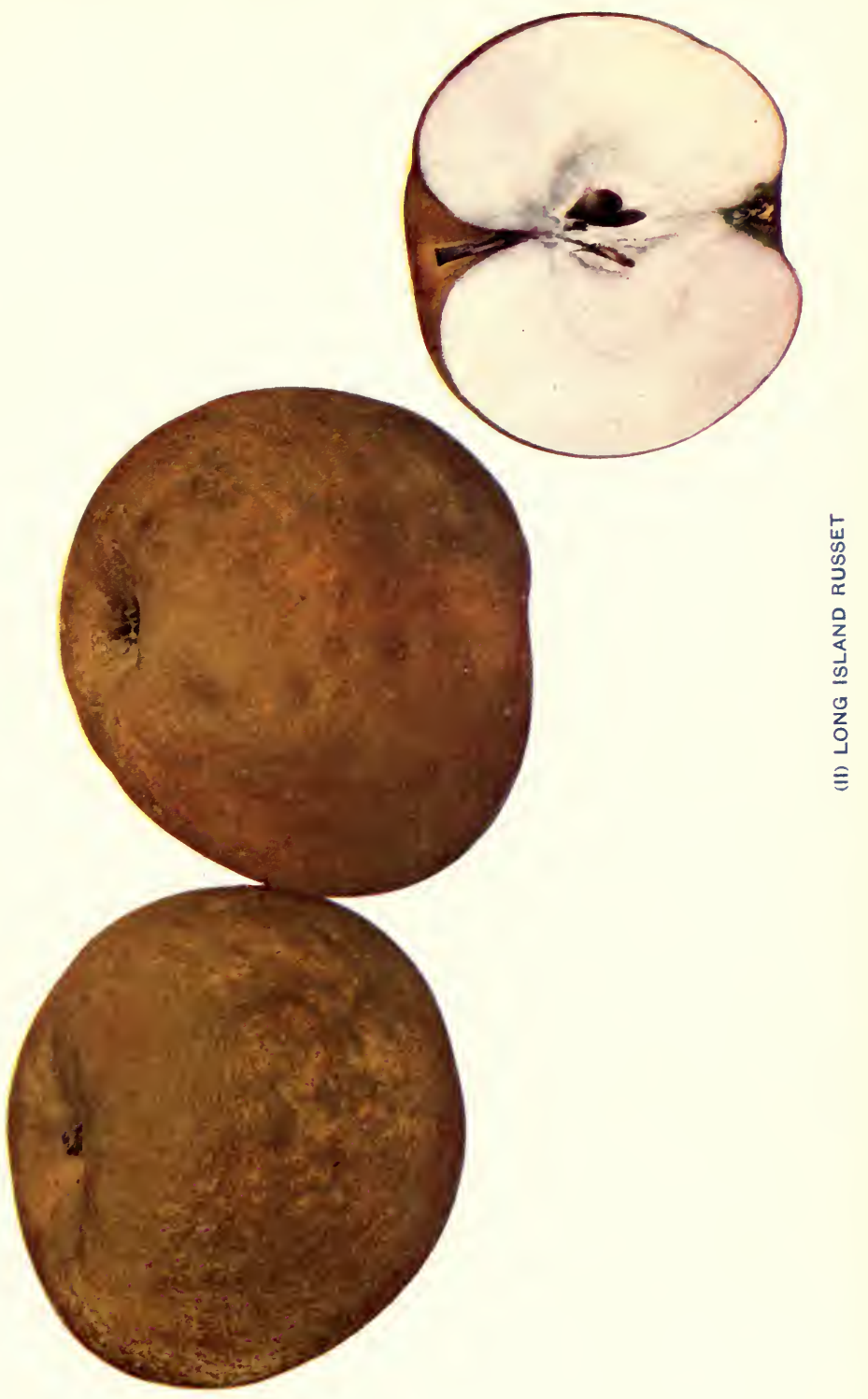



This variety was formerly much grown on Long Island and in Westchester county, where it was considered profitable and particularly valued for cider $(\mathrm{I}, 8)$. It is now nearly obsolete. Coxe describes it as "Small, *** rather oblong, diminishing towards the crown, which is very hollow; the stalk is a full inch in length, planted very deep-the flesh is dry and sweet; makes a very sweet, sirupy cider, which when fined is much admired-the skin is a yellow russet, clouded with black spots-this apple keeps well." Elliott gives its season as December to March (3). Downing (5) gives the season as October to February. "Flesh yellowish, tough, rather dry, almost sweet." Warder (4) classes it with the subacid apples. Hicks (8) says "it is a long keeper, sometimes keeping till apples come again." Its general appearance is attractive for a russet.

\section{(II) LONG ISLAND RUSSET.}

From various parts of Long Island and from one locality in Michigan we have received under the name Long Island Russet the variety which is described below and illustrated in the accompanying color plate. This fruit has also come to us from the Hudson valley. It is evident that it does not correspond with the description by Coxe cited above. We have been unable to identify it with any named variety. So far as we can learn this variety is no longer being planted and is fast becoming obsolete, being represented now only by old trees.

\section{FRUIT.}

Fruit medium to small, sometimes nearly large. Form roundish to somewhat oblong, narrowing toward the basin, sometimes approaching truncate cylindrical, often with an oblique axis, irregular; not very uniform in size and shape. Stem short to medium, moderately slender. Cavity large, acute, usually deep, broad, green or russeted, sometimes furrowed. Calyx closed or partly open; lobes rather narrow, acute. Basin often oblique, of medium depth, rather narrow to moderately wide, rather abrupt, a little furrowed and wrinkled.

Skin tough, more or less covered with golden russet but usually with some patches of smooth bright yellow or green, irregularly marked with indistinct grayish scarf-skin. Dots inconspicuous, scattering, gray or russet. Prevailing effect is usually golden russet.

Calyx tube conical to funnel-shape, with a wide limb and narrow cylinder. Stamens basal to nearly median.

Core rather small, sometimes medium, abaxile or sometimes axile; cells often unsymmetrical, closed or open; core lines meeting or somewhat clasp- 
ing. Carpels smooth or nearly so, broadly roundish to angular-ovate, wide at the middle and tapering toward the base and apex, but slightly emarginate if at all, sometimes slightly tufted. Seeds numerous, dark brown, medium in size, moderately narrow, plump, obtuse to acute, sometimes tufted.

Flesh tinged with a decided deep yellow, firm, at first rather crisp or hard, but often becoming tough, moderately fine, sprightly subacid, juicy, very good.

Season November to midwinter or later.

\section{LONG STEM OF PENNSYLVANIA.}

References. I. Brinckle, Mag. Hort., I9:169. I853. 2. Downing, 1857:86. 3. Warder, $1867: 725$. 4. Thomas, I885:236.

A Pennsylvania apple described by Dr. Brinckle in 1853 as a new variety (I). It is but seldom found in New York and is not recommended for planting in this state.

Other varieties which have been cultivated under the name of Long Stem will be noticed in Volume II.

\section{Fruit.}

Fruit below medium in size. Form roundish inclined to cylindrical, ribbed but faintly if at all. Stem long to very long, slender, bracted. Cavity medium to rather small, acuminate, rather narrow to moderately wide, usually smooth. Calyx medium to rather large; lobes often leafy, elongated, obtuse. Basin shallow to very shallow, narrow, furrowed and wrinkled.

Skin smooth, pale yellow or greenish, nearly covered with thin red and faintly marked with narrow stripes of carmine. Dots numerous, gray or russet.

Caly:x tube funnel-form approaching cylindrical, with pistil point extending into the base. Stamens median or above.

Core large, abaxile; cells symmetrical, open; core lines clasp the funnel cylinder. Carpels smooth, much concave, elongated approaching oval, slightly emarginate. Seeds very numerous, below medium to rather large, obtuse to acute, variable, plump, moderately wide.

Flesh tinged with yellow or greenish, firm, crisp, rather tender, juicy to very juicy, moderately fine-grained, sprightly subacid, good to very good.

Season November to February.

\section{MCAFEE.}

Referexces. I. Elliott, I854:158. 2. Downing, I857:I70. 3. Downing, Horticulturist, 16:42. I861. 4. Warder, 1867:601, 725. 5. Howsley, Am. Pom. Soc. Rpt., r871:76. 6. Am. Pom. Soc. Cat., r871. 7. Downing, 1872: 260, 363, 21 app. fig. 8. Fitz, 1872:143. 9. Barry, 1883:349. Io. Thomas, 1885:517. I1. Lyon, Mich. Hort. Soc. Rpt., I890:294. I2. Bailey, An. Hort., I892:244. I3. Beach, W. N. Y. Hort. Soc. An. Rpt., 4 I:76. 1901. I4. BudciHansen, I9o3:I 19. 15. Bruner, N. C. Sta. Bul., 182:27. 1903.

Srnoxyms. Gray Apple (7). Gray's Keeper (5). Indian Wyandotte (7). Large Striped Pearmain (4). Large Striped Pearmain ( I, 5, 6, 7). Large Striped Winter Pearmain (3). Large Striped Winter Pearmain (7, 9). McAfee (7). McAfee Red (14). McAfee's Nonesuch (8). McAfee's Nonesuch (5). McAfee's Nonsuch (2, 7, 9, 10). McAfees 
Red (5, 7). McAffee (4). McAffee's Nonesuch (6). Missouri Superior (5, 7, 13). Neze Missouri (5). Nonsuch (7). Park (5). Parks Keeper (5, 7, 13). Snorter (I, 7). Stevenson Pippin (13). Stine (I5). Storr's Wine (5). Striped Pearmain (1). Stripcd Sweet Pippin (7). Striped Winter Pearmain (7). Valandingham (5). White Crow (5). Winter Pearmain (5). Winter Pippin of some (7). Zeeke (5).

This is an old variety well known in portions of the South and of the Middle West. As grown in Western New York it is a reliable bearer giving moderately heavy crops, the fruit hangs well to the tree, develops good color and is a late keeper but its quality is not very satisfactory. It is not recommended for planting in this state.

Historical. An old variety which originated near Harrodsburg, Kentucky. At first it was called Nonesuch but afterwards became widely known under the name McAfee's Nonsuch. Dr. Howsley gives an extended account of its origin and of its dissemination under various synonyms (5).

\section{TREE.}

Tree medium in size, moderately vigorous to vigorous. Form roundish, somewhat spreading. Tavigs medium in length, rather slender with dark bark; slightly pubescent towards the tips; young twigs smooth, dark, reddishbrown.

\section{FrUit.}

Fruit medium to large. Form roundish oblate, regular. Stem short to long. Cavity large, wide, acute, rather deep, gently furrowed, often with thin outspreading russet. Caly.r small, closed. Basin shallow, usually rather narrow, sometimes broad, sometimes compressed, wrinkled and gently furrowed.

Skin ratler thin, smooth, yellow faintly washed with red and splashed and striped with carmine, often marked over the base with thin, grayish, mottled or streaked scarf-skin and sometimes with fine, irregularly broken russet lines. Dots minute, indented, gray or whitish mingled with some that are larger, areolar. Prevailing effect striped red.

Calyx tube funnel-form, sometimes elongated and constricted at the base of the limb, enlarging somewhat below and extending to the core. Stamens median to basal.

Core medium in size, decidedly abaxile, roundish; cells pretty symmetrical, open; core lines clasp the funnel cylinder. Carpels rather concave, tufted, very broadly obovate or approaching obcordate, narrowing towards the stem. Seeds numerous, large, long, rather wide, obtuse, dark.

Flcsh yellowish, somewhat coarse, somewhat breaking, tender, juicy, nild subacid approaching sweet, good to very good.

Season October to February.

\section{MCKINLEY.}

References. I. Am. Pom. Soc. Cat., 1862. 2. Warder, 1867;606. fig. 3. Downing, 1872:26I. 4. Thomas, 1885:517. 5. Bailey, An. Hort., 1892:244. 6. Ragan, U. S. B. P. I. Bul., 56:188. I905. Synonym. Mackinlay (i). MacKinlay (6). 
A dessert apple of pretty good size but the color is not very good and the fruit does not keep late. As grown at this Station the tree has come into bearing rather young but it has not been tested here long enough to determine its productiveness. It is not recommended for planting in this state.

It originated in Indiana (6) and is propagated to a limited extent in portions of the Middle West (5). It is practically unknown in New York.

Fruit.

Fruit medium to large, roundish oblate. Stem short to medium, slender. Cazity rather narrow, deep, thickly russeted. Calyx large, closed or varying to wide open; lobes small. Basin broad, rather abrupt, shallow to moderately deep, slightly furrowed. Skin dull yellow indistinctly blushed and striped with dull red, sprinkled with large areolar dots. Core medium, closed; core lines meeting. Flesh yellowish, rather fine-grained, moderately juicy, subacid, good.

Season December and January.

\section{McKINNEY.}

References. 1. Downing, 1876:56 app. 2. Am. Pom. Soc. Rpt., 1873. (cited by 3). 3. Ragan, U. S. B. P. I. Bul., 56:188. 1905.

Fruit yellow with a shade of brownish-red in the sun, of good size and mild subacid flavor; in season from January to April (I). Originated in Crawford, Ulster county. Evidently unknown outside the locality of its origin.

\section{MAGENTA.}

ReFerence. I. Leroy, I873:447. fig.

This is a variety which was brought to notice in France in I86I. It has been but little grown as yet in New York state, at least not under this name. It appears to be identical with Canada Reinette.

\section{Fruit.}

Fruit above medium to large. Form oblate conic, broadly angular, irregular. Stem short to very short, moderately thick, not exserted. Cavity large, moderately deep to deep, rather broad, acute or approaching acuminate, usually with outspreading russet. Caly.x medium, closed or partly open. Basin often irregular, rather abrupt, medium in width and depth, compressed or furrowed.

Skin yellow or greenish with a bronze blush and roughened with very large stellar or irregular russet dots or patches.

Calyx tube conical or somewhat funnel-form. Stamens median or below.

Core somewhat abaxile, below medium to rather small; cells usually symmetrical, closed or partly open; core lines clasping. Carpels roundish ovate, emarginate, somewhat tufted. Seeds medium or above, moderately wide, plump, obtuse, somewhat tufted.

Flesh yellowish, firm, moderately coarse, crisp, moderately tender, juicy, rich agreeable subacid, good to very good.

Season November to March. 


\section{MALA CARLE.}

References. I. Kenrick, 1832:79. 2. Floy-Lindley, 1833:39. 3. Manning, I838:6r. 4. Downing, I845:I I6. 5. Thomas, I849:182. 6. Cole, I849:1 6. 7. Emmons, Nat. Hist. N. Y., 3:82. I851. 8. Elliott, 1854:146. fig. 9. Hooper, I857:56. Io. Warder, I867:725. I I. Fitz, I872:I68. I2. Hogg, I884:I44. I3. Am. Pom. Soc. Cat., 1889:10. 14. Bailey, An. Hort., 1892:243.

Synonyms. Charles Apple (1, 2, 4, 8). Malcarle (2). Malcarle (I). Mal Carle (7). Male Carle (4, 5, 8, 9, io, in). Male Carle (6, I2). Marle Carle (7). Mela Carla (I, 3, I2). Mela Carla (2, 4, 5, 8, 9). Mela dé Carlo (8). Mela di Carlo (4). Pomme de Charles $(4,5,8)$. Pomme Finale $(1,4,8)$.

A very beautiful delicate skinned apple with white, tender, perfumed flesh. It is well adapted to certain regions of the South (II) but it does not succeed as far north as New York (4).

Historical. This is an old variety of Italian origin. Lindley says of it: "The Malcarle is a native of the territory of Finale, in Liguria. It is an important article of trade in the whole Genoese territory, and of exportation to Nice, Marseilles, Barcelona and Cadiz. The climate of the Italian territory is so entirely different from that of England, that we cannot expect the delicate Malcarle should succeed here, unless trained against a south or southeast wall, and in a warm and kind soil. Its great beauty in the dessert renders it an interesting object of cultivation" (2).

\section{MALINDA.}

References. I. Am. Pom. Soc. Rpt., I877:46. 2. Van Deman, U. S. Pom. Rpt., I891:39o. 3. Craig, Can. Dept. Agr. Rpt., r896:132. 4. Macoun, Can. Hort., 22:396. I899. 5. Hansen, S. D. Sta. Bul., 76:73. I902. fig. 6. Munson, Me. Sta. An. Rpt., 18:84. 1902. 7. Budd-Hansen, 1903:122. fig. 8. Ragan, U. S. B. P. I. Bul., 56:190. 1905.

Synonym. Melinda (8).

This variety is as yet untested in New York. It originated in Orange county, Vt., and was introduced into Minnesota about I860. The tree does not come into bearing young. It has done well in Iowa and Minnesota when top-worked on the very hardy Hibernal apple or on the Virginia crab stock (5). The fruit ranks only fair in quality. The variety does not appear worthy of testing for New York except possibly in those regions of the state where hardiness is a prime requisite.

\section{TREE (5).}

Tree a slender, straggling grower in the nursery. Twigs medium, rather slender, comparatively blunt at the tips, nearly straight; internodes short to medium. Bark dull brownish-red, uniformly overlaid with thin scarf-skin, slightly pubescent. Lenticels rather inconspicuous, rather few, medium or below, elongated or roundish, not raised. Buds rather small, hardly moderately projecting, somewhat pubescent, free from bark or slightly adhering. 
FRUIT (5).

Fruit above medium to large. Form sharply conical, somewhat angular and ribbed. Stem short, stout. Cavity acute, medium, regular, with stellate russet. Caly.r closed. Basin abrupt, narrow, deep, wavy, wrinkled.

Skin smooth, rich yellow with dull red blush. Dots minute, distinct, numerous, white.

Calyx tube conical. Stamens median.

Core closed; core lines meeting. fair.

Flesh yellowish-white, firm, juicy, very mild subacid with sweet after-taste,

Season late winter.

\section{MANCHESTER.}

References. I. Powell and Fulton, U. S. B. P. I. Bul., 48:48. I903. 2. Beach and Clark, N. Y. Sta. Bul., 248:I3I. I904.

This variety slows that it is of the Esopus Spitzenburg type by the size and form of the fruit and also by the texture and quality of the flesh. It is much inferior to the Esopus Spitzenburg in color and is not as good in quality. The flesh is liable to have brown discolorations commonly known as the "Baldwin spot." The fruit is often above medium or large but is not very uniform either in size or shape. The color is quite variable and lacks character, being yellow or dull green partly overspread with red. It is not sufficiently attractive in form and color for a good market fruit. The tree is not very slow in coming into bearing and is a reliable cropper. Not recommended for planting in New York.

Historical. Received here for testing from J. D. Adams, Mapleton, Cayuga county, N. Y., in 1890 . We have not learned where or when the variety originated. It is sparingly cultivated in a few localities in Western New York but does not appear to be known in other portions of the state.

TREE.

Tree rather small, only moderately vigorous; lateral branches willowy, slender. Form roundish or spreading, dense. Tavigs below medium to short, rather slender, nearly straight; internodes medium. Bark clear reddish-brown with a light coat of streaked scarf-skin, slightly pubescent near the tips. Lenticels quite numerous, very small, roundish to oblong, sometimes slightly raised. Buds medium to small, plump, roundish, obtuse to acute, appressed, pubescent, deeply set in bark.

\section{FRUIT.}

Fruit above medium to large. Form roundish to oblong, inclined to conic, somewhat angular or elliptical, usually pretty symmetrical. Siem medium to long. Cavity broad, deep, varying from somewhat obtuse to acuminate, often obscurely furrowed, usually russeted. Calyx small to medium, closed. Basin usually small, often oblique, varying from very shallow and obtuse to moderately deep and abrupt, often irregular, usually distinctly furrowed and wrinkled.

Skin slightly rough, dull grass-green varying to a rather deep yellow, thinly blushed with red and sparingly and obscurely striped with dull carmine. Prevailing color yellow. Dots rather numerous, small to medium, pale or russet, often irregular, often submerged. 

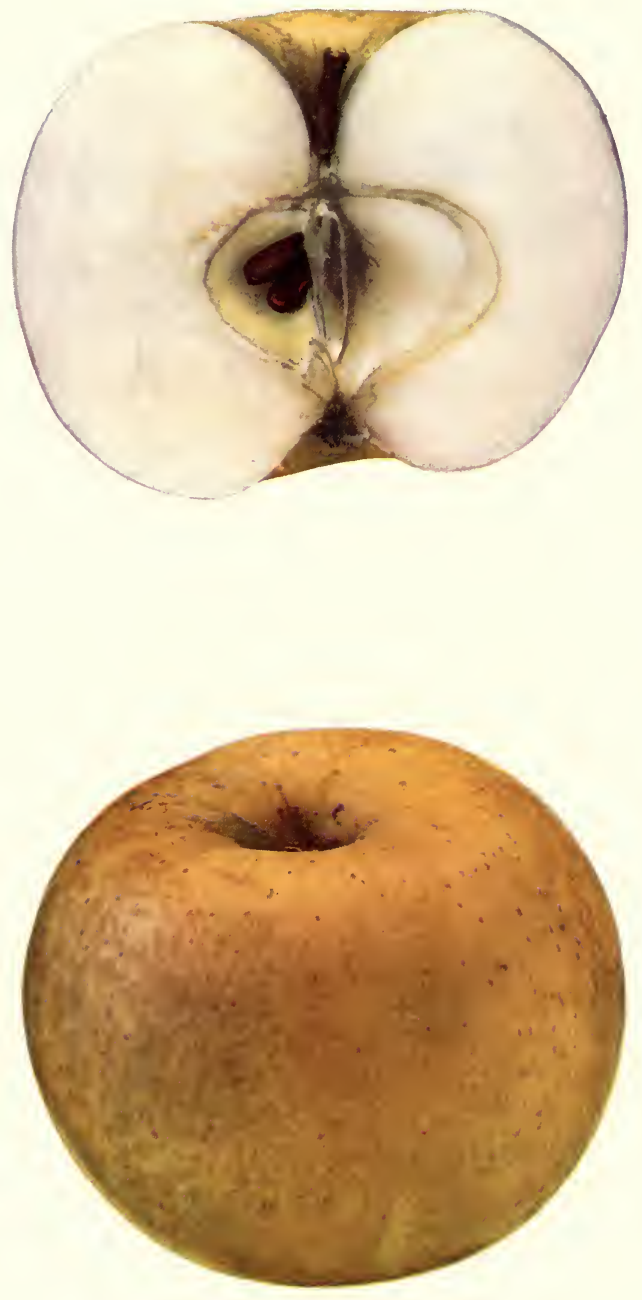

MANN 

Calyx tube narrow above, long, approaching cylindrical. Stamens marginal to median.

Core medium to large, varying from decidedly abaxile to nearly axile; cells often closed but sometimes unsymmetrical and wide open; core lines clasping. Carpels broadly ovate to roundish, mucronate, emarginate, distinctly tufted. Seeds above medium to rather small, plump, obtuse to acute.

Flesh yellowish, moderately crisp, firm, moderately fine-grained, rather tender, juicy, sprightly subacid, good to very good.

Season December to April or May.

\section{MANN.}

References. I. Downing, 1872:21 app. fig. 2. Am. Pom. Soc. Cat., 1877: 10. 3. Moody, Am. Pom. Soc. Rpt., 1881:124. 4. Barry, 1883:349. 5. Moody, Am. Pom. Soc. Rpt., 1885:27. 6. Thomas, 1885:517. 7. Can. Hort., II:II3. I888. 8. Lyon, Mich. Hort. Soc. Rpt., I890:294. 9. Bailey, An. Hort., I892: 244. Iо. Woolverton, Ont. Fr. Stas. An. Rpt., 5:18. 1898. figs. II. Ib., 6:35. I899. 12. Macoun, Can. Dept. Agr. Bul., 37:44. r9or. 13. Munson, Me. Sta. Bul., 82:95. 1902. 14. Budd-Hansen, 1903:I23. I5. Powell and Fulton, U. S. B. P. I. Bul., 48:48. 1903. I6. Beach and Clark, N. Y.Sta. Bul., 248:131. 1904. Synonym. Deiltz (3).

A hard, green, late-keeping apple used by the trade to some extent as a substitute for Rhode Island Greening late in the season when it often brings good prices. It is decidedly inferior to Rhode Island Greening in quality and does not always have a good clear green color, being sometimes streaked more or less with a network of russet. Its great merits are the productiveness of the tree and the smoothness, uniformity and superior keeping and shipping qualities of the fruit. The tree is superior to Rhode Island Greening and Baldwin in hardiness $(5,8)$ and usually is a reliable cropper, yielding good to heavy crops biennially or in some localities almost annually. It is a little slow about coming into bearing. In many cases the crops are so heavy that the percentage of loss in undersized fruit is rather high and the trees are damaged by the breaking of the limbs.

Historical. Originated as a chance seedling in the orchard of Judge Mooney of Granby, Oswego county, N. Y. (I), where it was formerly called the Deiltz. It was introduced into Niagara county by Dr. Mann, and on the suggestion of Elisha Moody of Lockport the Western New York Horticultural Society named the apple Mann (3). It is not grown extensively in any portion of the state but it is still being planted to a limited extent by commercial growers.

TREE.

Tree medium to large, moderately vigorous to vigorous. Form at first decidedly upright and rather dense but after bearing heavy crops becomes 
decidedly spreading with the laterals inclined to droop. Twigs medium to long, nearly straight, rather slender to moderately stout; internodes short. Bark more or less dark dull brown overspread with grayish-green and streaked with gray scarf-skin, slightly pubescent near tips. Lenticels numerous, dull, not very conspicuous, above medium to below, roundish, slightly raised. Buds medium to rather short, plump, obtuse, appressed, pubescent, deeply set in bark.

\section{FrUIT.}

Fruit medium to large. Form roundish, somewhat inclined to oblate, symmetrical, usually pretty regular, sometimes faintly ribbed; pretty uniform in size and shape. Stem short to medium, usually not exserted. Cavity acuminate, rather narrow to moderately wide, deep, usually russeted, and often with outspreading broken russet, somewhat furrowed. Calyx small to medium, closed or partly open; lobes medium in length, acute. Basin somewhat abrupt, rather narrow to moderately wide, usually pretty symmetrical, furrowed and wrinkled.

Skin moderately thick, tough, at first deep green, often partly overspread with a brownish-red blush tinged with shade of olive-green but late in the season it develops a pronounced yellow color. Dots numerous, large, conspicuous, areolar, whitish with russet center.

Calyx tube moderately wide, cone-shape. Stamens below median to basal.

Core below medium to small, usually axile or nearly so; cells pretty symmetrical, usually closed, sometimes open; core lines meeting or slightly clasping. Carpels smooth, broad, narrowing towards the base and apex or approaching truncate at the base, but slightly emarginate if at all. Seeds numerous, medium or above, wide, obtuse to acute, dark.

Flesh yellowish, moderately coarse, moderately juicy, at first very hard and firm but later becoming moderately tender and somewhat crisp, subacid, fair to good.

Season. Commercial limit March or April in ordinary storage and May in cold storage (I6).

\section{MARIGOLD.}

References, I. Bailey, An. Hort., r892:244. 2. Powell and Fulton, U. S. B. P. I. Bul., 48:49. 1903. 3. Beach and Clark, N. Y. Sta. Bul., 248:131. 1904.

Doubtful References. 4. Knight, Pomona Herefordiensis, r8i r. (cited by 6). 5. Kenrick, 1832:48. 6. Floy-Lindley, 1833:80. 7. Downing, 1869:294. 8. Hogg, I884:I64.

Doubtrul Synonyas. Isle of Wight Orange $(6,7)$. Isle of Wight Pippin $(6,8)$. Marigold Pippin (7). Marygold $(6)$. Orange Pippin $(6,7,8)$.

A good dessert variety of desirable size and rather attractive appearance for a yellowish apple but it does not excel standard varieties of its season in color, size or quality. The tree does not come into bearing very young. It is an annual or nearly annual bearer and yields moderate crops. As grown at this Station the commercial limit of Marigold appears to be November or December in ordinary storage, although some portion of the fruit may be kept till June. The fruit held in cold storage till May has been found still hard, free from decay and but slightly scalded $(2,3)$. 
Historical. Origin uncertain. It las long been known in the vicinity of Oyster Bay, Long Island. For upwards of a century it has been considered a desirable winter apple for that region, 1 and it has been propagated for years by the Westbury Nurseries. It is known to a limited extent in various localities in Southeastern New York and in Connecticut, but appears to be gradually going out of cultivation.

We have not had the opportunity of determining whether or not this Mariguld of Long Island is identical either with the Marigold described by Kenrick (5) or with the Orange Pippin $(6,7,8)$ which has Marigold as a synonym. The fruit corresponds pretty closely with Hogg's description of Orange Pippin except as to its quality and season.

The Marigold of Leroy ${ }^{2}$ is evidently distinct from the Long Island Marigold. Downing recognizes it under the name Creed Marigold ${ }^{3}$ under which name Hogg described it in 1859 , stating that it originated in Kent from seed of the Scarlet Nonpareil.

\section{TreE.}

Tree moderately vigorous. Form upright, somewhat spreading, rather open. Twigs rather short, slightly curved, moderately stout; internodes medium to short. Bark brown, tinged with clear reddish-brown, mottled with scarf-skin, pubescent. Lenticels quite numerous, rather conspicuous, slightly raised, oblong or roundish, medium to small. Buds medium to small, broad, plump, obtuse to acute, but slightly pubescent if at all, usually free.

\section{FRUIT.}

Fruit below medium to nearly large, pretty uniform in size and shape. Form roundish, often a little oblate and inclined to conic, quite regular, usually symmetrical; sides sometimes unequal. Stem rather slender. Cavity acute, deep, broad, symmetrical or somewhat furrowed, usually with greenish russet which often spreads beyond the cavity. Calyx small to medium, closed or partly open. Basin abrupt, shallow to moderately deep, rather narrow, sometimes obscurely furrowed, slightly wrinkled.

Skin nearly smooth, at first green but becoming good yellow with an orange blush which in highly colored specimens deepens to red and is somewhat mottled and splashed with bright carmine. Dots often submerged and yellow; others are large, irregular, russet and mingled with flecks of russet.

Calyx tube rather wide, deep, cone-shape or approaching funnel-form. Stamens median to marginal.

Core rather small, axile or nearly so; cells usually symmetrical, closed or partly open; core lines meeting or slightly clasping. Carpels smooth, elliptical or approaching obcordate, emarginate. Seeds few, often abortive, medium or below, wide, obtuse.

Flesh yellowish, firm, a little coarse, rather tender, juicy, subacid, somewhat aromatic; good for dessert but rather too mild for most culinary uses.

Season variable but usually extends from November to April or May; commercial limit December or January in ordinary storage and about May first in cold storage (3).

\footnotetext{
${ }^{1}$ Letter of Isaac Hicks, 1899 .

${ }^{2}$ Leroy, $1873: 457$.

3owning, $1869: 137$.
} 


\section{MASON ORANGE.}

References. I. Stayman, Mo. Hort. Soc. Rpt., 1883:75. 2. Am. Pom. Soc. Cat., 1883:12. 3. Ib., Rpt., 1883:135, 136. 4. Kan. Hort. Soc. Rpt., 1883:83. 5. Stayman, Rural N. Y., 43:83. I884. fig. 6. Bailey, An. Hort., 1892:244. 7. Lyon, Mich. Sta. Bul., 129:39, 42. 1896. 8. Thomas, 1897:644. 9. Dickens and Greene, Kan. Sta. Bul., 106:54. 1903. 10. Farrand, Mich. Sta. Bul., 205: 45. I903. II. Ragan, U. S. B. P. I. Bul., 56:41, 193. 1905.

Synonyms. Belleflower Improved (iI). Mason Orange (io). Mason's Improied (I I). Mason's Orange $(2,3,6,8,9)$.

A seedling of the Yellow Bellflower (5) which originated in Kansas $(1,3)$. Resembles its parent in its fruit which is medium to large, yellow with red cheek, of excellent quality, rather tender for market but valuable for home use. Season November to February (4, I0). It has not been tested sufficiently in New York to determine its value for this region.

\section{MASTEN.}

References. I. Horticulturist, I866. (cited by 4). 2. Downing, 1869:268. 3. Thomas, 1885:517. 4. Ragan, U. S. B. P. I. Bul., 56:193. 1905.

Synonya. Masten's Seedling (3). Mastens Seedling (2, 4).

A greenish-yellow winter apple of medium size or below, crisp, subacid, and of good quality $(2,3)$. Originated at Pleasant Valley, Dutchess county, N. Y. (2). It was brought to notice as a new variety about forty years ago $(\mathrm{I}, 2,3)$, but appears to have remained practically unknown outside of the locality where it originated.

\section{MELON.}

References. I. Ellwanger and Barry, Albany Cultivator, 2:56. I845. 2. Ib., Boston Cultivator, Mch., I845. (cited by 4, 13). 3. Watts, Mag. Hort., I3:I04. I847. 4. Hovey, Ib., I3:537. I847. fig. 5. Ib., I4:I2. I848. 6. Downing, Horticulturist, 2:356. 1848. fig. 7. Thomas, 1849:151. 8. N. Y. Agr. Soc. Rpt., 1848:283, 284. fig. 9. Cole, 1849:124. fig. 10. Emmons, Nat. Hist. N. Y., 3:76. 1851. col. pl. and fig. I1. Am. Pom. Soc. Cat., 1852. I2. Elliott, 1854:89. fig. 13. Horticulturist, 9:397. I854. col. pl. 14. Downing, 1857:87. I5. Warder, I867:488. fig. I6. Leroy, 1873:503. fig. I7. Barry, I883:349. 18. Hogg, I884:I45. I9. Lyon, Mich. Hort. Soc. Rpt., I89o:294. 20. Bailey, An. Hort., 1892:245. 21. Bunyard, Jour. Roy. Hort. Soc., 1898: 356. 22. Budd-Hansen, I903:I26. fig. 23. Powell and Fulton, U. S. B. P. I. Bul., 48:49. 1903. 24. Beach and Clark, N. Y. Sta. Bul., 248:132. 1904.

Synonyms. Melon $(8,20)$. Melon Apple (I8). Melon de Norton (i6). Melon Norton (22). Norton Watermelon (i6). Norton's Melon (I, 2, 5, 8, 10). Norton's Melon (4, 6, 7, 9, I2, 13, 23, 24). Watermelon (4, 6, 7, $8,9,12)$.

When it is properly developed the Melon is one of the best dessert apples of its season, being crisp, tender and delicious. It is especially adapted for local market, fancy trade and dessert use. Ordinarily it is in season in Western New York from 

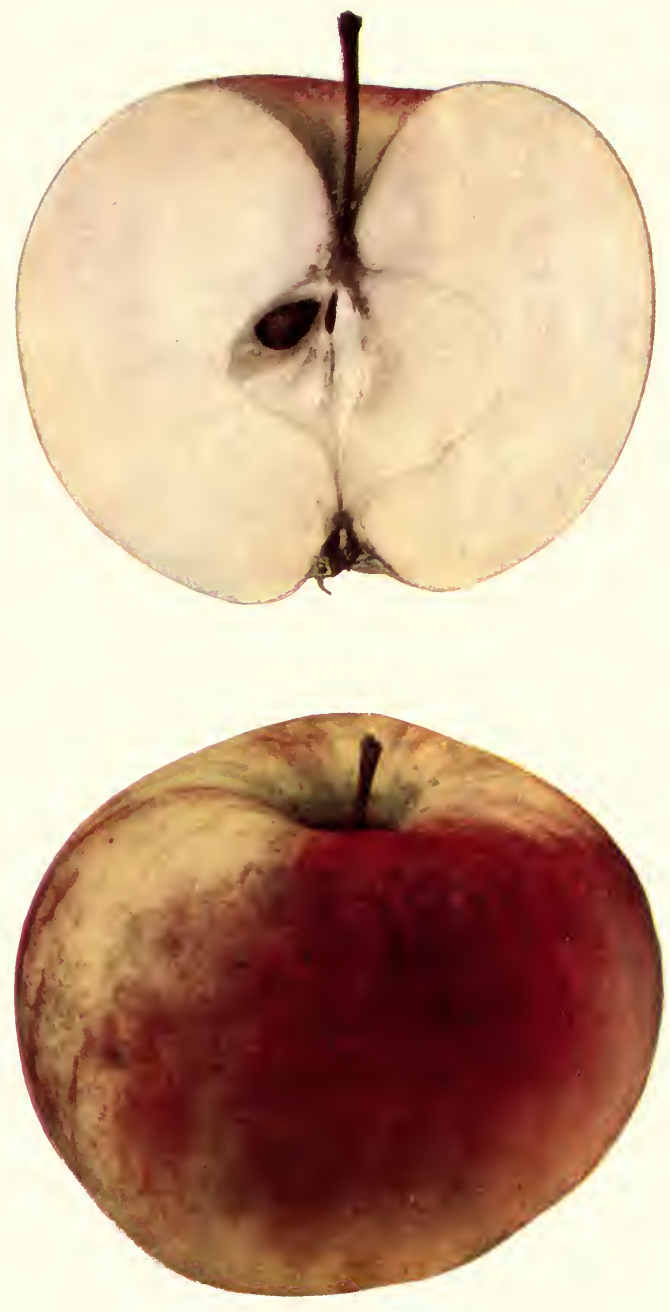

MELON 

October to midwinter. If kept later than January in ordinary storage it soon loses in flavor and quality (24). Some fruit growers find it profitable but more often it has proved an unsatisfactory variety in the commercial orchard. Under favorable conditions the fruit develops good size and good color and is smooth and decidedly attractive, but in many cases there is a rather high percentage of loss from undersized, poorly colored or otherwise imperfect fruit. In portions of Eastern New York it is reported as being especially susceptible to the attacks of the apple maggot or railroad worm, Rhagoletis pomonella Walsh. In some localities the foliage and fruit are both quite subject to the attacks of the apple-scab fungus and the tree is apt to be injured by canker on the limbs and on the body. The tree appears to be fully as hardy and productive as Tompkins King or perhaps more so, and after it attains mature bearing age it is often reliably productive, yielding good crops biennially or in some cases annually. It is an unsatisfactory grower in the nursery and makes but a moderately vigorous growth in the orchard, particularly when grown on its own body. On this account it is advisable to top-work Melon upon some stock that is healthier and more vigorous, such as Golden Russet, Roxbury, Northern Spy, Baldwin or Rhode Island Greening. The tree naturally develops a rather dense top and particular care is required in pruning to keep it sufficiently open.

Historical. Melon originated in East Bloomfield, Ontario county, in the old seedling orchard of Heman Chapin. This orchard was planted about I8001 with seedling trees grown from seed brought to East Bloomfield from Connecticut $\left(3,4,6, \mathrm{I}_{3}\right)$. Melon was introduced to the trade by Ellwanger and Barry about $\mathrm{I} 845(\mathrm{I}, 2,4,5,6, \mathrm{I} 3)$. It has been pretty widely disseminated but in no portion of the state is it grown extensively. It is now seldom offered by nurserymen (20) and seldom planted.

\section{Tree.}

Tree medium in size, moderately vigorous. Form upright, somewhat spreading or roundish. Twigs medium to long, erect or spreading, slender to moderately stout. Bark reddish-brown, lightly mottled with scarf-skin, pubescent. Lenticels numerous, usually small, round. Buds medium, plump, acute, somewhat pubescent. Leaves rather large, often rather broad.

\footnotetext{
${ }^{1}$ Letters, H. G. Chapin and Charles Chapin, 1905.
} VOL. I -9 


\section{FrUit.}

Fruit somewhat variable in size, usually above medium to large. Form roundish conic, sometimes inclined to oblate conic, often more or less elliptical and obscurely ribbed, usually symmetrical. Stem short to medium, slender. Cavity acute to acuminate, deep, narrow to moderately wide, often russeted and sometimes with outspreading russet rays. Calyx small to above medium, closed or partly open; segments narrow, acuminate. Basin rather small, shallow to moderately deep, narrow to medium in width, rather abrupt, often somewhat furrowed and wrinkled.

Skin pretty smooth, pale yellow or greenish-yellow and when well colored nearly overspread with rather light, bright red striped and splashed with carmine. Dots small, pale yellow or russet, not conspicuous. Prevailing effect red mingled with yellow.

Caly.x tube rather small, cone-shape varying to short funnel-form with fleshy pistil point projecting into the base. Stamens median to marginal.

Core medium to small, axile; cells symmetrical, closed; core lines clasping. Carpels broadly roundish or elliptical, sometimes slightly tufted, but slightly emarginate if at all. Seeds below medium to rather large, plump, moderately wide, often irregular or angular, very dark brown, sometimes tufted.

Flesh white slightly tinged with yellow, moderately firm, rather fine-grained, crisp, very tender, juicy, sprightly, somewhat aromatic, pleasantly subacid, very good.

\section{MÉNAGÈRE.}

References. I. Manning, 1838:56. 2. Manning, Mag. Hort., 7:46. I841. 3. Downing, I845:117. 4. Thomas, 1849:157. 5. Elliott, 1854:174. 6. Hooper, 1857:59. 7. Warder, 1867:726. 8. Downing, 1869:273. 9. Leroy, 1873:435. 10. Barry, 1883:340. II. Hogg, I884:146. I2. Bunyard, Jour. Roy. Hort. Soc., I898:356. 13. Van Deman, Rural N. Y., 58:278. 1899. 14. Beach and Clark, N. Y. Sta. Bul., 248:132. 1904. 15. Ragan, U. S. B. P. I. Bul., 56:196. 1905 .

Synonyms. Capp Mammoth (13). Combermere Apple (II). Dame de Ménage (9). Femme de Ménage (9). Flanders Pippin (II). Gros Rambour d'Hiver (9). Haus Mütterchen (9). Livre (9). Menage (15). Ménagère (9). Menagerie (5, 15). Mére DE Ménage (8, I1, 12). Mère de Ménage (9, 15). Pfund (9). Teller (9).

A very large apple suitable only for exhibition purposes. It is undesirable either for dessert or culinary use, being coarse-grained and only fair in quality. The tree is slow about coming into bearing, usually bears some fruit every year but is unproductive and the fruit drops badly.

Historical. This is an old German variety which is known in England under the name Mère de Ménage (9, I I, I2). The name Ménagère is recognized by certain English and French pomologists only as a synonym, but the variety has been described by so many American writers under this name that it is now best to recognize it as the American name, particularly since German, French and English pomologists are not agreed upon any one name for the variety. It is but little grown in this country. 

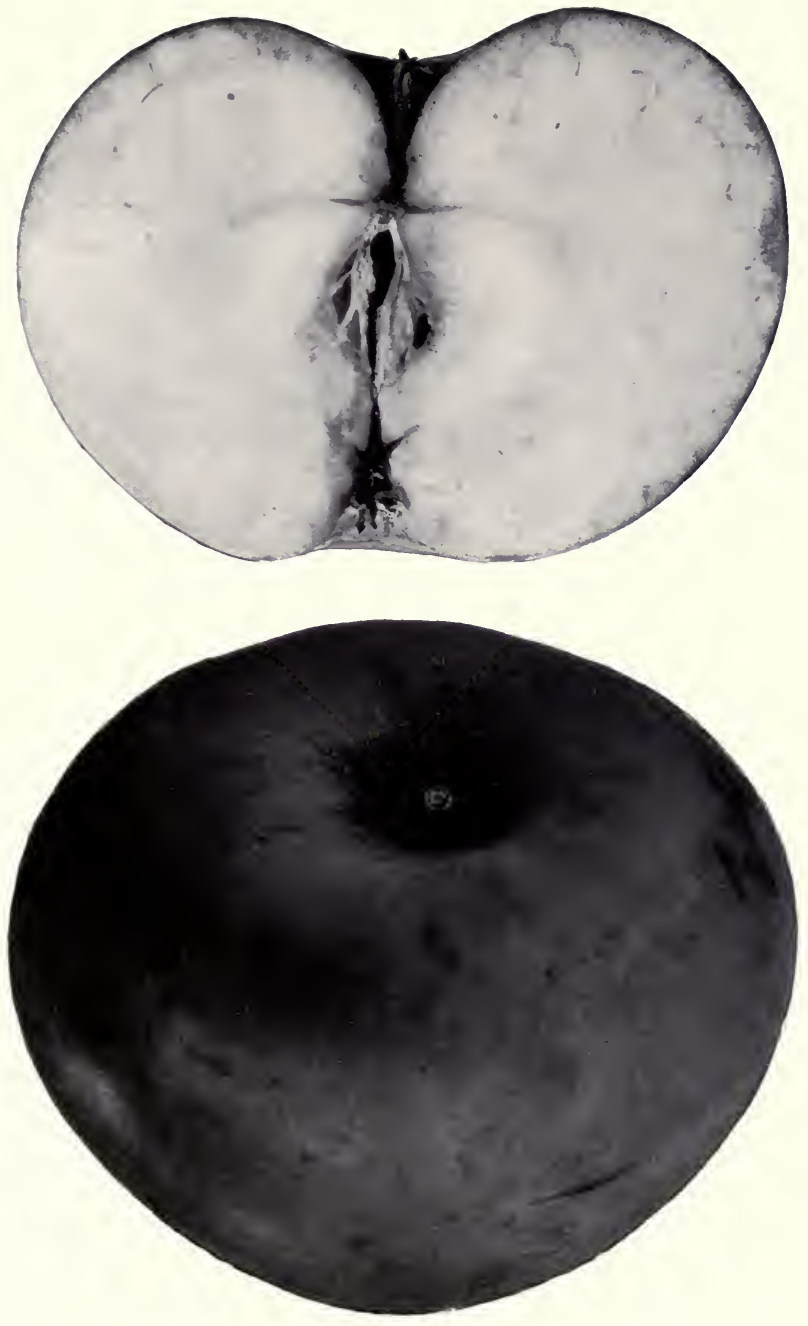

MENAGÈRE 
TREE.

Tree a moderate grower. Form upright. Twigs very short to below medium in length, very slender to medium in thickness, sometimes somewhat bowed and geniculate; internodes long or in the more slender limbs very long. Bark dull brownish-red with an undertone of olive-green in some specimens, uniformly overlaid with a thick scarf-skin, slightly pulsescent. Lenticels inconspicuous, only moderately numerous, medium, the larger ones roundish elliptical, the smaller, narrow. Buds medium in size, moderately projecting, rather fleshy, acute, not pubescent, slightly adhering to bark or free.

\section{Fruit.}

Fruit large to very large. Form oblate to oblate conic, pretty regular or somewhat ribbed; sides often unequal. Stem very short. Cavity acute, shallow to rather deep, moderately broad and marked with outspreading patches and flecks of russet. Calyx medium, closed or partly open; lobes long and reflexed. Basin somewhat abrupt, rather narrow, moderately deep, often irregular.

Skin pale yellow with faint blush on the exposed side. Dots scattering, light brown.

Calyx tube rather narrow, funnel-form, extending to the core. Stamens basal.

Core small, axile; cells symmetrical, closed; core lines clasping the funnel cylinder.

Flesh white, coarse-grained, moderately juicy, subacid, fair in flavor and quality.

Season October to January; under favorable conditions some portion of the fruit may be kept till spring.

\section{MERRILL.}

REFERENCE. I. Downing, I869:273.

Synonyms. Merrill's (I). Merrill's Apple (I).

Originated in Smyrna, Chenango county, N. Y. A medium sized, yellow apple with bright red cheek; flesh subacid, spicy, good; season December to March (I). This appears to be unknown outside of the place of its origin.

\section{MIDDLE.}

REFERENCES. I. Downing, 1857:172. 2. Warder, 1867:507. fig.

SyNonym. Mittle (I).

This fruit belongs in the same group as the Green Newtown and White Pippin but is less attractive than either. It is at first green and hard, but later in the season becomes crisp and rather tender. It is valued locally because it is an excellent dessert apple and a good keeper. The tree is an upright grower and sometimes bears heavy crops. 
Historical. The original tree was a chance seedling that grew on the land of Peter Bellinger in the village of Herkimer or rather on the line fence dividing two of the original tracts of land granted by the Crown in 1725 , and being a tree that neither party could claim it was called the Middle apple tree. ${ }^{1}$ Charles Downing included a description of it in his first revision of Fruits and Fruit Trees of America in 1857 ( 1 ). Warder (2) reports that it was introduced into Ohio by John Ludlow of Springfield in 1854 and propagated at the Oakland nurseries. In New York it remains practically unknown to fruit growers outside the vicinity of its origin.

\section{Fruit.}

Fruit medium to nearly large, rather uniform. Form varies from elongated ovate or oblong conic to roundish conic, often elliptical or somewhat angular; axis often somewhat oblique. Stem medium in length, rather slender. Cavity acute to acuminate, ustially moderately deep, narrow to moderately broad often compressed or lipped and often with outspreading russet. Caly $x$ medium to rather large, open. Basin often oblique, usually obtuse, shallow to medium in depth, medium in width to narrow, slightly furrowed or wrinkled, sometimes compressed.

Skin rather thin, moderately tender, somewhat rough, at first green but later becoming more or less marbled or shaded with yellow, sometimes lightly mottled with red or having red dots; often roughened at the base with broken russet. Dots numerous, russet.

Caly.x tubc small, conical or somewhat funnel-form with truncate cylinder. Stamens median.

Core medium to rather large, axile; cells symmetrical, closed or sometimes partly open; core lines meeting or somewhat clasping. Carpels thin, tender, deeply emarginate, roundish or varying to elongated ovate, much tufted. Seeds numerous, small to medium, rather narrow, acute.

Flesh yellowish, breaking, rather fine, crisp, juicy, rather sprightly subacid, somewhat aromatic, very good.

Season December to February or March; often some portion of the fruit may be kept till late spring.

\section{MILAM.}

References. I. Phoenix, Horticulturist, 4:470. I850. 2. Kennicott, $I b$., 7:431. 1852. 3. Elliott, 1854:174. 4. Robey, Horticulturist, II:89. 1856. 5. Downing, 1857:217. 6. Hooper, $1857: 60.7$. Am. Pom. Soc. Cat., 1862. 8. Warder, 1867:503. fig. 9. Downing, 1869:275. Io. Fitz, 1872:158. II. Barry, 1883:349. I2. Thomas, 1885:236. I3. Lyon, Mich. Hort. Soc. Rpt., I890:294. 14. Bailey, An. Hort, r892:244. I5. Budd-Hansen, 1903:127.

Synonyms. Blair $(6,8,9)$. Harrigan $(1,3,5,9)$. Thomas (9). Winter Pearmain of some ( $\mathrm{I}, 3,5,9)$.

A medium sized dessert apple which has something of the appearance of a highly colored Ralls. In season from November to March. The tree is thrifty and in favorable localities becomes productive when it is mature. Thousands of trees of this variety have been propagated from sprouts for it sprouts readily from the roots $(I, 8)$.

\footnotetext{
${ }^{1}$ Letter, Will E. Kay, 1901.
} 
Historical. Origin uncertain. Warder refers to it as "a little Southern favorite" (8). It was formerly quite popular in some portions of the Middle West where it is still propagated by nurserymen although it is not now planted as much as it was formerly (14). It has never been grown much in New York state and remains practically unknown among New York fruit growers.

TREE.

Tree moderately vigorous, with long, slender, curved branches. Form upright spreading or roundish, rather dense. Twigs above medium to long, slightly curved, rather slender; internodes long to medium. Bark dark brownish-red mingled with olive-green and streaked with grayish scarf-skin; heavily pubescent toward the tips. Lenticels quite numerous, small to rather large, roundish or elongated, slightly raised. Buds small to medium, broad, plump, obtuse to somewhat acute, free, pubescent.

\section{FRUIT.}

Fruit small to medium. Form roundish conic or short ovate, regular, not ribbed. Stem pubescent, medium to long, moderately slender. Cavity acute, moderately deep, moderately wide, smooth and green or partly covered with thin brownish russet. Calyx pubescent, medium in size, closed. Basin below medium in size, somewhat abrupt, moderately shallow, rather narrow to medium in width, gently furrowed.

Skin moderately thin, rather tender, smooth, dull yellow or greenish marbled and striped with dull red, in highly colored specimens deepening to crimson in the sun. Dots numerous, conspicuous, gray, often areolar with russet point.

Calyx tube conical to somewhat funnel-form with short truncate cylinder. Stamens basal.

Core rather small, axile or nearly so; cells symmetrical, closed. Carpels elongated, obovate, mucronate, but slightly emarginate if at all, slightly tufted. Seeds medium or above, plump, acute, slightly tufted.

Flesh slightly tinged with yellow, a little coarse, crisp, tender, juicy, mild pleasant subacid, good.

Season November to January or later.

\section{MILDEN.}

References. I. Am. Pom. Soc. Cat., 1873. 2. Downing, 1876:58 app. fig. 3. Bailey, An. Hort., I892:244. 4. Munson, Me. Sta. Rpt., I893:I33. 5. Ib., 1896:71. 6. Thomas, 1897:645. 7. Beach, W. N. Y. Hort. Soc. Rpt., 1900:36. 8. Munson, Me. Sta. An. Rpt., 18:89. 1902. 9. Budd-Hansen, 1903:127. Iо. Powell and Fulton, U. S. B. P. I. Bul., 48:49. I903. II. Beach and Clark, N. Y. Sta. Bul., 248:132. I904.

Synonym. Milding $(3,5,7,8,9)$. Milding $(2,4,6$, Io, I I ).

When well grown Milden is an apple of desirable size, good appearance and pretty good quality. The skin is smooth and glossy and the color is predominantly bright red over an attrac- 
tive pale yellow or whitish background. It is highly esteemed in portions of New England $(5,8)$, and is there being planted to some extent both for home use and commercial purposes. It is an excellent nursery tree and a good grower in the orchard. It is hardy, healthy, comes into bearing quite young and is a reliable cropper, yielding good crops biennially. There is some loss from drops, but the fruit averages pretty uniform in size with a rather low percentage of culls. So far as tested in this state it appears to be pretty reliable and satisfactory in color and quality and suitable for general market purposes and culinary use. It is evidently worthy of testing as a commercial variety, particularly in the more elevated and northern portions of the state. In the southeastern part of the state it would probably be classed as a late autumn variety, but as grown at this Station it becomes an early winter or midwinter variety (I I).

Historical. Milden is a variety of comparatively recent introduction. It originated at Alton, New Hampshire (2).

\section{TREE.}

Tree large, vigorous. Form upright becoming roundish, rather ciense. Trigs below medium to short, straight, moderately stout; internodes short to long. Bark very dark olive-green somewhat tinged with reddish-brown streaked with scarf-skin; pubescent. Lenticels quite numerous, small to medium, roundish, slightly raised. Buds prominent, below medium to large, broad, plump, obtuse, free, pubescent.

\section{Fruit.}

Fruit rather large; fairly uniform in size and shape. Form oblate, sometimes inclined to conic, pretty regular, often faintly ribbed; sides sometimes unequal. Stem short to medium, pubescent. Cavity acute to acuminate, deep, rather wide, symmetrical or somewhat furrowed, often russeted and with outspreading russet rays. Caly.x large, pubescent: lobes long, acuminate, closed or partly open. Basin obtuse to somewhat abrupt, usually rather shallow, moderately wide, often compressed or furrowed.

Skin waxy, rather thin, tough. Well-colored specimens are beautifully mottled with bright red and striped and splashed with bright carmine over a pale yellow background. Sometimes the red deepens to a solid blush. Dots inconspicuous, few, gray or russet.

Calyx tube rather large, long, cone-shape or somewhat funnel-form, meeting the core. Stamens median.

Core distant, medium or below, abaxile; cells pretty symmetrical, usually open; core lines clasping. Carpels roundish to elongated ovate, acuminate, slightly emarginate, tufted. Seeds variable in size and shape, often about medium sizc, moderately narrow, obtuse to acute; witen some are abortive. 

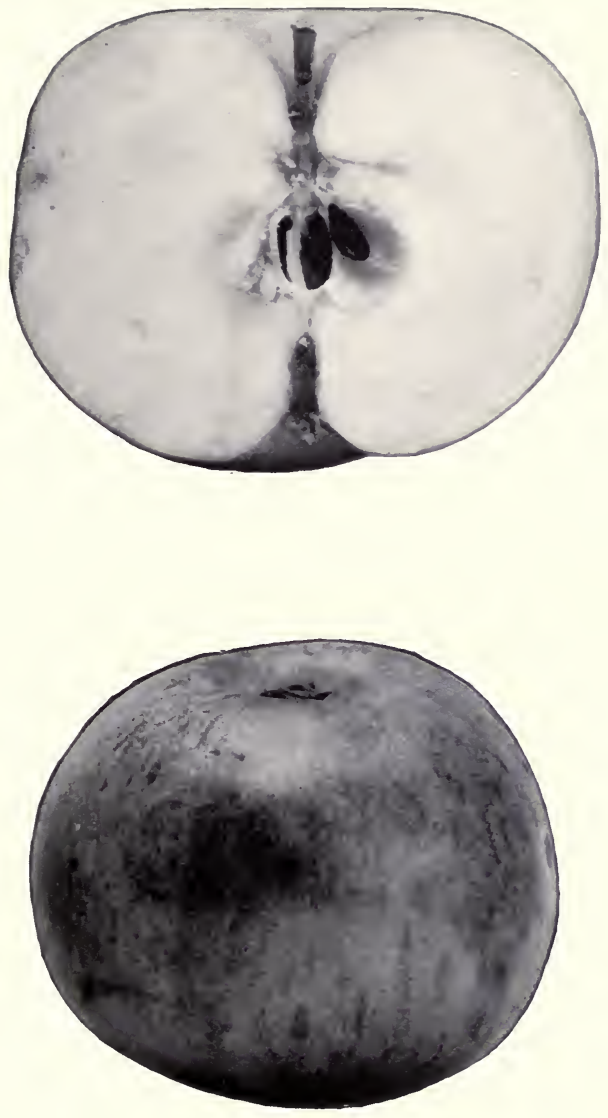

MILDEN 

Flesh whitish tinged with yellow, firm, crisp, breaking, moderately coarse, very juicy, subacid, good.

Season November to January or February; it may remain apparently sound till spring but after midwinter it deteriorates in texture and flavor.

\section{MILWAUKEE.}

References. I. Macoun, Can. Dept. Agr. Rpt., r899:77. 2. Ib., Can. Hort., 23:452. 1900. 3. Hansen, S. D. Sta. Bul., 76:74. 1902. 4. Farrand, Mich. Sta. Bul., 205:45. 1903. 5. Erwin, Am. Pom. Soc. Rpt., 1903:252. 6. Budd-Hansen, 1903:128. fig. 7. National Nurseryman, March, 1905:52.

Milwaukee is a winter fruit of the Oldenburg group, of good size and when highly colored fairly attractive in appearance, being clear yellow marked with bright red somewhat after the manner of Oldenburg. It is too briskly acid for a good dessert apple, but rather is suitable for culinary use and for market. It would be more desirable for market if it had more red color. It is in season from October to January. Some portion of the fruit may keep till February or March, but in ordinary storage there is a rather high percentage of loss after early winter. The fruit which remains till spring retains well its acidity and quality. The tree is very hardy, healthy, a pretty good grower and a good cropper. It comes into bearing young and is almost an annual bearer. It appears to be worthy of testing in the northern and more elevated regions of the state where hardiness is a prime requisite.

Historical. Originated with George Jeffry, Milwaukee, Wis., from seed of Oldenburg $(\mathrm{I}, 3,5,6)$.

TREE.

Tree moderately vigorous; branches long, slender, crooked. Form open, upright, becoming rather spreading with laterals inclined to droop. Twigs medium to long, varying from irregularly curved to straight, moderately stout; internodes generally long. Bark dark reddish-brown approaching black, streaked with grayish scarf-skin, quite pubescent. Lenticels quite numerous, small to medium, roundish or elongated, not raised. Buds medium or below, plump, obtuse to somewhat acute, free or slightly appressed, pubescent.

\section{Fruit.}

Fruit usually rather large, pretty uniform in size and shape. Form distinctly oblate, regular or obscurely ribbed; sides often unequal. Stem pubescent, short. Cazity rather large, acute to acuminate, deep, broad, furrowed, russeted and with outspreading brown russet rays. Calyx pubescent, large, leafy, usually partly open, sometimes closed; lobes wide, long, acute. Basin large, often oblique, deep, wide, abrupt to somewhat obtuse, furrowed, wrinkled. 
Skin thin, tough, smootl, glossy, pale yellow or whitish more or less blushed with red which in highly colored specimens deepens to a lively pinkish-red, conspicuously mottled and striped with rose-carmine. Dots numerous, small, whitish, often submerged, occasionally russet.

Calyx tube urn-shape to somewhat funnel-form with short cylinder and wide limb. Stamens median.

Core distant, a little abaxile, usually small; cells sometimes unsymmetrical, closed or slightly open; core lines clasping. Carpels elliptical to roundish obcordate, mucronate, but slightly emarginate if at all. Seeds few, often abortive, medium to short, wide, flat, obtuse.

Flesh whitish tinged with yellow, firm, somewhat coarse, crisp, very tender, very juicy, sprightly, brisk subacid, fair to good.

\section{MINISTER.}

References. I. Manning, I838:62. 2. Downing, 1845:116. 3. Ives, Mag. Hort., 14:264. I848. 4. Thomas, I849:169. 5. Cole, I849:124. 6. Emmons, Nat. Hist. N. Y., 3:61. 1851. 7. Hovey, 2:95. 1851. fig. and col. pl. 8. Elliott, 1854:147. 9. Am. Pom. Soc. Cat., 1854. ro. Hooper, 1857:61. I1. Warder, 1867:695. 12. Fitz, 1872:145. 13. Lyon, Mich. Hort. Soc. Rpt., 189o:294. 14. Munson, Me. Sta. Rpt., 1893:133. I5. Taylor, Am. Pom. Soc. Rpt., 1895: 193. 16. Burrill and McCluer, Ill. Sta. Bul., 45:332. 1896.

Synonyms. Minister (7). Minister Apple (7).

Fruit similar to Yellow Bellflower in form, pale waxen yellow splashed and striped with bright pale crimson (I, 7, II). In Middle New England it is in season from November to February or later (1, 5, 7, 14), and is there still regarded with favor in many localities on account of its productiveness and good quality. "In Ohio it becomes an autumn apple and is used only for cooking when we have plenty of others that are preferred" (II). When carelessly handled it rots from bruising or ripens prematurely while too acid, but when properly ripened it loses its brisk acidity and develops excellent quality (5). The tree is healthy, moderately vigorous, a rather early bearer and a regular and abundant cropper $(2,5,7$, II, 13$)$. It is said to succeed best on good sandy loam $(5,12)$.

The following accomnt of the tree and fruit is taken from descriptions given by various writers $(1,2,5,7,11,13)$.

Historical. Originated on the farm of David Saunders near Rowley, Massachusetts. Introduced by Robert Manning of Salem, Massachusetts, more than a half century ago $(1,7)$. It has failed to win favorable recognition in New York and is not recommended for planting in this state.

\section{TREE.}

Tree moderately vigorous. Form upright while young but becoming roundheaded as it matures. Tairigs slender, upright; internodes short. Bark dark reddish-chestnut. Lenticels numerous, gray. Buds small, short, ovate, flattened with prominent shoulders. Leaves medium in size, ovate, acute.

\section{Fruit.}

Fruit large to medium. Form roundish ovate to oblong conic, ribbed, irregular, flattened at the base. Stem curved to one side, short to long, slender. 

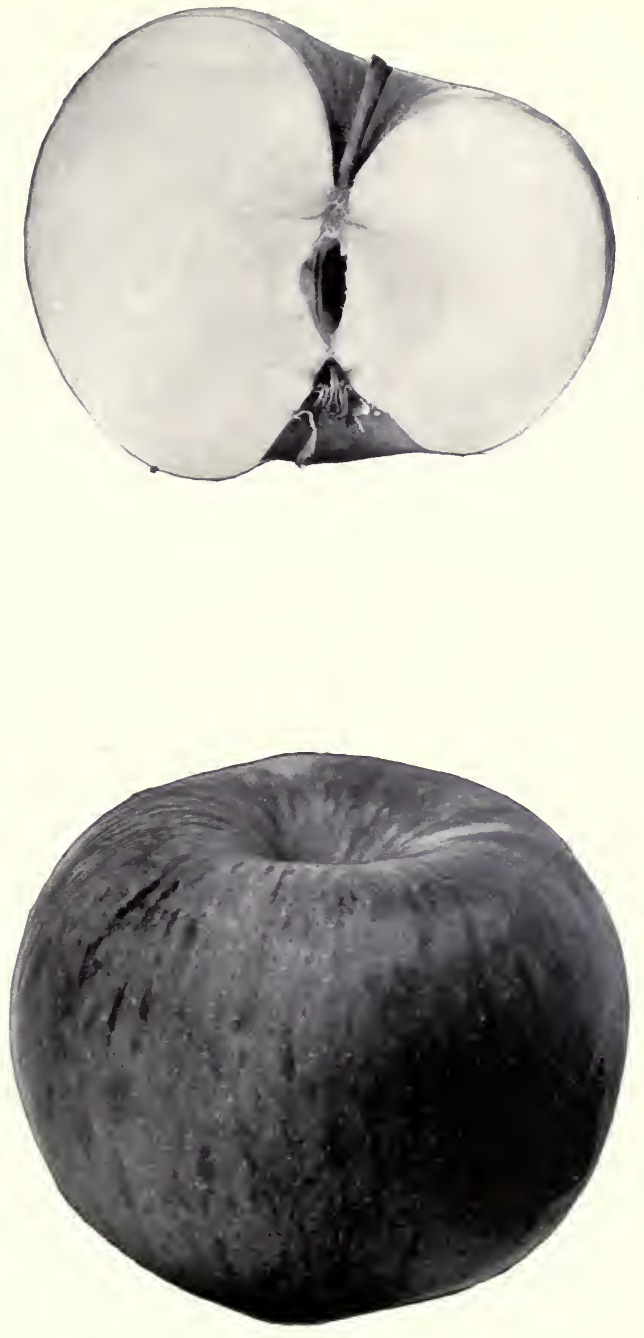

MILWAUKEE 

Cazity rather small, acute, shallow to rather deep, rather narrow, irregular, sometimes russeted. Calyx small, closed; lobes short and twisted. Basin rather small, moderately shallow, narrow, furrowed and wrinkled.

Skin smooth, waxen, pale yellow or greenish-yellow irregularly splashed and striped with bright red particularly over the base. Dots minute.

Core rather large; cells partly open. Seeds small, plump, obovate.

Flesh yellowish-white, crisp, very tender, breaking, juicy, at first briskly subacid but when properly ripened agreeable in flavor and quality.

\section{MINKLER.}

References. I. Am. Pom. Soc. Cat., 1862. 2. Ill. Hort. Soc. Rpt., I865:51. 3. Warder, 1867:444. fig. 4. Ill. Hort. Soc. Rpt., 1869:36. 5. Downing, 1869: 276. 6. Am. Pom. Soc. Rpt., 1875:128. 7. Ill. Hort. Soc. Rpt., 1875:4II. 8. Downing, 1876:59 app. 9. Downing, 1876: I I index, app. Io. Thomas, 1885:518. I1. Am. Pon. Scc. Cat., I889:10. 12. Bailey, An. Hort., 1892:244. I3. Lyon, Mich. Sta. Bul., 143:200, 202. IS97. 14. Budd-Hansen, I903:129. 15. Farrand, Mich. Sta. Bul., 205:45. 1903. 16. Powell and Fulton, U. S. B. P. I. Bul., 48:49. 1903. 17. Beach and Clark, N. Y. Sta. Bul., 248:132. 1904. I8. Ragan, U. S. B. P. I. Bul., 56:53, 181, 199, 205. 1905.

Synonyms. Brandywine ( 18, ?5). Logan's Northern Pippin (4, 9, I8). Mumper VAndevere $(6,8)$. Mumper Vandevere (I8).

The Minkler was brought to notice in Illinois something over forty years ago. Its cultivation is confined almost wholly to that and adjoining states. Like many other varieties of the Middle West it is popular because the tree is a strong grower and a good and regular cropper rather than on account of the quality of its fruit. In appearance the fruit is very good and dealers do not hesitate to take it in reasonable quantities in spite of the fact that it is only fairly good in quality and sonetimes scalds badly in storage. It is not a promising variety for New York fruit growers, competing as it does with the Baldwin and other good winter apples.

Historical. The history of this variety is confused with that of several similar, or as some have thought possibly identical, varieties. The Minkler, as such, was first exhibited before the Illinois Horticultural Society something. over forty years ago by Mr. S. G. Minkler. Having lost its name he exhibited it for identification. As it was not recognized by any one the Society named it Minkler, pending further investigation (5). Warder (3) in 1867 states that it very closely resembles Buchanan and Brandywine and adds that Minkler and Buchanan have "an entirely distinct origin," but there is no evidence that this is the case. In I 869 Galusina stated that he found Minkler cultivated in some localities in Illinois unde- the name Logan Northern Pippin and Dunlap found it identical with Brandywine (4) a decision which is approved by some other pomologists. The origin of Brandywine is also unknown (5, I8). Ragan makes Minkler identical with Mumper Vandevere (I8) which according to Downing (8) originated on the farm of John Mumper near Dillsbury, Pa.

Minkler is not grown to any considerable extent in New York.

TREE.

Tree large, very vigorous; branches large, strong, forming a very broad angle with the trunk and having a characteristically irregular, zigzag manner 
of growth. Form very spreading, frequently becoming drooping in old trees. Twigs short to long, moderately stout to moderately slender; internodes about medium, unequal in length. Bark dull brownish-red or reddish, irregularly overlaid with thin to thick scarf-skin, rather pubescent. Lenticels scattering, inoderately conspicuous, raised, medium to small, roundish. Buds medium, moderately projecting, acute or roundish, pubescent, appressed or slightly adhering.

\section{FRUIT.}

Fruit medium to above, uniform in size and shape. Form roundish inclined to oblate conic, rather regular. Stem medium to short, rather slender. Cavity acute or slightly acuminate, deep, medium in width, greenish or brown, faintly russeted. Calyx small to above medium, closed or slightly open; lobes medium in length, broad, acute, usually not separated at the base. Basin shallow to medium in depth, wide, obtuse, smooth or slightly wrinkled.

Skin thin, slightly tough, smooth, rather glossy, greenish-yellow changing to pale yellow, almost entirely overspread with rather light pinkish-red obscurely striped and splashed with dark dull carmine. Dots small to medium, yellow, grayish or russet, moderately conspicuous. Prevailing effect rather light red.

Calyx tube moderately short, rather wide, funnel-form with broad limb and narrow cylinder. Stamens median to marginal.

Core medium to rather large, axile; cells closed or partly open; core lines meeting or somewhat clasping. Carpels roundish, usually deeply emarginate, tufted. Seeds dark brown, rather large and wide, long, plump or sometimes flat, acute, sometimes tufted.

Flesh strongly tinged with yellow or greenish, very firm, a little coarse, not very crisp, rather juicy, mild subacid, slightly aromatic, fairly good.

Season in common storage November to April; in cold storage till May.

\section{MISSING LINK.}

References. 1. Ill. Hort. Soc. Rpt., r897:16r. 2. Jenkins, Mo. Hort. Soc. Rpt., 45:66. I902. 3. Shank, Missing Link Nur. Circ., 1903. 4. Erwin, Am. Pom. Soc. Rpt., 1903:253. 5. Van Deman, Rural N. Y., 62:369. I903. fig. 6. Buckman, Ib., 62:418. 1903. 7. Ragan, U. S. B. P. I. Bul., 56:199. 1905.

A variety of the Willow type recently introduced by Messrs. Shank, Clayton, Illinois (3). Some believe that it is identical with, IVillow $(4,7)$, but a comparison of its fruit with that of Willow leads us to endorse the opinion of Van Deman (5) and Buckman (6) that it is a distinct variety. The fruit is of good size, similar in form and appearance to Willow but less highly colored and different in texture and flavor becoming eventually distinctly sweet. It is undoubtedly a long keeper. As might be expected of an apple of this class it does not rank high in quality.

\section{FruIt.}

Fruit large. Form roundish, nearly symmetrical, regular; sides somewhat unequal. Stem medium. Cavity acuminate, moderately broad, deep, somewhat russeted. Calyx large, partly open. Basin slightly oblique, medium in depth to deep, moderately wide, abrupt, ridged, wrinkled. 
Skin smooth, glossy, light greenish-yellow or yellow, thinly mottled and striped with red on the exposed cheek. Dots small, fine, mingled with others that are large, conspicuous, irregular and brownish-russet. Prevailing effect green or yellowish.

Core below medium or even small; cells closed; core lines nearly meeting. Carpels obcordate, tufted. Seeds few, large, dark, flat, tufted.

Flesh yellowish, firm, coarse, tough yet somewhat crisp, moderately juicy, mildly subacid but eventually becoming sweet, fair in quality.

\section{MISSOURI PIPPIN.}

References. I. Warder, 1867:656. 2. Downing, 1872:23 app. 3. Am. Pom. Soc. Cat., I881:12. 4. Brackett, Am. Pom. Soc. Rpt., 188r:145. 5. Barry, 1883:349. 6. Thomas, 1885:518. 7. Coleman, Am. Pom. Soc. Rpt., 1885:28. 8. Bailey, An. Hort., 1892:244. 9. Wright, Am. Gard., I7:33. 1896. Iо. Powell, Del. Sta. Bul., 38:19. 1898. Ir. Macoun, Can. Dept. Agr. Rpt., I9or: 97. 12. Dickens and Greene, Kan. Sta. Bul., 106:54. 1902. 13. Budd-Hansen, 1903:130. fig. 14. Bruner, N. C. Sta. Bul., 182:27. 1903. 15. Powell and Fulton, U.S. B. P. I. Bul., 48:49. 1903. 16. Beach and Clark, N. Y. Sta. Bul., 248:132. 1904 .

Synonyms. Missouri (15). Missouri Keeper (i). Missouri Keeper (2, 3, 4, 5). Missouri Orange (4). Missouri Pippin (2, 3, 4, 5, 6, 7, 8, 9, 10, I1, 12, 14). Missouri Pippin (15).

This is one of the well-known market apples of the Middle West. As grown in that region the tree is short-lived, and in the Mississippi valley in orchards more than twenty years old it is seldom profitable, but it comes into bearing at an early age and is a reliable and heavy cropper. The fruit is of good color but only second rate in quality, and on old trees is inclined to be rather too small for market. It is regarded with favor by fruit dealers because of its attractive appearance and good keeping quality. There has been some complaint of its scalding in storage (I6), but this fault does not appear to be serious enough to affect materially its popularity. So far as we have been able to discover it is not grown in New York. It is quite doubtful whether its fruit would commonly develop here to good marketable size even if grown in the southeastern part of New York, where the climatic and soil conditions are more favorable to varieties of this class than they are in the more northern and western portions of the state.

Historical. The Missouri Pippin is supposed to have originated on the farm of Brinkley Hornsby, Kingsville, Johnson county, Missouri, from seed planted about $1840(2,4,7)$. Shortly after the Civil War it began to be 
disseminated outside of the locality of its origin and its cultivation spread with such rapidity that in a very few years it was being extensively planted in Missouri, Kansas, Illinois and adjacent states. The good degree of hardiness and vigor which it possesses, the ease with which it is propagated in the nursery, and particularly its habit of bearing early and abundantly were the qualities which recommended it to the fruit growers of that region. During the early years of fruit production in the prairie sections of that country this variety was more often seen than any other. As the trees became older it was found that they were inclined to overbear with a result that frequently a large percentage of the fruit failed to attain good marketable size. Then Missouri Pippin began to wane in popularity and to-day it is used chiefly as a filler for planting between the rows of permanent trees.

\section{TREE.}

Tree moderately vigorous with long, slender, curved branches, characteristic on account of its numerous, slender twigs and general crab-like appearance. Form upright becoming roundish or spreading. Twigs moderately long, straight, slender; internodes short. Bark dark brown, mottled with heavy scarf-skin, pubescent. Lenticels scattering, medium, oval to oblong, raised. Buds deeply set, small, plump, obtuse, appressed, slightly pubescent.

\section{Fruit.}

Fruit medium in size. Form roundish, somewhat inclined to conic. Stem medium in length, rather slender. Cavity acute to nearly acuminate, moderately wide, rather deep, faintly russeted. Calyx medium in size, closed or nearly so; lobes moderately long, rather narrow. Basin medium to deep, rather wide, abrupt, usually somewhat wrinkled.

Skin thick, tough, smooth, rather glossy, thinly coated with grayish bloom; color pale greenish or yellow overspread with bright red striped with purplish red. Highly colored specimens are almost of a solid red color. Dots conspicuous, russet, or rather large, pale gray.

Calyx tube funnel-form with wide limb, sometimes broadly conical. Stamens median.

Core small, axile, or nearly so; cells symmetrical, slightly open; core lines clasping. Carpels smooth, roundish elliptical to slightly obovate, sometimes emarginate. Sceds medium to rather small, moderately long and wide, slightly obtuse, dark brown.

Flesh tinged somewhat with yellow, firm, medium to rather fine-grained, not very tender, not very juicy, briskly subacid, fair to good in quality.

Season in common storage October to January; in cold storage January to April.

\section{MONMOUTH.}

References. 1. Mag. Hort., I4:141. 1848. 2. Emmons, Nat. Hist. N. Y., 3:74. 1851. col. pl. No. 57. 3. Barry, Horticulturist, 8:341. 1853. 4. Elliott, 1854:92. fig. 5. Am. Pom. Soc. Cat., 1854. 6. Downing, r857:88. 7. Hooper, 1857:61. 8. Warder, $1867: 577$. fig. 9. Barry, 1883:349. Io. Thomas, I885: 245. Ir. Wickson, 1889:246. I2. Lyon, Mich. Hort. Soc. Rpt., 1890:294. I3. Bailey, An. Hort., 1892:244. 14. Powell and Fulton, U. S. B. P. I. Bul., 48:49. 

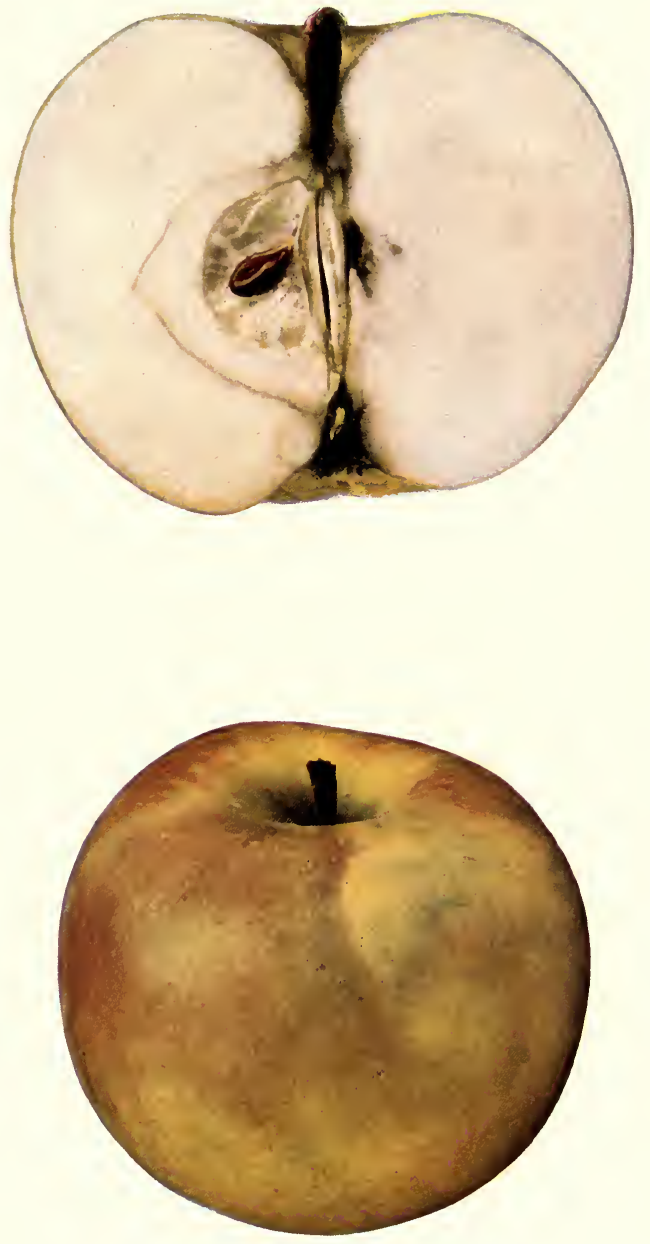

MONMOUTH 

1903. 15. Budd-Hansen, 1903:131. fig. 16. Beach and Clark, N. Y. Sta. Bul., 248: I33. 1904 .

Synonyms. Monmouth Pippin (1, 2, 3, 4, 6, 7, 8, 9, 10, i1, 13). Monmouth Pippin (16). Red Cheek (4,8). Red Cheeked Pippin (10). Red Cheek Pippin (4, 7, I1, 12, 15).

An apple of the Rhode Island Greening class, not equal to that variety in quality but more attractive in color, being often distinctly blushed with a lively pinkish-red. As grown at this Station :ts keeping quality varies much in different years. Sometimes it may be held in good condition through the winter or into the spring, but more often its commercial limit in ordinary storage hardly extends beyond November. When stored in good condition its season in cold storage may extend till June (14, I6). In ordinary storage the percentage of loss often becomes high early in the winter, but sometimes not before March. It appears to be much less subject to scald than Rhode lsland Greening. It it a good apple for the home orchard. It is not recommended for general commercial planting, but probably in favorable localities it would prove a profitable variety. The tree appears to be hardy and long-lived. It comes into bearing moderately young and is a reliable cropper, bearing good crops biennially or almost annually, but under ordinary cultivation it is hardly as vigorous as could be desired. The fruit of marketable grades is smooth and attractive in appearance, but there may be a considerable loss in low-grade fruit.

Historical. Monmouth is a native of Monmouth county, N. J. (4). It has long been known in cultivation and is found in scattering localities from the Middle West to the Atlantic, but in none of them is it grown extensively. It is still offered by nurserymen (13) and is planted to a limited extent.

\section{TREE.}

Tree of medium size, moderately vigorous; branches short, stout, crooked. Form roundish spreading, somewhat open. Twigs short to medium, straight, moderately stout or rather slender; internodes short to medium. Bark dark reddish-brown mingled with olive-green, lightly streaked with scarf-skin, heavily pubescent. Lenticels scattering, small to medium, oblong, slightly raised. $B u d s$ small to medium, obtuse to acute, appressed, very deeply set in the bark, somewhat pubescent.

\section{FRUIT.}

Fruit above medium to large. Form oblate to roundish, somewhat inclined to conic, flattened at the base, somewhat irregular, often obscurely ribbed; sides often unequal. Stem short to medium, rather thick. Cavity moderately 
large, acute to sometimes acuminate, deep, rather broad, somewhat furrowed or compressed, smooth or russeted, sometimes with outspreading russet rays. Calyx large, leafy, pubescent, open or partly closed; lobes often reflexed and separated at the base. Basin large, rather wide and deep, abrupt, often distinctly furrowed and wrinkled.

Skin moderately thin, tough, smooth toward the base, the upper half often roughened with russet dots or with capillary russet lines which become concentric toward the calyx, lively green marbled with yellow or becoming pale yellow as the season advances faintly shaded with red or in highly colored specimens blushed with lively pinkish-red. Dots variable, rather numerous, usually greenish and areolar with brown russet point, often elongated about the cavity.

Calyx tube large, wide, conical or urn-shape with fleshy pistil point projecting into the base. Stamens median to basal.

Core rather small, slightly abaxile with hollow cylinder in the axis; cells usually symmetrical and closed; core lines meeting or somewhat clasping. Carpels roundish or inclined to roundish obcordate, mucronate, slightly tufted.

Seeds few, long, somewhat acute, somewhat tufted.

Flesh decidedly tinged with yellow, firm, moderately coarse, somewhat crisp, tender, juicy, brisk subacid but becoming mild, aromatic, good to very good.

\section{MOON.}

References, I. Am. Pom. Soc. Rpt., I877:39. 2. Bailey, An. Hort., 1892: 244. 3. Beach and Clark, N. Y. Sta. Bul., 248:133. I904.

Fruit of good size, good quality and fairly attractive for a greenish-yellow apple. In the South it ripens its fruit in succession through the summer but as fruited at this Station it is in season from November to April or later. In ordinary storage there is a pretty high percentage of loss in autumn with a low rate of loss through midwinter. On the whole, as grown in this region it appears to be unsatisfactory for handling in common storage, notwithstanding the fact that a considerable portion of the fruit may be kept in good condition till February or later. The tree is not a strong grower but it comes into bearing young, is a reliable cropper and almost an annual bearer alternating light with heavier crops. It does not appear to excel standard sorts of its season for any purpose and is not recommended for planting in New York.

Historical. Moon originated as a chance seedling on the farm of Mr. I. W. Moon, Monroe, Walton county, Ga. It bore its first fruit in 1873 ( I). It appears to be practically unknown among New York fruit growers.

TREE.

Tree rather small with rather short, stout branches. Form roundish upright, open. Truigs below medium to short, somewhat curved, slender; internodes medium. Bark olive-green tinged with reddish-brown and streaked with gray scarf-skin, slightly pubescent near the tips. Lenticels quite numerous, medium to small, roundish, slightly raised. Buds medium to small, plump, obtuse, free, slightly pubescent. 


\section{FruIT.}

Fruit above medium, pretty uniform in size and shape. Form rather oblate not quite regular, being either somewhat elliptical or obscurely ribbed. Stem short to medium, rather slender. Cavity acute varying to acuminate, moderately deep to rather shallow, rather broad, nearly symmetrical, usually smooth, sometimes partly russeted. Caly $x$ small to medium, usually partly open; lobes often slender and acuminate, reflexed. Basin obtuse to abrupt, shallow to moderately deep, wide, obscurely furrowed or wrinkled.

Skin tough, smooth, waxy; the color is somewhat similar to that of a highly colored Rhode Island Greening being green mingled with yellow often with a shade of brownish-red deepening sometimes to a distinct red. Dots small, inconspicuous, often pale and submerged, sometimes russet.

Calyx tube cone-shape or approaching funnel-form with wide limb. Stamens median or below.

Core medium to rather small, axile or nearly so; cells usually fairly symmetrical, closed or partly open; core lines clasping. Carpels much concave, rather short, elliptical to obcordate, slightly emarginate, mucronate. Seeds numerous, medium or above, wide, obtuse.

Flesh tinged with yellow, firm, crisp, moderately fine, rather tender, juicy, slightly aromatic, mild subacid becoming sweet, good.

\section{MOORE SWEET.}

References. 1. New England Farmer, 1829. (cited by 17). 2. Cole, 1849: I3I. 3. Emmons, Nat. Hist. N. Y., 3:91. 1851. 4. Elliott, 1854:159. 5. Downing, 1857:218. 6. Hooper, 1857:6r. 7. Warder, 1867:396. fig. 8. Fitz, 1872:175. 9. Am. Pom. Soc. Cat., 1873. 10. Barry, 1883:349. II. Thomas, 1885:518. 12. Eailey, An. Hort., 1892:245. 13. Burrill and McCluer, Ill. Sta. Bul., 45:333. 1896. 14. Powell and Fulton, U. S. B. P. I. Bul., 48:49. 1903. 15. Budd-Hansen, 1903:132. 16. Beach and Clark, N. Y. Sta. Bul., 248:133. 1904. 17. Ragan, U. S. B. P. I. Bul., 56:202. 1905.

Synonyms. Black Sweet $(7,17)$. Josie Moore (17). Kelley's Sweet (17). Moore's Late Sweet $(2,3)$. Moore's Late Sweet (I7). Moore's Shanty (i7). Moore's Sweet (8, 10, 12). Moore's Sweet (17). Moore's Sweeting (1, 7, II). Moore's Sweeting (4, 17). Moor's Sweeting (6). Polhemus (17). Pound Sweet (of some West 4 and 6, of some 17). Red Sweet Pippin $(5,7,10,13,17$, of Indiana 4 and 6). Red Winter Sweet of some (17). Sweet Pippin (4). Szueet Pippin (6, 17).

Fruit fairly uniform, of pretty good size and rather dull red color; general appearance moderately attractive. In some portions of the state it has been valued particularly because it is an excellent keeper and acceptable in quality for culinary use. It is in season from November to May or June. As grown at this Station its commercial limit in ordinary storage is April (I6). The tree comes into bearing rather young. It is usually a good cropper, producing rather heavy crops biennially, or in some cases almost annually. 
Historical. Originated with J. B. Moore, Concord, Massachusetts. Cole in 1849 , speaks of it as a new variety (2) but it had been brought to notice at least twenty years previously (I). It is not grown extensively in any locality and is now seldom planted in this state but it is still occasionally offered by nurserymen (12).

TREE.

Tree medium to large, moderately vigorous; branches short, stout, crooked. Form open, upright, becoming roundish and somewhat spreading. Twigs short, straight or somewhat geniculate, rather stout with large terminal buds; internodes medium to short. Bark olive-green tinged with reddish-brown, streaked with gray scarf-skin; pubescent near tips. Lenticcls inconspicuous, scattering, small, roundish. Buds prominent, large to below medium, broad, plump, free, slightly pubescent.

FRUIT.

Fruit medium to large, uniform in size and shape. Form roundish, varying from oblate to somewhat conic, sometimes regular and symmetrical but more often somewhat elliptical or ribbed and with sides slightly unequal. Stem short, usually not exserted. Cavity medium to rather large, acuminate, moderately narrow to rather wide, deep, somewhat furrowed, usually russeted and with outspreading russet rays. Caly.x rather small, usually closed; lobes acute, erect or somewhat reflexed. Basin rather small, abrupt, narrow to moderately wide, medium in depth, slightly furrowed and wrinkled.

Skin smooth or nearly so, rather pale in color being yellow or greenish largely overspread with a red or pinkish-red blush and dulled by grayish scarfskin which often produces the effect of faint stripes over the base although the red is not striped. Dots pale russet, scattering. Prevailing effect red.

Calyx tube rather small, conical to funnel-form. Stamens below median to basal.

Core rather small, axile or nearly so; cells symmetrical, not uniform, closed or sometimes open; core lines meeting or clasping. Carpels roundish to elliptical, mucronate, emarginate, somewhat tufted. Seeds few, medium or above, wide, obtuse, somewhat tufted.

Flesh tinged with yellow or green, moderately firm, moderately fine-grained, tender, rather dry, sweet, good.

\section{MOYER.}

References. 1. N. Y. Sta. An. Rpt., 13:17o. 1894. 2. Ragan, U. S. B. P.I. Bul., 56:205. 1905 .

Synonym. Moyer Prize (1). Moyer Prize (2).

A chance seedling received in 1894 from Moyer and Cook, Laketon, Indiana, for testing at this Station. It is a rather large apple of the Yellow Bellflower group, yellow often somewhat blushed with red, hardly equal to the Yellow Bellflower in general appearance, but it appears to stand handling fully as well if not better. The flesh is moderately coarse, crisp, very juicy, mildly subacid eventually becoming sweet or nearly so, good to very good in flavor and quality. As tested here it has come into bearing young and is productive. It is not superior to other varieties of its season for either dessert or culinary uses and the fact that it is a yellow apple makes it of doubtful value for the commercial orchard. 

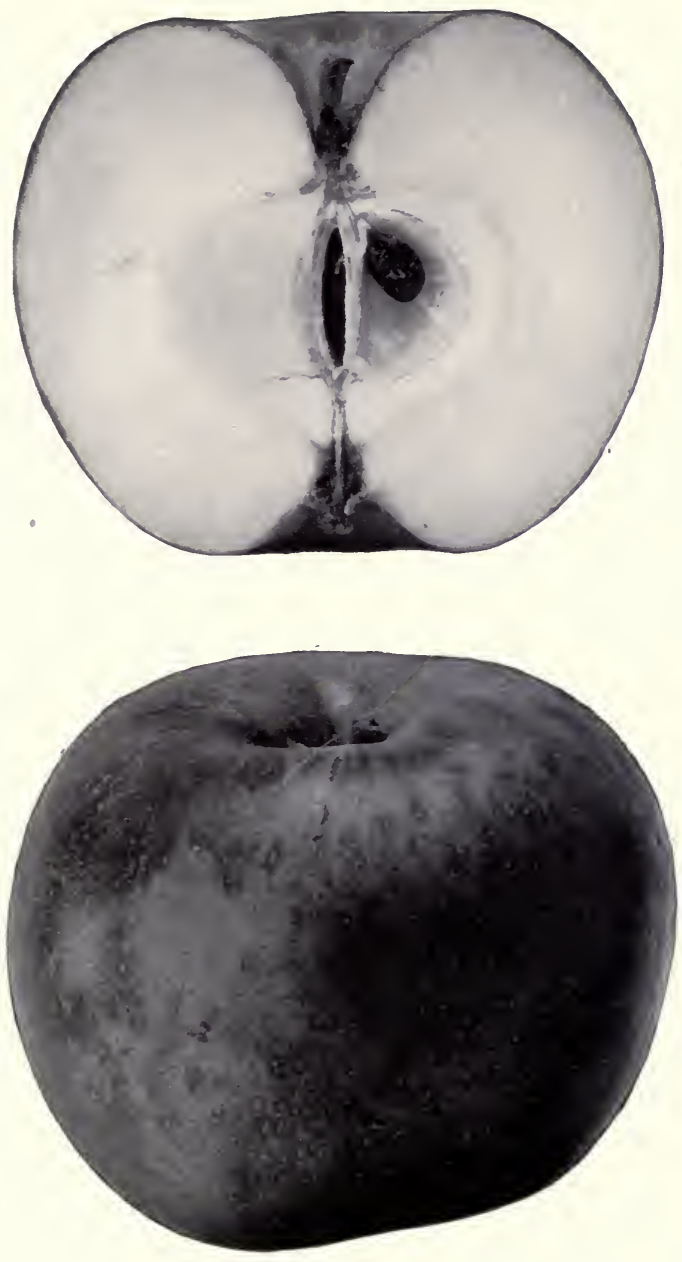

MOORE SWEET 



\section{NELSON.}

References. I. Am. Jour. of Hort., 2:16. 1867. 2. Downing, 1872:284. 3. Ill. Hort. Soc. Rpt., 1879. 4. Beach, N. Y. Sta. An. Rpt., 13:590. I894. 5. Ib., 14:262. 1895. 6. Ib., 15:282. I896. 7. Beach and Clark, N. Y. Sta. Bul 248:133. 1904 .

Synonym. Nelson SweEt $(3,4,6)$.

A good sweet apple of medium size, green with dull blush, in season from February to June. Its commercial limit here in common storage is April or May. The tree is a good grower and a reliable cropper. It comes into bearing rather young and is almost an annual bearer, yielding moderate to rather heavy crops. It is a good variety for the home orchard where a very late-keeping sweet apple is desired, but it is not considered valuable commercially because it is sweet, not large and not very attractive in appearance.

Historical. Nelson was first brought to notice in Illinois but its origin is uncertain. It was first exhibited before the Illinois Horticultural Society at its Champaign meeting, December, I866 (I). Received in 1889 from Benjamin Buckman, Farmingdale, Illinois, for testing here. It appears to be practically unknown in New York.

\section{TREE.}

Trce vigorous to moderately vigorous. Form open, spreading and rather flat. Twigs short to rather long, rather slender to stout with large terminal buds, nearly straight but geniculate; internodes medium to rather long. Bark clear reddish-brown tinged with olive-green, partly streaked with thin scarfskin, slightly pubescent. Lenticels quite numerous, small to medium, round or oval, usually not raised. Buds rather small to large, broad, plump, obtuse, free, slightly pubescent.

\section{FrUIT.}

Fruit medium to above, uniform in size and shape. Form roundish to roundish-ovate, sometimes inclined to oblong, pretty regular but sometimes inclined to elliptical and often somewhat ribbed. Stem below medium to above, rather slender, pubescent. Cavity rather small, usually narrow, moderately deep, acuminate, partly russeted, sometimes lipped. Calyx rather small to medium, usually closed, pubescent; lobes reflexed, long, acute. Basin shallow to moderately deep, often narrow, obtuse to somewhat abrupt, furrowed and wrinkled.

Skin moderately thick, tough, smooth, dull green at first, but eventually becoming more or less tinged with yellow, shaded with a brownish blush which sometimes partly deepens to red. A suture line often extends from the cavity to the basin. Dots numerous, often submerged and whitish, sometimes areolar with russet point; about the cavity they are larger, irregular and often elongated. Prevailing effect green or yellowish. 
Calyx tube large, narrow above, funnel-shape, sometimes approaching cylindrical. Stamens median to nearly marginal.

Core medium or above, axile; cells symmetrical, closed; core lines clasping the funnel cylinder. Carpels elliptical to broadly obcordate, somewhat tufted. Seeds often abortive, small to medium, plump, obtuse, moderately wide, rather light reddish-brown.

Flesh tinged with yellow or greenish, firm, moderately fine, not crisp but somewhat tough, juicy, sweet to very sweet, with distinct flavor and good quality.

\section{NERO.}

References. 1. Ill. Hort. Soc. Rpt., 23:79. 1889. 2. Bailey, An. Hort., 1892:245. 3. Brown, Rural N. Y., 55:1. 1896. fig. 4. Lyon, Mich. Sta. Bul., r69:187. 1899. 5. Am. Pom. Soc. Cat., r899:19. 6. Blackwell, Am. Pom. Soc. Rpt., r899:198. 7. Budd-Hansen, r903:134. 8. Powell and Fulton, U. S. B. P. I. Bul., 48:50. 1903.

This is a variety of the Minkler group. It resembles Minkler in fruit and in the nursery its trees appear to be almost identical with those of the Minkler. The fruit is of good medium size, attractive red color, firm, has a tough skin, handles well and keeps late, but it is inclined to scald considerably after midwinter unless highly colored (8). It has not yet been sufficiently tested here to demonstrate whether it is a desirable variety for this region but the fact that none of the group of apples to which Nero belongs has become a leading commercial variety in this state indicates that probably it will not be found well adapted to New York conditions.

Historical. Origin Princeton, New Jersey (7). It is regarded with favor in Central New Jersey (6) and has been disseminated to a considerable extent in regions farther west and south. As yet it is practically unknown in New York.

\section{Fruit.}

Fruit above medium. Form roundish, a little inclined to conical, pretty regular and symmetrical. Stem short to medium, moderately thick. Cavity acute to somewhat acuminate, medium in depth to deep, medium in width to rather broad, often russeted and with outspreading russet rays. Calyx medium or above, usually closed; lobes pubescent, often erect or convergent, usually not separated at the base. Basin obtuse to somewhat abrupt, shallow to moderately deep, rather wide, sometimes gently furrowed, wrinkled.

Skin moderately thick, tough, glossy, clear greenish-yellow mostly covered with bright red marked with numerous narrow rather inconspicuous carmine stripes. Dots mostly small, whitish or russet. Prevailing effect good bright red.

Calyx tube short, conical or funnel-shape. Stamens below median to basal.

Core median or inclined to sessile, rather small, axile or nearly so; cells symmetrical, closed; core lines meeting or clasping. Carpels roundish to elliptical, smooth or nearly so, deeply emarginate. Seeds large, moderately narrow, long, irregular, obtuse to acute.

Flesh yellowish, firm, moderately coarse, rather crisp, moderately tender, moderately juicy, mild subacid mingled with sweet, slightly aromatic, good to very good. 

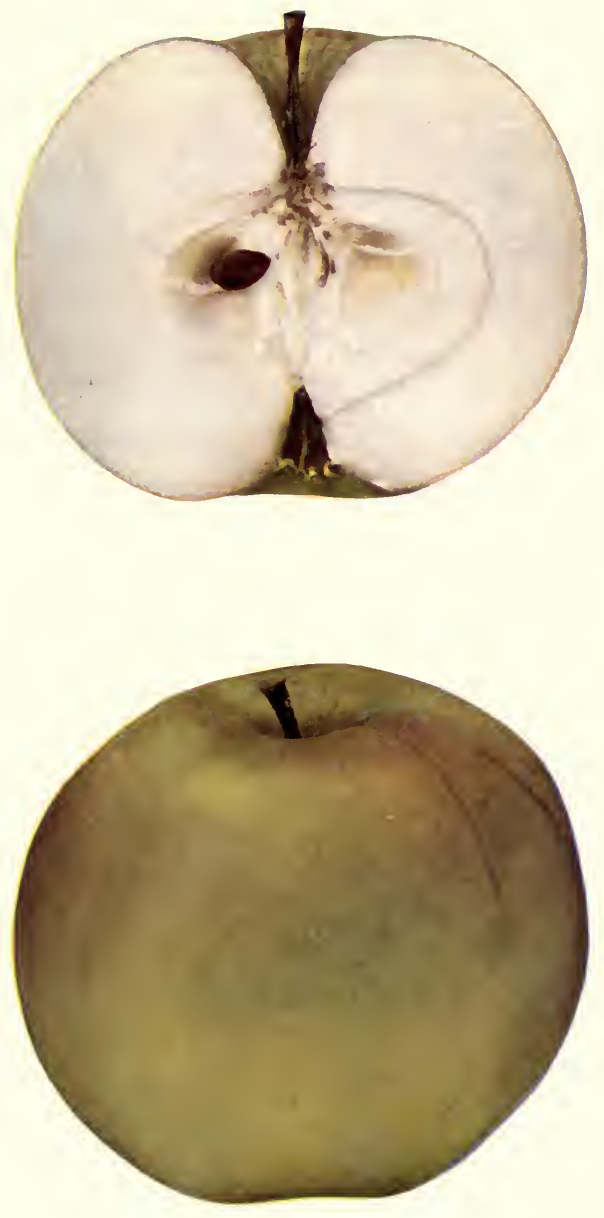

NELSON 



\section{NEWARK PIPPIN.}

Referfances. I. Coxe, I817:133. fig. 2. Buel, N. Y. Bd. Agr. Mem., 1826: 476. 3. Downing, 1845:121. 4. Thomas, I849:183. 5. Elliott, 1854:149. 6. Hooper, $1857: 63$. 7. Warder, $1867: 690$. fig. 8. Downing, $1869: 285$.

SyŃonyms. French Pippin $(2,3,4,5,6$, 8, of East New Jersey I). Yellow Pippin ( $1,3,5,8)$.

This is an apple of the Fall Pippin group, of good size, attractive yellow color and excellent quality. It is easily known by the crooked, irregular growth of the tree and the drooping habit of the branches (3). Coxe's description of this variety (I) is here given.

"Called the French Pippin in East-Jersey; and in other places denominated the yellow Pippin: this apple, on young trees, is sometimes large; it is usually above the middling size; the form is oblong-full, even and fair, hollowed at both ends-the skin has a greenish cast, turning yellow when fully ripe, with clouds of small black dots-the flesh is firm, very rich, juicy, and highly flavored; in taste and color like the yellow flesh of a pear: it is the finest early winter apple of the Middle States, and continues in full perfection until the maturity of the Newtown Pippin; it is also a much admired cider apple, and an abundant bearer, but apt to drop early in the autumn: the tree is of an irregular growth, the branches crooked and drooping, requiring great attention to pruning, which, when properly done, may be made conducive to the improvement of the natural growth-its excellence will remunerate any expense in rearing the tree, in the best form to promote its growth."

Historical. Newark Pippin is an old variety which appears to have been well known in portions of New Jersey a century ago (I). It was being cultivated by some fruit growers in New York early in the last century and was highly esteemed for table use and for cider (2). Downing calls it unprofitable (8). Notwithstanding the excellence of its fruit it appears to have become nearly obsolete in this state.

\section{FRUIT.}

Fruit above medium to rather large, pretty uniform in shape and size. Form roundish oblong to oblong, often somewhat elliptical or obscurely angular. Stem rather long, moderately slender. Cavity acute to acuminate, rather wide, deep, sometimes faintly russeted. Calyx large, open or sometimes closed. Basin large, wide, abrupt, deep, somewhat furrowed.

Skin smooth or slightly roughened with capillary russet lines, slightly waxy, moderately thin, tough, greenish, eventually developing a rich yellow tone. Dots numerous, varying from minute to rather large, rather conspicuous. Prevailing effect yellow.

Calyx tube large, wide, cone-shape or approaching funnel-form. Stamens median to basal.

Core large, abaxile to nearly axile; cells pretty symmetrical, open or closed; core lines clasping. Carpels broadly roundish to oval, mucronate, tufted. Seeds numerous, short, wide, medium or below, plump, rather light brown.

Flesh rather deeply tinged with yellow, tender, rather fine-grained, breaking, rich, juicy, subacid, aromatic, sprightly, very good to best for either dessert or culinary use. 


\section{NEWMAN.}

References. 1. Churchill, N. Y. Sta. An. Rpt., 9:346. I890. 2. Beach, Ib., 15:274. 1896. 3. Powell and Fulton, U. S. B. P. I. Bul., 48:50. 1903. 4. Beach and Clark, N. Y. Sta. Bul., 248:134. I904.

Synonym. Newman Seedling $(1,2)$.

Newman is a fruit of the Yellow Bellflower group. When it is well grown and properly colored it is rather attractive for a green or yellow apple. It is somewhat deficient in size for a good market apple and does not excel in quality, but late in the season is acceptable for dessert and very good for culinary uses. It is a good keeper and may perhaps be grown with profit to a limited extent but is not recommended for general planting in New York. The tree is a fairly good grower, comes into bearing young and is a reliable cropper, bearing full crops biennially. The fruit hangs well to the tree.

Historical. Received from George Townsend, Gordon, Ohio, in I890, for testing at this Station. It is as yet practically unknown in New York.

\section{TREE.}

Tree rather vigorous with very long, moderately stout, curved branches. Form upright becoming spreading and rather flat, open. Twigs short to rather long, curved, crooked, stout, with thick tips and large terminal buds; internodes short to rather long. Bark blackish-brown tinged with red and mingled with olive-green, slightly streaked with scarf-skin, heavily pubescent. Lenticels very conspicuous, quite numerous, medium to large, roundish to oval, raised. Buds prominent, large to rather small, broad, plump, obtuse to acute, free, pubescent.

\section{FRUIT.}

Fruit below medium to rather large. Form oblong inclined to conic, sometimes oblique, often faintly ribbed; sides unequal; pretty uniform in size and shape. Stem short to medium, rather slender. Cavity moderately shallow to deep, narrow to medium in width, symmetrical or sometimes compressed or slightly furrowed, russeted, occasionally with outspreading rays of russet, rarely lipped. Calyx medium, closed or somewhat open. Basin small, somewhat abrupt, shallow to medium in depth; furrowed and wrinkled.

Skin green changing to clear yellow with a faint shade of red or in highly colored specimens distinctly blushed with light red. Dots small to medium, green or dark, scattering, often areolar or red areolar.

Calyx tube short and conical varying to funnel-form. Stamens median or above.

Core large, abaxile; cells open or partly closed; core lines meeting or somewhat clasping. Carpels rather long, roundish, emarginate, slightly tufted. Seeds medium, acute, slightly tufted. 

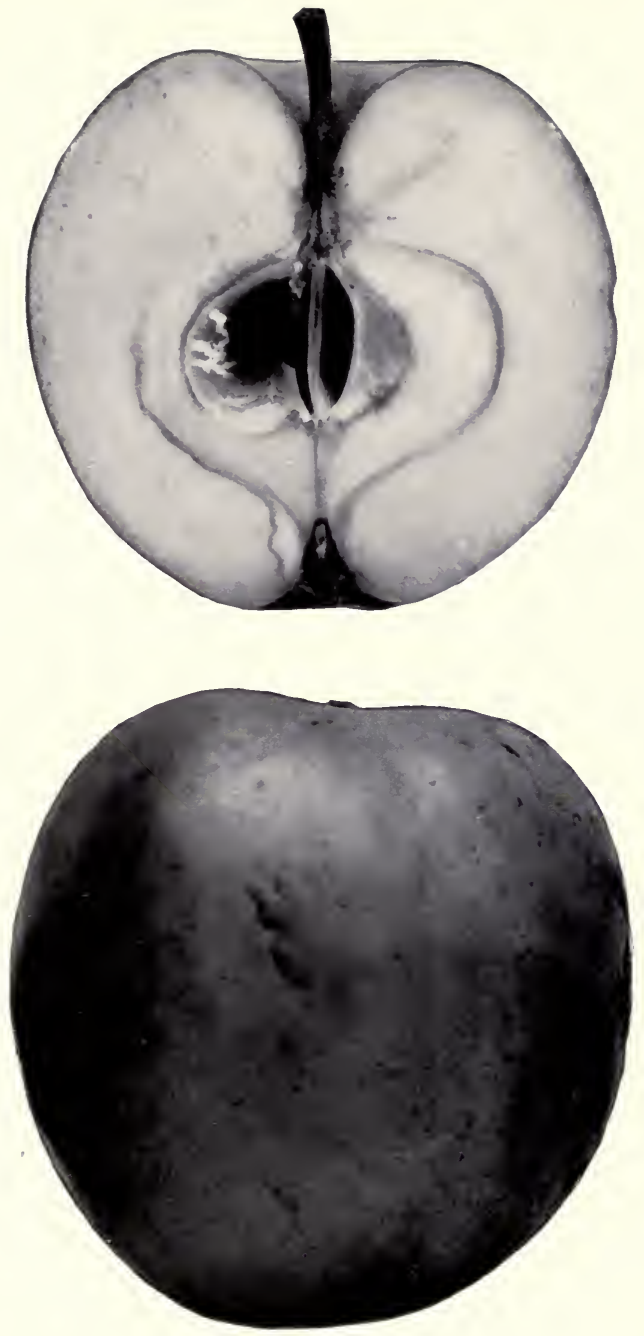

NEWMAN 

Flesh whitish, very firm, moderately fine-grained, rather tender, crisp, moderately juicy, subacid becoming nearly sweet, slightly aromatic, fair to good. Season December to May or June.

\section{NEWTOWN SPITZENBURG.}

References. I. Coxe, I8I7:I26. 2. Thacher, r822:137. 3. Buel, N. $Y . B d$. Agr. Mem., 1826:476. 4. Lindley, Pom. Mag., 3: No. I44. 1830. col. pl. 5. Cat. Hort. Soc. London, I831:36. 6. Ronalds, 1831:19. 7. Floy-Lindley, 1833: 40. 8. Manning, $1838: 58$. 9. Downing, $1845: 139$. I0. Downing, Horticulturist, I:341. 1847. II. Thomas, I849:173. 12. Cole, 1849:125. I3. Hovey, Mag. Hort., 15:539. 1849. fig. 14. Emmons, Nat. Hist. N. Y., 3:73. 1851. col. pl. fig. 15. Ib., 3:63. 185r. 16. Am. Pom. Soc. Cat., 1852. 17. Elliott, 1854: 94. fig. 18. Hooper, 1857:65. I9. Warder, 1867:445. 20. Am. Pom. Soc. Cat., I871 :8. 21. Fitz, 1872:121, I49, I53. 22. Downing, 1872:285. 23. Barry, 1883:350. 24. Hogg, I884:I56. 25. Wickson, 1889:246. 26. Lyon, Mich. Hort. Soc. Rpt., 1890:294. 27. Bailey, An. Hort., 1892:245. 28. Powell and Fulton, U. S. B. P. I. Bul., 48:50. 1903. 29. Budd-Hansen, 1903:134. fig. 30. Bruner, N. C. Sta. Bul., I82:21. I903. 31. Beach and Clark, N. Y. Sta. Bul., 248: I34. I904.

Synonyms. Barretts Spitzenburgh (22). Burlington (22). Burlington Spitzemberg (I). Burlington Spitzenberg (9, 17, 24). English Spitzemberg (1). English Spitzenberg $(3,24)$. Flushing (18) but incorrectly. Joe Berry ( I7, 19, 22). Kountz $(17,22)$. Matchless $(4,7,9,17,22,24)$. Newton Spitzemberg (i). Newton Spitszenburgh (2). Newtown Spitzemberg (7). Newtown Spitzenberg $(3,4,12$, I7, 19, 20, 24). Newtown Spitzenbergh (io). Newtown Spitzenburgh (15, 22, 23). Newtown Spitzenburgh (25). Ox Eye $(17,19,22)$. Spiced Ox Eye (22). Spitzenberg, Newtown (9). Spitzenburih, Newtown (i1). Spitzenburgh (22). Staalclubs (13) but erroneously. VAndevere (13, 21, 25). Vandevere of New York (20, 22, 23, 26). Vandervere (14, I6). Vandervere of New York (19). Wine (erroneously, 22).

This is the old Vandevere of New York, but it is not the true Vandevere. It is quite different also from the Esopus Spitzenburg which is commonly known among New York fruit growers by the simple name of Spitzenburg. The Newtown Spitzenburg is not a good commercial sort because it is an unreliable cropper, has too large a percentage of fruit of unmarketable size, and is not especially attractive in general appearance on account of its rather dull color. It is crisp, aromatic, rich, and mildly subacid mingled with sweet. Downing remarks that it is a most excellent fruit, suited to more tastes than any other apple of its season (22).

Historical. This variety originated in Newtown, Long Island. It was at one time quite popular in some sections of this state, particularly in the districts along the Hudson, but is now seldom planted and is gradually going out of cultivation. 
TREe.

Tree medium to large, vigorous or moderately vigorous with long, moderately stout, curved branches. Form spreading or roundish, rather dense. Twigs moderately long to short, straight, rather erect, geniculate, slender to moderately stout; internodes medium to long. Bark dull brown, rather heavily streaked with scarf-skin, pubescent in spots. Lenticels rather inconspicuous, quite numerous, small to medium, oblong or roundish, slightly raised. Buds medium to small, wide, plump, obtuse, free, with little pubescence or none.

\section{FrUit.}

Fruit about medium size. Form roundish approaching cylindrical or somewhat oblate; pretty regular and uniform in shape and size. Stem very short to rather long, rather slender, pubescent. Cavity acute, deep, broad, indistinctly furrowed, sometimes russeted. Calyx small, closed, sometimes partly open; lobes broad, obtuse. Basin small to medium, wide to rather narrow, shallow and obtuse to rather deep and abrupt, slightly furrowed.

Skin smooth, tough, eventually beconing deep yellow blushed and mottled with dull red striped with carmine, streaked with grayish scarf-skin and often overspread with a light bloom giving it a peculiarly bluish cast. Dots characteristic, conspicuous, very numerous, yellowish or peculiarly gray; often with russet center, small, very numerous and crowded about the basin but less numerous, larger and irregular toward the cavity.

Calyx tube cone-shape or approaching funnel-form with short, truncate cylinder. Stamens median.

Core above medium to rather small, more or less abaxile; cells usually pretty symmetrical and partly open, sometimes closed; core lines meeting or somewhat clasping. Carpels smooth or nearly so, approaching elliptical, often nearly truncate at the base and narrowing somewhat toward the apex. Seeds numerous, below medium to rather large, rather narrow, plump, acute.

Flesh yellowish, firm, fine-grained, crisp, tender, juicy, mild subacid mingled with sweet, rich, aromatic, very good to best in flavor and quality.

Season in Southeastern New York late fall or early winter; in Western New York it is easily kept till February or March in ordinary storage and often some portion of the fruit remains in fairly good condition till the close of April (3I).

\section{NEW WATER.}

References. I. Powell and Fulton, U. S. B. P. I. Bul., 48:50. 1903. 2. Beach and Clark, N. Y. Sta. Bul., 248:134. 1904. 3. Ragan, U. S. B. P. I Bul., 56:211. 1905.

A large winter apple, striped red, moderately attractive, of mild flavor and good quality. It is more suitable for dessert than for any other use. As grown in this locality it comes into bearing moderately young and is a reliable cropper yielding full crops biennially with occasional lighter crops in alternate years. It does not appear to be superior to standard varieties of its season either for home use or for market and for this reason it is not recommended for planting in New York.

Historical. Received from Josiah G. Youngken, Richlandtown, Pennsylvania, in $\mathbf{1 8 9 3}$ for testing at this Station. 

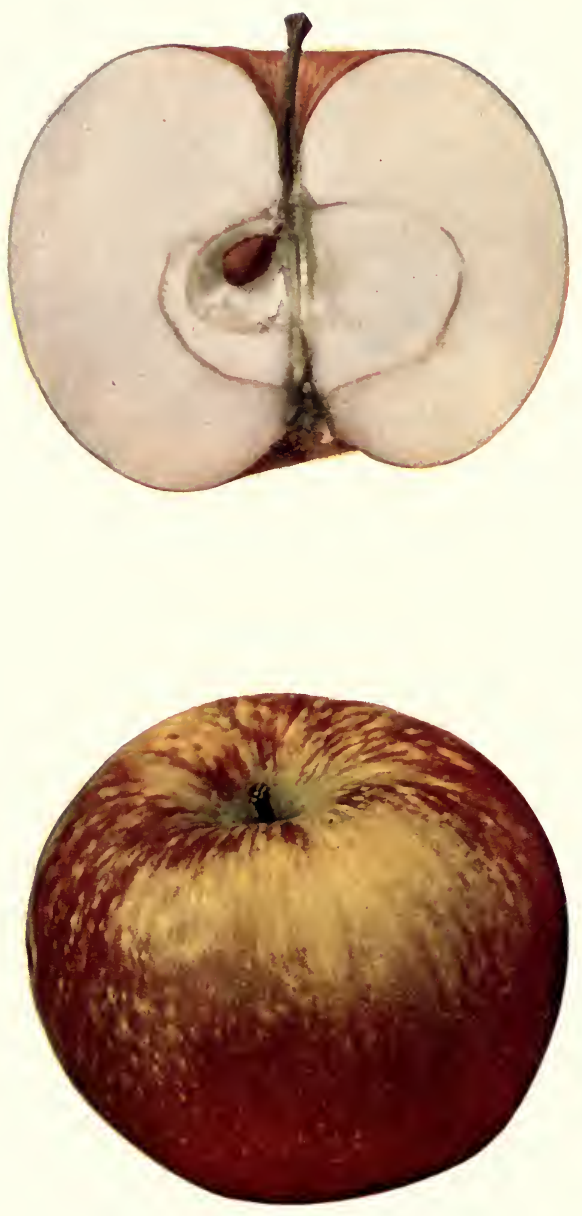

NEWTOWN SPITZENBERG 



\section{FRUIT.}

Fruit large or above medium. Form flat at base, oblate, narrowing and often somewhat ribbed toward the basin, often oblique. Stem short. Cavity large, acute, deep to very deep, broad, occasionally lipped, sometimes russeted. Caly $x$ large to medium, usually open, sometimes closed; lobes leafy, broad, long, acute. Basin usually rather large, sometimes oblique, moderately deep, varying from nerrow or compressed to moderately wide, abrupt, often somewhat furrowed and irregular.

Skin thin, tough, smooth, rather glossy, yellow or greenish blushed with orange-red and mottled and striped with pinkish-red over a large part of the surface. Dots inconspicuous, medium to small, pale gray or russet. Prez'ailing effect striped red.

Calyx tube remarkably large, varying from conical to long funnel-form and exteriding to the core. Stamens basal or nearly so.

Core very small to nearly medium, varying from axile to somewhat abaxile; cells sometimes unsymmetrical and open but usually closed; core lines meeting when the calyx tube is conical but clasping if it is funnel-form. Carpels roundish, slightly emarginate. Seeds few, dark, medium in size, wide, sometimes slightly tufted.

Flesh whitish tinged with yellow, firm, moderately fine-grained, crisp, tender, juicy or very juicy, mild subacid becoming nearly sweet, aromatic, good.

Season October to February or March; commercial limit January.

\section{NICKAJACK.}

References. I. Hovey, Mag. Hort., 19:565. I853. 2. Stanford, Horticulturist, II:255. 1856. fig. 3. Downing, 1857:175. fig. 4. Hooper, 1857:65. 5. Downing, Horticulturist, 16:40. 1861. fig. 6. Warder, 1867:445. fig. 7. Downing, 1869:286. fig. 8. Am. Pom. Soc. Cat., I871:8. 9. Fitz, 1872:143, I56, I66, I72. Io. Leroy, I873:488. fig. II. Barry, I883:35I. I2. Thomas, I885: 237. I3. Wickson, I889:248. I4. Lyon, Mich. Hort. Soc. Rpt., 1890:294. I5. Bailey, An. Hort., I892:245. 16. Budd-Hansen, 1903:136. fig.

Synonyms. Aberdeen $(5,7)$. Accidental $(5,7)$. Alleghany $(5,7)$. Berry (5, 7, 10, 12). Big Hill $(5,6,7)$. Carolina (5, 6, 10). Carolina Spice (5, 7, 10, 12). Caroline (7). Chatham Pippin (7). Chaltram Pippin $(5,7)$. Cheatan Pippin (5, 7). Cheataw (7). Dahlonega (5). Edwards (12). Edward Shantee (7). Forsythe's Seedling (7). Gozvden (7). Gowdie (5). Graham's Red Warrior (7). Howard (5, 7). Hubbard (5, 7, 10). Jackson Red (5, 6, 7). Leanham (7). Missouri Pippin (7). Missouri Red (7). Mobbs $(5,7)$. Nickejack (I). North Carolina (13). Pound (5, 7). Red Hazel (7, 12). Red Pippin (5, 7). Red Warrior (5, 7). Rickmans Red (5). Ruckman (5). Ruckmans Red (7). Summerour (1). Summerour (3, 5, 6, 7, 12). Treanham (5). Trenham (7). Walb (7). Wall (5, 7, 10). Wander (7). Winter Horse (7). Winter Rose (5, 7, I I). Wonder (3, 5). Worlds Wonder (7).

This variety has long been known in various portions of the South and Southwest. Its popularity in those regions is attested by its host of synonyms. It is said to have the habit of reproducing itself so nearly from seed that its scedlings in some cases can hardly be distinguished from the parent (7). In Vol. I - Io 
localities favorable to its proper development the tree is a strong grower and very productive and the fruit is large and sometimes well colored and showy but ustally it is rather dull colored and not very attractive. It ranks only second rate in quality but it is a remarkably good keeper. It is evidently not well adapted for regions as far north as this. It has failed to gain favorable recognition among New York fruit growers and has been planted but sparingly in this state.

Historical. This variety is supposed to have originated near a stream of the same name in Macon county, N. C., 1 among the Cherokee Indians (1, 2, $3,6,7)$. The time of its origin is not definitely known but the fact that in I86I it is referred to as an old variety cultivated in at least three states and having over twenty synonyms (5) indicates that it has probably been under cultivation for a century or more. Colonel Summerour of Lincoln county, N. C., early disseninated this variety under the name of Winter Rose ( 7$)$, but Silas McDowell of Franklin, N. C., at about the middle of the last century brought it to notice under the name Nickajack (2), which has now become the generally accepted name for the variety.

\section{TREE.}

Tree large, very vigorous. Form upright, moderately spreading. Twigs rather short, slender to rather stout, nearly straight, heavily pubescent; internodes medium to long. Bark smooth, of a rather clear dark red with some olive-green. Lenticels moderately conspicuous, quite narrow, small, raised. $B u d s$ small, rather projecting, sharply acute, appressed, moderately pubescent.

\section{FRUIT.}

Fruit above medium to large, rather uniform in size and shape. Form inclined to roundish conic varying sometimes to roundish oblate or rarely to roundish oblong; sides usually somewhat unequal; axis often slightly oblique. Stem usually short and thick. Cavity acuminate to acute, deep, rather broad, obscurely furrowed and partly covered with thin greenish-russet. Calyx rather large to below medium, closed or somewhat open; lobes short to medium in length, rather broad, acute. Basin often oblique, rather shallow, medium in width to wide, obtuse to somewhat abrupt, obscurely furrowed and slightly wrinkled.

Skin thick, tough, rather smooth, sometimes a little glossy, yellow or greenish, mottled and shaded with orange-red or red, irregularly splashed and streaked with bright carmine and somewhat flecked with russet. It is usually streaked over the base with grayish scarf-skin and overspread with thin bloom, giving it a rather dull appearance. Dots numerous, usually irregular in shape and of variable size, very conspicuous, pale or russet. Prevailing effect grayish-red.

Calyx tube rather large, wide, varying from short and urn-shape or coneshape to very long, approaching funnel-form. Stamens median to marginal.

Core medium or above, axile; cells closed or partly open; core lines clasping. Carpels rather concave, broadly ovate approaching roundish, tufted. Seeds below medium to above, light to dark brown, rather short and wide, plump, acute to somewhat obtuse, tufted.

\footnotetext{
'Warder gives it erroneously as Macon county, Ga.
} 

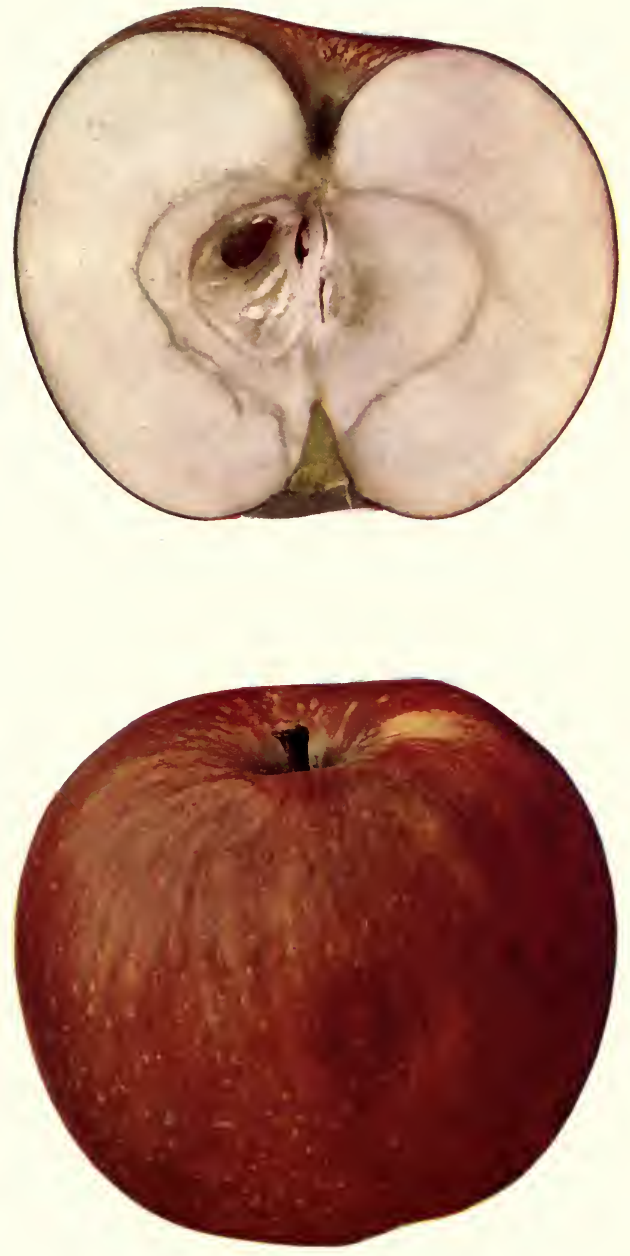

NICKAJACK 

Flesh yellowish, very firm, somewhat coarse, rather crisp, moderately tender, juicy, mildly subacid becoming nearly sweet, slightly aromatic. It ranks good but not high in flaver and quality.

Season December to May.

\section{NORTHERN SPY.}

References. I. Mag. Hort., I0:275. 1844. 2. Albany Cultivator, 2:41, 56. 1845. 3. Genesee Farmer, 1845. (cited by 6). 4. Downing, 1845:120. 5 . Horticulturist, $\mathbf{1}: 30,144.1846$. 6. Ib., $\mathbf{x}: 386,482$. 1847. 7. Hovey and Watts, Mag. Hort., 13:72, 104, 538. 1847. fig. 8. Hovey, Mag. Hort., 14:530. 1848. 9. Thomas, 1849:169, I74. fig. Io. Cole, 1849:134. fig. I1. Allen, Horticulturist, 6:351. 1851. 12. Emmons, Nat. Hist. N. Y., 3:70. I851. col. pl. No. 23. 13. Hovey, 1:19. 1851. col. pl. and fig. 14. Am. Pom. Soc. Cat., 1852. I5. Mag. Hort., 19:68. 1853. 16. Elliott, 1854:94. fig. 17. Smith, Horticulturist, I I :242. 1856. 18. Hooper, 1857:66. 19. Hoffy, N. A. Pom., 1860. col. pl. 20. Hovey, Mag. Hort., 29:459. I863. 21. Warder, 1867:541. fig. 22. Downing, 1869:289. fig. 23. Fitz, 1872:166. 24. Leroy, 1873:501. fig. 25. Barry, 1883: 351. 26. Hogg, 1884:161. 27. Wickson, 1889:248. 28. Lyon, Mich. Hort. Soc. Rpt., 1890:294. 29. Bailey, An. Hort., 1892:245. 30. Taylor, Am. Pom. Soc. Rpt., 1895:192. 31. Woolverton, Ont. Fr. Stas. An. Rpt., 3:15. 1896. figs. 32. Bruner, N. C. Sta. Bul., 182:21. 1903. figs. 33. Budd-Hansen, 1903: 137. fig. 34. Powell and Fulton, U. S. B. P. I. Bul., 48:51. 1903. 35. Beach and Clark, N. Y. Sta. Bul., 248:134. 1904.

Synonyms. Northern Spy (31). Spy (31). Spy (1, 19).

Northern Spy is often known among fruit growers and fruit buyers by the simple name of Spy. It ranks third in commercial importance among New York apples, being surpassed in this respect by Baldwin and Rhode Island Greening. When it is well grown it is superior to either of these in flavor and quality and easily ranks among the very best winter apples of New York. The fruit is large and attractive, being of a bright red color, overspread with a delicate bloom. The flesh is very juicy, crisp, tender and most excellent for either dessert or culinary uses. It is not a good variety for evaporating because it is too juicy and tender. It is well adapted for either local, general or fancy trade. It has a well-established reputation in market, and because of its size, beauty, fine flavor and high quality it often sells at more than average prices. It is ready for use in November and December, and retains its crispness and high flavor remarkably well until the close of the season (35). Its thin skin and juicy, tender flesh render careful handling absolutely necessary, otherwise there is much shrinkage in storage (35). It is particularly susceptible to attack from blue mold (Penicillium glau- 
cum Link) in storage, especially if bruised or delayed in reaching storage. If well colored, picked, packed and handled with great care and stored soon after picking, it may be carried in storage as long as most winter varieties (34). Its keeping quality varies considerably in different seasons and in different locations. In ordinary cellar storage its season sometimes closes in February, but more often extends to March or April, and if the temperature is very carefully regulated it may sometimes be held till May. It stands heat fairly well, but after being picked it should go into storage as soon as possible. Poorly colored fruit of this variety is not good in flavor and does not keep as well as well-ripened and highly colored fruit. In some localities it appears to require from two to three weeks longer than Rhode Island Greening to ripen properly.

Both the foliage and fruit of Northern Spy are noticeably susceptible to injury by the scab and thorough treatment is required to prevent loss from this disease. It comes into bloom remarkably late. On this account its blossoms sometimes escape destruction by late frosts when earlier-blooming varieties are much injured. Often it produces many small apples which are seedless or nearly so. This indicates an improper fertilization of the blossoms. It remains to be demonstrated whether or not this fault may be remedied by planting near the Northern Spy some other late-blooming variety bearing an abundance of fertile pollen.

Northern Spy is not as well adapted for general cultivation as is either Baldwin or Rhode Island Grcening because it is more or less variable in season and quality, and in some sections is an unreliable cropper. Usually it is rather slow in coming into bearing, although under favorable conditions it has been known to yield profitable crops within seven years from the time of planting. The young trees increase in productiveness as they advance in maturity. In favorable locations, under good care, they usually become reliable croppers yielding from moderate to heavy crops biennially, or in some cases almost annually. This variety succeeds better in the cooler regions of the interior of the state than it does on the warm slopes south of the Fishkill mountains and on the coastal plain. It 

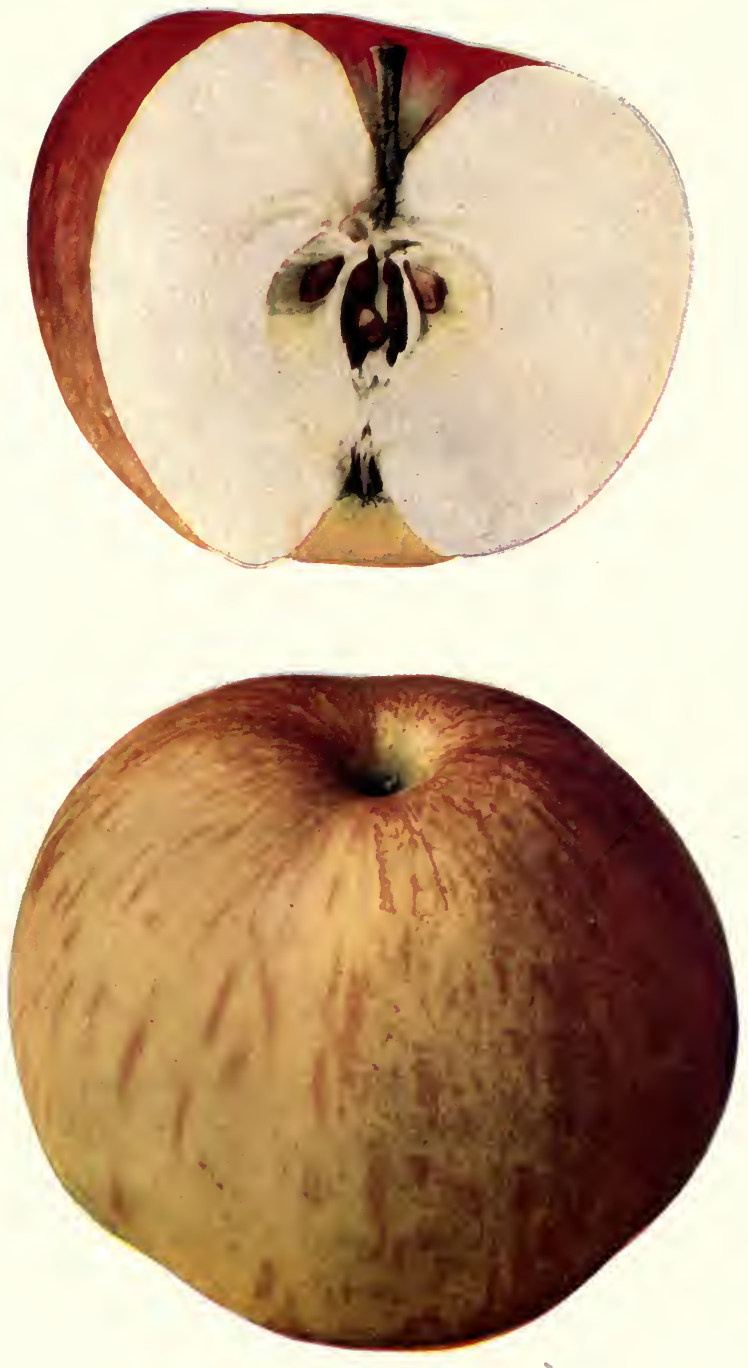

NORTHERN SPY 

generally does well on the hills and well-drained slopes in the more elevated regions from Chautauqua lake eastward to the Catskills, along the Champlain valley and in the uplands east of the Hudson as far south as the Fishkill mountains. In some portions of the regions just named it has become the leading variety in commercial orchards, but its cultivation is by no means confined to these regions, for it is grown quite extensively in many other localities and is generally well known throughout the state. Experienced fruit growers frequently express a preference for warm, fertile soil, either gravelly loam or clay loam, with well-drained subsoil, upon which to plant Northern Spy, although in some few districts there is a decided preference for rather heavy clay loam. In the territory best adapted to its cultivation it is grown satisfactorily upon different slopes and different soils. When grown in sod the trees may be less productive, but the fruit doubtless colors better and keeps better than when the orchard is given frequent and thorough tillage during the growing season.

The tree is very hardy and healthy, develops a strong root system both in the nursery and in the orchard, and has an upright, freegrowing habit. For these reasons it is much in favor as a stock upon which to top-work varieties that are less vigorous, less hardy or less healthy. The top tends to become dense and must be pruned regularly and thoroughly to keep it sufficiently open to admit light and air to the foliage in all parts of the tree; otherwise, especially on the older trees, much of the fruit is apt to be poorly matured and poorly colored. Pruning for this purpose should be done by removing the laterals and limbs that cross, being careful to leave the smaller twigs and spurs, as these are the ones upon which the most of the fruit is borne.

The head of the young orchard tree should be formed with great care. In the words of one of our correspondents, ${ }^{1}$ the wood of this variety is very straight-grained and the tree is liable to split when heavily loaded. To guard against this, when the head of the small tree is formed no two limbs should be left opposite or nearly opposite each other, but the three or four branches which are selected for

${ }^{1}$ E. W. Lamont, Cobleskill, N. Y. 
forming the head of the tree should be distributed along the main stem at some little distance apart. This distributes the load upon the trunk and gives more spring to the body of the tree, thus tending to prevent its splitting with heavy loads. Standard orchard trees of Northern Spy should stand forty to fifty feet apart in order to prevent their becoming too much crowded when fully matured.

Historical. Originated in a seedling orchard at East Bloomfield, N. Y., which is famous for the production of this variety, the Early Joe and the Melon. This orchard was planted by Heman Chapin with seedling trees grown from seeds brought from Salisbury, Connecticut, about the year I8oo $(3,4,5,6,7,18)$. Sprouts from the original tree were taken up and planted by Roswell Humphrey and by him the first fruit of the Northern Spy was raised as the original tree died before bearing. In 1847 nine of the trees set out by Humphrey were still living (6). The variety was confined to the vicinity of its origin for many years and it was not till about 1840 that it began to attract the attention of fruit growers in other localities $(6,12)$. Its great value then came to be more widely recognized and in 1852 the American Pomological Society not only listed it as a new variety of promise but also as a varicty worthy of general cultivation. Since that time it has become extensively planted not only in New York but in various other portions of the more northern apple-growing regions.

Tree.

Tree large, vigorous; branches long, moderately stout, curved. Form upright, dense, becoming roundish with willowy, slender laterals somewhat inclined to droop. Twigs long to medium in length, erect, straight or somewhat crooked, slender to moderately stout; internodes long to rather short. Bark dull, dark brownish-red mingled with olive-green lightly streaked with thick scarf-skin; heavily pubescent. Lenticels numerous, conspicuous, small, roundish or oblong, slightly raised. Buds deeply set in bark, medium to small, broad, plump, obtuse, appressed, slightly pubescent.

\section{Fruit.}

Fruit except when it is seedless is usually large or very large. Form roundish conical, sometimes inclined to oblong, often noticeably flattened at the base, nearly symmetrical, sometimes regular but often noticeably ribbed. Stem medium to long, moderately thick. Cavity large, acute, very wide and deep, often broadly furrowed, usually with greenish-russet radiating upwards to the brim. Caly $x$ usually small, closed, sometimes partly open; lobes short, broad, obtuse. Basin small to medium, narrow to medium in width, moderately deep, abrupt, usually somewhat furrowed.

Skin thin, tender and smooth. In highly colored specimens it is glossy and the clear pale yellow ground color is nearly concealed with bright pinkish-red mottled and splashed with carmine and overspread with a thin delicate bloom. Dots medium to small, not conspicuous, scattering, whitish, gray or russet. Prevailing effect bright red or striped red. Rarely the yellow or green color predominates. In such cases the quality of the fruit is low. 


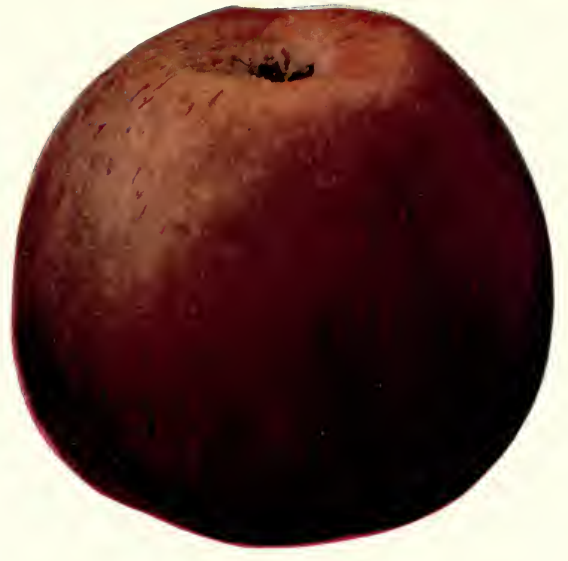

LEE

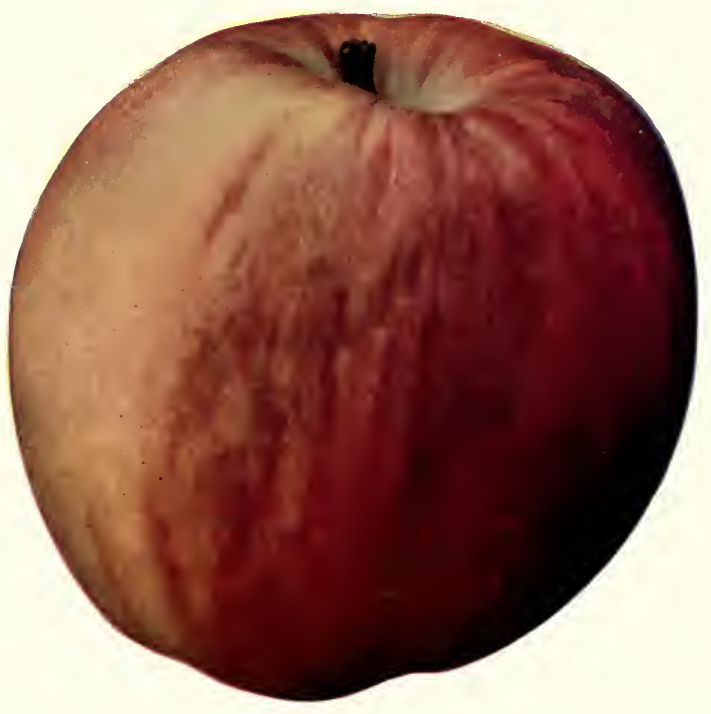

NORTHERN SPY 

Calyx tube sometimes large, long, cone-shape but more often narrow and somewhat funnel-form with very narrow cylinder. Stamens basal or nearly so.

Core usually large, sometimes medium, abaxile; cells pretty symmetrical, open or nearly closed, often not uniformly developed; core lines clasping the funnel cylinder. Carpels much concave, broadly roundish, emarginate, slightly tufted. Seeds small to medium, wide, often abortive and few but sometimes numerous, plump, obtuse, dark, somewhat tufted.

Flesh yellowish, rather firm, moderately fine-grained, very tender, crisp, very juicy, sprightly, aromatic, subacid, very good to best.

\section{NORTHWESTERN GREENING.}

References. I. Am. Pom. Soc. Rpt., I885:27. 2. Rural N. Y., 44:I50. 1885. figs. 3. Van Deman, U. S, Pom. Rpt., 1886:271. 4. Bailey, An. Hort., I892:245. 5. Shepherd, Can. Hort., 16:205. I893. 6. Ib., I7:84. I894. figs. 7. Beach, N. Y. Sta. An. Rpt. 14:254. I895. 8. Hansen, S. D. Sta. Bul., 76:77. 1902. fig. 9. Munson, Mc. Sta. An. Rpt., 18:84, 90. 1902. 10. Thomas, I903:343. I I. Budd-Hansen, I903:138. fig. I2. Macoun, Can. Dept. Agr. Rpt., 1903:95. 13. Powell and Fulton, U.S.B.P. I. Bul., 48:51. 1903. I4. Beach and Clark, N. Y. Sta. Bul., 248:135. I904.

Synonyms. North West Greening $(5,6)$. Northwestern Greening (I, $3,4,7,8,9$, I0, 12, I3).

Attractive in color for a green or yellowish apple but apt to be variable in size and not uniform in shape. It is hardier than Rhode Island Greening and on that account some consider it worthy of cultivation in districts where the climate is too severe for the Rhode Island Greening. The fruit has a serious fault in that the flesh within the core lines is apt to be corky and discolored. It cooks evenly and quickly and when cooked has a fine yellow color but is not of high flavor or quality being much inferior in this respect to Rhode Island Grcening. As a dessert apple it ranks fair to good in quality. At this Station it has not been a satisfactory keeper in common storage, the rate of loss being high in November and sometimes in December, moderate through the winter and gradually rising to high or very high in the closing weeks of its season. A large part of the fruit does not reach prime condition before January, a considerable portion of it remains sound at the close of the winter and some of it may keep till June. The tree is hardy, vigorous, a fine erect grower in the nursery, and a good strong grower in the orchard. It does not come into bearing very early but eventually becomes productive and is a reliable biennial cropper.

Historical. Originated in Waupaca county, Wisconsin. Introduced in 1872 by E. W. Daniels ( I, I I). It has been pretty widely disseminated throughout the northern portions of the apple belt where very hardy trees are desired $(\mathrm{I}, 4,5,8, \mathrm{II})$. It has as yet been planted but very little in New York.

\section{TREE.}

Tree vigorous with moderately long, stout, crooked branches. Form upright becoming quite roundish or spreading, inclined to droop, dense. Twigs moderately long, curved, stout with large terminal buds; internodes medium 
to long. Bark clear reddish-brown, lightly mottled with scarf-skin, lightly pubescent. Lenticels quite numerous, medium to large, oval or elongated, raised, very conspicuous, pale and contrasting clearly with the bright smooth bark. Buds large, broad, plump, obtuse, free, projecting, slightly pubescent.

\section{FrUIT.}

Fruit medium to large or very large, variable in size and form. Form commonly . roundish but varying to oblong or to oblate and often inclined to conic, more or less irregular, sometimes elliptical, sometimes ribbed. Stem medium to sho:t. Cavity rather small to large, acute to acuminate, moderately narrow to wide, deep, often compressed or lipped, often with outspreading russet. Calyx variable, small to large, closed or open. Basin small to large, narrow to wide, usually abrupt, moderately deep, furrowed and wrinkled.

Skin smooth, somewhat waxy, clear pale yellow or greenish, sometimes faintly blushed. Dots varying from small to large and irregular, usually whitish and submerged, sometimes gray with russet point. Prevailing effect clear yellow or greenish.

Calyx tube moderately wide, conical or approaching urn-shape. Stamens median.

Core medium or above, usually axile or nearly so; cells usually symmetrical, closed or sometimes open; core lines meeting or somewhat clasping. Carpcls broadly roundish, truncate at base, narrowing toward the apex, mucronate, but slightly emarginate if at all. Seeds very small, variable in sliape; often some are abortive.

Flesh tinged with yellow, medium in texture, crispness and firmness, juicy, with slight aroma, mild subacid, fair to good.

\section{OAKLAND.}

References. 1. Garfield, Am. Pom. Soc. Rpt., i883:120. 2. Am. Pom. Soc. Cat., I883:12. 3. Lyon, Mich. Hort. Soc. Rpt., 1890:294. 4. Thomas, 1897: 647. 5. Farrand, Mich. Sta. Bul., 205:45. 1903. 6. Powell and Fulton, U. S. B. P. I. Bul., 48:51. 1903. 7. Beach and Clark, N. Y. Sta. Bul., 248:135. 1904. Synonym. Oakland County Seek-No-Further (i). Oakland County Seek-No-Further $(2,4,6,7)$.

A mildly sweet apple of good medium size, attractive dark red color, pleasant flavor and good quality. In common storage it is in season from late November to midwinter or later; in cold storage it may be held till April (7). The tree is a rather slow grower. As fruited at this Station it comes into bearing rather young and is a reliable cropper, giving full crops biennially. Probably it would be an advantage to top-work this variety on some more vigorous stock.

Historical. This for many years has been a popular variety in Oakland county, Michigan, where it probably originated. In $188_{3}$ it was brought to the notice of the American Pomological Society by Charles W. Garfield (I) and was entered upon the list of that Society's Catalogue as a promising variety in Michigan (2). It was dropped from the list when the Catalogue was revised in 1897 . In 1903 Farrand (5) stated that in some portions of Michigan it is quite largely planted for commercial purposes. It is practically unknown in New York. 

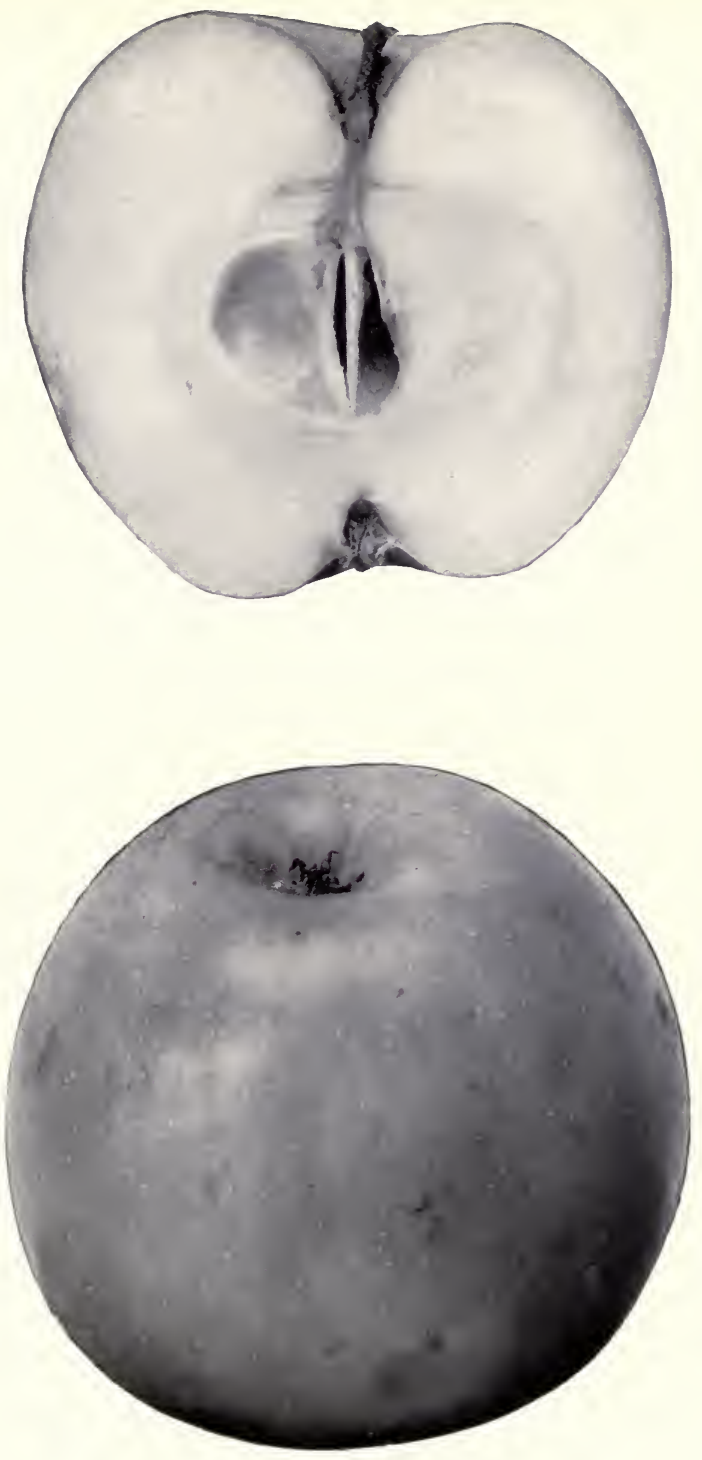

NORTHWESTERN Greening 


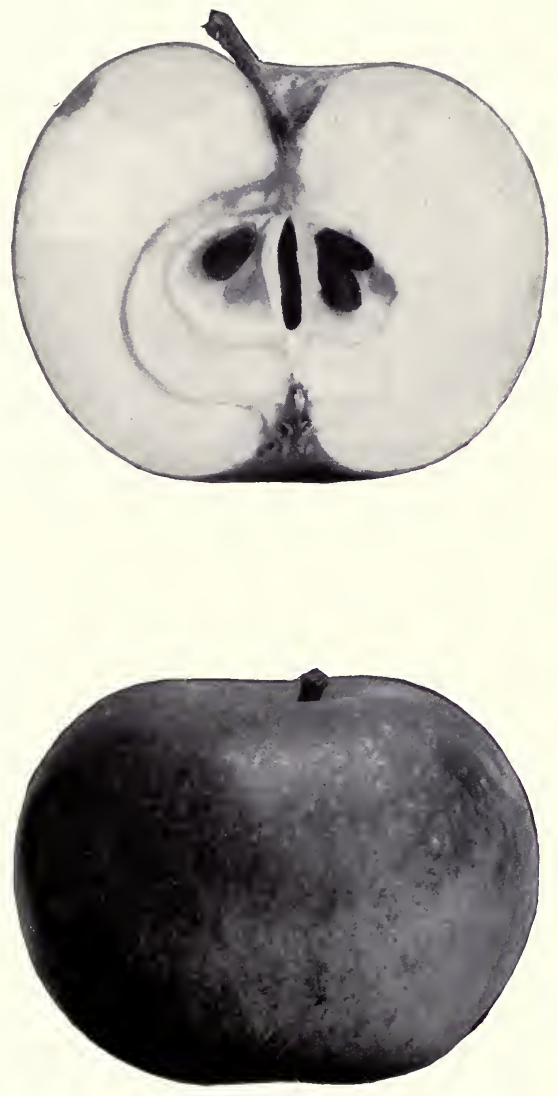

OAKLAND (Reduced Size) 



\section{TREE.}

Tree a slow grower with moderately long and stout branches. Form open, spreading, becoming rather flat-topped. Twigs short, straight, stout; internodes short. Bark clear brown tinged with olive-green, lightly streaked with scarf-skin, slightly pubescent. Lenticels quite numerous, very small, oval, not raised. Buds small, plump, obtuse, free, slightly pubescent.

\section{FrUIT.}

Fruit below medium to large, pretty uniform in size. Form roundish, usually somewhat oblate, sometimes inclined to conic, fairly symmetrical, irregular, often obscurely angular or ribbed. Stem rather slender. Cavity acuminate, moderately wide, moderately deep to deep, angular, sometimes lipped, often partly russeted and with some outspreading russet. Calyx pubescent, rather small, closed. Basin shallow to moderately deep, sometimes abrupt, compressed or furrowed.

Skin thin, tough, smooth, pale green or yellow blushed and mottled with dark red, striped with carmine and overspread with thin bloom; highly colored specimens become deep red and almost purplish. Dots medium in size, light, sometimes mingled with flecks of russet. Prevailing color dark red dulled by bluish bloom.

Calyx tube rather small, narrow, funnel-form. Stamens median to basal.

Core below medium, somewhat abaxile with hollow cylinder at the axis; cells usually symmetrical, partly open or closed; core lines clasping. Carpels smooth, distinctly concave, elliptical, obtusely emarginate, mucronate. Seeds numerous, variable, small to medium, obtuse.

Flesh white, very tender fine-grained, juicy, sweet, crisp, good.

\section{OCCIDENT.}

References. I. Goff, N. Y. Sta. An. Rpt., 2:35. 1883. 2. Bailey, An. Hort., I892:245. 3. Beach, W. N. Y. Hort. Soc. Rpt., 1896:52. 4. Beach and Clark, N. Y. Sta. Bul., 248:135. 1904 .

This fruit is of the Yellow Bellflower type, attractive bright yellow, excellent in quality and a remarkably good keeper. The tree is a little slow in coming into bearing but it is a strong grower, a reliable cropper and very productive. The fruit hangs well to the tree. As grown here it is not large. It sometimes averages above medium and sometimes below medium size. Usually it is pretty uniform for the crop both in size and shape. Apparently it would be a desirable variety for commercial planting in New York were it not somewhat deficient in size.

Historical. Originated by L. J. Fish, Martinez, California. Said to be a seedling of Yellow Bellflower. Scions of it were received in 1883 from Ellwanger and Barry for testing at this Station. It was being then regarded as one of the promising new varieties.

\section{Fruit.}

Fruit above medium to below medium. Form roundish oblate to roundish conic, often faintly ribbed. Stem long, stout. Cavity rather large, acuminate to acute, deep and moderately broad, sometimes russeted. Calyx closed or 
somewhat open; lobes long, acuminate, reflexed. Basin small to medium, shallow, medium in width to narrow, often abrupt, furrowed and wrinkled.

Skin smooth, clear yellow often with a shade of brownish-red, sometimes blushed with bright red. Dots numerous, light or russet.

Caly. $x$ tube rather narrow, funnel-form. Stamens median to basal.

Core large, usually abaxile; cells usually wide open as in Yellow Bellflower; core lines clasp the funnel cylinder. Carpels large, broadly roundish, tufted, slightly emarginate. Seeds long, acute, tufted.

Flesh whitish or slightly tinged with yellow, firm, fine-grained, rather tender, crisp, juicy, sprightly, rich subacid, very good.

Season January to May; usual commercial limit in cellar storage, March or April (4).

\section{OEL AUSTIN.}

References. I. Heiges, U.S. Pom. Rpt., r894:21. 2. N. Y. Sta. An. Rpt., I $5: 688$. 1896 .

Synonyms. Oel (1). Austin.

An attractive apple of the Blue Pearmain group, of fairly good quality. It varies in size from small to above medium. It is in season from November to March or April. It is said to be very hardy in St. Lawrence county and a good thrifty grower, and it may prove desirable for the home orchard in those sections of the state where superior hardiness is a prime requisite.

Historical. Received here from A. F. Clark, Raymondville, St. Lawrence county, in 1806 . The original tree, 16 to 18 inches in diameter, was then standing neglected in an old pasture. Mr. Clark began to propagate the variety about I89ז. He believes that it is a seedling of Stone, 1 a variety which is highly esteemed locally in St. Lawrence county. It is known locally as Austin.

\section{TreE.}

Tree rather vigorous. Form upright, somewhat spreading, rather dense. Tiigs medium to long, rather slender to moderately stout, nearly straight, somewhat pubescent; internodes short. Bark clear olive-green tinged with reddish-brown and mottled with gray scarf-skin. Lenticels rather numerous, small, scattering, round, raised but slightly if at all. Buds small, obtuse, appressed, pubescent.

\section{Fruit.}

Fruit small to above medium. Form broadly ovate to roundish conic, faintly ribbed, nearly regular, symmetrical, uniform. Stem pubescent, medium to long, moderately slender. Cavity small, acuminate, moderately shallow, narrow, sometimes russeted, symmetrical. Caly $x$ medium to small, open to nearly closed; lobes short, narrow, pubescent, converging and somewhat re-

\footnotetext{
${ }^{1}$ Stone was erroneously identificd by a leading pomologist for Mr. Clark as Bethel, and for this reason in the account given by Heiges (1) it is erroneously stated that Oel Austin is a seedling of Bethel. Both Stone and Bethel belong in the Blue Pearmain group, but they are quite distinct varieties. For a comparison of the two the reader is rcferred to Stone.
} 

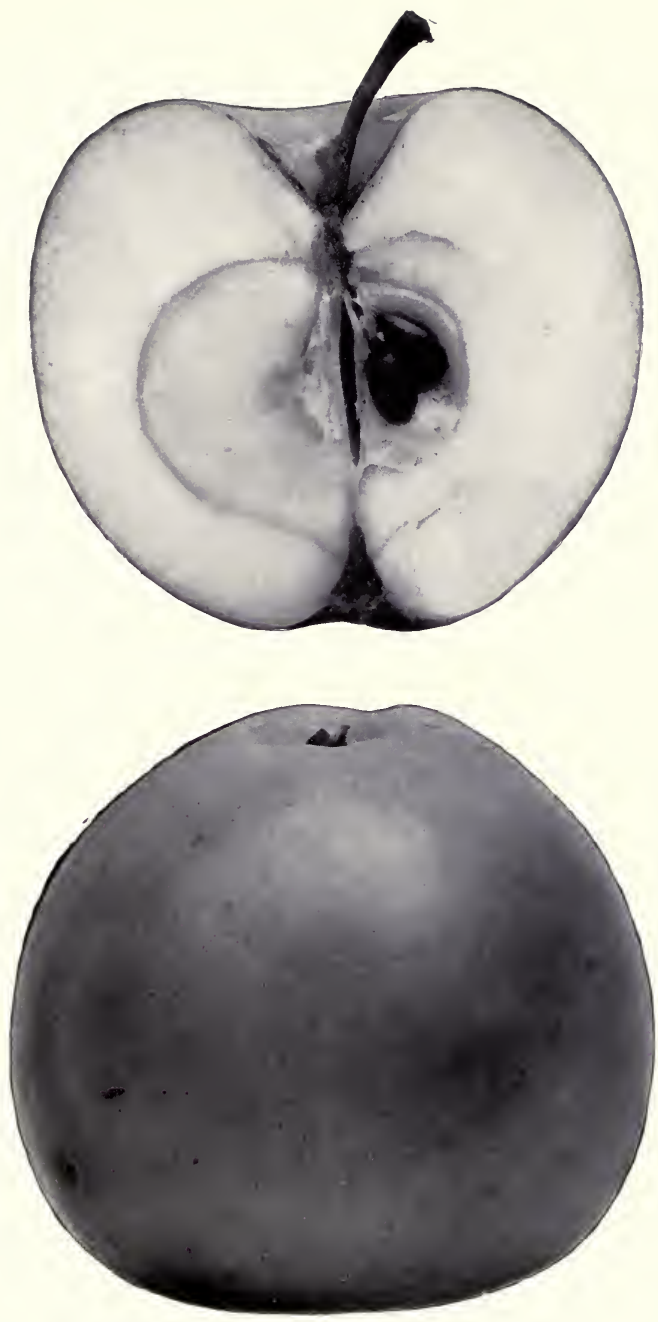

OCCIDENT 


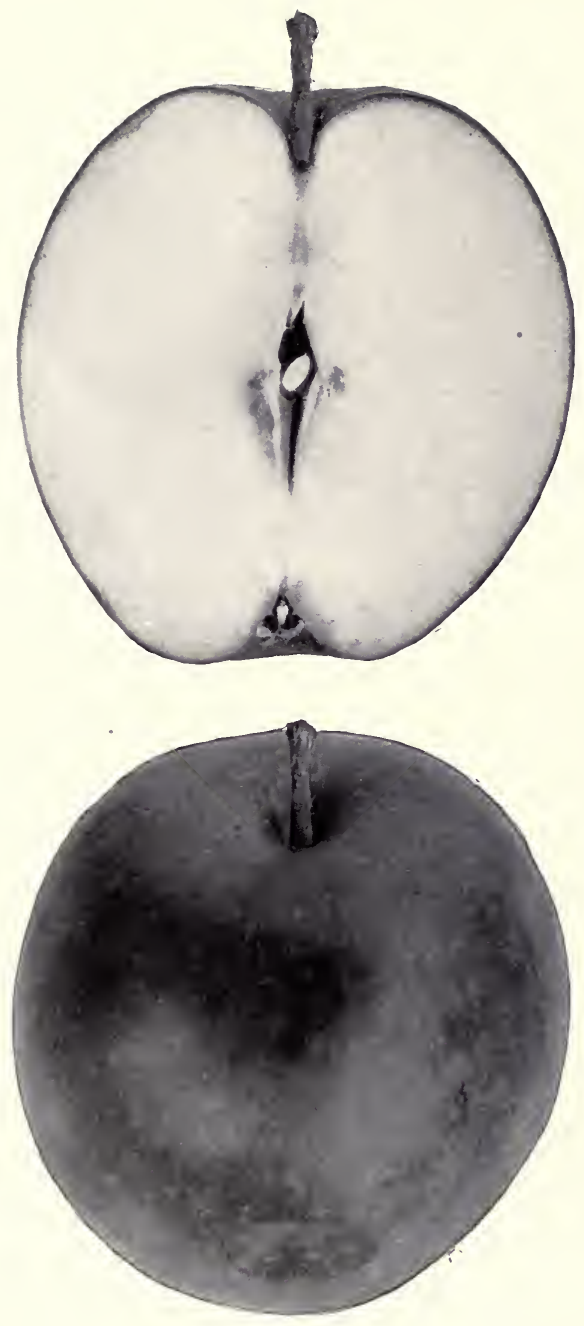

OEL AUSTIN 

flexed. Basin moderately abrupt, shallow, narrow, slightly furrowed or wrinkled.

Skin thin, yellow nearly overspread with dull, purplish-red and striped with purplish-carmine. Dots numerous, russet, sunken.

Calyx tube rather narrow, conical or approaching funnel-form. Stamens median.

Core abaxile, medium to large; cells open; core lines meeting or, when the calyx tube is funnel-form, clasping the funnel cylinder.

Flesh yellowish-white sometimes tinged with red next the skin, firm, finegrained, crisp, juicy, mild subacid, fair to good.

\section{OLIVE.}

References. I. Downing, I869:294. 2. Beach and Clark, N. Y. Sta. Bul., 248:136. 1904. 3. Ragan, U. S. B. P. I. Bul., 56:219. 1905.

A small red apple, rather attractive in color. Unworthy of consideration by New York fruit growers. The tree cones into bearing young and is productive being a reliable annual cropper. The fruit hangs well to the tree.

This is not the Olive of Coxe, 1 neither is it the Olive from Vermont noticed by Downing (I) and described in I86o in Gardeners Monthly (3).

Historical. Originated in Wake county, North Carolina (I). It is there a fall apple but as grown at this Station its season extends to midwinter and often a considerable portion of the fruit remains sound till April or later.

TREE.

Tree moderately vigorous. Form roundish, or upright spreading, rather dense. Tavigs short to above medium, slender, straight but geniculate; internodes long to medium. Bark clear brown with reddish tinge, lightly streaked with scarf-skin, slightly pubescent near tips. Lenticels rather conspicuous, quite numerous, small to above medium, oval or elongated, usually not raised. Buds deeply set in bark, small, plump, obtuse, appressed, not pubescent.

\section{FrUit.}

Fruit small to nearly medium, fairly uniform in size and shape. Form roundish inclined to conic, varying to obovate, obscurely ribbed, fairly symmetrical. Stem short to above medium. Cavity rather small, acute to acuminate, moderately deep, rather narrow, usually russeted, often somewhat furrowed, often lipped. Calyx medium or above, usually open; lobes often leafy. Basin abrupt, moderately shallow, moderately narrow to rather wide, often somewhat furrowed and wrinkled.

Skin thick, tough, entirely covered with bright, deep, dark red or mottled with red and striped with carmine over a deep yellow ground color, sometimes marked with broken stripes of grayish scarf-skin. Dots numerous, pale, often large, areolar and conspicuous.

Ca!y.x tube short, conical or urn-shape with fleshy pistil point projecting into the base, or approaching funnel-form. Stamens median to basal.

Core medium, somewhat abaxile; cells usually symmetrical and open; core lines meeting or slightly clasping. Carpels broadly roundish, slightly emargi-

${ }^{1}$ Coxe, 1817: 66. 
nate if at all, mucronate. Seeds brownish-black, small, rather short, wide, plump, obtuse.

Flesh deeply tinged with yellow, moderately coarse, rather crisp, somewhat tough, juicy, rich, mild subacid or nearly sweet, distinctly aromatic, fair to good in quality.

\section{OLIVER.}

References. 1. Ark. Hort. Soc. Rpt, 1893. 2. Heiges, U. S. Pom. Rpt., 1895:33. 3. Rural N. Y., 54:843. I895. fig. 4. Gard. and For., 8:520. I895. 5. Thomas, 1897:268. 6. Van Deman, Amer. Gard., 19:823. I898. 7. Stinson, Ark. Sta. Bul., 49:16. 1898. fig. 8. Beach, Amer. Gard., 20:124, 166. 1899. 9. Ib., $W . N . Y$. Hort. Soc. Rpt., I899:90, I38. ro. Stinson, Ark. Sta. Bul., 60:130. 1899. II. Brackett, Amer. Gard., 22:19I. I90I. I2. Budd-Hansen, 1903:143. fig. 13. Powell and Fulton, U. S. B. P. I. Bul., 48:51. 1903.

Synonyms. Oliver (2). Oliver's Red $(6,7,10$, II, I2). Senator $(2,4,5)$. Senator $(6,7,8$, IO, II, I2, I3).

An attractive dark red apple of good size and good quality. It is of desirable shape, smooth and pretty uniform. It appears to coincide pretty closely with Baldwin in season, but it may not keep quite so late. Its commercial season in ordinary storage appears to be December to midwinter; in cold storage it extends to March or April. Among the varieties which have been introduced from Arkansas and Missouri this appears to be one of the most promising for the New York fruit grower, but as yet it has not been sufficiently tested to determine its value in this region. It is doubtful whether it can always be properly ripened in the northern portion of the Baldwin apple belt, brt in the southern portion it appears to be more promising. The tree is evidently hardy in Western New York. It is healthy, vigorous, comes into bearing young, is productive and gives promise of being an annual or nearly annual bearer. The fruit hangs well to the tree, and there is little loss from drops or culls.

Historical. This variety has been propagated since about 1873 in Northwestern Arkansas where it has been known as Oliver Red or Oliver. It is supposed to have originated in that region $(7$, II $)$. It has been disseminated from the Stark Nurseries, Louisiana, Mo., under the name Senator.

\section{TrEe.}

Tree medium in size, very vigorous; branches long, rather stocky. Form roundish or somewhat spreading; top open. Twigs stocky, medium in length and thickness; internodes medium in length. Bark dull brown and olivegreen, pubescent. Lenticels numerous, large, mostly long, conspicuous, raised. Buds large, appressed, broad, obtuse, pubescent. Leaves medium or often large, long and rather broad, thick, dark green; foliage rather dense. 

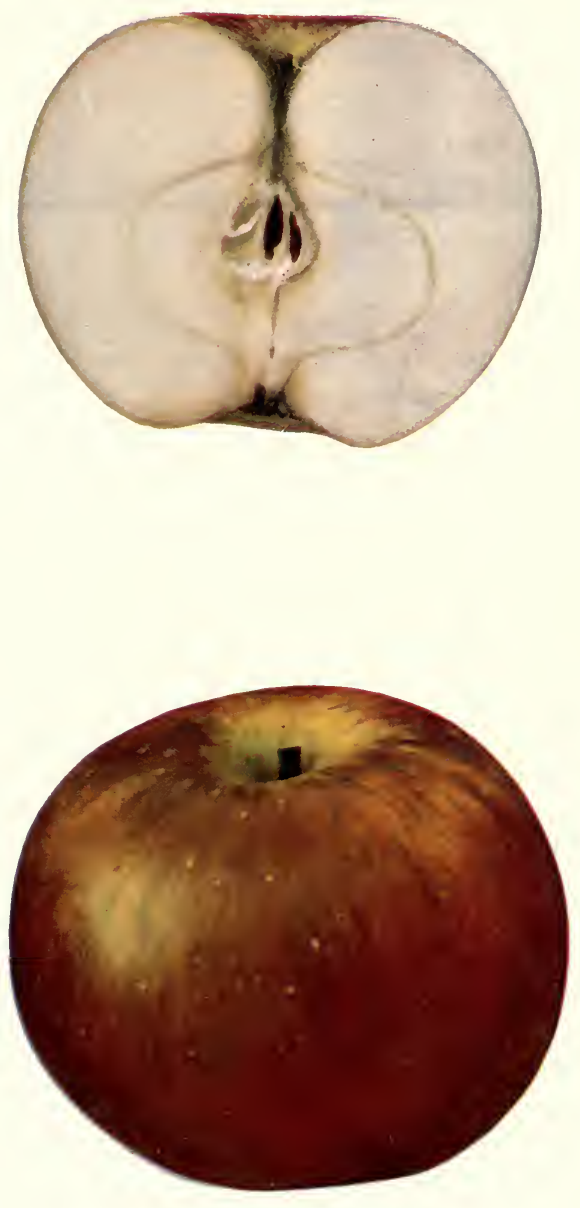

OLIVER 



\section{FrUIT.}

Fruit large or above medium, pretty uniform in size and shape. Form roundish or somewhat oblate, pretty symmetrical, regular or somewhat elliptical or obscurely angular; sides sometimes unequal. Stem short to moderately long, medium in thickness. Cavity medium to rather large, acute to decidedly acuminate, deep, moderately broad to rather narrow, regular, smooth and green or partly covered with greenish-russet, sometimes with outspreading russet rays. Caly.x medium to rather large, usually somewhat open; lobes often separated at the base, short, broad, obtuse, erect or somewhat reflexed. Basin large, usually saucer-shape, wide and abrupt, sometimes moderately shallow and rather obtuse, somewhat wrinkled.

Skin moderately thin, tough, somewhat waxy, smooth or slightly roughened with large russet dots, green or bright yellow, mottled and striped with red or nearly covered with bright deep red and splashed with purplish-carmine. Dots conspicuous, numerous, gray or russet, rather large, often somewhat elongated or irregular about the cavity.

Calyx tube obtusely cone-shaped, rarely somewhat funnel-form. Stamens below median to basal.

Core distant, rather small, axile or nearly so ; cells closed or slit; core lines meeting or when the calyx tube is funnel-form clasping the funnel cylinder. Carpels roundish or somewhat elongated, narrowing toward the base and apex, emarginate, mucronate, smooth or nearly so. Seeds irregular, large, numerous, completely filling the cells, moderately long, wide, obtuse, or sometimes acute, dark brown.

Fiesh whitish with tinge of yellow or green, moderately fine and crisp, rather tender, breaking, juicy, somewhat sprightly subacid eventually approaching sweet, good or possibly very good.

Season December to March or April.

\section{OLYMPIA.}

This strain of the Baldwin was discovered growing among some Baldwin trees in a small orchard of Mr. William Shincke, Olympia, Washington. The trees grow like the Baldwin and appear to have the general characteristics of the Baldwin, except that the twigs of one season's growth as compared with Baldwin twigs have darker bark with less red and more brown or olive-brown color. Other minor differences have been observed, such as shorter internodes, heavier scarf-skin, less conspicuous lenticels and more abundant pubescence on bark and buds. We have not had opportunity to determine whether these minor differences are constant.

The fruit, so far as we are able to judge from the rather limited quantities which we have had the privilege of examining, averages distinctly larger than Baldwin fruit grown in the same locality, and is clearly superior in color, both the red and the yellow tones being 
more brilliant. A very careful comparison of the fruit of Olympia with that of Baldwin discloses no constant differences in structural characters. For a technical description of the fruit aside from size and color, the reader is therefore referred to the description of Baldwin on page 59 .

Olympia is best known in the vicinity of Olympia and is there regarded as a valuable acquisition. It is attracting favorable attention also throughout the apple-growing districts of the state of Washington. The fact that it is regarded so highly in a region where the Baldwin succeeds well is a good indication that it may succeed equally well in the Baldwin districts of New York. It is therefore recommended as worthy of extended trial by New York fruit growers.

Historical. The following account of this strain of the Baldwin apple has been obtained from correspondence with W. W. Whidden, George Langridge and William Shincke of Olympia, Washington. The original tree from which Olympia was propagated was set forty years or more ago on the place of William Shincke, Sr., in Olympia, Washington. It was evidently planted for a Baldwin as it stood with other Baldwin trees. The fruit was at first sold as Baldwin but Mr. Shincke noticed that it was larger and better colored than that of the common Baldwin. Mr. George Langridge was supplied with scions from this tree and when this stock came into bearing with Mr. Langridge it was found that the fruit from these trees, like that of the original tree from which the scions were taken, was larger and better colored than the fruit of the ordinary Baldwin. About $\mathrm{I} 890$ it was first propagated for sale but under different names. Finally the County Horticultural Society named it Olympia.

\section{ONTARIO.}

References. 1. Horticulturist, 1874:312. (cited by 22). 2. Downing, 1876: 6r app. fig. 3. Montreal Hort. Soc. Rpt., 1880:100. 4. Brown, Can. Hort., 13: 114, 351. 1890. 5. Ib., 14:138. 189r. 6. Nicol, Can. Hort., 15:117. 1892. 7. Bailey, An. Hort., 1892:245. 8. Brown, Aner. Gard., 14:426. 1893. 9. Ont. Fr. Gr. Assn. An. Rpt., г:65. 1894. г. Dempsey, Ont. Fr. Stas. An. Rpt., I:24. I894. I1. Edwards, Can. Hort., I 7:212. 1894. 12. Am. Pom. Soc. Rpt., 1895:78. 13. Woolverton, Ont. Fr. Stas. An. Rpt., 3:1 1. 1896. figs. 14. Am. Pom. Soc. Cat., 1897. 15. Can. Hort., 23:231. I900. 16. Beach, E. N. Y. Hort. Soc. Rpt., 1900:43. I 7. Ib., W. N. Y. Hort. Soc. Rpt., 1900:36. 18. Macoun, Can. Dept. Agr. Bul., 37:45. 1901. rg. Budd-Hansen, 1903:143. 20. Powell and Fulton, U. S. B. P. I. Bul., 48:51. 1903. 21. Beach and Clark, N. Y. Sta. Bul., 248:136. 1904. 22. Ragan, U. S. B. P. I. Bul., 56:220. 1905.

Fruit in many respects intermediate in character between its parents, Northern Spy and Wagener. Like Wagener, it is oblate and ribbed; like the Spy, it has a large, deep cavity and its color 

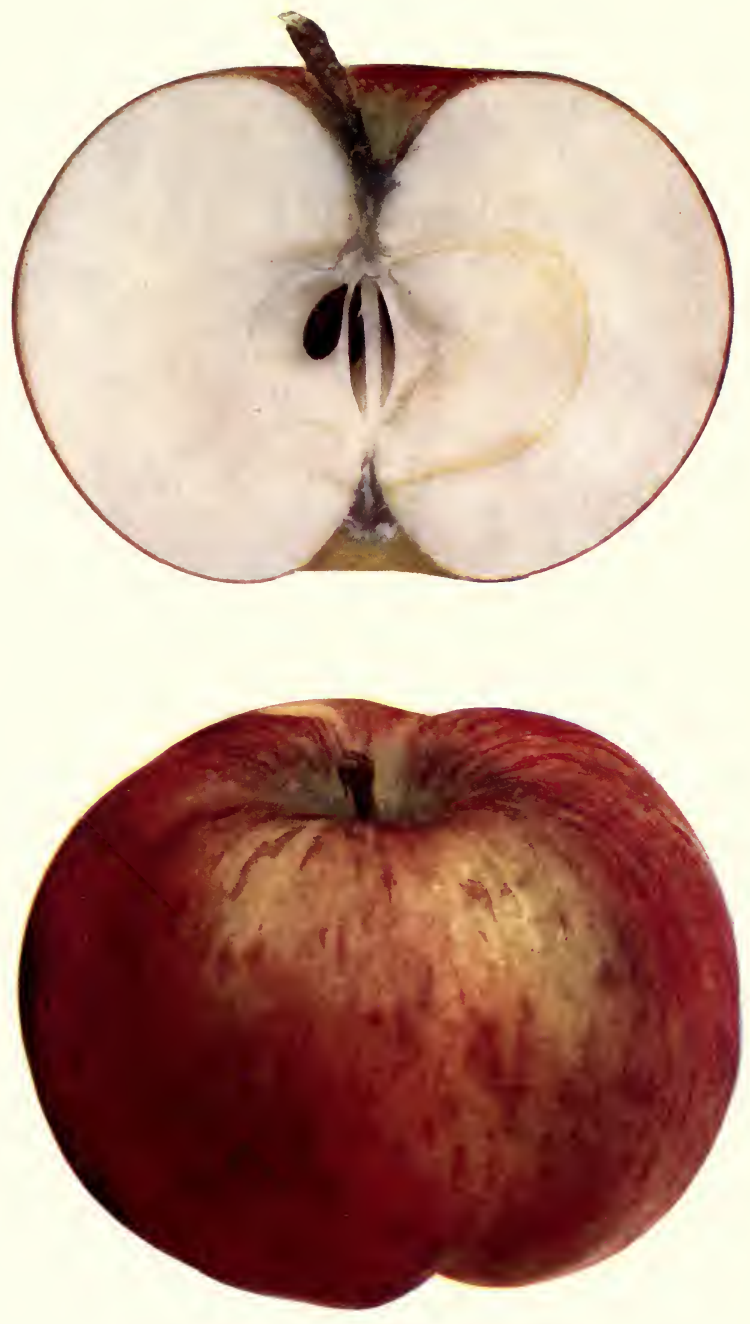

ONTARIO 

when highly developed is pinkish-red with carmine stripes over a clear, pale yellow background. As grown at this Station we have not been favorably impressed with it because it is inferior to Northern Spy both in color and quality. In fact it has been too deficient in color to rank as a good commercial sort. It is in season from November to March or April. So far as tested here it appears to follow Northern Spy in that it shows considerable variation in different seasons in its keeping quality (2I). It has been a strictly biennial bearer, yielding heavy crops in alternate years. It appears to be superior to Northern Spy in productiveness, but is less productive than Wagener. It is hardier and longer-lived than Wagener. In portions of Ontario it is regarded as one of the best apples both for commercial purposes and home use. (18). As grown in that region and also in some parts of Michigan it is on the average larger and more highly colored than we have found it to be at this Station. Doubtless there are localities in New York where it would succeed much better than it does at Geneva. On account of its good record in Canada as to its hardiness and productiveness it is certainly worthy of trial in Northern New York and in those portions of the state where the Spy succeeds best.

Historical. Originated by Charles Arnold, Paris, Ont., by crossing Northern Spy with Wagener.

TREE.

Trec medium to large, vigorous. Form upright, becoming spreading. Twigs rather short to moderately long, rather slender to moderately stout, quite pubescent; internodes medium or above. Bark dull, dark reddish-brown over olive-green, lightly mottled with scarf-skin. Lenticels rather numerous, small to medium, or sometimes large, usually oblong. Buds medium size, plump, acute to somewhat obtuse, projecting, pubescent. Leaves usually long and rather large.

\section{Fru1T.}

Fruit large to very large, uniform in size and shape. Form oblate to roundish inclined to conic, distinctly ribbed or even angular, pretty symmetrical. Stem medium in length and thickness. Cavity characteristically like that of the Northern Spy, large, acute or approaching acuminate, deep, wide to moderately wide, often thinly russeted and with outspreading rays of russet. Caly.x small to medium, closed or slightly open; lobes rather narrow, acute. Basin small to medium, deep, narrow to rather wide, abrupt, often furrowe:1 and wrinkled.

Skin thin, tough, smooth, bright pale yellow or greenish móre or less washed with brownish-red faintly splashed with carmine, in highly colored specimens becoming bright pinkish-red striped with bright carmine; often coated with 
whitish bloom and mottled and streaked with whitish scarf-skin, particularly over the base. Dots rather numerous, small, whitish, gray or russet.

Calyx tube narrow, funnel-form. Stamens median to basal.

Core usually rather small, abaxile with a rather large hollow cylinder at the axis; cells symmetrical, closed or partly open; core lines clasping the funnel cylinder. Carpels smooth or nearly so, roundish, narrowing toward the apex, often nearly truncate at the base, slightly emarginate. Seeds medium in size, moderately wide to wide, obtuse to acute, rather dark.

Flesh whitish tinged with yellow, rather firm, moderately fine or a little coarse, crisp, tender, very juicy, sprightly, rather brisk subacid, more so than Northern Spy, aromatic, good to very good; especially desirable for culinary use.

\section{OPALESCENT.}

References. 1. Rural N. Y., 58:224. 1899. 2. Ill. Hort. Soc. Rpt., r9or. (cited by 4). 3. Ohio Hort. Soc. Rpt., 1903:12. 4. Ragan, U. S. B. P. I. Bul., 56:220. 1905 .

When well grown Opalescent is a very attractive apple, being large, shapely, clear yellow, nearly or quite covered with brilliant red, in highly colored specimens becoming deep purplish-red. It has not been tested in New York sufficiently to show whether it may be considered a promising variety for this region. It does not appear to be as good a keeper as Baldwin.

Historical. Introduced about 1899 by McNary and Gaines, Xenia, Ohio.

TREE.

Tree vigorous. Form roundish, open. Taigs long to medium in length, erect, slender to moderately stout, curved or irregularly crooked; internodes short to above medium. Bark dark dull reddish-brown mingled with some olive-green and covered with a heavy coat of mottled scarf-skin, pubescent. Lenticels rather inconspicuous, scattering, medium in size, roundish, sometimes raised. Buds prominent, large to below medium, broad, plump, obtuse to somewhat acute, free or nearly so, pubescent.

\section{FRUIT.}

Fruit large to very large. Form roundish conic, symmetrical or sometimes with sides unequal, obscurely ribbed. Stem short to medium, moderately slender. Cazity pretty large, acuminate, very deep, sometimes partly russeted, usually symmetrical but sometimes compressed. Caly $x$ below medium or small, usually partly open; lobes small, obtuse to acute, reflexed. Basin small to medium in size, often oblique with the brim decidedly prominent on one side, narrow to moderately wide, moderately deep to deep, abrupt, sometimes slightly furrowed.

Skin moderately thick, rather tougl, glossy, takes a brilliant polish; color bright pale yellow nearly or quite overspread with dark deep red with scarcely perceptible streaks of purplish-carmine. Dots numerous, small to large, red, 


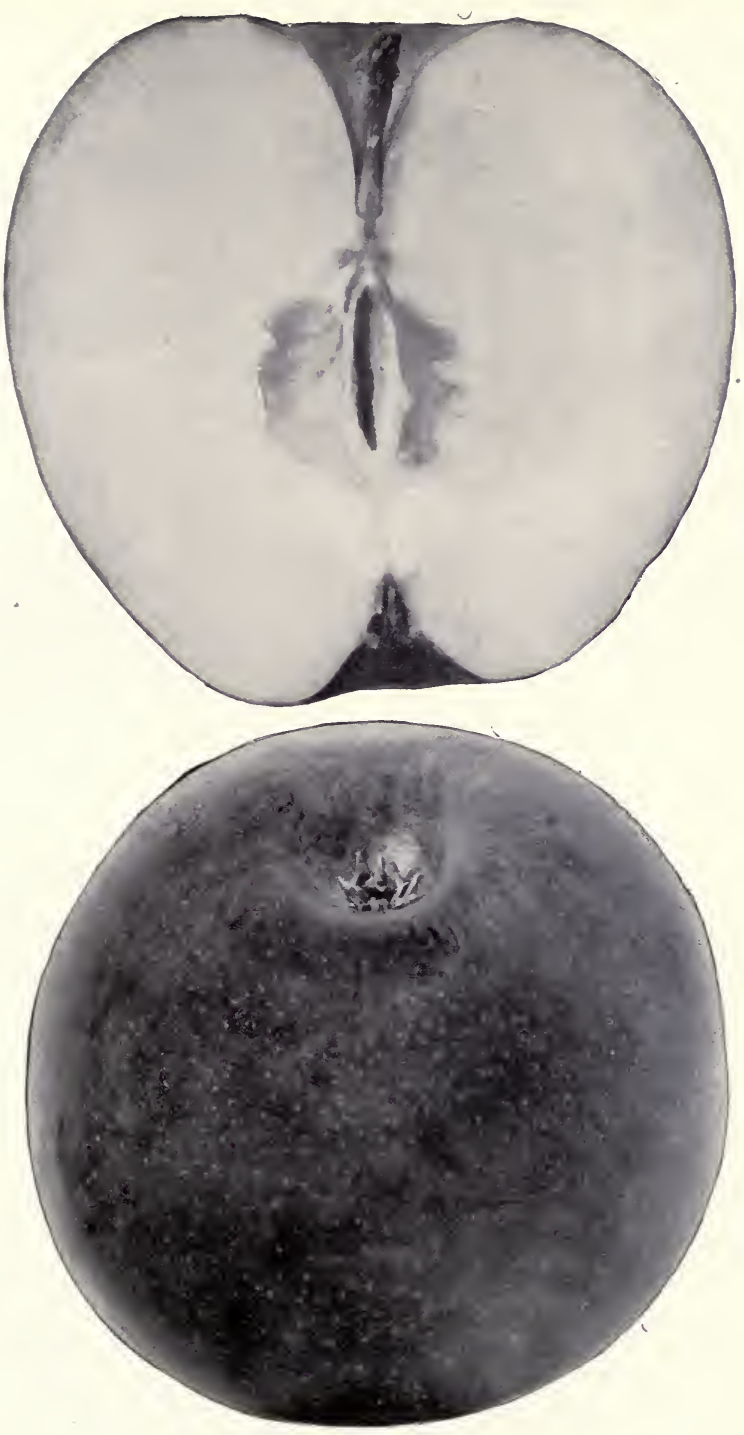

OPALESCENT 

yellowish or russet, often submerged, frequently mingled with irregular lines and flecks of russet. Prevailing effect brilliant deep red.

Calyx tube medium to rather small, cone-shape or short funnel-form. Stamens median to basal.

Core small to medium, abaxile; cells sometimes unsymmetrical, closed or open; core lines meeting or nearly meeting. Carpels smooth, roundish or broadly obcordate. Sceds acute, medium in size, form and color.

Flesh distinctly tinged with yellow, rather firm, moderately tender, a little coarse, juicy or moderately juicy, agreeable mild subacid, aromatic, good to very good.

Season November to February or March.

\section{ORNAMENT.}

References. I. Thompson, Cat. Hort. Soc. London, 1842:29. (cited by 2). 2. Leroy, 1873:520. fig. 3. Churchill, N. Y. Sta. An. Rpt., 8:355. 1889. 4. Beach, N. Y. Sta. An. Rpt., 13:590. 1894. 5. Ib., 14:254. 1895. 6. Burrill and McCluer, Ill. Sta. Bul., 45:334. 1896. 7. Powell and Fulton, U. S. B. P. I. Bul., 48:52. 1903.

Synonyms. Ornament de Table $(4,5,6)$. Ornament de Table (7). ORNEMENT DE TABle (2).

A rather attractive dessert apple of good form and fairly good color but hardly attractive enough for a good commercial variety. The flesh is tender, juicy and mildly subacid or nearly sweet; good in quality but surpassed by other dessert apples of its season. The tree comes into bearing rather young, is a reliable annual cropper and productive or moderately productive. It does not appear to be worthy of the attention of the fruit growers of New York.

Historical. This is a European variety of uncertain origin $(1,2)$. It has been disseminated but sparingly in America.

\section{TreE.}

Tree vigorous. Form roundish or spreading, rather dense. Twigs below medium to short, straight, slender; internodes medium or below. Bark dark brownish-red partly streaked with scarf-skin, slightly pubescent. Lenticels scattering, small, oblong or roundish, sometimes raised. Buds rather prominent, medium or below, broad, plump, obtuse, free or nearly so, quite pubescent.

\section{FruIT.}

Fruit medium or above, pretty uniform in shape and size. Form roundish inclined to conic or somewhat oblate, pretty regular and symmetrical. Stem short, rather slender. Cavity medium to rather small, acuminate or nearly so, rather deep, moderately narrow to rather wide, often partly russeted. Caly $x$ medium in size, usually open, pubescent; lobes long, acute, separated at the base, reflexed. Basin often somewhat oblique, shallow and obtuse to moderately deep and somewhat abrupt, slightly furrowed and wrinkled.

Skin rather thin, tough, smooth, clear yellow or greenish washed and mottled with dull red or orange-red and sparingly marked with narrow stripes of carmine. Dots numerous, small, gray or russet, not very conspicuous. Prevailing effect red and yellow, the red usually predominating. 
Calyx tube short funnel-form with moderately broad limb. Stamens below median to above.

Core medium or below, axile or nearly so; cells usually closed; core lines clasp the funnel cylinder. Carpels broadly roundish, obtusely emarginate, mucronate. Seeds few, dark, medium or above, wide, rather obtuse, often slightly tufted.

Flesh whitish with slight yellow tinge, firm, fine-grained, tender, moderately juicy, pleasant, mild subacid becoming nearly sweet, good.

Season October to February or March.

\section{ORTLEY.}

References. 1. Coxe, I8I 7:169. 2. Lindley, Trans. Royal Hort. Soc. London, 6:415. 1825. (cited by 4, 5). 3. Cat. Hort. Soc. London, 1831:39. 4. Kenrick, 1832:49. 5. Floy-Lindley, 1833:57. 6. Mag. Hort., I:364. 1835. 7 . Manning, I838:57. 8. Downing, I845:142. 9. Floy-Lindley, I846:41 2 app. 10. Kirtland, Horticulturist, 2:545. 1848. II. Downing and Ernst, Horticulturist, 4:74. 1849. fig. I2. Horticulturist, 4:144. 1849. I3. Thomas, 1849: 183, I88. fig. 14. Cole, I849:130. I5. Phoenix, Horticulturist, 4:472. I850. 16. Emmons, Nat. Hist. N. Y., 3:78. 1851. col. pl. 17. Elliott, 1854:95. fig. 18. Downing, 1857:90. 19. Hooper, 1857:67. 20. Hovey, Mag. Hort., 27:60. I861. 21. Am. Pom. Soc. Cat., 1862. 22. Warder, 1867:673. fig. 23. Fitz, I872:I 50. 24. Barry, I883:351. 25. Hogg, I884:249. 26. Wickson, I889:246. 27. Lyon, Mich. Hort. Soc. Rpt., 1890:296. 28. Bailey, An. Hort., 1892:245. 29. Bailey, An. Hort., 1892:252. 30. Burrill and McCluer, Ill. Sta. Bul., 45: 334. I896. 31. Budd-Hansen, 1903:144.

Synonyms. Crane's Pippin (11, 17). Detroit (11, 13, I7, 19). Detroit of the II'est (13, 14). Golden Pippin (I1, 19, of some 17). Greasy Pippin (II, I7, 18). Green Bellflower (II, I5, I7). Hollow Core Pippin (II, I7, I9). Hollow Cored Pippin (I8). Inman (I7). Jersey Greening (13, I7 but not of Coxe II). Melting Pippin (11, 17). Ohio Favorite (11, 17, 18). Ortley (i6, 25). Ortley Aprle (5). Ortley Apple (8, il, 14). Ortley Pippin (7, 19). Ortley Pippin (8, I0, I I, I3, I7, I8). Tom Woodward Pippin (17). l'an Dyme (I6). Van Dyne (II, I7, 25, of some 8). Warren Pippin (i6). Warren Pippin (II, I3, I7). White Bellefleur (I0, I1, I2). White Bellefleur $(17,23)$. White Bellflower ( I5, 29). White Bellflower (II, I3, 14, I7, 18, 19, 20, 22, 26). White Detroit (11, 13, 17, 18, 27). White Pippin (II, I8, erroneously I7). Willow Leaf Pippin (17, 18). Woodman's Song (18). Woodward's Pippin (II, I7). Woolman's Long (8, 14, 23, 25). Woolman's Long ( I0, II, I3, I7, 24). Woolman's Long Pippin ( I). Woolnary Long (6). Yellow Pippin ( I I, I7).

A pale yellow apple of the Yellow Bellflower type which has long been known in cultivation. Scattering trees of it are found in some of the very oldest orchards of the state, but it has never been grown to any considerable extent in New York and is now seldom or never planted, being less successful here than the Yellow Bellflower. It does better farther south and west. As grown in the North the 
fruit tends to be more oblong, smaller and of a paler yellowishwhite color, coarser texture and sprightlier flavor than when grown farther south (I7). The fruit has less acidity than Yellow Bellflower and is more pleasant in flavor for dessert use. The skin being whitish and tender, is easily bruised or discolored in handling. It is also apt to be marred on the tree by the chafing of the limbs. The wood is brittle and the bearing limbs are often broken by the weight of the fruit (22). Ortley is quite subject to attacks of various insects and of the scab fungus, and requires thorough treatment to protect it from these troubles.

Historical. This is an old New Jersey variety which Coxe described under the name Woolman's Long Pippin (I). In I825 Floy sent fruit of it to the Royal Horticultural Society, London, under the name of Ortley and in the Transactions of the Society for that year Lindley described it under this name giving Woolman's Long as a synonym. Kenrick (4), Manning (7), Thomas (13), Elliott (I7), Charles Downing (I8), and other American pomologists have followed Floy instead of Coxe and describe the variety under the name Ortley. Emmons (I6) gives Ortley as identical with Warren Pippin of Coxe but it is quite doubtful whether he was correct in this case. In portions of the South and West Ortley is an old favorite for planting in home orchards and has there been known under many different names prominent among which are White Bellflower and White Detroit.

\section{TREE.}

Tree moderately vigorous and medium in size or under favorable conditions large. Form at first upright with long slender shoots but when mature the tree becomes roundish or spreading. Twigs below medium to above, rather slender, straight, quite pubescent; internodes short. Bark dull reddish-brown often overlaid with thick scarf-skin. Lenticels small and scattering but rather conspicuous, mostly roundish, raised. Buds below medium, moderately projecting, roundish, slightly pubescent, free.

\section{FrUit.}

Fruit large or medium, not very uniform in size or shape. Form oblong conic and flattened at the base, varying to somewhat roundish conic, regular or obscurely ribbed. Stem long, often slender. Cavity often large, acute or approaching acuminate, deep, varying from moderately narrow to wide, usually partly russeted, somewhat furrowed. Calyx rather small to medium, closed or somewhat open; lobes long, acute, usually converging and reflexed. Basin small to medium, shallow to moderately deep, narrow to moderately wide, usually abrupt and wrinkled or slightly furrowed.

Skin moderately thin, tough, smooth, waxy, pale whitish-yellow varying to rich yellow in well developed fruit, rarely with a faint pinkish-red blush. Dots inconspicuous, usually whitish and submerged. 
Calyx tube funnel-form approaching cylindrical, sometimes constricted at the base of the limb and enlarging below, often characteristically elongated and extending to the core. Stanens median.

Core large, widely abaxile; cells ustually symmetrical and wide open, sometimes closed; core lines clasping the fumnel cylinder. Carpels roundish ovate, elongated, emarginate, mucronate. Seeds numerous, characteristically small and pointed, roundish, plump, light to medium brown.

Flesh whitish tinged with yellow, moderately fine, crisp, tender, juicy, sprightly subacid, very good.

Season October to February.

\section{PALMER.}

References. I. Ragan, U. S. B. P. I. Bul., 56:224. 1905.

SYNONYM. PA1MER OF N. Z.

A New Zealand apple received in 1897 for testing here from G. B. Brackett, U. S. Pomologist, Washington, D. C. The fruit is large or above medium, rather attractive in appearance for a yellow apple, brisk subacid in flavor and good in quality.

\section{TREE.}

Tree vigorous with long, moderately stout branches. Form roundish, rather dense. Treigs long, curved, moderately stout; internodes short. Bark dull brown, tinged with green, heavily streaked with scarf-skin, heavily pubescent. Lenticels scattering, small, round, not raised. Buds large, broad, plump, obtuse, free, pubescent.

\section{Fruit.}

Fruit medium to above or sometimes large. Form roundish varying to roundish oblate or to slightly oblong, irregular. Stcm long, moderately thick. Carity acuminate, deep, rather broad, sometimes faintly russeted, not symmetrical. Calyx open or nearly so, rather large. Basin deep, wide, abrupt, slightly wrinkled.

Skin rather attractive yellow or greenish-yellow. Dots conspicuous, large and small, russet, sometimes areolar.

Caly.r tube long, moderately wide to wide, funnel-shape or urn-shape. Stamens marginal.

Core large, abaxile; cells symmetrical, open; core lines slightly clasping. Carpels broadly roundish varying from somewhat elliptical to slightly cordate, tufted. Sceds large, moderately narrow, plump, acute, rather dark brown.

Flesh tinged with yellow or greenish-yellow, moderately coarse, rather tender, breaking, juicy, sprightly, brisk subacid, good.

Season winter.

\section{PARAGON.}

References. I. Van Deman, Am. Pom. Soc. Rpt., I891:123, I59. 2. Bailey, An. Hort., 1892:246. 3. Heiges, U. S. Pom. Rat., 1895:30. 4. Babcock, An. Pom. Soc. Rpt., 1895:190. 5. Amer. Gard., 16:419. 1895. 6. Ib., 17:12, 28, 33, 42, 65, 97, 146, 152, 194, 210, 306. 1896. fig. 7. Van Deman, Rural N. Y., 55:243. 1896. 8. Watts, Tenn. Sta. Bul., 1:24. 1896. fig. 9. Powell, Del. Sta. Bul., 38:19. 1898. 10. Stinson, Ark. Sta. Bul., 49:7. 1898. r1. Bruner, N. C. Sta. Bul., 182:21. I903. I2. Thomas, 1903:712. I3. Budd-Hansen, 1903:144. 

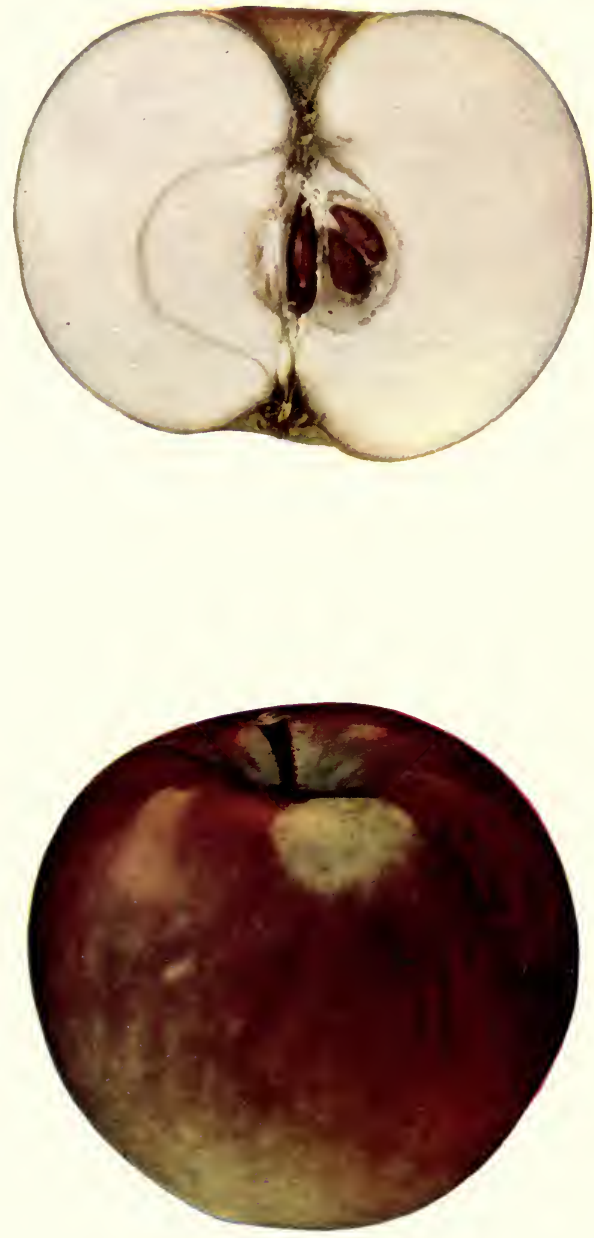

PARAGON 

fig. 14. Powell and Fulton, U.S. B. P. I. Bul., 48:52. 1903. 15. Beach and Clark, N. Y. Sta. Bul., 248:137. 1904.

Synonyms. Black Twig $(8,14)$, but erroneously. Mammoth Black Twig (8, I3, I 5), but erroneously. Twitty's Paragon (8).

This is a southern variety of the Winesap type. In the applegrowing regions of the South where it has been tested it has proven to be an excellent variety in many respects, but it is not generally regarded by the orchardists of that region as being especially promising for commercial orchards. The fruit evidently does not develop to as high a degree of perfection in New York as it does in more southern latitudes. It is not probable that it will prove successful as a commercial variety here, though it has sufficient merit to make it worthy of testing to a limited extent.

Historical. The Paragon originated on the farm of Major Rankin Toole near Fayetteville, Lincoln county, Tennessee $(3,6,7,8)$. The early history of the tree is not very clear but it probably came from a seed planted about 1830. Grafts from the original tree were taken in 1870 by Mr. Twitty, a local nurseryman, and later introduced to the public. It was badly confused for a while with an Arkansas seedling now properly known by the name of Arkansas but then passing under the name of Mammoth Black Twig. Some believed that the Arkansas was identical with Paragon. An extensive discussion and the testimony of many persons has since brought out the fact that these are two distinct although similar seedlings of Arkansas and Tennessee origin respectively. Many have thought that Paragon may be a seedling of the Winesap crossed by Limbertwig as it possesses some of the characteristics of both of these varieties.

\section{TREE.}

Tree moderately vigorous with rather short, stout, twisted branches. Form roundish to spreading, inclined to droop, rather dense. Twigs medium to rather long, nearly straight, stout to rather slender; internodes short to medium. Bark very dark reddish-brown, mottled with thin scarf-skin, pubescent. Lenticels scattering, medium in size, roundish to oval, raised. Buds large, prominent, broad, plump, acute to somewhat obtuse, curved, free, generally pubescent. Leaves medium in size, broad.

\section{FRUIT.}

Fruit medium or above, pretty uniform in size and shape. Form roundish or sometimes oblate, slightly conic, rounding toward stem and calyx; sides often a little unequal. Stem medium in length and thickness. Cavity nearly obtuse to acute, medium in width and moderately shallow to sometimes rather wide and deep, usually symmetrical, often furrowed or compressed, occasionally lipped, usually russet and with outspreading russet rays. Calyx rather small, closed. Basin rather shallow and obtuse varying occasionally to abrupt and medium in width and depth, often furrowed and wrinkled. 
Skin tongh, smooth, grass-green or yellowish, largely covered with rather du!l, deep red and indistinctly striped with darker red. Dots gray or whitish, small, sometimes rather conspicuous. Prevailing effect dark red.

Caly.x tube rather small, varying from conical to funnel-form. Stamens median to slightly marginal.

Core rather small; cells partly open; core lines clasping. Carpels much concave, roundish varying to nearly cordate, slightly emarginate. Seeds rather large, long, acute, dark; often some are abortive.

Flesh greenish or tinged with yellow, firm, a little coarse, rather tender, juicy, mild subacid, somewhat aromatic, good to very good.

Season January to May.

\section{PARK SPICE.}

References. I. Carpenter, Horticulturist, I9:II4. I864. figs. 2. Am. Pom. Soc. Rpt., 1867. (cited by 5). 3. Downing, r869:298. 4. Thomas, 1897:648. 5. Ragan, U.S. B. P. I. Bul., 56:225. 1905.

Synonyms. Park (5). Park Apple (3, 4, 5). Park Spice (5).

As described by Carpenter, Downing and Thomas (I, 3, 4) the fruit of the Park Spice apple is medium to rather large, yellowish shaded with red and striped with crimson; the flesh is yellowish-white, fine-grained, crisp, juicy, mild subacid, pleasantly aromatic, very good in quality; in season from December to March.

Historical. Originated on the Park farm in Harrison, Westchester county, New York. In I864 Carpenter stated that the original tree, then supposed to be over a hundred years old, was still vigorous and productive (I). So far as we can learn the variety is now obsolete.

\section{PARLIN.}

References. I. Heiges, U. S. Pom. Rpt., I894:21. 2. Ill. Hort. Soc. Rpt., 1899. (cited by 4). 3. Macoun, Can. Dept. Agr. Rpt., rgor:97. 4. Ragan, U. S. B. P. I. Bul., 56:225. 1905.

Synonym. Parlin's Beauty (3). Parlin's Beauty (4).

An attractive red apple of pretty good quality for dessert but being mildly sweet in flavor is less suitable for culinary uses. It has not as yet been tested sufficiently to determine its value for this region.

Historical. In 1894 the original tree over fifty years old was still standing at Norridgewock, Maine, still vigorous, healthy and productive (I). The variety has as yet been but little disseminated in New York.

TREE.

Tree not a strong grower, below medium size; branches rather short and moderately stout. Form upright and somewhat spreading or roundish. Twigs short, straight, moderately stout with large terminal buds; internodes long to mediun. Bark brown tinged with red, partly overlaid with rather thick scarf-skin; pubescent near tips. Lenticels scattering, medium to small, roundish or elongated, raised but slightly if at all. Buds large to medium, prominent, broad, plump, acute, free, pubescent. 
FRUIT.

Fruit medium to large, pretty uniform in size. Form rather variable, roundish to oblate, often inclined to conic, more or less irregular, somewhat angular; sides sometimes unequal. Stem medium or sometimes long, rather slender. Cavity acute, usually deep, moderately wide or wide, often furrowed or compressed, marked with yellowish-russet which sometimes extends beyond the cavity, sometimes lipped. Calyx small, closed or partly open; lobes small, narrow, reflexed. Basin rather small, deep, narrow to moderately wide, very abrupt, nearly symmetrical or slightly furrowed, sometimes wrinkled.

Skin rather thin, tough, smooth, bright pale yellow blushed and mottled with pinkish-red and striped with darker red, highly colored specimens being nearly overspread with bright red becoming on the exposed cheek nearly as dark red as Jonathan or Gano, often irregularly veined with russet. Dots usually small, yellowish or pale gray, sometimes large.

Calyx tube funnel-form.

Core medium to small, axile; cells closed or nearly so; core lines clasping or meeting. Carpels smooth, wide at the middle, emarginate, often approaching obcordate. Seeds below medium or small, irregular, dark, obtuse.

Flesh whitish with yellow tinge, moderately firm, tender, moderately finegrained, not crisp, moderately juicy, sweet or very mildly subacid, slightly aromatic, good or sometimes very good.

Season October to midwinter or later.

\section{PARSON.}

References. I. Bailey, An. Hort., I892:246. 2. Craig, Can. Dept. Agr. Rpt., I896: I32.

Synonym. Parson's Sweet (I). Parson's Sweet (2).

A large, handsome, dark red, early winter apple of excellent flavor. It has not been sufficiently tested in this vicinity to determine its value for this region. Professor John Craig states that it resembles the Sweet Winesap but is of much purer quality.

Historical. Said to have originated near Springfield, Mass., as a seedling in one of the old orchards of that locality. Fowler Brothers brought the stock to Geneva, New York, about 1880 where it was propagated for their own sales as it was known only locally in the vicinity of Springfield. Mr. A. L. Root, of the Fonthill Nurseries, Welland, Ontario, who obtained the variety from Fowler Brothers, sent scions of it to this Station for testing in 1901 .

TREE.

Tree vigorous with long, moderately stout branches. Form upright and somewhat spreading or roundish, open. Twigs long, stout, slightly curved; internodes short. Bark very dark brown lightly streaked with scarf-skin, pubescent. Lenticels numerous, medium in size, oblong, slightly raised, rather conspicuous. Buds deeply set in bark, large, broad, flat, obtuse, appressed, pubescent.

\section{FrUIT.}

The following is Craig's description of the fruit (2). "Large, roundish, oblique, conical. Skin moderately smooth; colour, yellow, nearly covered with VOL. I - II 
rich dark red, marked with large white or russet-coloured dots marbled on the shaded side. Cavity, deep, narrow, regular; stem half to three-quarters inch long, deeply inserted, curved, slender. Basin large, slightly ribbed; calyx, large, open. Flesh white, tender, flaky, fairly juicy, very sweet; core small. A large handsome sweet early winter apple. One of the best of the class."

\section{PAWPAW.}

REFERENCES. I. Horticulturist, I3:149. I858. 2. Warder, I867:728. 3. Downing, 1869:299. 4. Thomas, 1875:508. 5. Lyon, Mich. Hort. Soc. Rpt., 1890:206. 6. Farrand, Mich. Sta. Bul., 205:42. 1903.

Synonyms. Ball Apple (3). Pawpaw Seedling (I). Rubicon (3, 5). Western Baldain (3).

A late-keeping winter apple of medium size, attractive red color and good quality. A hardy, moderate grower and regular bearer; must have suitable soil and good culture (5). It is not recommended for planting in this state.

Historical. Origin Paw Paw, Michigan ( 1,3$)$. It has long been cultivated ju Michigan to a limited extent, but is practically unknown to New York fruit growers.

\section{FRUIT.}

Fruit large. Form roundish or somewhat oblong, inclined to conic, faintly ribbed; axis slightly oblique; sides unequal. Stem medium in length, moderately slender. Cac'ity acuminate, deep, rather broad, compressed, irregularly russeted. Calyx medium in size, slightly open. Basin medium in depth and width, somewhat abrupt, slightly furrowed and wrinkled, compressed.

Skin smooth, rather glossy, yellow overspread and mottled with attractive red irregularly splashed and striped with carmine. Dots moderately numerous, variable in size, russet or light colored, rather conspicuous, often areolar. Prez'ailing color red.

Calyx tube short, conical. Stamens basal.

Core medium in size, axile; cells closed or partly open; core lines meeting or slightly clasping. Carpels broadly roundish, slightly emarginate, slightly tufted. Seeds numerous, above medium size, rather wide, plump, acute, irregular, somewhat tufted, rather dark brown.

Flesh tinged with yellow, firm, moderately fine-grained, rather tender, juicy, subacid, good to very good.

Season December to June.

\section{PAYNE.}

References. 1. Bailey, An. Hort., 1892:246. 2. Wild, Mo. Hort. Soc. Rpt., 1902:203. 3. Stinson, Mo. Fr. Sta. Bul., 3:23. 1902. fig. 4. Budd-Hansen, 1903:146.

Synonyms. Payne's Keeper (1, 2, 3). Payne Late Keeper (4).

An attractive apple, valued in the Ozark region because of its excellent keeping qualities. It is somewhat deficient in size, good in quality and nearly sweet. It is duller in color than Ben Davis, but better in flavor and quality. It has not yet been sufficiently 
tested in New York to indicate its value for this region, but it is probably not well suited to the conditions existing in this state.

Historical. Originated on the Payne farm near Everton, Missouri. It is supposed to have originated from seed brought from North Carolina about 1840 .

FRUIT.

Fruit below medium to above medium, sometimes rather large. Form roundish conic, somewhat elliptical, ribbed very obscurely if at all. Stem short, usually not exserted, rather slender. Cavity large, remarkably acuminate, very deep, often somewhat furrowed or compressed, usually covered with thin outspreading russet. Calyx small, closed or partly open; lobes often flat and convergent, sometimes separated at the base. Basin commonly very small to medium, often oblique.

Skin smooth, moderately thick, very tough, yellow or greenish washed and blushed with red and pencilled with narrow, obscure, carmine stripes, more or less streaked over the base with thin, dull scarf-skin. Highly colored specimens are almost wholly covered with bright deep red. Dots scattering, moderately conspicuous, rather large, pale gray or whitish often with russet point.

Calyx tube small, funnel-form or nearly so. Stamens median to basal.

Core medium in size, slightly abaxile; cells often not quite uniform in size but usually symmetrical, partly open or closed; core lines clasp the funnel cylinder. Carpels tender, slightly tufted, ovate, mucronate, but slightly emarginate if at all. Seeds medium or above, wide, rather flat, obtuse, tufted, often adhering to the carpels, rather dark.

Flesh tinged with yellow, firm, a little coarse, moderately juicy to somewhat dry, moderately tender, pleasant in flavor, mild subacid becoming nearly sweet, good to very good.

Season January to June.

\section{PEACH.}

References. I. Downing, 1869:299. 2. Bailey, An. Hort., 189z:246. 3. Burrill and McCluer, Ill. Sta. Bul., 45:335. 1896. 4. Beach and Clark, N. Y. Sta. Bul., 248:137. 1904.

Synonyms. Peach of Kentucky (3). Winter Peach (3).

Fruit white-skinned, often with delicate pink cheek overspread with whitish bloom. In general appearance it is quite attractive, but it does not always average good marketable size. It has a perfumed, subacid flesh of pretty good quality. The tree is long-lived and a pretty reliable biennial cropper, but hardly as uniformly productive as is desirable in a commercial variety. Although it has long been known in cultivation and is considered by some a profitable sort, generally speaking it has won but little recognition among fruit growers. It is not recommended for general planting, but it may be valuable locally. 
Historical. Origin unknown (I). It is but very little grown in New York.

TREE.

Tree medium in size, moderately vigorous to vigorous with moderately long, slender, crooked branches. Form roundish or nearly upright, open. Twigs medium to short, straight, moderately stout; internodes medium to short. Bark brown or somewhat tinged with red, lightly streaked with scarf-skin, pubescent. Lenticels quite numerous but not conspicuous, small, roundish or elongated, not raised. Buds medium to small, plump, obtuse, free or nearly so, pubescent.

\section{Fruit.}

Fruit below medium to above. Form oblate varying to roundish, flat at base, inclined to conic, somewhat ribbed and often irregularly elliptical; sides often unequal. Stem short to long, sometimes swollen. Cavity rather large, acute, moderately deep, rather broad, furrowed, usually russeted. Calyx small to above medium, closed or partly open. Basin small to medium, shallow to moderately deep, narrow to moderately wide, abrupt to rather obtuse, sometimes furrowed, often wrinkled.

Skin moderately thin, rather tender, smooth, clear pale yellow or whitish, often with a faint blush sometimes deepening in part to pink, mottled about the cavity with whitish scarf-skin and overspread with a white bloom which produces a delicate and beautiful effect. Dots numerous, whitish or areolar with russet point, often submerged.

Calyx tube usually funnel-shape and ratler narrow with wide limb, sometimes conical. Stamens basal.

Core medium or below medium in size, abaxile; cells usually symmetrical, sometimes open; core lines clasping or meeting. Carpels elliptical to somewhat obcordate, emarginate, smooth. Sceds few, above medium to rather small, wide, obtuse.

Flesh whitish tinged with yellow, very firm, moderately fine-grained, breaking, tender, very juicy, rather briskly subacid, perfumed, slightly astringent, good or sometimes very good in quality.

Season December to May or June.

\section{PEARMAIN.}

The term Pearmain, like the term Pippin, has been applied to very many different varieties of apples. In this country it is used now much less than it was formerly. Hogg states that it " signifies the Great Pear Apple. In olden times it was variously written Pearemaine or Peare-maine, being the Anglicised equivalent of Pyrus Magnus, just as Charlemagne is of Carolus Magnus. A Pearmain, therefore, ought to be a long or pear-shaped apple."

Among the varieties described in this volume with the term Pearmain appearing either in the accepted names or in synonyms are those listed below. Synonyms appear in italics. 
Autumn Pearmain. See Winter Pearmain.

Blue Pearmain.

Cannon Pearmain.

Cogszuell Pearmain. See Cogswell.

Green Winter Pearmain. See Winter Pearmain.

Great Pearmain. See Winter Pearmain.

Hollow Crown Pearmain. See Wine.

Hoopes Pearmain. See Greyhouse.

Large Striped Pearmain. See McAfee.

Large Striped Winter Pearmain. See McAfee.

Lop-sided Pearmain. See Greyhouse.

Old Pearmain. See Winter Pearmain.

Pearmain. See Winter Pearmain.

Pearmain Herefordshire. See Winter Pearmain.

Pryor's Pearmain. See Pryor.

Red Winter Pearmain. See page 279.

Red Winter Pearmain. See Westfield Seek-No-Further.

Russet Pearmain. See Hunt Russet.

Striped Winter Pearmain. See McAfee.

White Pearmain.

White Winter Pearmain. See White Pearmain.

Winter Pearmain.

Winter Pearmain. See McAfee.

Winter Pearmain. See Milam.

\section{PECK PLEASANT.}

References. I. Kenrick, I832:50. 2. Bull, Mag. Hort., 6:172. I840. 3. Downing, 1845:126. fig. 4. Floy-Lindley, I846:4I I app. 5. Hovey, Mag. Hort., I4:249. I848. 6. Thomas, I849:I83. 7. Horticulturist, 4:344. I849. 8. Cole, 1849:125. 9. N. Y. Agr. Soc. Rpt., 1849:355. fig. 10. Emmons, Nat. Hist. N. Y., 3:84. 1851. col. pl. and fig. II. Elliott, 1854:97. fig. I2. Hooper, 1857: 69. I3. Mag. Hort., 26:Ior. I860. 14. Am. Pon. Soc. Cat., 1862. I5. Mag. Hort., 30:162. I864. I6. Warder, 1867:641. fig. I7. Downing, I869:30r. I8. Fitz, 1872:168. 19. Barry, 1883:351. 20. Rural N. Y., 46:202. 1887. 21. Ib., 47 :749. I888. 22. Wickson, 1889:247. 23. Lyon, Mich. Hort. Soc. Rpt., 189o: 296. 24. Bailey, An. Hort., I892:246. 25. Munson, Me. Sta. An. Rpt., 1893: 133. 26. Taft, Mich. Sta. Bul., ro5:109. I894. 27. Alwood, Va. Sta. Bul., r30:135. r9or. 28. Van Deman, Rural N. Y., 60:37. r901. 29. Budd-Hansen, 1903:147. 30. Powell and Fulton, U. S. B. P. I. Bul., 48:52. 1903. 31. Beach and Clark, N. Y. Sta. Bul., 248:137. 1904.

Synonyms. Dutch Greening. Peck (26). Peck's Pleasant ( I, 2, 3, 4, 5, $6,7,8,9$, I0, II, I2, I3, I4, I5, I8, 20, 21, 22, 23, 24, 25, 27, 28, 30). Waltz Apple (I7). Watts Apple (I2).

This variety evidently belongs in the same group with Green Newtown, Rhode Island Greening and Perry Russet. It is an old favorite for home use in many parts of the state. It is more highly esteemed for dessert than for culinary uses. The flesh is tender, 
pleasantly flavored and ranks very good to best in quality. The color is good for a yellow apple, being at first predominantly green, but as the fruit approaches full maturity it becomes waxen-yellow with an orange or pinkish blush. The fruit very often scalds in storage, but it is less apt to do so if placed in cold storage immediately after picking. Its season for home use extends from October to March. Ordinarily February is its commercial limit in Western New York, but in cold storage it may be held till April (3r). The tree is somewhat subject to root-rot and canker and it is not considered as long-lived nor as healthy as either Baldwin or Rhode Island Greening. It has the reputation of being often a shy bearer. In some localities it may bear pretty regularly, but it is only occasionally that it gives full crops. The better grades of the fruit are of good size and attractive appearance, but there is apt to be a rather high percentage of loss from ill-shapen, undersized or otherwise unmarketable fruit.

It is said to be known locally in some portions of the state under the name Dutch Greening.

Historical. In 1845 Downing expressed the opinion that Peck Pleasant originated in Rhode Island and stated that it had long been cultivated in that state and in Northern Connecticut (3). It has been pretty thoroughly disseminated throughout New York state but it is found chiefly in the older orchards and is now seldom or never planted. In I89o Lyon (23) reported concerning the status of this variety in Michigan that it was generally and deservedly popular, the fruit being beautiful and excellent, and the tree in habit like Rhode Island Greening but less vigorous.

\section{TREe.}

Tree medium in size, moderately vigorous or a rather slow grower. Form upright spreading or roundish, rather dense. Twigs medium to short, nearly straight, moderately stout; internodes mediun to short. Bark brown tinged with red often mingled with olive-green, lightly streaked with scarf-skin; sliglitly pubescent near tips. Lenticels quite numerous, small, oblong or roundish, not raised. Buds very deeply set in bark, medium to small, broad, plump, obtuse to acute, appressed to nearly free, pubescent.

\section{FRUIT.}

Fruit medium to sometimes large, somewhat variable in shape and size. Form oblate to roundish, sometimes a little inclined to conic, often obscurely ribbed or irregularly elliptical, sometimes with furrow on one side. Stem medium to short and usually thick or fleshy. Cavity variable, obtuse or sometimes acute, rather wide, shallow to deep, nearly symmetrical or a little furrowed, often lipped or compressed, sometimes partly russeted. Calyx pubes- 

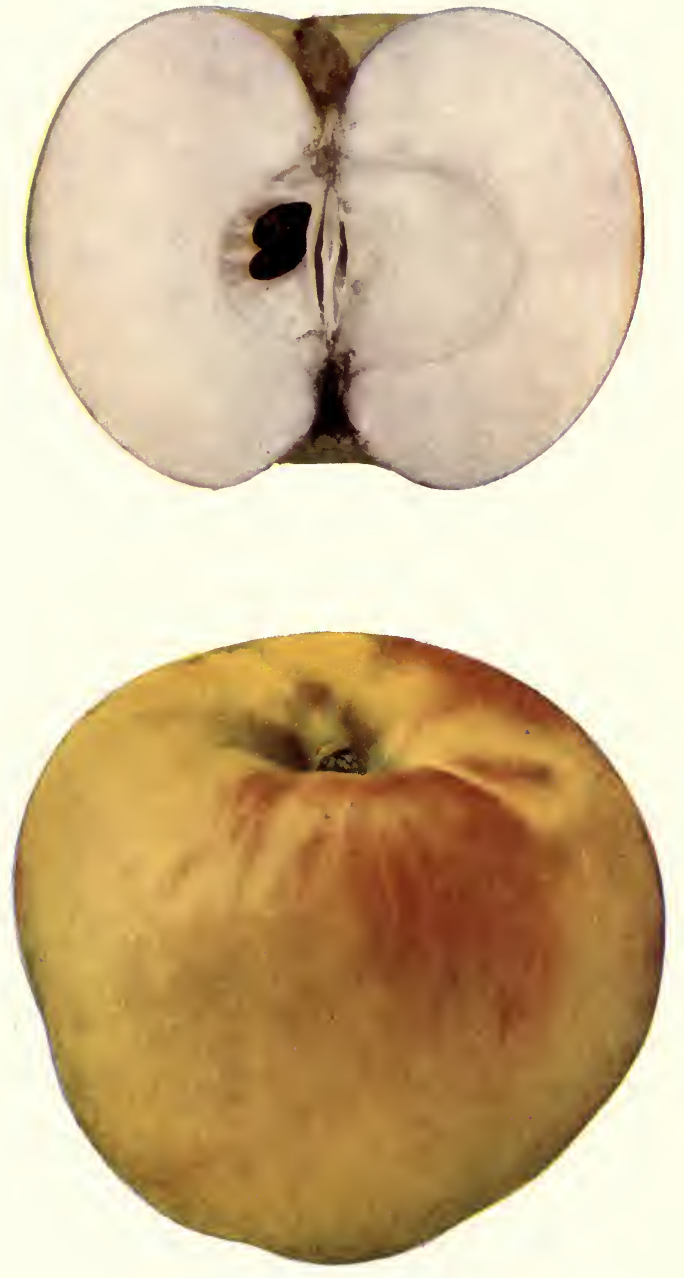

PECK PLEASANT 

cent, medium to rather large; lobes long, open or closed, sometimes distinctly separated at the base, rather obtuse. Basin varies from broad to rather narrow, from obtuse to abrupt, and from nearly symmetrical to irregular and furrowed or wrinkled.

Skin moderately thick, tough, smooth, green becoming bright waxen yellow with orange-red blush, sometimes partly deepening to pink. Dots numerous, whitish and submerged or with russet point. Prevailing effect yellow.

Calyx tube funnel-form. Stamens basal.

Core medium to rather small, abaxile to nearly axile; cells not uniformly developed, usually closed or slit; core lines clasp the funnel cylinder. Carpels rather tender, broadly roundish, often nearly truncate, emarginate, mucronate. Seeds numerous, rather dark, long, narrow, acute, below medium or above, sometimes slightly tufted.

Flesh yellowish, firm, tender, crisp, fine-grained, juicy, pleasant subacid, aromatic, very good to best. Toward the close of the season it becomes inferior in quality although it may appear to be still in good condition.

\section{PENNOCK.}

References. I. Coxe, 1817:145. fig. 2. Thacher, r822:132. 3. Buel, N. Y. Bd. Agr. Mem., 1826:477. 4. Fessenden, 1828:131. 5. Cat. Hort. Soc. London, 1831:27. 6. Mag. Hort., I:364. 1835. 7. Manning, Ib., 7:47. I841. 8. Downing, 1845:125. 9. Kirtland, Horticulturist, 2:545. 1847. ro. Longworth, $I b ., 3: 395$. I848. II. Phoenix, Ib., 4:470. I849. I2. Thomas, I849:I70. I3. Cole, 1849:128. 14. Emmons, Nat. Hist. N. Y., 3:59. 1851. col. pl. 15. Elliott, 1854:176. г6. Hooper, 1857:68. г7. Horticulturist, 15:183. 1860. 18. Warder, 1867:449. 19. Downing, 1869:302. 20. Hogg, 1884:I71. 21. Lyon, Mich. Hort. Soc. Rpt., 1890:296. 22. Bailey, An. Hort., 1892:246.

Synonyms. Big Romanite (15, 16, 19). Gay's Romanite (19). Large Romanite (I5, I6, I9). Neisley's Winter (I5). Neisley's Winter Penick (19). Pelican (19). Penick. Pennick. Pennock (8). Pennock's Red Winter (2, 5, 6, 8, I0, I3, I6). Pennock's Red Winter (12, I5, I8, I9, 20). Phoenix (16). Pomme Roye (19, of some West, 15). Prolific Beauty (15, 19). Red Ox (19). Red Pennock (15, 19). Romanite (18). Roman Knight (19).

A rather large, red winter apple, pretty uniform in size and shape and attractive in appearance, but only fair to good in quality. It is much subject to the trouble commonly known as "Baldwin Spot," for which no remedy is known. ${ }^{1}$ The tree is hardy, very long-lived and a strong grower. It comes into bearing rather young and is a reliable cropper, usually yielding heavy crops biennially and bearing some fruit every year. Generally speaking it is not regarded with favor as a commercial variety because the fruit ranks but second or third rate in quality and, as above mentioned, is subject to the "Baldwin Spot." It is not recommended for planting in New York. 
Historical. This old variety has been long known among New York fruit growers by the names Pennock, Pennick, Penick and Phoenix. The true Phoenix is a distinct variety which apparently has never been known among New York fruit growers. Pennock is said to have been first cultivated by Joseph Pennock, of Springfield township, Delaware county, Pennsylvania. It was formerly grown to a considerable extent in Pennsylvania and New Jersey and was at one time popular in the Philadelphia market $(1,2)$. In 1867 Warder remarked that it was then universally cultivated in nearly all parts of the country. In New York state it is found principally in old orchards and is now seldom planted.

\section{TREE.}

Tree large or medium, often very vigorous. Form regular, symmetrical, upright spreading.

\section{FRUIT.}

Fruit large, uniform in size and shape. Form roundish to oblate or slightly oblong, often inclined to conic, sometimes obscurely ribbed or elliptical but usually pretty regular; axis sometimes oblique. Stem short, moderately thick, not exserted. Cazity medium in size, acute or approaching acuminate, moderately narrow to rather broad, deep, usually symmetrical, green or russeted, sometimes with outspreading russet rays. Caly'x medium to rather large, closed or partly open; lobes medium to long, acute, connivent or varying to flat and convergent, pubescent. Basin medium in size, shallow to medium in depth, rather narrow to moderately wide, somewhat abrupt, sometimes obtuse, often a little furrowed or slightly wrinkled.

Skin rather thick, tough, smooth, yellow or greenish washed and mottled with red rather indistinctly striped with carmine and somewhat mottled and streaked with thin scarf-skin. Well-colored specimens are almost wholly covered with bright deep red. Dots numerous, conspicuous, large, gray or yellowish, often areolar with russet point.

Calyx tubc rather large, moderately wide, usually conical, sometimes approaching truncate funnel-shape. Stamens basal to nearly median.

Core small, axile; cells uniformly developed, closed; core lines meeting or slightly clasping. Carpels ovate to roundish obcordate, emarginate, sometimes tufted. Seeds medium to large, moderately narrow, rather long, plump, somewhat acute, rarely tufted.

Flesh yellowish, firm, somewhat coarse, rather crisp, tender, rather juicy, subacid to mild subacid or nearly sweet; flavor lacking in character; quality fair to good.

Season December to April or May.

\section{PERRY RUSSET.}

References. I. Willey, Horticulturist, I7:168. 1862. 2. Warder, 1867:468. fig. 3. Downing, 1869:303. 4. Am. Pom. Soc. Cat., 1873. 5. Thomas, 1875: 509. 6. Lyon, Mich. Hort. Soc. Rpt., 1890:296. 7. Harris, U. S. Pom. Rpt., 1892:271. 8. Bailey, An. Hort., 1892:246. 9. Hansen, S. D. Sta. Bul., $76: 84$. 1902. 10. Budd-Hansen, 1903:149. 11. Beach and Clark, N. Y. Sta. Bul., 248:137. 1904. 

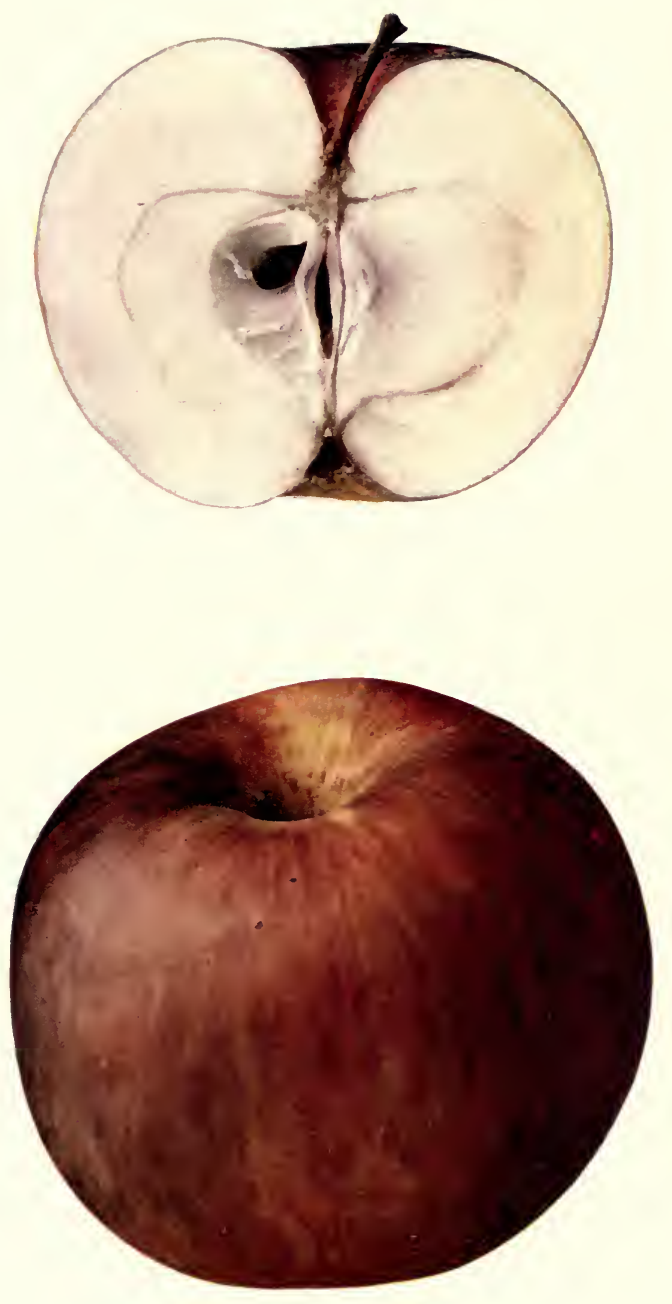

PENNOCK 

Synonyms. Golden Russet (I, 3), but erroneously. Pineapple. Pineapple Russet. Poughkeepsie Russet (I), but erroneously. Rhode Island Russet. Winter Russet (I).

This variety evidently belongs in the same group as Peck Pleasant, Rhode Island Greening and Green Newtown. The fruit is of good size, pretty uniform and fairly attractive in appearance for a yellowish apple. It has a crisp, subacid flavor and easily ranks good in quality for either dessert or culinary purposes. It is in season from December to midwinter or later. Its commercial limit in ordinary storage is November or December; in cold storage it may be held till March. It does not stand heat well before going into storage. In going down it often shrivels, becomes mealy and goes down quickly. It varies greatly in keeping quality in different seasons and in different localities, and is not regarded favorably for storage purposes. The tree is very hardy, healthy, very long-lived and a reliable cropper, giving good crops biennially or in some cases almost annually. The fruit hangs well to the tree, being borne on slender twigs. It is perhaps worthy of attention for planting in the home orchard where very hardy varieties are particularly desired, but is seldom regarded as a profitable commercial variety in New York state.

Historical. This variety has long been cultivated locally in the vicinity of Berwyn, Onondaga county, N. Y., where some trees of it nearly one hundred years old are said to be still very productive. It has always been known there under the name of Rhode Island Russet only ${ }^{1}$ and not until I904, when it was identified by U. S. Pomologist Brackett, was it discovered that it was identical with Perry Russet. The fact that long before it was known as Perry Russet it had the local name Rhode Island Russet indicates that it was probably known in Rhode Island before it was introduced into New York.

Warder (2) publishes a description which was made from a specimen exhibited by Mr. Utters at a meeting of the Northwestern Fruit Groivers in I850. Willey (I), writing from Madison, Wisconsin, made the following statement concerning it in $\mathbf{1 8 6 2 .}$ " Perry Russet is a sort sent from the East under various cognomens, as Winter Russet, Poughkeepsie Russet, Golden Russet, etc. It is universally hardy, succeeding in all locations, and much esteemed everywhere. Tree good grower, forms a round even head; fruit large, fair and excellent; keeps well through the winter. Too many cannot be had, as it is the best of all the Russets." We are also informed that it has been known under the names Pineapple Russet and Pineapple.2 Downing, in I869 stated that this variety "was many years since carried from Perry,

${ }^{1}$ Letters, L. L. Woodford, 1904.

${ }^{2}$ Report by F. Newhall and Sons, Chicago, Ill., I904. 
Wyoming county, New York, to the West under the name of Golden Russet, but as it was entirely distinct from the true Golden Russet it soon became known as Perry Russet."

\section{TREE,}

Tree medium to large or eventually very large. Form symmetrical, roundish or spreading. Twigs medium to short, straight, slender; internodes medium. Bark reddish-brown, lightly streaked with scarf-skin, pubescent. Lenticels scattering, very small, oval. Buds small, plump, obtuse, free, pubescent.

\section{Fruit.}

Fruit above medium to nearly large, pretty uniform in size and shape. Form roundish oblate to oblate conic, slightly ribbed. Stem often swollen at base, short, thick or moderately so. Cavity very obtuse to acute, shallow to medium in depth, broad, often thinly russeted and with outspreading russet rays, a little wavy and often rather strongly lipped. Calyx medium in size, somewhat open; lobes often separated at the base, narrow, acute to acuminate. Basin medium in depth to deep, medium to rather wide, abrupt, somewhat furrowed, not symmetrical, irregular.

Skin thick, tough, nearly smooth or roughened more or less with russet, rather pale yellow with rather dull blush of bronze or brownish-red and sometimes with obscure dark reddish splashes. Dots very numerous, usually small, sometimes rather large, prominent, russet, irregular and mingled with russet flecks or netted russet. Prevailing color yellowish.

Calyx tube rather wide, short, conical. Stamens median.

Core medium size, axile; cells closed; core lines meeting or slightly clasping. Carpels broadly ovate, tufted. Seeds medium, narrow, rather long, acute to acuminate.

Flesh whitish a little tinged with yellow, medium to rather fine-grained, moderately tender or somewhat tough, juicy, with an agreeable subacid russet flavor, sprightly, aromatic, good.

\section{PEWAUKEE.}

References. I. Willey, Horticulturist, 1870. (cited by 2 and 20). 2. Am. Pom. Soc. Rpt., 1871:5I. 3. Downing, 1872:26 app. 4. Am. Pom. Soc. Cat., 1875:12. 5. Barry, 1883:351. 6. Thomas, 1885:520. 7. Can. Hort., 14:139. I891. 8. Ib., 14:260. 1891. 9. Bailey, An. Hort., 1892:246. ro. Can. Hort., 17:69. 1894. I1. Ib., I7:25I. 1894. I2. $I b$., 18:379. 1895. 13. Munson, $M c$. Sta. An. Rpt., 1896:71. 14. Waugh, Vt. Sta. Bul., 61:31. 1897. 15. Dickens and Greene, Kan. Sta. Bul., ro6:54. 1902. r6. Hansen, S. D. Sta. Bul., 76:85. 1902. 17. Budd-Hansen, I903:150. fig. 18. Powell and Fulton, U. S. B. P. I. Bul., 48:52. I903. 19. Beach and Clark, N. Y. Sta. Bul., 248:137. 1904. 20. Ragan, U.S. B. P. I. Bul., 56:231. 1905.

Synonym. Peewaukee $(7,10)$.

Fruit above medium to large; often it is poorly colored, being greenish striped with dull red. When well colored it is of fairly good yellow color largely washed and mottled with red and splashed with dark carmine. It is overspread with a heavy bluish bloom 


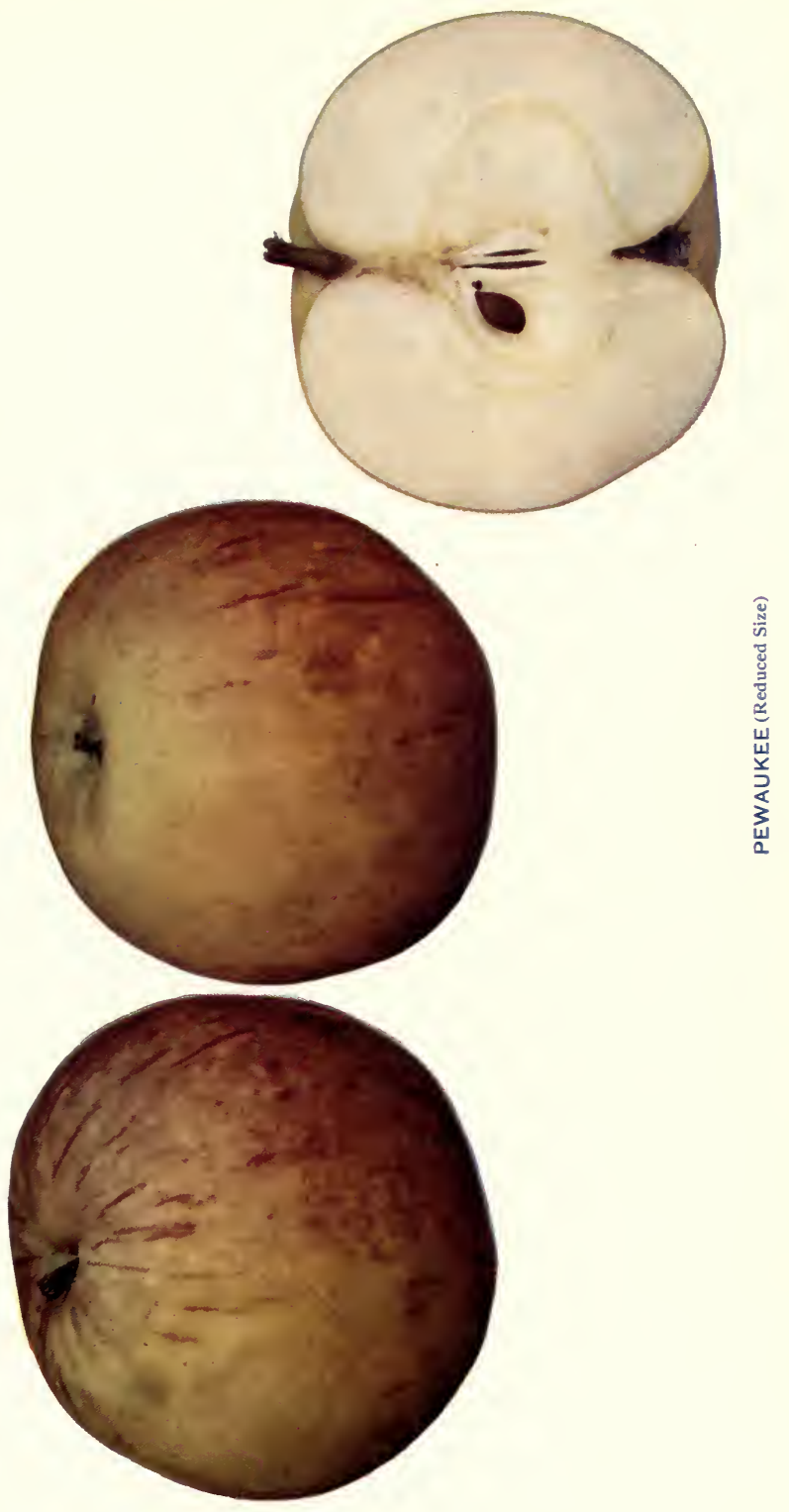



which produces a rather dull effect, but it becomes bright and glossy when polished. Its quality ranks fair to good for either culinary or dessert uses.

Pewaukee varies much in keeping qualities in different seasons (19). In ordinary storage its commercial limit varies from November to January, or under favorable conditions till February. The rate of loss in the stored fruit is often high in November, then becomes lower till midwinter, after which it rises again. Its season in cold storage is variously reported as extending from November to February or March, or exceptionally to May (19).

This variety was produced by crossing Oldenburg with Northern Spy. As might be expected from its parentage, it is very hardy, although it has not proven as hardy in the North and Northwest as was at first expected, being inferior to Wealthy in this respect ( I6, I7).

Pewaukee makes a moderately vigorous root development in the nursery, but in the orchard it becomes a good, strong grower and succeeds well under ordinary care. Usually it is healthy and longlived, but in some localities it is said to suffer from canker. The tree comes into bearing rather early and is a reliable cropper, bearing biennially or almost annually and often yielding heavy crops. It is not generally considered a desirable variety for commercial planting in New York, except in those portions of the state where hardiness is a prime requisite, for in spite of its vigor, hardiness and productiveness it is usually found less profitable than standard commercial varieties because it is deficient in color and in quality and generally is not very well known in market.

Historical. Originated by George P. Peffer, Pewaukee, Wisconsin, by crossing Oldenburg with Northern Spy. It was first brought to the notice of fruit growers about $1870(1,2,3)$. It has been sparingly disseminated through this state but has not been cultivated largely in any locality and its planting does not appear to be increasing.

\section{Tree.}

Tree vigorous or moderately vigorous, medium to large, with stout curved branches. Form upright spreading or roundish, open. Twigs long to below medium, curved or irregularly bent, moderately stout; internodes long. Bark clear dark reddish-brown lightly mottled and streaked with gray scarf-skin; slightly pubescent near tips. Lenticels conspicuous being of a clear light color, scattering, usually medium or below, elongated, not raised. Buds large, broad, 
plump, obtuse, free or nearly so, much pubescent; the shoulder of the bud is flattened so that it bulges slightly on the sides.

\section{FrUIT.}

Fruit above medium, cften large, fairly uniform in size but not in shape. Form roundish oblate, sometimes approaching roundish ovate, characteristically rounded toward the cavity, ribbed, more or less irregularly elliptical. Stem ustrally short, often fleshy and often inserted under a lip. Cavity varies from moderately large to small, sometimes being scarcely at all developed, narrow to wide, very shallow to moderately deep, often furrowed and sometimes thinly russeted. It is acuminate at the insertion of the stem but the outer portion is often moderately obtuse. Caly.x below medium to large, partly open or sometimes closed. Basin medium in depth and width, usually somewhat abrupt, wrinkled.

Skin smooth, moderately thin, rather tough, grass-green becoming yellow washed and mottled with orange-red or red, striped and splashed with carmine, often covered with bloom. Dots moderately conspicuous, pale gray or whitish, some being large, obscurely defined and areolar.

Calyx twbe funnel-form varying to cone-shape. Stamens median to basal.

Core below medium to large, axile to somewhat abaxile; cells irregularly developed, usually closed or slit; core lines clasp the funnel cylinder. Carpels obcordate, tufted. Seeds numerous, medium to large, rather long, moderately narrow, acute, plump, tufted, light brown.

Flesh nearly white, moderately firm, slightly coarse, rather tender, very juicy, subacid, slightly aromatic, fair to good.

Season variable; commonly November to April in Northern and Western New York.

\section{PICKARD RESERVE.}

References. 1. Mo. Hort. Soc. Rpt., 1863. (cited by 9). 2. Warder, 1867: 413. fig. 3. Downing, 1869:304. 4. Am. Pom. Soc. Cat., 1873. 5. Bailey, An. IIort., r892:246. 6. Burrill and McCluer, Ill. Sta. Bul., 45:335. I896. 7 . Thomas, 1897:648. 8. Sharpe, Can. Dcpt. Agr. Rpt., rgor:543. 9. Ragan, U. S. B. P. I. Bul., 56:232. 1905.

Synonyms. Picard (7). Picard's Reserve (7). Pickard (4). Pickard's Reserve (9).

A large, green or yellow fruit with reddish-bronze cheek which in highly colored specimens becomes in part pinkish-red. It is evidently allied to the Green Newtown group of apples. This is indicated by the elliptical form, occasional oblique axis, truncate base, the color and markings of the skin, particularly the outspreading russet rays about the cavity, the gray dots and the brownish-pink blush; also by the texture, aroma and quality of the flesh. Although inferior to Green Newtown in aroma and quality it is excellent in both. It does not appear to show any marked resemblance to the group which includes Ortley and Yellow Bellflower and it is strikingly different from this group in its core characters.

As fruited at this Station the tree has not come into bearing very young but with advancing maturity has proved a reliable bearer giving full crops in alternate years. So far as we can learn it has not been sufficiently tested in 
New York to determine its value for this region either for the home or for market purposes but so far as it has been tried it has proved desirable for home use, and it appears worthy of trial for commercial planting where a yellow fruit of this class is desired. Its culture in the Middle West is said to have declined in recent years on account of the susceptibility of the variety to the attacks of the apple scab. We have found no difficulty in protecting it from this disease by the ordinary line of treatment with bordeaux mixture.

Historical. Originated in Park county, Indiana, from seed brought from North Carolina (2). Professor W. H. Ragan has kindly supplied the following statement concerning its history and habits of growth in Indiana. "It originated with the late $\mathrm{Wm}$. Pickard, of Park county, Ind., and about 40 miles from the place of my birth. Wm. Pickard was a Friend (Quaker) and had a pioneer seedling orchard. By chance he had several fairly good varieties and he boasted that he had as good fruit as those of his neighbors who had cultivated varieties. To convince them of this fact he invited his friends to a test of his varieties. To them he presented several varieties which in turn were pronounced good, bad and worse. Finally he brought out his 'best,' that is in his own opinion, but only announced that this was the last. On testing it they were all charmed with its high quality and it was suggested that this was 'Pickard's Reserve,' it having been reserved until the last of the feast.

"Your inquiry concerning its quality, and your mention in that connection of Grimes Golden indicates that you know of its high character as a fruit. There is no mistake on this point, and yet I am hardly prepared to claim that it is the equal of that fine variety. But it ranks 'very good' if not quite 'best.'

"The tree is upright and inclines to make splitting forks that are liable to split down and thus destroy the tree. It is fruitful almost to a fault, and if not overloaded, the fruit is of good size, averaging about with Yellow Newtown in this particular, which it somewhat resembles in appearance. Its flesh is, however, much more tender and less acid than the Yellow Newtown. Its parentage is not certainly known, though it has been suggested that it may have been from seed of 'Ortley.' It was one of the very first (along with the Ortley itself) to yield to the attack of the apple scab, when it first invaded our country, and hence its culture has been largely discontinued with us."

\section{TREE.}

Tree vigorous; branches long, moderately stout, liable to split at the forks. Form upright spreading, open. Twigs moderately long, straight, rather stout; internodes medium to short. Bark dull brown tinged with red, heavily coated with scarf-skin, slightly pubescent. Lenticels rather conspicuous, numerous, medium size, somewhat elongated; slightly raised. Buds medium to below medium, broad, plump, obtuse to somewhat acute, free or nearly so, pubescent.

\section{FruIT.}

Fruit large, fairly uniform in shape and size. Form inclined to oblate, rather irregularly elliptical, sometimes broadly or obscurely ribbed, often lopsided or with one side bulging; axis often oblique. Stem short, usually rather slender. Cavity pretty large, acuminate, irregular, wide, very deep, often com- 
pressed and sometimes lipped, russeted and with very conspicuous, outspreading russet rays. Calyx small to medium, partly closed or sometimes open; lobes acuminate, reflexed. Basin small to medium, narrow to rather wide, deep, rather abrupt, furrowed, slightly wrinkled.

Skin smooth or slightly roughened witl russet dots, green changing to yellow when fully ripe, often with faint streaks of brownish or pinkish blush. Bright and rather attractive for a yellowish apple. Dots russet and gray.

Calyx tube conical or approaching truncate funnel-form. Stamens median to basal.

Core small to medium, usually axile or nearly so; cells often not uniform in size but symmetrical, closed or partly open; core lines meeting when the calyx tube is cone-shape, clasping when it is funnel-form. Carpels elongated, pointed ovate, smooth or nearly so. Seeds acute to slightly obtuse, long, medium size, brown, sometimes tufted.

Flesh yellowisl, firm, moderately fine-grained, crisp, tender, juicy, subacid becoming mild subacid, somewhat aromatic, sprightly, very good.

Season in Western New York November to February or March.

\section{PIFER.}

References. I. Mag. Hort., 19:210. 1853. 2. Horticulturist, 8:342. 1853. 3. Warder, 1867:728. 4. Downing, 1869:304. 5. Burrill and McCluer, IIl. Sta. Bul., 45:336. 1896. 6. Powell and Fulton, U. S. B. P. I. Bul., 48:52. 1903. 7. Beach and Clark, N. Y. Sta. Bul., 248:138. 1904.

Synonyus. Pfeifer $(4,7)$. Pfelffer $(1,2,3)$. Piper (6).

A dull red fruit of medium size and fair quality. Its chief merit is that it keeps fresh and firm till very late in the season. The tree does not come into bearing very young but so far as tested here it appears to be a reliable bearer yielding full crops biennially. Not recommended for planting in New York.

Historical. Originated in Springfield township, Pennsylvania. Brought to the attention of the Pennsylvania Horticultural Society in $1853(1,2)$. It does not appear to be known among New York fruit growers.

\section{TREE.}

Tree moderately vigorous with moderately long, slender, curved branches. Form upright to roundish, rather dense. Tavigs medium in length to very short, straight or nearly so, slender, with large terminal buds; internodes rather short. Bark clear reddish or olive-green, lightly streaked with scarfskin, slightly pubescent. Lenticels quite numerous, small to very small, elongated, usually not raised. Buds rather small, plump, acute, appressed, slightly pubescent.

\section{Fruit.}

Fruit below medium to above, uniform in size and shape. Form roundish inclined to oblate, regular or sometimes obscurely ribbed, usually symmetrical ; sides sometimes unequal. Stem short to medium, rather slender. Cavity acute to acuminate, rather shallow to moderately deep, moderately broad, smooth and greenish or occasionally slightly russeted. Caly $x$ small to medium, closed or partly open; lobes long, recurved. Basin varies from moderately 
deep and abrupt to rather shallow and obtuse, rather narrow to moderately wide, slightly furrowed or wrinkled.

Skin tough, leathery, smooth, dull greenish-yellow blushed with dull red, becoming deep pinkish-red in highly colored specimens, with numerous narrow stripes of dark carmine, and overspread with a thin bloom which gives a dull effect. Dots small, gray.

Calyx tube long, very narrow below, funnel-shape. Stamens median to basal.

Core medium in size, axile or nearly so; cells usually partly open; core lines clasping. Carpels obcordate, emarginate. Seeds numerous, medium or above, rather wide, plump, somewhat acute.

Flesh tinged with yellow, firm, hard, pretty coarse, somewhat crisp, not tender, juicy, mild subacid, somewhat aromatic, fair or possibly good.

Season January to July.

\section{PINE STUMP.}

References. I. Bercknians, Am. Pom. Soc. Rpt., I891:160. 2. Lyon, Mich. Sta. Bul., 143:201. I897. 3. Massey, N. C. Sta. Bul., 149:318. 1898.

As fruited at this Station this is a dull red apple hardly medium in size. It is in season from November to February. It originated in Granville county, North Carolina. In that region it is in season from the middle of September to early winter and it is said to be a very showy fruit and an excellent market apple of fine flavor and good quality $(I, 3)$. It does not appear to be adapted to New York conditions and is not recommended for planting in this state.

\section{PIPPIN.}

The word Pippin, from the old English word Pippin, a seed, or the French Pepin, a pip or kernel, formerly signified a seedling apple in distinction from a budded or grafted tree. Hogg remarks that, " Leonard Mascal, writing in 1572 , says, ' Then shall you cover your seedes or pepins with fine erth so sifting al over them'; and 'when the winter is past and gone, and that ye see your Pepins rise and growe'; and again, 'When so euer ye doe replante or change your Pepin trees from place to place, in so remouing often the stocke the frute there of shall also change; but the frute which doth come of Graffing doth always kepe the forme and nature of the tree whereof he is taken'.

"It is evident from this last quotation that Pippin is synonymous with seedling, and is used to distinguish a tree raised directly from seed from one that has been raised from grafts or cuttings. The Golden Pippin, which, by the way, was raised in Sussex, where Mascal also was born, means simply Golden Seedling. 
"But there was another meaning attached to the word. In Henry IV., Shallow says to Falstaff, 'Nay, you shall see mine orchard; where in an arbour we will eat a last year's pippin of my own graffing.' And this is interpreted by what Sir Paul Neile says in his Discourse of Cider, written in the time of the Commonwealth, wherein speaking of 'pippin cider,' he says, 'For by that name I shall generally call all sorts of cider that is made of apples good to eat raw, and that is evidently the signification in the above quotation from Shakspeare.

" Coming to more modern times, we have the word kernel, which is the English equivalent of Pepin, also used to signify a seedling apple tree; as, for example, Ashmead's Kernel, the seedling raised by Dr. Ashmead, of Gloucester; Cook's Kernel, Knott's Kernel, and many others."

In this country the term Pippin has been applied to very many different varieties of apples. In Eastern and Southeastern New York when this word is used alone it signifies either the Green Newtown or Yellow Newtown specifically, or the group of green or yellow skinned apples to which these belong, while in Central and Western New York it refers to either the Fall Pippin specifically or to the group to which that variety belongs. In certain portions of the Middle West it is understood as referring to Missouri Pippin.

\section{POMME GRISE.}

References. I. Forsyth, 1803:53. 2. Ronalds, 1831:32. 3. Manning, Mag. Hort., 7:51. 1841. 4. Cat. Hort. Soc. London, 1842. 5. Downing, 1845:124. 6. Thomas, 1849:184. 7. Cole, 1849:129. 8. Hovey, Mag. Hort., 17:17. I851. fig. 9. Emmons. Nat. Hist. N. Y., 3:94. 1851. fig., col. pl. No. 77. ro. Elliott, 1854:99. II. Hooper, 1857:70. I2. Downing, 1857:180. 13. Am. Pom. Soc. Cat., 1862. 14. Warder, 1867:469. fig. 15. (?) Leroy, 1873:684. figs. I6. Barry, 1883:352. 17. Hogg, 1884:179. 18. Lyon, Mich. Hort. Soc. Rpt., 189o: 296. 19. Bailey, An. Hort., 1892:246. 20. Dempsey, Ont. Fr. Stas. An. Rpt., 2:34. 1895. 21. Budd-Hansen, 1903:152. fig. 22. Beach and Clark, N. Y. Sta. Bul., 248:138. 1904.

Synonyms. (Bec de Lievre, 15)? (Belle Fille, 15)? (De Cuir, 15)? French Russet (22). Gray Apple $(5,6,10,12,2 \mathrm{I})$. Grise $(5,8,10,12)$. Leather Apple of Turic (12). (Leder, 15)? (De Maroquin, 15)? (Di Peau, 15)? Pomme de Cuir (12). Pomme Gree (1). Pomme Gris (3, 9, 13, 18, 19, 20, 21). (Prager Reinette Franche de Grandville, 15)? (Reinette de Darnetal, 15)? (Reinetre Grise, 15)? (Reinette Grise de Darnetal, 


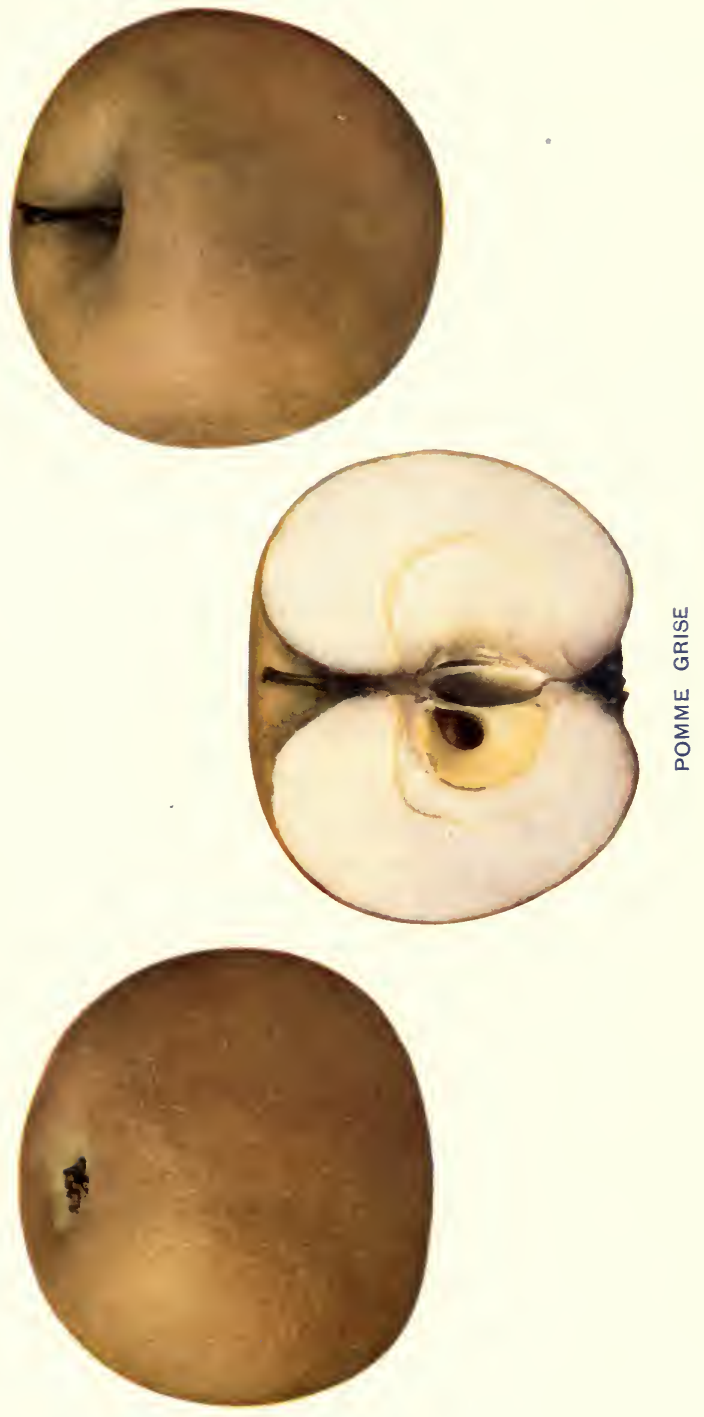



I5)? (Reinette Grise Double, I5)? (Reinette Grise extra, I5)? (Reinette Grise Francaise, 15)? (Reinette Grise de Grandville, 15)? (Reinette Grise d'Hiver, 15)? (Rcinette toute Grise, 15)?

A little russet apple valued only because of its excellent dessert quality. Its keeping quality varies much in different seasons. In cold storage its season extends from December to February or March, and in ordinary storage, from the middle of October to January or possibly February. After midwinter it is apt to deteriorate in quality, although it may remain apparently in good condition till March or April. It has the reputation of developing particularly fine flavor when grown in the St. Lawrence valley. In New York it is seldom produced profitably in large quantities for the general market, not being attractive enough in size and color to command remunerative prices, but it is sometimes grown successfully to a limited extent for local or special trade. It is recommended for home use because of its juiciness and fine dessert quality. The tree is hardy, healthy and moderately long-lived. In favorable locations it is a pretty good bearer, the fruit hangs well to the tree and is fairly uniform in size and appearance.

The Swazie is an apple of the Pomme Grise type. It is described on a subsequent page.

Historical. The Pomme Grise or fruit of this type has long been known in cultivation among the French in the vicinity of Montreal and in other portions of the St. Lawrence valley. According to Forsyth (I7) it was introduced into England from Canada. Possibly it is identical with the Reinette Grise of Leroy (I5) but we have not had the opportunity of determining this point definitely. If it is in fact the Reinette Grise it has been cultivated in Europe for more than 250 years.

\section{TREE.}

Tree moderately vigorous. Form dense, roundish or spreading. Twigs short, straight, rather slender with large terminal buds; internodes short to medium. Bark clear reddish-brown mingled with olive-green lightly streaked with gray scarf-skin, pubescent. Lenticels clear in color, quite numerous, medium to small, generally elongated, slightly raised. Buds rather prominent, medium in size, broad, plump, obtuse to acute, free, pubescent.

\section{Fruit.}

Fruit below medium to small, fairly uniform in size and shape. Form oblate varying to roundish, sometimes inclined to conic, slightly ribbed, pretty symmetrical. Stem usually slender, much pubescent, often bracted and streaked with reddish-brown. Cavity pretty large, obtuse, deep, usually rather wide, 
often compressed or gently furrowed. Caly.x small to medium, usually closed; lobes long, narrow, acuminate, pubescent. Basin variable, pubescent, often somewhat sancer-shaped, narrow to rather wide, moderately shallow, obtuse to moderately abrupt, furrowed.

Skin moderately thick, rather tough, deep yellow or greenisin partly or entirely covered with russet. In highly colored specimens the cheek is often partly smooth and yellowish-brown mottled and striped with bright dark red. Dots gray or whitish, scattering and usually inconspicuous.

Calyx tube cone-shape. Stamens basal or nearly so.

Core medium in size, slightly abaxile; cells symmetrical, usually closed or partly so; core lines clasping. Carpels roundish, narrowing toward the apex, slightly emarginate, mucronate, smooth or slightly tufted. Seeds medium in size, plump, irregular, moderately obtuse, slightly tufted.

Flesh yellowish, firm, crisp, moderately fine-grained, juicy, rich, subacid, aromatic, very good to best.

\section{POUND SWEET.}

The apple most commonly known in Central and Western New York under the name of Pound Sweet is large, roundish, marbled with light and dark green, eventually becoming more or less yellow and conspicuously streaked over the base with whitish scarf-skin. It is in season from October to January. The name now generally accepted by pomologists for this variety is Pumpkin Sweet. It is also known by some as the Lyman Pumpkin Sweet. It is described under the name Pumpkin Sweet in the succeeding volume.

Several distinct varieties of apples have been known in cultivation under the name Pound Sweet, but so far as we have been able to discover only the one above referred to is green, all others being either more or less russeted or marked with distinct red.

\section{PRATT SWEET.}

References. I. Downing, I869:312. 2. Ragan, U. S. B. P. I. Bul., 56:24I. 1905.

Synonyms. Pratt (2). Pratt Sweet (2).

A sweet winter apple which originated on the farm of Daniel Pratt, Richland, Oswego county, N. Y. We have not seen this variety. According to Downing ( $I$ ) the tree is vigorous and annually productive; the fruit large, roundish conical, yellow striped and shaded with clear pinkish-red; the flesh is yellowish-white, breaking, tender, juicy, rich and very good in quality. So far as we can discover it is not now known among New York fruit growers, nor do we find any record of its having been grown outside of the locality of its origin. Humrickhouse, in a list of new American seedling apples pub- 
lished in 1853 , mentions a fall variety under the name of Pratt. 1 Since Pratt Sweet appears to have been but a local variety and since it was not brought to notice in New York till 1869, and since its season is given as December to March, it would seem that it is distinct from the Pratt of Humrickhouse. Ragan at first listed them as identical (2) but now considers them as "possibly identical."'2

\section{PRIESTLY.}

References. I. Coxe, I817:146. fig. 2. Thacher, 1822:132. 3. Buel, N. $Y$. Bd. Agr. Mem., 1826:476. 4. Wilson, 1828:136. 5. Kenrick, 1832:51. 6. Downing, 1845:126. 7. Horticulturist, 2:483. 1848. 8. Emmons, Nat. Hist. N. Y., 3:72. 1851. 9. Elliott, 1854:176. 10. Hooper, 1857:72. II. Warder, I867:729.

Synonyms. Priestley (3, 5, 10). Priestley's American $(6,9)$. Red Cathead (9).

Fruit medium to large, blushed or faintly striped with red. Although it ranks only fair to good in quality it is an agreeable dessert apple especially in the spring when it is fresh, juicy and rildly subacid. It is less desirable for culinary uses because it lacks acidity. The tree is a pretty vigorous grower, hardy, healthy, long-lived and comnonly bears good crops annually. The fruit hangs well to the tree. It is surpassed by standard varieties of its season and is not recommended for planting.

The following is Coxe's description of this variety: "This apple is said to be a native of the county of Bucks in Pennsylvania, where it was first cultivated by a person from whom it has obtained its name. The tree has a handsome, upright form, vigorous growth, and large leaves; it is well suited to light soils-the fruit is large, of an oblong form-the skin smooth, the colour usually a dull red, streaked faintly with green, with spots of the same colour; the flesh is white, has a pleasant spicy taste-it is an excellent table and kitchen apple; hangs late on the tree; is an abundant bearer, and makes good cider late in the season, but not of the first quality."

\section{Fruit.}

Fruit large to medium. Form roundish oblate to roundish oblong, usually quite regular and symmetrical. Stem long, usually rather slender. Cavity acute to acuminate, moderately deep to very deep, broad, russeted and with outspreading russet rays, sometimes faintly furrowed. Calyx large, usually closed, sometımes partly open; lobes connivent, erect or reflexed, broad, acute. Basin very shallow to moderately deep, wide, obtuse or somewhat abrupt, distinctly furrowed and wrinkled.

Skin tough, smooth, green or yellow washed and blushed with red and inconspicuously striped with dark carmine; highly colored specimens are nearly covered with deep red. Dots rather numerous toward basin, larger and more scattering toward cavity, gray or russet.

Calyx tube rather wide, conical. Stamens median or below.

Core medium to small, axile: cells symmetrical, closed; core lines meeting or clasping. Carpels roundish, emarginate. Seeds large, wide, flat, obtuse to somewhat acute, very dark brown. 
Flesh yellowish, firm, rather coarse, crisp, juicy, agreeable mild subacid, somewhat aromatic, medium to good in quality.

Season December to April.

\section{PRINCE ALBERT.}

References. I. Hogg, I884:I28. 2. Bunyard, Jour. Roy. Hort. Soc., I898: 356, 359. 3. Can. Hort., I2:10. 1889. 4. Garden, 64:322. 1903. fig. 5. Ragan, U. S. B. P. I. Bul., 56:172. 1905 .

Synonyms. Lane Albert (5). Lane's Prince Albert (1, 2, 3). Lane Prince Albert (5). Prince Albert (Lane) (2).

Fruit large, grass-green eventually becoming yellowish with part of the exposed cheek covered with a thin blush and splashed with bright carmine. The general appearance is rather attractive for a green apple. It is too briskly subacid in flavor for a dessert apple but is valued for culinary uses. So far as tested at this Station the tree sustains the reputation which it has gained in England of coming into bearing young and being a reliable cropper and very productive $(1,4)$. Its season has not been proved here but it evidently extends from midautumn to midwinter. Hogg gives its season as December to March. Further testing is required to determine whether it is a desirable variety for this region.

This variety is found in common cultivation in some parts of England and it is there usually called the Lane Prince Albert (4). Bunyard lists it first as Prince Albert (Lane) and afterwards as Lane Prince Albert (2). Ragan has abbreviated the name to Lane Albert (5). We prefer to follow Bunyard in calling it Prince Albert as that appears to approach more closely to the name by which it is commonly known in England.

Sharpe lists a Prince Albert of Prussia which is distinct from Prince Albert. 1

Historical. Intfoduced by H. Lane \& Son, Berkhampstead, England, and exhibited by them at a meeting of the British Pomological Society, October $26,1857(I, 4)$. The original tree was still in existence in a Berkhampstead garden in 1903 (4). In I88 I Prince Albert received a first-class certificate from the Royal Horticultural Society (2). In an article on "Progress in Fruit Culture in Queen Victoria's Reign I837-1897," Bunyard presents a list of fruits introduced into cultivation in England in the last sixty years likely to prove permanent additions which includes but ten varieties of apples and one of them is Prince Albert (2). This variety is but little known as yet in America.

\section{TREE.}

Tree very vigorous. Form spreading, rather dense. Twigs stocky, moderately long. Bark dark greenish-brown. Lenticels numerous, roundish, medium in size, conspicuous. Buds large, plump, obtuse, pubescent. Leaves large, broad; foliage dense.

\section{FrUIT.}

Fruit pretty uniformly large, sometimes very large. Form roundish somewhat flattened at the base and inclined to conic with broad obtuse ribs toward the basin, somewhat irregular. Stem medium to short, moderately thick.

${ }^{1}$ Can. Dept. Agr. Rpt., $1900: 457$ and letter, 1905. 
Cavity acute, varying from slightly obtuse to slightly acuminate, medium in depth or sometimes deep, rather broad, somewhat furrowed, frequently compressed, sometimes faintly russeted. Calyx below medium to above, closed or slightly open; lobes rather short and wide, inclined to acute. Basin usually below medium in size, often oblique, medium in depth to rather deep, rather narrow to medium in width, abrupt, irregular, deeply furrowed and wrinkled.

Skin smooth, moderately thick, tough, grass-green becoming yellowish with part of the exposed cheek shaded with red and striped with carmine, mottled and streaked with scarf-skin. Dots small, often submerged, whitish or sometimes with russet point, numerous toward the basin, larger and more scattering toward the cavity.

Caly:x tube rather short, moderately wide, cone-shape or approaching funnelshape. Stamens median to basal.

Core large to very large, abaxile; cells usually symmetrical, open or sometimes closed; core lines meeting or slightly clasping. Carpels elongated or broadly roundish, obtusely emarginate, often tufted. Secds numerous, medium or above, moderately narrow to rather wide, obtuse to acute, rather dark.

Flesh tinged with yellow or green, firm, moderately fine, crisp, tender, very juicy, briskly subacid or sour; suitable for culinary uses but has too much acidity for a good dessert apple.

\section{PRYOR.}

References. I. Kenrick, 1832:59. 2. Mag. Hort., I0:207. I844. 3. Byram, Horticulturist, 2:18. I847. 4. Rice, Ib., 4:289. I849. 5. Phoenix, Ib., 4:47I. 1849. 6. Emmons, Nat. Hist. N. Y., 3:67. 1851. 7. Horticulturist, 6:181. 1851. 8. Mag. Hort., I9:242. 1853. 9. Elliott, 1854:99. fig. 10. Downing, 1857:96. I1. Hooper, 1857:72. 12. Am. Pom. Soc. Cat., 1860. 13. Downing, Horticulturist, 16:42. I861. I4. Mag. Hort., 30:162. 1864. I5. Warder, 1867: 627. fig. I6. Fitz, I872:I43, I49, I72. I7. Leroy, 1873:780. fig. 18. Barry, 1883:352. 19. Bailey, An. Hort., 1892:247. 20. Clayton, Ala. Sta. Bul., 47:8. 1893. 21. Powell and Fulton, U. S. B. P. I. Bul., 48:52. 1903. 22. Bruner, N. C. Sta. Bul., 182:21. 1903. 23. Budd-Hansen, 1903:155. fig. 24. Ragan, U. S. B. P. I. Bul., 56:244. 1905.

Synonyms. Bersford (24). Big Hill (9, I0, 17, 24). Bonford (24). Conford (24). Pitzer Hill (9, IO, I7, 24). PRIOR's Red (10). Prior's Rcd (3, 9, 24). Prior's Late Red (24). Pryor's Pearmain (24). Pryor's Red (I, 2, 3, 4, 5, 6, 7, 8, 9, II, I3, I4, I5, I6, I8, I9). PRYOR Red (23). Pryor Red (I7, 24). Red Russet (of some 24). Rouge DE PRyor (I7).

A southern apple of good size and rich subacid flavor; in season from December to February. Although it has long been known in cultivation it is seldom found in New York orchards, which is evidence that it is not well adapted to this region ( 13 ).

Historical. This is said to have originated in Virginia (4, I2). Hooper remarks that "it varies much in its appearance, being sometimes green russeted, then sometimes dull orange-russet with a trace of red, and again deeply red or striped, and sometimes almost black with depth of color" (II). Warder ( 15 ) remarks "it is singularly affected by change of soil and climate; thus, on the Ohio River, it is seen quite flat and regular, with a dull green 
russeted skin, becoming yellow and ruddy; in one part of the state of Indiana, on limestone, it is gibbous, round, often very large, and covered with a rich cinnamon russet, while on the coal measures, west of the center of the state, it is smaller, regular, and distinctly striped deep red on red, with very little russet. Specimens from Rochester, New York, have been shown with scarcely a trace of russet, and having the stripes as distinct and almost as beautiful as those of a Dutchess of Oldenburgh, so that no southern or western man would have recognized it for his home favorite. The distinctive ieathercracking about the eye was present, however, in all."

\section{TREE.}

The tree as described by Byram (3), Warder (15), Downing (10, 23), Rice (4), and others attains large size and is productive when old, requiring a deep, rich soil and a warm season or southern climate for its proper development. Form upright, somewhat spreading, twiggy; branches sometimes form peculiarly acute angles. Taigs slender, clear reddish-brown with some olivegreen. Lenticels large, conspicuous, gray. Foliage scattering, folded, grayishgreen, subject to leaf-blight.

\section{FrUit.}

The following description of the fruit is taken from Byram (3), Elliott (9), Downing (Io), Hooper (II), and Warder (15).

Fruit medium to large. Form variable but usually roundish oblate; axis often oblique and sides unequal. Stem short, thick to moderately thick. Cavity small, acute to acuminate, often lipped, russeted and with some outspreading brownish-russet. Caly.x small, closed. Basin small, shallow, regular.

Skin thick, greenish to brownish-yellow tinged with dull red, rather indistinctly striped with dark crimson, slightly russeted. Dots numerous, large, gray or greenish.

Core closed; core lines meeting. Sceds numerous, angular, acute.

Flesh yellowish-white, tender, fine-grained, juicy to rather dry, subacid, very good to best.

Season December to March.

\section{RALLS.}

Refrerences. 1. Cat. Hort. Soc. London, 1831:22. 2. Kenrick, 1832:59. 3 . Mag. Hort., I:149. 1835. 4. Hovey, Ib., 10:207. 1844. 5. Byram, Horticulturist, 2:19. 1847. fig. 6. Springer, Ib., 2:147. I847. 7. Ib., 2:291, 388, 483. 1847. 8. Mallinckrott, Ib., 3:369. I848. 9. Phoenix, Ib., 4:470. I849. Iо. Cole, 1849:136. fig. I1. Thomas, 1849:170. 12. Emmons, Nat. Hist. N. Y., 3:63. 185I. 13. Elliott, 1854:100. fig. I4. Downing, 1857:99. I 5. Hooper, 1857:75. I6. Mag. Hort., 26:102. I860. I7. Ib., 27:101. 1861. 18. Ib., 27: 262. I86r. 19. Am. Pom. Soc. Cat., 1862. 20. Mag. Hort., 30:162. 1864. 21. Warder, 1867:517. fig. 22. Downing, 1869:321. fig. 23. Howsley, Am. Pom. Soc. Rpt., 1871:74. 24. Fitz, 1872:141, 143, I47, I49, 156, 165, 175, I77. 25. Leroy, 1873:713. 26. Downing, I88I: I i index, app. 27. Barry, 1883:353. 23. Wickson, 1889:248. 29. Lyon, Mich. Hort. Soc. Rpt., 1890:296. 30. Bailey, An. Hort., 1892:242. 31. Ib., 1892:2.47. 32. Mathews, Ky. Sta. Bul., 50:32. 


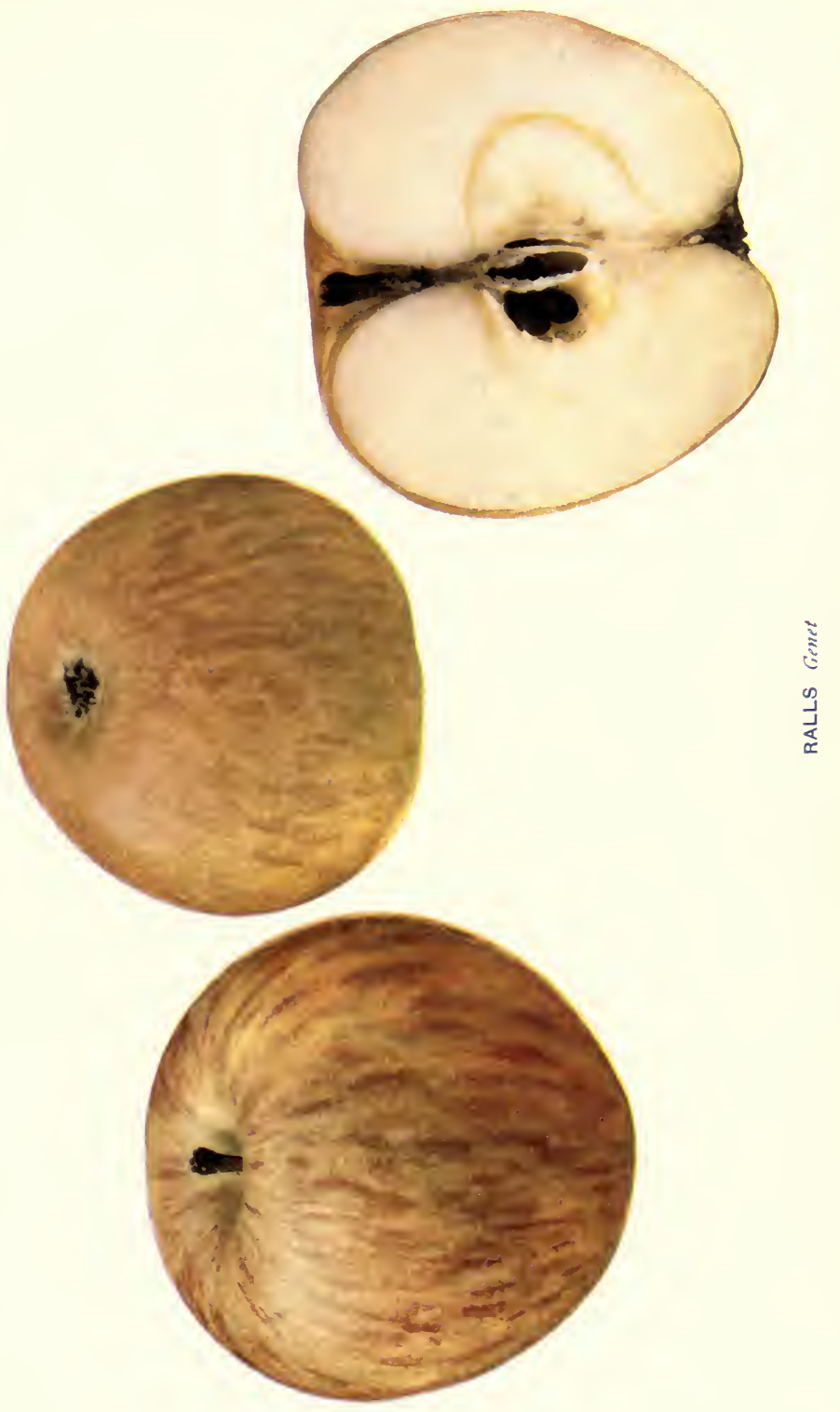



1894. 33. Taylor, Am. Pom. Soc. Rpt., r895:198. 34. Heiges, Mechan's Monthly, 6:136. 1896. 35. Gard. and For., 9:310. 1896. 36. Munson, Me. Sta. An. Rpt., 18:95. 1902. 37. Hansen, S. D. Sta. Bul., 76:88. 1902. 38. Stinson, Mo. Fr. Sta. Bul., 3:27. 1902. 39. Powell and Fulton, U. S. B. P. I. Bul., 48:53. 1903. 40. Budd-Hansen, 1903:156. fig. 41. Bruner, N. C. Sta. Bul., 182:27. 1903. 42. Beach and Clark, N.Y.Sta. Bul., 248:139. 1904. 43. Ragan, U. S. B. P. I. Bul., 56:10. 1905.

Synonyms. Genet (23). Gencton (21, 23). Geniton (8). Geniton (39). Gennetin (4). Genneting (14). Gennetting (42). Ginet (23). Indiana Jannetting ( $13,14,22)$. JANET (30). Janct (31, 37, 40, 41, 42). Janetting (21). Jefferson Pippin $(23,26)$. Jeniton $(22,27,37,38)$. Jennett (14, 22). Jennette (13). Jenniton (42). Missouri JANET (I8). Missouri Janet? (22). Never Fail (21). Neverfail (4, 6, I I, I2, 13, 14, 15, 22, 33, 37, 39, 40, 4I, of Ohio 10). Ralls Genet $(33,35,37,40,41)$. Ralls Genet (39, 42). Ralls Janet (36). Raule Jannet (12). Raule's Genet (24). Raule's Janet (13, I5). Raule's Janett (5). Raule's Janette (10). Raule's Jannet (14). Raule's Jannette (13). Raule's Jannetting (14, 22). Raule's Jeniletting (io). Raul's Gennetting $(6,22)$. Raul's Gennetting (13). Rawle's Genet $(23,24,26)$. Rawle's Genet (22). Rawle's Janet (9, 16, I7, 20, 21, 22, 27, 28, 29, 31, 32, 38). Raucle's Janct (30, 35). RAwle's JANETT (2,3). Rawle's Jannet (11). Rawle's Jannet (22). Rawle's Jennet (8). Rawle's Jenneting (II). Rawle's Jennette (13). Rawl's Janct (13). Red Neverfail? (22). Rockremain (12). Rockremain (6, II). Rock Remain (13, 14, 22). Rockrimmon (10). Rock Rimmon (13, 14, 21, 22). Royal Janette (33). Winter Genneting (13). Winter Jannetting (14,22). Yellow Janette (13). Yellow Janett (14, 22).

Ralls, although a southern variety, often develops pretty good quality when grown as far north as Western New. York and Southern Michigan. As grown here it seldom reaches marketable size unless it is thinned and it is rather dull in color being at the best only moderately attractive but it has the merit of being a good keeper and holds its flavor well till late in the season. In ordinary storage it is in season from December to May with April as the commercial limit (42).

In districts farther south and west and, generally speaking, throughout the Ben Davis apple regions it produces fruit of superior quality, is generally held in high esteem for home use and has a recognized standing in market. It has there been cultivated extensively either under the common names of Jeniton or. Ralls Janet or under some variation of these names. It has also been grown to a limited extent under the names Neverfail and Rock Rimmon. The younger trees frequently bear annually and yield fruit of fairly good size but with increasing age the trees often become biennial or occasional croppers and in bearing years are apt to be so overloaded 
that the fruit is small. On account of the lateness of its blooming season Ralls frequently sets a good crop of fruit when earlier blooming varieties fail on account of unfavorable weather during the blossoming season.

Ralls is but little known among New York fruit growers and is not recommended for planting in this state.

Historical. The first that is definitely known of this variety is that trees of it were growing on the farm of Mr. Caleb Ralls in Amherst county, Virginia, something over a hundred years ago. There is no evidence to show whether it was a local seedling or an importation from some other section. Howsley (23) states that it was brought from France to President Jefferson by M. Genet at that time the minister from that country. This claim does not seem to have been made in print till about one hundred years after the time of its alleged occurrence and as there are no records to verify it, its truth seems problematical. We regard it as probably a Virginia seedling. Spreading from Virginia it has come into more or less common cultivation southward into the Carolinas and Georgia, northward into Southern Michigan and westward across the Mississippi valley to and beyond the Ozarks, but it remains practically unknown among New York fruit growers.

\section{TREE.}

Tree medium in size, moderately vigorous. Form upright becoming spreading and inclined to droop, dense. Twigs short, curved, moderately stout; internodes short. Bark dull brown mingled with olive-green, lightly mottled with scarf-skin, slightly pubescent. Lenticels numerous, small, oblong, not raised. Buds medium in size, broad, plump, obtuse, free or nearly so, slightly pubescent.

\section{FRUIT.}

Fruit below medium to above, pretty uniform in size and shape. Form roundish oblate varying to roundish inclined to conic, rather symmetrical. Stem often long and slender. Cavity obtuse to acute, deep, sometimes compressed or somewhat furrowed, often russeted. Calyx small to medium, usually somewhat open. Basin often a little oblique, wide, rather shallow to moderately deep, inclined to abrupt, wrinkled.

Skin smooth, yellow or greenish blushed and mottled with pinkish red, indistinctly striped with dull carmine, overspread with a light bloom which together with broken stripes of thin whitish scarf-skin combine to give the fruit a rather dull appearance. Dots numerous, small, whitish or russet.

Calyx tube broad cone-shape or frequently funnel-shape. Stamens marginal or nearly so.

Core medium in size, axile or slightly abaxile; cells closed or partly open; core lines meeting or slightly clasping. Carpels rather flat, broadly roundish, emarginate, slightly tufted. Seeds medium or above, narrow, plump, acute, dark.

Flesh whitish, firm, moderately fine-grained, crisp, moderately tender, juicy, subacid with a slight mingling of sweet, aromatic, pleasant, very good for dessert. 


\section{RAMBO.}

References. I. Dom. Ency'c., 1804. (cited by 40). 2. Coxe, I8r7:1i6. fig. 3. Thacher, I822:134. 4. Buel, N. Y. Bd. Agr. Mem., I826:476. 5. Wilson, 1828:136. 6. Fessenden, 1828:131. 7. Cat. Hort. Soc. London, 1831:28. 8. Kenrick, I832:37. 9. Manning, Mag. Hort, 7 :49. I84I. Io. Downing, I845: 93. fig. I1. N. Y. Agr. Soc. Trans., I846:191. fig. I2. Elliott, Horticulturist, I:388. I847. 13. Kirtland, Ib., 2:544. I848. I4. Thomas, I849:I5I. I5. Cole, 1849:1 16. fig. I6. Phoenix, Horticulturist, 4:472. 1850. I7. Humrickhouse, Mag. Hort., 15:28. I849. fig. I8. Emmons, Nat. Hist. N. Y., 3:29. I851. Ig. Elliott, I854:102. fig. 20. Horticulturist, 10:87. 1855. 21. Am. Pom. Soc. Cat., 1856. 22. Hooper, 1857:73. 23. Ib., I857:74. 24. Gregg, 1857:57. 25. Horticulturist, I3:144. I858. 26. Mag. Hort., 30:162. I864. 27. Warder, 1867: 454. fig. 28. Downing, I869:3I9. fig. 29. Fitz, I872:163. 30. Barry, 1883:352. 31. Hogg, 1884:184. 32. Wickson, I889:245. 33. Lyon, Mich. Hort. Soc. Rpt., 1890:296. 34. Bailey, An. Hort., 1892:247. 35. Mathew's, Ky. Sta. Bul., 50: 32. 1894. 36. Burrill and McCluer, Ill. Sta. Bul., 45:337. I896. 37. BuddHansen, I903:I58. fig. 38. Powell and Fulton, U. S. B. P. I. Bul., 48:53. I903. 39. Beach and Clark, N. Y. Sta. Bul., 248:140. I904. 40. Ragan, U.S. B. P. I. Bul., 56:247. 1905.

Synonyms. American Seek-No-Further (7). Bread and Chcese (27, 40, of New Jersey 18). Bread and Chcese Apple (2, 19, 28, of New Jersey ro, 15 and 17). Delaziare $(28,40)$. Fall Romanite $(28,40)$. Gray Romanite (28, 40). Large Rambo? (28, 40). Rambo (5). Rambouillct (28, 40). Rambovlettf. (23). Ramboulctte? (40). Romanite (5). Romanite (2, 4, 7, 8, 15, 19, 28, 40, of New Jersey 10, 14, 17, I8 and 27). Seek-No-Farther (19, of Philadelphia 2). Seek-No-Further (4, 28, 40, of New Jersey Io, I7

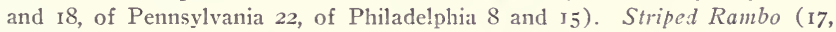
28, 40). Terry's Redstreak ( $19,28,40)$. Trumpington (40, ? 28 ).

The accompanying plate shows the whole fruit of Rambo. The section is shown on the same plate as that which shows the whole fruit of Walbridge.

This fruit belongs in the same group as the Domine. Downing states $^{1}$ that "Domine so much resembles the Rambo externally, that the two are often confounded together, and the outline of the latter fruit may be taken as nearly a facsimile of this. The Domine is, however, of a livelier color, and the flavor and season of the two fruits are very distinct,- the Rambo being rather a high-flavored early winter or autumn apple, while the Domine is a sprightly, juicy, long-keeping winter fruit." Rambo when well grown is an apple of excellent quality but in this state it does not take first rank for any purpose. It is less attractive in size and color and less desirable for market than Baldwin or Northern Spy. For culinary

${ }^{1}$ Downing, 1869 : 147. 
uses it is easily surpassed by Rhode Island Grccining and for dessert by Tompkins King, Hubbardston and other apples of Rambo season. When well colored it is rather attractive, the prevailing color being a good bright red which forms a pleasing contrast with the yellow ground color. Very often, however, the red color is not predominant and the fruit is rather dull and not particularly attractive. Often a considerable portion of the fruit does not reach good marketable size, particularly when borne on old trees that are overloaded. The tree is less hardy than some standard varieties of this region and in unfavorable locations it is sometimes more or less injured by winter. It seems to do particularly well on rather light, rich soils, either sandy or of limestone formation with well-drained subsoil. The wood is rather brittle and the trees often break with heavy crops.

Warder (27) says that "It is a fall and early winter fruit, and some pomologists on the southern borders of its culture object to it that it will not keep long, and that it soon becomes dry and mealy when put away. When grown further north it is smaller, but more solid, and remains juicy until spring. It should be gathered early, even before it is well colored, and kept cool to make it retain its flavor and juiciness."

As grown at this Station its commercial limit appears to be November, although some of the fruit may be kept till March in apparently good condition. Storage men give its season as extending in cellar storage to November and in chemical cold storage to February. It does not stand heat well before going into storage and goes down quickly, losing in quality and firmness, shriveling, becoming mealy and bursting (39). It was formerly grown to some extent for market in some portions of the state but during the last half century it has gradually lost ground in competition with other better conmercial sorts. It is not now recommended for planting in commercial orchards in New York, but on account of the agreeable dessert qualities of the fruit it will doubtless continue to be grown to a limited extent for home use.

Historical. Origm unknown. In I8I7 Coxe (2) remarked that it was much cultivated in Delaware, Pennsylvania and New Jersey. The extent of its cultivation at that time indicates that it must have originated at least fifty years previous to that date. According to Coxe it takes its name from the 


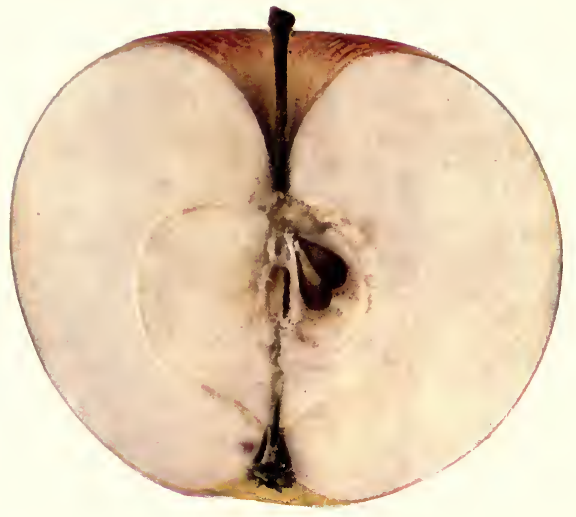

WALBRIDGE

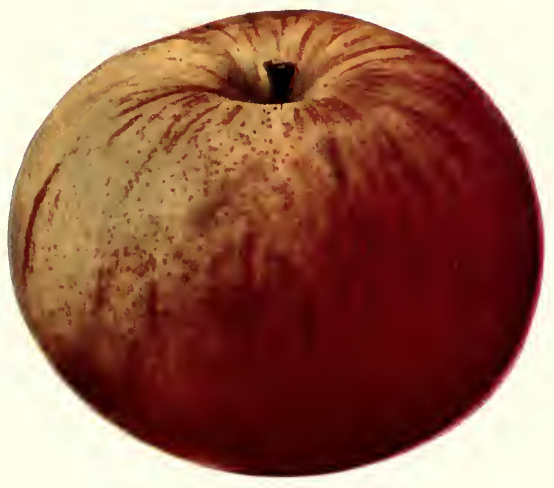

RAMBO 

families by whom it was brought into notice (2). It was introduced into Ohio by the early settlers from Pennsylvania and its cultivation gradually spread westward with the tide of emigration (27). In many localities in the central portion of the Mississippi valley it is still a favorite fruit. Wickson (32) says that on the Pacific Coast it has failed to sustain the reputation which it gained in the East. Generally speaking, it appears to be less popular and certainly less widely planted to-day than it was a quarter of a century ago.

\section{TREE.}

Tree medium size, moderately vigorous to vigorous. Form upright spreading, open. The old bark is peculiarly rough. T wigs medium to long, moderately stout, broad; internodes medium. Bark brownish-red mingled with olive-green, lightly blotclied and irregularly streaked with scarf-ski11, slightly pubescent. Lenticels numerous, small to medium, round, not raised. Buds medium, broad, plump, obtuse, free or nearly so, slightly pubescent.

\section{FrUIT.}

Fruit medium or sometimes large, often averaging no more than medium size, pretty uniform in size and shape. Form usually roundish and somewhat oblate but varies to roundish oblong approaching truncate, symmetrical, usually regular but sometimes faintly ribbed. Stem short to medium in length, rather slender. Cazity pretty regular, moderately wide, rather deep, acute or acuminate, sometimes smooth but usually with some outspreading russet. Caly.x small to medium, usually closed; lobes medium to long, rather narrow, acute to acuminate. Basin wide, moderately deep, rather abrupt, often furrowed and somewhat wrinkled.

Skin thin, a little tough, smooth or slightly roughened with russet dots, pale greenish-yellow, mottled with red, striped with carmine and overspread with grayish bloom. Dots conspicuous, rather large, whitish, gray or russet. In highly colored specimens the red is predominant.

Calyx tube funnel-form, rather long with wide limb. Stamens median to marginal.

Core medium to small, axile; cells closed; core lines clasping. Carpels roundish to broadly obovate, emarginate, slighly tufted. Seeds medium to rather large, broad, rathcr flat, obtuse, slightly tufted, light and dark brown.

Flesh whitish with tinge of yellow or green, firm, rather fine, very crisp, tender, juicy, mildly subacid, aromatic, good to very good. Particularly desirable for dessert.

\section{RED CANADA.}

References. I. Thacher, r822:131. 2. Fessenden, 1828:131. 3. Manning, Mag. Hort., 7:47. I84I. 4. Hovey, Ib., I3:75. 1847. fig. 5. Watts and Downing, Horticulturist, $\mathbf{I}: 482$. 1847. 6. Downing, Ib., 2:289. I847. 7. Hovey, Mag. Hort., I4:I24. I848. 8. Horticulturist, 2:483, 544. I848. 9. Thomas, 1849:I7I. fig. Io. Cole, 1849:127. Ir. Emmons, Nat. Hist. N. Y., 3:ror. I851. col. pl. No. 42. 12. Am. Pom. Soc. Cat., 1852. 13. Mag. Hort., 19:68. 1853. 14. Elliott, 1854:102. fig. I5. Hooper, I857:76. I6. Downing, 1857:97. fig. 17. Warder, 1867:542. I8. Regel, 1868:465. I9. Barry, 1883:353. 20. Wickson, 1889:247. 21. Lyon, Mich. Hort. Soc. Rpt., 189o:296. 22. Bailey, An. Hort., 1892:247. 23. Amer. Gard., 20:104. 1899. 24. Budd-Hansen, r903:161. 
fig. 25. Powell and Fulton, U. S. B. P. I. Bul., 48:53. 1903. 26. Beach and Clark, N. Y. Sta. Bul., 248:140. 1904.

Synonyms. Bristol of some. Canada Red (25). Canada Redstreak (26). Nonesuch (2). Nonsuch (1, 3, 8, 13). Nonsuch (9). Old Nonsuch (7, 10). Old Nonsuch (6, 9, 14, 15, 21, of Massachusetts 8 and 16). Red Canada (13, of Western New York 8 and 10). Red Winter (26). Richfield Nonsuch (10, II, I4, I5, 16, I9, of Ohio 9). Steele's Red Winter (20, 24, 25, 26, of Michigan 16). Steel's Red (17). Winter Nonsuch (10). Not the Canada Red of some portions of Ontario. See Roseau, page 292.

This is a red winter apple which belongs in the same group with Baldwin and Esopus Spitzenburg. When well grown and in prime condition it is one of the best apples of its season for dessert use on account of its desirable size, attractive form and color and superior quality. It is well adapted to either general or special markets and often brings more than average prices. The quality of the fruit varies much in different seasons and in different localities. When grown on heavy clay soils its quality in some seasons is decidedly inferior to that of Baldwin and would be rated only fair to good; but when grown on certain fertile soils of a gravelly or sandy nature in favorable seasons it develops color, flavor and quality fully equal to that of Esopus Spitwenburg. It stands heat well before going into storage and goes down gradually (26). Its season is somewhat variable. The commercial limit in ordinary storage is January or February, and in cold storage, April. Its season for home use usually extends from November to March or later. Although the fruit may remain apparently sound it is apt to lose much of its high flavor after midwinter. The tree is somewhat lacking in liardiness and is but a moderate grower. It should be top-worked on some hardier and more vigorous variety such as Baldwin or Northern Spy. In some cases it is an annual bearer but more often it is not a sure cropper.

Waugh recognizes Roseau as the correct name for an apple which is commonly known in Ontario under the name of Canada Red. It is quite distinct from the variety above described. ${ }^{1}$ For further consideration of this matter the reader is referred to Roseau, page 292.

Historical. This variety probably originated in New England but its origin is obscure. Thacher (I) in 1822 described it under the name Nonsuch and later Fessenden (2), Manning (3), Hovey (7) and other New England writers

\footnotetext{
${ }^{1}$ Can. Hort., 18:184. 1895. Waugh, Rural N. Y., 62:143. 1903. Rural N. Y., 62:238,
282. 1903.
} 


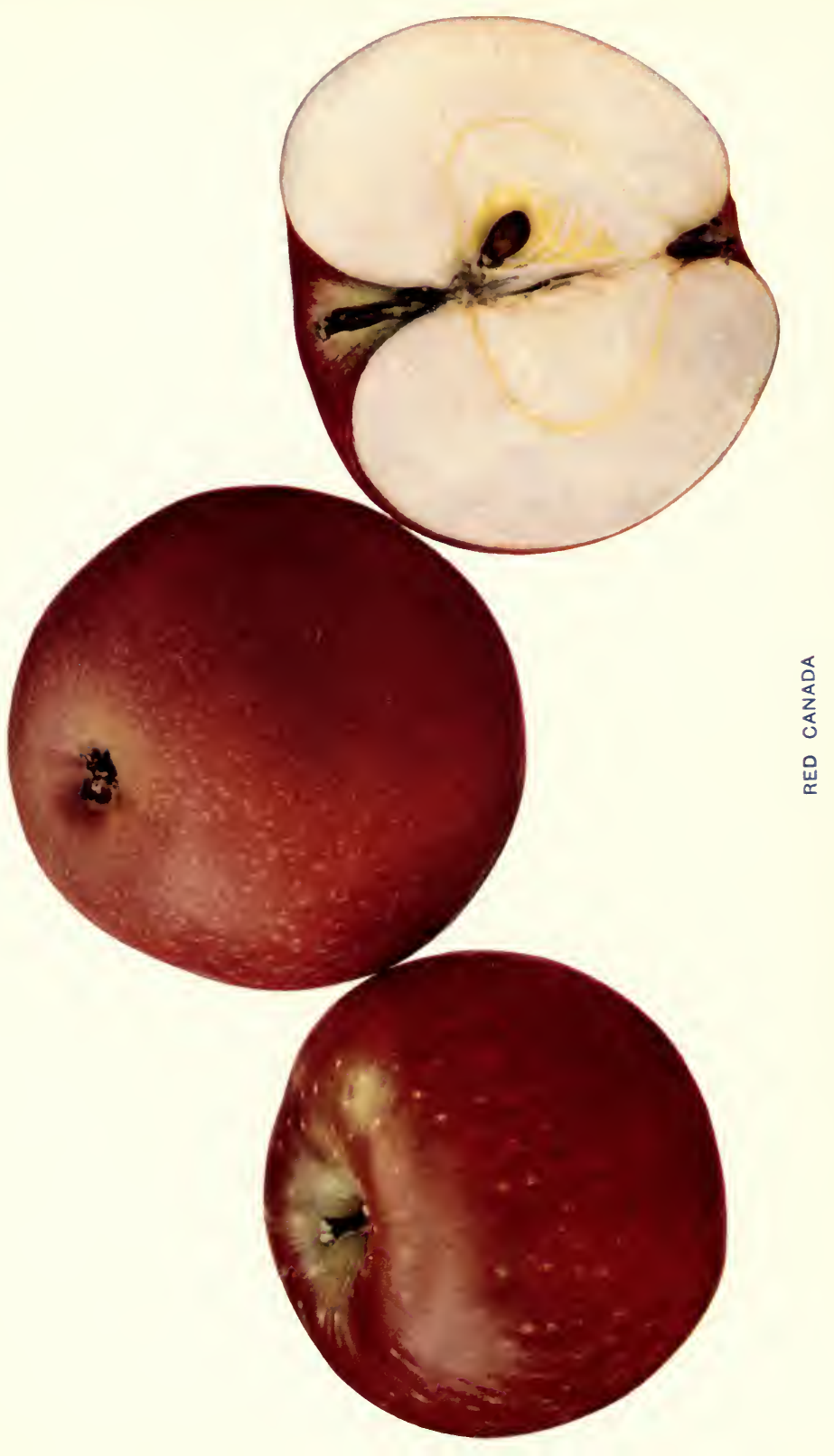



recognized this name for the variety. In 1849 Cole (Io) described it as the Old Nonstcl. It appears to have been brought into Western New York from the vicinity of Toronto, Canada, and afterwards cultivated in this region under the name Canada Red. The earliest mention we find of the variety under the name Red Canada or Canada Red, as these names appear to have been used interchangeably, is that of Watts and Downing in I847 (5). In Michigan it has been often cultivated under the name of Steele's Red Winter. In some portions of Eastern New York it is grown under the name Bristol. It has been pretty generally distributed throughout the state. In some few localities its cultivation in commercial orchards is increasing but seldom has it been planted to any considerable extent, and, generally speaking, it is found only in old orchards.

\section{TREE.}

Tree medium to large, moderately vigorous to vigorous; branches short, stout, curved, crooked. Form upright to roundish, rather dense. Twigs medium in length, straight or nearly so, rather slender to moderately stout; internodes below medium to long. Bark olive-green tinged with reddishbrown, netted or streaked with thin scarf-skin, slightly pubescent. Lenticels scattering, not very conspicuous, small, round, slightly raised. Buds prominent, large to medium, long, narrow, plump, acute, free or nearly so, slightly pubescent. Leaves medium to broad, rather thin.

\section{FrUit.}

Fruit medium to nearly large, pretty uniform in size and shape. Form roundish inclined to conic and somewhat flattened at the base, nearly symmetrical and pretty regular but sometimes elliptical or obscurely ribbed and with sides a little unequal. Stem medium to rather slender, pubescent. Cavity usually large, acuminate, deep, wide, often partly russeted and with radiating green or russet rays, usually symmetrical, sometimes slightly furrowed. Calyx small, closed or partly open, pubescent. Basin small, usually narrow, shallow to moderately deep and rather abrupt, furrowed and sometimes slightly wrinkled, often somewhat oblique.

Skin tough, nearly smooth especially toward the cavity, slightly rough about the basin, rather clear light yellow or green largely overspread in well-colored specimens with a fine deep red blush, indistinctly striped with deeper red. Dots conspicuous, grayish or fawn colored. Toward the cavity they are scattering, large and often elongated as in Baldwin and Esopus Spitzenburg, but as they converge toward the apex they becone more numerous and smaller. Prevailing effect very attractive bright deep red.

Calyx tube elongated cone-shape or somewhat funnel-form. Stamens marginal.

Core sessile, axile or nearly so, medium to rather small; cells symmetrical, closed or slit; core lines clasping. Carpcls usually smooth, roundish, narrowing somewhat toward the apex, mucronate, but slightly emarginate if at all. Secds very numerous, medium to rather large, angular, long, moderately wide, plump, obtuse.

Flesh whitish with yellow or greenish tinge, firm, crisp, rather fine-grained, tender, juicy, aromatic, rich, agreeably subacid but becoming rather too mild toward the close of the season, good to best. 


\section{RED RUSSET.}

References. r. Cole, r849:131. 2. Emmons, Nat. Hist. N. Y., 3:95. I851. 3. Hovey, Mag. Hort., I9:125. 1853. 4. Downing, 1857:97. 5. Hovey, Mag. Hort., 29:260. 1863. fig. 6. Warder, I867:628. 7. Thomas, I875:229. 8. Barry, 1883:353. 9. Can. Hort., Ir:283. I888. 1о. Lyon, Mich. Hort. Soc. Rpt., 1890:296. I1. Bailey, An. Hort., 1892:247. 12. Maynard, Putnam and Fletcher, Mass. Hatch. Sta. Bul., 44:4. I897. 13. Powell and Fulton, U. S. B. P. I. Bul., 48:53. 14. Beach and Clark, N. Y. Sta. Bul., 248:140. I904.

This is one of the russet Baldwins referred to on page 59. It originated as a sport on a Baldwin tree on the farm of Mr. Aaron Sanborn, Hampton Falls, N. H., about 1840 . It was introduced to notice by Cole in $1849(1,3)$. It is distinct from the Red Russet of Hooper ${ }^{1}$ which is the Golden Pearmain of Elliott ${ }^{2}$, Downing ${ }^{3}$ and other pomological writers. Instances are known where it has borne smooth fruit intermingled on the same twigs with russet fruit. ${ }^{4}$ The Red Russet is almost universally considered less valuable than Baldwin both by fruit growers and fruit dealers. It is known in many parts of New York but is nowhere planted extensively and is gradually going out of cultivation.

For a technical description of the tree and fruit the reader is referred to the description of Baldwin on page 59.

\section{REDSTREAK.}

References. I. Forsyth, I803:56. 2. Coxe, I8I7:157. fig. 3. Thacher, I822: 133. 4. Forsytl, 1824:123. 5. Wilson, 1828:136. 6. Floy-Lindley, 1833:8I. 7. Downing, 1845:146. 8. Thomas, 1849:171. 9. Cole, r849:137. ro. Emmons, Nat. Hist. N. Y. 3:74. I851. fig. II. Townley, Horticulturist, 6:496. I851. 12. Elliott, I854:177. I3. Warder, I867:718. I4. Fitz, I872:147, I59. I5. Leroy, I873:781. fig. I6. Pa. Fr. Gr. Soc. Rpt., 1881:65. I7. Hogg, I884:188.

Synonyms. English Red Streak (i6). English Redstreak (io, 13). Herefordshire Red Streak (7, 12). Herefordshire Redstreak (15, 17). Johnson (I7). ReD STREAK (1, 3, 4, 7, 9, II, I2, 17). Red Streak (15). Rouge Rayée. (15). Scudamore's Crab (7, 15, I7). Scudamous Crab (12).

An English cider fruit formerly cultivated extensively in some portions of New York but now practically obsolete here. Downing (7) remarks that it is a capital English cider apple which thrives admirably in this country and is very highly esteemed as it makes a rich, high-flavored, strong liquor, and the tree is a handsome grower and a great bearer. He describes the fruit ( 7 ) as of medium size, roundish, with small calyx, rather deep basin, rather slender, short stem; skin streaked with rich red anc with a few spots and streaks of yellow; flesh yellow, rich, firm, dry, good.

Coxe published the following description of it in 1817 (2). "This tree was originally brought from England, where it possessed a ligh reputation as a

\footnotetext{
'Hooper, 1857:78.

${ }^{2}$ Elliot1, $1854: 171$.

${ }^{3}$ Downing, $1869: 194$.

At the meeting of the Ohio State Horticultural Society December, 1903, Mr. H. H. Aultfather exhibited samples of russeted Red Russet and smooth-skinned Red Russet grown by Mr. W. P. Myers, Minerva, Ohio. Fruits of the two types grew on different parts of the tree and were intermingled on the same twigs.
} 

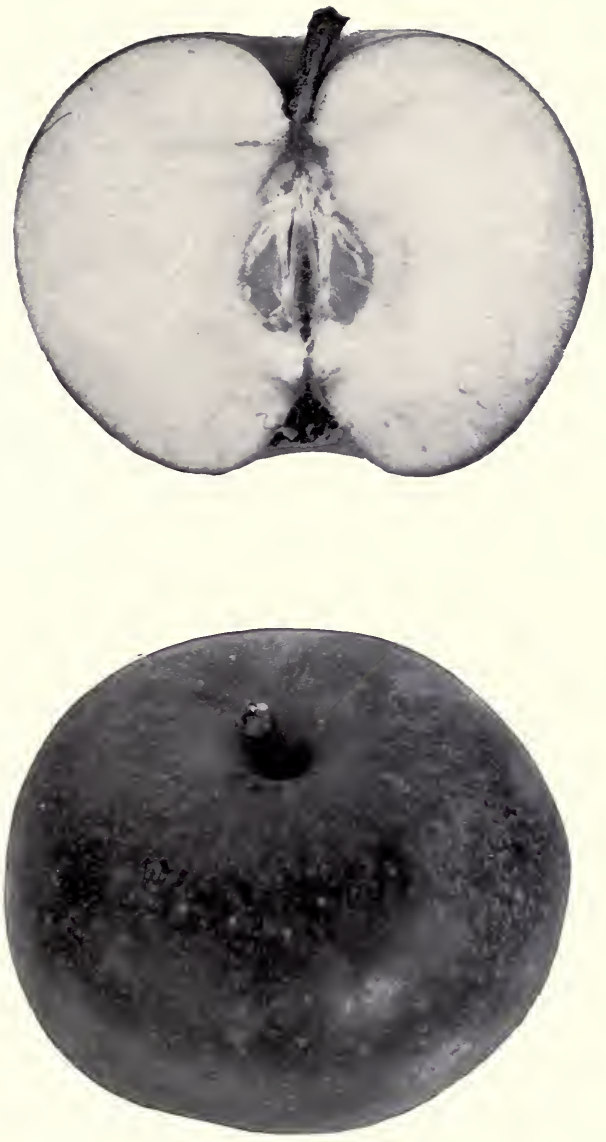

RED RUSSET 

cider fruit; it has been cultivated extensively in this country, by the descendants of the English settlers in New York, New Jersey and Pennsylvania. The climate of America is supposed to have revived the character of this apple, which had deteriorated in its native soil, from the long duration of the variety-the fruit is rather small; the form is oblong, fattened at both ends, the stem and crown both sunk-the skin is red, faintly streaked and spotted with yellow-the flesh is yellow, rich, firm, and dry; it hangs late, and requires to be matured by housing to make the finest cider. The character of the cider, when properly made and fined, is very high, both for strength and flavour-the apple keeps well through the winter, and is much esteemed as an excellent kitchen fruit in the latter part of the winter. The tree is of handsome, regular growth, and a great bearer; the opinion of dealers is, that this cider is difficult to fine fit for bottling: when perfectly cleared, it ranks among our first fruit liquors."

\section{RED WINTER PEARMAIN.}

REFERENCES. I. Elliott, I854:141. fig. 2. Elliott, I854:115. fig. 3. Downing, 1857:182. 4. Downing, 1869:329. fig. 5. Ill. Hort. Soc. Rpt., 1870. 6. Ragan, U. S. B. P. I. Bul., 56:256. 1905 .

Red Winter Pearmain is not now accepted by pomologists as the correct name of any apple but it is recognized as a synonym for several different varieties. The following is a list of synonyms as corrected by Ragan (6).

Red Winter Pearmain $(3,4)$. Synonym of Buncombe.

Red Winter Pearmain ( $\mathrm{I})$. Synonym of Long Red.

Red Winter Pearmain (5). Synonym of Milam.

Red Winter Pearmain (2). Synonym of Westfield Seek-No-Further.

\section{REINETTE.}

The term Reinette, as designating a certain class of apples, has been introduced into English from the French. Leroy ${ }^{1}$ tells us that French horticultural literature shows that the word has been in use atout four hundred years. Starting in with only one variety of this name the number has gradually increased until to-day there are several hundred. Leroy thinks they are all descended from the or ginal variety, the Reinette franche or Reinette Blanclee, which is the French Reinette of Downing. ${ }^{2}$ The derivation of the word is a disputed point, certain etymologists holding that it is the diminutive form of Reine, or queen, and others thinking that it is a corruption of Rainet, a colloquial French word meaning a small frog. While European pomologists spea': of t':e Reinettes as a distinct type, an examination of the technical descriptions of the various

\footnotetext{
${ }^{1}$ Leroy, $1873 \cdot 6$ i 4 .

${ }^{2}$ Downing, $1869: 184$.

VOL. I - I2
} 
Reinettes does not show that they have any constant characters which are in any way peculiar to themselves. Diel gives the following eight characters by which Reinettes can be recognized. ${ }^{1}$

“I. They have a fine-grained, delicate, crisp, firm flesh.

"2. They are mostly the ideal of a handsomely shaped apple; in them the convexity or bulge of the middle of the apple towards the eye is the same as that towards the stalk, or not much different.

“ 3. They are all gray dotted, or have russety patches, or completely covered with russet.

"4. They have rarely an unctuous skin.

" 5. They have all the rich, aromatic, sugary, and brisk flavor, which is called the Reinette flavor.

“ 6 . They decay very readily, and must, of all apples, hang longest on the tree.

“7. The really sweet and at the same time aromatic apples belong to the Reinettes, only as regards their shape, their character, and their fine and firm flesh.

"8. Apples with fine, firm, crisp flesh, which cannot of themselves form a distinct class; for instance, the Pippins belong to this class."

This classification of Diel is evidently an arbitrary one and differs in spirit at least from the conception of Leroy that the Reinettes represent one family descended from a single original variety.

\section{REINET'TE PIPPIN.}

References. I. Downing, I869:332. 2. Leroy, 1873:724. fig. 3. Powell and Fulton, U.S. B. P. I. Bul., 48:54. I903. 4. Beach and Clark, N. Y. Sta. Bul., 248:140. I904.

Synonyms. Reinette Pepin (2). Reinette Pippin (2).

Fruit pretty uniform in size but often a little unsymmetrical with sides unequal. It is green in autumn but eventually becomes more or less tinged with pale yellow. It is an uncertain keeper in storage. It sometimes keeps well till midwinter but it often shows a high rate of loss during November. Early November is the common commercial limit for handling this variety in ordinary storage, although its season extends from October to March. The commercial limit in cold storage appears to vary from February first

W Warder, 1867:370. 

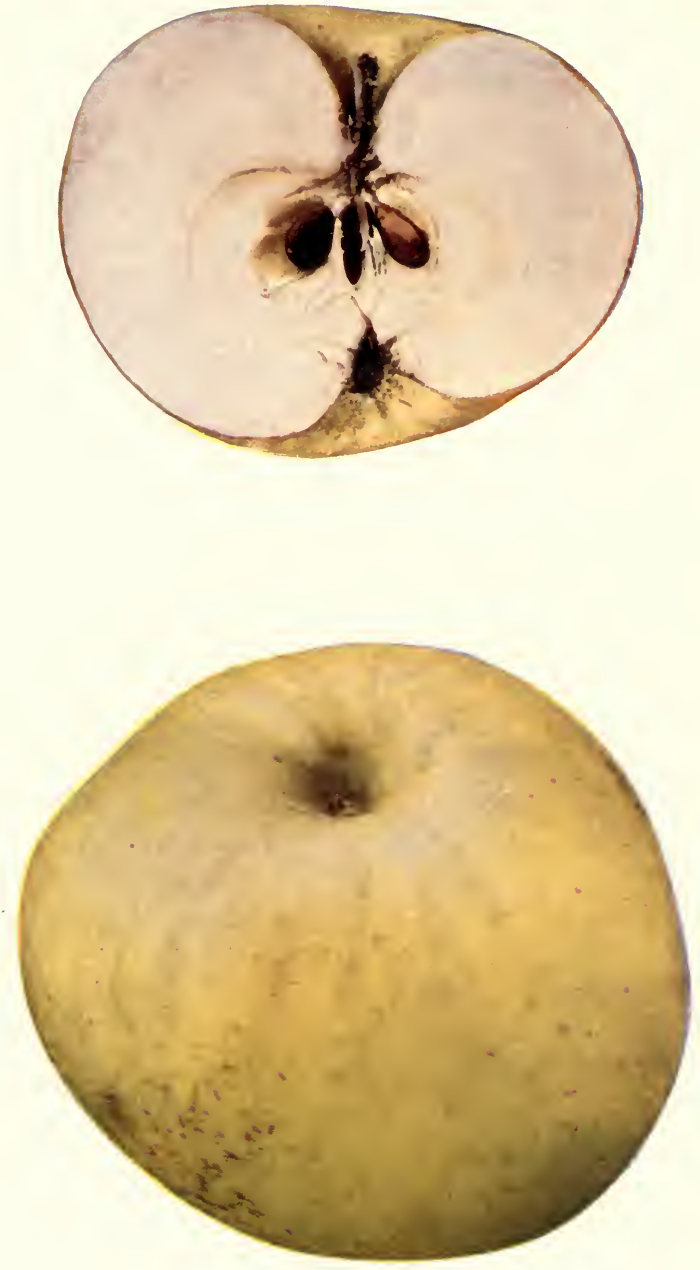

REINETTE PIPPIN 

to March first. As grown at this Station the tree is healthy, strong and a reliable cropper, yielding moderate to heavy crops annually. In fact it is one of the most productive of the varieties thus far tested here, often bearing so heavily that a considerable portion of the fruit is below medium size. Although Reinette Pippin is excellent in quality, Rhode Island Greening surpasses it for culinary use as it also does in size and symmetry.

Historical. This variety originated in France where it has been known in cultivation for more than one hundred years (2). It appears to be but little known in this country.

\section{TREE.}

Tree medium to rather large, vigorous; branches short, curved; laterals willowy, slender and somewhat drooping. Form roundish to upright and rather spreading, open. Tzuigs medium to short, straight or somewhat curved, stout to moderately slender; internodes medium to short. Bark reddish-brown mingled with olive-green, partly streaked with thin scarf-skin, heavily pubescent. Lenticels scattering, medium, roundish or oblong, slightly raised. Buds very deeply set in bark, below medium to small, broad, flat, very obtuse, appressed, quite pubescent.

\section{Fruit.}

Fruit above medium, sometimes large or very large, pretty uniform in size but variable in shape. Form oblate, occasionally roundish, rarely slightly inclined to conic, often irregularly elliptical or obscurely angular; sides characteristically unequal as shown in the accompanying colored plate. Stem short to very short. Cazity medium or below, acute or acuminate, deep, moderately wide or rather narrow, often slightly furrowed, sonetimes compressed, sometimes with outspreading rays of thin greenish-russet. Calyx small to above medium, open to nearly or quite closed; lobes long, acute to acuminate, reflexed. Basin variable, small to rather large, moderately shallow to rather deep, narrow to rather wide, rather abrupt, slightly furrowed and wrinkled.

Skin moderately thick, tough, smooth, green or pale yellow or often whitish especially toward the cavity, occasionally very slightly blushed. Dots numerous, whitish or russet, areolar.

Calyx tube large, deep, flaring, cone-shape to almost funnel-form. Stamens median to basal.

Core small to nearly medium, usually more or less abaxile; cells irregular in size, sometimes unsymmetrical, partly open or closed; core lines clasping. Carpels roundish to elliptical, obtusely emarginate, smooth. Seeds variable, irregular, often large, wide, obtuse.

Flesh whitish slightly tinged with yellow, firm, tender, rather crisp, moderately coarse-grained, subacid, rich, juicy, good for either dessert or culinary uses.

\section{REPKA MALENKA.}

References. 1. Budd, Ia. Hort. Soc. Rpt., r880:525. 2. Am. Pom. Soc. Rpt., r881:118. 3. Webster, Am. Pom. Soc. Rpt., 1883:113. 4. Budd, Ia. Agr. Coll. Bul., 1885:16. 5. Ib., 189o:24. 6. Bailey, An. Hort., 1892:248. 7. 
Taylor, Me. Pom. Soc. Rpt., r892:57. 8. Harris, U. S. Pom. Rpt., r892:274. 9. Budd, Ia. Sta. Bul., 19:541. 1892. Io. Am. Pom. Soc. Cat., I899:20. II. Ragan, Am. Pom. Soc. Rpt., rgor:49. 12. Hansen, S. D. Sta. Bul., 76:92. 1902. fig. I3. Budd-Hansen, I903:163. fig. 14. Ragan, U. S. B. P. I. Bul., 56: 181. 1905. 15. Ragan, U. S. B. P. I. Bul., 56:260. 1905.

Synonyms. Dept. No. 418 (4). Green Sweet (12). Little Repka (14). Little Seedling (2). Little Seedling (3, 12, 14, 15). No. 410 (1, 5, 9, 12, 13). Riipka Melenkaya (14). Repka Malenka (14).

Repka Malenka is said to be one of the best keepers among the Russian varieties but the fruit is too small to be valuable (7).

Hansen (12) gives the following description of this variety: "Fruit below medium, conical to roundish conical, obscurely angular, somewhat irregular and unequal; surface yellow, striped, splashed, mixed and dotted dull red on sunny side; dots obscure, few, very minute, white; cavity regular, obtuse, with considerable radiating russet; stem medium to long; basin abrupt, narrow, shallow, slightly corrugated and wrinkled; calyx open or closed, segments erect convergent, very long. Core closed, clasping; cells round; tube funnelshaped, sometimes linear (long and very narrow); stamens marginal or median; seeds about ten, large, plump, packed tightly in the small cells; flesh white, firm, mild subacid, good. Late winter and spring."

\section{RHODE ISLAND GREENING.}

References. I. Coxe, I817:I29. fig. 2. Thacher, 1822:134. 3. Buel, N. Y. Bd. Agr. Mem., 1826:476. 4. Fessenden, 1828:131. 5. Cat. Hort. Soc. London, 1831:32. 6. Kenrick, 1832:52. 7. Floy-Lindley, 1833:37. 8. Ib., 1833:86. 9. Mag. Hort., I:326, 364. 1835. Io. Manning, I838:56. I I. Ib., Mag. Hort., 7:5I. 184I. 12. Downing, 1845:128. fig. I3. Horticulturist, I:257. 1846. I4. Ib., I:361, 407, 431. I847. I 5. Ib., 2:545. I848. I6. Ib., 3:292. I848. I7. Thomas, 1849:184. I8. Cole, 1849:123. fig. I9. Elliott, Horticulturist, 3:420. 1849. 20. Phoenix, Ib., 4:472. 1850. 21. Enmons, Nat. Hist. N. Y., 3:90. 1851. col. pl. No. 22. 22. Hovey, 2:79. 1851. 23. Am. Pom. Soc. Cat., r852. 24. Elliott, I854:104. fig. 25. Bivort, An. de Pom. Belge, 1855:60. 26. Gregg, 1857:58. 27. Hooper, 1857:79. 28. Horticulturist, 13:144. I858. 29. Ill. Handb. Obst., I:265. I858. 30. Warder, 1867:414. fig. 31. Regel, I868: 453. 32. Mas, Le Verger, I868:II. 33. Leroy, I873:853. fig. 34. Lauche, I: col. pl. No. 62. I882. 35. Barry, 1883:353. 36. Hogg, I884:194. 37. Rural .V. Y., 43:681. 1884. 38. Wickson, 1889:246. 39. Lyon, Mich. Hort. Soc. Rpt., I890:296. 40. Bailey, An. Hort., I892:248. 4I. Bredsted, I893:I7I. 42. U. S. Pom. Bul., 7:354. 1898. 43. Adams, Amer. Gard., 22:599. I901. 44. Eneroth-Smirnoff, Igor:425. 45. Budd-Hansen, I903:I63. fig. 46. U.S. Dept. Agr. Yr. Bk., I903:233. col. pl. No. 26. 47. Powell and Fulton, U. S. B. P. I. Bul., 48:54. 1903. 48. Beach and Clark, N. Y. Sta. Bul., 248:141. I904.

Synonyms. Burlington Greening (1, 6, 12, 24, 33, 36). Grecning ( 17 and common colloquial usage). Green Newrown Pippin ( 7 ) erroneously, corrected by Floy. Grecn Nezutown Pippin (36, erroneously 33). HAMPShire Greening (33). Hampshire Greening (24). Jersey Greening (i, 3). Jersey Greening ( $6,24,33,36, ? 2$ and 12). Rhode IsLand (47). Rhode Island Greening $(1,2,3,4,5,6,8,9,10,11,12,13,14,15,16,17$, 

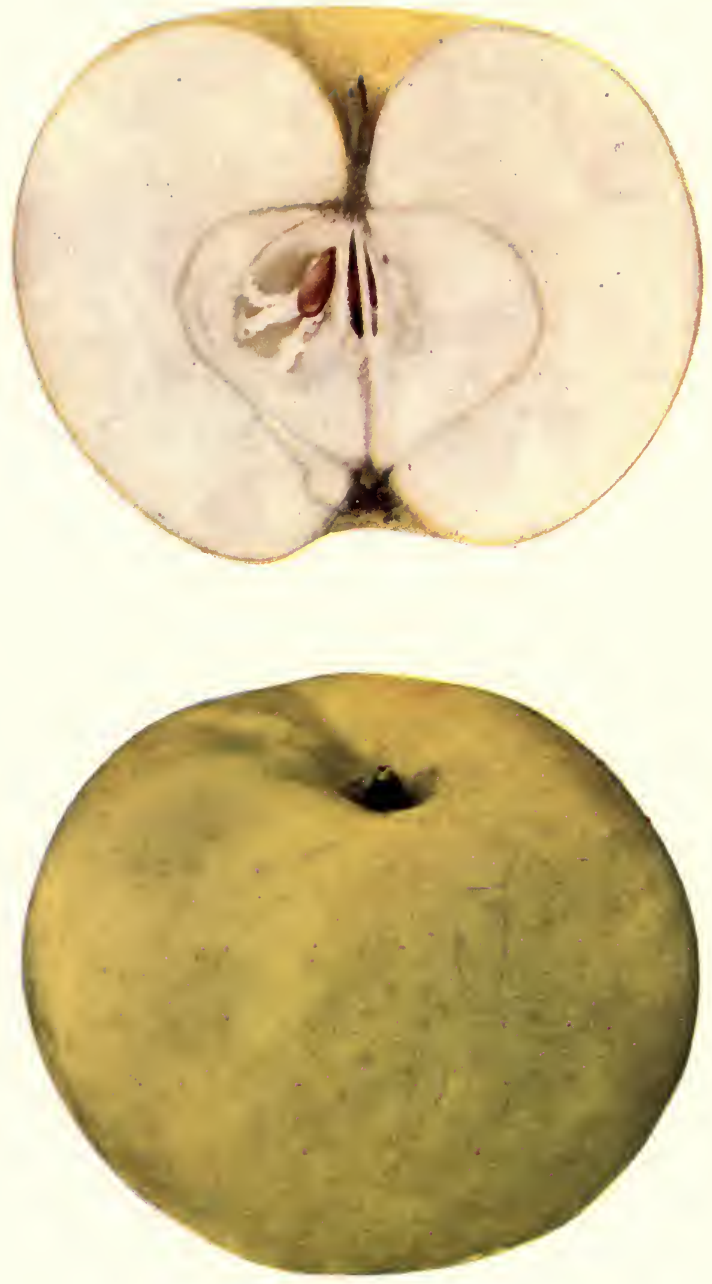

RHODE ISLAND GREENING 

I $8,19,20,21,22,23,24,25,26,27,28,30,31,32,33,35,36,37,38,39,40$, 41, 44, 46, 48). Rhode Island Greening (47). Verte de l'Ile de Rhodes (33). Verte de Rhode Island (33).

Rhode Island Greening is grown more extensively in New York than any other apple except the Baldwin and in a few sections of the state it surpasses even Baldwin. Its range of distribution on this continent is nearly coextensive with that of Baldwin.

In accordance with the usage of the American Pomological Society (23) the word Greening in the name of this variety is put in italics as the first step toward shortening the name to Rhode Island. Fruit growers and fruit dealers know the variety very well by the name Rhode Island Greening but commonly call it by the simple name Greening. Among these classes of people it will doubtless continue to be known by the name Greening or Rhode Island Greening as long as it remains in cultivation.

The apple, as the name indicates, is green in color. It is commonly deep grass-green in autumn, and later, as it ripens, develops more or less of a yellow color. It often has a dull blush and occasionally develops a rather bright red cheek but is never striped. Generally it is a reliable cropper and productive. The fruit has a recognized standing both in domestic and foreign markets and sells readily at good prices. It is generally regarded as one of the very best cooking apples grown being almost the peer of Esopus Spitzenburg and decidedly superior to Baldwin for all culinary purposes. It is also very good in quality for dessert use. Hovey well remarks (22): "As a cooking apple, the Greening is unsurpassed; and as a dessert fruit of its season, has few equals. To some tastes it is rather acid; but the tenderness of its very juicy flesh, the sprightliness of its abundant juice, and the delicacy of its rich and fine flavor is not excelled by any of the numerous varieties that we at present possess. In addition to these merits, it ripens up of a fine mellow shade of yellow, and its entire flesh, when well matured, is of the same rich tint." It is a favorite variety in nearly all of the apple-growing sections of the state but it succeeds particularly well in Central and Western New York and in the middle portion of the Hudson valley. When grown farther south it is less desirable for commercial purposes because it ripens earlier and is not so good a keeper. In the North it is a little less hardy than Baldwin. It is a 
good variety to grow with the Baldwin in commercial orchards because, being a little earlier in season, it can be picked and marketed before it is necessary to pick Baldwin. Moreover it bears good crops some years when there is but a light crop of Baldwins or perhaps none at all.

In regions best adapted to its cultivation it thrives on different slopes and on a variety of soils, but generally, it appears to do particularly well on fertile gravelly or sandy loam with well-drained clay subsoil. The tree is long-lived and eventually becomes large although it is not an exceptionally rapid grower. It is hardy, strong, vigorous, and usually pretty healthy but unless thorough preventive treatment is given, both the foliage and the fruit are often injured by the apple-scab fungus. In some locations the limbs are rather susceptible to the disease known as canker. ${ }^{1}$

The tree does not come into bearing very young and in many cases it is classed as a biennial cropper, but in favorable locations with goorl care it becomes almost an annual bearer yielding moderate to heavy crops. The fruit hangs well to the tree until it begins to ripen, but then is apt to drop to a considerable extent especially in high winds. The tree has a tendency to form a rather dense head particularly when the soil is kept fertile and well tilled and the foliage is thoroughly protected from the attacks of insects and fungi. In pruning, special care should be taken to keep the head sufficiently open so that the light may reach the foliage in all parts of the tree. Sometimes the orchardist makes the mistake of cutting out large branches from the center of the tree thereby exposing the remaining limbs to injury by sunscald. A better way is, thin the top every year by removing as many of the smaller branches as may be necessary to make it uniformly open. In training the young tree it is well to form the head rather high because as it matures the branches become long, wide-spreading and more or less drooping, and where the tree is headed low the lower branches eventually are so much in the way that it is necessary to remove them. Moreover when loaded with fruit these bend so close to the ground as to interfere with the free circulation of the air beneath the tree, and thus condi-

${ }^{1}$ Paddock, N. Y. Sta. An. Rpt., 18:331. 1899. Ib., 19:342, 1900. 
tions are produced which favor the development of the apple scab and other fungous diseases. When well grown, Rhode Island Greening produces a large percentage of high-grade fruit that is smooth, uniform and pretty large with little loss from undersized or other low-grade apples. It appears to be somewhat more subject than Baldwin to the attacks of apple scab and unless thorough preventive treatment is given this trouble is apt to cause very serious loss both by direct injury to the fruit and by opening the way to the attacks of other fungi, notably the pink-rot fungus. ${ }^{1}$

In ordinary storage it is in season from October to March or April and its common commercial limit is January or early February. It may be held commercially in cold storage till March or April (48). It ripens rapidly during periods of warm weather in autumn and does not stand heat well before going into storage as this induces scald. If put in cold storage in good condition the fruit keeps well and goes down gradually but if affected by scald or disease it goes down quickly. In going down, it scalds badly in storage, loses in quality, turns yellow, becomes mealy and large specimens are liable to burst (48). The markets of the East prefer the green-colored fruit probably because this color is regarded as an indication that the apples are not over-ripe. In some western markets however the more attractive yellow and blushed fruit sells well. Some fruit growers follow the practice of picking the fruit while it is still quite green in order to hold its green color. Such fruit does not have as good flavor and quality as that which is allowed to become properly ripened on the tree and probably it is more liable to scald but storage men differ in their opinions on this point. It is very important that fruit of this variety which is intended for cold storage should be hurried into storage as soon as it is picked. This practice is more essential with Rhode Island Greening than with the average variety $(48)$.

Historical. The locality of the origin of Rhode Island Greening is not known with certainty but there is little reason to doubt that it originated in the State of Rhode Island and probably in the vicinity of Newport near the place now known as Green's End (43), "where, in olden times, there was a tavern kept by Mr. Green, who raised apple trees from seed. Among the trees

${ }^{1}$ Eustace, N. Y. Sta. An. Rpt., 22:108. 1903. 
thus produced was one which bore a large green apple. The scions of this tree were in such demand by the people who stopped there as guests, that the tree died from excessive cutting and exhaustion. The fruit which resulted from grafting with these scions was known by different names-in Rhode Island as the 'apple from Green's Inn,' while in adjoining States it was called the 'Green's Inn apple from Rhode Island.' * * * In the town of Foster, upon the farm of Thomas R. Drowne, at Mt. Hygeia, stands an old Rhode Island Greening tree, which is supposed to be nearly 200 years old. * * * This tree, to the knowledge of members of the family now living, has borne uninterruptedly until within a few years. $1 * * *$ On the farm of Frederick W. Winslow, a few rods southwest of the lime kiln on the northern verge of Fruit Hill, stands a Rhode Island Greening tree, which is locally known as the 'Daughter Tree.' This tree is a limb of the mother tree, which was broken off in the September gale of ISI 5 , and which upon being thrust into the rich moist soil, took root and became an independent tree. The mother tree was planted $* * *$ in I748. It was, therefore, I4I years old when it was cut down in 1889 . * * * Authentic records of trees of this variety that were planted about 150 years ago in the soil of North Providence, on the farm of the late Lemuel Angell, are still in possession of that family. It was introduced into the old Plymouth colony from Newport in 1765 ; from there (?) it was carried into Ohio in 1796 by General Putnam."

While we have no record of its earliest introduction into this state it is well known that Rhode Island Greening was pretty widely disseminated in the older settled regions of New York during the eighteenth century. It is often found in the very oldest orchards now in existence in New York and it also ranks as one of the most important varieties in recently planted orchards.

\section{Tree.}

Tree large or above medium, strong, vigorous. Form wide-spreading, somewhat drooping, rather dense. Twigs medium to long, often somewhat crooked, rather stocky; internodes usually short. Bark olive-green with reddish-brown tinge, thinly covered with lines of gray scarf-skin, pubescent. Lenticels scattering but rather conspicuous, medium in size to rather large, usually roundish, raised. Buds medium to large, broad, plump, obtuse, appressed, pubescent. Leaves rather large, broad; foliage rather dense.

\section{FRUIT.}

Fruit above medium to large or very large, quite uniform in shape and size. Form roundish to roundish oblate or sometimes slightly inclined to conic, regular or a little inclined to elliptical, sometimes obscurely ribbed, symmetrical or sides slightly unequal. Stem medium in length and thickness, partly green,

\footnotetext{
${ }^{1}$ This tree on the Drowne farm is supposed by some to be the original Rhode Island Greening tree. An illustrated description of it appeared in the Providence Sunday Journal October 2, 1898. Witt:in recent years a sprout has grown out from the base of this old tree. In 1900 Senator T. R. Drowne very kind:y furnished this Station with scions from this sfrout and also from the upper branches of the tree. A comparison of the trees propagated from these scions, which are now growing at this Station, shows that the trees from scions taken from the upper branches of the old tree are the true Rhode Island Greening, but those grown from scions taken from the sprout at the base of the old tree are very different, thus demonstrating that the old tree on the Drowne farm is not growing on its own roots and, therefore, is not the original Rhode Island Greening tree.
} 
pubescent. Cavity medium in size, acute, medium in depth and width, symmetrical or rarely lipped, usually smooth, sometimes russeted and with narrow, outspreading russet rays. Calyx below medium to rather large, usually closed, sometimes partly open, pubescent; lobes moderately long, acute. Basin small to medium, shallow and obtuse to moderately deep and abrupt, regular or slightly furrowed.

Skin moderately thick, tough, smooth, waxy, grass-green varying to rather yellow, sometimes with brownish-red blush which rarely deepens to a distinct bright red (37). Dots greenish-white or russet, especially numerous toward the basin and often submerged. Prevailing effect green or yellowish.

Calyx tube rather wide, usually cone-shape with fleshy pistil point projecting into the base but occasionally funnel-form. Stamens median to basal.

Core medium or below, somewhat abaxile to axile or nearly so; cells pretty uniform, symmetrical, closed or partly open; core lines meeting if the calyx tube is cone-shape, otherwise clasping. Carpels rather thin, flat, emarginate, roundish to roundish cordate, sometimes tufted. Seeds few; often some are abortive. The plump ones are large, moderately narrow, long, acute to acuminate and sometimes tufted.

Flesh yellowish, firm, moderately fine-grained, crisp, tender, juicy, rich, sprightly subacid, peculiarly flavored, very good in quality.

\section{RIDGE.}

References. I. Genesee Farmer, 1833. (cited by 10). 2. Emmons, Nat. Hist. N. Y., 3:46. 185I. col. pl. No. 55. 3. Downing, 1857:184. 4. Am. Pom. Soc. Cat., 1852. 5. Warder, $1867: 536$. 6. Thomas, 1875:510. 7. Barry, r883: 354. 8. Bailey, An. Hort., I892:248. 9. Budd-Hansen, I903:I66. тo. Ragan, U. S. B. P. I. Bul., 56:262. 1905 .

Synonyms. Ridge Pippin (i, 3, 4, 5, 6, 7, 8). Ridge Pippin (9). Ridge Pippin (10). Ridged Pippin (2). Not the Ridge of Bul. 248 of this Station.

Fruit of good yellow color, not particularly attractive in form, a late keeper and good in quality for either dessert or culinary uses. It averages pretty uniform in size with comparatively few culls. The tree is healthy, hardy, long-lived and a reliable cropper yielding good crops biennially. Some growers consider it a fairly profitable variety for local markets.

Since Bulletin 248 was published it has been discovered that the variety therein mentioned under the name of Ridge or Ridge Pippin is in fact Ribston. It appears that the name Ridge Pippin is used by some dealers as a trade synonym for Ribston, and this use of it led us into the error of publishing a duplicate report on Ribston under the name Ridge.

Historical. According to Warder (5) this variety originated in the vicinity of Philadelphia but Downing (3) regarded this as uncertain. Although it has 
long been known in cultivation it has gained but little recognition in New York state either for home or for commercial orchards.

TREE.

Tree large, vigorous. Form upright. Tarigs erect, long to below medium, somewhat stont, straight or somewhat bent toward the tip and rather blunt; internodes medium. Bark dull brownish-red overlaid with a thin to rather heavy scarf-skin, quite pubescent. Lenticels not conspicuous, scattering, medium to small, slightly raised, roundish or elongated. Buds medium, moderately projecting, roundish, quite pubescent, appressed.

\section{Fruit.}

Fruit above medium to large. Form flat at the base, roundish conic to oblong conic, prominently and irregularly ribbed; axis sometimes oblique. Stem short to long, pubescent. Cavity small to large, acute to acuminate, very shallow to deep, ustually furrowed, often with outspreading russet rays. Calyx small to sometimes medium, usually closed. Basin rather small, often oblique, moderately shallow to rather deep, moderately wide, abrupt, characteristically ridged and wrinkled.

Skin smooth, glossy, clear yellow, often with a faint blush which sometimes deepens to a pinkish-red shade similar to that seen in a highly colored Yellow Newtown, sometimes veined and flecked with russet. Dots numerous, fine to moderately coarse, russet, or pinkish-white and areolar or submerged.

Calyx tube rather large, wide at top, cone-shape to funnel-form. Stamens marginal to median.

Core axile, rather small; cells usually closed; core lines meeting or slightly clasping. Carpels roundish, rather wide, broadly emarginate, slightly tufted. Seeds light and dark reddish-brown, short to moderately long, wide, plump, obtuse, sometimes tufted.

Flesh tinged with yellow, very firm, somewhat coarse, crisp, moderately tender, juicy, slightly aromatic, mild subacid, good.

Season February to April or May.

\section{ROCK PIPPIN OF EASTERN NEW YORK.}

A variety is grown under this name in Eastern New York, particularly in Dutchess county, which we have been unable to identify as any other named variety. G. B. Brackett, U. S. Pomologist, writes us that it certainly is not Lansingburg of which Rock is given by Downing 1 as a synonym and adds that he is unable to identify it. It is neither the Rock of New Hampshire, the Rock of Pennsylvania ${ }^{2}$ nor the Rock Pippin of Ohio.2,3 It somewhat resembles Tewksbury but is distinct from that variety. It also bears some resemblance to Yellow Newtown but is smoother and has a redder cheek. It is know to some under the name Winter Blush.4 All of the descriptions of Winter Maiden Blush or Winter Blush which we have been able to find are brief and unsatisfactory. So far as we can determine none of them refer to the variety under discussion. Fruit of what appears to be the same variety

'Downing, 1881:1 2 index, app.

${ }^{2}$ Downing, $1889: 33^{8}$

Warder, 1887:691.

- Letter, C. II. Deuell, Bangall, N. Y., 1904. 

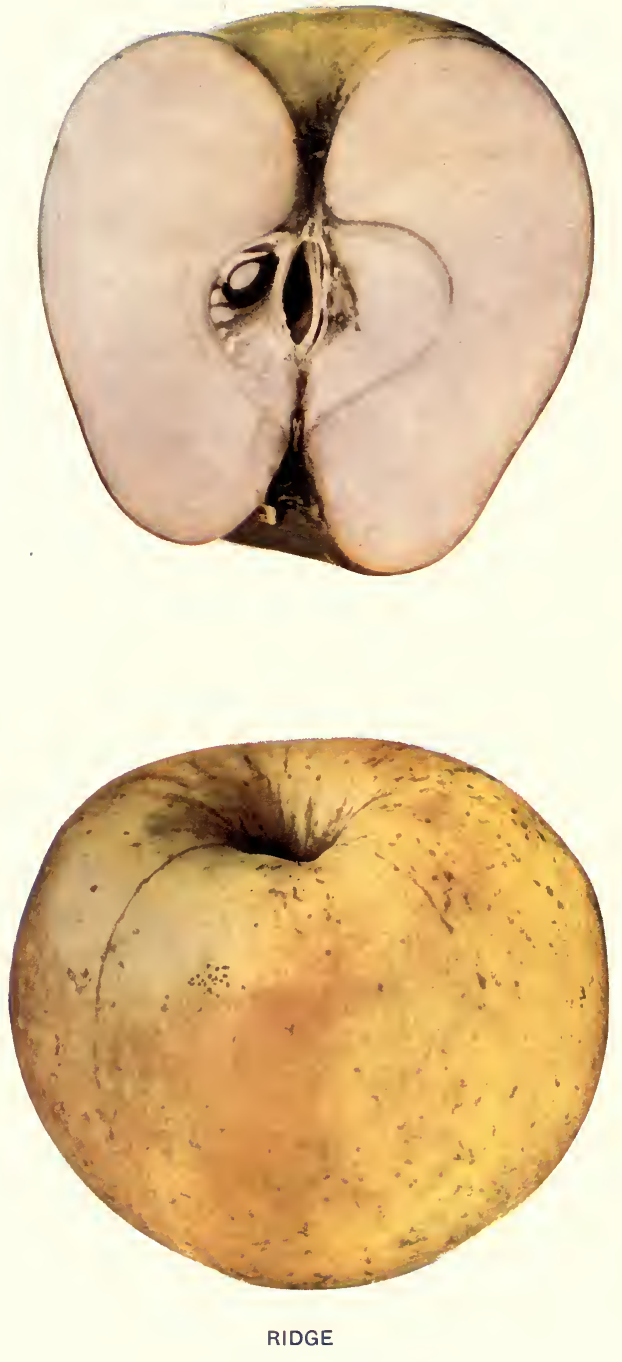

as this Rock Pippin has been sent us from Pullman, Washington, under the name Rock.

W. H. Hart of Poughkeepsie informs us that Rock Pippin is found in many orchards in Dutchess county but in no large blocks. He considers it a good variety to grow for profit because it keeps very late and is a good export apple to succeed the Newtown at the end of the season. In some seasons it is inclined to scab. It does not average as large as Baldwin and grades less No. I fruit than that variety. Its commercial season in ordinary storage extends to April and in cold storage to June or July. Mr. Hart reports that the tree is large, very vigorous, upright, with long, erect, stout, yellowish-brown twigs. It is hardy, very healthy, long-lived, a reliable cropper and, if kept free from scab, yields good to heavy crops biennially. The tree does not come into bearing very young. The fruit hangs to the tree exceptionally well.

\section{FrUit.}

Fruit below medium to above, uniform in size and shape. Form roundish oblate to roundish, not inclined to conic, regular or nearly so; sides sometimes unequal. Stem short to medium, moderately thick, pubescent. Cavity small to above medium, acute to somewhat acuminate or sometimes approaching obtuse, moderately deep to deep, narrow to moderately broad, furrowed obscurely if at all, usually somewhat russeted. Calyx medium to small, closed; lobes convergent to connivent. Basin scarcely depressed and very obtuse or varying to moderately deep and abrupt, wide, slightly furrowed and wrinkled.

Skin moderately thick, tough, smooth or slightly roughened with russet dots, rather glossy, green or light yellow thinly washed with pinkish-red often deepening to a distinct bright blush, streaked and mottled with pale scarf-skin toward the cavity. Dots numerous, mostly irregular, submerged and whitish around the basin, sometimes areolar with fine russet point; the russet ones are larger, more irregular and scattering toward the cavity. Prevailing effect pale yellow.

Calyx tube small, conical to funnel-form. Stamens median to basal.

Core medium to small, axile; cells closed; core lines clasping. Carpels thin, broadly roundish to somewhat obcordate, emarginate, somewhat tufted. Seeds rather dark brown, medium to large, rather wide, acute to obtuse, sometimes tufted, compactly filling the cells.

Flesh whitish or slightly tinged with yellow, very firm, rather hard, a little coarse, somewhat crisp, rather tender, aromatic, juicy, sprightly subacid, good but not high in flavor.

\section{ROMANITE.}

References, I. (?) Phoenix, Horticulturist, 4:471. I850. 2. Downing, 1869: 339. fig. 3. Am. Pom. Soc. Cat., 1871:8. 4. Fitz, 1872:143. 5. Wickson, 1889:247. 6. Bailey, An. Hort., 1892:248. 7. Clayton, Ala. Sta. Bul., 47:6. I893. 8. Stinson, Ark. Sta. An. Rpt., 7:47. I894. 9. Budd-Hansen, 1903: 66. fig.

Synonyms. Broad Rizer (2). Little Red Romanite. (Red Romanite, I)? Romanite of the South $(3,4)$. Romanite, South (9). Southern Romanite $(2,8)$. 
The name Romanite has been and is still applied to several different varieties of apples. In the earlier history of orcharding in this country it was applied very generally to the Rambo, but this synonymy has now become practically obsolete. The Gilpin or Carthouse apple has also passed under the name of Romanite and it is still so called in a great many districts. The true Romanite of to-day, according to the accepted nomenclature of the American Pomological Society, is the old southern variety of this name. It is also known in various parts of the South under the name of Little Red Romanite. The fruit of this variety is small but has a good color, is of good quality and keeps remarkably well, this last characteristic being one of its chief recommendations in the South where it is usually quite difficult to get varieties that are late enough for their long seasons. It is not recommended for planting in this state being evidently not well adapted to regions as far north as this.

Historical. The origin of this apple is mnknown although it is probable from the region in which it was being grown when it first became known to pomologists that it originated in one of the Carolinas or in Georgia. So far as we know it is not grown in New York.

\section{ROME.}

References. I. Ohio Convention of Fr. Gr. Rpt., 1848. (cited by 2). 2. Hodge, Horticulturist, 6:181. 1851. 3. Emmons, Nat. Hist. N. Y., 3:102. 1851. fig. 4. Ellictt, 1854:106. fig. 5. Horticulturtst, 9:193. 1854. 6. Mag. Hort., 20: 241. I854. 7. Ib., 22:130. I856. 8. Wood, Horticulturist, I2:149. I857. 9. Downing, 1857:102. fig. ro. Gregg, 1857:57. I1. Hooper, 1857:81. I2. Mag. Hort., 26:101. 1860. 13. Am. Pom. Soc. Cat., 1862. 14. Warder, 1867:458. fig. I5. Fitz, 1872:172, I75. 16. Leroy, I873:124. fig. I7. Thomas, I875:221. 18. Earry, 1883:341. Ig. Wickson, I389:2.48. 20. Lyon, Mich. Hort. Soc. Rpt., 1890:296. 21. Bailey, An. Hort., 1892:248. 22. Mathews, Ky. Sta. Bul., 50: 32. 1894. 23. Beach, N. Y. Sta. An. Rpt., 14:254. 1895. 24. Rural N. Y., $55: 1$. 1896. 25. Ib., 56:244. I897. 26. Massey, N. C. Sta. Bul., 149:317. 1898. 27. Beach, IV. N. Y. Hort. Soc. Rpt., I900:36. 28. Lazenby, Columbus Hort. Soc. Rpt., Igoo:138. 29. Beach, WV. N. Y. Hort. Soc. Rpt., rgor:76. 3o. Van Deman, Rural N. Y., 60:209. I901. 31. Coxe, Ib., 60:266. 1901. 32. Alwood, Va. Sta. Bul., 130:136. I901. 33. Black, Rural N. Y., 6r:185. 1902. 34. Stinson, Mo. Fr. Sta. Bul., 3:27. I902. 35. Dickens and Greene, Kan. Sta. Bul., 106:55. 1902. 36. Budd-Hansen, I903:167. fig. 37. Powell and Fulton, U. S. B. P. I. Bul., 48:54. 1903. 38. Bruner, N. C. Sta. Bul., 182:22. 1903. fig. 39. Beach and Clark, N. Y. Sta. Bul., 248:142. I904.

Synonyms. Belie de Rome (16). Faust's Rome Beauty (23). Gillett's Scedling (4, 9, I4, I6). Phoenix, erroneously (29). Roman Beauty (4, 16). Rome Beauty $(2,3,4,5,6,7,8,9,10,11,12,13,14,15,17,18,19,20,21$, $23,24,25,26,30,31,32,33,34,35)$. Rome Beauty $(16,27,37,39)$. Rome Beauty $(36,38)$.

When well grown this fruit is of good size, uniform, fair, smooth and handsomely colored. It is thick-skinned, stands handling remarkably well and is a good keeper. It is held in cold storage till May or later. It goes down gradually in storage and if properly 

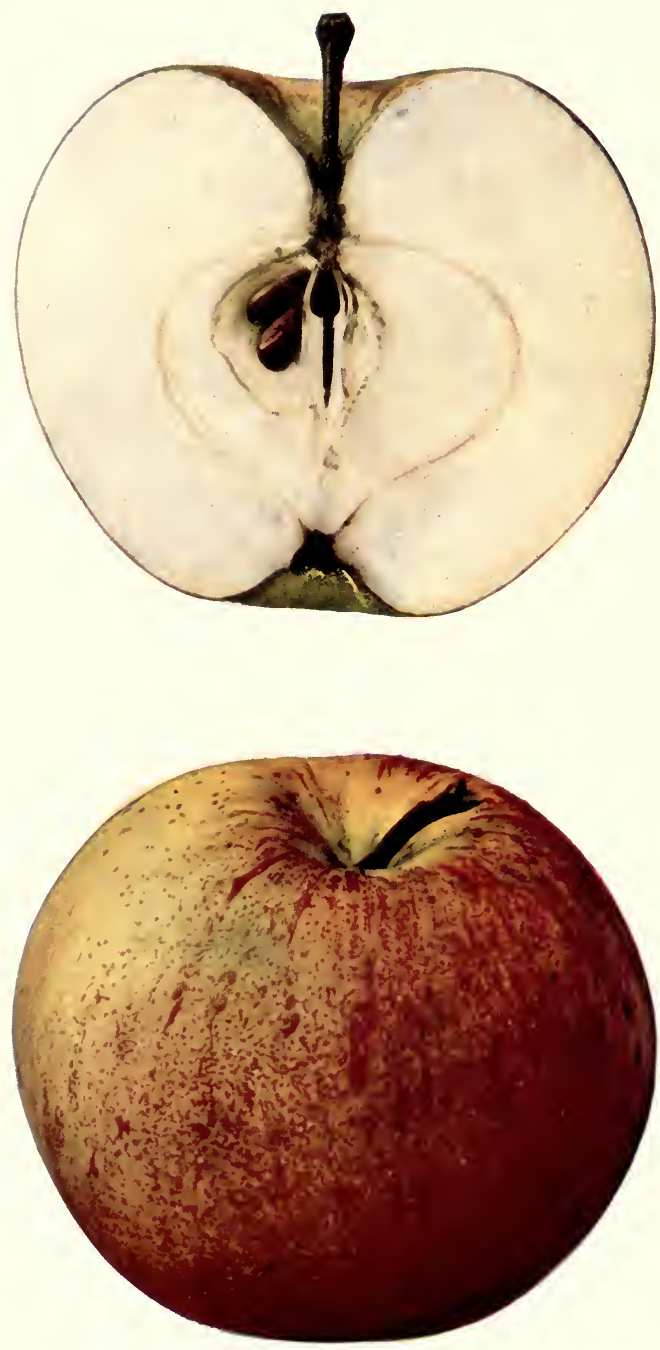

ROME 

colored is not subject to scald (39). It has an established reputation in market and sells at good prices. As compared with Baldwin it is not quite so good in quality either for dessert or for culinary uses but the tree comes into bearing at a much earlier age and under right conditions is more nearly an annual cropper. It is not as well adapted as Baldwin for general cultivation in New York state, the fruit often being less reliable and less satisfactory in size and color, the foliage less healthy and the tree less vigorous and not so large. Although it is an old variety it has not been sufficiently tested in New York to determine the range of its proper cultivation. Generally speaking it succeeds better farther south, as, for example, in some districts in New Jersey and along the Ohio river. It appears to be better adapted to bottom lands and to fertile sandy or gravelly loams than to heavy clay soils. Evidently it develops proper size, color and quality more often when grown in Southeastern New York than it does in cooler and more elevated regions in the interior of the state yet in some localities in Western New York on warm, fertile, well-drained soils it attains good size and good color and gives promise of being satisfactory in commercial orchards. The tree is apt to overbear and in unfavorable locations as it advances in maturity there is often a considerable loss in undersized or poorly colored fruit. Although it is a good grower there appears to be some advantage in top-grafting it upon some more vigorous stock. When top-worked on bearing trees it usually produces some fruit within two or three years from the time of grafting or budding. The fruit is supported by a long stem and usually hangs to the tree remarkably well even in high winds. It is somewhat subject to the attacks of the scab and requires thorough and careful preventive treatment in order to protect it from injurious insects and diseases.

Historical. Originated by H. N. Gillett in Lawrence county, Ohio. Brought to the notice of the Ohio Convention of fruit growers in 1848 as a new variety ( $I, 14)$. It is holding its own as a profitable commercial variety in that section of the country (3I) and also in certain other southern apple-growing districts $(30,34,38)$, but Stinson reports that in Missouri it is an uncertain bearer and not a safe variety to recommend for general planting although some Missouri fruit growers recommend it for planting in some locations (34). Although occasionally old trees of this variety are found in New York, Rome is as yet but little known among New York fruit growers. Within recent years it has been planted or grafted in commercial orchards to a limited extent and for the most part in an experimental way. 


\section{TREE.}

Tree not a very strong grower in the nursery but in the orchard it is rather vigorous and attains good medium size. Form at first upright but later it is roundish to somewhat spreading and drooping, with rather slender lateral branches. Twigs moderately stout, sometimes slender, moderately long; internodes sliort. Bark mottled brownish-red and green, rather bright. Lenticels medium to large, scattering, conspicuous, round to oblong, raised. Buds deeply set in bark, very short, broad, obtuse, appressed. Leaves rather long; foliage not particularly robust.

FRUIT.

Fruit medium to very large, usually averaging above medium, pretty uniform in size and shape. Form roundish to roundish conic or slightly oblong, regular or faintly ribbed, usually symmetrical but sometimes with sides unequal. Stem characteristically long, slender, and often oblique. Cavity medium to rather large, characteristicaily obtuse and smooth, moderately shallow to rather deep, wide, sometimes compressed or lipped, often gently furrowed, green or red, never russeted. Caly $x$ rather small to medium, closed or somewhat open; lobes usually converging above but slightly separated toward the base. Basin small to medium, shallow to moderately deep, narrow to medium in width, sometimes abrupt, usually a little furrowed or wrinkled.

Skin thick, tough, smooth, yellow or greenish, more or less mottled with bright red which in highly colored specimens deepens to almost solid red on the exposed cheek, striped with bright carmine. Dots rather numerous, whitish or brown, small. Prevailing effect red or red mingled with yellow.

Calyx tube cone-shape or approaching short truncate funnel-form, often with fleshy pistil point projecting into the base. Stamens marginal to median.

Core medium to large, abaxile; cells sometimes unsymmetrical, open; core lines meeting or slightly clasping. Carpels roundish to ovate, narrowing both toward base and apex, sometimes obtusely emarginate, mucronate. Seeds numerous, medium in size, plump, acute to somewhat obtuse, slightly tufted, light and dark brown.

Flesh nearly white with slight tinge of yellow or green, firm, moderately fine-grained to a little coarse, rather crisp, juicy, slightly aromatic, agreeable mild subacid, commonly good but not high in quality.

Season November to April or May.

\section{ROSEAU.}

References. I. North American Pomological Convention, 1849. (cited by 6). 2. Downing, r869:340. 3. Plumb, Can. Hort., 18:184, I895. 4. Waugh, Rural N. Y., 62:141, 143, 282. 1903. figs. under name Canada Red. 5. Rural N. Y., 62:238. 1903. 6. Ragan, U. S. B. P. I. Bul., 56:267. I905.

Synonyms. Baltiatore (3). Canada Red (5). Canada Red of Ontario, not Red Canada of Western New York (4). Flushing Spitzenburg (3). French Spitzenburg of Vermont (4). Pomme de Fer of Quebec (4). Red Canada of Ontario, not Red Canada of Western New York (3). Rosseau (6). Winesap of Vermont (4).

A variety is known in portions of Ontario under the name of Red Canada or Canada Red which is said to be quite different from the Red Canada of 


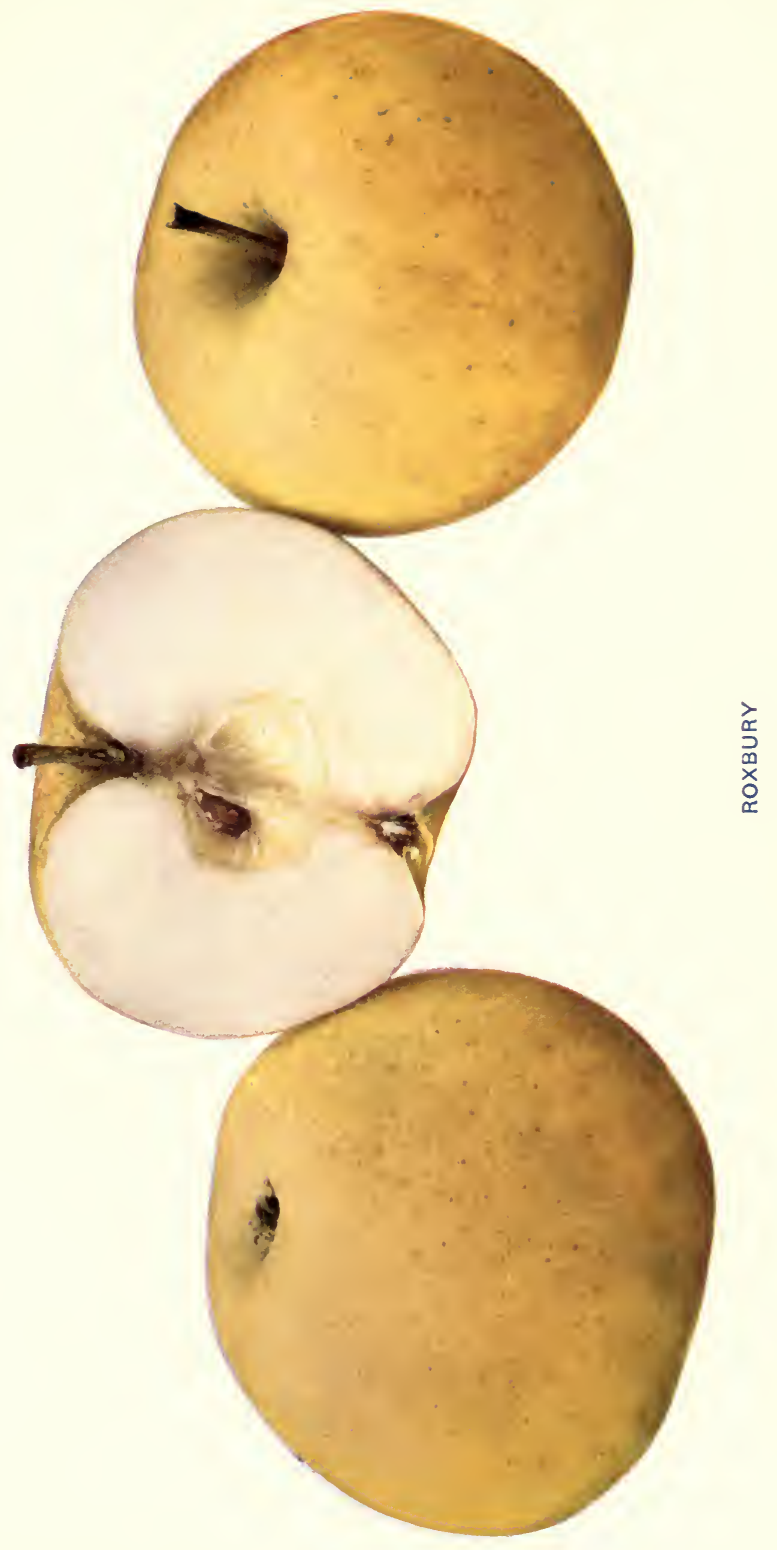




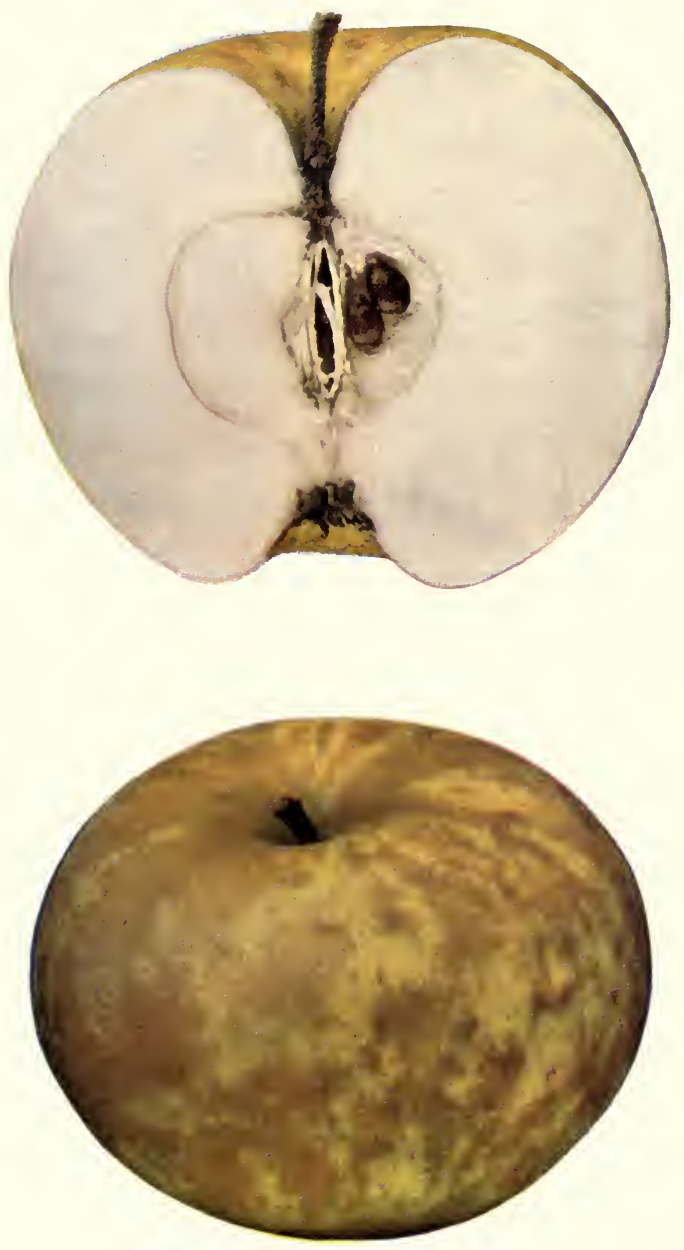

ROXBURY 

Western New York described on page 275. Waugh identifies this variety as the Roseau of Downing and remarks that it is really an important apple.1 He states that it is known in some parts of Vermont as the Winesap and that it is the Pomme de Fer of Quebec (4). Plumb (3) gives Flushing Spitzenburg as its correct name and calls it identical with the variety described by Downing under the name Baltimore. We have not had an opportunity of verifying the conclusions of either Waugh or Plumb with regard to this matter.

The following is Waugh's description of the variety.

"The distinguishing good qualities of this variety are its peculiarly firm, solid flesh, making it a late keeper and a good shipper, and its fine solid red color, which makes it attractive in the barrel. It is unusually hardy in tree, so that it may be grown in northern latitudes with great success. So far as I know it is as hardy as Duchess of Oldenburg. Here is the technical description of the variety made from Vermont specimens: Fruit irregular, oblate, size medium to large, cavity irregular, medium deep, stem medium long, basin shallow, usually smooth, calyx small, closed, color two shades of dull red, mottled and splashed, nearly covering dull green ground, dots many, yellowish, very conspicuous, bloom thin, skin tough, flesh white, core medium, slightly open, flavor subacid, quality good, season midwinter."

\section{ROXBURY.}

References. I. Thacher, I822:136. 2. Fessenden, I828:130. 3. Kenrick, 1832:53. 4. Mag. Hort., I:364. I835. 5. Manning, 1838:62. 6. Mag. Hort., 7:48. I841. 7. Downing, I845:I33. fig. 8. Floy-Lindley, I846:4I I app. 9. Horticulturist, I:52, 34I, 361. I846-47. Io. Ib., 2:483. I848. II. Hovey, Mag. Hort., 14:I12, 173. I848. I2. Thomas, 1849:185, 190. fig. 13. Cole, 1849: 135. fig. I4. Phoenix, Horticulturist, 4:472. I850. 15. Emmons, Nat. Hist. N. Y., 3:96. 1851. col. pl. No. 18. 16. Am. Pom. Soc. Cat., 1852. 17. Elliott, I854: I06. I8. Hooper, I857:73, 82. I9. Gregg, I857:59. 20. Horticulturist, 13:144. 1858. 21. Mag. Hort., 26:6, I0I. I860. 22. Ib., 29:437. 1863. 23. Ill. Handb. der Obstk., 8:157. I865. 24. Warder, I867:25, 49I. fig. 25. Regel, I868:444. 26. Thompson, Mich. Pom. Soc. Rpt., I:3I. I870. 27. Leroy, 1873:153. fig. 28. Gardiner, Me. Pom. Soc. Rpt., 1882. (cited by 35). 29. Barry, I883:354. 30. Hogg, I884:27. 3I. Wickson, I889:245. 32. Lyon, Mich. Hort. Soc. Rpt., I89o:296. 33. Failey, An. Hort., 1892:248. 34. Munson, Me. Sta. Rpt., I893:133. 35. Kncwlton, Me. Pom. Soc. Rpt., 1894:126. 36. Lyon, Mich. Sta. Bul., 118:62. 1895. 37. Woolverton, Ont. Fr. Stas. An. Rpt., 3:13. I896. fig. 38. Bunyard, Jour. Roy. Hort. Soc., I898:356. 39. Eneroth-Smirnoff, I90I:434. 40. Budd-Hansen, 1903:r69. fig. 4I. Powell and Fulton, U. S. B. P. I. Bul., 48:55. 1903. 42. Beach and Clark, N. Y. Sta. Bul., 248:142. 1904.

Synonyms. Belpre Russet (17, 18, 27). Boston Russet $(25,27,30)$. Boston Russet (9, 12, 13, 15, 17, 18, 24, 37). Marictta Russet (17, 18, 27). Putman's Russet (27, 30). Putnam Russet (23, 39). Putnam Russet (9, Io, II, I7, I8, 24, 27, of Ohio I2, I3 and I5). Roxbury Russet (4, 5, 6, 8, 9, IO, II, 12, I3, I4, I7, I8, I9, 20, 21, 22, 24, 29, 31, 32, 33, 34). Roxbury Russet (3, 27, 30, 40, 41, 42). Roxbury Russeting (I, 2, 3). Roxbury

${ }^{1}$ Letter, 1905 . 
Russeting $(7,27)$. Rox or Rox Russet (colloquial). Russet, Boston oR Roxbery (7). Russet (27). Shippon's Russet (27, 30). Sylvan Russet $(17,18,27)$.

The Roxbury is the most popular russet apple cultivated in New York. When well grown it is of good marketable size, and rather attractive for a russet, but it varies greatly in size and appearance in different localities. Being an excellent keeper it is well liked for southern trade. It also sells well in western and northwestern markets. The recent increase in cold storage facilities has had the effect of lessening the demand for long-keeping russet apples, and neither the Roxbury nor the Golden Russet is being planted as extensively as they once were, but within recent years there has been increasing demand for them for export. Roxbury fruit that is grown in Central and Western New York keeps better than that produced in more southern localities, and for this reason is preferred by fruit buyers. This variety has consequently been planted more extensively in this region than in any other. It generally has the reputation of being a biennial bearer and when grown on rich soils in favorable locations it is a pretty reliable cropper, but in many places it has proved but a moderate cropper and not very satisfactory.

Historicai. It is generally supposed that this variety originated in Roxbury, Massachusetts, early in the seventeenth century. Soon after 1649 it was taken to Connecticut. About 1797 it was introduced from Connecticut into Ohio and afterwards disseminated there under the name Putnam Russet, Marietta Russet, etc. (9, I I, 24).

\section{Tree.}

Tree medium to large, moderately vigorous to vigorous. Form roundish spreading or flat. Tirigs above medium to short, straight or nearly so, stout, often with large blunt terminal buds; internodes medium to rather long. Bark rather light, dull, reddish-brown and olive-green, streaked lightly with grayish scarf-skin, much pubescent. Lenticels not conspicuous, scattering, medium to above, roundish, oval or elongated, sometimes raised. Buds large, broad, plump, obtuse, free or nearly so, slightly pubescent.

\section{FrUIt.}

Fruit usually above medium to nearly large, sometimes large, variable in size and shape. Form oblate to oblate inclined to conic, often broadly and obscurely angular and sometimes remarkably elliptical as shown in the accompanying half-tone illustration; sides sometimes unequal. Stem short to medium rather thick or swollen, pubescent, often red on one side. Carity acute rarely acuminate, rather deep, medium in width to rather wide, sometimes lipped. Calyx sometimes small but usually medium to rather large, pubescent, closed 


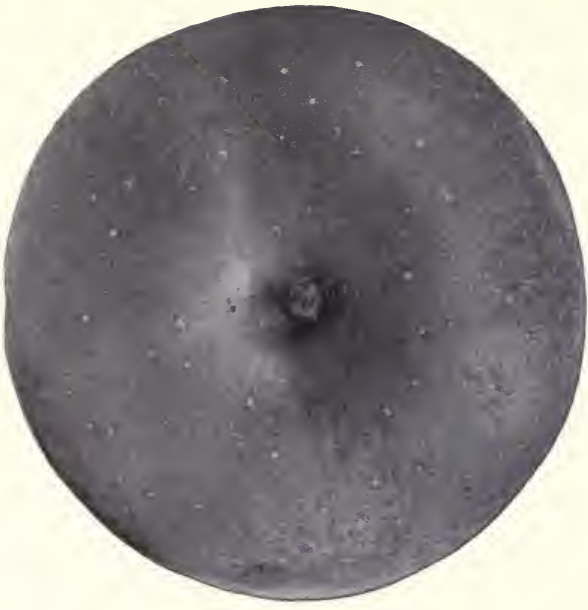

GOLDEN RUSSET

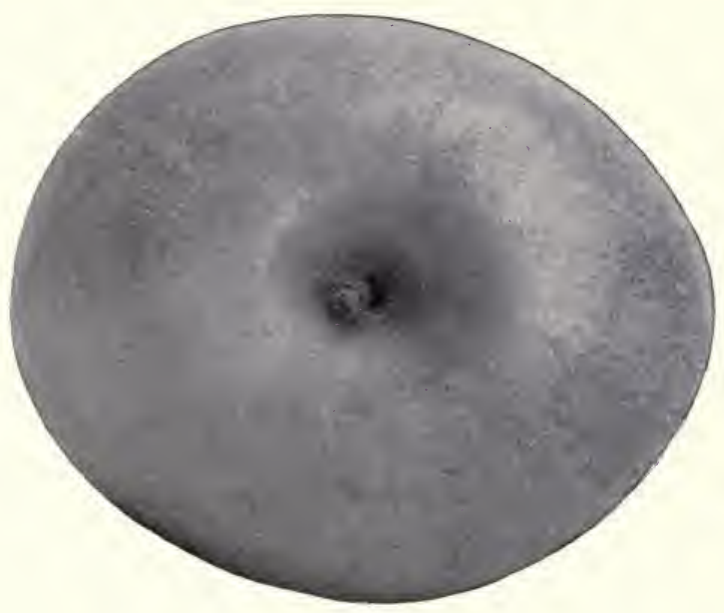

ROXBURY 

or partly open; lobes variable; medium to rather large and long; sometimes short, obtuse or acute. Basin variable, usually medium in width and depth, varying from narrow to rather wide, and from obtuse to abrupt, furrowed and often slightly wrinkled.

Skin tough or moderately tender, sometimes almost smooth, but usually largely covered with greenish to yellowish-brown russet. Highly colored specimens develop a bronze blush which rarely deepens to red. Dots russet or gray.

Calyx tube rather large, moderately wide, with fleshy pistil point projecting into the base, usually conical, sometimes funnel-shape. Stamens basal to median.

Core above medium to small, axile; cells usually symmetrical, closed, rarely partly open; core lines meeting if the calyx tube is conical but clasping if it is funnel-shape. Carpels rather flat, elongated and narrowing toward the apex, or roundish ovate, sometimes slightly emarginate, mucronate, tufted. Seeds few, often abortive, medium or above, long, plump, acute, tufted.

Flesh tinged with yellow or greenish, firm, somewhat coarse, moderately tender, breaking, juicy, sprightly subacid, good to very good.

Season December to May or in cold storage to July (42).

\section{Roxbury Compared with Golden Russet.}

As compared with the Golden Russet the Roxbury tree is larger, more spreading and more productive. The dots on the shoots of the Golden Russet are more conspicuous and more numerous than on the Roxbury. The fruit of Roxbury is larger, more oblate and it may be characteristically elliptical as shown in the accompanying half-tone plate; that of the Golden Russet is less variable in color and more uniform in size and shape. The Roxbury stem is thicker than that of Golden Russet, often tinged with red on one side and often swollen. The stem of the Golden Russet is usually shorter, not swollen and not tinged with red. The cavity of Roxbury is more often furrowed; that of the Golden Russet more often green and marked with greenish-gray dots. The flesh of the Golden Russet is more sprightly subacid, finer-grained and of richer flavor, that of the Roxbury being rather coarser, yellower, and more mildly subacid. The seeds of the Golden Russet are shorter than those of Roxbury and not so dark colored.

\section{RUSSIAN BALDWIN.}

References. I. Hoskins, Rural N. Y., 53:573. I894. 2. Can. Hort., I8:222, 266. 1895 3. Heiges, U. S. Pom. Rpt., 1895:32. 4. Can. Hort., 20:242. 1897. 5. Budd-Hansen, 1903:170. 
A Russian apple commended very highly by Dr. T. H. Hoskins, Newport, Vermont, who was instrumental in introducing Yellow Transparent and Scott. He believed this to be worth more than both of the others and said of it, 1 "The Russian Baldwin has all the merits with none of the defects of the old Baldwin-being as large and handsome, as good a bearer, better quality, and a much better keeper."

\section{Fruit.}

Fruit medium or above medium. Form roundish oblate, faintly ribbed. Stem short, moderately thick. Cavity deep, narrow to moderately wide, russeted, somewhat furrowed, sometimes lipped. Calyx above medium to small, usually partly open; lobes short, wide. Basin small, shallow, narrow, somewhat furrowed.

Skin thin, smooth, almost entirely mottled and splashed with bright red over a clear yellow background, becoming deep red on the exposed cheek with some indistinct streaks of purplish-carmine. Dots small, pale or russet.

Core above medium to large, wide; cells partly open; core lines clasping. Secds numerous, small, plump, dark brown.

Flesh whitish tinged with yellow, moderately fine, crisp, moderately juicy, mild subacid, good.

\section{RUTLEDGE.}

References. I. Bailey, An. Hort., 1892:248. 2. N. Y. Sta. An. Rpt., I I: 223. 1892. 3. Ragan, U. S. B. P. I. Bul., 56:272. 1905.

This evidently belongs in the same group as the Bethel and Blue Pearmain. Its affinity to the Blue Pearmain group is shown by the texture, flavor and quality of the flesh and by the bloom, conspicuous dots and characteristic yellow and red colors of the skin. It is less highly colored than either Blue Pearmain or Bethel but is a better keeper than either. The fruit is pretty uniformly of good size and desirable form. The tree is a good strong grower, - does not come into bearing very young, but is an annual cropper, yielding moderately heavy to good crops. It does not appear to be of sufficient value for New York state to be worthy of testing except perhaps in those regions where Bethel and Blue Pearmain are most valued.

Historical. Received for testing at this Station from T. V. Munson, Denison, Texas, in 1892 (2).

TreE.

Tree vigorous with very long and moderately stout branches; laterals characteristically covered with numerous small spurs. Form upright spreading or roundish, dense. Tavigs short to rather long, curved or nearly straight, moderately stout; terminal buds large; internodes medium to long. Bark olivegreen washed with reddish-brown, lightly streaked with scarf-skin; heavily pubescent. I.cnticels numerous, small to medium, round or slightly elongated, slightly raised. Buds medium in size, plump, acute, free, pubescent.

\section{Fruit.}

Fruit above medium, pretty uniform in size and shape. Form nearly globular varying to roundish oblate or to slightly oblong, regular or somewhat ribbed, usually symmetrical. Stem short to medium, moderately slender

${ }^{2}$ Letter, 1897. 
to thick, sometimes inserted under a lip. Cavity medium in size, acute to slightly acuminate, deep, rather broad or somewhat compressed, often slightly furrowed, sometimes partly russeted. Calyx small to medium, closed or partly open; lobes moderately narrow, acute to acuminate. Basin small to medium, often oblique, very shallow and obtuse to moderately shallow and somewhat abrupt, narrow to moderately wide, somewhat furrowed, wrinkled.

Skin rather thick, tough, smooth about the cavity but somewhat roughened toward the basin with russet dots and fine capillary russet lines, yellow or greenish largely overspread with orange-red, in well colored specimens becoming rather dull deep red, mottled and narrowly striped with purplish-carmine, often faintly marked with grayish scarf-skin toward the cavity and covered with a thin bloom which gives the fruit a dull appearance. Dots scattering, conspicuous, large, areolar, pale gray or russet toward the cavity but numerous and smaller about the basin. Prevailing effect red and yellow.

Calyx tube urn-shape. Stamens median to marginal.

Core small to medium, abaxile; cells not uniform in size, usually symmetrical, closed or partly open; core lines clasping. Carpels broadly roundish or sometimes inclined to ovate, usually smooth. Seeds small to nearly medium, obtuse to somewhat acute, plump, sometimes slightly tufted, light and dark brown.

Flesh tinged with yellow, firm, a little coarse, not very crisp, rather tender, moderately juicy, somewhat aromatic, mild subacid becoming nearly sweet, fair to good in quality.

Season January to May.

\section{SALISBURY.}

RefERENCES. I. Emmons, Nat. Hist. N. Y., 3:51, 78. I851. fig. 2. (?) Ragan, U. S. B. P. I. Bul., 56:273. 1905 .

Synonyms. (Salisbury Pippin, 2)? Salisbury Pippin, locally. Salisbury Winter (I).

A roundish yellow apple of excellent quality. So far as we have been able to learn it is known only in the vicinity of Cortland where it is grown to a limited extent. We have not seen the fruit. Mr. Nathan Salisbury, after whose father this variety was named (I), reports 1 that the fruit resembles Swaar in shape but is a little larger, ripens slowly and has very brittle flesh which is slightly acid. According to Emmons' description the fruit is yellow with a faint shade of orange; stem short, slender and peculiarly inserted in a very shallow depression; flesh tender, juicy, subacid, very pleasant, equal to Swaar.

Historical. The arigin of this variety is unknown. It was grafted into a nursery on the old Salisbury farm in Cortland, N. Y., some years prior to 1850. It is known in Cortland by the name Salisbury Pippin. We have not had opportunity to determine whether it is identical with the Salisbury or Salisbury Pippin catalogued by Lyon (2).

\section{SALOME.}

References. 1. Hatheway, Ill. Hort. Soc. Rpt., 1878:133. 2. Ib., I879:195. 3. Downing, 1881:103 app. fig. 4. Thomas, 1885:523. 5. Budd, Am. Pom.

\footnotetext{
${ }^{1}$ Letter, F. E. Brogden, 1905.
} 
Soc. Rpt., I885:26. 6. Can. Hort., II 8. I888. 7. Bailey, An. Hort., I892:249. 8. Brown, Can. Hort., 17:252. 1894. 9. Craig, Can. Dept. Agr. Rpt., 1894:125. 10. Waugh, V't. Sta. Bul., 6r:32. I897. I1. Am. Pom. Soc. Cat., 1899:20. 12. N. C. Bd. Agr. Bul., 1900:10. 13. Can. Hort., 24:454. 1901. 14. Dickens and Greene, Kan. Sta. Bul., ro6:55. 1902. 15. Budd-Hansen, I903:172. I6. Powell and Fulton, U.S. B. P. I. Bul., 48:55. 1903. 17. Beach and Clark, N. Y. Sta. Bul., 248:143. 1904. 18. Can. Hort., 27:242, 245, 1904. fig. 19. Nat. Nurseryman, 13:52. 1905.

This fruit is usually below medium size and but moderately attractive in color but sometimes it develops good size and good color. As grown in New York it does not excel standard sorts of its season in size, color or quality. In some parts of the state it is regarded with considerable favor as a promising commercial variety because the fruit hangs well to the tree in high winds, is firm, stands handling well and usually keeps pretty well, is smooth and usually free from scab; and because the tree is vigorous, very hardy, healthy, comes into bearing early and is a reliable cropper, yielding moderate to good crops biennially or nearly annually. It appears to vary somewhat in keeping qualities in different seasons and in different localities. As grown at this Station its usual commercial limit is March but exceptionally it shows a rather rapid rate of loss in early winter. It stands heat well before going into storage and goes down rapidly (I7). In Central and Western New York it appears to require a warm soil and warm exposure together with careful attention to training that the top may be kept sufficiently open to admit the sunlight to the foliage in all parts of the tree so as to hasten the ripening of the fruit and improve its color. Because the fruit lacks in size and color probably it will never be planted very extensively in this state.

Historical. Salome originated about 1853 in a nursery in Ottawa, Illinois. The property afterwards came into the hands of Mr. E. C. Hatheway who discovered the merits of the variety and began its propagation. He exhibited it before the Illinois State Horticultural Society in 1878 under the name of Salome. In 1884 it was introduced to the trade by Arthur Bryant, Princeton, Illinois. It has been disseminated sparingly in various parts of this state. Thus far it has been but little planted in New York archards but in some localities its cultivation is perhaps increasing slightly.

TREe.

Tree a vigorous, upright grower in the nursery; in the orchard it becomes large. Form upright, becoming roundish, dense. Twigs short to long, rather 

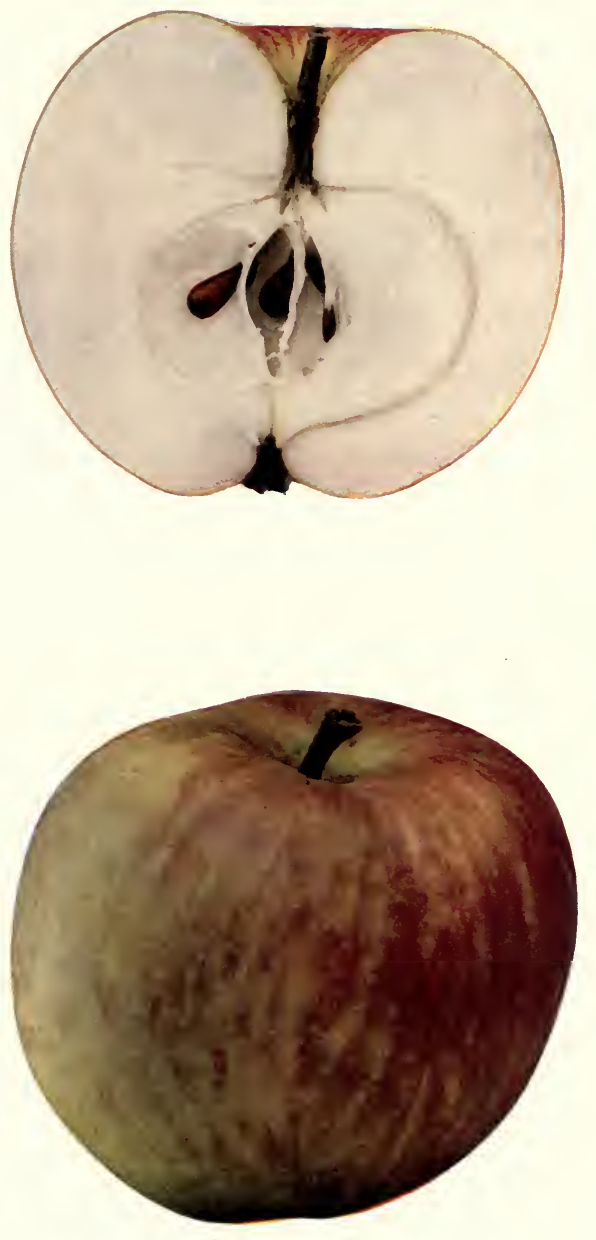

SALOME 

slender to stout with large terminal buds, straight or nearly so; internodes short to rather long. Bark clear reddish-brown tinged with olive-green, lightly mottled with scarf-skin, slightly pubescent. Lenticels clear in color, conspicuous, rather scattering, narrow, elongated, pointed, slightly raised. $B u d s$ medium to rather small, plump, obtuse to acute, free or partly adhering, slightly pubescent.

\section{FrUIT.}

Fruit below medium to above, uniform in size and shape. Form roundish oblate to roundish ovate inclined to conic, often somewhat elliptical or obscurely ribbed, usually symmetrical. Stem long, usually slender. Cavity above medium, acute to acuminate, deep, broad, often compressed or obscurely furrowed, thinly russeted. Calyx small, usually closed. Basin often but slightly depressed, but sometimes moderately deep and inclined to abrupt, ısually rather narrow, furrowed and wrinkled.

Skin thin, tough, smooth, rather pale yellow or greenish, more or less mottled and blushed with pinkish-red rather obscurely striped with carmine, marked toward the cavity with grayish scarf-skin and covered with whitish bloom. Sometimes a considerable portion of the fruit is overspread with a good red color. Dots conspicuous, whitish or pale gray, often areolar with russet point.

Calyx tube small to medium, cone-shape. Stamens basal to nearly median.

Core rather large, abaxile; cells often unsymmetrical, usually wide open, sometimes closed; core lines meeting or slightly clasping. Carpels thin, smooth, often decidedly concave, broadly roundish, sometimes slightly emarginate. Seeds rather numerous, medium or above, wide, obtuse, light and dark brown.

Flesh tinged with yellow, firm, moderately fine-grained, crisp, rather tender, juicy, sprightly, subacid, good to very good.

Season November to March but sometimes it does not extend through January.

\section{SAVEWELL.}

REFERENCE. I. Downing, I869:346.

Synonyms. Cornell's Savewell (I). Putnam's Savervell (I).

A Westchester county apple described by Downing as a valuable keeper. Fruit yellow with shade of dull red, medium in size, roundish oblate inclining to conic. Flesh pleasantly subacid, juicy, tender, good. Season February and March (I). So far as we have been able to learn this variety has not been cultivated outside the vicinity of its origin.

\section{SCARLET CRANBERRY.}

References. I. Rural N. Y., 45:593. 1886. figs. 2. Bailey, An. Hort., r892: 249. 3. Dickens and Greene, Kan. Sta. Bul., 106:55. 1902. 4. Powell and Fulton, U. S. B. P. I. Bul., 48:55. 1903 .

This is a southern variety and when grown as far north as New York it does not develop properly either in quality or in size although it often colors pretty well. It keeps in ordinary storage till late spring and has been held. 
in cold storage till May without scald or decay (4). It is not recommended for planting in this state.

This is a very different variety from Cranherry Pippin.

Historical. Originated in Scott county, Virginia, from seed of an unknown variety forty or more years ago (I). It is said to be a vigorous grower and very productive in that region, yielding very large, handsome and showy fruit. It has been disseminated by nurserymen in the South Atlantic states and in the Central Mississippi valley (2), but it is practically unknown among northern fruit growers.

\section{FruIT.}

Fruit medium in size but in the South grows large $(\mathrm{I}, 4)$. Form roundish varying to slightly oblate or to broadly ovate, often somewhat ribbed, usually symmetrical. Stem short to rather long, moderately thick. Cavity moderately large, acite to acuminate, deep to moderately deep, rather narrow to moderately wide, pretty symmetrical, gently furrowed, sometimes lipped, often partly russeted. Calyx medium to rather large, closed or partly open; lobes acute to acuminate, sometimes separated at the base. Basin often oblique, very shallow to moderately shallow, narrow to moderately wide, obtuse, furrowed, wrinkled.

Skin rather thick, tough, smooth, yellow, largely overspread with pinkishred striped with purplish-carmine, mottled and striped over the base with thin scarf-skin which produces a grayish appearance. Dots conspicuous, numerous, small to large, pale, often areolar with russet center. Prevailing effect attractive red.

Caly.x tube wide, cone-shape to urn-shape. Stamons marginal to median. Core small to above medium, axile or sometimes abaxile; cells often not uniformly developed, usually symmetrical, closed or sometimes open; core lines meeting or slightly clasping. Carpels rather flat, broadly ovate to somewhat elliptical, mucronate, usually not emarginate, smooth or slightly tufted. Seeds medium or above, moderately narrow, plump, acute, sometimes tufted.

Flesh whitish tinged with yellow, firm, rather coarse, moderately crisp, a little tough, moderately juicy, slightly astringent, mild subacid, fair to good.

\section{SCHODACK.}

References, I. N. Y. Sta. An. Rpt., II:224. I892. 2. Beach and Clark, N. Y. Sta. Bul., 248:143. 1904.

This fruit is worthy of notice only because it keeps remarkably late. Its general appearance is good for a green apple and it retains good color, firm texture and a good degree of acidity till very late in the season. As fruited at this Station it seldom averages above medium size. It is fairly acceptable for culinary purposes from March till July but it is not good enough in quality to be classed as a dessert apple. The tree is a pretty good grower, comes into hearing rather young and is a reliable cropper, yielding moderate to good crops almost annually.

Historical. Received here for testing from E. L. Smith, South Schodack, Rensselaer county, N. Y., in 1892 . 


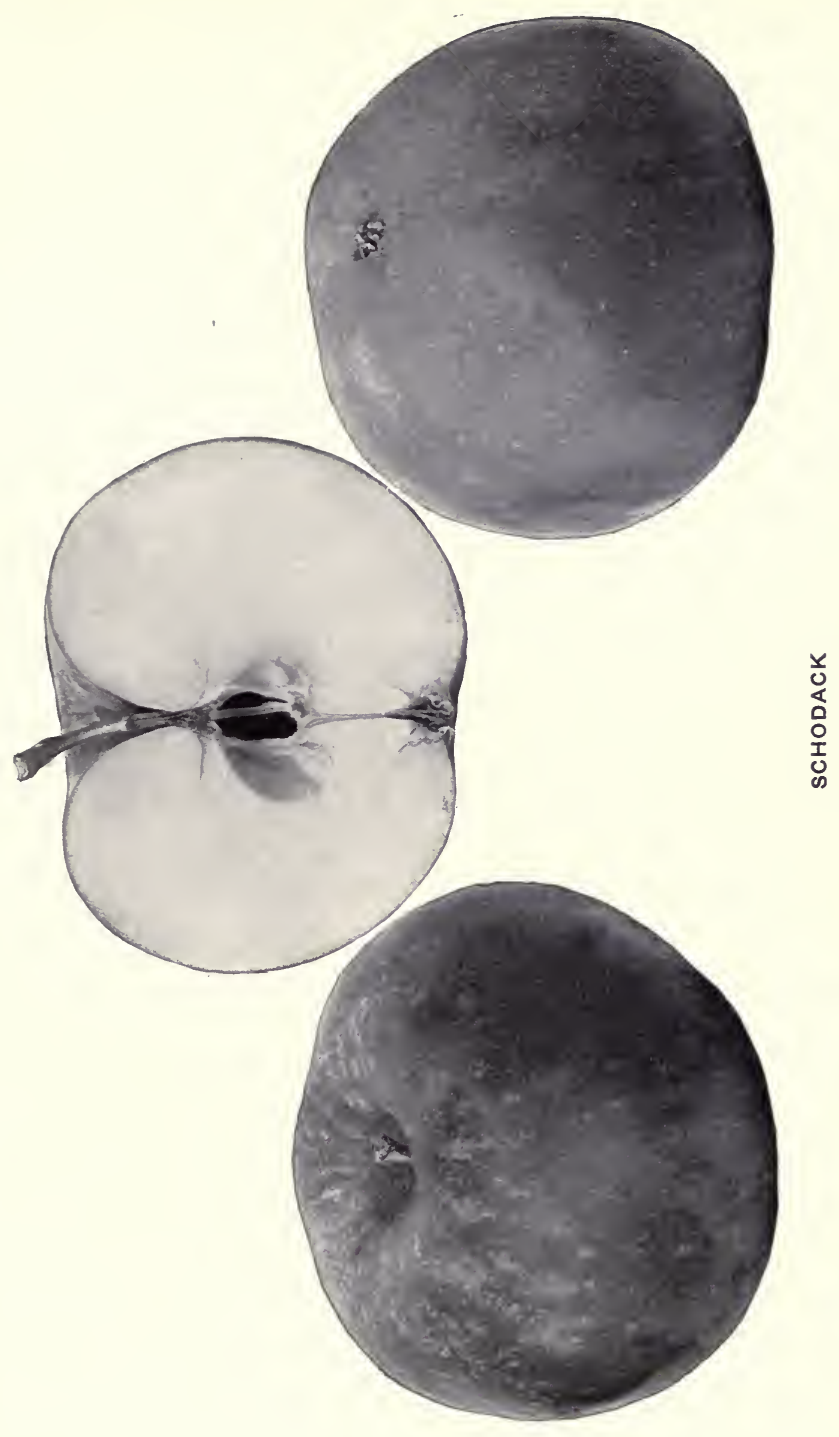





\section{TREE.}

Tree moderately vigorous with long, slender branches. Form roundish to spreading, open. Twigs medium in length, slender, curved; internodes rather long. Bark dark brown tinged with red, streaked with searf-skin, pubescent near tips. Lenticels dull, inconspicuous, scattering, medium, roundish or oval, not raised. Buds medium to below medium, prominent, plump, obtuse to acute, free or nearly so, slightly pubescent.

\section{FRUIT.}

Fruit usually medium to rather small, uniform in size and shape. Form roundish oblate varying to roundish inclined to conic, often obscurely ribbed. Stem often long and slender. Cavity usually acute, deep, broad, often slightly furrowed, sometimes partly russeted and marked with some large, elongated, irregular whitish dots and also with patches of whitish scarf-skin. Calyx small, closed. Basin shallow, obtuse, furrowed, wrinkled.

Skin thick, tough, smooth, grass-green eventually becoming tinged with yellow, blushed with rather dull pinkish-red which often deepens to a distinct red. Dots scattering, very large to small, russet or irregular, whitish and areolar with russet point. Prevailing color green.

Calyx tube deep, long, funnel-form. Stamens marginal.

Core abaxile, medium in size; cells usually symmetrical, often wide open, sometimes closed; core lines clasping. Carpels broadly roundish, emarginate, mucronate, sometimes tufted. Seeds numerous, large, rather wide, long, plump, acute, usually smooth.

Flesh whitish tinged with yellow, firm, coarse, rather tough, juicy, briskly subacid, fair or possibly sometimes good for culinary use.

\section{SCHOONMAKER.}

REFERENCES. I. Elliott, I854:156. 2. Downing, I869:348. 3. Thomas, 1875: 5II.

Synonym. Schoolmocker $(\mathrm{I}, 2)$.

This old variety is still grown to a limited extent in some portions of Southeastern New York where it is esteemed as an apple of very good quality. Elliott (I) remarks that it is probably of foreign origin and that it was grown in Detroit as early as $\mathrm{I} 804$. The tree is upright spreading and moderately vigorous. Fruit large, roundish oblate, sometimes angular. Stem short and stout. Cavity deep. Skin a little rough, yellow or greenish with bronze blush. Core small. Flesh yellowish-white, crisp, briskly subacid.

Season January to March $(1,2)$.

\section{SCOTT.}

References. I. Montreal Hort. Soc. Rpt., 1877. (cited by 24). 2. Budd, Ia. Hort. Soc. Rpt., 1880:524. 3. Thomas, 1885:523. 4. Van Deman, U. S. Pom. Rpt., 1886:271. fig. 5. Montreal Hort. Soc. Rpt., 1886-87:9, 94. 6. Rural N. Y., 47:249, 646. 1888. 7. Can. Hort., I3:174, I87, 216. 1890. 8. Bailey, An. Hort., I892:249. 9. Can. Hort., 15:159. I892. col. pl. Io. Ib., I6: 204. I893. I I. Heiges, U.S. Pom. Rpt., I894:22. 12. Craig, Can. Dept. Agr. Rpt., 1894:125. 13. Ont. Fr. Gr. Assn. An. Rpt., 26:16, 75. 1894. 14. Gard. 
and For., 8:200. 1895. 15. Craig, Can. Dept. Agr. Rpt., 1895:93. figs. 16. Budd, Ia. Sta. Bul., 31:333. I895. 17. Waugh, Vt. Sta. Bul., 61:32. 1897. 18. Am. Pom. Soc. Cat., 1897:14. 19. Waugh, Vt. Sta. An. Rpt., 14:308. I901. 20. Hansen, S. D. Sta. Bul., 76:98. 1902. fig. 21. Budd-Hansen, 1903:173. fig. 22. Powell and Fulton, U.S.B.P. I. Bul., 48:55, 1903. 23. Beach and Clark, N. Y. Sta. Bul., 248:144. 1904. 24. Ragan, U. S. B. P. I. Bul., 56:277. 1905. Synonyms. Scott's Red Winter $(8,22)$. Scott Winter $(2,3,4,5,6,7$, $8,9,10,11,12,13,14,15,16,17,18,20,21,22,24$ ). Scott's Winter (II, I9, 23, 24). Wilcox's Winter (24).

Fruit medium to rather small, of pretty good form and attractive color. It is especially suitable for culinary purposes in the spring because it retains a good degree of acidity later than most varieties of its season. Toward the close of its season its acidity is somewhat subdued and it then becomes an acceptable dessert fruit although it is not of high quality. The tree is very hardy, healthy, comes into bearing young and is a reliable cropper, yielding moderate to rather heavy crops biennially or in some cases annually. The fruit hangs well to the tree but it is apt to be uneven in size and unless proper preventive treatment is given is liable to be injured by scab so that, on the whole, there is often considerable loss in undersized or otherwise unmarketable fruit. In ordinary storage it is in season from December to May with March as its commercial limit (23).

Scott is valuable for regions where the climate is too severe to permit varieties of the grade of hardiness of Northern Spy and Rhode Island Grecning to be grown profitably. It should not be grown in sod because the fruit is naturally small and becomes unprofitably so unless the orchard is heavily manured and given thorough tillage $(12,15)$. In some localities in this state it is grown with profit for local market, and in portions of New England and Canada it is classed among the commercial varieties.

Historical. Originated about 1864 on the Scott Farm at Newport, Vermont, and brought to notice by Dr. T. H. Hoskins of that place. It is not generally known among New York fruit growers. It has been sparingly disseminated in various portions of this state but has not been planted extensively in any locality.

\section{TREE.}

Tree medium to rather large, vigorous. Form upright, becoming roundish or spreading, rather dense. Twigs medium to long, stout to somewhat slender; internodes medium to long. Bark dull reddish-brown mingled with olive- 


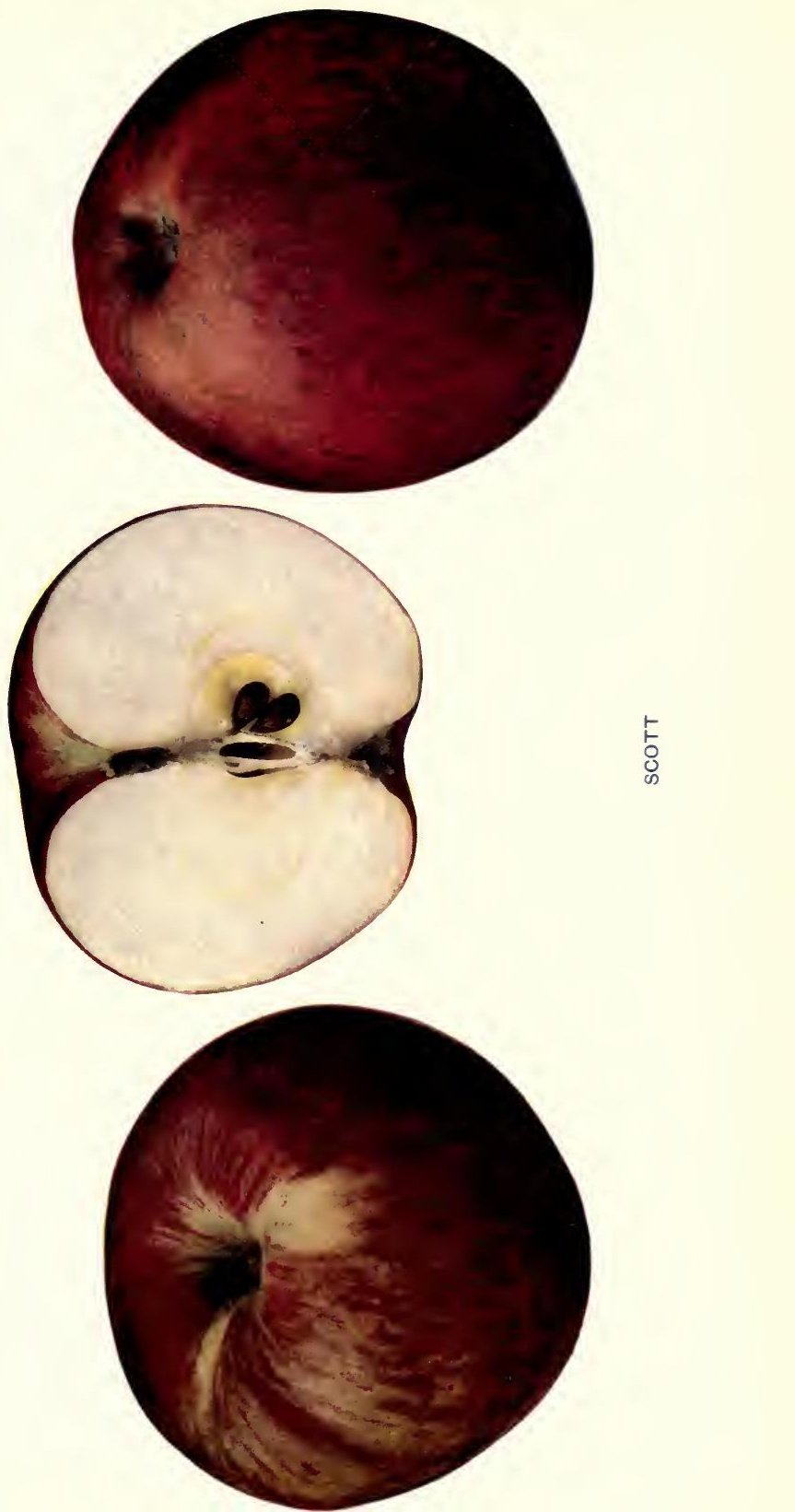



green, irregularly streaked with scarf-skin; pubescent. Lenticels scattering, small to medium, roundish, slightly raised. Buds medium or below medium in size, broad, plump, obtuse to somewhat acute, free or nearly so, slightly pubescent.

\section{FRUIT.}

Fruit below medium or sometimes medium. Form roundish conic to roundish oblate, often irregularly elliptical, broadly but obscurely ribbed. Stem short to very short. Cavity above medium to rather small, acuminate, deep, narrow to rather wide, sometimes gently furrowed, usually russeted and often with outspreading russet rays. Calyx small, closed or nearly so; lobes medium in length, converging and usually reflexed, rather narrow, acute. Basin below medium to rather small, abrupt, usually deep and rather narrow, slightly furrowed, often pubescent.

Skin smooth, rather thin, moderately tough, pale yellow or greenish mostly covered with a bright deep red mottled and striped with darker red. Highly colored specimens have a very dark and almost purplish-red cheek. Dots scattering, obscure, pale yellow or russet. General appearance good red or striped red.

Calyx tubc rather long, cone-shape or approaching funnel-form, sometimes extending into the core. Stamens median to marginal.

Core rather small to moderately large; axile or somewhat abaxile with hollow central cylinder; cells pretty uniformly developed, symmetrical, closed or partly open; core lines meeting or somewhat clasping. Carpels broadly roundish, varying from nearly elliptical to nearly cordate, slightly emarginate, mucronate, smooth or nearly so. Sceds numerous, above medium to rather small, rather narrow to moderately wide, acute to acuminate, plump, dark, sometimes a little tufted.

Flesh slightly tinged with yellow, sometimes stained with red, firm, crisp, a little coarse, tender, very juicy, briskly subacid, eventually becoming rather mild subacid, aromatic, good.

\section{SCRIBNER.}

References. 1. American Farmer, 1859. (cited by 4). 2. Downing, 1872: 3I app. 3. Burrill and McCluer, Ill. Sta. Bul., 45:340. I896. 4. Ragan, U. S. B. P. I. Bul., 56:277. 1905 .

Synonyms. Scribner's Spitzenberg (3). Scribner's Spitzenburgh (2). Scribner's Spitzenburgh (4).

A medium-sized midwinter apple of very good quality which originated with Elijah Scribner, Plattsburg, New York. Downing describes the fruit as "angular, roundish conical, shaded with bright deep red; flesh crisp, tender, juicy, subacid, slightly aromatic; in season from December to February" (2). This variety appears to be practically unknown among New York fruit growers.

\section{SEEK-NO-FURTHER.}

The meaning of this name is evident. It has been applied to many different apples but the variety which pomologists know as the Westfield Seek-No-Further New York fruit growers and fruit 
buyers commonly call by the simple name Seek-No-Further or its abbreviation, Seek. For an account of this apple the reader is referred to Westfield Scck-No-Further.

Among the other varieties described in this volume with SeekNo-Further occurring in either the accepted name or in a synonym are those mentioned in the following list.

Long Island Scck-No-Further see Ferris. May Seck-No-Further see Grayhouse. Oakland County Seek-No-Further see Oakland. Rhode Island SeekNo-Further see Ferris. Seek-No-Further of some see Rambo. Westchester Seek-No-Further see Ferris.

\section{SHACKLEFORD.}

References. I. Ill. Hort. Soc. Rpt., 1883:57, 126, 129. 2. Mo. Hort. Soc. Rpt., I885:34. 3. Gano, Am. Pom. Soc. Rpt., I889:130. 4. Bailey, An. Hort., 1892:249. 5. Stinson, Ark. Sta. Bul., 43:104. 1896. 6. Thomas, $1897: 653$.

Synonym. Shackleford's Best (I).

An apple of the Ben Davis type. It ranks close to Ben Davis in quality but is less highly colored and is hardly as good a keeper as that variety. The fruit is smooth, uniform, of good size and under favorable conditions it develops good color but as grown at this Station on rather heavy clay loam its general appearance is not especially attractive. When grown as far north as this it evidently requires a warm slope and warm soil to develop good color. So far as tested in this region it sustains the reputation it has gained elsewhere of being very hardy, coming into bearing young and of producing good crops regularly. It is evidently less desirable than Ben Davis for planting in New York.

Historical. Originated near Athens, Missouri. It was generally disseminated in that locality as early as 1883 (I). Thus far it has been planted in New York only in an experimental way.

TrEe.

Tree medium in size, moderately vigorous. Form rather flat, spreading, somewhat drooping, open. Tarigs short to above medium, curved or nearly straight, moderately stout; internodes short. Bark clear brownish-red with some olive-green, partly streaked with scarf-skin, smooth or slightly pubescent near tips. Lenticels inconspicuous, scattering, small to medium, varying from roundish to elongated, not raised. Buds set deeply in the bark, small, with large broad shoulders, flat, obtuse, appressed, slightly pubescent.

\section{Fruit.}

Fruit medium to rather large, uniform in size and shape. Form roundish to roundish ovate, pretty regular and symmetrical. Stem long, rather slender. Cazity medium to rather small, acuminate or approaching acute, shallow to medium in depth, narrow to medium in width, usually symmetrical and slightly russeted. Calyx above medium to medium, usually closed; lobes long, moderately broad, acute to acuminate. Basin medium to rather large, medium in 

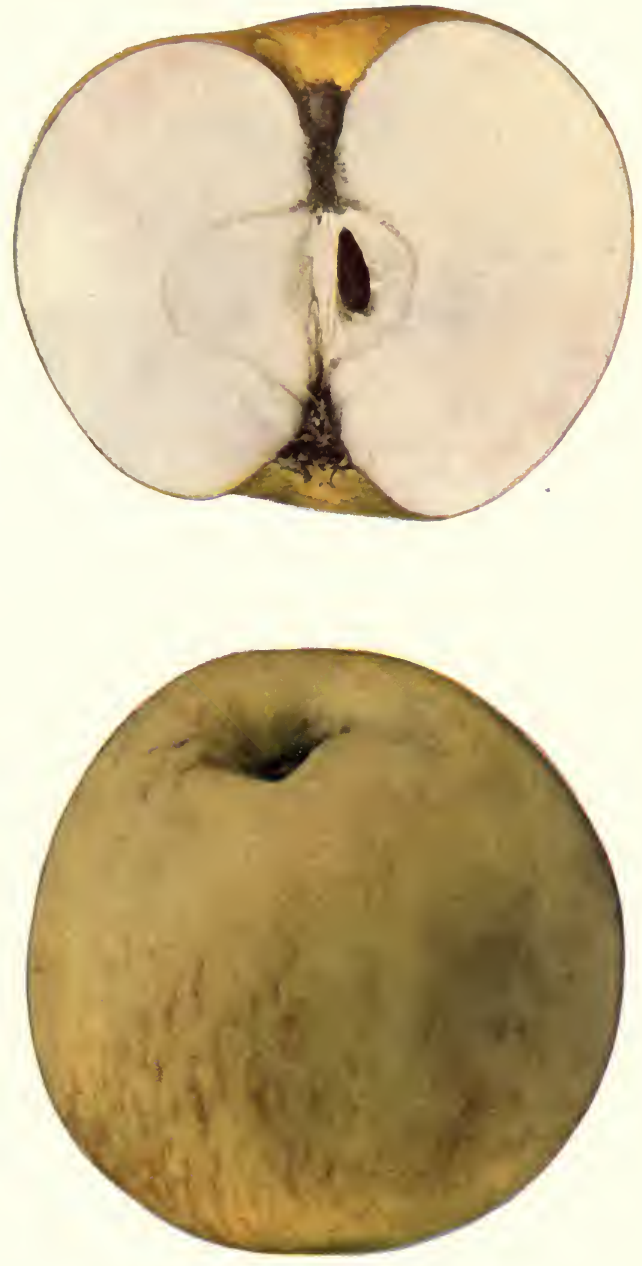

SHACKLEFORD 

depth to sometimes deep, moderately wide to wide, rather abrupt to very abrupt, usually wrinkled and furrowed.

Skin moderately thick, tough, waxy, smooth, pale greenish-yellow becoming nearly clear yellow, washed with red, mottled and striped with carmine. Dots inconspicuous, small, numerous, sometimes submerged, sometimes russet.

Calyx tube varies from short to long and from cone-shape to funnel-form, often with a fleshy pistil point projecting into the base. Stamens median to basal.

Core usually axile, above medium to rather small; cells usually symmetrical, closed or sometimes open; core lines meeting or clasping. Carpels pointed ovate, emarginate. Seeds numerous, medium or above, moderately wide, plump, acute or nearly so.

Flesh slightly tinged with yellow, firm, moderately coarse, crisp, moderately tender, juicy, mild subacid, fair to good.

Season November to April.

\section{(I) SHANNON.}

References. I. Downing, I881:I04 app. 2. Am. Pom. Soc. Rpt., 1885:25. 3. Van Deman, U. S. Pom. Rpt., 1886:269. fig. 4. Babcock, Rural N. Y., 49: 873. 189o. figs. 5. McNeil, Ark. Sta. Rpt., 1890:33. 6. Bailey, An. Hort., 1892:249. 7. Clayton, Ala. Sta. Bul., 47:7. 1893. 8. Stinson, Ark. Sta. Bul., 43:104. I896. 9. Ib., 60:133. I899. Io. Dickens and Greene, Kan. Sta. Bul., 106:55. 1902 .

Synonym. Shannon Pippin $(1,7)$.

Fruit large, yellow, smooth, pretty uniform, rather attractive in appearance and very good in quality; suitable for either home use or market. So far as tested here it is not sufficiently productive to be valuable in this region.

Historical. The history of the Shannon is rather obscure. For some time it was supposed by leading pomologists that Shannon was an Arkansas name given to the Ohio Pippin.1,2 Later investigators however have been led to question the correctness of this view $(1,3,9)$ and the bulk of the evidence now seems to indicate that the Shannon is an Arkansas seedling closely resembling the Ohio Pippin yet with sufficient difference to distinguish the varieties. As fruited at this Station the tree of Ohio Pippin is slightly less vigorous than that of Shannon. The fruit averages smaller, is usually somewhat conic, the seeds are more numerous, the flavor is milder and the season is decidedly earlier than that of Shannon. Shannon is said to have originated near Boonsboro, Washington county, Ark. (9). It has been but little disseminated in New York.

\section{TREE.}

Tree vigorous with long and rather stout branches. Form rather open, spreading. Twigs medium to long, moderately stout, crooked to nearly straight, quite pubescent; internodes moderately short to very short. Bark reddish-brown, mottled with thin scarf-skin. Lenticels numerous, inconspicuous, very small, roundish or sometimes elongated. Buds medium to large, roundish, plump, somewhat acute to rather obtuse, appressed, pubescent.

1 Warder, 1867: 484,731 .

2Downing, 1869: 292. 


\section{Fruit.}

Fruit large. Form oblate to roundish oblate, often somewhat elliptical and obscurely ribbed; sides sometimes unequal. Stem short, moderately thick. Carity moderately large, acute to acuminate, deep, moderately broad to very broad, symmetrical or somewhat furrowed, often with radiating russet rays or overspread with russet. Caly.x large, open or partly open; lobes separated at base. Basin above medium to rather small, moderately shallow to deep, moderately narrow to rather wide, abrupt, usually indistinctly furrowed but sometimes smooth.

Skin rather thin, tough, smooth, bright, clear pale yellow, usually somewhat blushed. Dots inconspicuous, pale green or whitish, often submerged, sometimes witl russet point.

Calyx tube yellow, rather long, very wide, cone-shape or somewhat funnelform and sometimes extending to the core. Stamens median.

Core medium to rather small, slightly abaxile; cells often not uniformly developed, symmetrical, partly open or closed; core lines slightly clasping or meeting. Carpels thin, tender, roundish, mucronate, but slightly emarginate if at all, usually smooth. Sceds few, short to medium, plump, narrow to rather wide, acute.

Flesh whitish tinged with yellow, moderately firm, moderately fine-grained, breaking, tender, juicy to very juicy, sprightly subacid, good to very good.

Season at Geneva November to April or May.

\section{(II) SHANNON.}

\section{Reference. I. J. R. Johnson, Cat., r894.}

The variety described below, so far as we know, has not been disseminated in New York. The following account is given in order that the reader may distinguish between this Shannon and the Shannon above described.

This originated as a chance seedling on the farm of Wm. Shannon, Coshocton county, Ohio. It was introduced by J. R. Johnson, of Coshocton, who stated that it is "yellow, of good size and good quality, keeps till April and holds its flavor; tree a good grower and a good bearer" (I). Mr. Johnson reports that he ventured to catalogue it under the name Shannon for local trade although he knew that a very different apple had been previously introduced under that name by A. H. Ernst.1

\section{SHEDDAN.}

Reference. I. Tenn. Sta. Bul., I:29. 1896. fig.

Although this is a variety of Tennessce origin it appears to have considerable merit as grown in New York and is worthy of further testing in this region. As grown at this Station the tree is thrifty, comes into bearing young and gives promise of being productive. The fruit is of desirable size and good quality and is suitable for either home use or market. It somewhat resembles a well-grown Rhode Island Greening in color but has the advantage over that variety in being a much better keeper and evidently not liable
to scald.

\footnotetext{
${ }^{1}$ Letter, J. R. Johnson, 1895.
} 
Historical. Originated as a chance seedling with John E. Sheddan, Friendsville, Blount county, Tennessee, about 1882 (I). It probably grew from a seed of Green Crank near which the original Sheddan tree stood. So far as we know this variety has not been grown in New York except at this Station.

TREE.

Tree vigorous. Form upright spreading, rather open. Twigs short, rather stout to sometimes slender. Bark dull green and reddish. Lenticels numerous, very small, roundish, dark. Buds small, appressed, rather obtuse.

\section{FRUIT.}

Fruit above medium to large. Form roundish, slightly oblate, regular, symmetrical. Stem moderately long and rather slender to short and thick, sometimes swollen at the base. Cavity medium in size, obtuse to acute, moderately shallow to deep, rather broad, usually obscurely furrowed, sometimes lipped, somewhat russeted. Calyx small, closed or partly open. Basin shallow to moderately deep, narrow to moderately wide, obtuse to rather abrupt, somewhat furrowed, wrinkled.

Skin smooth, grass-green changing to yellow with an orange blush which sometimes deepens to red. Dots often submerged, numerous, pale or yellowish especially toward the basin but toward the cavity they are larger, more scattering and more often areolar with russet point. Prevailing effect attractive yellow when the fruit is fully ripe.

Calyx tube nearly urn-shape or approaching funnel-form. Stamens median.

Core medium to rather small, somewhat abaxile to nearly axile, sometimes with hollow cylinder in the axis; cells not always uniformly developed, symmetrical, closed or partly open; core lines clasping. Carpels thin, smooth or nearly so, broadly roundish to broadly obovate, mucronate, emarginate. Secds moderately dark reddish-brown, medium to small, plump, acute to obtuse, sometimes slightly tufted; often some are abortive.

Flesh tinged with yellow or greenish, hard, firm, moderately fine-grained or slightly coarse, crisp, somewhat tender, moderately juicy, mild subacid, good to very good.

Season January to May.

\section{SHEEPNOSE.}

References. I. Coxe, I8I $7: 125$. 2. Warder, 1857:645. 3. Downing, i 869: $35 \mathrm{I}$.

This name has been applied to several different varieties of apples having a conical shape. In some localities Yellow Bellflower is known by this name. In other places it is a common name for the Black Gilliflower.

Warder (2) describes Sheepnose of Mears as a medium, roundish, slightly conic apple, smooth, greenish-yellow, in some respects resembling White Pearmain; flesh juicy, subacid, good; season December to February.

Vol. I $-\mathrm{I}_{3}$ 
In the time of Coxe, Bullock was commonly known in New Jersey by the name of Sheepnose (I).

Downing (3) describes another Sheepnose as grown in New Jersey and Pennsylvania the fruit of which is of medium size, roundish conical, yellow, sometimes blushed; flesh subacid, good; season November and December.

There are also other varieties which are known under the name Sheepnose.

\section{SHERIFF.}

References, I. Ia. Hort. Soc. Rpt., 1880:600. 2. Downing, I881:105 app. 3. Am. Pom. Soc. Cat., 1889:12. 4. Taylor, Am. Pom. Soc. Rpt., 1895:193, 199. 5. Hansen, S. D. Sta. Bul., 76:98. 1902. fig. 6. Budd-Hansen, 1903:174.

Symonym. American Beauty incorrectly $(2,5,6)$.

This variety has received attention in some parts of the West on account of its superior hardiness. The fruit is of medium size and pleasant flavor but not high quality. The tree comes into bearing young, is a reliable cropper and productive $(\mathrm{I}, 2,5,6)$.

Historical. Downing reports that this variety was brought from Pennsylvania by James Sheriff and the original name having been lost it was called Sheriff (2). It was placed upon the list of the American Pomological Society in 1889 (3) as a variety worthy of testing but was dropped from that list in 1897 .

$$
\text { TREE }(2,5,6) \text {. }
$$

Tree very hardy, vigorous, tall, with few branches. Form symmetrical, somewhat spreading, open.

$$
\text { FRUit }(2,5,6) \text {. }
$$

Frust medium or below medium. Form roundish to roundish oblate or somewhat cylindrical, flattened at the ends, nearly regular. Stem short to long and slender. Cavity small, acuminate, deep, very narrow, regular, green and russeted. Calyx closed; lobes erect, convergent. Basin large, wide, shallow to deep, wavy or slightly ribbed.

Skin pale yellow or greenish, nearly covered with light and dark red obscurely striped and splashed with carmine. Dots numerous, small, distinct, pale or whitish.

Caly.x tube funnel-shape. Stamens median.

Core very large; cells ovate, slit, closed. Seeds few to many, plump, pointed.

Flesh whitish, fine-grained, tender, juicy, mild subacid, good but not rich In quality.

Season December to February.

\section{SHIRLEY.}

References. I. $N$. Y Sta. An. Rpt., II:223. r892. 2. Bailey, An. Hort., 1892:249. 3. Ragan, U. S. B. P. I. Bul., 56:282. 1905. 
This is a bright-colored apple of the Ben Davis type. As grown at this Station it appears to be less valuable than Ben Davis being decidedly inferior to that variety in size and no better in quality. It is in season about with Ben Davis.

Historical. This variety has been propagated by some nurserymen in Texas. In $\mathrm{I}_{9} 92$ it was received for testing here from T. V. Munson, Denison, Texas. So far as we know it has not been disseminated among New York fruit growers.

\section{TREE.}

Tree moderately vigorous; branches long, slender, curved. Form upright spreading varying to roundish, open. Twigs short, straight, slender, with large terminal buds; internodes short to below medium. Bark clear reddishbrown, lightly streaked with scarf-skin, slightly pubescent. Lenticels scattering, small to very small, round or elongated, not raised. Buds deeply set in bark, small, broad, obtuse, appressed, slightly pubescent.

\section{FrUit.}

Fruit medium to rather small. Form roundish inclined to conic, sometimes oblate, usually symmetrical. Stem medium to rather long and slender. Cavity rather large, obtuse to acute, deep, wide, usually symmetrical, sometimes indistinctly furrowed, the lower part often russeted but the russet seldom extending beyond the cavity. Calyx small to medium, somewhat open or sometimes closed. Basin small to medium, abrupt, moderately shallow to moderately deep, rather narrow to moderately wide, usually smooth and symmetrical.

Skin thick, tough, smooth, waxy, glossy, yellow blushed and mottled with bright deep red, marked rather indistinctly with narrow stripes and splashes of purplish-carmine and overspread with a thin bloom which gives it a slightly dull appearance but when polished the fruit has a bright red color. Dots inconspicuous, small, pale, sometimes brown. Prevailing effect deep red.

Calyx tube large, deep, urn-shape varying to elongated cone-shape or funnelform. Stamens median to marginal.

Core distant, medium or above, abaxile, with hollow cylinder in the axis; cells symmetrical, closed; core lines decidedly clasping. Carpels broadly roundish or approaching roundish obcordate, somewhat emarginate, usually smooth. Seeds somewhat variable, usually large, long, wide, obtuse, somewhat tufted, rather dark brown.

Flesh whitish or tinged with green, firm, not tender, crisp, moderately fine, juicy, sprightly, mild subacid, fair to good.

Season December to May.

\section{SKANK.}

Fruit uniform, of good size and attractive in color when highly colored; but usually it is not highly colored and on this account would not rank as a firstclass commercial variety. When well grown it is one of the best dessert apples of its season and it should not be allowed to pass out of cultivation. It is in season from October to February or later. The tree is hardy, healthy, long-lived and a reliable cropper, yielding heavy crops in alternate years. 
Historical. This is an old variety which, so far as we know, is now grown only in Southern Seneca county. It was brought to our attention by M. C. Brokaw of Interlaken, N. Y., who reports that it was once cultivated in New Jersey under the name Skank. We have been unable to find any mention oi it by pomological writers.

\section{TREE.}

Tree medium to large, vigorous. Form spreading. Twigs medium in length, spreading, medium in thickness.

\section{Fruit.}

Fruit large or above medium, uniform in size and shape. Form roundish conic to roundish, regular, pretty symmetrical. Stem medium in length, moderately thick to rather slender. Carity acute to acuminate, deep, broad, sometimes compressed, thinly russeted, the russet not extending beyond the cavity. Caly.r medium or below, closed or slightly open; lobes short to rather long, acute. Basin rather small, moderately shallow to rather deep, medium in width to narrow, somewhat abrupt, slightly wrinkled.

Skin rather thin and tender, smooth, bright pale yellow partially overspread and mottled with attractive red, distinctly splashed and often broadly striped with bright carmine. Well-colored specimens are nearly covered with red. Dots scattering, medium to above, russet or areolar with russet center.

Caly.r tube medium to rather large, funnel-form to cone-shape. Stamens median to marginal.

Core small, sessile or nearly so, abaxile; cells pretty symmetrical, usually open or partly open; core lines uswally somewhat clasping. Carpels much concave, broadly roundish to slightly elliptical, emarginate. Seeds numerous, medium or below, rather narrow, quite plump, irregular, moderately acute to acuminate, rather dark brown.

Flesh yellowish, sometimes with faint reddish tinge, rather firm, fine-grained, crisp, tender, juicy, mild subacid, agreeably aromatic, good to very good for dessert.

\section{SLEIGHT.}

References. I. Am. Pom. Soc. Rpt., r867. (cited by 3). 2. Downing, 1869:353. j. Ragan, U. S. B. P. I. Bul., 56:285. 1905.

Synonyms. Sleigirt's Lady Apple (2). Sleight's Lady Apple (3). Slight's Lady Apple (i). Slight's Lady Apple (3).

An apple of the Lady type which originated with Edgar Sleight, Dutchess county, N. Y. Downing describes it as an almost perfect facsimile of Lady except that it is nearly twice as large and ripens a little earlier.

We have not scen this variety and have received no report of its being grown ontside of the locality of its origin.

\section{SMITH CIDER.}

References. I. Coxe, I8I7:131. fig. 2. Thacher, r822:123. 3. Elliott, 1854:157. 4. Am. Pom. Soc. Cat., 1856. 5. Downing, 1857:189. 6. Hooper, 1857:84. 7. Horticulturist, 15:184. I860. 8. Mag. Hort., 26:102. 1860. 9. Hovey, Ib., 29:262. I863. fig. Io. Warder, 1867:6I 4. fig. II. Downing, I869: 354. fig. 12. Fitz, I872:I43, I53. I3. Leroy, I873:579. fig. I4. Thomas, I875: 


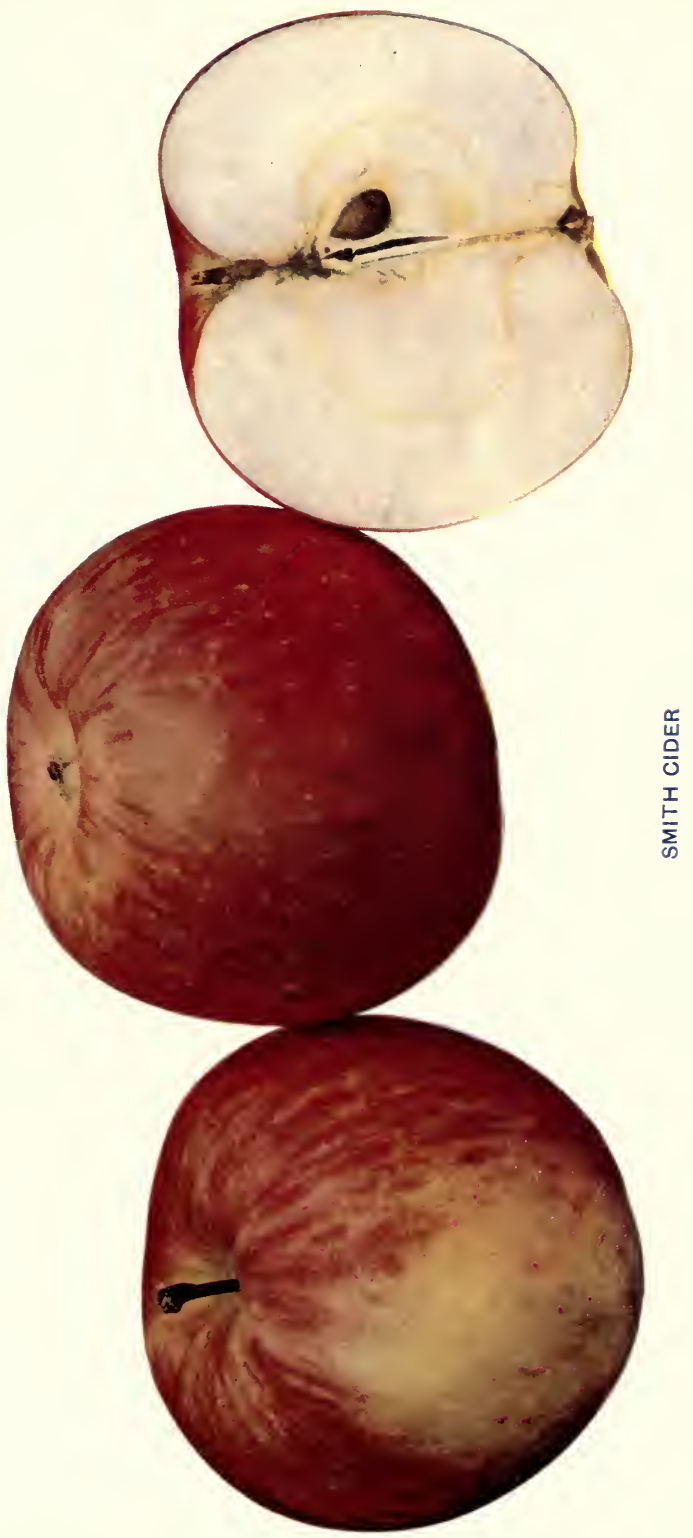



222. I 5. Barry, I883:354. I6. Wickson, I889:247. I7. Lyon, Mich. Hort. Soc. Rpt., I89o:296. г8. Bailey, An. Hort., I892:249. I9. Can. Hort., 16:435. I893. 20. Mathews, Ky. Sta. Bul., 50:32. I894. 2r. Burrill and McCluer, Ill. Sta. Bul., 45:341. 1896. 22. Beach, W. N. Y. Hort. Soc. Rpt., I9or:76. 23. Alwood, Va. Sta. Bul., 130:124. I901. 24. Waugh, Vt. Sta. An. Rpt., 14: 308. I901. 25. Kan. Sta. Bul., го6:55. 1902. 26. Powell and Fulton, U. S. B. P. I. Bul., 48:56. 1903. 27. Budd-Hansen, 1903:176. fig. 28. Beach and Clark, N. Y. Sta. Bul., 248:144. I904. 29. Ragan, U. S. B. P. I. Bul., 56:72, 286. 1905 .

Synonyms. Choice Kentuck (29). Cider (9). Cider (29). Cider ApPle (I, 2). Fowvler (II, I3, 29). Fuller (II, I3, 29). Jackson Winesap (29). Pennsylvania Cider (I I, I3, 29). Poplar Bluff (29). Popular Bluff (13). Popular Bluff (I I, 29). Smith's (10, 26, 29). Smith's (II, 13, 29). Siith's Cider $(3,4,5,6,7,8$, II, I2, I4, I5, I6, I7, 18, 19, 20, 21, 22, 23, 24, 25). Smith's Cider (9, 10, 13, 26, 29).

When well grown this is a beautiful fruit. It ranks good but not high in quality. Coxe ( $\mathrm{I}$ ) observes that it bears some resemblance to the old Vandevere of Pennsylvania. He describes it under the name Cider Apple by which name it is still commonly known in some sections of the country. Warder (IO) remarks that it cannot be recommended for the table but gives great satisfaction for culinary purposes and for market, being "one of the most profitable apples planted in Southwestern Ohio and adjacent counties of Indiana." The tree is a good grower, comes into bearing young and usually is very productive. As grown in New York the fruit usually fails to develop properly in size and quality, and is, on the whole, unsatisfactory and unprofitable.

Historical. This has long been a favorite apple in Bucks county, Pennsylvania where it originated ( I, 5, 9, IO, II, I9), and it is highly esteemed in certain regions farther south and west (I, 3, I0, 19, 23). Although it has long been known in cultivation it has not gained much recognition among New York fruit growers.

\section{TREE.}

Tree moderately vigorous with long, moderately stout, straggling branches. Form tall, upright spreading or roundish, rather open. Twigs above medium to long, curved, rather slender; internodes short to medium. Bark dark brownish-red lightly mottled with scarf-skin, pubescent. Lenticels quite numerous, inconspicuous, small to medium, round, not raised. Buds medium in size, plump, obtuse to somewhat acute, free or nearly so, pubescent.

\section{Fruit.}

Fruit medium to large when well grown but it often averages below medium. Form roundish oblate inclined to conic or varying to oblong and truncate, regular to somewhat elliptical; axis often oblique; sides sometimes unequal. 
Stem short to moderately long, slender. Cazity rather large, acute or sometimes obtuse, moderately deep, moderately narrow to broad, often with outspreading russet. Caly $x$ below medium to large, partly open or sometimes closed; lobes leafy, long, acute to acuminate. Basin wide, varying from very shallow and obtuse to rather deep and abrupt, somewhat furrowed and wrinkled.

Skin thin, tough, smooth or slightly roughened with capillary russet lines about the basin, glossy, bright pale yellow or greenish mottled and shaded with pinkish-red, splashed and striped with bright carmine. Dots whitish or russet, often areolar, rather large and conspicuous. Prevailing effect bright pinkish-red.

Calyx tube short and obtusely cone-shape or sometimes approaching funnelform. Stamens median.

Core below medium to rather large, abaxile to nearly axile; cells symmetrical, open or sometimes closed; core lines meeting or somewhat clasping. Carpels thin, usually smooth, broadly roundish to elongated or narrowing irregularly toward the apex, acuminate, emarginate. Seeds numerous, above medium, wide, plump, obtuse, dark.

Flesh whitish, firm, moderately fine-grained, crisp, tender, juicy, subacid becoming mildly subacid, aromatic, sprightly, good but not high in flavor or quality.

Season at Geneva November to March.

"MAKEFIELD is the name given to an apple shown at the meeting of the New Jersey Horticultural Society in Igoo. It originated in Makefield township, Bucks Co., Pa., hence its name. It is supposed to be a sport from Smith's Cider, which it resembles in tree. It is fully as prolific as Smith's Cider. The fruit is like Smith's Cider in all respects, except that it has a deep red color, making it more valuable for market. The distinctive feature is that the red is not in stripes as in Smith's Cider, and even the small specimens are red" (22).

\section{SMOKEHOUSE.}

References. I. Horticulturist, 2:482, 570. 1848. 2. Brinckle, Ib., 3:333. 1849. fig. 3. Thomas, 1849:152. 4. Horticulturist, 4:340, 414. 1850. 5. Am. Pom. Soc. Cat., 1852. 6. Horticulturist, 7:475. 1852. 7. Mag. Hort., 19:68. 1853. 8. Hovey, Ib., 22:558. 1856. fig. 9. Horticulturist, II:289. I856. 10. Downing, 1857:104. I1. Hooper, 1857:85. 12. Hoffy, N. A. Pom., 1860. col. pl. 13. Horticulturist, 15:184. 1860. 14. Warder, 1867:732. 15. Fitz, 1872: 143, 153. 16. Leroy, 1873:815. figs. 17. Barry, 1883:355. 18. Wickson, 1889: 244. 19. Lyon, Mich. Hort. Soc. Rpt., 1890:296. 20. Bailey, An. Hort., 1892: 249. 21. Hicks, Rural N. Y., 53:205. 1894. 22. Alwood, Va. Sta. Bul., 130: 136. 1901. 23. Dickens and Greene, Kan. Sta. Bul., 106:55. 1902. 24. Bruner, N. C. Sta. Bul., 182:22. 1903. 25. Budd-Hansen, 1903:177. fig.

Synonyms. English Vandevere (10). Gibbons Smokehouse (I). Millcreck (12). Millcreek Vandevere (4, 9, 10, 16). Red Vandevere (16). SMoke House (11, 12). Vandervcre (12). Vandevere English (16). 

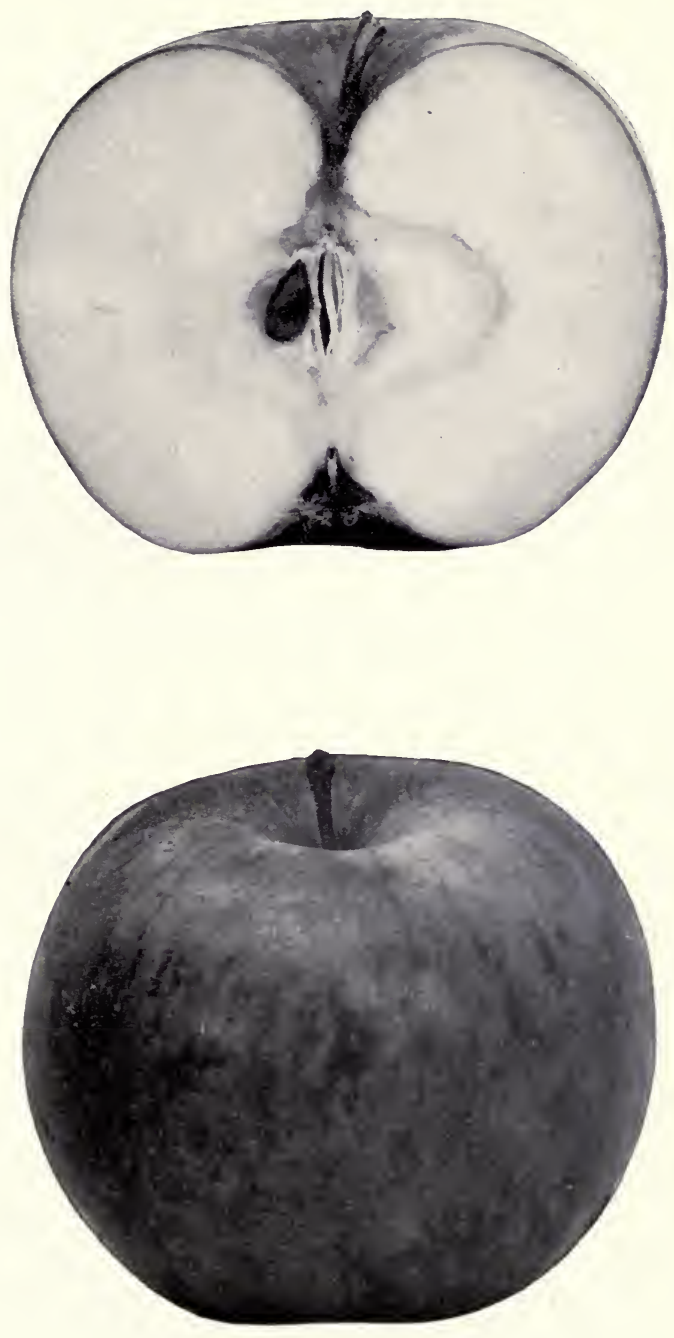

SMOKEHOUSE 

Fruit uniform in size, symmetrical and attractive in appearance when well colored; but too often its color lacks character, being neither distinctly yellow nor distinctly red. It is a very pleasant flavored dessert apple but hardly acid enough for most culinary uses. The tree is a good, vigorous grower, healthy, hardy and usually a reliable cropper, alternating good with moderate crops. It comes into bearing moderately young. The fruit hangs well to the tree. It is somewhat subject to apple scab and requires thorough preventive treatment to insure clean fruit. The tree tends to form a rather dense head and requires frequent pruning to keep the top sufficiently open to develop fruit of good color and good quality. Some fruit growers regard it with favor as a commercial variety on account of its being reliably productive and yielding a very good grade of smooth fruit; but it is not grown extensively in any part of the state, and, so far as we can learn, its cultivation is not being extended.

Historical. Originated with William Gibbons, Lampeter township, Lancaster county, $\mathrm{Pa} .(2,12)$. It took its name from the fact that the original tree grew near his smokehouse. It was brought to notice about I837 by Ashbridge though it had long before been propagated in a nursery near the locality of its origin. It is supposed to be a seedling of the old Vandevere of Delaware and Pennsylvania as it much resembles that variety; in fact Elliott fell into the error of calling it identical with Vandevere. 1 It has been grown more extensively in New Jersey and Pennsylvania than it has in this state. It is cultivated to a limited extent in many portions of New York but is not generally known among New York fruit growers.

\section{Tree.}

Tree medium to large, vigorous. Form roundish to wide-spreading, dense; lateral branches willowy, slender. Twigs moderately long, straight, slender; internodes long. Bark reddish-brown mingled with olive-green, lightly streaked with scarf-skin, slightly pubescent. Lenticels very scattering, oblong, not raised. Buds set deeply in bark, medium in size, broad, flat, obtuse, appressed, pubescent.

\section{FrUIT.}

Fruit above medium to large, uniform in size and shape. Form roundish oblate or approaching oblate conic, rather regular, symmetrical or nearly so. Stem medium to long, slender. Cavity acute to acummate, medium to rather deep, moderately narrow to rather wide, sometimes gently furrowed, often thinly russeted. Calyx large, open or nearly so; lobes often flat, convergent, separated at the base. Basin moderately shallow to rather deep, rather wide; sometimes compressed, somewhat abrupt, slightly wrinkled.

${ }^{1}$ Elliott, 1854: I $_{3}$. 
Skin thin, tough, smooth or slightly roughened with capillary russet lines and russet dots; color yellow or greenish mottled with rather dull red, sometimes deepening to a solid bright red, indistinctly mottled, striped and splashed with carmine. Dots generally conspicuous, large, irregular, gray or russet, becoming smaller and more numerous about the basin. Prevailing effect greenish-yellow; but in highly colored specimens, red.

Calyx $t u b c$ rather wide, short, obtusely cone-shape or approaching funnelform. Stamens median to basal.

Core rather small, axile or nearly so; cells symmetrical, closed or partly open; core lines meeting or with funnel-form calyx tube, clasping. Carpels flat, broadly elliptical to roundish or somewhat cordate, usually smooth. Seeds few, very dark, large, narrow, long, acute to acuminate, sometimes tufted.

Flcsh slightly tinged with yellow, rather firm, moderately fine, crisp, moderately tender, juicy, mild subacid, delicately aromatic, with an agreeable but not high flavor, good.

Season October to February or March.

\section{SPITZENBURG.}

New York fruit growers and fruit dealers commonly use the simple name Spitzenburg or its colloquial abbreviation Spitz, in referring to the variety known to pomologists as Esopus Spitzenburg. Pomologists are now publishing this name with Spitzenburg in italics as the first step toward shortening the name to Esopus, but comparatively few New York fruit growers would recognize it by the name Esopus and it will doubtless continue to be called Spitzenburg as long as it remains in cultivation. For an account of this variety the reader is referred to Esopus Spitzenburg.

This word has been variously spelled by different pomologists as, Spitzemberg, Spitzenberg, Spitzenbergh, Spitzenburgh and Spitszenburgh, but Spitzenburg is now the commonly accepted spelling.

Many different varieties have the word Spitzenburg appearing either in the accepted name or in a synonym; those which are described in this volume are Esopus Spitzcnburg, Flushing Spitzenburg. Newtown Spitzenburg and Scribner Spitzenburg (see Scribner).

\section{SPRING PIPPIN.}

References. 1. Elliott, 1854:158. 2. Warder, 1867:732. 3. Downing, 1869: 358. 4. Thomas, 1875:512. 5. Burrill and McCluer, Ill. Sta. Bul., 45:342. 1806. 6. Ragan, U.S. B. P. I. Bul., 56:29I. 1905.

Synonyms, Spring Pippin (6). Springport (6). Springport Pippin (4). Springport Pippin ( $1,3,5,6)$. 

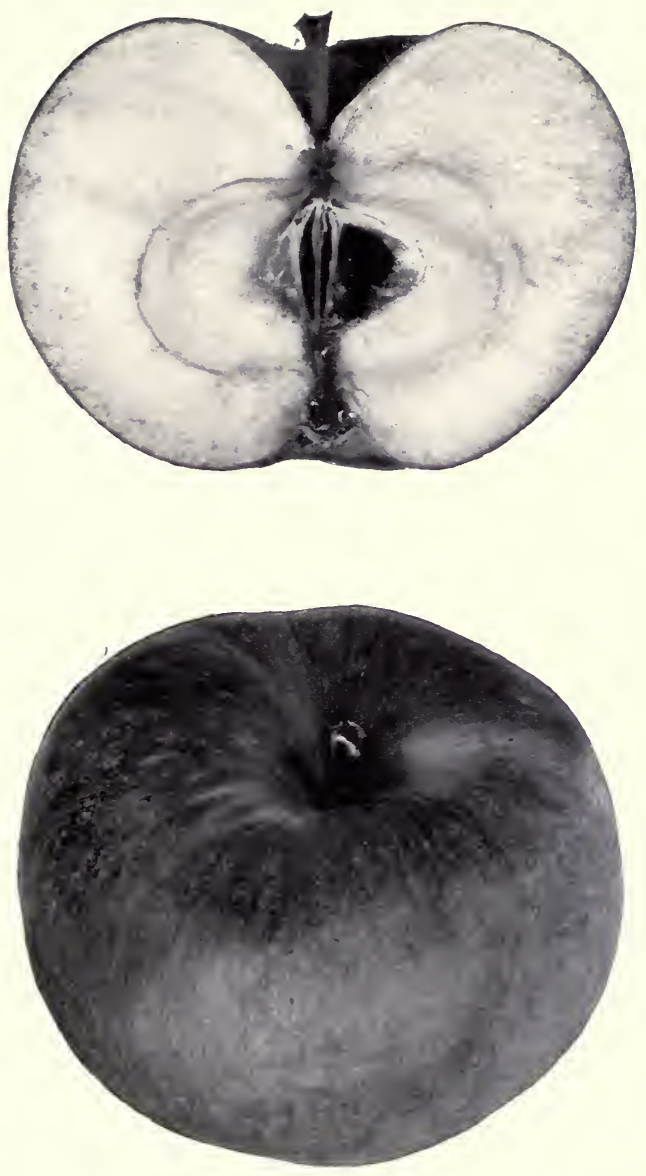

STANARD 

An old variety which originated in Springport, Cayuga county, N. Y $(3,4)$. It is probably now obsolete. The tree is upright, thrifty and unproductive. Fruit above medium, roundish, yellowish-green, with few scattering minute dots. Caly'x closed. Stem short. Flesh crisp, sprightly subacid, very good. Season December to May $(I, 4)$.

The variety described by Burrill and $\mathrm{McCl}$ uer under this name is evidently not the true Spring Pippin (5).

\section{SPY.}

Fruit growers and fruit dealers commonly mention the Northern Spy by the simple name of Spy. For a description of this variety the reader is referred to Northern Spy.

\section{STANARD.}

References. I. N. Y. Agr. Soc. Trans., 1848:22, 276. 2. Emmons, Nat. Hist. N. Y., 3:78. 1851. 3. Elliott, 1854:158. 4. Warder, 1867:544. fig. 5. Downing, 1869:359. 6. Fitz, 1872:121. 7. Thomas, 1875:512. 8. Bailey, An. Hort., 1892:250. 9. Powell and Fulton, U. S. B. P. I. Bul., 48:56. 1903. 10. Beach and Clark, N. Y. Sta. Bul., 248:144. I904.

Synonyms. Stanard's Seedling $(3,5)$. Stannard (8). Stannard's Seedling (2).

Stanard is a good apple but other varieties of its season are superior to it for either home use or commercial purposes. The fruit is of good marketable size and fairly attractive in general appearance but as grown at this Station it does not develop as bright red color as either Baldwin or Northern Spy and is decidedly inferior to either of these varieties in the texture, flavor and quality of its flesh. Its season extends to January but some portion of the fruit may be kept till spring. Its ordinary conmercial limit is October or in cold storage March or April (I0). The tree is rather vigorous, comes into bearing early and is an annual bearer, alternating heavy with light crops. It is not recommended for planting in New York.

Historical. In 1848 Stanard was exhibited before the New York Agricultural Society as a new seedling by Benjamin Hodge, Jr., of Buffalo, by whom it was afterwards introduced ( $\mathrm{I}$ ). It has been disseminated in portions of the Middle West $(4,5,8)$ but it has not won the favor of New York fruit growers and remains practically unknown in this state.

\section{TREE.}

Tree moderately vigorous; branches short, stout, curved. Form spreading, open. Trigs generally short, somewhat curved, rather stout; internodes medium to very short. Bark dark reddish-brown mingled with olive-green, partly streaked with thin scarf-skin, heavily pubescent. Lenticels scattering, small to medium, often elongated, usually not raised. Buds prominent, large, broad, plump, obtuse to acute, free or nearly so, quite pubescent.

FrUit.

Fruit large to above medium, somewhat variable in size. Form oblate conic to roundish conic, wide and flat at the base, regular or obscurely ribbed; 
sides sometimes unequal. Stem short to medium, moderately slender, usually not exserted. Cavity rather large, acute or approaching acuminate, moderately deep to very deep, wide, symmetrical, usually slightly furrowed or compressed, occasionally lipped, often russeted and with outspreading russet rays. Calyx small to above medium, partly open or closed; lobes often somewhat separated at the base, narrow, acuminate to acute. Basin below medium to rather large, often oblique, varying from rather shallow, narrow, symmetrical and somewhat obtuse to deep, rather wide, somewhat furrowed and distinctly abrupt, pubescent.

Skin thin, tough, smooth or slightly roughened by russet dots, somewhat glossy, greenish becoming pale yellow shaded with red. Highly colored specimens are almost completely covered with moderately dark, rather dull red, sparingly and rather indistinctly splashed and striped with dark carmine but usually the predominant color is yellow. Dots pale or russet, numerous and small ncar the basin, becoming larger, scattering, more conspicuous and irregular toward the cavity.

Calyx tube rather large, long, urn-shape varying to cone-shape or sometimes funnel-form. Stamens below median.

Core medium or below, somewhat abaxile; cells not uniformly developed, symmetrical, open or closed; core lines somewhat clasping. Carpels much concave, roundish to elliptical, emarginate. Seeds moderately light brown, medium or below, rather short, wide, plump, acute to somewhat obtuse.

Flesh slightly tinged with yellow, firm, a little coarse, crisp, tender, juicy, brisk subacid becoming rather mild and pleasant, aromatic, good to very good.

\section{STARK.}

References. I. Warder, I867:732. 2. Prairie Farmer, I868. (cited by 25). 3. Downing, 1869:360. 4. Fitz, 1872:170. 5. Am. Pom. Soc. Cat., 1873. 6. Thomas, 1875:512. 7. Mo. Hort. Soc. Rpt., I888:327. 8. Clark, Mo. Sta. Bul., 6:8. 1889. 9. Wickson, 1889:249. г. Lyon, Mich. Hort. Soc. Rpt., 1890:298. I1. Bailey, An. Hort., 1892:250. 12. Can. Hort., 16:112. 1893. 13. Munson, Me. Sta. Rpt., I893:133. I4. Stinson, Ark. Sta. Bul., 43:104. I896. I5. Rural N. Y., 55:1. 1896. fig. 16. Can. Hort., 20:35. I897. I7. Lazenby, Columbus Hort. Soc. Rpt., I900:139. 18. Can. Hort., 23:126. I900. 19. Dickens and Greene, Kan. Sta. Bul., 106:55. 1902. 20. Can. Hort., 25:303. 1902. figs. 21. Woolverton, Ont. Fr. Stas. An. Rpt., 9:2. 1902. figs. 22. Budd-Hansen, r9o3: 179. figs. 23. Powell and Fulton, U. S. B. P. I. Bul., 48:56. 1903. 24. Beach and Clark, N. Y. Sta. Bul., 248:144. 1904. 25. Ragan, U. S. B. P. I. Bul., 56:291. 1905.

Synonyms. Robinson (25). Starke Apple (4). Yeats (7, 25).

Stark is regarded as a good variety for the commercial orchard by some New York fruit growers particularly because the tree is thrifty, hardy, healthy, a reliable cropper and very productive and because the fruit is fair, smooth, uniform and keeps well. It is often dull and not attractive sometimes having but very little red color yet under favorable conditions it is nearly covered with red 

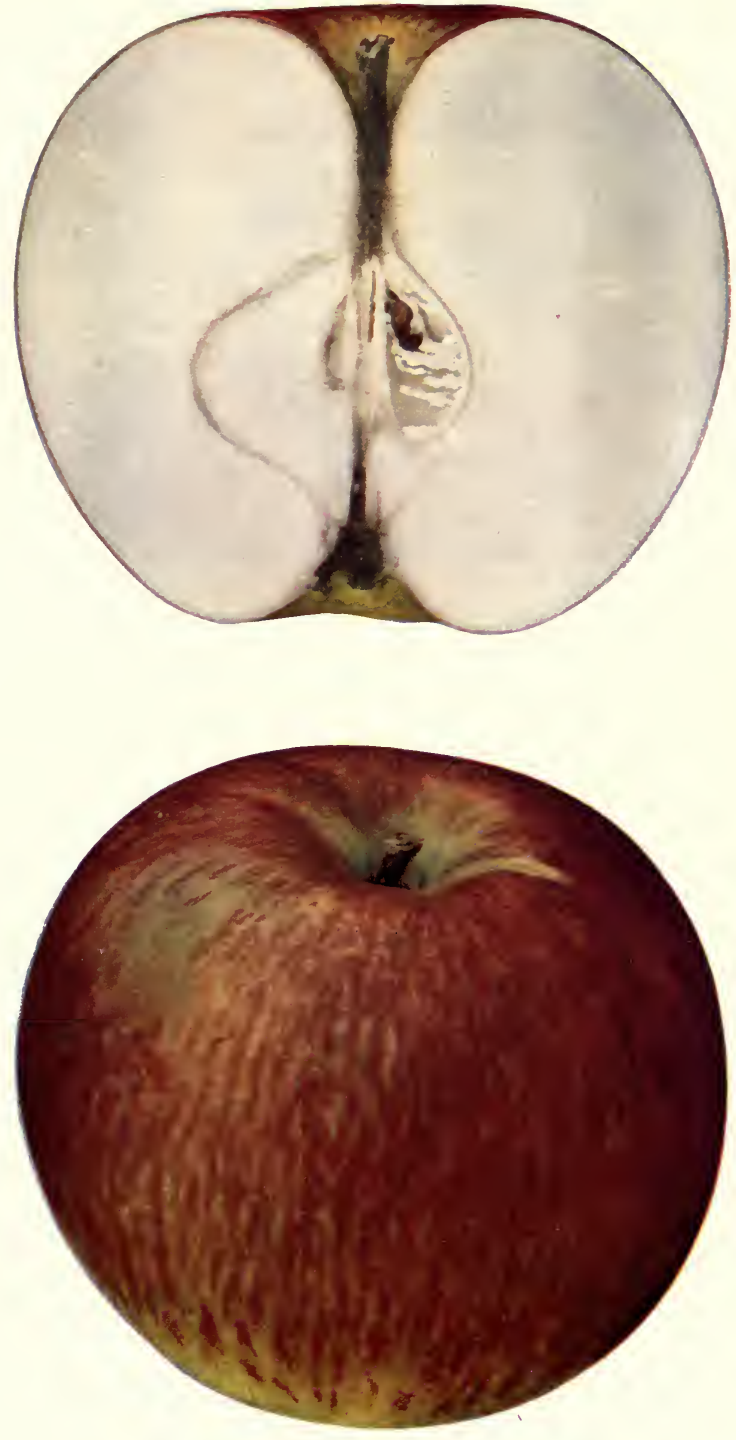

STARK 

and in the spring when the contrasting yellow tints are fully developed it becomes quite attractive. The accompanying illustration shows a highly colored Stark which was grown in Dutchess county. At Geneva its season in ordinary storage extends from January to June with May as the usual commercial limit. The fruit stands handling well because it is very firm and has a thick, tough skin. It has a mild flavor and ranks only medium in quality but is well liked for baking and evaporating. It often sells in the general market at remunerative prices and is regarded by some as a good apple for export trade $(2 \mathrm{O}, 2 \mathrm{I})$. Stark not only does well throughout the region where Baldwin succeeds but also has won recognition as a desirable commercial variety in certain districts in the North, South and West outside the range of profitable cultivation of Baldwin.

Historical. Stark was first brought to notice in Ohio (3) and is said to have originated in that state (25). It is grown successfully over a wide range of territory and has received favorable notice in various regions from the Atlantic to the Pacific. In 1892 it was offered by nurserymen in all of the apple-growing sections of the country with the exception of the northern portion of the Mississippi valley and the Rocky Mountain region from Montana to Arizona and Texas (II). Thus far it has not been largely planted in New York but its cultivation in this state appears to be slowly increasing.

\section{TREE.}

Tree strong, straight, healthy in the nursery; vigorous and large or moderately large in the orchard, with long, strong branches. Form upright spreading to roundish, rather dense. Twigs above medium length, nearly straight, slender to rather stout; internodes short to long. Bark reddish-brown tinged with olive-green, lightly streaked with gray scarf-skin; pubescent near tips. Lenticels quite numerous, conspicuous, small to large, roundish or oblong, slightly raised. Buds medium to large, plump, obtuse to acute, free, slightly pubescent.

\section{FRUIT.}

Fruit large to medium, sometimes very large, quite uniform in size and shape. Form roundish inclined to conic varying to slightly oblate or to roundish ovate; sides sometimes unequal. Stem short to medium in length, moderately stout. Cavity medium in size, acuminate or approaching acute, moderately deep, rather wide to moderately narrow, sometimes gently furrowed, occasionally lipped, sometimes russeted and with outspreading russet. Calyx medium to rather large, closed or partly open. Basin shallow and obtuse to medium in depth and somewhat abrupt, rather wide, slightly wrinkled.

Skin smooth or slightly roughened with russet dots, pale green becoming yellow more or less blushed and mottled with red and rather indistinctly 
striped with darker red. Prevailing effect dull green and red, but in highly colored specimens fairly bright red.

Calyx tube rather wide, truncate cone-shape with fleshy pistil point projecting into the base, or approaching funnel-form. Stamens median or below.

Core medium to rather small. axile; cells uniform, symmetrical, closed or partly open; core lines meeting or slightly clasping Carpels thin, tender, flat, broadly roundish to obcordate, emarginate, mucronate, tufted. Seeds few, long. acute, tnfted.

Flesh yellowish, firm, moderately fine to rather coarse, breaking, rather tender, juicy, sprightly, mild subacid, not high in flavor, fair to good, or nearly good, in quality.

\section{STAYMAN WINESAP.}

Refrerences. I. Downing, r881:106 app. fig. 2. Stayman, Mo. Hort. Soc. Rpt., I883:77. 3. Bailey, Mich. Sta. Bul., 31:54. 1887. 4. Rural N. Y., 55:1. 1896. 5. Amer. Gard., I7:33. 1896. 6. Van Deman, Rural N. Y., 57:201. 1898. 7. Powell, Del. Sta. Bul., 38:20. 1898. fig. 8. Van Deman, Rural N. Y., 58:800. 1899. 9. Am. Pom. Soc. Cat., 1899:20. 10. Rural N. Y., 59:466, 510. 1900. fig. I1. Amer Gard., 22:191. 1901. 12. Van Deman, Rural N. Y., 6o: 124, 210, 307, 532. 1901. 13. Taylor, U. S. Dept. Agr. Yr. Bk., r9o2:470. col. pl. 14. Rural N. Y., 6r:688. 1902. I5. Bruner, N. C. Sta. Bul., 182:22. I903. 16. Powell and Fulton, U. S. B. P. I. Bul., 48:57. 1903. I7. Budd-Hansen, 1903:18o. fig. r8. Beach and Clark, N. Y. Sta. Bul., 248:145. I904.

Synonyms. Stayman $(4,5,6,8$, io, 12). Stayman (13, 16). Stayman's Winesap (1, 2, 3, 7, II). Stayman's Winesap (13).

Van Deman calls this the best variety of the Winesap class for general cultivation (I2). Taylor remarks that the only particular in which it does not equal its parent is in its color which is somewhat less brilliant than that of Winesap and adds that it appears to be adapted to a wider range of soil and climate and well worthy of testing throughout the middle latitudes, both for home use and for market (13). As tested at this Station the tree is moderately vigorous, comes into bearing young and is a reliable annual cropper, alternating heavy with light crops; but the fruit, as shown by the accompanying illustration, does not develop properly here in size and color. It is evidently not well suited for regions as far north as this.

Historical. This variety was originated from seed of Winesap in 1866 at Leavenworth, Kan., by Dr. J. Stayman and bore its first fruit in 1875 (13). The earliest published descriptions of it were given by Downing (1) and Stayman (2). "Further than these descriptions the variety does not appear to have attracted any special attention until after 1890 , when its good qualities were discovered almost simultaneously by Mr. R. J. Black, of Bremen, Ohio, and Mr. J. W. Kerr, of Denton, Md., both of whom fruited it on top grafts 


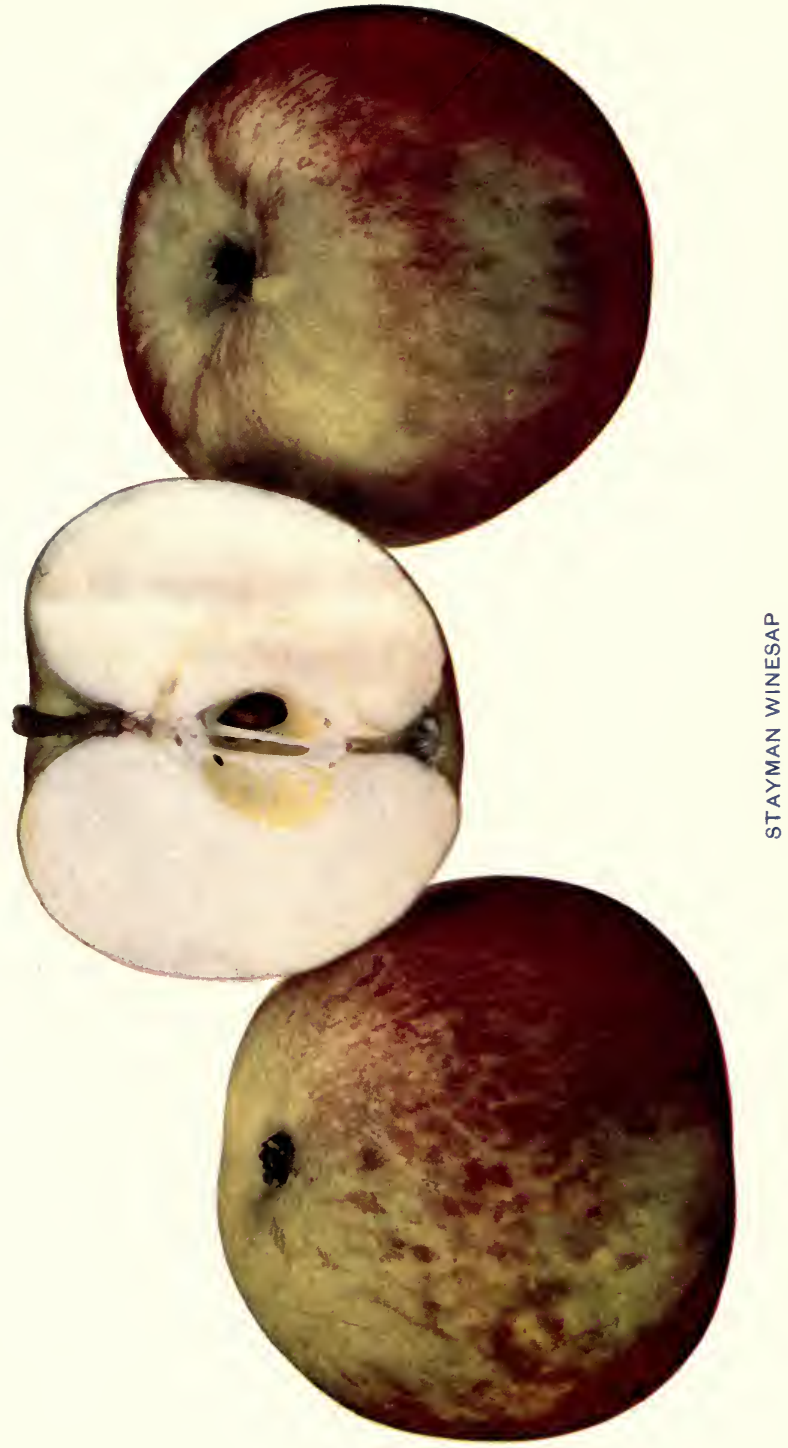



at about that time. It was first catalogued by the latter in I894-I895, and has been quite extensively planted in New Jersey, Pennsylvania, Delaware, Maryland and Virginia since that date, and somewhat in other States" (13).

TREE.

Tree moderately vigorous. Form spreading and somewhat open. Twigs below medium to rather long, irregularly crooked, moderately stout, with large terminal buds; internodes medium to long. Bark dark brown or reddishbrown with some olive-green, heavily coated with scarf-skin, pubescent near tips. Lenticels inconspicuous, scattering, small to large, roundish, raised. Buds prominent, above medium to large, broad, plump, obtuse to acute, pubescent.

\section{FRUIT.}

Fruit medium to large, uniform in size and shape. Form roundish conic to globular, flattened at the base and rounding toward the basin; sides sometimes slightly unequal. Stem medium to short. Cavity large, acuminate to acute, deep to very deep, medium in width to wide, often gently furrowed, sometimes compressed, usually partly russeted and sometimes with outspreading broken russet rays. Calyx small to medium, closed or sometimes partly open; lobes long, acute to acuminate. Basin small, sometimes oblique, varying from shallow, narrow and obtuse to medium in width and depth and abrupt, furrowed, somewhat wrinkled.

Skin smooth, rather thick, tough, green becoming yellowish, often nearly completely covered with rather dull mixed red and rather indistinctly striped with dull carmine. In less highly colored specimens the striped effect is more noticeable. Dots light gray and russet, often rather large and conspicuous.

Calyx tube cone-shape to elongated funnel-form, sometimes extending nearly or quite to the core. Stamens median.

Core small to medium, abaxile to nearly axile; cells symmetrical, closed or open; core lines clasping the funnel cylinder. Carpels thin, tender, quite concave broadly roundish to elliptical, emarginate. Seeds variable, medium or above, long, obtuse to acute, plump; often some are abortive.

Flesh tinged with yellow or slightly greenish, firm, moderately fine-grained, tender, moderately crisp, breaking, juicy to very juicy, aromatic, sprightly, pleasant subacid, good to very good.

Season Decenber to May; commercial limit, April.

\section{STERLING.}

References. I. Elliott, I854:I67. 2. Downing, I857:II5. 3. Warder, I867: 7II. 4. Downing, r869:75. 5. Am. Pom. Soc. Cat., 1877. 6. Barry, 1883: 341. 7. Am. Pom. Soc. Cat., r897:14. 8. Budd-Hansen, r9o3:18r. 9. Thomas, 1903:689. 1о. Page 45 .

Synonyms. American Beauty $(2,3,4,5,6,9$, io). American Beruty (7,8). Beauty of America ( I). Beauty of America $(4,1$ ) leterling Beauty (2, 4, 6, 9, 10).

This is the variety described on page 45 under the name of American Beauty. At the time that description was written it escaped our notice that 
the accepted name for this variety in the American Pomological Society Catalogue was changed in 1897 from American Beauty to Sterling. This statement is made for the purpose of revising and correcting the synonymy of this variety.

\section{STONE.}

Reference. I. Hoskins, Montreal Hort. Soc. Rpt., 5:18. 1879.

An apple of the Blue Pearmain group somewhat similar to Bethel in general appearance. We find no published description of this variety. It is highly esteemed locally in St. Lawrence county where it has come to be recognized as a very hardy, healthy, thrifty and long-lived variety. It has a tendency to overbear or to set more fruit than it can properly mature. It is an advantage to have the fruit thoroughly thinned early in the season. It has the habit of ripening its wood and shedding its foliage early in the autumn. Young trees in the nursery row have a rather rough, sprawling habit of growth. The fruit when well grown is rather large and although rather dull red in color is fairly attractive in appearance. It ranks good or sometimes possibly very good in quality.

Historical. This variety was brought from Bethel, Vermont into Potsdam, St. Lawrence county, about 1836 or 1837 by a Mr. Stone. He propagated it in that locality and it came to be known locally as the Stone apple. For a time the Stone and the Snow or Fameuse were about the only grafted apples known in that vicinity. During the last sixty years it has been grown in some sections of St. Lawrence county more extensively than any other variety 1 and has there become a standard winter apple for home use. Apparently it is unknown outside of Northern New York.

\section{Fruit.}

Fruit above medium to very large, quite uniform in size and shape. Form round to somewhat ovate, rounding toward base and apex, regular or sometimes slightly ribbed. Stem very short to medium, rather slender. Cavity very small, usually acuminate, very narrow, somewhat unsymmetrical, partly russeted; the russet does not often extend beyond the brim of the cavity. Calyx medium to rather small, usually open, sometimes nearly closed; lobes rather broad and acute. Basin usually shallow, sometimes moderately deep, medium in width to rather narrow, sometimes slightly wrinkled.

Skin thick, tough, rather smooth, takes a high polish; color pale yellow or greenish washed and mottled with rather dull dark red which in highly colored specimens deepens to solid red, irregularly splashed and striped with deep carmine, overspread with bluish bloom and often noticeably marked with bluish-white scarf-skin. Dots numerous. Some are very large, irregular, very conspicuots, grayish and often areolar with russet point; others are small, round, pale gray or whitish and often submerged.

Calyx tube short, broadly conical. Stamens usually basal.

4 Letters of A F. Clark, Raymondville, 1896, 1905. 

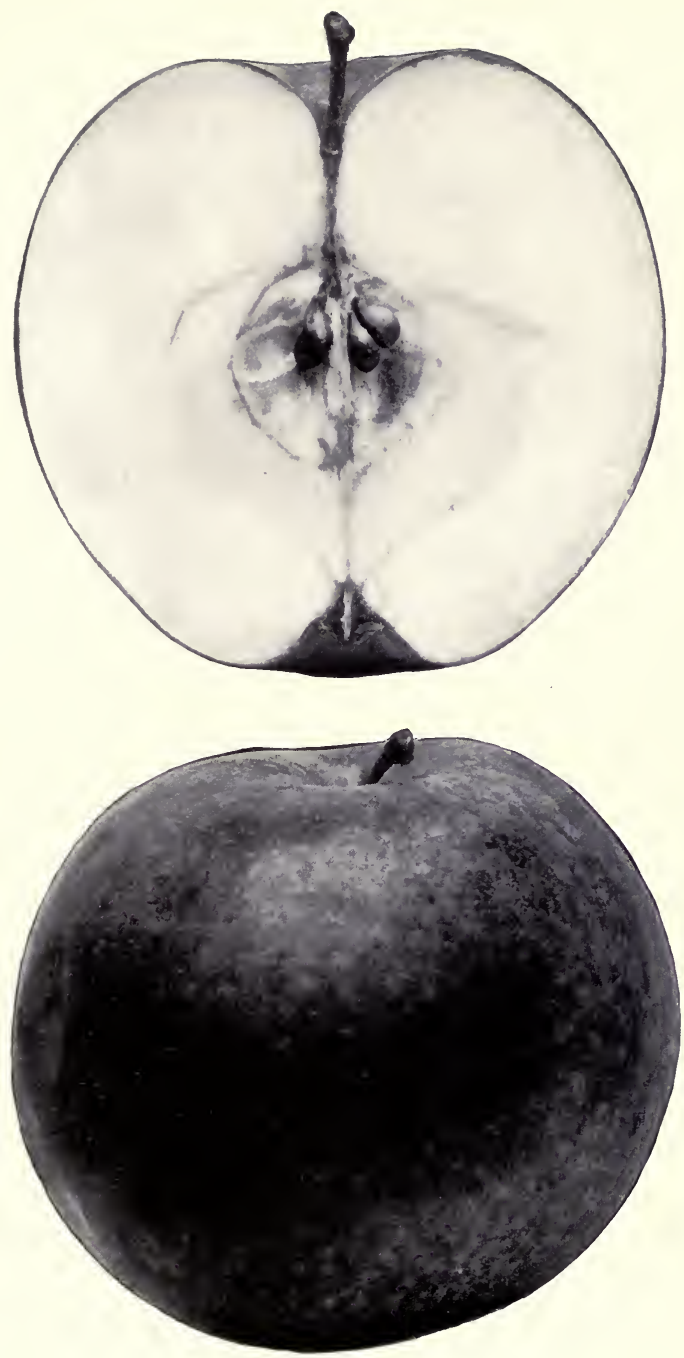

STONE 

Core slightly abaxile with a hollow cylinder, at the axis which becomes narrow above and extends to the calyx tube; cells not uniformly developed, closed or open; core lines nearly meeting or clasping. Carpels roundish to roundish ovate, a little tufted. Seeds not numerous, small to medium, varying from rather long, narrow and acuminate to short, blunt and nearly obtuse.

Flesh nearly white. with yellowish tinge, moderately firm, a little coarse, rather tender, juicy or moderately juicy, mildly subacid becoming nearly sweet, somewhat aromatic, good to possibly very good in quality.

\section{Stone and Bethel Compared.}

Some have supposed that Stone is identical with Bethel (I) but as received from various parts of Northern New York it is certainly distinct. The fruit averages larger than that of Bethel, sometimes becoming very large, and its form is more elongated and more inclined to roundish ovate. Its color is duller than that of Bethel, being not quite so dark red in tone, and it is noticeably less striped and splashed. The dots of Stone are considerably the larger, more irregular and more noticeably areolar. The dots of Bethel are the brighter; its stem usually shorter and more slender; its cavity decidedly smaller and narrower; its basin slightly narrower and more regular; its core less abaxile and slightly smaller, and its cells less uniformly developed.

\section{STOWE.}

References. I. Me. Pom. Soc. Rpt., 1895. (cited by 2). 2. Munson, Me. Sta. Rpt., $1902: 02$.

Synonym. Stowe's Winter (I).

This variety has attracted the attention of Maine fruit growers because of its superior hardiness. Munson (2) considers it "well worthy of general dissemination as a valuable iron-clad variety." He reports that "the tree is vigorous and an annual bearer; fruit medium to large, greenish-yellow with blushed cheek; flesh subacid, good; season February to May in Aroostook county, Me."

Historical. Originated in Perham, Aroostook county, Me., from seed planted about 1862. Known locally in Maine as Stowe's Winter (I). So far as we know it is not cultivated in New York.

\section{STREAKED PIPPIN.}

References. I. Downing, r869:362. 2. Burrill and McCluer, Ill. Sta. Bul., 45:342. 1896. 3. Beach and Clark, N. Y. Sta. Bul., 248:145. I904.

Synonyms. Hempstead (I). Quaker of some (I). Red Pippin (I). Skunk, erroneously (I). 
Fruit large, yellow streaked with red, the yellow usually predominating. It is pretty uniform in size and when highly colored rather attractive in appearance. It ranks good to very good in quality either for dessert or culinary use. On Long Island it is grown more commonly than any other variety except Rhode Island Greening. In that portion of the state it is in season during late fall and early winter but as grown at this Station it keeps till February with practically no loss (3) and its season extends to April or May. It is not sufficiently attractive in color to be desirable for general market purposes but it sells well in Long Island local markets. This variety is grown successfully on sandy or gravelly loam and also does well on clay loam. It is hardy, healthy, longlived, vigorous, comes into bearing moderately young and is a reliable cropper, yielding moderate to heavy crops biennially or almost annually. The crop ripens rather unevenly and there is considerable loss from dropping of the fruit.

It appears from reports received from Northern and Northwestern New York that in some portions of those regions an inferior variety is known locally under the name Streaked Pippin but we have not seen this fruit.

Historical. Origin, Westbury, N. Y. It is generally cultivated on Long Island and occasionally is found in the Hudson valley but it is little known in other portions of the state.

TREE.

Tree large, moderately vigorous to very vigorous. Form upright becoming wide-spreading and very drooping, rather dense. Twigs medium to short, straight, stout to rather slender; internodes medium to short. Bark clear reddish-brown tinged with olive-green, lightly streaked with scarf-skin, slightly pulescent. Lenticels quite numerous, but not very conspicuous, medium to small, roundish or elongated, slightly raised. Buds medium size, broad, plump, acute to obtuse, free, slightly pubescent.

\section{FrUit.}

Fruit large, uniform in size and shape. Form roundish oblong to roundish conic, often faintly ribbed, symmetrical. Stem short to medium, slender to moderately thick. Cavity acuminate, sometimes acute, moderately narrow to rather broad, often slightly furrowed, occasionally compressed, sometimes lipped, sometimes russeted. Caly.x small to medium, closed or partly open; lobes usually short, obtuse. Basin shallow, narrow and obtuse, varying to medium in width and depth and somewhat abrupt, often somewhat furrowed. Skin thin, tough, nearly smooth, covered with a thin whitısh bloom which 

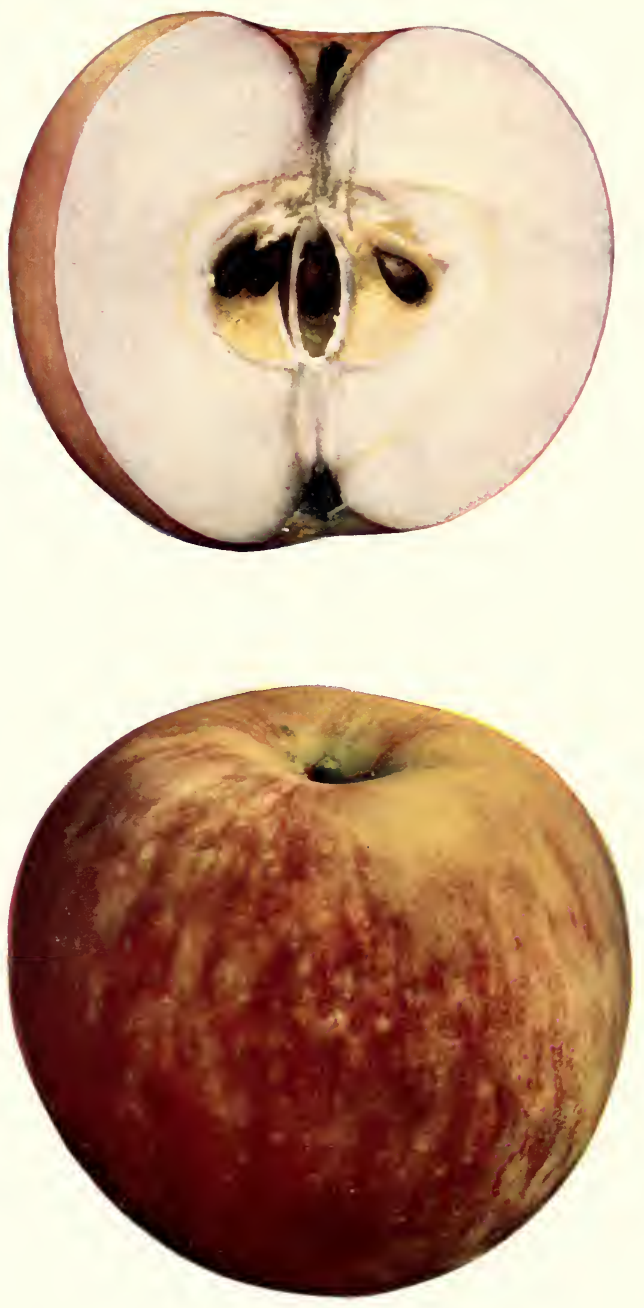

STREAKED PIPPIN 

gives a slightly dull effect, bright and glossy when polished, predominantly yellow or greenish partly mottled and blushed with orange-red and distinctly striped with bright carmine. Dots rather numerous and conspicuous, whitish or with russet point, often areolar.

Calyx tube conical. Stamens median.

Core rather large, abaxile; cells open or partly closed; core lines slightly clasping. Carpels much concave, broadly roundish or approaching elliptical, mucronate, slightly tufted. Seeds medium to large, rather plump, acute to obtuse, somewhat tufted.

Flesh whitish tinged with yellow, firm, rather coarse, breaking, tender, juicy, pleasant subacid, slightly aromatic, good to very good.

\section{STUART GOLDEN.}

References. I. Downing, r881 :108 app. fig. 2. Mo. Hort. Soc. Rpt., r886: 232. 3. Bailey, An. Hort., 1892:250. 4. Dickens and Greene, Kan. Sta. Bul., ro6:55. 1902. 5. Powell and Fulton, U. S. B. P. I. Bul., 48:57. I903. 6. Farrand, Mich. Sta. Bul., 205:46. 1903.

Synonyms. Stuart (6). Stuart's Golden (I, 2, 3, 4). Stump, incorrectly (I).

Fruit rather attractive in color for a yellow apple, not large enough for a good commercial variety but a very late keeper and of excellent dessert quality. The tree is not large, comes into bearing moderately young and is a reliable cropper, yielding full crops biennially. Not recommended for commercial planting in New York.

Historical. Originated on the farm of Wm. Stuart, Rush Creek, Ohio (I). It has been disseminated to some extent in the Middle West; but, so far as we know, it is not grown in New York except at this Station.

TREE.

Tree small to medium size, low with short, stout branches. Form very much spreading, open. Twigs below medium to short, straight or slightly curved, moderately stout to slender; internodes short. Bark smooth, clear reddish-brown tinged with olive-green, lightly streaked with scarf-skin, pubescent. Lenticels clear in color, scattering, small to medium, oblong, usually not raised. Buds prominent, medium in size, plump, acute, free, slightly pubescent.

\section{FrUIT.}

Fruit usually below medium but sometimes medium or above. Form roundish oblate or inclined to oblong truncate, often slightly oblique. Stem slender, often short, sometimes with fleshy protuberance. Cavity moderately shallow to deep, varying from acuminate and narrow to acute and rather wide, usually symmetrical, often thinly russeted. Calyx small to medium, closed. Basin moderately deep, rather narrow to moderately wide, somewhat abrupt, usually symmetrical, often wrinkled.

Skin thin, tough, smooth, waxy, pale yellow or greenish with orange blush, sometimes deepening to pinkish-red. Dots often submerged, pale or russet, numerous and rather small toward the basin, becoming larger, more scattering and often areolar toward the cavity. 
Caiyx tube rather small, rather short, cone-shape, sometimes approaching funnel-form.

Core rather small to above medium, abaxile; cells open; core lines meeting or slightly clasping. Carpels broadly elliptical. Seeds below medium to medium, plump, rather obtuse, moderately dark brown.

Flcsh whitish tinged with yellow, firm, moderately fine, rather crisp, tender, very juicy, agreeably mild subacid, rich, aromatic, very good for dessert.

Season December to May or June.

\section{SUTTON.}

References. I. Cole, I849:I30. 2: Hovey, Mag. Hort., I5:249. I849. fig. 3. Elliott, $1854: 85$ 4. Downing, $1857: 190$ 5. Warder, $1867: 616$. fig. 6. Thomas, 1875:513. 7. Am. Pom. Soc. Cat., 1877:14. 8. Mich. Pom. Soc. Rpt., I880:50, I84, 207. 9. Barry, 1883:355. 1о. Can. Hort., I I:8. I888. ir. Lyon, Mich. Hort. Soc. Rpt., 1890:294. I2. Can. Hort., 14:36, 274. I891. 13. Bailey, An. Hort., 1892:250. 14. Munson, Me. Sta. Rpt., I893:133. 15. Rural N. Y., 55:115, I81. I896. 16. Lyon, Mich. Sta. Bul., 143:200. 1897. 17. Rural N. Y., $57: 178,239,244$. I898. 18. Woodward, $I b ., 58: 264$. I899. I9. Beach, $W . N$. Y. Hort. Soc. Rpt., I899:90. 20. Van Denian, Rural N. Y., 60:54, 789. 1901. 21. Can. Hort., 24:121. I901, 22. Waugh, I't. Sta. An. Rpt., 14:309. I901. 23. Budd-Hansen, 1903:I84. 24. Powell and Fulton, U. S. B. P. I. Bul., 48: 57. 1903. 25. Farrand, Mich. Sta. Bul., 205:45. 1903. 26. Beach and Clark, N. Y. Sta. Bul., 248:145. 1904.

Synonyms. Beauty (4). Hubbardston Nonsuch (3) but incorrectly. Morris ReD (8, II, 25). Morris Red (i6). Morris Red (i9). Steele's Red (8, erroneously II). Steele's Red Hinter (8, of Ohio I9). Sutton Beatty ( $1,2,4.5,6,7,9,10,12,13,15,17,18,20,21)$. Sutton Beauty $(3,14,22,23,24,26)$.

Sutton is supposed by some to be a seedling of Hubbardston $(22,23)$. The tree certainly resembles Hubbardston somewhat but is much more vigorous and healthy. In color, texture, quality and season the fruit is intermediate between Hubbardston and Baldwin. Its uniform size, symmetrical shape, beautiful color and pleasant quality unite to make the Sutton an excellent dessert apple, but being mild in flavor it is less desirable for culinary use. It sells well in the general market but it appears especially suitable for fancy market and fruit-stand trade. It does not keep quite so long as Baldwin, hardly averages as large and because it is more tender requires more careful handling. Although in some regions its fruit seems to be somewhat more subject to scab than that of the Baldwin, yet in many localities it has gained a reputation of being remarkably healthy in foliage and fruit. The fruit hangs well to the tree. In favorable locations the tree has vigorous dark green foliage, is 

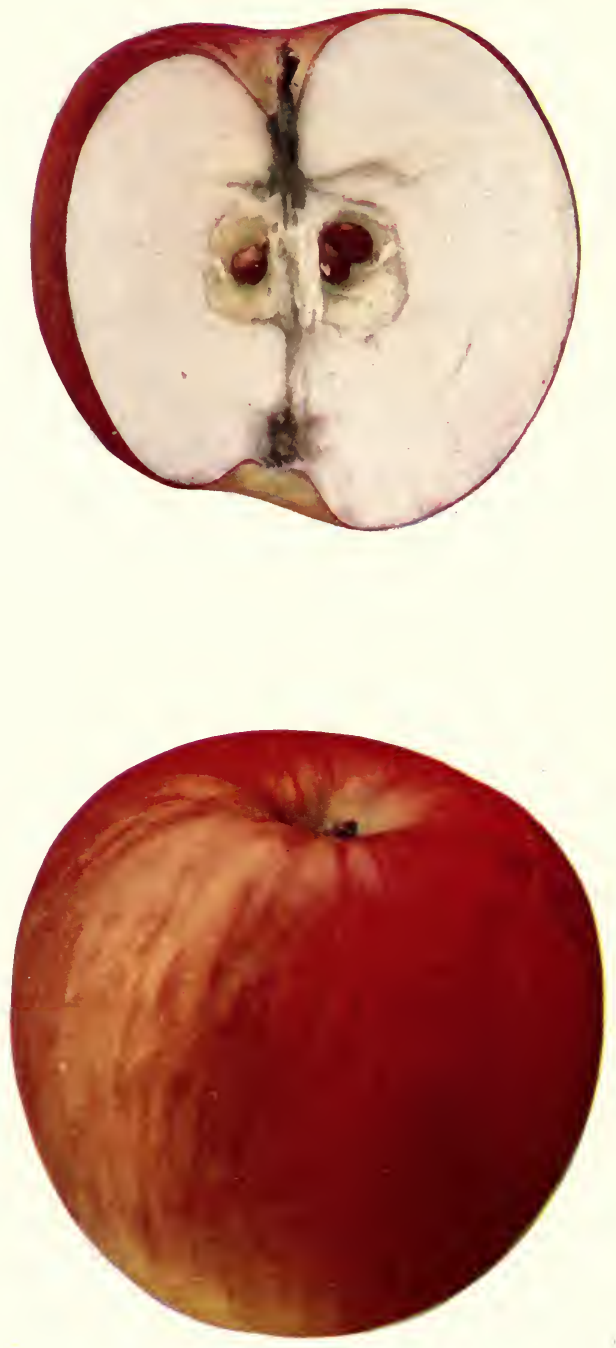

SUTTON 

handsome in form, a strong grower and productive, with a marked tendency to bear biennially.

Sutton has been practically unknown in New York state until recent years but it is now being introduced quite extensively for commercial purposes. Although it has not done well in some localities, yet in most parts of the state it is regarded as one of the most promising of the newer varieties. Because the trees of this variety are still young the value of the Sutton for commercial planting in New York has not been fully determined.

Sutton has been disseminated in Michigan under the name Morris Red with Steele's Red or Steele's Red Winter of Ohio as erroneous synonyms. Ragan recognizes Morris Red as possibly identical with Sutton. Morris Red as fruited at this Station from stock obtained from D. G. Edmeston, Adrian, Mich., who has pronounced the fruit borne by this stock to be the true Morris $\operatorname{Red}^{1}$, is certainly identical with Sutton.

Leroy refers to Sutton Beauty erroneously as a synonym for Wellington. ${ }^{2}$

Historical. Sutton takes its name from the town of Sutton, Mass., in which it originated. It was brought to notice through the Worcester County Horticultural Society in 1848 (2). In 1849 Hovey included it in a descriptive list of select varieties in the belief that it would become a popular fruit and remarked that it had as yet been but little disseminated. It was not included in the American Pomological Society Catalogue till 1877 (7). Within recent years it has been planted and top-worked upon older trees to a considerable extent in New York commercial orchards, but we do not know of any old trees of this variety in this state.

TREE.

Tree vigorous with stout branches. Form upright spreading, eventually becoming roundish, dense. Twigs short to medium in length, straight, moderately stout to stocky; internodes short to medium. Bark dark olive-green somewhat tinged with reddish-brown, mottled and streaked with gray scarfskin, pubescent. Lenticels few, very scattering, not conspicuous, small to medium, elongated or roundish, not raised. Buds prominent, large, broad, obtuse to acute, pubescent, free. Leaves somewhat narrow, medium to large; foliage vigorous, dark green, healthy, rather dense.

\section{FRUIT.}

Fruit medium or rarely large, pretty uniform in size and shape. Form roundish or slightly oblong rounding toward cavity and basin, symmetrical, regular or very slightly ribbed. Stem medium to short, sometimes fleshy.

\footnotetext{
${ }^{1}$ Letters, D. G. Edmeston, 1897.

${ }^{2}$ Leroy, 1873: 864 .
} 
Carity acute or sometimes acuminate, moderately deep to deep, moderately wide to narrow, symmetrical, often with some greenish russet. Calyx medium size, partly open, sometimes closed, pubescent; lobes vary from medium and obtuse to long and acuminate. Basin moderately shallow and obtuse to rather deep and abrupt, medium in width, somewhat furrowed and slightly wrinkled, sometimes compressed.

Skin moderately thin, tough, often slightly roughened toward the basin by inconspicuous, concentric broken russet lines and fine russet dots, otherwise glossy and smooth; color attractive bright red striped with carmine or purplish carmine nearly overspreading the lively yellow or greenish ground color. Precialing effect attractive red. The less highly colored fruit has a distinctly striped appearance.

Caly.x tube symmetrical, conical or sometimes funnel-form. Stamens median.

Corc medium or below, slightly abaxile; cells symmetrical, closed; core lines slightly clasping. Carpels broadly cordate approaching elliptical, emarginate, sometimes slightly tufted. Secds rather light brown, small to above medium, plump, acute, sometimes a little tufted.

Flesh slightly tinged with yellow, rather firm, moderately fine-grained, crisp, tender, juicy, mild subacid, good to very good.

Scason intermediate between Hubbardston and Baldwin; early winter in the southern part of the state but farther north it is in season for home use from November to March, and the commercial limit extends to February.

\section{SWAAR.}

References. I. Dom. Encyc., I804. (cited by 33). 2. M'Mahon, Gard. Cal., r806:585. 3. Coxe, 1817:16r. 4. Thacher, 1822:138. 5. Cat. Hort. Soc. London, 1831:37. 6. Kenrick, 1832:53. 7. Floy-Lindley, 1833:85. 8. Man11ing, 1838:60. 9. Manning, Mag. Hort., 7:50. 1841. Io. Downing, 1845:134. fig. II. Thomas, 1849:185. fig. 12. Cole, 1849:126. fig. 13. Emmons, Nat. Hist. N. Y., 3:88. 1851. col. pl. No. 22. 14. Am. Pom. Soc. Cat., 1852. I 5. Elliott, 1854:108. fig. I6. Hooper, 1857:90. I7. Gregg, 1857:59. fig. I8. Ill. Handb. Obst., 8:83. I865. 19. Warder, 1867:632. fig. 20. Downing, 1869:373. fig. 2r. Fitz, 1872:167. 22. Leroy, 1873:834. fig. 23. Barry, 1883:355. 24. Wickson, 1889:246. 25. Lyon, Mich. Hort. Soc. Rpt., 1890:298. 26. Bailey, An. Hort., 1892:250. 27. Waugh, Vt. Sta. An. Rpt., 14:310. 1901. 28. Eneroth-Smirnoff, Igor:463. 29. Dickens and Greene, Kan. Sta. Bul., ro6:55. 1902. 30. Powell and Fulton, U.S. B. P. I. Bul., 48:57. 1903. 31. BuddHansen, 1903:184. 32. Beach and Clark, N. Y. Sta. Bul., 248:146. 1904. 33. Ragan, U.S. B. P. I. Bul., 56:302. 1905.

Synonyms. Der Schwere Apfel (18). Hardwick (20, 22, 33). Swaar Apple $(2,3,4,7)$.

In many parts of the state, and particularly in portions of the Hudson valley, Swaar has long been a favorite variety for the home orchard, being valued especially for dessert use because of its rich flavor and fine quality. It is less suitable for cooking and there is little demand for it in market except among the comparatively few 

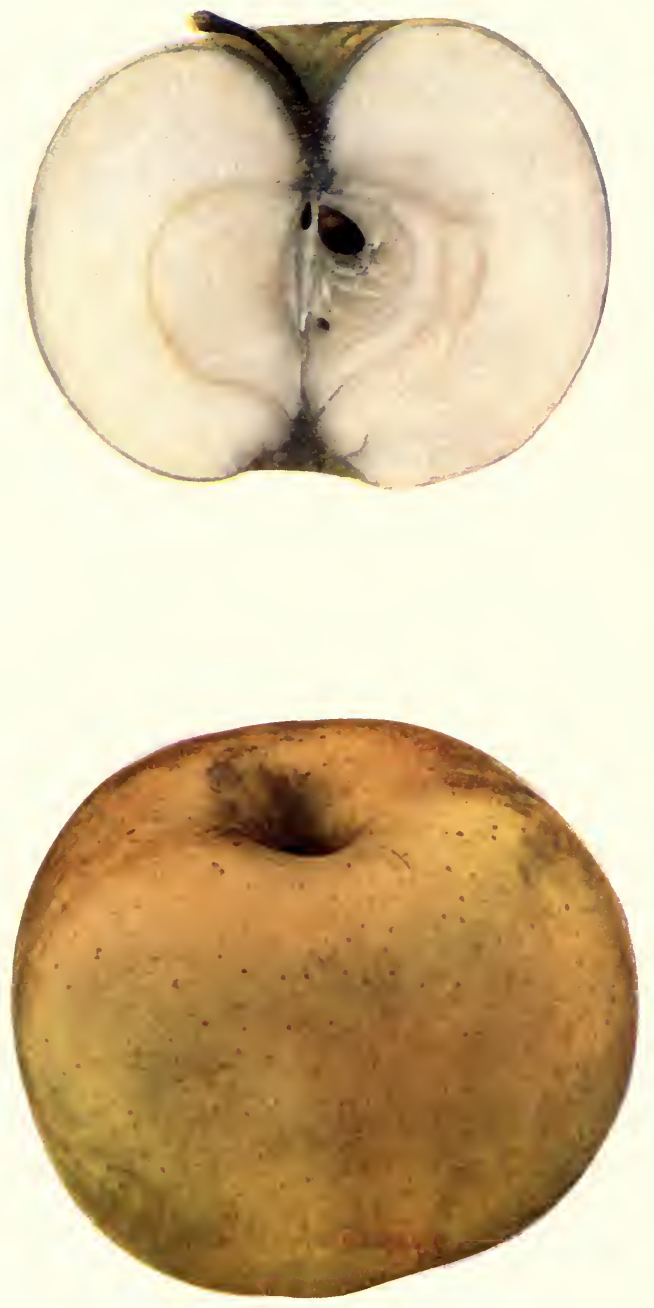

SWAAR 

people who know its good qualities. The fruit is usually of good size and form but not very attractive in color. Downing observes that this variety requires a deep, rich, sandy loam to bring it to perfection but that it does not stucceed well in damp or cold soils, and adds that in its native soil he has seen it 12 inches in circumference and of a deep, golden yellow color (IO). The tree is not as longlived nor as hardy as either Baldwin or Rhode Island Greening. In many cases it is injured by apple canker ${ }^{1}$ or by sunscald and occasionally it suffers from winter injury. In some localities it appears to be thriftier, hardier, and, on the whole, more successful when topworked upon some hardier and more vigorous variety such as Baldwin, Rhode Island Grecning or Northern Spy than it does when grown upon its own trunk. Generally speaking it has the reputation of being a shy bearer, yielding moderate crops biennially; but in some cases it is regarded as a heavy cropper and an annual bearer. Often a comparatively large amount of the crop is lost in drops and culls. Its season is somewhat variable but in ordinary storage commonly extends from November or December to March or April (32).

Historical. Downing states "This is a truly noble American fruit, produced by the Dutch settlers on the Hudson, near Esopus" (10). Coxe (3) remarks that "In the Low-Dutch language this name signifies a heavy appleit is a highly celebrated winter table fruit in some parts of New-York, and New-Jersey; it is a large green apple, of great and uncommon flavour and richness; highly deserving of cultivation, in every collection of fine fruits." It has been widely disseminated through the state and often a few trees of it are still found in old orchards but it has nowhere been cultivated extensively and is now seldom planted.

\section{TREE.}

Tree usually medium or below medium size, moderately vigorous; branches somewhat inclined to droop. Form roundish to quite spreading, rather dense, somewhat resembling that of Rhode Island Greening. Twigs below medium to short, straight or nearly so, rather slender to stout with prominent terminal buds; internodes short. Bark of the trunk and older limbs peculiarly rough, that of the new twigs clear dark brownish-red mingled with olive-green, lightly streaked with scarf-skin and pubescent. Lenticels numerous, small to medium, elongated, slightly raised. Buds prominent, below medium to large, plump, acute, free or nearly so, slightly pubescent.

\section{Fruit.}

Fruit above medium to large, fairly uniform in size and shape. Form roundish varying from oblate to somewhat oblong, often ribbed, regular, sym-

\footnotetext{
${ }^{1}$ For an account of this disease see Paddock, N. Y. Sta. An. Rpt., 18:331, 1899 and $19: 342.1900$.
} 
metrical. Stcm medium in length, rather slender. Cavity below medium to rather large, usually round, acute to somewhat acuminate, rather deep, moderately wide, often somewhat furrowed, usually russeted and with broken outspreading russet. Caly.r small to medium, closed or somewhat open; lobes broad, obtuse, usually connivent. Basin small to medium, usually shallow and obtuse, sometimes moderately deep and abrupt, moderately wide, a little furrowed and wrinkled.

Skin medium in thickness, tough, somewhat roughened with dots and flecks of russet, green or eventually deep yellow, often shaded with a bronze blush. Dots numerous, greenish or russet. Prevailing effect green or yellow.

Calyx tube cone-shape or elongated funnel-form. Stamens median or approaching marginal.

Core small to medium, axile to slightly abaxile with hollow cylinder in the axis; cells symmetrical, closed or sometimes partly open; core lines clasping. Carpels thin, tender, broadly roundish, emarginate, mucronate, sometimes tufted. Seeds numerous, below medium to above medium, broad, plump, obtuse, rather light brown.

Flesh yellowish, firm, moderately tender, rather fine-grained, juicy, mild or very mild subacid, aromatic, rich, very good to best.

\section{SWAZIE.}

Reffrences. I. Downing, 1872:27 app. fig. 2. Montreal Hort. Soc. Rpt., 1883. 3. Ib., 1886-87:96. 4. Bailey, An. Hort., 1892:250. 5. Woolverton, Ont. Fr. Stas. An. Rpt., 3:16. 1896. figs. 6. Am. Pom. Soc. Cat., 1899:20. 7. Macoun, Can. Dept. Agr. Bul., 37:46. 1901. 8. Waugh, Rural N. Y., 62:185, 186. 1903. figs. 9. Budd-Hansen, 1903:185. fig. Io. Ragan, U. S. B. P. I. Bul., 56:123. 1905. 11. Ib., 56:303. 1905.

Synonyms. Golden Gray? (10). Pomme Grise dor (i). Pomme Grise d'Or $(5,9,10)$. Swaysie Pomme Grise (3). Sivayzie (ii). Sivayzie Pomme Grise (4, 7). Siíayie Pomme Grise (ii). Swazie Pomme Grise (5,8). Sacazie Pomme Grise (1). Savazie's Pomme Gris (10). Swazy (II). Swazy Pomme Gris $(6,9)$.

This is a variety of the Pomme Grise group. As compared with Pomme Grise it is more oblong, has more of a golden color, is more highly aromatic and superior in quality $(\mathrm{I}, 6)$. The fruit is small to nearly medium, of a golden russet color and excellent dessert quality. Woolverton ranks it best in quality for dessert but poor for cooking or for either home or foreign market. He remarks that it succeeds well in Southern Ontario especially in the Niagara district; but, unfortunately, it is not very productive and consequently not profitable, one large tree at Maplehurst, 75 years planted, having yielded only an average of four barrels of fruit each alternate year (5).

The first published description of this variety which we find is that given by Downing (I) under the name Pomme Grise d'Or with 
Swazie Pomme Grise as a synonym. Woolverton (5) gives an excellent illustrated description of the same variety under the name Swazie Pomme Grise with Pomme Grise d'Or as a synonym. The name Swazie has been spelled variously by different writers. We follow the form used by Downing (I) and accepted by Woolverton (5) and Waugh (8) as that appears to have priority in the published accounts of this variety.

Historical. Supposed to have originated on the Swazie farm near Niagara $(\mathrm{I}, 5,7,8)$. It is more generally known in Ontario and Quebec than in New York. It is not grown extensively in any portion of this state.

\section{TREE.}

Tree fairly vigorous, upright $(1,5,7)$. Twigs long, rather slender, straight; internodes medium or below. Bark clear, light brownish-red, quite pubescent. Lenticels numerous, rather conspicuous, irregular in size and shape, raised. Buds medium, moderately prominent, acute or roundish, adhering to the bark or partly free, moderately pubescent.

\section{FRUIT.}

Fruit small or sometimes nearly medium. Form oblate conical to roundish. Stem short to medium length, slender. Cavity narrow to moderately wide, acute, deep. Caly.r closed or partly open; lobes broad, obtuse. Basin narrow to moderately wide, medium in depth, furrowed gently if at all, slightly wrinkled.

Skin rather pale yellow or greenish-yellow with some cinnamon-russet. Dots numerous, whitish.

Caly $x$ tube elongated, cone-shape. Stamens median.

Core rather small to medium, somewhat abaxile, often with hollow cylinder in the axis; cells usually symmetrical, closed or open; core lines meeting. Carpels broadly roundish, nearly truncate at the base, narrowing toward the apex, mucronate. Seeds numerous, small to medium, variable in form, narrow to broad, often angular, usually obtuse or nearly so.

Flesh whitish tinged with pale yellow, fine-grained, tender, crisp, juicy, highly aromatic, sprightly, rather mild subacid, pleasant, very good to best for dessert.

Season December to March.

\section{SWEET AND SOUR.}

References. I. Coxe, I817:172. 2. Thacher, 1822:22. 3. Floy-Lindley, I833:87. 4. Cultivator, $1: 390$. I844. 5. Ib., $2: 20$, I02, I06, I53. I845. 6. Ib., 3:130. 1846. 7. Thomas, 1849:186. 8. Emmons, Nat. Hist. N. Y., 3:90. 1851. 9. Mag. Hort., 18:153, I852. Io. Elliott, 1854:178. II. Horticulturist, I1:46. 1856. 12. Warder, 1867:475. fig. 13. Downing, 1869:374. 14. Rural N. Y., 56:I76, 412, 436, 55I, 567, 770. I897. I 5. Van Deman, Ib., 59:I43. I 900.

Synonyms. Bower's Apple (9). Compound (I4). 
Scattering trees of this variety are found in various parts of the state. It is of no special value but is propagated as a curiosity. Thacher (2) quotes the following very interesting description of the variety and account of its origin by the Rev. Peter Whitney in the Memoirs of the American Academy of Arts and Sciences, Volume I.

"There is now growing, in an orchard lately belonging to my honoured father, the Reverend Aaron Whitney, of Petersham, deceased, an apple tree very singular with respect to its fruit. The apples are fair, and when fully ripe, of a yellow colour, but evidently of different tastes-sour and sweet. The part which is sour is not very tart, nor the other very sweet. Two apples, growing side by side on the same limb, will be often of these different tastes; the one all sour, and the other all sweet. And, which is more remarkable, the same apple will frequently be sour one side, end, or part, and the other sweet, and that not in any order or uniformity; nor is there any difference in the appearance of one part from the other. And as to the quantity, some have more of the acid and less of the sweet, and so vicc versa. Neither are the apples, so different in their tastes, peculiar to any particular branches, but are found promiscuously, on every branch of the tree. The tree stands almost in the midst of a large orchard, in a rich and strong soil, and was transplanted there forty years ago. There is no appearance of the trunk or any of the branches having been engrafted or inoculated. It was a number of years, after it had borne fruit, before these different tastes were noticed; but, since they were first discovered, which is about twenty years, there has been, constantly, the same variety in the apples. For the truth of what I have asserted, I can appeal to many persons of distinction, and of nice tastes, who have travelled a great distance to view the tree, and taste the fruit, but to investigate the canse of an effect, so much out of the common course of nature, must, I think, be attended with difficulty. The only solution that I can conceive is, that the corcula, or hearts of two seeds, the one from a sour, the other from a sweet apple, might so incorporate in the ground as to produce but one plant; or that farina from blossoms of those opposite qualities, might pass into and impregnate the same seed. If yon shonld think the account I have given you of this singular apple tree will be acceptable to the American academy, please to communicate it."

At the time when this account was first published it was custonlary in planting to set orchards with seedling trees from some local nursery, as was evidently done in this case, and if cultivated varieties were ever included they were later top-worked upon these seedling trees with which the orchard was first planted. From the account given by Whitney it is probable that the original tree of the Sweet and Sour apple originated in a seedling nursery from which it was transplanted into the orchard of his father where it first attracted attention because of the curious character of its fruit. 
When this variety is discussed by fruit growers it is not unusual to hear some one relate the legend that it was produced by joining two half buds, one of a sweet the other of a sour variety, and inserting them as one bud under the bark of the stock as is ordinarily done in budding. This legend is recognized in the name "Compound" by which this apple has been known to some in Western New York (I4). The supposed split-bud origin of Sweet and Sour is occasionally discussed pro and con in horticultural periodicals. An early discussion of this kind is found in the Cultivator from 1844 to 1846 $(4,5,6)$ and a more recent one in the Rural New Yorker (I4, I 5).

The tree is vigorous, spreading and often quite productive. The fruit bears some resemblance to Rhode Island Greening in form, color, and occasionally to some degree in flavor. It is more marbled with green and yellow than Rhode Island Greening, more oblate and more often the sides are noticeably unequal.

\section{FRUIT.}

Fruit above medium to rather large. Form oblate, ribbed and rather unsymmetrical. Cavity rather shallow, broad, slightly furrowed. Calyx large; lobes reflexed. Basin shallow, broad, irregular.

Skin green, especially along the ribs, with a shade of yellow on the intervening surface and particularly on the exposed cheek.

Flesh under the yellow skin very deeply tinged with yellow, mildly subacid or sweetish; but under the greenish skin, less yellow and more acid; quality remarkably variable, fair to good.

\section{SWEET GREENING.}

References. I. Thacher, I822:I38. 2. Downing, I869:375. 3. Bailey, Mich. Sta. Bul., 31:54. I887. 4. Waugh, Vt. Sta. An. Rpt., I4:310. I901. 5. Ragan, U. S. B. P. I. Bul., 56:303. 1905.

Doubtful References. 6. Warder, I867:668, 716, 722. 7. Downing, i88I: 109 app. 8. Ragan, U. S. B. P. I. Bul., 56:209. 1905.

Synonyms. Curtis Greening (6)? Curtis Greening $(7,8)$ ? Illinois Greening (6)? New Greening (8)? New Rhode Island Greening $(7,8)$ ? Sweet greening (i). Sweft Rhode Island Creening (7)? Srucet Rhode Island Greening (8)?

This, as the name indicates, is a sweet apple of green color. Thacher (I) describes it as "a large, handsome apple, resembling in size and form, the Rhode Island greening. Ripens in autumn, and possesses the valuable property of retaining its soundness and flavour till the middle of June. It is an excellent apple for baking, and deserves to be more extensively cultivated. Its origin is uncertain, and it is doubtful whether this fine fruit is known out of the old Plymouth colony." 
As grown in this state it is usually not as large as Rhode Island Greening particularly when it is borne on overloaded trees, but under favorable conditions the fruit becomes large as Thacher describes it. The tree is medium in size, upright, hardy, long-lived, comes into bearing moderately young, is a reliable biennial or sometimes almost annual bearer and often yields heavy crops. The twigs are medium to long, erect or spreading and stout. The fruit hangs well to the tree. Where this variety is known it is quite highly esteemed for lome use because it is a good keeper and very good in quality for dessert and for baking or other culinary uses. Generally it is not considered a good variety for the commercial orchard because sweet fruit of this color meets with little demand in the general market. It may be disposed of in limited quantities in some local markets. Some growers find that it takes better in southern than in northern markets. It is in season from December to April or May.

Sweet Greening is quite distinct from Green Sweet, page I5o. From the accotunts of Swect Greening and Sweet Rhode Island Greening given by Downing $(2,7)$ and some other pomologists, there seems to be some reason for questioning whether or not these are distinct. We have not seen the fruit of Sweet Rhode Island Greening but the fruit of Sweet Greening which we have obtained from various sources corresponds fairly well with Downing's description of Sweet Rhode Island Greening. Ragan makes Sweet Rhode Island Greening synonymous with New Greening and probably identical with Curtis Greening and Illinois Greening (8).

Historical. Origin unknown but from the statement of Thacher (I) it is probable that it originated in the old Plymouth Colony, Massachusetts. It is grown in some localities in Central and Western New York but has not been reported to us fron any other portion of this state. It is now seldom or never planted.

\section{FRUIT.}

Fruit medium to large, uniform in shape and size. Form roundish oblate or sometimes approaching roundish conic, regular or somewhat elliptical; sides sometimes unequal. Stem medium to short, moderately thick. Cavity medium in size, acuminate or approaching acute, deep or moderately deep, rather broad, sometimes gently furrowed, russeted and with some outspreading or broken rays of russet. Calyx partly open or closed; lobes convergent or connivent, hroad, acute. Basin moderately shallow and somewhat obtuse to moderately deep and rather abrupt, medium in width, slightly furrowed and wrinkled.

Skin thick, tough, smooth, bright, grass-greer becoming yellowish or yellow, usually with no red but sometimes slightly bronze with reddish spots or dots or even with a well-developed brownish-red blush. Irregular, large, whitish dots and streaks of whitish scarf-skin appear about the cavity, sometimes mingled with a little russet. The whitish dots are rather conspicuous, numerous and broad toward the basin; the rough or russet dots are more scattering.

Calyx tube truncate funnel-form. Stamens median or below.

Core small to medium, nearly axile with a hollow cylinder in the axis; cells symmetrical, closed or slit; core lines clasping. Carpels broadly roundish, enlarginate, mucronate, somewhat tufted. Seeds very numerous, below medium to rather small, moderately narrow to rather wide, obtuse to somewhat acute, plump, sometimes tufted. 
Flesh whitish with yellow tinge, firm, breaking or loose-grained, tender, moderately juicy or when over-ripe rather dry, very sweet, good to very good. Season December to April or May.

\section{SWEET KING.}

Reference. I. Downing, I869:376.

A striped red apple of medium size, sweet flavor and good to very good quality; in season from October to March (I). It originated at Oyster Bay, Nassau county. So far as we have discovered it has not been cultivated outside the locality of its origin.

\section{SWEET RUSSET.}

RefFrence. I. Downing, I869:377.

Synonym. Summer Russet (I).

Various varieties have been cultivated under the name Sweet Russet. The one here noticed, Downing states (I) has been grown in New York, Massachusetts and elsewhere and is a good apple for culinary use, in season from November to March. The fruit is medium in size, yellow, mostly covered with patches and network of russet and the flesh is rich and sweet. We do not know this variety and we have no report of its being grown anywhere in New York at the present time.

\section{SWEET WINESAP.}

References. 1. Elliott, I854:I60-not the Sweet Winesap of Downing. 2. Warder, r857:721, 734. 3. Downing, r869:378. 4. Am. Pom. 'Soc. Cat., r871: I0. 5. Thomas, I875:501. 6. Ib., 1875:514. 7. Lyon, Mich. Hort. Soc. Rpt., 1890:298. 8. Thomas, r897:270. 9. Budd-Hansen, 1903:186. Io. Beach and Clark, N. Y. Sta. Bul., 248:124. I904. Ir. Ragan, U.S. B. P. I. Bul., 56:14I. 1905. I2. Ib., 56:I70. I905. I3. Ib., 56:304, 305. I905.

Synonyms. Bailey Sweet (Io) incorrectly. Hendrick (I0). Hendrick Siceet (io). Henrick (iI). Henrick Sweer (2, 5). Henrick Sweet (7, 8, II, I3, ? 3). Henry Sweet (3, I3). Ladies' Sweet of some (3, 12, I3), but crroneously. Iady Sweet of some, but erroneously. Lady Sweeting of some, but erroneously. Red Sweet Winesap (3, I3). Rose Szceet. SweEt Pearmain (8). Szeet Pearmain of some (3, I3). Sweet Wine Sap (6).

An attractive red winter apple, symmetrical, uniform, of good medium size, or, under favorable conditions, rather large. It is excellent in quality for dessert or for baking or other culinary uses. Some fruit growers report that the tree is satisfactorily hardy, but others find that it is a little lacking in hardiness and for that reason prefer to top-work it upon some vigorous, hardy stock such as Northern Spy, Roxbury or Golden Russet. It is usually healthy and moderately long-lived. It tends to form a rather dense head, particularly where thorough tillage is practiced, and for this reason VOI.. I - I4 
the top should be made sufficiently open so that the foliage may be kept in good working condition throughout the tree. The tree is not an early bearer, but when it comes into bearing it is a reliable cropper. In many cases it is inclined to overbear and produce a considerable amount of undersized fruit Some few hold that two pickings should be made on account of the tendency of the fruit to drop, but others report that it hangs to the tree well enough so that but one picking is needed if the fruit is gathered before it is too far advanced in maturity The fruit has a tough skin, stands heat well before going into storage and remains sprightly and crisp till late in the season As grown in Western New York it ordinarily comes into season in November and may be held in common storage till April first or in cold storage till May fifteenth (10). It sells well in markets where there is any considerable demand for a red winter apple of sweet flavor. It is often shipped to Baltimore, Washington and other southern markets.

Historical. Downing described Sweet Winesap in 1869 as a variety from Pennsylvania (3), with Henrick Sweet as a syno:yym. In I879 fruit of the variety commonly known in Western New York as Henrick Sweet was identified by Charles Downing for William J. Edmunds, of Brockport, N. Y., as undoubtedly Sweet Winesap. Mr. Edmunds has very kindly supplied us with some of his Sweet Winesap fruit which certainly is identical with the apple grown at Geneva and in other parts of the state as Henrick Sweet or Hendrick Swect. He has also presented us with Downing's letter, the text of which is here given in full. "In looking over the apples you sent me a month or more since, I am now certain it is the Sweet Winesap which is described in Downing's second reviserl edition, page 378 . Many years since the late Isaac Hildreth, a nurseryman at Geneva, sent me a barrel of this kind which he said went by the name of Henricks Sweet and as you say, they kept through the winter into Marcl with very little waste. Ladies Sweet keeps still later and is one of the best of its season."

Sweet Winesap has long been cultivated in Western New York under the names Henrick Swcet and Hendrick Sweet. In some localities, particularly in Wayne county, it is known as Rose Sweet. Occasionally it is erroneously called Ladies Sweet, Lady Sweet or Lady Sweeting. Since it bears some reseinblance to the true Lady Sweet it is not strange that it is sometimes thus confused with that variety. Warder listed it under the separate names of Sweet IVinesap and Henrick Sweet. Thomas in 1875 followed Downing in giving Sweet Winesap as a variety from Pennsylvania and notices Henrick Sweet as a separate variety. Evidently he was not familiar with this variety under the name Sweet Winesap, but he must have recognized that it was identical with the apple commonly known in his own section as Henrick Sweet. The 1897 edition of Thomas (8), makes Henrick Sweet a synonym for Sweet Pearmain, but I,yon doubted the correctness of this decision (II). 

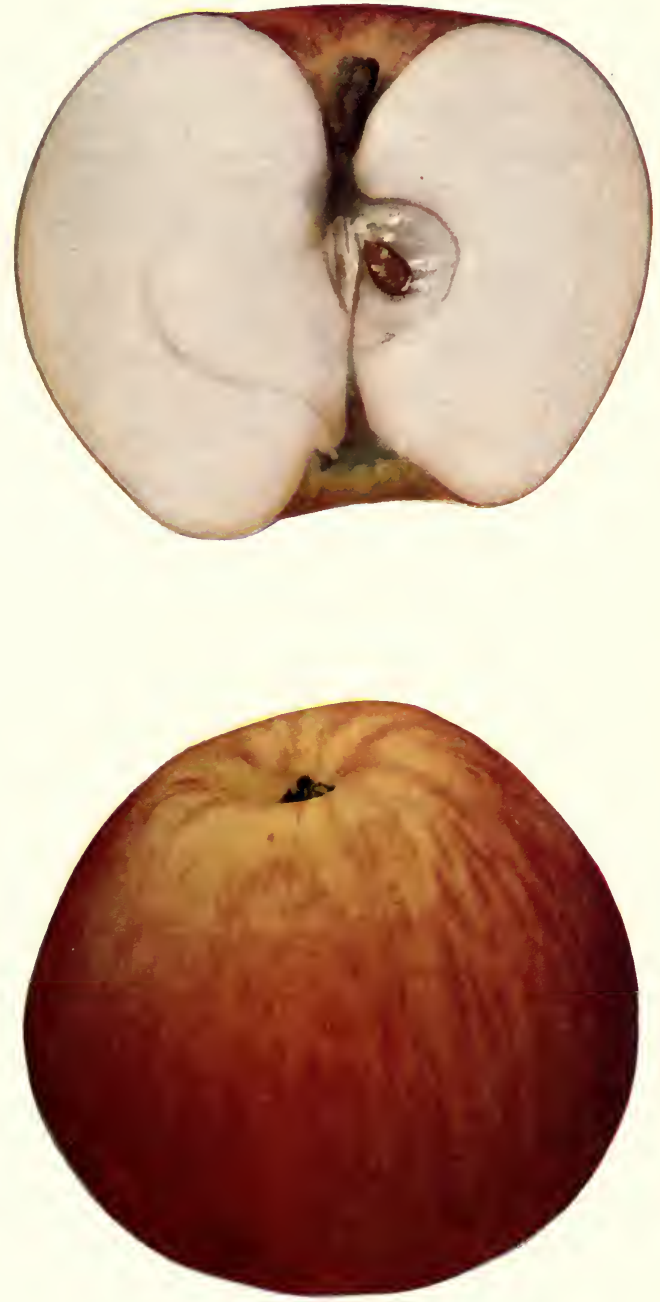

SWEET WINESAP 

We have not seen Swect Pearmain but the descriptions of that variety given by Downing (3) and Elliott (I) do not apply closely to Sweet Winesap.

\section{TREE.}

Trec medium in size, vigorous or moderately vigorous. Form upright spreading to roundish, rather dense. Twigs medium to long, rather slender to moderately stout; internodes medium. Bark brownish tinged with dark red, mottled with inconspicuous grayish scarf-skin, scarcely pubescent. Lenticeis scattering, small to medium, often elongated. Buds medium in size, broadly roundish, obtuse or sometimes acute, somewhat pubescent, generally appressed.

Fruit.

Fruit varies under different conditions from medium to large but under fairly similar conditions is pretty uniform in size and shape. Form roundish conic, wide and flattened at the base, varying to roundish ovate or to oblate conic, regular or slightly elliptical, pretty symmetrical. Stem short to moderately long, moderately slender. Cavity above medium size, acuminate to acute, moderately shallow to rather deep, moderately wide to wide, symmetrical or gently furrowed, sometimes partly russeted. Caly $x$ medium or above, usually somewhat open; lobes often long and acuminate. Basin medium to rather large, often oblique, roundish, deep, moderately narrow to rather wide, decidedly abrupt, sometimes slightly furrowed.

Skin tough, smooth, clear pale yellow or greenish nearly overspread with bright light red, plainly marked with long narrow carmine stripes, covered with a thin bloom and often to a considerable extent with thin, light gray scarf-skin producing a slightly dull effect. Dots small to medium, scattering, whitish or russet. Previling effect red or striped red.

Calyx tube funnel-shape, with broad, yellowish limb and narrow cylinder, sometimes nearly or quite cone-shape. Stamens median to marginal.

Core small to medium, axile or sometimes abaxile; cells usually symmetrical, closed or partly open; core lines clasping. Carpels flat, roundish to broadly elliptical, emarginate. Seeds medium or below, plump, obtuse.

Flesh nearly white, firm, rather fine, moderately crisp, tender, juicy, distinctly sweet, good to very good.

\section{SWENKER.}

References. I. Churchill, N. Y. Sta. An. Rpt., 9:346. I890. 2. Beach, Paddock and Close, Ib., 15:276. I896. figs. 3. Beach and Clark, N. Y. Sta. Bul., 248:146. 1904.

This variety was received in 1890 from J. G. Youngken, Richlandtown, Pa., for trial at this Station. So far as tested here, the tree is vigorous, comes into bearing young and yields full crops in alternate years. The fruit is of good size but only fair in quality and not particularly attractive in appearance. It does not excel standard sorts for any purpose and is not recommended for planting in New York state.

\section{TREE.}

Tree moderately vigorous with long, moderately stout branches. Form open, spreading. Trvigs short to moderately long, straight, rather slender to 
stout, terminal buds large; internodes medium to short. Bark brownish-red tinged with olive-green, lightly streaked with scarf-skin, pubescent. Lenticels very scattering, medium in size, elongated, slightly raised. Buds prominent, medium to large, broad, plump, obtuse to acute, free or nearly so, pubescent.

\section{Friti.}

Fruit medium to large. Form roundish to oblate conic, broadly or obscurely ribbed; sides often unequal. Stem short or medium, slender. Cavity acute to acuminate, deep, moderately narrow to rather broad, often russeted. Caly $x$ small to medium, partly open or sometimes closed; lobes reflexed. Basin usually very small, shallow and narrow or sometimes abrupt and moderately deep, seldom furrowed or wrinkled.

Skin thin, tongh, smooth, somewhat waxy, pale yellow or greenish partly washed with light red, rather indistinctly striped with carnine and marked toward the cavity with broken stripes of grayish scarf-skin. Dots large, grayish, rather obscure, mingled with numerous others that are small and russet. Prezailing effect yellowish.

Caly.x tube medium to large, conical to funnel-form, sometimes extending to the core. Stamens median.

Core below medium to medium in size, somewhat abaxile to nearly axile; cells usually symnetrical, partly open or closed; core lines clasp the funnel cylinder. Carpels roundish to obcordate, emarginate, slightly tufted. Seeds medium to rather large, dark, plump, obtuse, sometimes tufted.

Flesh whitish tinged with yellow, or greenish, moderately firm, moderately fine, rather crisp, somewhat tender, juicy, mild subacid with a peculiar but not altogether agreeable aroma, fair quality.

Season November to March or April. Commercial limit, February.

\section{TEWKSBURY.}

Referfances. I. Coxe, I817:156. fig. 2. Buel, N. Y. Bd. Agr. Mem., i825: 476. 3. Wilson, 1828:136. 4. Downing, I845:I40. 5. Thomas, 1849:186. 6. Cole, 1849:136. 7. Emmons, Nat. Hist. N. Y., 3:88. 1851. 8. Elliott, 1854: 160. 9. Hooper, I857:93. Io. Gregg, I857:59. II. Warder, I867:406, 4 I6. 12. Downing, 1869:382. fig. 13. Am. Pom. Soc. Cat., 1871:10. 14. Barry, 1883:355. 15. Lyon, Mich. Hort. Soc. Rpt., I89o:298. 16. Bailey, An. Hort., 1892:251. 17. Amer. Gard., 16:14. 1895. 18. Ragan, U. S. B. P. I. Bul., 56:309. 1905 .

Synonyms. Fink (9), but incorrectly. Fink (II), but incorrectly. Fink's Secdling (8, 18). Tewkesbury Winter Blush (10, 12, 16). Tewkesbury Blush (i2). Tewksberry Winter Blush (3). Tewksbery Winter Blush (2). Tewksbury Blush (5, 7, 8, 17). Tewksbury Blush (i8). Tewksbury Winter Blush ( I, 4, 6, II, I3, I4). Tewksbury Winter Blush (5, 8, 9, I8).

Valued chiefly because it is a long keeper and holds its quality well late in the season. The color is briglit yellow or greenish with a beautiful pinkishred blush somewhat like that of Maiden Blush; decidedly attractive. Although it is an old variety it is but very little grown in New York state which is pretty good evidence that it does not possess superior value for New York fruit growers. 

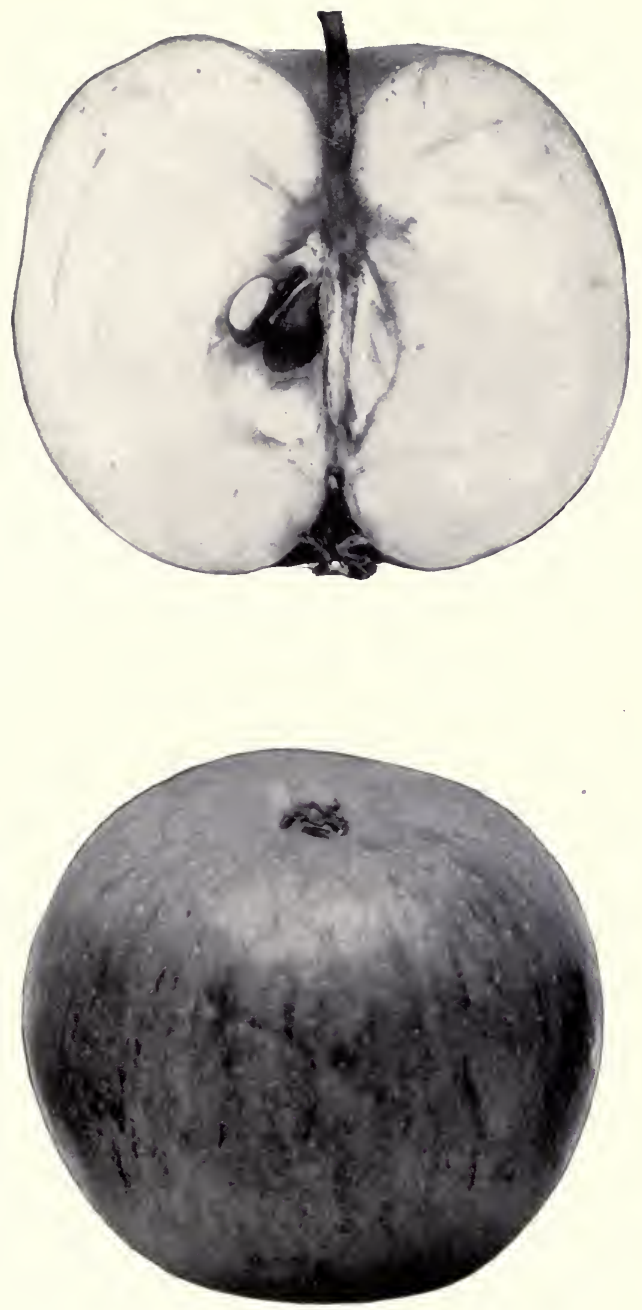

TEXAS 

Historical. Coxe (I) states that it came from the town of Tewksbury in Hunterdon county, N. J. In I $8 \mathrm{I} 7$ he gave the following excellent description of it.

"It is a very handsome fair fruit, with more flavour and juiciness than is to be usually found in keeping apples; I have eaten them in good condition in August of the second year, preserved without particular care, perfectly plump and sound. The size is small; the form round; the skin smooth: the colour yellow, with a bright red cheek-the flesh yellow, tolerably juicy and well flavoured with a considerable degree of sprightliness: the tree is of vigorous growth, straight and well formed-the fruit hangs late in the autumn."

Hooper erroneously reported it as identical with Fink and retained Fink as the correct name for the variety (9). Elliott gave Tewksbury Blush as the correct name with Fink's Seedling as a synonym (8), but Warder (II) considered Fink distinct as shown in the following quotation from his description of that variety. "This long keeper was brought before the notice of the Ohio Pomological Society many years ago by Mr. Clarke, of Somerset, Ohio. Mr. Elliott considered it the same as Tewksbury Winter Blush, and introduces Fink's Seedling as a synonym of that variety. Others think it a different fruit, among whom is that practical Pomologist, the Secretary of that association, M. B. Bateham, Esq., who has propagated and planted the trees extensively. It was described as Fink's Seedling in the Ohio Cultivator, May, I847. At the meeting of 1854 , the merits and claims of this variety were freely discussed, and the Society named it the Fink, after admitting that it was an original seedling, as stated by Mr. Fink, in whose seedling orchard it had originated."

Tewkshury was given a place in the catalogue of the American Pomological Society in I87I (13) and was dropped from that list in I890.

\section{FrUIT.}

Fruit small to nearly medium, uniform in size and shape. Form roundish conic, a little flat at the base, rather symmetrical. Stem medium in length, moderately thick. Carity acute or acuminate, shallow, rather broad, symmetrical, slightly russeted. Calyx very small, closed. Basin very small, very shallow and narrow, slightly wrinkled.

Skin smooth, yellow with pinkish-red blush. Dots many, numerous, small, russet and areolar.

Calyx tube small, long, narrow, funnel-shape. Stanens median to marginal.

Core medium in size, axile or nearly so; cells often unsymmetrical, closed or somewhat open; core lines clasping. Carpels roundish ovate, emarginate. Seeds light brown, medium size, narrow, irregular, acute.

Flesh slightly tinged with yellow, firm, moderately fine, crisp, rather tender, rather juicy, aromatic, sprightly, brisk subacid, good.

\section{TEXAS.}

References. I. Churchill, N. Y. Sta. An. Rpt., 8:355. I889. 2. Bailey, An. Hort., 1892:247. 3. Beach, Paddock and Close, N. Y. Sta. An. Rpt., 15:274. I896. 4. Powell and Fulton, U. S. B. P. I. Bul., 48:58. 1903. 5. Beach and Clark, N. Y. Sta. Bul., 248:146. 1904. 6. Ragan, U. S. B. P. I. Bul., 56:242, 309. 1905.

Synonym. Pride of Texas $(1,2,3)$. Pride of Texas $(4,5,6)$. 
A late-keeping southern apple $(1,2,3,6)$. As fruited at this Station it is only moderately attractive in general appearance, medium in size, yellow, shaded and striped with red, mildly subacid, good in flavor and quality. Usually a considerable portion of the crop may be held in good condition in cellar storage till early summer $(3,5)$. The tree is a good grower, comes into bearing young, is a reliable cropper and productive. Not recommended for planting in New York.

Historical. Received from Benjamin Buckman, Farmingdale, Illinois, in I88, for testing here ( $\mathrm{I}$ ). It has been propagated by some southern nurserymen $(2,6)$. It is practically unknown among New York fruit growers.

\section{TREE.}

Tree rather vigorous. Form roundish or somewhat spreading, rather dense. Truigs moderately long, slender, straight or slightly curved; internodes medium to long. Bark rather clear brownish-red mingled with olive-green, slightly streaked with grayish scarf-skin; somewhat pubescent. Lenticels moderately numerous, conspicuous, medium to large, elongated, raised. Buds below medium to large, rather prominent, plump, acute, free or nearly so, somewhat pubescent.

\section{FrUIT.}

Fruit medium in size. Form slightly oblate to roundish or roundish conic, somewhat ribbed; pretty uniform in size and shape. Stem medium to long. Cazity acute to acuminate, rather narrow to moderately wide, moderately shallow to deep, usually partly russeted. Caly.x small, closed or slightly open. Basin very shallow, rather narrow, wrinkled.

Skin smooth, clear light yellow, largely washed with faint red splashed and striped with carmine, in highly colored specimens becoming deep red on the exposed cheek; streaks of whitish scarf-skin are conspicuous over the base. Dots whitish or pale russet, especially numerous toward the basin.

Calyx tube long, funnel-form. Stamens basal or nearly so.

Corc medium, axile or nearly so; cells closed or partly open; core lines clasping the funnel cylinder. Sceds large to very large, long, rather flat, acute, dark, often tufted. Carpcls broadly roundish inclined to roundish cordate.

Flesh yellowish, sometimes tinged with red, firm, crisp, moderately juicy, breaking, mild suhacid eventually becoming nearly sweet, good in quality and flavor.

Season at Geneva, January to May or June.

\section{TITUS PIPPIN.}

References. I. Manning, Mag. Hort., 7:50. 1841. 2. Downing, 1857:224. 3. Hooper, 1857.93 . 4. Warder, $1867: 734$. 5. Downing, $1869: 383$. 6. Thomas, 1875:514. 7. Powell and Fulton, U. S. B. P. I. Bul., 48:58. I903. 8. Ragan, U. S. B. P. I. Bul., 56:311. 1905. 

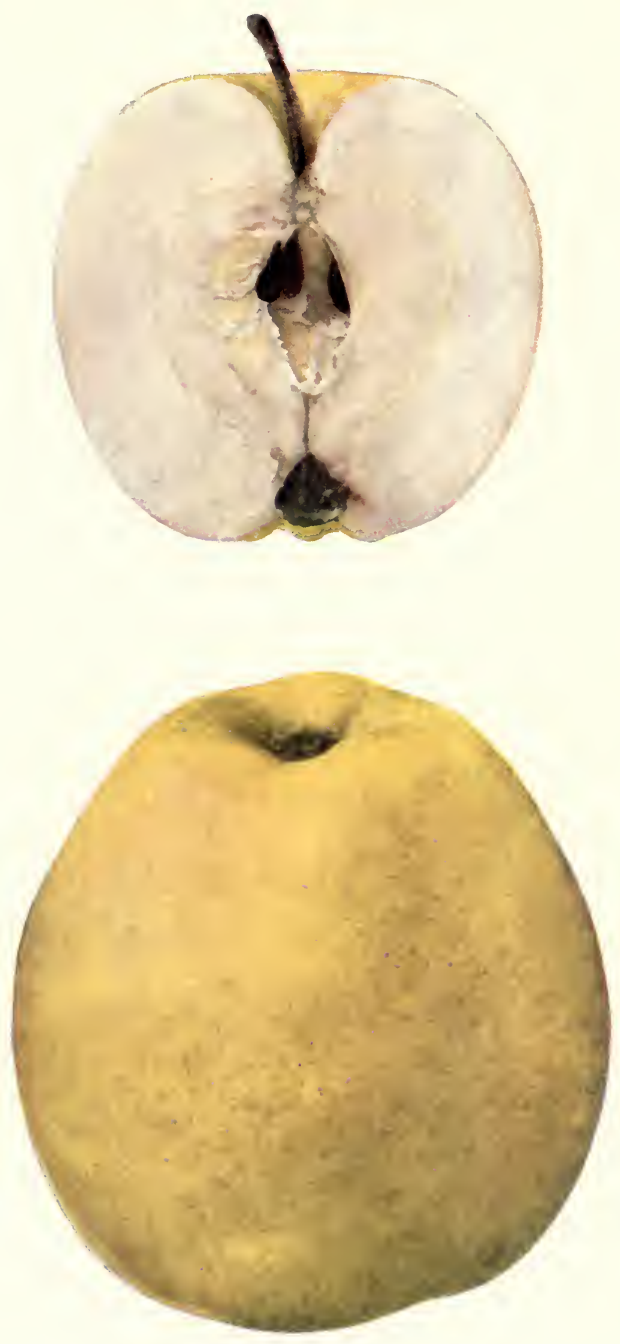

TITUS 

Synonyms. Hang-On (5). Timothy (5). Timothy Titus Sort (5). Tirus $(7,8)$. Titus Pippin $(7,8)$. Well Apple $(5)$.

This variety evidently belongs in the Yellow Bellflower group. The fruit is large, predominantly yellow, smooth, fair, attractive, agreeably flavored, good either for dessert or culinary uses. The tree is a good grower, hardy, healthy, long-lived, comes into bearing rather young and is a reliable cropper, yielding good to heavy crops biennially or almost annually. The fruit hangs well to the tree. Usually a rather high percentage of the crop is of marketable size, but it does not ripen evenly. Some of the fruit becomes very ripe before winter sets in, but as grown at this Station the bulk of the crop keeps well into the winter in ordinary storage. A considerable portion of it may be held in pretty good condition till April in cold storage and it has been held till May firm and with no decay or scald (7). As grown on Long Island it is in season in fall and early winter.

The accompanying plate should bear the legend Titus Pippin instead of Titus, since the name Titus has been used for a fall apple of Russian origin.

Historical. Originated near Hempstead, Long Island (5). We find no record of the time of its origin but as long ago as $184 \mathrm{I}$ Manning gave a description of this fruit and stated that he received the variety from Flushing, N. Y. (I). It is quite commonly cultivated on Long Island but is little known in other portions of the state.

TREE.

Tree large, rather vigorous. Form upright spreading, rather dense. Twigs below medium to short, straight, moderately stout, with large terminal buds; internodes short to rather long. Bark olive-green tinged with reddish-brown, lightly mottled with scarf-skin; slightly pubescent. Lenticels brownish, very scattering, small to medium, roundish, slightly raised. Buds rather prominent, about medium size, plump, acute, free, slightly pubescent.

\section{Fruit.}

Fruit above medium to large. Form oblong conic varying to roundish conic, often irregularly elliptical or obtusely ribbed; sides somewhat unequal; axis often somewhat oblique. Stem medium in length and thickness. Cavity small to medium, acuminate or acute, moderately decp to deep, narrow to rather broad, somewhat furrowed, often partly russeted and with narrow, outspreading russet rays. Calyx usually large and open or partly so; lobes leafy, long, acute. Basin small, often distinctly oblique, shallow to moderately deep, narrow to medium in width, abrupt, often prominently ribbed, sometimes with mammiform protuberances. 
Skin rather tender, smooth, waxy, yellow, often clouded with green, sometimes with orange blush, rarely with distinct red lines or dots. Dots numerous, small, russet or submerged. Prevailing effect attractive clear yellow.

Caly $x$ tube large, wide above, deep, cone-shape with fleshy pistil point projecting into the base. Stamens median or below.

Core large, abaxile; cells usually symmetrical, wide open, sometimes partly closed; core lines partly clasping or meeting. Carpels elongated ovate, emarginate, tufted. Seeds irregular, often imperfectly developed, medium to rather large, long, moderately acute.

Flesh white tinged with yellow, firm, a little coarse, rather crisp, moderately tender, juicy, subacid with pleasant aroma, good to very good.

\section{TOBIAS.}

References. I. Goff, N. Y. Sta. An. Rpt., $7: 90$. I888, 2. Macomber, Amer. Gard., II:I40. I890. 3. Beach and Clark, N. Y. Sta. Bul., 248:146. I904.

Synowym. Tobias Apple $(1,2)$.

As fruited at this Station this is a yellow apple of fairly attractive appearance averaging hardly medium size. It is fair to good in quality. It is in its prime in midwinter but its season extends from November to April. The tree is hardy, comes into bearing rather young and is a reliable cropper, yielding from moderate to good crops biennially or almost annually. It does not excel standard varieties for any purpose and is not worthy of the attention of fruit growers except perhaps in Northern New York where it may be desirable on account of its superior liardiness.

Historical. Originated with Mr. James Tobias in Grand Isle county, Vt. (2). So far as we know it is practically unknown outside of the Lake Champlain district. It was received for testing at this Station in I888 from J. T. Macomber, Grand Isle, Vt.

\section{TREE.}

Tree moderately vigorous. Form roundish or spreading, rather dense. Tiuigs long to medinm, irregularly curved, stout; internodes medium to long. Bark dull brown tinged with red, heavily streaked with scarf-skin; slightly pubescent. Lenticels scattering, medium to large, roundish to oblong, slightly raised. Buds deeply set in bark, medium size, broad, flat, obtuse, appressed, pubescent.

\section{FrUIT.}

Fruit below medium to sometimes rather large. Form oblate, varying to roundish, often a little inclined to conic, regular to broadly angular, sometimes distinctly furrowed from basin to cavity. Stem medium to rather long, slender to moderately stout, pubescent, often obliquely set. Cavity small to medium, varying from slightly acuminate to a little obtuse, deep, moderately narrow to rather broad, somewhat furrowed, sometimes thinly russeted and with outspreading russet rays. Caly.x medium to rather large, usually partly open; lobes long, acute. Basin small to medium, shallow and obtuse to moderately deep and somewhat abrupt, narrow to medium in width.

Skin moderately tender, smooth or roughened with russet dots and flecks, yellow, occasionally with slight blush. Dots distinct, numerous, medium to small, russet-gray or whitish, often submerged. 
Caly.x tube variable, cone-shape to truncate funnel-form. Stamens median to basal.

Core small, axile to somewhat abaxile; cells usually symmetrical, closed or sometimes open; core lines meeting. Carpels rather flat, roundish, slightly emarginate. Seeds numerous, often with some abortive. The plump ones are large, long, rather wide, obtuse, slightly tufted, clear reddish-brown.

Flesh yellowish, firm, moderately coarse, crisp, moderately tender, juicy, sprightly subacid, fair to good.

\section{TOBIAS BLACK.}

References. I. Goff, N. Y. Sta. An. Rpt., 7:54, 90. 1888. 2. Macomber, Amer. Gard., I1:140. ISgo. 3. Waugh, Vt. Sta. An. Rpt., 14:311. Igor.

Fruit of desirable size and fairly good form but of an unattractive dull red and greenish color. The flavor is nearly sweet, the quality hardly good. The tree is said to be very hardy and very productive (2). As grown at this Station it comes into bearing rather young, yields moderate to good crops and is almost an annual bearer. Its fruit is not equal to standard varieties of its season and the variety is not worthy of planting where these can be grown.

Historical. Originated with Mr. James Tobias in Grand Isle county, Vt. (2). So far as we know it is practically unknown outside of the Lake Champlain district. It was received for testing at this Station in I888 from J. T. Macomber, Grand Isle, Vt.

\section{TREE.}

Tree rather large, moderately vigorous. Form flat, spreading, open. Twigs below medium to above, moderately stout, straight or somewhat curved; internodes medium or below. Bark dark clear brown with reddish tinge, lightly streaked with scarf-skin, quite pubescent. Lenticels quite numerous, medium or below, elongated, raised. Buds rather prominent, medium size, broad or roundish, plump, obtuse, free, pubescent.

\section{Fruit.}

Fruit medium to large, fairly uniform in size, somewhat variable in shape. Form roundish oblate varying to roundish or a little oblong, somewhat truncate, frequently irregularly elliptical or obtusely ribbed; sides sometimes unequal. Stem below medium to long, rather slender. Cavity medium to large, acute to acuminate, deep, rather narrow to moderately wide, often somewhat furrowed or compressed, sometimes partly russeted. Calyx medium size, closed or somewhat open; lobes long, acuminate. Basin rather large, deep, wide, rather abrupt, furrowed, sometimes compressed.

Skin thin, tough, grass-green becoming clouded with yellow, largely overspread with dark dull red and striped with purplish-carmine, often clouded with scarf-skin toward the cavity and marked with scattering flecks of russet. In lighly colored specimens the red becomes dark and bright and the stripes indistinct. Dots conspicuous, pale green or grayish, sometimes with russet point, numerous toward the cavity, sometimes areolar. Prevailing effect dull red predominating over dull green.

Calyy tube large, elongated cone-shape or fumel-form. Stamens median or below. 
Core medium or below; nearly axile with hollow cylinder in the axis; cells usually symmetrical, closed or sometimes slightly open; core lines clasping. Carpels thin, broadly roundish to elliptical, obtusely emarginate, mucronate, somewhat tufted. Seeds numerous, medium or below, rather short, obtuse to rather acute, slightly tufted.

Flesh tinged with green or yellow, moderately firm, breaking, moderately fine-grained, tender, juicy, mild subacid becoming nearly sweet, fair to nearly good.

Season November to April.

\section{TOBIAS PIPPIN.}

References. I. Goff, N. Y. Sta. An. Rpt., 7:90. 1888. 2. Beach and Clark, N. Y. Sta. Bul., 248:146. 1904.

Tobias Pippin is of pretty good size, fair to good quality, and rather attractive appearance for a yellow apple. It comes in season in October and some portion of the crop may be kept till March, but in ordinary storage November is its commercial limit. The tree is a pretty good grower and as tested at this Station comes into bearing rather young and produces full crops in alternate years. As compared with standard sorts of its season it does not appear to be worthy of general planting. Received here for testing from J. T. Macomber, Grand Isle, Vt., in I888. So far as we know it is practically unknown outside of the Lake Champlain district.

TREE.

Tree moderately vigorous. Form upright spreading or roundish, dense. Taigs short to medium, straight, stout to somewhat slender, with large terminal buds; internodes short to medium. Bark clear brown with tinge of red, lightly streaked with scarf-skin, slightly pubescent near tips. Lenticels quite numerous, small to medium, roundish or somewhat elongated, not raised. Buds deeply set in bark, below medium to small, flat, obtuse, appressed, but slightly pubescent if at all.

\section{FrU1T.}

Fruit varies from rather small to nearly large but when well grown averages above medium size. Form oblate conic to roundish ovate, often somewhat ribbed, fairly uniform. Stem short to medium, moderately slender. Cavity variable, rather large, varying from rather obtuse to nearly acuminate, moderately deep to deep, moderately narrow to broad, often furrowed or compressed, sometimes partly russeted and with outspreading russet. Calyx small to medium, closed or partly open. Basin small to medium, varying from shallow and narrow to medium in depth and width, abrupt, usually somewhat furrowed.

Skin rather tender, nearly smooth, rather glossy, yellow mottled and streaked with whitish scarf-skin, sometimes distinctly blushed. Dots numerous, small, irregular, whitish and submerged or areolar with russet point.

Calyx tube funnel-form or nearly so. Stamens median to basal.

Core below medium to rather large, somewhat abaxile; cells usually symmetrical, closed or partly open; core lines clasping the funnel cylinder. Carpels broadly elliptical, emarginate. Seeds numerous, rather dark brown, medium to small, plump, rather acute. 
Flesh tinged with yellow, moderately firm, a little coarse, moderately crisp, rather tender, juicy, mild subacid becoming sweet, aromatic, good or sometimes very good.

\section{TOLMAN SWEET.}

References. 1. Thacher, 1822:139. 2. Buel, N. Y. Bd. Agr. Mem., 1826: 476. 3. Manning, Mag. Hort., 7:50. I84I. 4. Downing, 1845:137. 5. Phoenix, Horticulturist, 1:361. 1846. 6. Thomas, 1849:162. 7. Hovey, Mag. Hort., 15: 162. 1849. fig. 8. Cole, 1849:131. fig. 9. Emmons, Nat. Hist. N. Y., 3:87. I 85 I. fig. Io. Elliott, 1854:I 10. fig. II. Gregg, 1857:60. fig. I2. Hooper, 1857:93. 13. Horticulturist, I7:I50, 167. 1862. 14. Am. Pom. Soc. Cat., 1862. I 5. Warder, 1867:557. fig. 16. Barry, 1883:35.5. I7. Lyon, Mich. Hort. Soc. Rpt., 1890:208. 18. Manning, Am. Pom. Soc. Rpt., r89r:137. r9. Taylor, Me. Pom. Soc. Rpt., 1892:57. 20. Bailey, An. Hort., 1892:251. 21. Woolverton, Ont. Fr. Assu. An. Rpt., 26:169. 1894. 22. Can. Hort., 17:229, 280. 1894. col. pl. 23. Hoskins, Rural N. Y., 53:310. I894. 24. Alwood, Va. Sta. Bul., 130: I25. I90I. 25. Waugh, $V t$. Sta. An. Rpt., 14:3II. I90I. 26. Hansen, S. $D$. Sta. Bul., 76:106. 1902. fig. 27. Budd-Hansen, 1903:189. fig. 28. Powell and Fulton, U. S. B. P. I. Bul., 48:58. 1903. 29. Beach and Clark, N. Y. Sta. Bul., 248:146. 1904.

Synonyms. Broz'n's Golden Siceet (io). Tallman's Sweet (15). Tallman Sweet (26). Tallman Sweet (27). Tallman Sweeting (2, 6, I1). Tallman's Siveeting (10). Talman Sweet (5, 17, 20, 21, 22, 23). Talman's Sweet (14, I6, I9). Talman Siveet (28). Talman Sweeting (8). Talman's Siveeting $(9,10,12)$. Tolman $(25,28)$. Tolman Sweet $(3,13,18,24)$. Tolman Sweet $(25,28)$. Tolman's Sweeting $(4,7)$. Tolman Sweeting (I). Tolman's Sweeting $(6$, Io).

Fruit medium or below, rather attractive for a yellow apple. It meets with little demand in the general market, but is sold to a limited extent in special markets and to special classes of trade. The fruit is generally much esteemed for certain culinary purposes as pickling, boiling and baking. Its keeping quality varies in different seasons. In ordinary storage it is in season from November to January with December as the commercial limit. In cold storage its commercial limit varies under different conditions from February I to April (29). Some find that it stands heat well before going into storage; others report that it does not. It shows bruises very readily and requires careful handling. The fruit hangs pretty well to the tree, is quite uniform in grade and suffers comparatively little loss in drops and culls. The tree is a good grower, long-lived and very hardy. Throughout Northern New York, Northern New England, certain portions of Canada and the northern portion of the apple belt in the prairie region of the Middle West, Tolman 
Sricet has gained the reputation of being one of the hardiest of the old New England varieties. For this reason it is often selected as a stock upon which to top-graft less hardy kinds. The tree comes into bearing at a moderately early age, and, generally speaking, is a reliable cropper, yielding from moderate to heavy crops biennially or sometimes almost annually.

Historical. Thacher's description of this variety is the earliest one of which we have any record. He was miable to trace it to its origin (I). Manning (I8) in I89I called attention to the correct orthography, the name having been differently spelled by various authors, and mentioned the supposition that the variety originated in Dorchester (Massachusetts). It has loug been known in cultivation in New York and it appears that it is more generally grown in the home orchards of this state than any other sweet apple.

TREE.

Tree moderately vigorous. Form upright, very spreading, drooping, open; top roundish; branches long, moderately stout, curved and drooping. Twigs medium to long, straight or bowed, stout; internodes medium to short. Bark clear brownish mingled with olive-green, lightly streaked with scarf-skin, heavily pubescent. I.cnticcls rather conspicuous, scattering, medium or above, roundish or oval, not raised. Buds medium in size, broad, plump, obtuse, appressed, pubescent.

FRUIT.

Fruit commonly averages below medium but sometimes grows rather large. It is pretty uniform in size and shape. Form nearly globular or varying to roundish conical or to roundish oblate, often inclined to elliptical or obscurely ribbed. Stem medium to rather long, slender. Cavity obtuse to acute, broad, deep, often russeted, often obscurely furrowed yet pretty symmetrical. Calyx medium to small, somewhat open or sometimes closed; lobes often long and acuminate. Basin small to medium, often oblique, moderately shallow to moderately deep, medium in width, rather abrupt, furrowed, wrinkled, sometimes compressed.

Skin tough, often marked by a suture line extending out from the cavity, sometimes reaching even to the basin; color pale clear yellow or whitishyellow, sometimes a little blushed. Dots small, inconspicuous, pale yellow or faint russet. The skin is apt to be roughened slightly by very inconspicuous capillary russet lines over the entire surface, becoming heavier and concentric at the basin.

Calyx lube urn-shape to truncate funnel-form. Stamens basal or nearly so.

Core medium to rather small, axile; cells symmetrical, closed; core lines slightly clasping. Carpels rather flat, broadly roundish, slightly emarginate, tufted. Secds medium in size, wide, plump, acute to somewhat obtuse, tufted.

Flesh white, firm, neither tender nor crisp, rather hard, moderately fine, rather dry to moderately juicy, decidedly sweet, good to very good. 

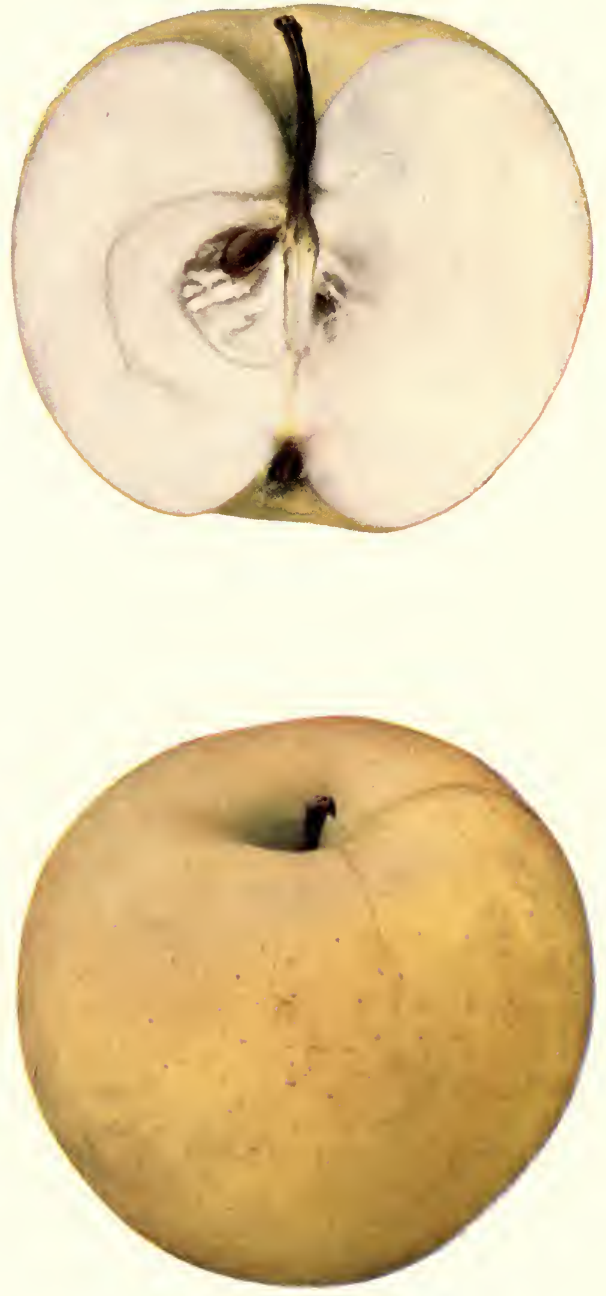

TOLMAN SWEET 



\section{TOMPKINS KING.}

References. I. New Genesee Farmer, 3:57. 1842. 2. Cultizator, I:390. I844. 3. Ellwanger and Barry, Ib., 2:57. I845. 4. Thomas, Ib., 5:306. 1848 . fig. 5. Cole, r849:122. 6. Emmons, Nat. Hist. N. Y., 3:73. 1851. col. pl. No. 38. 7. Hovey, Mag. Hort., 20:178, 509. I854. fig. 8. Elliott, 1854:142. 9. Am. Pom. Soc. Cat., 1856. 10. Horticulturist, II:397. 1856. fig. II. Mag. Hort., 22:545. 1856. I2. Downing, 1857:84. fig. 13. Hooper, 1857:50. I4. Mag. Hort., 24:III. I858. I5. Mattison, Horticulturist, I5:213. 1860. I6. Mag. Hort., 27:98. I861. I7. Warder, 1867:655. fig. 18. Fitz, 1872:157. I9. Thomas, 1875:217. 20. Barry, 1883:348. 21. Hogg, 1884:124. 22. Wickson, I889:245. 23. Lyon, Mich. Hort. Soc. Rpt., I890:298. 24. Bailey, An. Hort., 1892:242. 25. Rural N. Y., 53:28. 1894. 26. Hoskins, Ib., 53:310. 1894. 27. Woolverton, Ont. Fr. Stas. An. Rpt., 2:10. 1895. fig. 28. Gard. and For., 9:10. 1896. 29. U. S. Pom. Bul., 7:356. 1898. 30. Bunyard, Jour. Roy. Hort. Soc., I898:356. 31. Waugh, I't. Sta. An. Rpt., I4:297. I901. 32. Can. Hort., 26: 405. 1903. 33. Budd-Hansen, I903:190. 34. Powell and Fulton, U. S. B. P. I. Bul., 48:58. 1903. 35. Beach and Clark, N. Y. Sta. Bul., 248:I47. I904.

Synonyms. Flat Spitzenburg (28). KIng $(5,7,17,19,24,27,31)$ King (15, 34). King Apple (I, 2, 3, 4, 32, of New York io, of Western New York 8 and 13). King Apple (12). King of Tompkins County (12, I4, 15, 16, I8, 20, 21, 22, 26, 30). King of Tompkins County (17, 27, 28, 33, 35). Toma Red (15). Tommy Red (2I). Tompkins County King (19). Tom's Red (2I). Winter King (6).

This apple is commonly called King. Less frequently it is called Tompkins County King or King of Tompkins County. Pomologists now accept Tompkins King as the correct name.

The fruit has a beautiful red color, with enough clearly contrasting yellow to make a very attractive appearance. It is symmetrical, uniformly large, and excellent in quality for either dessert or culinary uses. It is well adapted for marketing in fancy packages and is in good demand for both special and general trade, often selling at an advance over standard varieties in both domestic and foreign markets. The principal demand for it comes in late fall and early winter. It does not keep quite as late in storage as Rhode Island Greening, but rather later than Hubbardston. It is in season from October or late September to December and January or later. In common storage its commercial limit is December, or exceptionally January, and in cold storage usually February, but in some cases later. The fruit often begins to show some decay in November and sometimes even in October. Its keeping qualities do not vary so much in different seasons as is the case with many other sorts (35). Some of the fruit is often kept in cellars till spring, 
but not with prime flavor, for usually it begins to lose flavor by nidwinter or earlier.

Tompkins King has been quite generally cultivated throughout the principal apple-growing districts of the state and often with fairly good success, particularly when planted on fertile, welldrained soils or top-worked upon thrifty, hardy stock. In the lake region of Central and Western New York in many cases it appears to succeed better on the uplands than it does close to the lakes. The fruit being large, there is often a considerable loss in windfalls, and on this account it is well to select a location for this variety that is well sheltered from prevailing winds. Generally it is regarded as more liable to loss from wormy fruit and less subject to injury from apple scab than either Baldwin or Rhode Island Grecning. As a rule the tree does not come into bearing very young, but with maturity usually becomes a regular bearer, yielding rather light to moderately heavy crops biennially or sometimes nearly annually. Frequently it is regarded as a shy bearer and too unproductive for a good commercial variety, and it nowhere has the reputation of being a heavy cropper, yet many fruit growers find it a profitable commercial variety. Taking the state as a whole, it probably ranks fourth in commercial importance, being surpassed by Baldwin, Rhode Island Greening and Northern Spy. ${ }^{1}$

Were the tree hardier, healthier, longer-lived and more productive, Tompkins King would be much more extensively grown in commercial orchards. In the nursery it makes but a moderate root growth, and in the orchard it is somewhat subject to sun-scald and canker as well as to injury at the surface of the ground from what is commonly called "collar rot" or "collar blight." The cause of this collar rot is not definitely known. Some suppose that it may be due to a parasitic fungus; others that it is caused primarily by winter injury. Tompkins King is certainly more liable to winter injury than are most of the standard sorts of this region. Even in some parts of Central New York, when standing in unfavorable locations, and particularly if on heavy, poorly drained soils, trees have sometimes been entirely killed by the winter, yet in many

\footnotetext{
See page 17.
} 

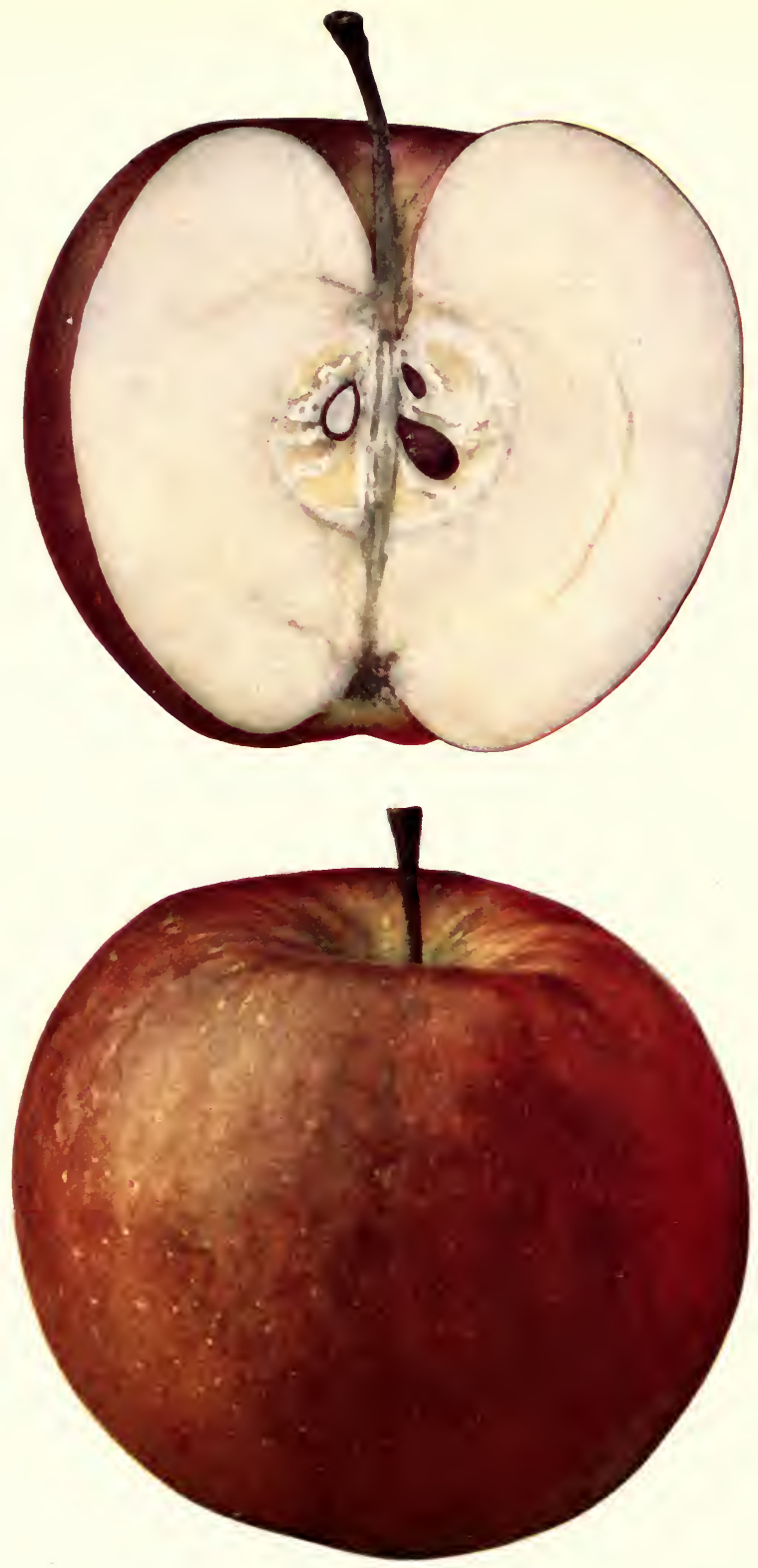

TOMPKINS KING 

localities the variety has succeeded so well that it is regarded as pretty hardy and long-lived. E. W. Catchpole of North Rose, Wayne county, reports that in an orchard planted in that locality in I86I with Baldwin, Rhode Island Greening and Tompkins King, the Tompkins King has been neither as hardy nor as productive as either of the other two varieties named and already shows a considerable number of vacancies in the rows. H. D. Cole of Interlaken, in southern Seneca county, reports that he has an orchard of Tompkins King top-grafted about seventy years ago upon trees which were planted about one hundred years ago. These trees are still bearing good crops. He regards this variety as not sufficiently hardy if grown on its own trunk, but vigorous, healthy, long-lived and reliably productive when top-worked upon hardy stock. The experience of many other fruit growers throughout the state corroborates that of $\mathrm{Mr}$. Catchpole and $\mathrm{Mr}$. Cole and goes to show, that because of its comparatively weak root development and liability to collar rot and winter injury, Tompkins King should be topworked upon some variety which has a stronger root development and a more hardy trunk. Some have had good success in using common seedling stock for this purpose and others have found satisfactory results from top-working it upon Tolman Sweet, Northern Spy, Rhode Island Greening, Oldenburg, Golden Russet, Roxbury and other vigorous, hardy varieties.

Historical. Some have thought that the original tree of Tompkins King grew at Jacksonville, Tompkins county, N. Y., but Bailey found that that tree had been grafted and therefore it could not be the original seedling (28). The variety appears to have originated near Washington, Warren county, $\mathrm{N}$. J. It is said to have been brought from that locality to Tompkins county, N. Y., by Jacob Wycoff in $\mathrm{I} 8 \mathrm{O}_{4}$ by whom it was named King. The Congress of Fruit Growers at Rochester added Tompkins County to its name to distinguish it from other King apples (15). James M. Mattison of Jacksonville, N. Y., investigated the subject of "the origin of Tompkins King during the winter of $I 860$ and published an account of his investigation in the April number of the Horticulturist of that year. We quote his report in full.

"Having given the subject a pretty thorough investigation, I present the following as the true history of the King Apple of Tompkins County:

"About fifty-six years ago, Jacob Wycoff brought it from Warren county, N. J. Mr. Wycoff moved to this county about sixty years ago, and finding the art of grafting practised here, procured the grafts while on a visit fiftysix years ago. Mr. Wycoff is now dead, but always claimed it to be a seed. 
ling, and it was named by him, King. The Congress of Fruit Growers at Rochester added Tompkins County to it, to distinguish it from another of the same name.

"On a visit this winter I undertook to trace out its origin, and went to the place where it is said to have originated. This is about one and a half to two miles from Washington, Warren county, N. J. I found very old trees that had been grafted; they seemed to be over fifty years old; two aged men, Daniel Fleet and William Crivling, near Asbury, were both acquainted with it from boyhood. It originated on the north side of the Musconetcong mountain, about one mile from where these gentlemen live. Mr. Jesse Weller says he knew one very old tree on his farm forty years ago; it has been dead several years. They call the apple Toma Red throughout that section. It does not appear to be much disseminated, being confined to a small locality. I brought some of the apples with me, and compared them with mine. I also gave them some that were raised in my own orchard. They are not quite as high flavored in New Jersey as they are here between the lakes (Cayuga and Seneca).

"The trec is entirely distinct in growth. When I was in New Jersey I pointed out trees as I was going along the road, and inquired if they were not what we call the King of Tompkins County, and they said they were. The limbs grow so very horizontal that the tree needs scarcely any pruning, and one of its good qualities is, it is a regular bearer every year, and a fine, thrifty grower. Hundreds of barrels have been sold from this vicinity this year, and we are all of one mind, that it is the most productive, and will sell for the largest price per barrel of any market apple that is raised in this vicinity. Dealers realized four and five dollars per barrel last fall. The apple is one of those crimson red with yellow ground that attracts the eye, and its color will not disappoint you when you come to eat it. Its very agreeable perfumed flavor is equal to the Swaar. It wants gathering ten to fifteen days before the Baldwin or Greening, and if carefully done, will keep good until the first of May."

The first published description of the variety which we have found is that given in the New Genesee Farner in 1842 , under the name of King Apple (I). The earliest mention which we find of the propagation of this variety by nurserymen is the statement made by Ellwanger and Barry of Rochester, N. Y., in 1845 , that they had trees of it for sale (3). In $1848 \mathrm{~T}$. C. Maxwell and Brothers of Geneva, N. Y., began to propagate it extensively and were active in disseminating it. Thomas, in 1848 , described it under the name of King and stated that it was cultivated in Tompkins and Cayuga counties but not widely spread (4). In 1849 Cole mentioned it under the name of King from Ellwanger and Barry, and in $185 \mathrm{I}$ Emmons described it as the Winter King from Tompkins county $(5,6)$. In 1856 the American Pomological Society at its Rochester meeting included this variety in its catalogue under the name of Tompkins King, using the word Tompkins to distinguish it from other varicties which were then known under the name King.

During the last sixty years its cultivation has extended through New England, portions of Canada, Michigan, New Jersey, Pennsylvania and Ohio. It has practically failed to establish itself in the Mississippi valley but is quite well known on the Pacific Coast, from Washington southward into California. 

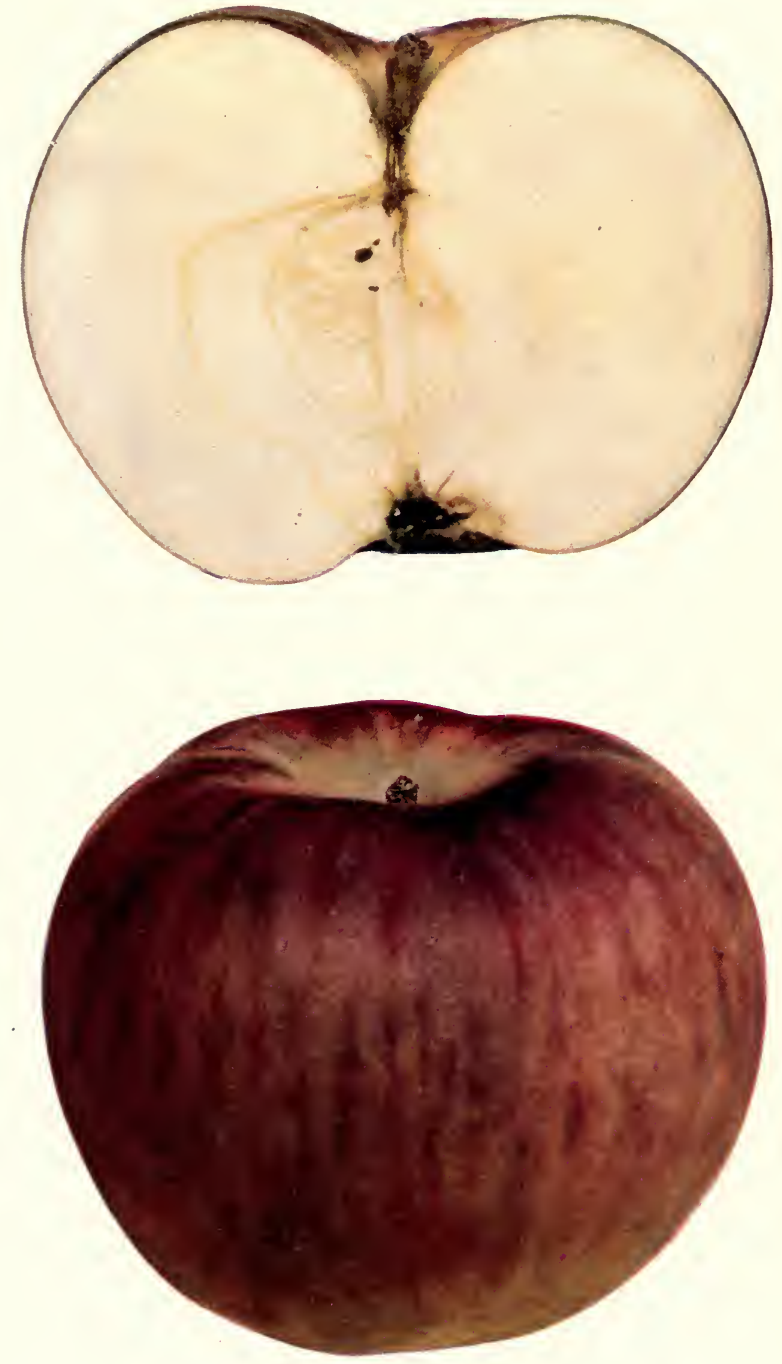

TWENTY-OUNCE PIPPIN 



\section{TreE.}

Tree vigorous. Form spreading, open; lateral branches rather slender and somewhat drooping. Twigs long to above medium, curved or irregularly crooked, moderately stout with thick tips; internodes long to below medium. Bark dark brownish-red mingled with yellowish-green, lightly mottled with scarf-skin; pubescent. Lenticels rather dull but conspicuous, numerous, large to small, roundish to oblong, raised. Buds prominent, large, broad, plump, obtuse to acute, free or nearly so, pubescent.

\section{FrUIT.}

Fruit large to very large, pretty uniform in shape and size. Form roundish to somewhat oblate, sometimes slightly inclined to conic, regular or obscurely ribbed. Stem short to rather long, often stout, sometimes thick and swollen. Cavity medium to rather large, obtuse to acute, moderately deep to rather shallow, moderately narrow to rather wide, often gently furrowed or wavy, occasionally lipped, often russeted, sometimes with fine outspreading russet. Caly.x medium to rather large, closed or somewhat open; segments long, acuminate. Basin small to medium, varying from narrow, shallow and rather obtuse to moderately wide, rather deep and abrupt, regular or sometimes obscurely ridged and wrinkled.

Skin smooth or somewhat roughened with russet dots, fine yellow mottled and washed with orange red, often shading to lively deep red, striped and splashed with bright carmine. Dots rather numerous, conspicuous, white or russet. Prevailing color attractive red over yellow.

Calyx tube small to above medium, cone-shape to funnel-form. Stamens median to marginal.

Core below medium to rather large, abaxile to nearly axile; cells symmetrical, closed or partly open; core lines meeting or slightly clasping the apex of the tube when it is cone-shape or the limb when it is funnel-shape. Carpcls roundish to somewhat ovate or obovate, tufted, mucronate, but slightly emarginate if at all. Seeds few, rather large, long, irregular, obtuse to somewhat acute, often abortive, somewhat tufted.

Flesh attractive yellowish, rather coarse, crisp, tender, aromatic, juicy, subacid, very good to best.

\section{TWENTY OUNCE PIPPIN.}

References. I. Downing, I845:I40. 2. Thomas, I849:I53. 3. Emmons, Nat. Hist. N. Y., 3:2 1, 33. 1851. fig. 4. Ib., 3:64. I851. fig. 5. Elliott, 1854: 126. 6. Warder, 1867:461. 7. Downing, 1869:113. 8. Lyon, Mich. Hort. Soc. Rpt., 1890:290. 9. Woolverton, Ont. Fr. Stas. An. Rpt., 2:8. 1895. fig. 10. Ib., 3:3. 1896. figs.

Synonyms. Cabashea (7, 8, 9, 10). King (4). King (7). Oxheart. Not Twenty Ounce $(2,5,6,9,10)$.

Attractive in appearance, but second or third rate in quality. In season about with Tompkins King. It is grown commercially to a limited extent and some find it profitable, but, generally speaking, it is not a favorite with fruit growers. Undoubtedly there would be 
fewer trees of it growing to-day had it not sometimes been purchased by mistake for the true Twenty Ounce. The tree is a vigorous grower, hardy, healthy and long-lived, but often it is not a satisfactory cropper. The fruit is large, noticeably heavy and apt to drop from the tree.

Historical. The origin of this variety is uncertain. So far as we can learn it has always been commonly known to fruit growers and fruit buyers by the name Twenty Ounce Pippin and doubtless will continue to be so known as long as it remains in cultivation. Occasionally it has been grown under the name King. It should be remarked, however, that it is quite distinct from Tompkins King. It is known locally as Oxheart.

Thomas in 1849 (2) recognized it as less desirable than the Twenty Ounce. Elliott (5) and Warder (6) adopted the name Cayuga Red Streak for the Twenty Ounce hoping thereby to prevent their readers from confusing its name with that of Twenty Ounce Pippin. Downing (7) added to the confusion by applying the name Cabashea to the Twenty Ounce Pippin which name had already been given to a fall variety, 1 and was so recognized by Thomas, Emmons and Warder. This fall Cabashea comes in season about with the true Twenty Ounce but is quite distinct from that variety.

\section{TREE.}

Tree medium to large, moderately vigorous. Form spreading or somewhat drooping. Tairgs medium to long, moderately stout to stout; internodes short. Bark dark brownish-red, mottled with scarf-skin; pubescent. Lenticels numerous, moderately conspicuous, romi, raised. Buds large, broad, plump, obtuse, appressed, pubescent.

\section{FRUIT.}

Fruit large to very large, noticeably heavy. Form variable, somewhat oblate to globular with flattened base, often slightly inclined to conic, pretty regular but often somewhat, elliptical or obscurely ribbed; sides frequently a little unequal. Stcm usually short and thick to sometimes moderately thick and of medium length. Cavity medium or below, acute to nearly obtuse, moderately shallow to deep, wide, somewhat furrowed, sometimes lipped, bright deep green with elongated whitish dots, often partly russeted and with outspreading russet rays. Caly $x$ medium to large, closed or partly open; lobes separated at the base, wide, nearly flat or somewhat reflexed, pubescent. Basin below medium to large, shallow to moderately deep, obtuse to somewhat abrupt, irregularly furrowed and wrinkled.

Skin rather thick, tough, smooth, clear palc yellow or greenish, in highly colored specimens largely washed, mottled and blushed with bright deep red striped and splashed with carmine. Dots numerous, small or narrow and elongated, moderately conspicuous, often submerged or depressed, whitish, sometimes with russet point. When well grown the general appearance is decidedly attractive and the color is somewhat like that of the Baldwin, particularly about the base.

Calyx tube short, varying from funnel-shape with wide limb to obtuse coneshape. Stamens median to basal.

'N. Y. Agr. Soc. Rpt., $1849: 350$. 


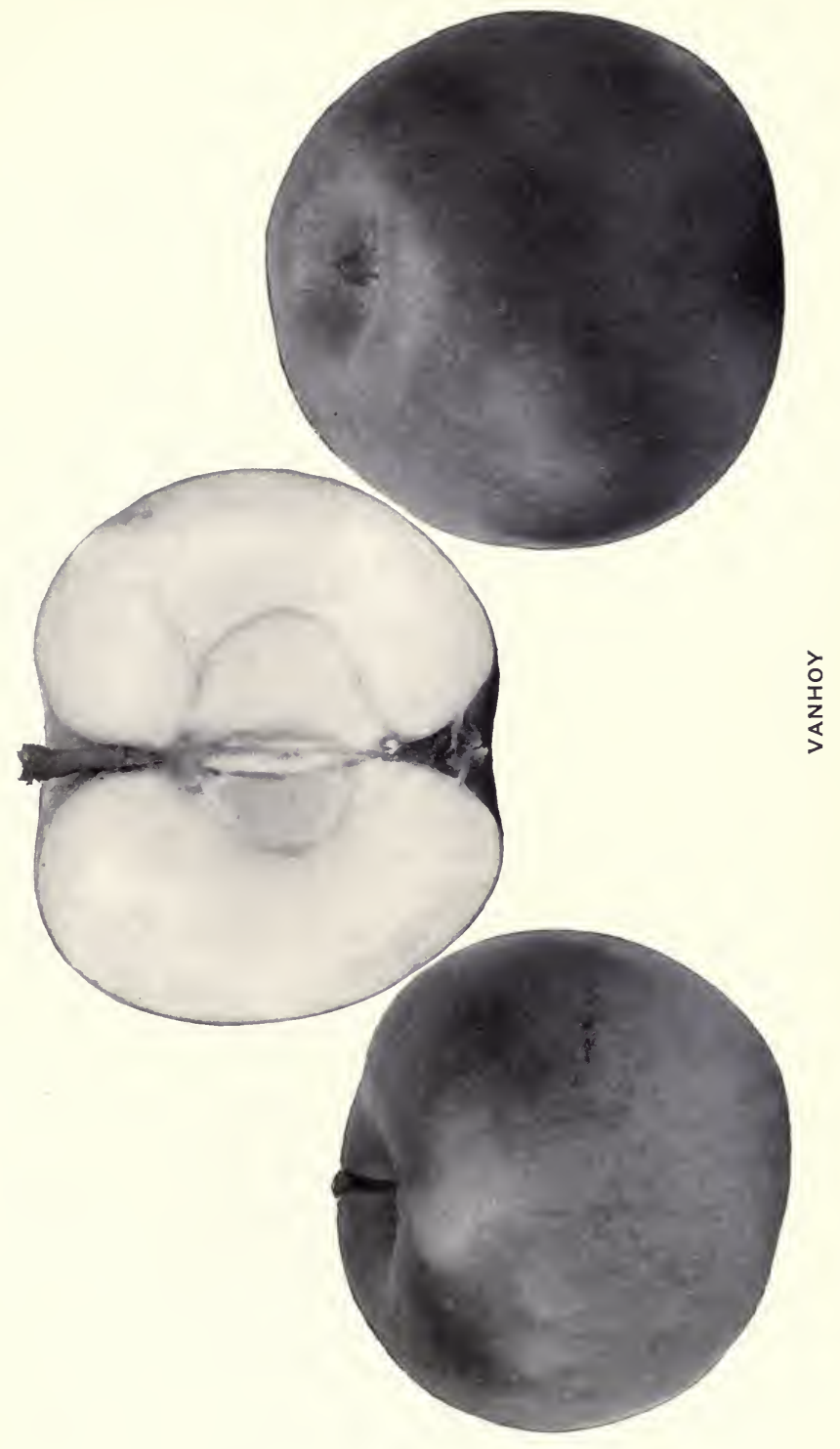



Core medium to rather large, axile or nearly so; cells usually symmetrical and closed, sometimes open; core lines clasping the funnel cylinder. Carpels broadly roundish or inclined to ovate or to obcordate, slightly emarginate, tufted. Seeds few, often abortive; when well developed they are medium to large, rather long, plump, acute to somewhat obtuse, sometimes tufted, medium brown.

Flesh whitish tinged with yellow, firm, coarse, rather tender, rather crisp or breaking, moderately juicy, sprightly subacid with a peculiar but not high flavor, fair or sometimes nearly good in quality.

Season October to January or February.

\section{VANHOY.}

References. I. N. Y. Sta. An. Rpt., 8:356. 1889. 2. Beach, Ib., 15:276, 284. I896. 3. Massey, N. C. Sta. Bul., 149:318. I898. 4. Bruner, N. C. Bd. Agr. Bul., 1900:I I. 5. Budd-Hansen, 1903:194. 6. Powell and Fulton, U.S. B. P. I. Bul., 48:59. 1903. 7. Beach and Clark, N. Y. Sta. Bul., 248:148. 1904. 8. Ragan, U. S. B. P. I. Bul., 56:319. 1905. 9. J. Van. Lindley, Cat. Pomona. N.C. (cited by 8 ).

Synonyms. Van Hoy (3). Van Hoy No-Core $(1,2)$. Van Hoy NoCore $(5,8)$.

As grown at the Geneva Station, Vanhoy lacks character, being unattractive in general appearance and only fair in quality. It is not desirable for any purpose and is remarkable only because the core is small and usually has no well-developed seeds.

Historical. This is a variety of North Carolina origin and in its native state it is said to be a fair dessert apple with good market qualities $(3,4)$. It is practically unknown in New York.

\section{TREE.}

Tree moderately vigorous, not large. Form spreading, rather flat, open. Twigs below medium to short, straight, slender to moderately stout; internodes long to below medium. Bark dark clear reddish-brown with some olive-green, lightly streaked with scarf-skin, but slightly pubescent if at all. Lenticels rather conspicuous, scattering, medium to small, elongated, slightly raised. Buds large to below medium, broad, plump, acute to obtuse, free or somewhat appressed, slightly pubescent.

\section{FRUIT.}

Fruit medium, sometimes large: Form oblate to roundish, a little inclined to conic; axis sometimes oblique; sides often somewhat unequal. Stem medium to long, moderately thick. Cavity medium in size, acute to acuminate, moderately narrow to rather wide, moderately deep to deep, often compressed or obscurely furrowed, sometimes lipped, sometimes thinly russeted. Caly $x$ below medium to large, closed or partly open; lobes often leafy, long, acute to acuminate. Basin small to medium, somewhat obtuse to rather abrupt, medium in width and depth or sometimes deep, occasionally slightly furrowed. 
Skin thick, leathery, smooth, dull yellowish-green largely overspread with dull red and marked with narrow, obscure splashes or stripes of dark carmine. Dots rather conspicuous, pale yellow or russet.

Caly.x tube rather large, cone-shape to funnel-forn. Stamens median.

Core small, abaxile or nearly so; cells symmetrical, closed; core lines meeting or, when the tube is cone-shape, slightly clasping. Carpels rather flat, roundish ovate to obcordate, slightly emarginate, mucronate. Seeds few, rarely plimp, wide, rather long, obtuse to acute, sometimes tufted; often all are abortive.

Flesh whitish tinged with yellow or green, firm, a little coarse, quite crisp, breaking, moderately juicy, mild subacid, fair quality.

Season at Geneva January to May.

\section{VIRGINIA GREENING.}

References. 1. Prince, N. E. Farmer, 8:1. I829. 2. Kenrick, 1832:60. 3. White, Horticulturist, 7:319. I852. 4. Elliott, 1854:160. 5. Downing, 1857: 200. 6. Hooper, 1857:95. 7. Warder, 1867:416. fig. 8. Downing, r869:393. 9. Am. Pom. Soc. Cat., 1873. 10. Thomas, 1875:230. II. Barry, 1883:356. 12. Wickson, 1889:248. 13. Bailey, An. Hort, 1892:251. r4. Budd-Hansen, 1903: 195 .

Synonyms. Green Mountain Pippin (8). Ross Greening (8). Virginia Pippin? (8).

A large, oblate, yellowish-green apple with hard, firm flesh. In the South, where it is supposed to have originated, it is valued as a late keeper. The tree is large, spreading, vigorous and productive. It is but little grown in this state.

\section{Frult.}

Fruit medium to nearly large, uniform in size and shape. Form oblate or roundish oblate varying to roundish conic, regular or nearly so, symmetrical. Stcm medium to long, moderately slender. Cavity medium in size, acute to acuminate, deep, moderately narrow to rather broad, often slightly furrowed, russeted and with outspreading russet. Caly $x$ medium or below, partly open; lobes slightly separated at the base, usnally short and obtuse to acute. Basin medium size, usually rather shallow but varies to moderately deep, moderately wide, obtuse or occasionally rather abrupt, furrowed obscurely if at all, slightly wrinkled.

Skin thick, tough, smooth or slightly roughened with russet dots and flecks, grass-green sometimes with brownish blush. Dots distinct, usually areolar with russet center, whitish or fawn-colored on the blushed portion, often irregular toward the cavity.

Caly:x tube cone-shape to funnel-form. Stamens median.

Core small to medium, axile or with a narrow, hollow cylinder in the axis; cells symmetrical, closed or sometimes slightly open; core lines meeting the limb of the calyx tube or clasping the funnel cylinder. Carpels roundish to broadly obovate or approaching obcordate, deeply emarginate, smooth or slightly tufted. Seeds numerous, small, rather narrow, plump, acute to obtuse, usually smooth. 

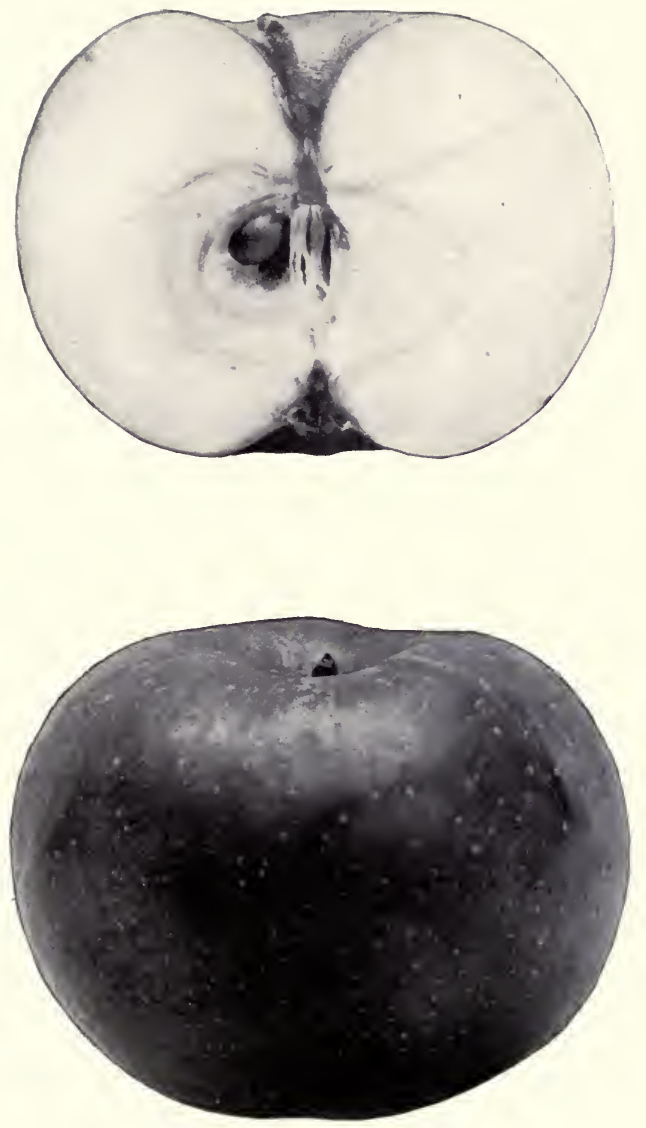

WABASH RED 

Flesh creamy yellow or greenish, very firm, hard, breaking, coarse, moderately juicy, mild subacid becoming somewhat sweet, fair to good.

Season February to June.

\section{WABASH RED.}

References. I. $N$. Y. Sta. An. Rpt., II:223. 1892. 2. Ib., 13:170. I894.

SyNonym. Wabash Red Winter (2).

As grown at this Station, Wabash Red is a rather attractive apple of fairly good size, bright color, smooth and uniform appearance and good dessert quality for a late-keeping apple, but rather too mild in flavor for most culinary uses. It has the merit of retaining its texture and flavor well till very late in the season. As tested here the fruit shows a tendency to be deficient in size. The tree is a good grower, is not slow in coming into bearing and yields moderate to good crops nearly annually. It is sufficiently promising to be worthy of further testing.

This is distinct from Wabash or Wabash Bellflower.

Historical. Received in 1892 and 1894 from Downing and Morris, Clinton, Ind., for testing at this Station $(1,2)$.

\section{TreE.}

Tree vigorous. Form upright to roundish, rather dense. Twigs short to above medium, straight or somewhat curved, stout and with large terminal buds; internodes medium to short. Bark brownish-red mingled with olivegreen, lightly mottled with scarf-skin; slightly pubescent. Lenticels conspicuous, quite numerous, small to medium, roundish or a little elongated, slightly raised. Buds medium to large, broad, plump, obtuse, free or nearly so, slightly pubescent.

\section{FrUIT.}

Fruit large to medium, quite uniform in size and shape. Form roundish oblate, a little inclined to conic, usually regular; sides sometimes unequal. Stem short to above medium, rather thick. Cavity small to medium, acuminate to nearly obtuse, moderately deep to deep, rather narrow to moderately broad, sometimes lipped, usually russeted and with outspreading russet. Calyx small to medium, closed or partly open; lobes sometimes separated at the base. Basin medium size, usually shallow and obtuse but varying to moderately deep and somewhat abrupt, wide, somewhat furrowed and wrinkled.

Skin moderately thick, tough, nearly smooth, bright clear yellow, in highly colored specimens largely overspread with bright red or orange-red obscurely striped with darker red. Dots numerous, rather conspicuous, small to medium, whitish or pale yellow and russet. Prevailing effect red.

Calyx tube cone-shape to truncate funnel-form. Stamens median. 
Core rather small, axile or nearly so; cells symmetrical, usually closed; core lines somewhat clasping. Carpels roundish, smooth or nearly so. Seeds compactly filling the cells, medium or above, rather wide, somewhat obtuse, tufted; often some are abortive.

Flesh whitish slightly tinged with yellow, very firm, a little coarse, crisp, not tender, moderately juicy, mild subacid, pleasant, sprightly, good.

Season December to May.

\section{WAGENER.}

References. I. N. Y. Agr. Soc. Trans., 1847:31 5. fig. 2. Ib., 1848:275, 285. fig. and col. pl. frontispiece. 3. Horticulturist, 3:95. I848. 4. Thomas, 1849:173. fig. 5. Mag. Hort., r6:158. 1850. 6. Emmons, Nat. Hist. N. Y., 3:73. I851. col. pl. No. 41. 7. Elliott, 1854:114. fig. 8. Am. Pon. Soc. Cat., 1856. 9. Downing, I857:I IO. fig. I0. Hooper, 1857:95. II. Horticulturist, I 7:150. 1862. 12. Hovey, Mag. Hort., 29:261. I863. fig. 13. Warder, 1867: 490. fig. I4. Waring, Mich. Pom. Soc. Rpt., I871 :40. I5. Wagener, Ib., 1872: 454. fig. I6. Fitz, 1872:175. I7. Barry, I883:356. I8. Rural N. Y., 47:749. I888. I9. Wickson, I889:248. 20. Lyon, Mich. Hort. Soc. Rpt., I890:298. 21. Can. Hort., I4:9I, I3I. I891. 22. Bailey, An. Hort., I892:252. 23. Can. Hort., I6:406. I893. 24. Rural N. Y., 56:3I7, 359. I897. 25. Waugh, Vt. Sta. Bul., 6r:32. I897. 26. Ib., Rp!., I4:31 I. I9oI. 27. Alwood, Va. Sta. Bul., I30:I25. I90I. 28. Budd-Hansen, I903:195. fig. 29. Powell and Fulton, U. S. B. P. I. Bul., 48:59. 1903. 30. Beach and Clark, N. Y. Sta. Bul., 248:148. I904.

Wagener, at its best, is an apple of superior excellence. The color is a beautiful bright red with some contrasting pale yellow; it has fine texture, high flavor and excellent quality. It is very desirable for culinary uses but is especially esteemed for dessert. It is in season about with Tompkins King or from October to February, yet often some portion of the fruit may be kept in ordinary storage till late spring. Its conmercial limit is December, or, in cold storage, about February Ist. It does not stand heat well before going into storage and is quite apt to scald toward the close of the season, particularly if not well colored. After scalding it goes down quickly $(29,30)$. Often there is some loss from drops, especially if the crop is not picked as soon as it is well colored, and many times there is a rather high percentage of loss in fruit that is ummarketable because it is undersized or misshapen. In the nursery Wagener is a pretty good grower, upright and wellformed; in the orchard it is quite vigorous at first, but as it advances in maturity it usually becomes a rather weak grower, with branches full of fruit spurs. It comes into bearing at an early age and so long as it remains healthy it is a reliable cropper, yielding 

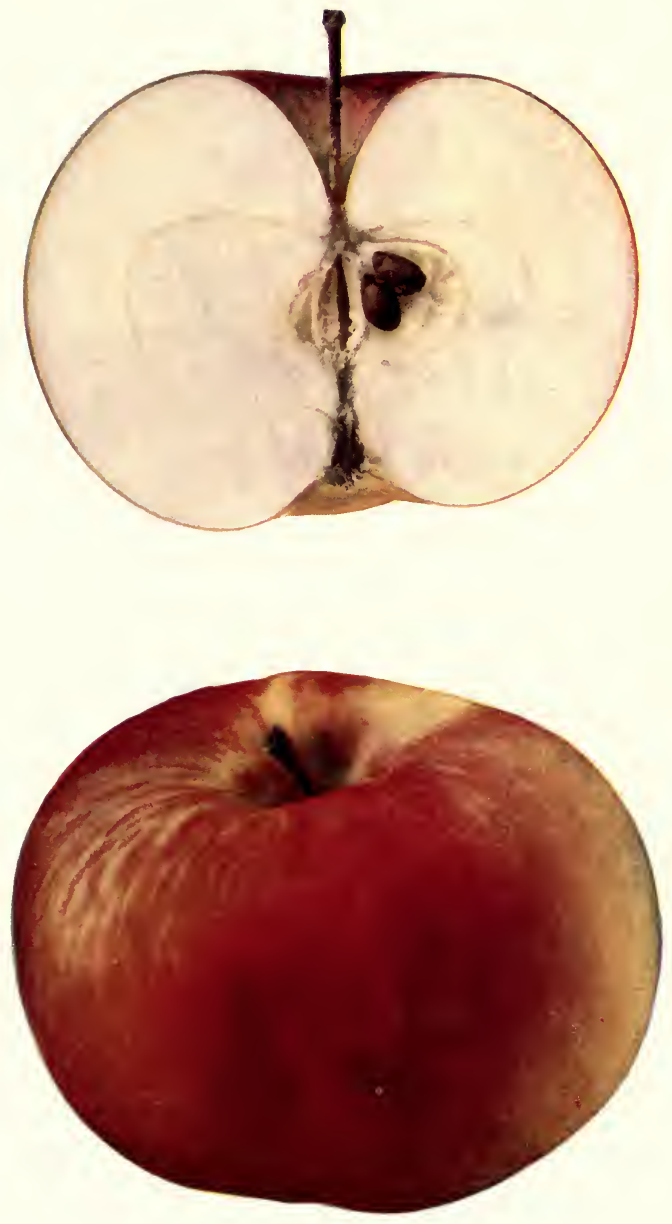

WAGENER 

moderate to rather heavy crops biennially or nearly annually. In many cases it overbears so that the fruit does not all develop properly in size and color. Under such circumstances it is a great advantage to thin the fruit. To get best results the thinning should be done as early as June. Under favorable conditions the crop is pretty uniform in size, color and quality.

The tree is often short-lived, but some report that it is longerlived when top-worked upon hardier and more vigorous stock such as Northern Spy, Baldwin and Tolman Srceet. On account of its dwarfish form and habit of coming into bearing at an early age it is recommended by some fruit growers as a filler to plant between the rows of longer-lived apple trees. Some fruit growers consider it a profitable variety, but many do not. Although it was introduced about a half century ago and it is now sufficiently well known so that it may perhaps be regarded as a standard market variety, yet it has not established itself to any considerable extent in the commercial orchards of this state and is not being extensively planted.

Historical. The first published reference to the Wagener which we find is that given in the Report of the N. Y. State Agricultural Society for 1847 , in which it is stated that it was awarded second premium as a seedling of merit (I). In $I 848$ it was again presented for competition and was placed by the committee in the list of first-class apples, awarded an additional premium and also a diploma. An illustrated description of it was published in the report of this Society for that year with the remark "This very fine apple the committee consider a desirable addition to the list of first-rate fruits. Its appearance is prepossessing as is also its size and form" (2). An account of the history of Wagener was also given in which it was stated that in the spring of 1791 Mr. George Wheeler brought with him from Dover, Dutchess comnty, N. Y., to Penn Yan, Yates county, a quantity of apple seeds which he sowed that spring in the nursery upon his farm which he was then reclaiming from the wilderness. In I796 Abraham Wagener, from whom the name of the apple is derived, bought this seedling nursery and planted trees from it upon his place in what is now the village of Penn Yan. In 1848 it was remarked that the old tree was producing an annual and abundant yield of beautiful and delicious fruit (2). It continued to bear full crops till about the year 1865 (I5). After it was brought to the notice of the State Agricultural Society, the Wagener soon began to be propagated quite extensively and it has since become widely disseminated throughout the country. In I 892 Wagener was being offered quite generally by nurserymen throughout the country except in the North Mississippi valliy, the Rocky Mountain region and the plains from Nebraska to Texas (22). It is generally known throughout New York but is not planted extensively in any section of the state. 
TREE.

Tree dwarfish to medium size, at first moderately vigorous but soon becoming a slow grower; branches short, stout and filled with spurs. Form roundish to spreading, open. Twigs short to medium, often somewhat curved, moderately stout, usually quite blunt; internodes medium to short. Bark clear dark reddish-brown mingled with olive-green, lightly streaked with scarf-skin; pubescent near tips. Lenticels scattering, medium or below, elongated or sometimes roundish, not raised. Buds medium to rather large, sometimes projecting, plump, acute, free, pubescent.

\section{FRUIT.}

Fruit medium to rather large. Form oblate to roundish oblate, broadly ribbed or irregularly elliptical; sides often unequal. Stem short to moderately long, moderately thick to rather slender. Cavity variable, acute, moderately deep to deep, broad or sometimes compressed and rather narrow, often angular or furrowed, sometimes thinly russeted. Calyx small to medium, closed or partly open; lobes small, usually short, acute to acuminate, connivent, reflexed. Basin medium in width and depth, abrupt, somewhat furrowed.

Skin thin, tough, smooth, glossy, bright pinkish-red striped with bright carmine and mottled and streaked with thin whitish scarf-skin over a clear, pale yellow background. Dots numerous, whitish or russet, sometimes mingled with light russet flecks. Prezailing color bright light red.

Calyx tube long, rather narrow, funnel-form, often elongated and extending to the core. Stamens median to marginal.

Core below medium to moderately large, somewhat abaxile with hollow cylinder in the axis, varying to nearly axile; cells symmetrical, closed or open; core lines clasping the funnel cylinder. Carpels broadly roundish or approaching elliptical, but little emarginate if at all, smooth or nearly so, mucronate. Seeds moderately numerous, rather small to above medium, short to moderately long, moderately wide, obtuse, rather light brown; often some are abortive.

Flesh whitish slightly tinged with yellow, moderately firm, rather finegrained, crisp, tender, juicy to very juicy, subacid, aromatic, sprightly, very good to best.

Season October or November, to February or later.

\section{WALBRIDGE.}

References. I. Rural N. Y., 1870:204, 205. fig. 2. Am. Pom. Soc. Cat., 1873. 3. Am. Pom. Soc. Rpt., I875:36, 68, 124; Cat.: 8. 4. Downing, 1876:50 app. fig. 5. Ill. Hort. Soc. Rpt., I877:21 3. 6. Burrill, Ib., 1878:226. 7. Ia. Hort. Soc. Rpt., $1882: 343^{*}$ 8. Gibb, Am. Pom. Soc. Rpt., I883:124. 9. Thomas, 1885:527. Io. Bailey, An. Hort., I892:252. II. Ib., I892:238. I 2. Craig, Can. Dept. Agr. Rpt., I894:126. 13. Can. Hort., 17:69, 70. 1894. 14. Beach, N. Y. Sta. An. Rpt., I3:592. I894. 15. Maynard, Putnam and Fletcher, Mass. Sta. Bul., 44:4. I897. r6. Am. Pom. Soc. Cat., 1897:15. I7. Waugh, Vt. Sta. An. Rpt., 14:3II. I90I. 18. Craig, Can. Hort., 24:76. I901. fig. 19. Munson, Me. Sta. Rpt., 1902:96. 20. Dickens and Greene, Kan. Sta. Bul., 106:56. 1902. 21. Hansen, S. D. Sta. Bul., 76:112. 1902. fig. 22. Budd- 

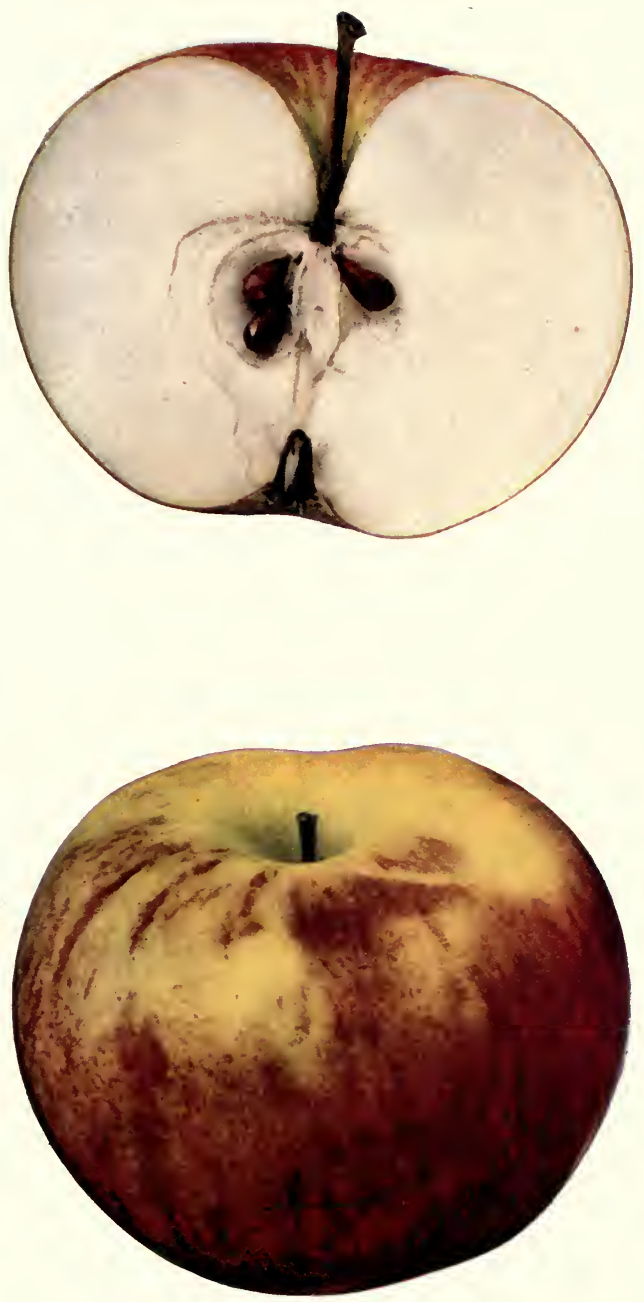

WALBRIDGE 

Hansen, r903:196. fig. 23. Powell and Fulton, U. S. B. P. I. Bul., 48:59. I903. 24. Beach and Clark, N. Y. Sta. Bul., 248:149. I904.

Synonyms. Edgar County Red Streak $(7,8)$. Edgar Redstreak (2, II). Edgar Redstreak (9, I7, 21, 22). EDGAR RED STREAK (4). Edgar Red Streak (16). Kentucky Red Strcak (7). Walbridge (4). Wallbridge (13, 20).

The accompanying colored plate shows the whole fruit of Walbridge. The section is shown on the same plate as that which shows the whole fruit of Rambo.

Fruit red-striped, rather attractive when well colored, good for culinary purposes, but not equal to standard varieties of its season for dessert use. Season, November to February or March. Commercial limit, in ordinary storage, February; in cold storage, April or May $(23,24)$. The fruit hangs well to the tree so that there is little loss from drops, but often a comparatively large amount of it is undersized, misshapen or otherwise unmarketable. This variety has been planted to a considerable extent in Wisconsin, Iowa and adjacent portions of the Mississippi valley and has been grown quite successfully in many localities in that region. It appears to be less well adapted to New York conditions and is of comparatively little value for planting in this state. The tree makes a good growth in the nursery. In the orchard it is moderately vigorous, comes into bearing rather young and yields full crops biennially.

Historical. The first description of this variety which we have been able to find is a very good one which appeared in the Rural New Yorker for 1870 under the name Walbridge (I). It was disseminated from Wisconsin under the name Walbridge and has long been in cultivation under this name $(4,6)$. The American Pomological Society listed it as Walbridge in 1873 (2), but at the following meeting of the Society in Chicago, in 1875 , it was decided that it was identical with Edgar Red Streak which originated with Joseph Curtis, Paris, Edgar county, I1l., in 1818 (3), and accordingly it was entered on the Society's Catalogue as Edgar Red Streak with Walbridge as a synonym. It continued to be thus listed until 1897 when the popular name Walbridge was finally accepted by the Society (I6).

TREE.

Tree medium in size, moderately vigorous. Form upright becoming roundish or spreading, open. Twigs medium to long, usually curved, moderately stout, with large terminal buds; internodes short to medium. Bark moderately dark reddish-brown, mingled with olive-green, lightly streaked with scarf-skin; heavily pubescent. Lenticels scattering, small to medium, round to oblong, not raised. Buds prominent, medium to rather large, broad, plump, obtuse, free or nearly so, pubescent. 
FRUit.

Fruit sometimes nearly large but usually medium or below. Form roundish conic, flattened at the base, varying to roundish or to oblate conic, often onesided. Stem short to medium. Cavity medilm, acute to acuminate, deep to moderately deep, rather narrow to broad, symmetrical, furrowed gently if at all, sometimes partly covered with fine russet. Calyx small, usually closed, pubescent. Basin small, characteristically shallow or scarcely at all depressed, often oblique, somewhat furrowed and wrinkled.

Skin moderately thin, tough, smooth, green becoming clear pale yellow or whitish, washed with red, conspicuously mottled and striped with bright carmine and overspread with thin bloom. Dots numerous, often submerged, sometimes whitish and rather conspicuous; a few are russet. Prevailing effect in well-colored specimens, striped red.

Caly $x$ tube long, narrow, cone-shape to truncate funnel-form with fleshy pistil point projecting into base. Stamens median to marginal.

Core small to medium, abaxile with a wide, hollow cylinder in the axis, or sometimes axile; cells symmetrical, closed or sometimes partly open; core lines clasping the funnel cylinder. Carpels broadly roundish, emarginate, mucronate. Seeds few, dark, below medium to rather large, moderately wide, obtuse to somewhat acute.

Flesh whitish a little tinged with yellow, firm, moderately fine to a little coarse, crisp, moderately tender, juicy, sprightly, rather mild subacid, slightly aromatic, fair to good in flavor and quality.

\section{WALKER BEAUTY.}

References. I. N. Y. Sta. An. Rpt., II:223. I892. 2. Bailey, An. Hort., 1892:252. 3. Smith Co., W. and T., Cat., r897:14. 4. Farrand, Mich. Sta. Bul., 205:47. 1903. 5. Ragan, U. S. B. P. I. Bul., 56:223. I905.

DoubtFll References. 6. ? Warder, 1867:735. 7. ? White, Gard. for the South, I868:349. 8. ? Downing, 1869:395. 9. ? Thomas, I875:515.

SrNonyms. WALKer $(4,5)$. Walker's Beauty (5). Walker Yellow (7, 8, 9)? Walker's Winter (6)?

Fruit predominantly yellow, rather attractive in color but not very uniform in size or shape and rather too acid in flavor to be acceptable for dessert. As tested at this Station the tree is a good grower, comes into bearing rather young and is an annual cropper but not very productive. In the nursery the tree makes a fine upright growth but it is somewhat subject to bark-splitting in the spring.

Historical. Received in 1892 from W. and T. Smith, Geneva, N. Y., for sesting at this Station ( $r$ ). Walker Beauty is reported to have originated in Allegheny county, $\mathrm{Pa}$. (3), but we have been unable to verify this statement. The fruit corresponds closely with Downing's brief description of Walker Yellow, a native of Pulaski county, Ga. (8). Thus far it has been disseminated but little in New York.

\section{TREE.}

Tree vigorous; hranches long, slender, curved. Form upright or roundish, dense. Trigs moderately long, curved, slender; internodes medium. Bark 


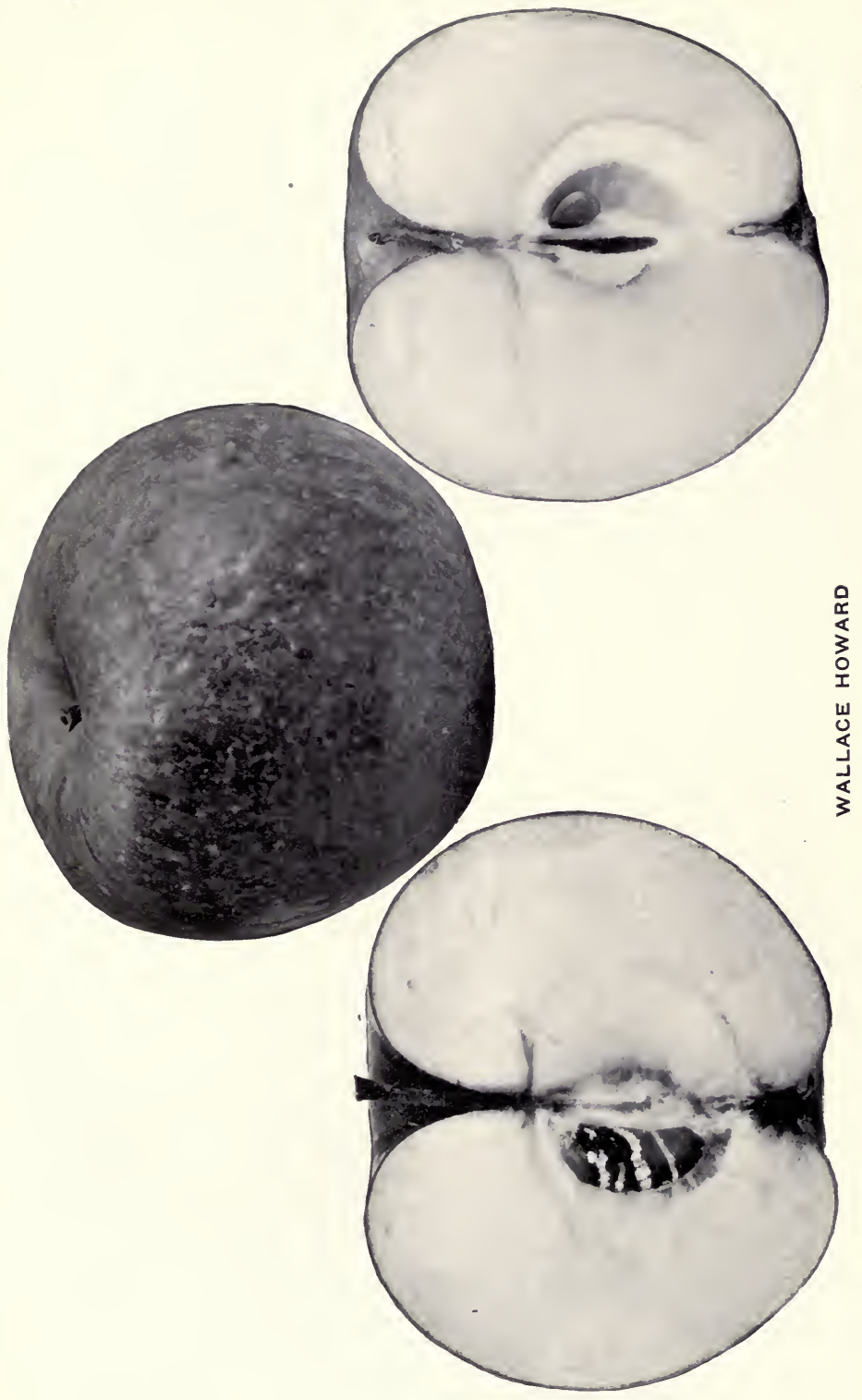

Vol. I - 15 

brown tinged with olive-green, lightly mottled with scarf-skin; pubescent. Lenticels quite numerous, small, oblong, not raised. Buds set deeply in the bark, medium in size, plump, obtuse, appressed, slightly pubescent.

\section{FRUIT.}

Fruit variable in size and form, usually medium to rather large. Form roundish conic varying to somewhat oblong or sometimes a little oblate, often distinctly inclined to conic, regular to irregularly elliptical, sometimes obscurely ribbed; sides unequal. Stcm short to medium, slender to moderately slender, sometimes swollen, pubescent, usually with a distinct reddish tinge on one side. Cavity medium in size, acute varying to somewhat acuminate or sometimes to obtuse, narrow to moderately wide, deep to moderately shallow, often compressed and furrowed, sometimes partly russeted. Calyx small to medium, closed or partly open; lobes rather leafy, medium to long, acute. Basin small to medium, varying from medium in width and depth to narrow and moderately shallow, abrupt, furrowed and wrinkled, often compressed.

Skin moderately thick, tough, smooth, clear yellow usually more or less blushed and sometimes with a distinctly red cheek with a few obscure carmine stripes, sometimes marked with suture line. Dots numerous, inconspicuous, small, green or whitish, often submerged, sometimes with fine russet point. Prevailing effect yellow.

Calyx tube rather large, conical varying to funnel-form. Stamens median or below.

Core small to medium, usually axile but varying to somewhat abaxile; cells symmetrical, closed or sometimes partly open; core lines clasping. Carpels roundish to elongated, slightly emarginate, mucronate. Sceds below medium to above, smooth, plump, wide, obtuse to somewhat acute, rather dark brown.

Flesh whitish with yellow tinge, firm or very firm, moderately coarse, crisp, tender, juicy, very brisk subacid, too acid for dessert, good.

Season November to April.

\section{WALLACE HOWARD.}

References. 1. Am. Pom. Soc. Rpt., r881:66. 2. Ib., 1883:93. 3. Ib., 1887: 93. 4. Rural N. Y., 46:751. 1887. 5. Bailey, An. Hort., 1892:252. 6. Taylor, U. S. Pom. Rpt., r893:288. 7. Thomas, 1897:658. 8. Beach and Clark, N. $Y$. Sta. Bul., 248:149. 1904.

Synonym. Boatman's Seedling $(1,2)$.

Fruit of pretty good size and attractive color, but the flesh lacks character. Suitable only for dessert use. As tested at this Station the tree is a pretty good grower, comes into bearing rather young and yields moderate to good crops nearly annually, but the fruit is not specially desirable for either home use or market. It is not recommended for planting in New York. As grown in the South it has been called a magnificent fruit of best quality (I) and one of the finest apples cultivated in that region (3). 
Historical. Originated from seed by Robert Boatman, Dillon, Walker county, Ga., on the Lookout Mountain Range and first described as Boatman's Seedling (I). It was afterwards called IVallace Howard by the Atlanta Pomological Society, in honor of Reverend Wallace Howard of Georgia $(2,6)$.

\section{TREE.}

Trce vigorous to moderately vigorous. Form upright spreading to roundish, rather dense. Taigs short, generally straight, stout or moderately stout, with large terminal buds; internodes short or below medium. Bark brown or reddish-brown with some olive-green, lightly mottled with scarf-skin, pubescent. Lenticcls rather conspicuous, numerous, medium size, roundish or oval, slightly raised. Buds prominent, medium to large, broad, plump, acute, free or nearly so, slightly pubescent.

\section{FRUIT.}

Fruit above medium to large, pretty uniform in size and shape. Form roundish or roundish oblong, often somewhat flattened at the base and inclined to conic; axis sometimes oblique; sides often unequal. Stem short to medium, rather slender. Cavity acuminate or somewhat acute, deep, sometimes compressed and rather narrow but more often wide, often gently furrowed, sometimes lipped, usually russeted. Calyx small to medium, closed or partly open; lobes often long, narrow, acuminate. Basin rather small, often oblique, sometimes with decided protuberance above one side, narrow, varying from very shallow to moderately shallow and abrupt, often distinctly furrowed, wrinkled.

Skin smooth or roughened with russet dots and flecks, yellow nearly overspread with orange-red mottled and distinctly striped with bright carmine. Dots numerous, conspicuous, gray or russet, rather large. Prevailing effect striped red.

Calyx tube rather small, rather narrow, short, cone-shape varying to truncate funnel-form with fleshy pistil point projecting into the base. Stamens marginal.

Corc rather small to above medium, axile or somewhat abaxile with a hollow cylinder in the axis; cells symmetrical, closed; core lines clasping the funnel cylinder. Carpels rather flat, roundish ovate, but slightly emarginate if at all, somewhat tufted. Seeds numerous, small to medium, moderately wide, rather short, plump, obtuse, sometimes tufted.

Flesh tinged with yellow, firm, a little coarse, crisp, moderately tender, rather juicy, mild subacid becoming nearly sweet, somewhat aromatic, good.

Scason Noveniber to March (8).

\section{WANDERING SPY.}

\footnotetext{
References. 1. Bailey, An. Hort., 1892:252. 2. Mo. Hort. Soc. Rpt., 1902: 204.

This variety originate $\mathrm{f}$ in the Ozarks with Wyatt Coffelt, Mason Valley, Benton county, Ark. It has not yet been fruited to any considerable extent outside the locality of its origin. As grown in that region the fruit appears to be pretty uniform in size, above the average of Jonathan, fairly free from disease and of satisfactory color and is in season from December to March.
} 

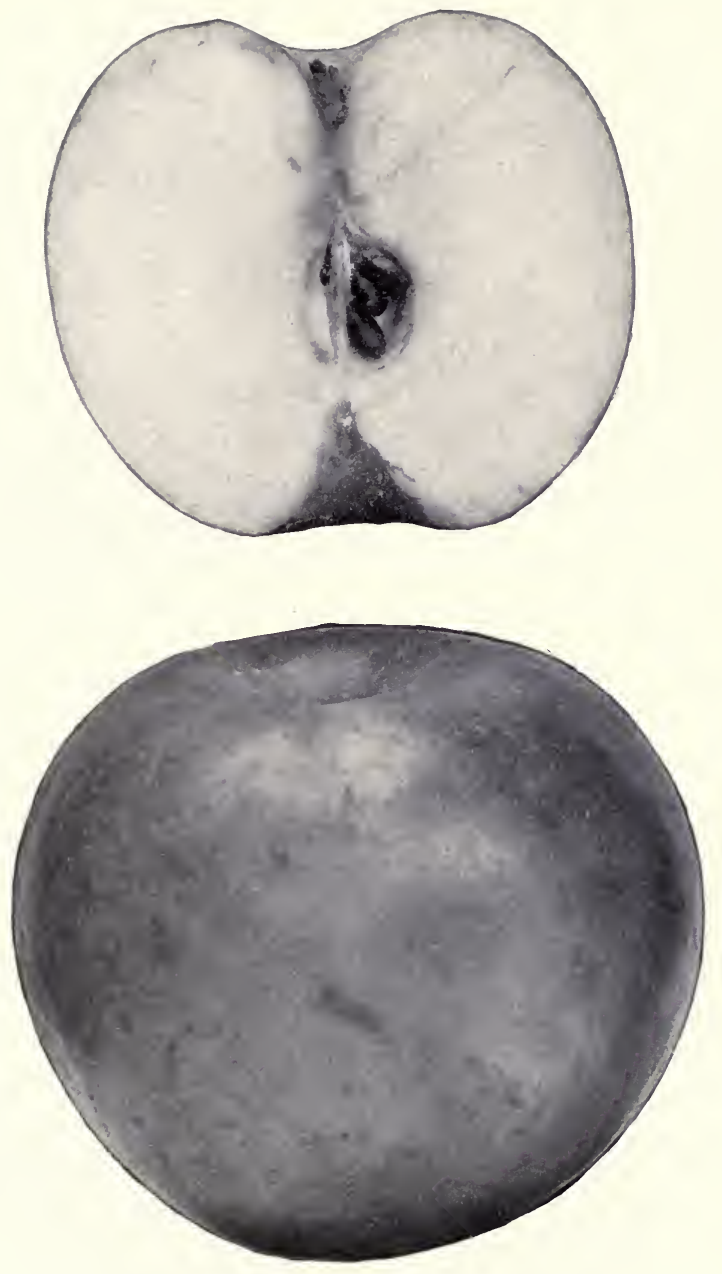

WANDERING SPY 

It is said to keep well in storage, holding firm with good color and fine flavor till late in the season.

Stock of this variety was received for testing at this Station in 1900 from J. B. Wild \& Bros., Sarcoxie, Mo. It has not yet been tested here sufficiently to show whether it pronises to be of value for commercial planting in New York. Thus far the fruit has not been nearly so attractive in color nor as good in quality as Tompkins King, Baldwin or Northern Spy, but it averages good marketable size and is superior in quality to Ben Davis and other apples of that class. It has been grown here on heavy clay loam. It is quite probable that on warmer, lighter soils it would develop better color and flavor. The tree is a vigorous grower, comes into bearing early and gives evidence of being a reliable biennial bearer.

\section{FrUit.}

Fruit large to medium as grown at this Station. Form slightly oblate inclined to conic. Stem medium to short. Cavity acute to acuminate, deep, rather narrow to moderately wide, symmetrical or slightly furrowed, russeted and often with outspreading russet rays. Calyx small to medium, partly open, sometimes closed. Basin abrupt, symmetrical or somewhat compressed.

Skin rather thick, tough, dull greenish becoming yellow, blushed with dull red sparingly and faintly striped with dull carmine, in highly colored specimens developing deep dull red over a large part of the fruit. Dots scattering, medium to large, pale gray or russet.

Calyx tube short cone-shape varying to short funnel-form with fleshy pistil point projecting into the base.

Core medium to below; cells closed; core lines meeting or slightly clasping. Carpels roundish, deeply emarginate. Seeds medium to large, light brown, rather narrow, acute.

Flesh whitish or tinged with green, firm, fine, moderately crisp, very tender, moderately juicy to juicy, subacid, good.

Season January to April or May.

\section{WASHINGTON ROYAL.}

References. I. Robbins, N. E. Farmer, 7:231. 1855. 2. Downing, 1857: 201. 3. Warder, I867:735. 4. Downing, I869:396. 5. Am. Pom. Soc. Cat., 1871. 6. Thomas, 1875:515. 7. Lyon, Mich. Hort. Soc. Rpt., 1890:298. 8. Bailey, An. Hort., I892:246. 9. Maynard, Putnam and Fletcher, Mass. Sta. Bul., 44:4. I897. Io. Waugh, Amer. Gard., 20:221. I899. fig. II. Van Deman, Rural N. Y., 60:69. I901. 12. Waugh, Vt. Sta. An. Rpt., 14:312. I901. I3. Mead, Rural N. Y., 6r:67. 1902. 14. Ib., 62:50. 1903. figs. 15. Powell and Fulton, U. S. B. P. I. Bul., 48:60. 1903. 16. Beach and Clark, N. Y. Sta. Bul., 248:I49. I904.

Synonyms. I.ock's Favorite (12). Palmer Greening (8, 9, 13, 14). Palmer Greening (4, IO, I I, I2, I5). Washington Royal (14).

Fruit yellow or greenish usually somewhat shaded with red, rather attractive in color, quite variable in size, good in quality but mild in flavor and eventually becoming nearly sweet. More suitable for dessert than for culinary use. As grown at Geneva 
some portion of the fruit may often be kept till May or June in ordinary storage, yet its season is so variable that November may be regarded as the usual safe commercial limit for handling this variety (16). It is favorably regarded locally in New England, where it is commonly grown under the name Palmer Greening (9, IO, 12). Taling all things into consideration, it is hardly equal to standard varieties of its season and is not recommended for commercial planting in New York.

Historical. Originated in Sterling, Nass. It was brought to notice by Ephraim Robbins of Leominster in 1855 (I). It has been planted but sparingly in New York state.

\section{TREE.}

Tree vigorous. Form upright spreading to roundish. Twigs telow medium to rather long, curved, slender to moderately stout; internodes medium to short. Bark dark brown with some green, heavily streaked with scarf-skin, somewhat pubescent. Lenticels scattering, small to medium, roundish, usually not raised. Buds medium to small, broad, rather plump, obtuse, free, pubescent.

\section{Fruit.}

Fruit medium or above. Form a little oblate, often somewhat ribbed, irregular. Stcm short to medium. Cazity medium to rather large, acuminate to acute, rather narrow to moderately broad, often somewhat furrowed, usually smonth and green. Caly.r small to medium, partly open, sometimes closed; lohes erect. Basin moderately shallow, rather narrow, abrupt, often somewhat furrowed, wrinkled.

Skin thin, moderately tender, waxy, yellow or greenish, usually with thin dull orange blush which sometimes deepens to clear red. Dots numerous, whitish or areolar with russet center, characteristic and conspicuous. Prevailing effect rather attractive greenish-yellow.

Calyx tube conical to somewhat urn-shape or fumnel-form. Stamens median.

Core medium to large, somewhat abaxile to nearly axile; cells closed or partly open; core lines clasping the funnel cylinder. Carpels rather concave, broadly roundish, emarginate. Secds dark, medium, rather wide, plump, obtuse, or somewhat acute.

Flesh whitish, firm, moderately fine, crisp, tender, juicy, pleasant subacid becoming nearly sweet, somewhat aromatic, good to very good.

\section{WATWOOD.}

Reff.rences, I. Downing, 1876:7I app. 2. Bailey, An. Hort., I892:252. 3. Beach, N. Y. Sta. An. Rpt., II:223. I892.

Fruit medium size, rather dull colored, green or yellowish partly washed and splashed with red, mild, pleasant subacid, good quality; in season from December to May. It originated at Blandville, Ballard county, Ky., and is valued in that region because it is a long keeper and the tree is a uniformly good 

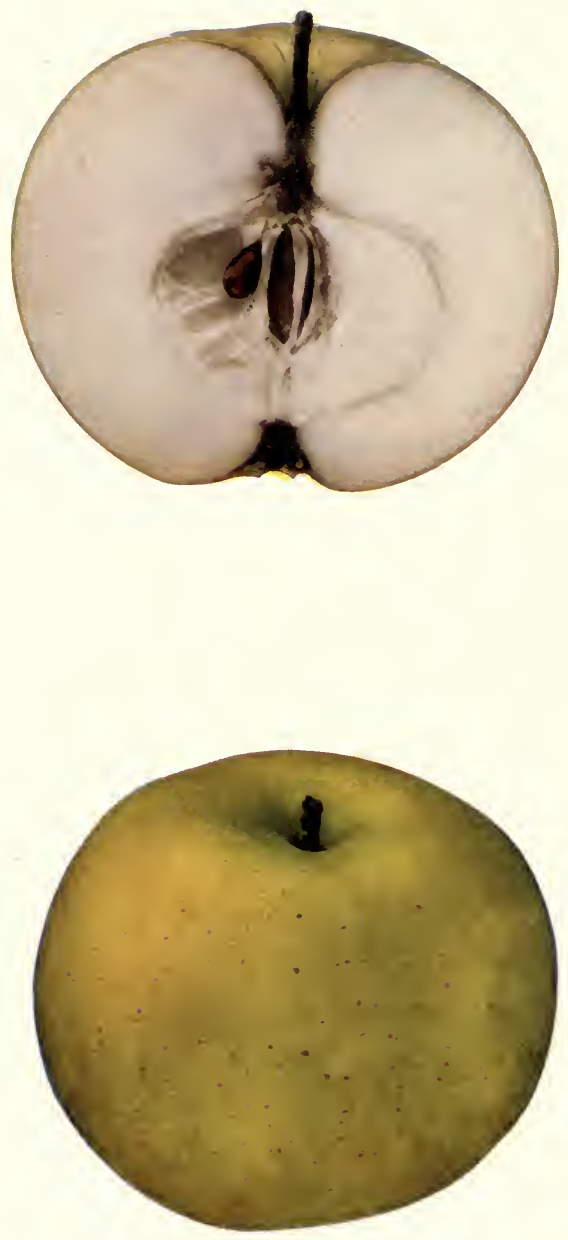

WASHINGTON ROYAL 


\section{WESTFIELD SEEK-NO-FURTHER.}

References. I. Downing, 1845:96. 2. N. Y. Agr. Soc. Trans., 1846:207. fig. 3. Kirtland, Horticulturist, 2:544. I848. 4. Hovey, Mag. Hort., I5:26. 1849. fig. 5. Thomas, 1849:175. fig. 6. Cole, 1849:127. fig. 7. Horticulturist, 4:470. 1850. 8. Emmons, Nat. Hist. N. Y., 3:24. I85I. fig. 9. Elliott, 1854: 115. tig. 10. Hooper, 1857:97. I1. Gregg, 1857:61. 12. Am. Pom. Soc. Cat., 1862. 13. Warder, 1867:520, 707, 708. fig. 14. Downing, 1869:399. fig. I5. Barry, 1883:356. 16. Lyon, Mich. Hort. Soc. Rpt., 189o:298. 17. Bailey, $A n$. Hort., 1892:249. 18. Ib., 1892:252. I9. Burrill and McCluer, Ill. Sta. Bul., 45:3II, 340, 345. 1896. 20. Waugh, Vt. Sta. An. Rpt., 14:312. I90I. 2 I. Munson, Mc. Sta. Rpt., I902:90. 22. Budd-Hansen, 1903:I99. 23. Powell and Fulton, U. S. B. P. I. Bul., 48:60. 1903. 24. Beach and Clark, N. Y. Sta. Bul., 248:150. 1904.

Synoxyms. Connecticut Seeknofurther (5). Connecticut Seek-No-Further (9). Marictta Seek-No-Further (3,4). New-England Seeknofurther (5). Red Winter Pearmain, of some (9). Russet Seek-No-Further (4). SEEKNo-Further (17). Seeknofurther (23). Seek-No-Further (4, 19, 20, 21, of Connecticut I and 2). Westfield (I6, 20, 21, 23). WVestfield Seek-NoFartiler (7). Westfield Seek-No-Further ( I, 2, 3, 4, 6, 9, Io, II, I2, 13, I4, I5, I8, I9). Westfield Scek-No-Further (5, 8).

Among fruit growers and fruit dealers this variety is commonly called Seek or Seek-No-Further and doubtless will continue to be so called as long as it remains in cultivation. Pomologists recognize Westfield Scek-No-Further as the correct name, thus distinguishing this from certain other varieties which have been cultivated under the name Seek-No-Further. In I845 Downing observed, "The Seekno-further of New-Jersey and Pennsylvania is the Rambo, that of some parts of New-York is the (American) Domine. The Seekno-further of Coxe is a large, roundish fruit, narrower at the eye. Skin smooth, pale yellowish-green, or nearly white. $* * *$ Ripe in October, and will keep a couple of months."

Westfield Seck-No-Further is an old favorite dessert apple. It is but little valued for cooking. The fruit usually averages about medium size. It is not remarkably attractive in appearance, being creamy-yellow striped with dull red and sometimes partly russeted, but at its best it has a peculiarly pleasant, rich, mild subacid flavor which has made it popular. Its season in ordinary storage is late fall and early winter, but when properly handled it may be held in cold storage about as late as Baldwin. It stands handling and shipping well, but toward the close of the season it is apt to shrive! badly. Since it is not particularly attractive in color and is used 


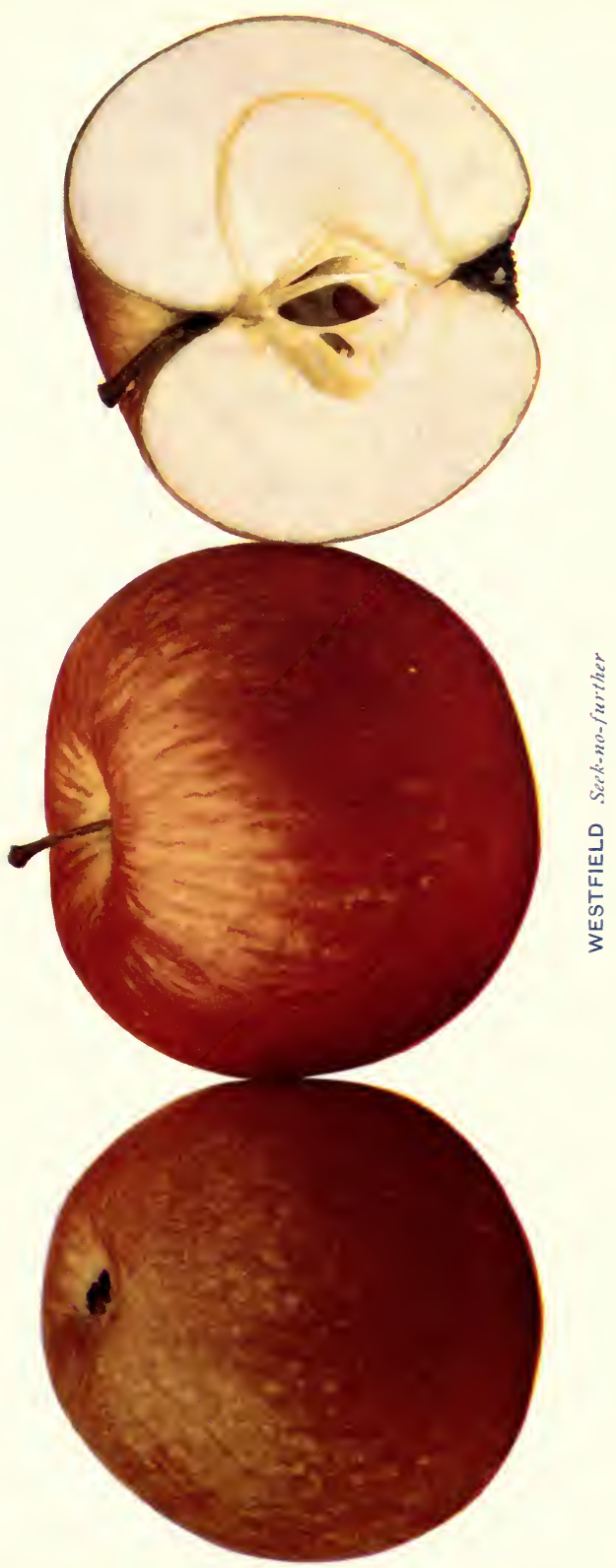



only for dessert purposes it commonly finds but a limited demand in general market and often brings less than the average prices for the leading standard commercial varieties of its season. It has gained the reputation of being a very hardy variety, being superior to Baldwin and Rhode Island Greening in this respect, but its successful cultivation is more restricted to particular districts or regions than is the case with either of the other varieties named. It does not commonly develop as good color or quality on heavy, cold soils, particularly if they are not well drained, as it does on welldrained, fertile, gravelly or sandy loam. In I854 Elliott observed that in Ohio and adjoining states the fruit of this variety differed remarkably when grown in different regions. He reported that as " grown in rich loamy alluvial soils of the South, it is much russeted, and about the stem the russet has appearance of rich bronze; progressing northward, it gradually loses its russet, until on light sandy soils in Michigan, it becomes a pale-yellow ground, with stripes and splashes of clear red and minute dots."

In many parts of New York it has not proved reliably productive, but in other regions, particularly in certain localities in the Lake Ontario apple belt, it has been a regular and abundant cropper, developing good color and fine flavor and is still regarded as a good commercial variety. Generally the tree is very hardy, remarkably healthy and long-lived. There is usually little loss from drops if the crop is picked at the proper season. The fruit is quite uniform in grade and the amount of culls is comparatively small.

Historical. This old variety found its way into this state from New England with the early settlers more than one hundred years ago. It was introduced into Ohio from Connecticut as early as 1796 (2). In 1846 the committee of the New York State Agricultural Society on the selection of the best varieties of apples for cultivation in New York reported concerning the Westfield Seek-No-Further:

"This truly excellent apple originated in Westfield, or its neighborhood, a beautiful meadow town, about ten miles west of Springfield, in the Connecticut valley, in Massachusetts. For many miles up and down, and round about that river, it is the apple, par excellence, of that locality; as much so as is the Newtown Pippin on Long Island, or the Esopus Spitzenburgh in Ulster. Whole orchards are planted of this fruit, and no where does it flourish in higher luxuriance and perfection. It loves a warm, free soil; is hardy, vigorous and prolific. In flavor, it is excelled by few apples whatever for all household purposes. It flourishes well in this State, particularly in the western 
counties. Wherever it will grow, its cultivation is recommended, both for domestic and market purposes."

It is generally well known throughout the state but for the most part is found only in old orchards, and there are few, if any, localities where its cultivation is being extended.

\section{TREE.}

Tree medium to large, rather slender, moderately vigorous to vigorous. Form spreading or roundish. Taigs above medium, sometimes long; internodes short, varying from rather slender to moderately stout. Bark dark brownish-red or brownish-green, mottled or blotched with gray scarf-skin, sparingly pubescent. Lenticels of a clear light color, rather conspicuous, irregular in size and shape. Buds medium, often projecting, obtuse or sometimes acute, often not pubescent, free from bark.

Frult.

Fruit usually about medium size, sometimes below medium, sometimes rather large, uniform. Form usually roundish conical varying occasionally to roundish ovate and less often to rather oblong conical, regular or obscurely ribbed, symmetrical or nearly so. Stem medium to long, rather slender. Cavity medium in size, acuminate, deep, narrow to medium in width, usually symmetrical, russeted and with some outspreading green or yellow russet. Caly.r small to medium, usually partly open; lobes short, reflexed, obtuse or acute. Basin small, shallow, narrow to medium in width, obtuse or somewhat abrupt, sometimes decidedly furrowed.

Skin tough, smooth, rather deep yellow or greenish, shaded and splashed with rather dull red but in highly colored specimens largely overspread with bright pinkish-red, striped with deep carmine. It is overspread with a thin bloom which gives it a somewhat bluish cast but when polished it is bright and glossy. Dots characteristically large and conspicuous, pale yellow, grayish or russet, often areolar with russet center, smaller and more numerous toward the basin, larger and more scattering and more often areolar toward the cavity.

Caly.r tube rather wide, cone-shape. Stamens basal.

Core medium, axile; cells usually symmetrical, open; core lines meeting or slightly clasping. Carpels somewhat elliptical or varying to roundish and approaching truncate at the base and narrowing toward the apex, mucronate, but slightly emarginate if at all. Seeds numerous, rather small to medium, plump, acute to somewhat obtuse.

Flesh slightly tinged with pale yellow, firm, medium in grain or a little coarse, crisp, tender, breaking, juicy, mild subacid, rich, sometimes a little astringent, peculiarly aromatic, sprightly, very good to best.

\section{Red Type of Westfield Scck-No-Further.}

Besides the general type of the Westfield Scck-No-Further above described some growers hold that there is a distinct strain with characteristically deep red fruit. W. J. Gahan of Clarkson, Monroe county, N. Y., reports that he has always thought that there were 


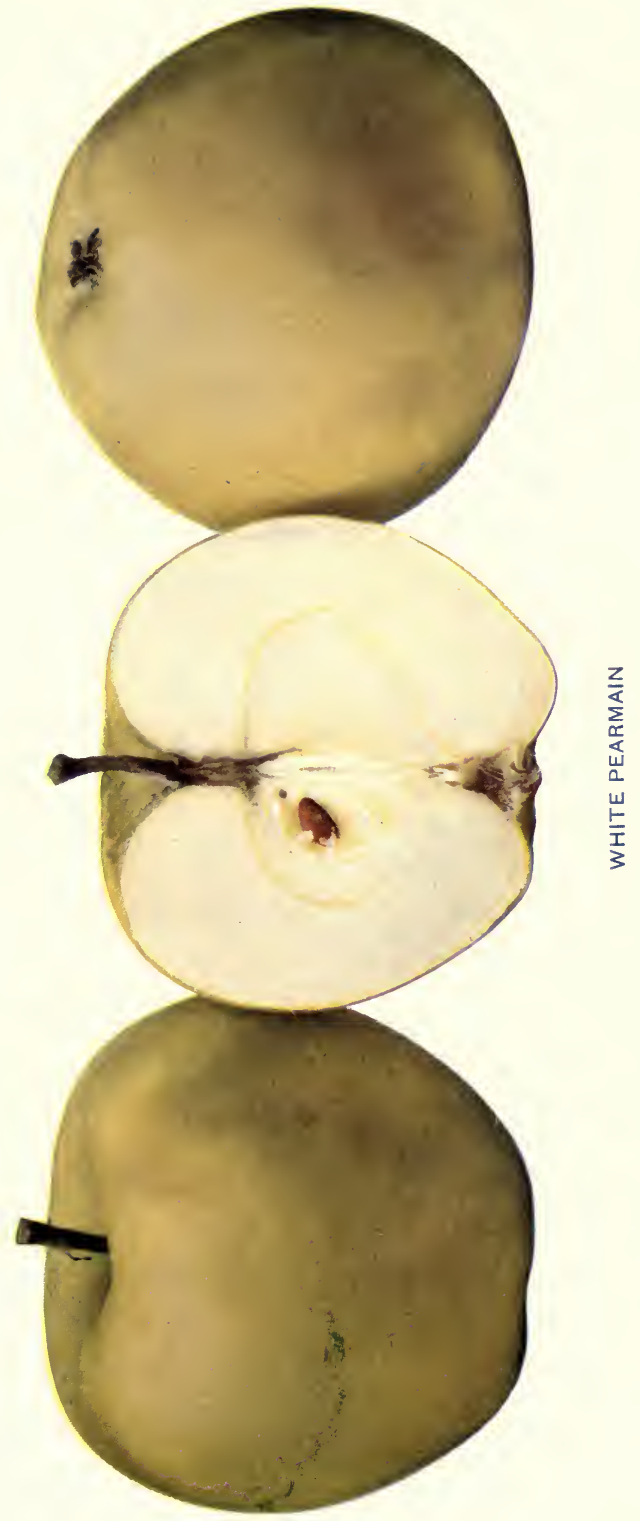



two strains of this variety-a red Seek-No-Further and a gray SeekNo-Further. D. D. Stone of Lansing, Oswego county, N. Y., grows Westfield Seek-No-Further which, as compared with the common type, is considerably more highly colored, having more of a solid red color and being less noticeably striped. The dots are decidedly more conspicuous; the flesh is perhaps more highly flavored but otherwise identical with the common type as also are the core characters. Mr. Stone reports that the tree of the red type is of a more roundish form, that of the common type more spreading. We have not had the opportunity of determining whether there is in fact a distinct type characterized by more highly colored fruit or whether such differences as are above mentioned are brought about altogether by differences in the conditions under which the fruit is grown.

\section{WHITE PEARMAIN.}

References. I. N. Y. Agr. Soc. Trans., I849:124. 2. Phoenix, Horticulturist, 4:47I. I850. 3. Downing, r857:I Io. fig. 4. Hooper, 1857:59, 60, 99, ıоo. 5. Am. Pom. Soc. Cat., 1858. 6. Mag. Hort., $27: 60,62$. I861. 7. Warder, 1867:508. 8. Thomas, 1875:232. 9. Barry, 1883:357. Io. Wickson, 1889:248. I1. Bailey, An. Hort., 1892:252. 12. Stinson, Ark. Sta. An. Rpt., 7:47. 1894. 13. Am. Pom. Soc. Cat., I897:15. 14. Dickens and Greene, Kan. Sta. Bul., 106:56. 1902. 15. Powell and Fulton, U. S. B. P. I. Bul., 48:60. 1903. г6. Budd-Hansen, I903:20I. fig.

Synonym. White Wrnter Pearmain (1, 2, 3, 4, 5, 6, 7, 8, 9, Io, II, 12, 14). White Winter Pearmain (15, I6).

This is an old favorite dessert apple in portions of the Middle West from Ohio to Kansas. It appears to succeed better in those regions than it does in New York. It is not recommended for planting in this state.

Historical. Warder says "This favorite fruit was brought to Indiana by some of the early pomologists, in the days of saddle-bag transportation. In a lot of grafts, two varieties, having lost their labels, were propagated and fruited without name. Being considered Pearmain-shaped, they were called respectively Red and White Winter Pearmains. The former proved to be the Esopus Spitzenberg; the latter has never yet been identified, though believed to be an old eastern variety." For a time it was confused with an old New Jersey apple by the name of Michael Henry Pippin, and Elliott fell into the error of publishing White Pearmain and White Winter Pearmain as synonyms of Michael Henry Pippin1 but it was finally conceded that White Pearmain and Michael Henry Pippin are distinct varieties $(4,7)$. In 1858 it was cata-

${ }^{1}$ Elliott, $1854: 91$. 
logued by the American Pomological Society as White Winter Pearmain (5). Since 1897 (13) it has been listed as White Pearmain but it is very doubtful whether this change will be generally accepted by fruit growers and fruit dealers. This variety has been little grown in New York and is now seldom or never planted here.

\section{TREE.}

Tree vigorous. Form spreading. Twigs short, stout, blunt at tips, generally straight; internodes vary from short to long. Bark reddish-brown overlaid with heavy scarf-skin, quite pubescent. Lenticels conspicuous, numerous, above medium, elongated, raised. Buds large, projecting, acute, quite pubescent, free.

\section{FRUIT.}

Fruit below medium to nearly large, uniform in size and shape. Form roundish ovate or roundish approaching oblong conic, varying to roundish conic, somewhat ribbed, pretty symmetrical. Stem medium to long. Cavity rather small to above medium, acute, deep, moderately narrow to broad, somewhat furrowed, sometimes russeted. Calyx medium to large, usually closed; lobes long, acute. Basin small to medium, oblique, shallow and obtuse to medium in depth and rather abrupt, medium in width, often distinctly furrowed, wrinkled, pubescent.

Skin tough, smooth, slightly waxen, pale yellow, or at first greenish, with a shade of brownish-red. Dots numerous, pale or russet, often submerged, usually larger and much elongated about the cavity.

Calyx tube long, conical.

Core medium to ratler large; cells closed or partly open; core lines somewhat clasping. Carpels rather flat, broad or roundish-cordate, emarginate, mucronate, tufted. Sceds light brown, medium to large, rather wide, plump, obtuse to acute, tufted.

Flesh slightly tinged with yellow, firm, fine-grained, crisp, tender, juicy, mild subacid, sprightly, very pleasantly aromatic, very good to best.

Season December to March.

\section{WHITE PIPPIN.}

References. I. Mag. Hort., 14:113, 1848. 2. Emmons, Nat. Hist. N. Y., 3:85. 18.5 . 3. Downing, 1857:203. 4. Am. Pom. Soc. Cat., 186o. 5. Mag. Hort., 27:100. I86r. 6. Warder, 1867:647. fig. 7. Ia. Hort. Soc. Rpt., г880: 277. 8. Barry, 1883:356. 9. Lyon, Mich. Hort. Soc. Rpt., 189o:300. ro. Bailey, An. Hort., 1892:252. I1. Beach, N. Y. Sta. An. Rpt., I1:589, 596. I892. I 2. Ib., E. N. Y. Hort. Soc. Rpt., r9oo:44. 13. Ib., W. N. Y. Hort. Soc. Rpt., 1900:37. 14. Brackett, Amer. Gard., 22:191. 1901. 15. Budd-Hansen, 1903: 202. fig. r6. Bruner, N. C. Sta. Bul., 182:23. 1903. 17. Powell and Fulton, U. S. B. P. I. Bul., 48:60. 1903. 18. Beach and Clark, N. Y. Sta. Bul., 248: 150. 1904 .

Synonym. Canada Pippin (3).

Fruit medium to large, often averaging rather large. The general appearance is good for a yellow apple. It is suitable for home use or for general market purposes. In ordinary storage it is in 

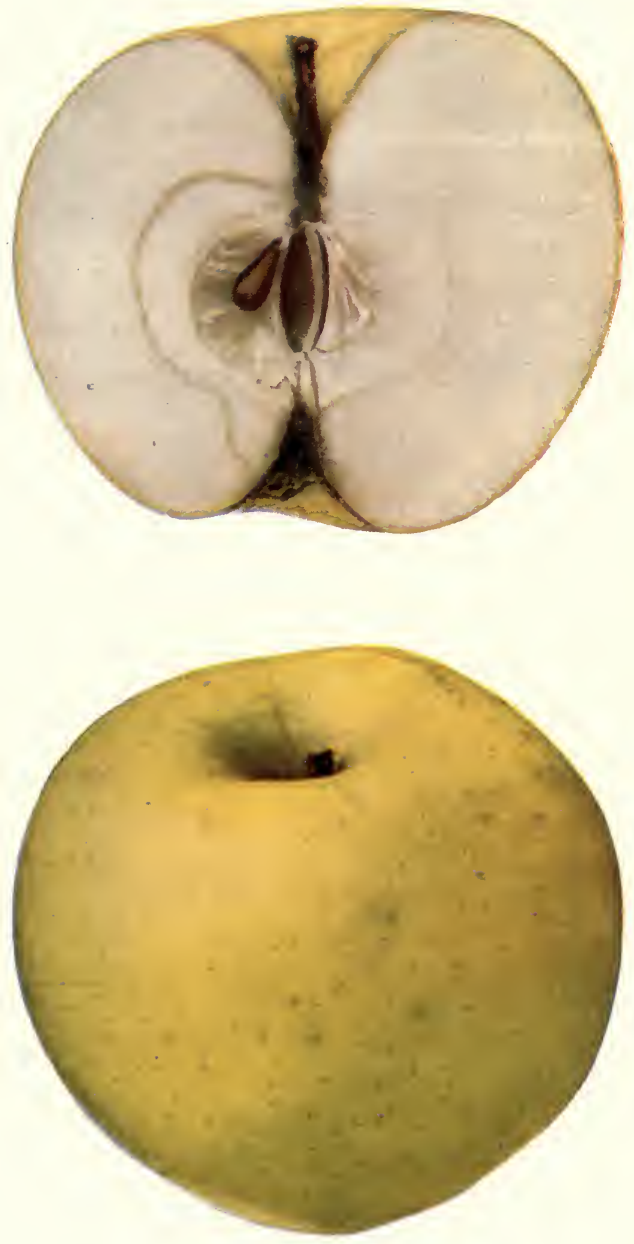

WHITE PIPPIN 

season from November to May with February as the ordinary commercial limit. It varies considerably in keeping qualities in different seasons (18). Warder (6) observes that "in some of its external characters it more nearly resembles the Yellow Newtown Pippin than any other fruit; but, while it lacks the high, spicy flavor of that apple, it is found to be much more profitable in the orchard." It has long been highly esteemed in some sections of Ohio and other portions of the Middle West. In Central and Western New York it generally succeeds better than does either the Yellow Newtown or the Green Newtown. The tree is a good thrifty grower, comes into bearing young and is a reliable cropper, yielding moderate to good crops annually or nearly annually. Some New York fruit growers consider it a profitable commercial variety because the fruit is large, pretty uniform, rather attractive and generally keeps pretty well. It is not recommended for general planting in New York.

Historical. Warder remarks that "the origin of this valuable fruit is en: tirely unknown, and its history can only be traced to the nursery of Silas Wharton, who may have brought it with him from the East. For a time some of our leading pomologists 1 thought it was the Canada Reinette, but this idea has long since been relinquished, and all agree that it is sui generis, though it may have had a different name." It has been grown to a limited extent in some portions of New York, but, so far as we can learn, its planting is not being extended.

TREE.

Tree large, vigorous. Form upright spreading to roundish, rather dense. Twigs long to rather short, straight, moderately slender to rather stout and often very blunt; internodes short. Bark very dark brown, lightly streaked with scarf-skin, heavily pubescent. Lenticels numerous, large to medium, oval or irregular, raised, conspicuous. Buds deeply set in bark, medium to short, flat, obtuse, more or less appressed or sometimes free, pubescent.

\section{FRUIT.}

Fru:t medium to large, often averaging rather large, pretty uniform in size and shape. Form roundish or roundish oblate, inclined to conic, irregular or somewhat angular, sometimes symmetrical. Stem short. Cavity medium or above, acute or approaching acuminate, deep, moderately narrow to rather wide, often wavy, sometimes lipped, partly russeted and often with a strip of russet extending out on one side. Calyx small to medium, closed or partly open: lobes long, narrow, acuminate. Basin small to medium, moderately shallow to medium in depth, rather narrow to moderately wide, rather abrupt, usually somewhat furrowed and slightly wrinkled.

\footnotetext{
${ }^{1}$ See Elliott, 1854:72, who describes Canada Reinette under name of Canada Pippin; Cole, 1849:154; Thomas, $1849: 178$.
} 
Skin pale yellow or greenish, sometimes blushed, mottled and striped with thin brownish-red or brownish-pink. Dots small, characteristically whitish and submerged, or green with fine russet point. They are more scattering, larger, irregular and more often russet toward the cavity. Prevailing color yellow or green.

Calyx tube long, narrow, elongated conical to somewhat funnel-form. Stamens median to nearly basal.

Core small to medium, somewhat abaxile with hollow cylinder in the axis; cells not uniformly developed but usually symmetrical, closed or sometimes open; core lines clasping. Carpels roundish to somewhat ovate varying to elongated and narrow, sometimes emarginate, slightly tufted. Seeds small to above medium, plump, rather narrow, elongated, acuminate, medium brown to rather dark brown.

Flesl slightly tinged with yellow, firm, moderately fine-grained to a little coarse, tender, crisp, juicy, sprightly subacid, good or sometimes very good.

\section{WILLOW.}

References. I. Mag. Hort., I4:II3. I848. 2. Thomas, I849:175. 3. Emmons, Nat. Hist. N. Y., 3:77. 1851. fig. 4. Elliott, 1854:164. fig. 5. Horticulturist, 10:87. 1855. 6. Downing, 1857:204. 7. Hooper, 1857:96. 8. Am. Pom. Soc. Cat., 1860. 9. Mag. Hort., 27:99. I861. го. Warder, 1867:619. fig. I1. Barry, 1883:357. I2. Lyon, Mich. Hort. Soc. Rpt., I890:300. I3. Taylor, Me. Pom. Soc. Rpt., 1892:57. 14. Bailey, An. Hort., 1892:252. 15. Hoskins, Rural N. Y., 53:310. 1894. 16. Burrill and McCluer, Ill. Sta. Bul., 45:346. 1896. 17. Richman, Utah Sta. Bul., 45:17. I896. 18. Stinson, Mo. Fr. Sta. Bul., 3:27. 1902. I9. Budd-Hansen, 1903:205. fig. 20. Powell and Fulton, U. S. B. P. I. Bul., 48:61, r 903 .

Synonyas. James Rizer (9, 10, 12). Willow Leaf (4). Willow Twig (2, 5, 6, 7, 8, 9, I1, 12, 14, 15, 17, 18). Willow Twig (19). Willow Tarig ( $1,3,4,10,16,20)$.

Willow is a southern or semi-southern variety. It has been cultivated chiefly in the central portion of the Mississippi valley. Like many other southern winter apples its quality is not the best, but it is a good, long keeper. The tree is a strong grower and a rather early and regular bearer. Willow is less attractive than Ben Davis, both in size and in color, but after coming into season it does not become mealy and deteriorate in quality as soon as Ben Davis does in the regions where it is most popular. Willow has proved to be quite hardy in the North, but it requires a rather long and favorable season for the proper development of its fruit. The fruit is not as attractive as that of the Baldwin, neither is it as good in quality, but it is valuable because it keeps late. When well grown it is, on the whole, rather attractive, being quite uniform in size and shape, 

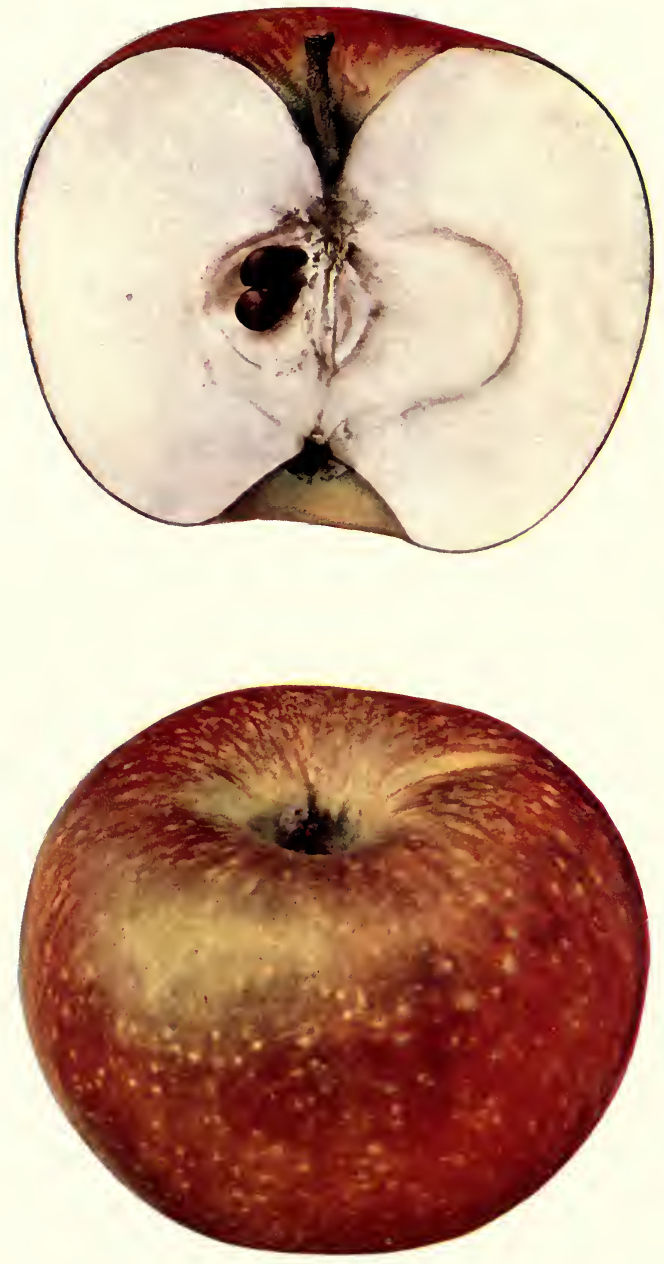

WILLOW TWIG 


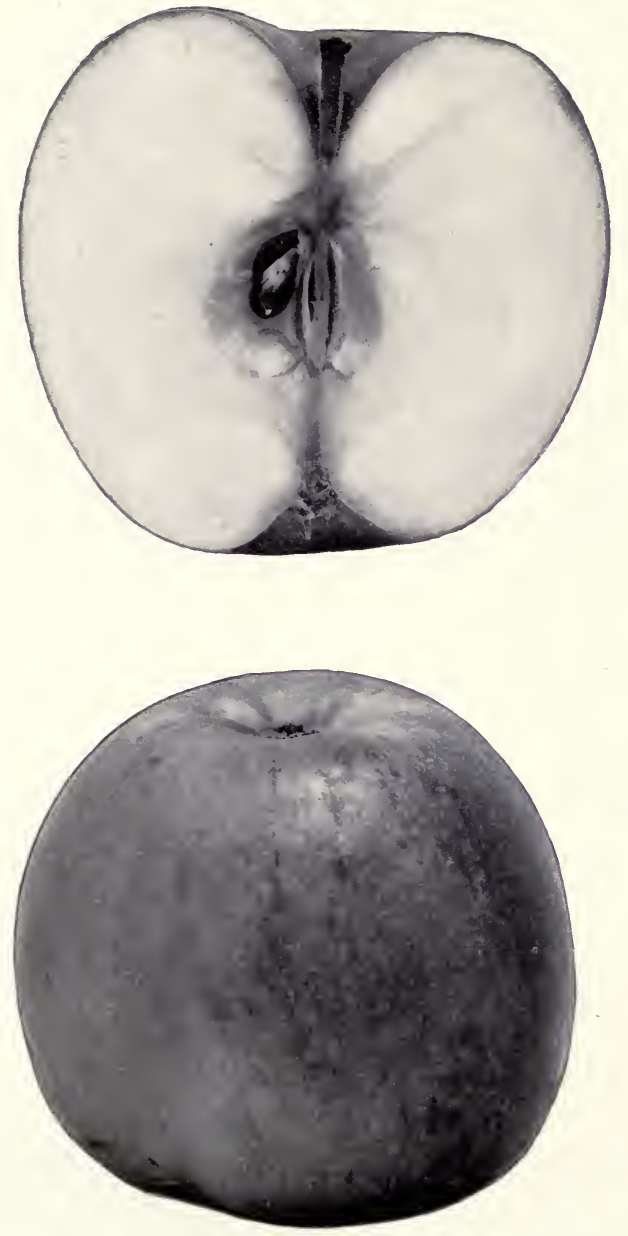

WILLOW 

large and nearly symmetrical. The prevailing color, though somewhat dull, is a pretty good red with contrasting green showing through the stripes. It is not recommended for general planting in New York state.

Historical. The origin of Willow is uncertain. The first that written pomology knows of this variety is that it was being grown in the state of Ohio about the middle of the last century. It was said to have been brought there from New Jersey ( $\mathrm{I}, 4)$, but these statements are hardly convincing because they lack definiteness. Warder refers to it as a Virginia fruit but the authority for the statement is not given. Its cultivation gradually spread from Olio throughout the Middle West. The fruit was found particularly desirable for shipping to New Orleans and other southern markets. $U_{p}$ to about twenty years ago, Willow was esteemed very highly as a commercial variety in the apple-growing portions of Illinois, Missouri, Arkansas and Kansas, but during the last two decades it has fallen very much into disfavor on account of its susceptibility to scab, blight, and bitter rot and many cultivators have gone so far as to cut the trees out altogether on account of the menace from the spread of these diseases to other varieties. So far as we have learned it has been quite free from disease when grown in this state. It has been cultivated in New York in a limited way only and the planting of it does not appear to be increasing very much.

\section{Tree.}

Tree makes a poor growth in the nursery but under favorable conditions it becomes large and vigorous in the orchard. Form upright spreading with terminals drooping on bearing trees. Twigs short to medium, very slender, straight, limber; internodes long. Bark clear yellowish-green or light reddish with no noticeable scarf-skin; quite pubescent. Lenticels scattering, small, generally elongated, raised. Buds small to medium, projecting a little, moderately obtuse, rather pubescent, adhering to the bark.

\section{Fruit.}

Fruit large to medium. Form usually roundish inclined to conic, varying sometimes to roundish oblate, regular or faintly ribbed, symmetrical. Stem short. Cavity acute, deep, wide, often irregular or compressed, sometimes lipped, usually smooth green or red with pale dots but sometimes thinly russeted. Caly.x small, closed. Basin medium size or above, moderately wide to wide, irregular or compressed, rather deep, often abrupt, sometimes ridged, wrinkled.

Skin smooth, pale yellowish-green or dull green mottled and blushed with red and irregularly striped and splashed with deeper red. Dots numerous, rather large, russet-gray or yellowish. Prevailing color fairly good red but usually rather dull.

Caly.x tube rather long, narrow, funnel-shape. Stamens marginal to median.

Core medium or above, axile; cells not uniformly developed, symmetrical, closed or partly open; core lines clasping. Carpels thin, tender, rather flat, broadly roundish narrowing toward the base. Seeds medium to large, flat, wide, plump, rather blunt. 
Flesh yellowish or greenish, very firm, coarse, crisp, moderately tender, juicy, sprightly, slightly aromatic, fair to good.

Season January to May.

\section{WILLSBORO.}

Reffrences. I. Downing, I869:409. 2. Ragan, U. S. B. P. I. Bul., 56:336. 1905.

Downing describes this fruit as medium, yellow mostly overspread, mottled and marbled with dull red; flesh sprightly subacid; season December to February. Supposed to have originated at Willsboro, Essex county, N. Y. (I).

\section{WINDSOR.}

Rererences. I. Van Deman, U. S. Pom. Rpt., 1889:442. col. pl. 2. Am. Pom. Soc. Rpt., 1891:123. 3. Bailey, An. Hort., 1892:252. 4. Am. Pom. Soc. Cat., 1897:15. 5. Thomas, 1897:285. fig. 6. Hansen, S. D. Sta. Bul., 76:115. 1902. fig. 7. Can. Hort, 25:49. I902. 8. Budd-Hansen, 1903:205. fig. 9. Erwin, Am. Pom. Soc. Rpt., 1903:252. Io. Macoun, Can. Dept. Agr. Rpt., rg०3:95.

Synonym. Windsor Chief $(3,6,9,10)$. Windsor Chief $(5,8)$.

On account of its superior hardiness, Windsor is regarded as a promising variety for rigorous climates. The fruit is of good size, attractive red color although rather dark, pleasant subacid flavor and good quality. The tree is very hardy, comes into bearing rather early and is a reliable cropper, yielding moderate to good crops nearly annually. The fruit hangs well to the tree. It is in season from December to April. It has not yet been grown to any considerable extent in New York, but it probably would never find more than a very limited demand in our markets because its flavor is rather too mild for a good culinary apple and it does not excel standard varieties of its season for dessèrt purposes.

TREE.

Tree moderately vigorous. Form upright spreading or roundish, dense, with laterals inclined to droop. Twigs below medium to medium length, slender, irregularly curved; internodes nedium to long. Bark clear reddishbrown lightly mottled with scarf-skin; sliglitly pubescent near tips. Lenticels inconspicuous, rather numerous, small to medium, reınd or somewhat elongated, not raised. Buds medium to small, projecting, plump, acute to acuminate, free, slightly pubescent.

\section{Fruit.}

Fruit above medium to below medium. Form roundish conic varying to oblate, rather broad, flat at the base, often one-sided and faintly ribbed. Stcm medium to long, rather slender. Cavity rather large, obtuse to somewhat acute, wide, rather deep or sometimes varying to moderately shallow, 

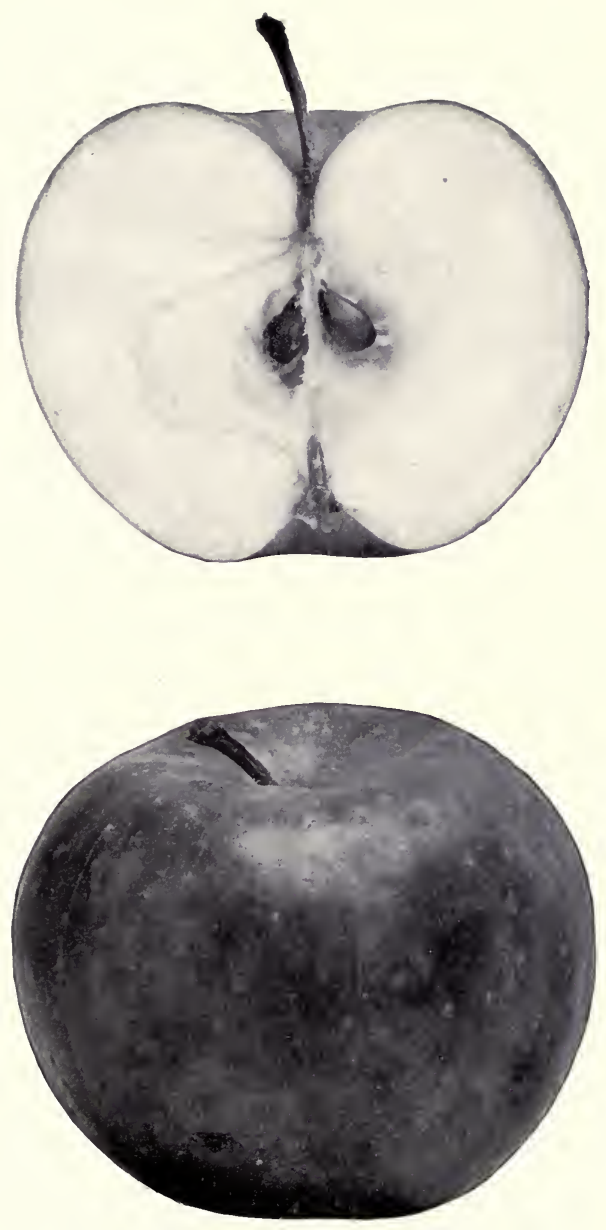

WINDSOR 

russeted and with coarse outspreading russet rays. Calyx rather small, closed or partly open; lobes small, connivent, acute, pubescent. Basin medium in size, abrupt, moderately shallow to rather deep, usually rather wide, often somewhat furrowed, wrinkled.

Skin moderately thick, smooth, somewhat waxy, pale yellow or greenish blushed with thin dull red or in highly colored specimens predominantly deep red, sometimes obscurely striped with dull carmine. Dots characteristically conspicuous, usually rather large, dull, pale, often areolar with russet center, sometimes mingled with flecks of russet.

Caly.r tube funnel-form. Stamens median or below.

Core small, axile; cells not uniformly developed, closed; core lines clasping the funnel cylinder. Carpels broad narrowing toward base and apex, varying to obcordate, tufted. Secds variable, below medium to rather large, moderately narrow to rather wide, obtuse or approaching acute, tufted, light brown.

Flesh nearly white, tinged with green or yellow, firm, moderately finegrained to somewhat coarse, juicy, somewhat aromatic, mild subacid becoming nearly sweet, good to possibly, very good for dessert.

\section{WINE.}

References. I. Coxe, I8I7:I21. fig. 2. Thacher, I822:140. 3. (?) Wilson, I828:136. 4. Fessenden, I828:I3I. 5. Kenrick, 1832:54. 6. Floy-Lindley, 1833:87. 7. Mag. Hort., I:364. 1835. 8. Manning, 1838:55. 9. Ib., Mag. Hort., 7:5 I. I84 I. I0. Downing, I845:143. II. N. Y. Agr. Soc. Trans., 1849:354. fig. I2. Thomas, I849:175. I3. Cole, I849:120. 14. Emmons, Nat. Hist. N. Y., 3:63. I851. 15. Am. Pom. Soc. Cat., 1852. 16. Elliott, 1854:116. fig. I7. Gregg, 1857:60. I8. Hooper, 1857:43, 96. I9. Warder, 1867:466. 20. Fitz, 1872:143, I50. 21. Barry, 1883:357. 22. Lyon, Mich. Hort. Soc. Rpt., 1890:300. 23. Bailey, An. Hort., I892:252. 24. Munson, Me. Sta. Rpt., I893: I34. 25. Budd-Hansen, I903:206. 26. Bruner, N. C. Sta. Bul., I82:23. I903.

Synonyms. Fine Winter $(1,2,5,6)$. Hays $(21,25,26)$. Hays Apple (5, II, I2, I4, 18). Hays Wine (24). Hays Winter (1, 2, 6, I0, I1, I2, I3, I6, 17, I8, 19, 22). Hays Winter Wine (16). Hollow Crown Pearmain (16). Large Winter Red (1, 2, 5). Pennsylvania Redstreak (19). Pennsylvania Red Strcak $(21,24,25)$. Wine Apple $(1,2,5,6,7,8,9$, 10, 11, 14, I7). Wine Apple (16). Winter Wine (16, 21).

Wine is a large and rather attractive red apple of good to very good quality for dessert use. It is in season from late October to March or April. Coxe published the following description of it in 1817 (I). "An uncommonly large, fair, handsome red apple-the form is round, flat at the ends: the skin is a lively red, streaked and spotted with a small portion of yellow: the stalk end frequently of a russet colour, both ends deeply indented; the stalk very short, the taste is rich and pleasant, an admired table fruit, and excellent for cooking as well as for cider; it ripens in October, and keeps well through the fall and winter. The tree is uncommonly large and handsome, the leaves small, it bears abundantly; from its spreading form, it does not require much trimming-it is probably as saleable an apple as any sold in the Philadelphia market: in the state and county of Delaware it is called Hays Winter; and in some places in New-Jersey, the fine Winter, and large Winter Red." 
In 1849 the Committee on Fruits for the N. Y. State Agricultural Society added Wine to the list previously recommended for general dissemination and cultivation and gave the following description of the variety (II). "Fruit large; form globular and slightly oblate; color of a deep rich red, striped and dashed with yellow, often quite indistinctly, and frequently a yellowish russet around the base of the stem : texture crisp, but tender and juicy; flesh yellowish-white; flavor rich and sprightly vinous, acid. Core large; stem short, seldom or ever rising above the outline of the fruit, and inserted in a deep, round and smooth cavity; eye large and set in a deep and broad basin; season, ripe in Octoher and keeps in fine condition until March. Its growth is thrifty and vigorous, making a beautiful tree, it is also hardy and productive, its leaves are small and easily recognized.

"The Wine apple is richly entitled to a place on our list, for it is not only beautiful in appearance but it is hardy, productive and of a flavor which is peculiarly agreeable to most persons; it is also equally well adapted to the dessert and kitchen, and makes most delicions cider; in fact we could not recommend to our agricultural population a more useful fruit. It originated in the State of Delaware and is very popular where well known. As there are many spurious varieties sold as the Wine apple, cultivators must be cautious of whom they purchase their trees."

In regions farther south and west it has long been a favorite fruit for either market or kitchen use for which its size and form render it peculiarly attractive (I9). It appears less well adapted to the conditions existing in this state for although it has long been known here it has established itself in but comparatively few localities and is now seldom if ever planted.

This is quite distinct from the Twenty Ounce which is known to some under the name of the Wine Apple. The name Wine has also been applied to two other varieties. 1

\section{WINESAP.}

References. I. Coxe, I8I 7:153. fig. 2. (?) Thacher, I822:140. 3. Buel, N. Y. Bd. Agr. Mem., 1826:476. 4. Wilson, 1828:136. 5. Cat. Hort. Soc. London, 1831:39. 6. Manning;, Mag. Hort., 7:50. 1841. 7. Downing, 1845: 143. 8. Kirtland, Horticulturist, $2: 545.1848$ 9. Thomas, 1849:i75. Io. Elliott, Horticulturist, 3:420. I849. Ir. Cole, 1849:130. I2. Phoenix, Horticulturist, 4:472. 1850. 13. Emmons, Nat. Hist. N. Y., 3:68. 1851. 14. Am. Pom. Soc. Cat., 1852. I5. Elliott, 1854:I17. fig. 16. Hooper, 1857:97. I7. Gregg, 1857:60. 18. Mag. Hort. 30:162. I864. I9. Warder, 1867:546. fig. 20. Downing, I872:I0, I2 index, app. 21. Fitz, I872:I43, I55, I72. fig. 22. Barry, 1883:357. 23. Rural N. Y., 47:749. I888. 24. Wickson, 1889:246. 25. Lyon, Mich. Hort. Soc. Rpt., r890:300. 26. Beach, N. Y. Sta. An. Rpt., I I:589, 596. I892. 27. Bailey, An. Hort., 1892:252. 28. Clayton, Ala. Sta. Bul., $47: 7$. 1893. 29. Munson, Mc. Sta. Rpt., r893:134. 3o. Stinson, Ark. Sta. An. Rpt., 7:46. I894. 31. Mathews, Ky. Sta. Bul., 50:32. I894. 32. Rural N. Y., 54: 859. I895. 33. Ib., 55:I, 51, I90, 250, 34I. 1896. 34. Burrill and McCluer, Ill. Sía. Bul., 45:346. 1896. 35. Taylor, U. S. Pom. Bul., 7:357. 1898. 36. Massey, N. C. Sta. Bul., 149:318. I898. 37. Van Deman, Rural N. Y., 59:224.

'Cole, 1849:108. Phoenix, Horticulturist, 4:471. 1850. Schroeder, Montreal Hort. Soc.
Rht., 1886-87:76. 


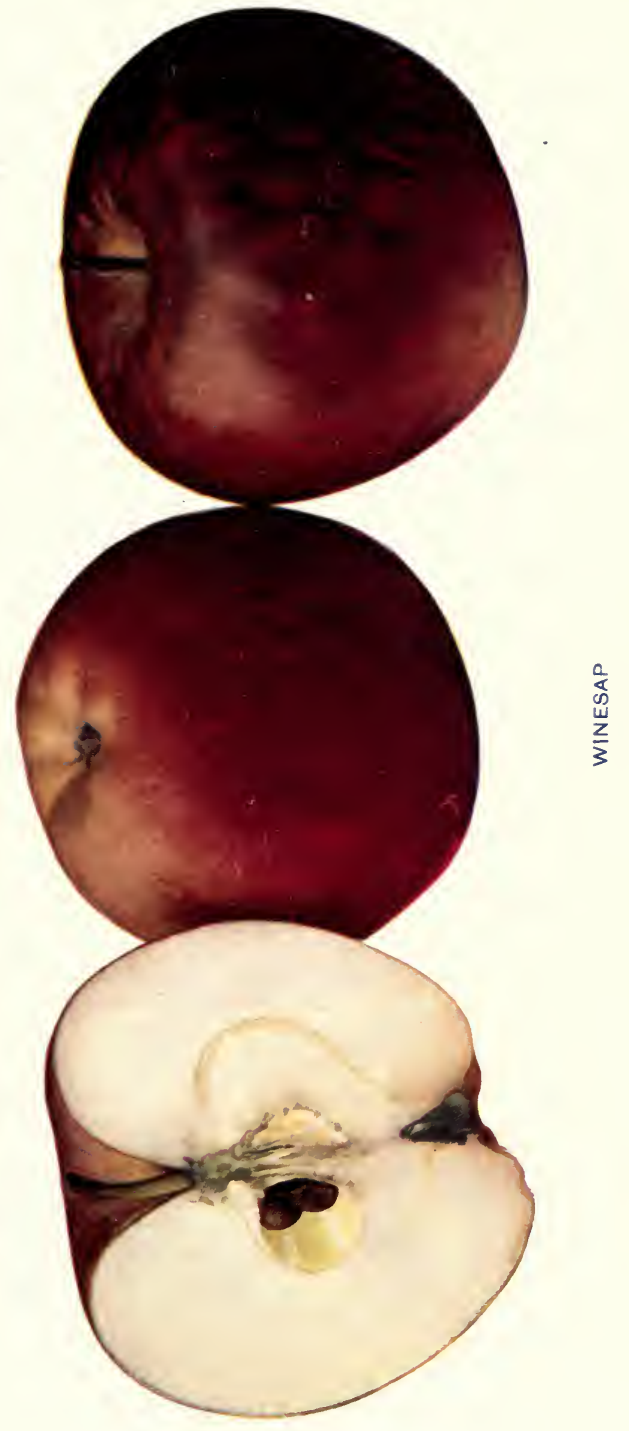



1900. 38. Alwood, Va. Sta. Bul., 130:138. г901. figs. 39. Munson, Me. Sta. Rpt., I902:96. 40. Dickens and Greene, Kan. Sta. Bul., ro6:56. I902. 41. Hansen, S. D. Sta. Bul., 76:1 16. 1902. 42. Stinson, Mo. Fr. Sta. Bul., 3:26. 1902. 43. Budd-Hansen, 1903:206. fig. 44. Bruner, N. C. Sta. Bul., 182:27. 1903. figs. 45. Powell, U. S. Dept. Agr. Yr. Bk., r9o3:232. col. pl. 46. Powell and Fulton, U. S. B. P. I. Bul., 48:6r. 1903. 47. Beach and Clark, N. Y. Sta. Bul., 248:15I. I904.

Synonyms. Holland's Red Winter (20). Royal Red of Kentucky (20). Texan Red (20). Wine SAP (12, I3, I5, I7, 21, 27, 28, 31). Wine Sop ( $15, ? 7)$.

Winesap is one of the oldest and most popular apples in America. It is known in all the apple-growing sections from Virginia westward to the Pacific Coast. An indication of its popularity may be gained from the fact that according to Bailey's Inventory (27) there were, in 1892 , seventy-three nursery firms offering Winesap for sale as compared with sixty-four firms offering Baldwin, fifty-eight offering Northern Spy and forty-eight offering Rhode Island Greening. It should te borne in mind however that the number of firms selling a variety is not an altogether true criterion of the number of trees sold.

Like various other old varieties, Winesap has many seedlings which partake more or less of the characters of the parent. The best known of these are Arkansas, Arkansas Black, Paragon and Stayman Winesap.

The tree is a rather vigorous though not particularly rank grower, comes into bearing early and is a remarkably regular cropper. It does best on rather light, rich, deep soils and does not succeed on heavy clays or in low, damp locations. In unfavorable situations the trees are apt to be short-lived and in New York are less hardy than the leading commercial varieties of this region. Although Winesap is a well-known market apple, yet with the exception of the Piedmont region in Virginia and certain districts elsewhere it has not proved generally successful for the commercial orchard. In New York it seldom reaches good medium size. In more southern latitudes and under favorable conditions the fruit is well colored and of good quality, but excepting on young trees or on soils of more than average fertility it averages too small for a good market variety. When well grown it is of very good quality and attractive 
in appearance, being quite uniform in shape and size and of good dark red color. As grown at this Station it is in' season from January to June with April as the ordinary commercial limit (47). When grown farther south its season extends to February in ordinary storage and to April in cold storage. It is a good shipper and stands heat well before going into storage, but late in the season it often scalds, particularly when not well colored.

Historical. Nothing definite is known of the origin of Winesap. Coxe speaks of it as being "the most favored cider fruit in West Jersey." From this fact many writers have referred to West Jersey as the region of its origin or probable origin but such statements seem hardly warranted by the evidence.

TREE.

Tree medium size, vigorous. Form roundish spreading, rather straggling and open. Twigs rather stout, rather short to above medium; internodes short. Bark very dark reddish-brown with thin gray scarf-skin, somewhat pubescent. L.enticels especially clustered just below the nodes, conspicuous, round or elongated, variable in size but usually above medium. Buds large to medium, hroad, usually rather obtuse but sometimes acute, free or nearly so. Foliage thin; leaves usually not large, narrow.

FrUIT.

Fruil as grown in New York averages even smaller than that which is grown farther south. It is pretty uniform in size and shape. Form usually conical, sometimes roundish, nearly truncate at base, nearly regular or obscurely ribbed, symmetrical. Stèm medium to short, rather slender. Cavity medium to rather small, acute to acuminate, narrow to rather broad, deep, symmetrical or somewhat furrowed, often more or less lipped, often russeted or with outspreading russet rays. Caly.x medium to large, closed; lobes long, narrow, acuminate. Basin rather small to medium, often oblique, shallow to rather decp and abrupt, narrow to moderately wide, distinctly furrowed, somewhat wrinkled.

Skin medium in thickness, tongh, smooth, glossy, bright deep red indistinctly striped and blotched with very dark purplish-red over a distinctly yellow ground color or green if not fully mature, overspread with faint bloom. Dots rather small, scattering, whitish, sometimes in conspicuous contrast with the deep red skin especially toward the cavity. Prevailing effect bright deep red.

Calyx tube quite variable, conical or funnel-shape. Stamens marginal.

Core medium to small, abaxile with a hollow cylinder in the axis, narrowing toward the apex; cells pretty uniformly developed, symmetrical, open or nearly closed; core lines clasping. Carpels broadly roundish, much concave, but slightly emarginate if at all, mucronate. Seeds below medium to above, wide, plump, obtuse.

Flesh tinged with yellow, reins sometimes red, very firm, rather coarse, moderately crisp, very juicy, sprightly subacid, good to very good. 


\section{WINTER BANANA.}

References. I. N. Y. Sta. An. Rpt., II:224. I892. 2. Heiges, U. S. Pom. Rpt., 1895:20. 3. Am. Pom. Soc. Rpt., 1897:36. 4. Beach, Eastern N. Y. Hort. Soc. Rpt., 1900:44. 5. Ib., Western N. Y. Hort.Soc. Rpt., 1900:37. 6. Macoun, Can. Dept. Agr. Rpt., r9or:98. 7. Beach and Clark, N. Y. Sta. Bul., 248:151. 1904 .

Synonyms. Banana $(2,3)$. Winter Banana $(2,3)$.

Fruit large, clear pale yellow with beautiful contrasting pinkish-red blush, attractive in appearance, characteristically aromatic, of good dessert quality, but too mild in flavor to excel for culinary uses. The tree is a pretty good grower, comes into bearing young, is almost an annual bearer and yields moderate to rather heavy crops. In ordinary storage the fruit is in season from mid-November to the first of April, but its safe commercial limit in this climate probably would not extend much beyond December. In cold storage it ranks as a keeper about with Rhode Island Grecning, but is not equal to Baldwin. It could perhaps be used to advantage commercially to follow the Maiden Blush and extend the season for fruit having the general appearance of that variety. As compared with Maiden Blush this is larger, neither as uniform nor as symmetrical, better for dessert use but less desirable for culinary purposes. Its color is such that it shows bruises more readily than do red apples like Baldwin or Tompkins King. It is sufficiently promising to be worthy of further testing where an apple of this color is desired.

Another variety which has been disseminated under the name Banana is a sweet apple. It is described on page 60 under the name Banana Sweet.

Historical. Winter Banana originated on the farm of David Flory near Adamsboro, Cass county, Ind., about 1876 . It was introduced by Greening Brothicrs, Monroe, Michigan, in $1890(4,5)$. It has as yet been but little planted in this state.

\section{TREE.}

Tree medium in size, vigorous. Form rather flat, spreading and somewhat inclined to droop, open. Twigs long, curved or nearly straight, moderately stout; internodes long. Bark reddish-brown mingled with olive-green, lightly and irregularly coated with scarf-skin, pubescent. Lenticels conspicuous, numerous, medium to large, round or slightly elongated, raised. Buds sunk in the bark, medium or above, plump, acute to obtuse, free, slightly pubescent.

\section{Fruit.}

Fruit nearly large to very large, not very uniform in size or shape. Form roundish conic to oblong conic, or sometimes oblate and noticeably flat at the 
base, often irregularly elliptical and somewhat ribbed; axis sometimes oblique; sides often unequal. Stem short to moderately long, medium in thickness to rather slender. Cavity usually rather large, acute to acuminate, moderately shallow to deep, broad, gently furrowed, sometimes lipped, smooth or sometimes partly russeted. Calyx small to medium, partly open or sometimes closed; lobes convergent or connivent, short to medium length, obtuse to acute. Basin small to medium, often decidedly oblique, rather shallow to moderately deep, usually rather narrow but sometimes moderately wide, obtuse to rather abrupt, furrowed and wrinkled.

Skin smootl, moderately thick, tough, waxy, bright pale yellow, often with a blush which in well-colored specimens deepens to dark pinkish-red. Often a suture line extends from the basin nearly or quite to the cavity. Dots numerons, whitish and submerged or with fine russet point. Prevailing effect yellow with a pretty contrasting blush.

Caly.r tube wide above, rather short, cone-shape or funnel-form. Stamens median to marginal.

Core rather small to above medium, abaxile; cells not uniformly developed, usually symmetrical and open, sometimes closed; core lines somewhat clasping. Carpels elongated ovate, narrow, emarginate, tufted. Seeds often abortive; the plump ones vary from small to rather large and are more or less irregular, usually obtuse to acute, dull dark brown, sometimes tufted.

Flesh whitish tinged with pale yellow, moderately firm, a little coarse, somewhat crisp, tender, juicy, mild subacid, distinctly aromatic, good to very good.

\section{WINTER HOG ISLAND SWEET.}

\section{ReFerence. Downing, r869:4I3.}

This variety is mentioned by Downing as having originated on Long Island. We are unacquainted with it and have received no reports concerning it from any portion of the state. Downing describes it as medium or below, pale yellow striped and shaded with light and dark red; flesh tender, rather rich and sweet, good; season November to February.

\section{WINTER PEARMAIN.}

References. I. Forsyth, 1803:51, 2. Thacher, 1822:131. 3. Forsyth, 1824: I 8 . 4. Ib., I824:130. 5. Floy-Lindley, 1833:62. 6. Cultivator, $3: 36$. 1846. 7. Thomas, 1849:175. fig. 8. Gregg, 1857:60. 9. Mas, LeVerger, 4:19. 1865. 10. Warder, $1867: 736$. I1. Downing, I869:413. I2. Fitz, 1872:167. I3. Leroy, 1873:54r. fig. 14. Hogg, :884:169. I5. Ib., 1884:246. 16. Bailey, An. Hort., $1892: 253$.

Synonyms. Autumn Pcarmain, erroneously (7). Ducks Bill (15). Germaine (13). Great Pearmain (II). Green IVinter Pearmain (12). Herefordsilire Pearmatn (6). Hertfordshire Pearmain (i). Hertfordshire Pcarmain (4). Old Englisir Pearmarn (3). Old English Pearmain (14). Old Pearmain (5, 7, II, I 4, of Lindley I3). Parmain d'Angleterre of Knoop I760 (13). Parmain d'Hiacr (5, II). Parmain-Pepping (13). Pearmain (2, I4). Pearmain (II). Pcarmain Herefordshire (12). Pearmain d'Hiver (13). Pepin Parmain d'Angleterre (5, II). Pepin Parmain d'Hiver (II). 

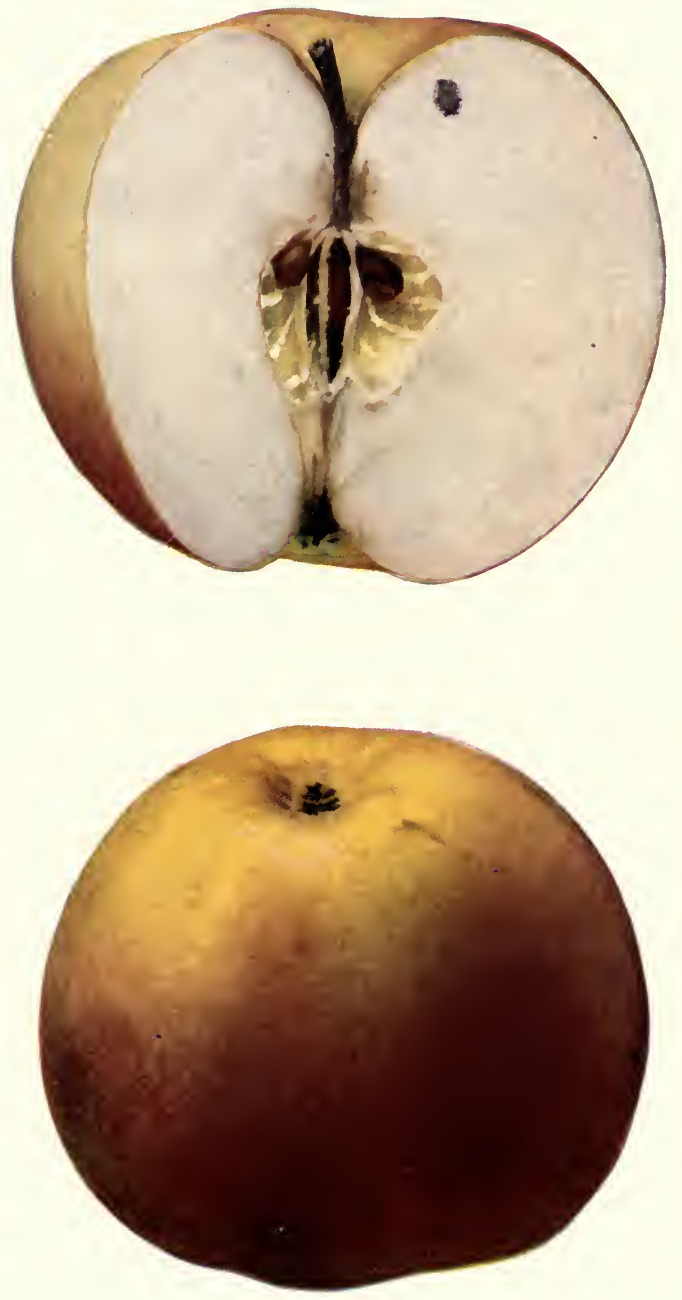

WINTER BANANA 

Pcremenes (I1). Permaine (13). Permein (13). Platarchium (13). Sussex Scarlet Pearmain (15). Winter Pearmain (2, 6, of Ray 13).

Several different varieties have been known under the name Winter Pearmain both in Europe and in this country. The references given above do not all refer to the same variety and in some cases it is impossible to determine which Winter Pearmain the writer has in mind.

In 1822 Thacher (2) gave the following account of the Winter Pearmain of the old Plymouth Colony in Massachusetts. "The winter pearmain is among the first cultivated apples by the fathers of the old Plymouth colony, and is, undoubtedly, of English descent. Many trees of this kind are now supposed to be more than one hundred years old, and grafted trees from them produce the genuine fruit in great perfection. The tree is tall and upright, forming a handsone regular top: it is hardy, and will flourish in a light soil. It is not an early bearer, but when attained to about twelve years, from having been grafted, it produces more abundantly and uniformly than any other kind within our knowledge. The fruit is scarcely excelled as a table apple or for cookery; and the cider, made from it, is said to be inferior to none. The apple is of a moderate size; fair and smooth; of a reddish colour; interspersed with green and yellow; the flesh a rich yellow; the flavour slightly aromatick, and agreeable. There are two or three varieties of this apple, but rather of an inferiour quality."

The following is the description given by Floy-Lindley (5) of the Winter Pearmain mentioned by Ray in I688: "fruit medium, regular, tapering to the crown, grass-green with a little red on the sunny side; in season from November to March." Downing (II) remarks that the tree of this variety is a free and healthy grower and productive. This is the Pearmain d'Hiver of Leroy (13), the English Winter Pearmain of Mas (9), the Winter Pearmain or Old Pearmain of Downing (II) and the Pearmain or Old Pearmain of Hogg (I4). Hogg (I4) states that this is the oldest English apple on record and that its cultivation in Norfolk can be traced back to the year I 200. He says that the Winter Pearmain of the London market is a different apple (I5).

An apple is grown in the Middle West under the name of Winter Pearmain which is of medium size, oblate inclined to conic, yellowish, shaded and striped with light and dark red, subacid, good; in season from November to February (II).

There is a Winter Pearmain of Pennsylvania which is below medium, oblate to roundish oblate, yellow splashed and shaded with brownish-red, mild subacid, good; in season from January to May (I I).

\section{WINTER ST. LAWRENCE.}

References. I. Shepherd, Montreal Hort. Soc. Rpt., 1885:17. fig. 2. Ib., 1886-87:9, 99. 3. Can. Hort., I I :7, 145. 1888. col. pl. and fig. 4. Woolverton, Am. Pom. Soc. Rpt., r889:155. 5. Hoskins, Rural N. Y., 48:88. i889. 6. Burnet, Can. Hort., I2:337. I889. 7. Budd, Ib., I3:24. I89o. 8. Hoskins, Aner. Gard., 15:288. I894. 9. Craig, Can. Dept. Agr. Rpt., I896:135. figs. Io. Waugh, Vt. Sta. Bul.,6r:32. 1897. Ir. Can. Hort., 25:49. 1902. I2. BuddHansen, 1903:206.

Synonyms. Mank's Codling (9). Rambour Barré (9). 
The following account of Winter St. Lawrence is given by Macoun. "Imported in I833 from Manchester, England, under the name of Mank's Codling, by the late Wm. Lunn, of Montreal. Named Winter St. Lawrence by the Montreal Horticultural Society about I873. Fruit medium to large, roundish, slightly conical; skin greenish yellow well covered with deep red through which are dark purple splashes and streaks; dots fairly numerous, pale, distinct; cavity rather deep and medium in width; stem short, slender; basin narrow, almost smooth, of medium depth; calyx partly open, sometimes closed. Flesh white, rather soft, melting, moderately juicy, subacid, good flavour; core small; quality good; season, early winter. Tree a moderately spreading, strong grower and apparently very hardy. A shy but annual bearer at Ottawa."

This variety is but little known among New York fruit growers.

\section{WINTER SWEET PARADISE.}

References. I. Downing, r845:124. 2. Cole, r849:130. 3. Emmons, Nat. Hist. N. Y., 3:85. I851. 4. Elliott, 1854:150. fig. 5. Hooper, 1857:102. 6. Mag. Hort., 27:99. 1861. 7. Kirtland, Ib., 33:53. 1867. 8. Warder, 1867:737. 9. Fitz, $1872: 143$, I 56 . 10. Downing, 1872 : 10 index, app. II. Thomas, $1875: 212$. 12. Barry, 1883:357. 13. Bailey, An. Hort., 1892:253. 14. Ill. Sta. Bul., 45: 346. 1896 .

Synonyms. Honey Sweet of some (4). Paradise Winter (8). Paradise Winter Sweet (4). White Robinson (14). Wine Siveet (10).

Fruit large, roundish oblate, dull green with brownish-red blush, finegrained, juicy, sweet; in season during early winter and midwinter. Tree a vigorous, upright grower and productive, but it is not an early bearer (12).

Historical. In $18+5$ Downing made the following observation concerning this variety. "We received it some years ago along with the Summer Sweet Paradise from Mr. Garber of Columbia, Pa., and consider it a native fruit" (I). From Pennsylvania it was carried into Ohio and later its cultivation was extended into other portions of the Middle West. Although an old variety it is but little known in New York. It is still propagated to a considerable extent by nurserymen.

\section{WISMER.}

Refrenences. I. Amer. Gard., 18:142. 1897. fig. 2. Can. Hort., 20:78. 1897. 3. Rural N. Y., 55:54. I897. 4. Ragan, U. S. B. P. I. Bul., 56:341. 1905.

Synonyms. Wismer's Dessert $(1,2,3)$. Wismer's Dessert (4). Wisner's Dessert (4).

This is an apple of Canadian origin introduced in 1897 by J. H. Wismer, Port Elgin. Ontario. In color it is said to resemble Esopus Spitzenburg (3). The tree is said to be very hardy, vigorous and productive and the fruit medium to large, yellow shaded and striped with bright red; the flesh mild subacid, of excellent flavor and exceedingly fine, tender texture. We are not acquainted with this apple. It has not yet been tested sufficiently in this state to indicate whether it has any value for this region. 


\section{YELLOW BELLFLOWER.}

References. I. M'Mahon, I806:585. 2. Coxe, I8r7, i20. fig. 3. Thacher, I822:121. 4. Buel, N. Y. Bd. Agr. Mem., I826:476. 5. Fessenden, 1828: I30. 6. Wilson, г828:136. 7. Cat. Hort. Soc. London, г831 : No. 75. 8. Kenrick, 1832: 42. 9. Floy-Lindley, $1833: 86$. Io. Mag. Hort., I :326, 78. 1835. I1. Manning, 1838:60. 1 2. Ib., Mag. Hort., $7: 5$ I. I841. I3. Downing, 1845:100. fig. 14. Horticulturist, I :482. I846. I 5. Ib., 2:36I, 482, 545. I848. I6. Cole, I849:I19. fig. I7. Thomas, 1849:187. I8. Phoenix, Horticulturist, 4:472. I850. Ig. Emmons, Nat. Hist. N. Y., 3:79. I851. col. pl. No. 46 and fig. 20. Am. Pom. Soc. Cat., 1852. 21. Hovey, Mag. Hort., 18:542. 1852. fig. 22. Ib., 19:244. 1853. 23. Biedenfeld, I854:102. 24. Elliott, I854:70. fig. 25. Hooper, I857:16, I03, 106, I08. col. pl. 26. Gregg, 1857:50. fig. 27. Flotow, I:69. I859. 28. Oberdieck, 4:197. 1862. 29. Warder, 1867:692. fig. 30. Regel, I868:442. 31. Fitz, 1872: I 43, I 45, I63. 32. Mas, LeV erger, I873: I 51 . 33. Leroy, I873:432. 34. Lauche, I: No. 3. 1882. col. pl. 35. Barry, 1883:358. 36. Rural N. Y., $47: 749$. I888. 37. Cat. Cong. Pom. France, r889:278. 38. Wickson, r889:247. 39. Lyon, Mich. Hort. Soc. Rpt., I89o:300. 40. Bailey, An. Hort., 1892:235. 4I. Ib., I892:253. 42. Bredsted, I893:405. 43. Gaucher, I894: No. 6. col. pl. 44. Waugh, Vt. Sta. An. Rpt., 14:3 13. I90I. 45. Eneroth-Smirnoff, Igor:266. 46. Sears, Can. Hort., 25:325. 1902. 47. Budd-Hansen, 1903:210. fig. 48. Farrand, Mich. Sta. Bul., 205:43. 1903. 49. Powell and Fulton, U. S. B. P. I. Bul., 48:62. 1903. 50. Beach and Clark, N. Y. Sta. Bul., 248:151. 1904.

Synonyms. Belle Flavoise (28). Belle Flavoise (33, 43). BelleFlour JAune $(32,37)$. Belie-Fleur (33). Belle-Flower (33). Bell-Flower (2). Bell Flower (9). Bell flower (3). Bellflower (4, 6, 8, i I , 2 I , 24, 40). Bellfower $\left(\mathrm{I} 3,{ }^{\prime} \mathrm{I} 7,25,43,49\right)$. Bell-Flower (5). Bishop's Pippin of Nova Scotia (33). Gelber Bellefleur $(23,27,34,43,45)$. Gelber Bellefleur (28). Gelber Belle Fleur (33,43). Gelber Englischer Schonbluhender (43). Gul. Bellefleur (42). Lady Washington (24,33,43). Lincoln Pippin (43). Lineous Pippin (43). Linnoeus Pippin (33). Metzgerapfel (43). Metzger Calvill (28). Metzger's Calvill (33,43, of John 34). Yellow Belle Fleur (7, 13). Yellow Bellefleur (19, 20, 31). Yellow Bellefleur (17, 21, 24, 33, 43). Yellow Belleflower (46). Yellow Bellflower (8, 13, 21, 24, 33, 40, 43). Warren Pippin $(33,43)$. Weisser Metzgerapfel (43).

Yellow Bellflower grows large or even very large, but usually it is so variable in size that the marketable grades are not very uniform and there is a relatively large percentage of apples that are too small for market. It is decidedly attractive in color for a yellow apple and the color improves in storage, becoming more clearly yellow as the fruit matures. It is well known throughout the state and is generally highly esteemed for culinary uses and also for its excellent dessert qualities, although it is rather too briskly subacid to suit the tastes of some, particularly during the early part of its season. It does not reach its best condition for dessert use till January or later, when its acidity becomes somewhat subdued. It is quite susceptible 
to injury by the apple-scab fungus. It must be handled very carefully because it very easily shows bruises. It does not stand heat well before going into storage and when it begins to deteriorate goes down quickly. Some do not regard it as a good keeper, while others find that it keeps pretty well. To get best results in storage the fruit must be thoroughly protected from the scab in the orchard, picked and handled with extra care and kept from heat from the time it is picked till it is stored as well as while it is in storage. As grown at Geneva it is in season from December to April with January or February as the commercial limit. In cold storage it keeps about with Tompkins King, but not as well as Rhode Island Greening.

The tree is a good grower and pretty hardy. In favorable locations it is healthy and long-lived. It seems to thrive particularly well on warm, well-drained soils. Many orchards are found throughout the state having from one to several trees of this variety and the aggregate yield of Yellow Bellflower in New York is of considerable importance. The surplus over what is required for home use is commonly disposed of in the local market. Although the fruit sells at good prices, Yellow Bellflower is not generally a satisfactory cropper and is not a good variety to plant in commercial orchards in New York except in the few districts where it has proved profitable.

Historical. In $18 \mathrm{I} 7$ Coxe (2) reported that the original tree, very large and old, was said to be still standing on a farm near Crosswicks, Burlington county, N. J. In 1852 Hovey (2I) remarked that the Bellflower was then extensively cultivated in New Jersey, but its cultivation in New England was as yet extremely limited. A century or more ago it was being grafted into the farm orchards and propagated in the nurseries throughout New York, and it is to-day well known among fruit growers in most parts of the state but it is nowhere extensively cultivated. It was early introduced into cultivation through the Middle West and within recent years it has come to be one of the important commercial varieties in certain apple-growing districts in the Pacific states. Wickson says that "The Yellow Bellfower, as grown in California, has such conspicuous excellence that during its season it is hardly likely to be misplaced for any other variety." 1 It is now offered by nurserymen in nearly all of the more important apple-growing sections of the country.

\section{TREE.}

Tree medium to large, vigorous to very vigorous. Form upright spreading; laterals drooping, particularly after they have borne heavy crops. Tuigs medium to long, rather stocky, geniculate; internodes medium to large. Bark

\footnotetext{
${ }^{1}$ Letter, E. J. Wickson, 1899.
} 

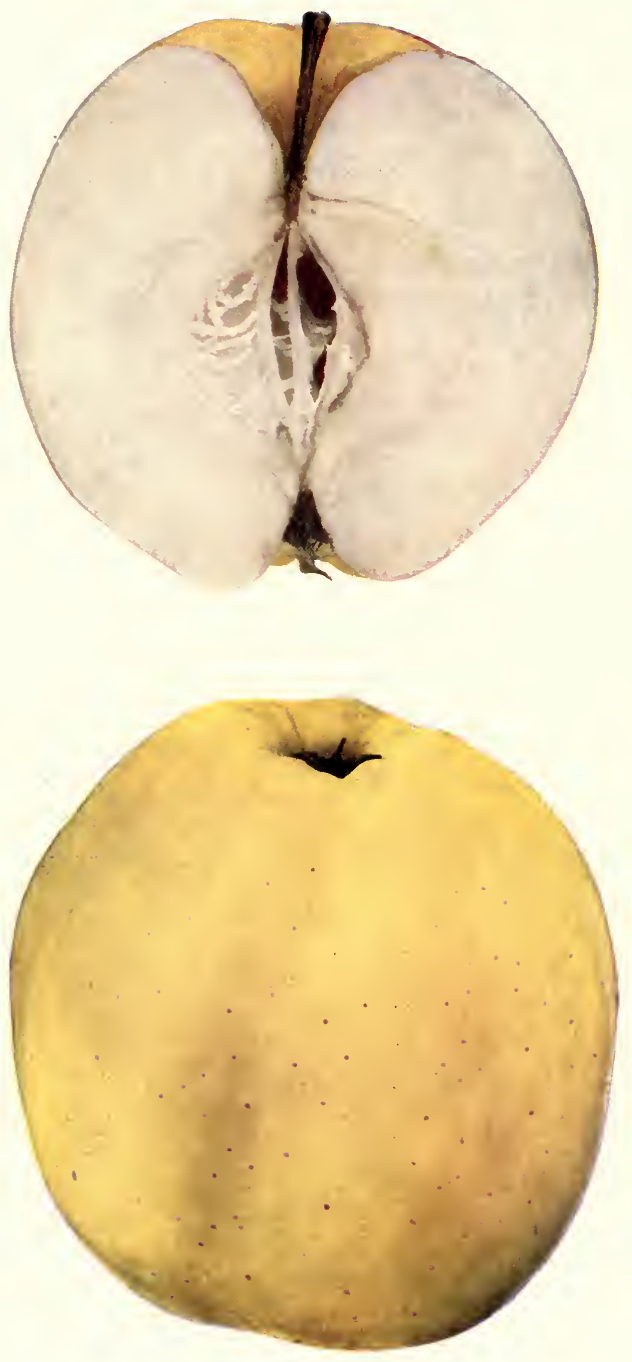

YELLOW BELLFLOWER 

dull brownish-red with shades of green, uniformly overlaid with moderately thick scarf-skin; more or less pubescent. Lenticels rather inconspicuous, above medium in size, roundish to elliptical; rather numerous, dull, not raised. Buds above medium to large, rather prominent, acute to roundish acute, free or nearly so, quite pubescent.

\section{FruIT.}

Fruit variable in size, small to large or very large. Form roundish oblong narrowing toward the basin varying to oblong conic, frequently somewhat ovate, irregularly elliptical and more or less ribbed, often with prominent ridges at the apex; sides usually unequal. Stem medium to rather long, rather slender to moderately stout. Cavity medium to large, acute to acuminate, deep to very deep, moderately narrow to wide, furrowed, sometimes compressed, sometimes lipped, usually with outspreading broken rays of brownishrusset. Caly.x below medium to above, closed or partly so; lobes narrow, acuminate, pubescent. Basin small, oblique, abrupt, narrow, shallow to rather deep, distinctly ridged and wrinkled.

Skin smooth, bright, pale lemon-yellow varying to whitish in the shade and often with a shade of brownish-red in the sun which in highly colored specimens deepens to a pinkish-red blush. Dots whitish or russet, numerous and small toward the basin, larger, irregular and scattering toward the cavity. Prevailing effect bright pale yellow.

Caly.x tube yellowish, elongated funnel-shape, sometimes extending to the core. Stamens median to basal.

Core large, long, remarkably abaxile; cells sometimes unsymmetrical, wide -open or partly closed; core lines clasping the funnel cylinder. Carpels long, narrow, roundish obovate, much concave, much tufted. Seeds large, long, obtuse to acute.

Flesh whitish tinged with pale yellow, firm, crisp, moderately fine-grained, rather tender, juicy, aromatic, very good for culinary use, rather too acid for dessert early in the season but later its acidity becomes somewhat subdued.

\section{The Yellow Bellflower Group.}

The Yellow Bellflower belongs to a group of apples most of which have fruit that is predominantly yellow. The fruit of the group is characteristically oblong or roundish oblong and often markedly ovate or conic, with the core large and remarkably abaxile, cells wide open and carpels elongated, rather narrow and much concave. The group is now represented by varieties well known in cultivation in various parts of the country. It appears that the oldest members of which we have any record in this country are Yellow Bellflower and Ortley, both of which originated in New Jersey. The varieties mentioned in this volume which appear more or less closely identified with the Yellow Bellflower group are Dickinson, Flory, Kirkland, Mason Orange, Minister, Moyer, Newman, Occident, Ortley, Titus Pippin, Yellow Bellflower.

Vo1. I - I6 


\section{YELLOW FOREST.}

References. I. Gardencr's Monthly, 1885. (cited by 7). 2. N. Y. Sta. An. Rpt., 8:349. 1889. 3. Bailey, An. Hort., 1892:253. 4. Beach, N. Y. Sta. An. Rpt., 13:592. 1894. 5. Stinson, Ark. Sta. Bul., 43:104. 1896. 6. Beach and Clark, N. Y. Sta. Bul., 248:ı52. 1904. 7. Ragan, U. S. B. P. I. Bul., 56:345. 1905.

\section{Synonym. Wild Apple (7).}

Fruit medium to rather small, yellowish or green with dull blush, fair to good in quality. It is too deficient in size and color for a good market apple but may have some value for the home orchard because late in the season it is of fairly good quality and a considerable portion of the fruit may be held in good condition in cellar storage till summer. For dessert use during June it has been one of the best in quality among a large collection of latekeeping varieties grown at this Station. The tree is a good grower, comes into bearing rather young and is a reliable cropper.

Historical. This variety was introduced by L. T. Sanders, Collingsburg, La., irom whom it was received in 1888 for testing at this Station. Mr. Sanders states that it is a wilding which Captain Joe Winston found in the woods near his residence in Bossier Parish, La., when it was quite small, and transferred to his orchard. It ripens in Louisiana about the middle of September. We do not know that the variety is being grown in New York outside of the orchards at this Station.

\section{TREE.}

Trec vigorous. Form somewhat upright and spreading, moderate-y dense. Taigs slender, long; internodes below medium. Bark rather dark reddishbrown with gray scarf-skin, slightly pubescent. Lenticels numerous, small to above medium, conspicuous, usually round, sometimes raised. Buds medium in size or below, narrow, acute, appressed.

\section{Fruit.}

Fruit small to medium, quite uniform in shape and size. Form roundish, slightly oblate or sometimes a little conic, symmetrical. Stem variable, often long and slender. Cavity acute or approaching acuminate, medium in depth and width, often covered near the base of the stem with greenish-russet. Calyx small, closed or a little open; lobes slender, recurved. Basin rather abrupt, medium in depth and width, slightly wrinkled.

Skin thin, tough, smooth, green or eventually more or less yellow, sometimes with brownish blush. Dots small to medium, numerous, reddish or greenish-russet or whitish and submerged.

Calyx tube medium in size, narrow, conical to elongated conical or funnelshape; pistil persistent. Stamens below median to above.

Core distant, small, axile or nearly so; cells symmetrical, closed or a little open; core lines meeting the limb of the calyx tube or clasping the funnel cylinder. Carpels narrow, roundish ovate, slightly tufted. Seeds below medium to small, plump, moderately acute to acuminate, light colored.

Flesh nearly white with green or yellow tinge, fine, sprightly, rather crisp, moderately tender, juicy, aromatic, agreeable mild subacid, good.

Season for home use January to the last of June. 


\section{YELLOW NEWTOWN.}

This variety is described in connection with the Green Newtown on pages I 45 to I 52 .

\section{YORK IMPERIAL.}

References. I. Mag. Hürt., I9:210. 1853. 2. Horticulturist, 8:342. 1853. 3. Elliott, 1854:166. 4. Downing, r857:206. 5. Warder, r867:693. 6. Am. Pon. Soc. Cat., 1871:10. 7. Fitz, 1872:143. 8. Thomas, 1875:517. 9. Rural N. Y., 46:494. 1887. ro. Clark, Mo. Sta. Bul., 6:8. 1889. I1. Stayman, Aner. Gard., II:272. I890. fig. 12. Van Deman, U. S. Pom. Rpt., I891:389. col. pl. 13. Bailey, An. Hort., 1892:253. 14. N. Y. Sta. An. Rpt., 13:592. 1894. I5. Stinson, Ark. Sta. Bul., 43:104. I896. I6. Can. Hort., 19:84, 343. I896. fig. and col.pl. 17. Rural N. Y., 55:1, 190. 1896. 18. Wright, Amer. Gard., 17:33. I896. I9. Powell, Del. Sta. Bul., 38:20. 1898. 20. Taylor, U. S. Pom. Bul., 7:36r. 1898. 21. Massey, N. C. Sta. Bul., 149:318. 1898. 22. Rural N. Y., 57: 164, 178, 239. I898. 23. Taft and Lyon, Mich. Sta. Bul., 169:192. 1899. 24. Amer. Gard., 20:540. 1899. 25. Bruner, N. C. Sta. Bul., 21:130. 1900. col. pl. 26. Amer. Gard., $21: 76,372$. I900. 27. Can. Hort., 23:75, 249, 414. I900. 28. Beach, Western N. Y. Hort. Soc. Rpt., r900:37. 29. Rural N. Y., 59:450. 1900. 30. Brackett, Amer. Gard., 22:190. I901. 31. Alwood, Va. Sta. Bul., 130:142. 1901. fig. of tree. 32. Rural N. Y., 60:68, 406, 470. I901. 33. Stewart, Md. Hort. Soc. Rpt., rgor:73. 34. Munson, Me. Sta. Rpt., rgo2:91. 35. Dickens and Greene, Kan. Sta. Bul., 106:56. 1902. 36. Stinson, Mo. Fr. Sta. Bul., 3:27. I902. 37. Powell and Fulton, U.S.B.P. I. Bul., 48:62. 1903. 38. BuddHansen, 1903:213. fig. 39. Bruner, N. C. Sta. Bul., 182:27. 1903. figs. 40. Beach and Clark, N.Y. Sta. Bul., 248:152. 1904.

Synonym. Johnson's Fine Winter ( $1,2,3,4,6,8$, 12, 16, 20, 21, 24, 25, 28,3 I, 37, 38, 39, 40).

York Imperial is an important apple which is grown commercially in the Middle Atlantic states and over a belt of country extending from these states westward into Missouri and Kansas. The tree is a thrifty, vigorous grower and a pretty regular annual or biennial bearer. It seems to prefer rather heavy clay soils and seldom does well on soils that are light or in any way thin or leachy.

When properly developed the fruit is large, finely colored and of good quality. There are some objections to it on account of the shape of the fruit, which is oblique or lopsided, and consequently difficult to pare with a machine. Storage men give its season in cellar storage as extending to December and in cold storage to February. It stands heat fairly well before going into storage, but often scalds badly and when it begins to deteriorate goes down rather quickly. As grown at this Station the fruit comes in season in January and keeps well in ordinary storage till April or May if it 
does not scald. Its commercial limit is March. When grown as far north as this the fruit is deficient in color, size and quality. The reports from the growers in this state are generally adverse to its culture here and it is not recommended for planting in New York except perhaps in the southeastern part of the state.

Historical. The following excellent historical account of the York Imperial is given by Taylor (20). "The variety bearing this name originated early in the present century on a farm adjoining the then borough of York, Pa. The attention of the owner, a Mr. Johnson, was attracted to the tree by the presence of schoolboys who visited it in early spring to get the apples that had passed the winter on the ground, covered by leaves. On securing some of the fruit he found it in fine condition, and when the next crop was ripe took specimens to Mr. Jonathan Jessop, a local nurseryman, who began the propagation of the variety before 1830, under the name 'Johnson's Fine Winter.' Under this name it was known until after the middle of the century, when, after an inspection of specimens, the late Charles Downing pronounced it the 'imperial of keepers' and suggested that it be named 'York Imperial.' Mr. Jessop did not find ready sale for trees of the variety at first, and dumped the surplus trees from his nursery into a hollow beside the turnpike passing his place. They were picked up by farmers returning from market and taken home for planting on their farms in the lower end of York county. After its merit as a variety for market orchards was established, it became widely distributed throughout Pennsylvania, Maryland and Virginia, and soon became a leading market variety in those States. So far as known, the variety was first described in print by Dr. W. D. Brincklé in 1853 .

"Warder states that specimens of it were exhibited at the meeting of the Ohio State Pomological Society in I855, but it does not seem to have become generally popular west of the Alleghany Mountains until a comparatively recent date. Since about 1880 it has been widely disseminated through the Middle Western States and has become one of the leading market varieties of that region."

\section{TREE.}

Tree vigorous or moderately vigorous. Form upright spreading or roundish, rather dense. Twigs short to above medium, straight or nearly so, stout or moderately stout and tapering at the tips; internodes medium to long. Bark dull brownish-red streaked and mottled with scarf-skin, quite pubescent. Lenticels dull, moderately conspicuous, rather scattering, small to medium, roundish, not raised. Buds deeply set in bark, small to medium, plump, obtuse to somewhat acute, appressed except the largest which are free, pubescent.

\section{FRUIT.}

Fruit pretty uniform in size and shape. When it is well grown it varies from above medium to large, but in many parts of the state when the trees become mature the fruit usually averages below medium to small. Form roundish oblate or truncate, usually with an oblique axis. Stem short. Cavity medium to rather large, acuminate to acute, deep, medium to rather broad, often gently furrowed, smooth and green or partly russeted. Calyx small to 


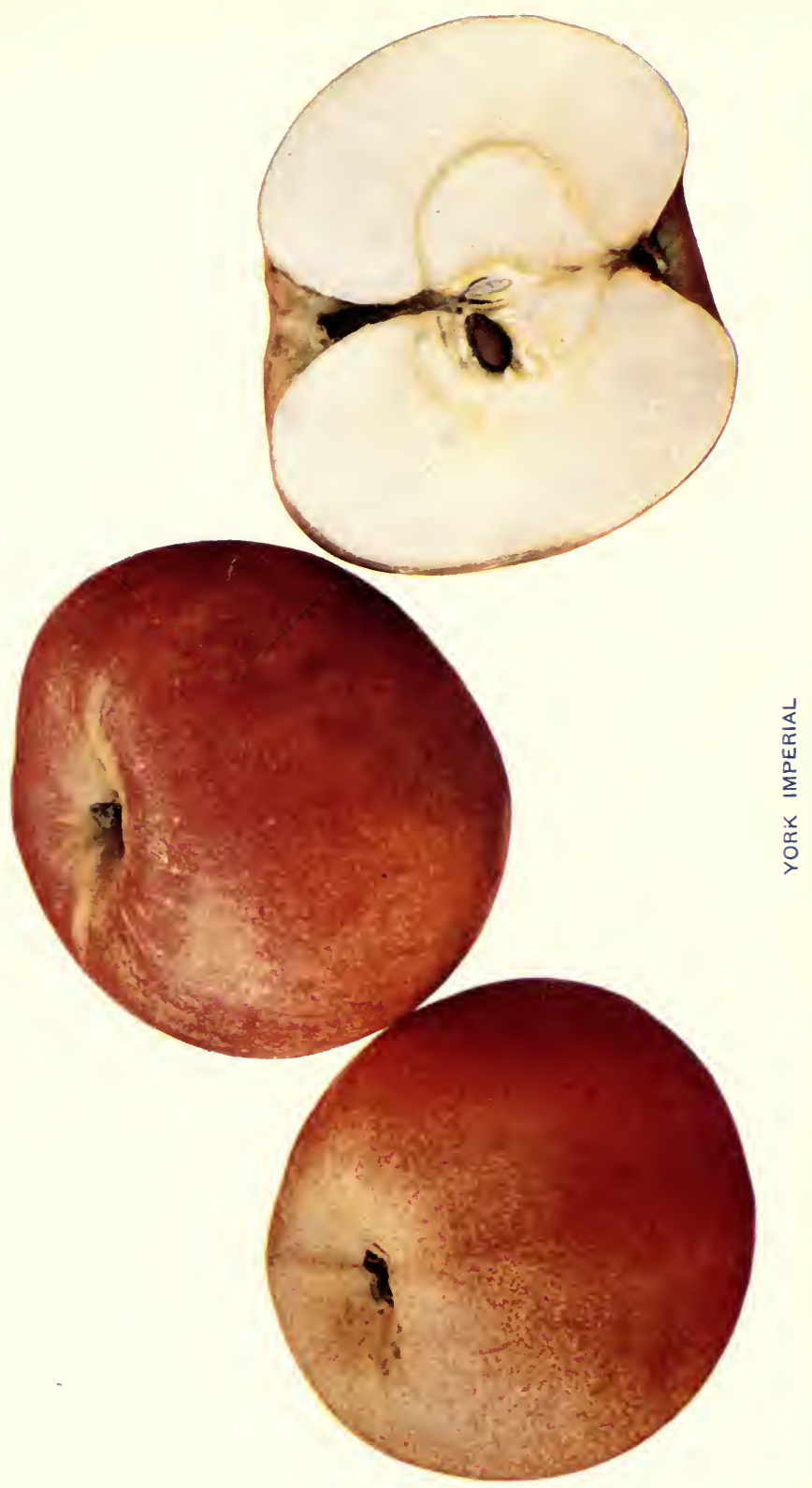



medium, closed or sometimes partly open. Basin rather large, abrupt, deep or moderately deep, wide to medium, often slightly furrowed.

Skin tough, bright, smooth, green or yellow blushed with moderately light red or pinkish-red and indistinctly striped with carmine. Dots pale or russet, often conspicuous, rather numerous toward the eye, scattering, very large and elongated toward the cavity where they are often mingled with narrow, broken streaks of grayish scarf-skin.

Calyx tube elongated cone-shape to funnel-form. Stamens median to marginal.

Core medium to rather small, axile or nearly so; cells usually symmetrical, closed or partly open; core lines slightly clasping. Carpels broadly roundish, slightly emarginate, sometimes tufted. Seeds few, rather dark, wide, flat, obtuse, compactly filling the cells; often some are abortive.

Flesh yellowish, firm, crisp, somewhat breaking, a little coarse, moderately tender, moderately juicy, at first sprightly subacid but becoming mild subacid or nearly sweet, somewhat aromatic, good to very good.

\section{ZURDEL.}

References. I. N. Y. Sta. An. Rpt., 8:356. i 889. 2. Burrill and McCluer, Ill. Sta. Bul., 45:345. I896. 3. Beach and Clark, N. Y. Sta. Bul., 248:152. I904.

Synonym. White Zurdel $(1,2)$. White Zurdel (3).

Fruit grass-green with dull blush somewhat like that of Rhode Island Greening. As grown at this Station it is hardly fair in quality. It is in season from January to April or May. It is worthy of mention only for the purpose of stating that it has no value for the New York fruit grower. 


\section{ERRATA - VOL.I.}

Page 24. Under Rhode Island Greening group, “Northwestern Greening” should be omitted.

25. Under Alexander group, "Bismark" should be "Bismarck."

71. Under Different Types of Ben Davis, in the last paragraph omit Rutledge.

76. Under Black Annette, second line, "I 1886 " should be " 1866 ."

95. First line of text, under Carlough, (2) should be (3).

IfI. Under Golden Medal, fourth line, reference "U. S. B. P. I. bulletin 56:124" should be "U. S. B. P. I. bulletin 56:125."

I68, Colored plate facing. Legend "Jacob Sweet" should be "Jacobs Sweet."

196. McAfee, first line of second paragraph, insert $(\tau)$. between Indian and Wyandotte; Wyandotte (7). should precede Zeeke on p. 197 .

270, Colored plate facing. "Genet," in italic should be omitted.

333. Under Sweet Russet all of the second line, including the words "Synonym" and "Summer Russet (I)," should be omitted.

392. Twenty-sixth line, second column, "Bismark" should be "Bismarck."

403. "Pomme Grise," first column, fifteenth line, should be roman instead of italic.

409. Eighth line from bottom of left column, "Winter Sweet Paradise" should be roman capitals and small capitals instead of italic.

\section{ERRATA-VOL. II.}

Page 222. Under Thompson, paragraph 3, line 2, "Season late winter" should be "Season early winter."

245. Eighth line from bottom, last word, "sometimes" should be "somewhat."

28I. Second paragraph, insert "to $98 \mathrm{I}$ inclusive," so that the sentence will read: "The following numbers to $98 \mathrm{I}$ inclusive are those given the varieties included in the Department of Agriculture importations of 1870 ."

282. "Number 2I Veronesh" should be "No. 2I Voronesh." 


\section{INDEX TO TECHNICAL TERMS.}

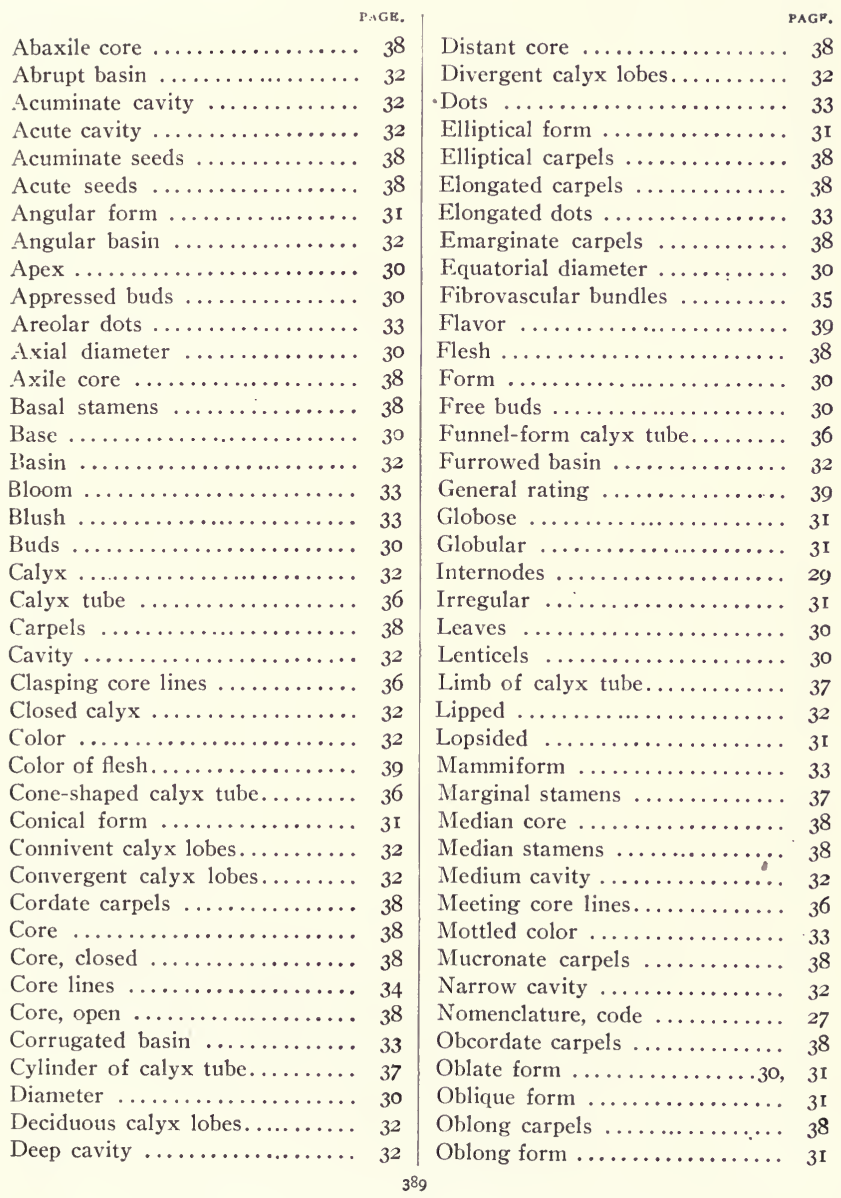


Index to Technical Terms.

\begin{tabular}{|c|c|}
\hline Obtuse basin $\ldots \ldots \ldots \ldots \ldots \ldots$ & Size $\ldots . . . \ldots \ldots \ldots \ldots \ldots \ldots \ldots$ \\
\hline btuse cavity $\ldots \ldots \ldots \ldots \ldots \ldots$ & Skin...$\ldots \ldots \ldots \ldots \ldots \ldots \ldots \ldots \ldots$ \\
\hline Obtuse seeds $\ldots \ldots \ldots \ldots \ldots \ldots$ & Splashes...$\ldots \ldots \ldots \ldots \ldots$. \\
\hline Open calyx $\ldots \ldots \ldots \ldots \ldots \ldots$ & 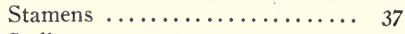 \\
\hline Ovate form $\ldots \ldots \ldots \ldots \ldots \ldots$ & Stellate ................... \\
\hline Pistil point $\ldots \ldots \ldots \ldots \ldots \ldots$. & Stem $\ldots \ldots \ldots \ldots \ldots \ldots \ldots \ldots \ldots$ \\
\hline Pubescence...$\ldots \ldots \ldots \ldots \ldots$. & Submerged dots $\ldots \ldots \ldots \ldots \ldots$ \\
\hline Radiating $\ldots \ldots \ldots \ldots \ldots \ldots$ & Suture $\ldots \ldots \ldots \ldots \ldots \ldots \ldots \ldots$ \\
\hline Rating, general ............. & trical.......... \\
\hline Reflexed calyx lobes........... & Symmetrical basin...$\ldots \ldots \ldots$ \\
\hline Regular basin ............. & Texture $\ldots \ldots \ldots \ldots \ldots \ldots \ldots$ \\
\hline Regular form $\ldots \ldots \ldots \ldots \ldots \ldots$ 3r & Тор $\ldots \ldots \ldots \ldots \ldots \ldots \ldots \ldots \ldots$ \\
\hline Ribbed $\ldots \ldots \ldots \ldots \ldots \ldots \ldots \ldots \ldots \ldots \ldots \ldots$ & Transverse diameter...$\ldots \ldots$. \\
\hline Ribbed basin ............... & Truncate form...$\ldots \ldots \ldots \ldots$ \\
\hline Ridged basin $\ldots \ldots \ldots \ldots \ldots \ldots \ldots \ldots \ldots \ldots$ & Tufted carpels...$\ldots \ldots \ldots \ldots$ \\
\hline Round form $\ldots \ldots \ldots \ldots \ldots \ldots$ & Twigs $\ldots \ldots \ldots \ldots \ldots \ldots \ldots \ldots$ \\
\hline Roundish carpels $\ldots \ldots \ldots \ldots \ldots$ & Uniform shape $\ldots \ldots \ldots \ldots \ldots$. \\
\hline Russet skin $\ldots \ldots \ldots \ldots \ldots \ldots \ldots$ & Uniform size $\ldots \ldots \ldots \ldots \ldots \ldots$ \\
\hline Scarf-skin $\ldots \ldots \ldots \ldots \ldots \ldots \ldots$, & Use $\ldots \ldots \ldots \ldots \ldots \ldots \ldots \ldots \ldots$ \\
\hline 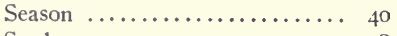 & Vertical diameter ............ \\
\hline n....................... & Wavy basin ................ \\
\hline sile core $\ldots \ldots \ldots \ldots \ldots \ldots \ldots, \quad 38$ & Waxen $\ldots \ldots \ldots \ldots \ldots \ldots \ldots \ldots$ \\
\hline Self-colored .................. & in $\ldots \ldots \ldots \ldots \ldots \ldots \ldots$ \\
\hline Shallow cavity $\ldots \ldots \ldots \ldots \ldots \ldots, 32$ & Wide cavity $\ldots \ldots \ldots \ldots \ldots \ldots \ldots$ \\
\hline
\end{tabular}




\section{INDEX TO VARIETIES.}

(Accepted names appear wholly or in part in roman type; synonyms in italic.)

\begin{tabular}{|c|c|}
\hline berdeen ................. 227 & American Newtown Pippin...... 146 \\
\hline ccidental ................. 227 & American Nonparcille......... I6 $\mathrm{I}$ \\
\hline cuba-leaf Reinette.......... 52 & American Pippin $\ldots \ldots \ldots \ldots \ldots \quad 45$ \\
\hline cuba-leaved Reinette......... 52 & American Seek-No-Further..... 273 \\
\hline sopus Spitzemberg.......... 120 & American Summer Pearmain.... 15 \\
\hline sopus Spitzenberg........... 120 & Амов..$\ldots \ldots \ldots \ldots \ldots \ldots \ldots \ldots \ldots$ \\
\hline sopus Spitzenburg .......... 120 & Amos Jackson............... \\
\hline sopus Spitzenburgh......... I20 & ANDREWS $\ldots \ldots \ldots \ldots \ldots \ldots \ldots \ldots$ \\
\hline$n \ldots \ldots \ldots \ldots \ldots \ldots \ldots \ldots \ldots \ldots \ldots \ldots$ & Andrews Winter............. \\
\hline ikin's Red.................. & Anis $\ldots \ldots \ldots \ldots \ldots \ldots \ldots \ldots \ldots \ldots$ \\
\hline ns Winter (of Downing).... & hi \\
\hline 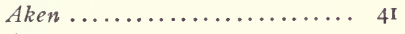 & Api eller.... \\
\hline 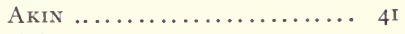 & 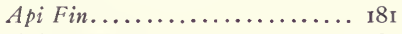 \\
\hline$d \ldots \ldots \ldots \ldots \ldots \ldots \ldots$ & $\ldots \ldots \ldots \ldots \ldots \ldots$ \\
\hline 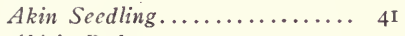 & Api Petit.................... \\
\hline 's Red................... & 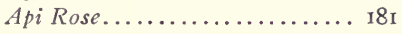 \\
\hline Seedling.............. 4I & $e \ldots \ldots \ldots \ldots \ldots \ldots \ldots \ldots \ldots$ \\
\hline arle $\ldots \ldots \ldots \ldots \ldots \ldots \ldots \ldots$ & JP..............20, \\
\hline rle Pippin...........18, 146 & le of Commerce............. \\
\hline ANDER.......I7, $18,20,25$ & Apple of the Well........... 363 \\
\hline ANDER GROUP. . . . . . . 25 & Rouge............... $8 \mathrm{x}$ \\
\hline$\ldots \ldots \ldots \ldots 227$ & rIc $\ldots \ldots \ldots \ldots \ldots \ldots \ldots \ldots$ \\
\hline$\ldots \ldots \ldots \ldots \ldots, 42$ & ARKANSAS ................24, \\
\hline ngton Pippin............. $4^{2}$ & sas Baptist.............. 140 \\
\hline$\ldots \ldots \ldots \ldots \ldots, 43$ & ansas Beauty . .......... 49 \\
\hline Almindelig $\ldots \ldots \ldots \ldots \ldots \ldots$ I $8 \mathrm{I}$ & Arkansas Black..........24, \\
\hline IA $\ldots \ldots \ldots \ldots \ldots \ldots \ldots \ldots, 44$ & Arkansas Black (synonym of \\
\hline an Beauty (synonym of & 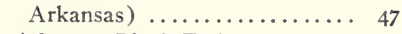 \\
\hline terling ) ..............45, 319 & Arkansas Black Truig........47, \\
\hline American Beauty (synonym of & 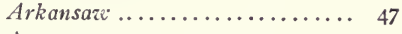 \\
\hline ............ 308 & \\
\hline RICAN Blush........... 45 & Arnold's Beauty............ \\
\hline rican Blush............. 16 & Arsapple .................. \\
\hline American Golden Russet....... 89 & ARthUR $\ldots \ldots \ldots \ldots \ldots \ldots \ldots \ldots \ldots \ldots \ldots \ldots$ \\
\hline $\begin{array}{l}\text { American Golden Russet of New } \\
\text { England ............... I }\end{array}$ & 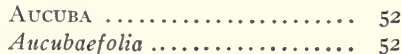 \\
\hline
\end{tabular}




\begin{tabular}{|c|c|}
\hline & \\
\hline Aunt Dorcas................ 145 & Bellflower ... \\
\hline Austin .................. 236 & Bellyband ................... \\
\hline utuma Bough $\ldots \ldots \ldots \ldots \ldots$ I 5 & BeLmont $\ldots \ldots \ldots \ldots \ldots \ldots \ldots$ \\
\hline Iutumn Pearmain............ 378 & $\begin{array}{l}\text { Belmont Late................ } 67 \\
\text { Bclpre Russ.t............. } 293\end{array}$ \\
\hline APBITT $\ldots \ldots \ldots \ldots \ldots \ldots \ldots \ldots \ldots \ldots \ldots$ & Ben Davis.....17, 18, 19, 21, 24, 68 \\
\hline Bachelor ................. 88 & Bentley $\ldots \ldots \ldots \ldots \ldots \ldots \ldots \ldots$ \\
\hline Back Creck.................. 146 & Bentley's Swect................ \\
\hline Bacr ..................... ${ }^{5} 8$ & Bcntley Sweet.................. \\
\hline cy's Golden Siveet.......... 54 & Bergen $\ldots \ldots \ldots \ldots \ldots \ldots \ldots \ldots \ldots \ldots \ldots \ldots \ldots$ \\
\hline Bailey Sicect $\ldots \ldots \ldots \ldots \ldots \ldots$. 54 & Berry $\ldots \ldots \ldots \ldots \ldots \ldots \ldots .227$ \\
\hline Bailcy Sw'ect................ & Bersford .................... 269 \\
\hline Bailey Sacet (synonym of Sweet & Bess Pool $\ldots \ldots \ldots \ldots \ldots \ldots \ldots \ldots \ldots \ldots$ \\
\hline Winesap) $\ldots \ldots \ldots \ldots \ldots \ldots, 333$ & Best Pool................ 72 \\
\hline BAKER $\ldots \ldots \ldots \ldots \ldots \ldots \ldots \ldots \ldots \ldots \ldots$ & Bethel ............ 19, 24, 72, 32I \\
\hline BALDWIN . I2, 15, 17, $18,19,24,32$ & HLEHEMite $\ldots \ldots \ldots \ldots \ldots \ldots .74$ \\
\hline livin Rosenapfel........... 56 & ite $\ldots \ldots \ldots \ldots \ldots \ldots \ldots \ldots$. 74 \\
\hline Rother Pippin....... 56 & (synonym of Nickajack) 227 \\
\hline$l e \ldots \ldots \ldots \ldots \ldots \ldots 250$ & )...269 \\
\hline$\ldots \ldots \ldots \ldots \ldots \ldots 292$ & nanite (synonym of Grey- \\
\hline ippin ........... 69 & ) $\ldots \ldots \ldots \ldots \ldots \ldots \ldots \ldots{ }^{153}$ \\
\hline$d \ldots \ldots \ldots \ldots \ldots \ldots 69$ & Pen- \\
\hline treak.......... 69 & $\ldots \ldots \ldots \ldots \ldots 255$ \\
\hline$\ldots \ldots \ldots \ldots 377$ & s $\ldots \ldots \ldots \ldots \ldots \ldots \ldots \ldots$ \\
\hline T. . . . . . . .60, 377 & Pippin of Nova Scotia.. 38I \\
\hline sт $\ldots \ldots \ldots \ldots \ldots \ldots \ldots$ 6r & 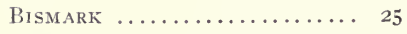 \\
\hline L $\ldots \ldots \ldots \ldots \ldots \ldots \ldots \ldots \ldots \ldots \ldots$ 6r & merican................ \\
\hline burgh.........225 & Annette. . . . . . . . . . \\
\hline $\mathrm{R} \ldots \ldots \ldots \ldots \ldots \ldots \ldots \ldots, 62$ & 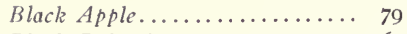 \\
\hline$\ldots \ldots \ldots \ldots \ldots \ldots \ldots \ldots 6_{3}$ & Baldzin ............... \\
\hline ellor ................. 88 & 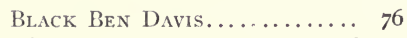 \\
\hline$\ldots \ldots \ldots \ldots \ldots \ldots \ldots 6_{4}$ & Black Bin Davis (synonym of \\
\hline$\ldots \ldots \ldots \ldots \ldots \ldots \ldots 6_{4}$ & Gano) ............... I35 \\
\hline${ }^{\prime}{ }^{\prime} s \operatorname{Red} \ldots \ldots \ldots \ldots \ldots \ldots 6_{4}$ & Blackburn ............... 88 \\
\hline$\ldots \ldots \ldots \ldots \ldots \ldots \ldots \ldots 66$ & Black Gilliflower, ...12, 16, I7, I8 \\
\hline$\ldots \ldots \ldots \ldots 324$ & \\
\hline$\ldots \ldots \ldots+45,319$ & Black Jack...... \\
\hline$\ldots \ldots \ldots \ldots .26_{4}$ & sey..... \\
\hline$\ldots \ldots \ldots \ldots \ldots, 75$ & Y Apple......... I 82 \\
\hline$\ldots \ldots \ldots \ldots 75$ & $\ldots \ldots \ldots \ldots$ r53 \\
\hline$\ldots \ldots \ldots .290$ & Black Spitz................. 77 \\
\hline$\ldots \ldots \ldots \ldots 67$ & Black Spitzcnberg........... I32 \\
\hline$\ldots \ldots \ldots \ldots \ldots 26_{4}$ & $y \ldots \ldots \ldots \ldots \ldots \ldots \quad 189$ \\
\hline$\ldots \ldots \ldots \ldots \ldots 38 \mathrm{r}$ & Black Saect.............. 219 \\
\hline$\ldots \ldots \ldots \ldots 3^{8} \mathrm{I}$ & Black Taitig............. \\
\hline jaunc............. $38 \mathrm{I}$ & Black Vandervere............... I53 \\
\hline ... $38 \mathrm{I}$ & Black Vandevere............. I53 \\
\hline Improved.. & Blair .................. \\
\hline${ }^{c} r \ldots \ldots \ldots \ldots \ldots 3^{8}$ & Blue Baldwin ............... \\
\hline
\end{tabular}


PAGE.

PAGE.

Blue Pearmain .....17, 18, 19, 24, S5

Blue Pearmain group......... 24

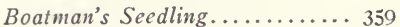

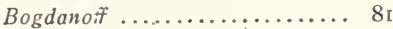

BogdanofF GLASS............ 8 $8 \mathrm{I}$

Bogdanoff's Glass............. 8r

BoIkeN .................. 82

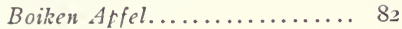

Boikenapple............... 82

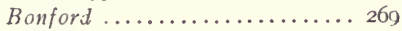

Borovitsky ................ 25

BorSDORF ...................... $8_{3}$

Borsdorfer .................. 8 8

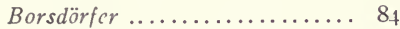

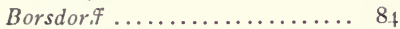

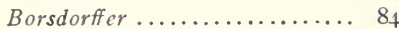

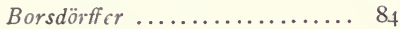

Boston Russet.............. 85

Boston Russet (synonym of Rox-

bury) $\ldots \ldots \ldots \ldots \ldots \ldots \ldots .293$

Bottle Greening ..........24, 85

Boucken ............................. 86

Bough Sweet ...........12, 15, I6

Bower's Apple.............. 329

Boys Delight............. 86

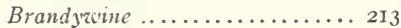

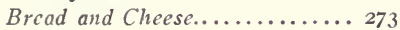

Bristol ................... 86

Bristol (synonym of Red Canada) 276

Broad Ricer................. 289

Brooke Pippin.............. I46

Brozun's Golden Sweet........ 343

BrownleEs ............... 86

Brownlei's Russet............ 86

Brou'nlecs' Secdling Russet..... 86

Brown SWEET.............. 87

Buckingham ............... 88

Buler.................... I74

Bullock .................. I5, 89

Bullock (synonym of Hunt Russet) $\ldots \ldots \ldots \ldots \ldots \ldots \ldots \ldots \ldots \ldots \ldots \ldots$

Bullock's Pepping.............. 89

Bullock's Piptin (synonym of Bullock) .................

Bullocks Pippin (synonym of Ewalt ) ................ I24

Burlington ................. 225

Burlington Greening.......... 282

Burlington Spitzemberg........ 225
Burlington Spitzcnberg........ 225

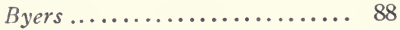

Byers Red................ 88

Cabashea (Winter)......9I, 176

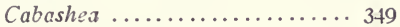

Calcille Butter............... 56

Campfield ................. 9I

Canfield .................. 9I

Canada Baldwin.........25, 92

Canada Pippin (synonym of Canada Reinette)........... 93

Canada Pippin (synonym of

White Pippin)............ 368

Canada Red (synonym of Red

Canada) .................276

Canada Red (synonym of Ro-

seau) .................. 292

Canada Redstreak........... 276

Canada Reinette..........32, 93

Canadian Reinctte............ 93

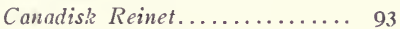

CAnnon Pearmain ........... 95

Cannon Pearmain............. 95

Capp Mammoth............. 206

Cardinale .................. I8 $\mathrm{r}$

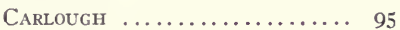

Carnation Apple.............. 96

Carolina .................. 227

Carolina Red Streak.......... 69

Carolina Spice.............. 227

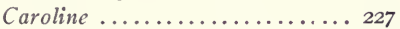

Carpentin ................... 96

Carpentin Reinette........... 96

Carthouse................... I 38

Caux.................... II4

CAYWOOD ................... 96

Chaltram Pippin............ 227

Champion ................. 99

Champion Red.............. 99

Charles Apple.............. 199

Chase .................... 166

Chatham Pippin............. 227

Cheat (synonym of Domine)... I09

Cheat (synonym of Wells) .... 363

Cheatan Pippin............. 227

Cheataw ...................227

Christmas Apple.............. I8I

Christ's Golden Reinette......... II4 
Choice Kentuck............... 3I I

Cider ..................... 3II

Cider Apple................. 3I I

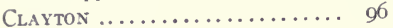

Cling Tight................ 109

Clothes-yard Apple............ I45

Coffelt .................. 97

Coffelt Beauty.............. 97

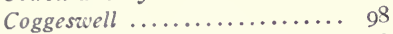

Cogswel. .................. 99

Cogswell Pearmain............ 99

Cogswell's Pearmain........... 98

Colliss .................. 99

Collins' Red................ 99

Combermere Apple........... 200

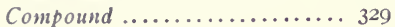

Conford ...................269

Connecticut Seek-No-Further... 364

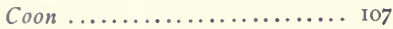

Coon Red................. Iо

Cooper ...................... I6

CoOper MARKet .............. IOJ

Cooper's Market.............. IOI

Cooper's Red (synonym of

Cooper Market) ............ IOI

Cooper's Red (synonym of Etowah) ............... I 23

Cooper's Redling............. I0I

Copmanthorpe Crab........... II

Cornell's Sairewell............ 299

Cornish Gilliflower.......... I 38

Coss Champion.............. 99

Coss's Champion............. 99

Cranberry Pippin............ 300

Crane's Pippin............... 24

Crotts .................... 102

Crowss .................. 102

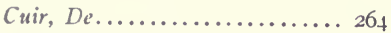

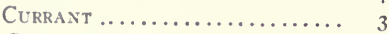

Curtis Grecning..............3

Dahlonega................227

Dame de Menage............ 206

Daviers Swcet .............. 103

Danvers Swcet.............. 103

Danvers Winter............... 103

Danvers Winter Sweet........15, 103

Dark Balda'in.............. 60

Deacon Jones............... 104
PAGE.

De Bretagne................ 93

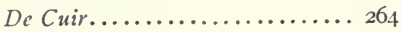

Deiltz ................. 20I

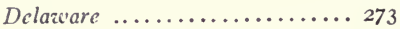

Delac'are Red Winter......... I 89

Delaciare Winter............ I 89

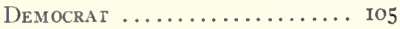

Dept. No. $410 \ldots \ldots \ldots \ldots \ldots \ldots .282$

Dept. No. $418 \ldots \ldots \ldots \ldots \ldots \ldots .282$

Dept. No. $467 \ldots \ldots \ldots \ldots \ldots \ldots$ 6r

Der Carpentin.............. 96

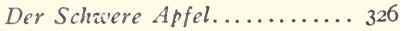

Detroit .................. 244

Detroit ReD............... I2

Detroit of the West.......... 244

Derit Apple................ 107

De $\|$ itt.................. 107

Dickenson ................. 106

Dickinson ................. 106

Die Haarlemer Reinette........ 93

Dic Veiberreinette.......... 93

Disharoon ................ I07

Doctor ................. 17, 107

Doctor Dewitt.............. I07

Doctor WaLker.............. I08

Dodge's Black............... 79

Domine ................. 109

Domine (synonym of Wells?) ... 363

Dominie .................. I09

Doppelte Casseler Reinette...... II 4

D'Or d'Angleterre........... I4I

Double Rose................ I I

Downing Winter Maiden Blush. . 152

Du Bors ................ I I I

Ducks Bill............................ 378

Duitsch Mignonne........... 114

Duke of Devonshire.......... III

Duke of Wellington......... II 2

DuMELOW ................ II 2

Dumelow's Crab............. II 2

Dumelow's Pippin............ I12

Dumelow's Seedling.......... II 2

Duncan ................. II3

Durable Trois ans........... I 16

Dutch Greening............. 253

Dutch Mignonne .........32, 14

Dutch Minion.............. I14

Duzenbury .............. I I5 
PAGE.

EARLY ChandLER............ I6

EARLY HaRVEST........... I5, I7, I8

EARLY Strawberry.......... I5, I7

Edelborsdorfer ............. 84

Edgar County Red Streak...... 357

Edgar Rcd Strcak........... 357

Edgar Redstreak............ 357

Edgerly's Sweet............ 5t

Edgerly Sweet............. 5t

EDWARDS ............... II5

Edwards (synonym of Nickajack) ................ 227

Edwards Faworite............ II5

Edward Shantee........... 227

EISER .................. II6

Eiser Rouge............... I 6

ElLsworth .............. II7

English Beauty of $\mathrm{Pa} . . . . . .$. IOg

English Golden............. I43

English Golden Pippin......... I4I

English Golden Russet........ I43

English Pearia Ain.......... í

English Pippin............ I42

English Rambo (synonym of Domine)

English Rambo (synonym of Wells ) ................. 363

English Red Streak (synonym of Domine)

English Red Streak (synonym of Redstreak)

English Red Streak (synonym of

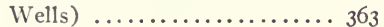

English Redstreak........... 278

English Russet ............. II8

English Russet (synonym of Long

Island Russet I) . . . . . . . . . . I94

English Spitzemberg.......... 225

English Spitzenberg.......... 225

English Vandevere........... 312

English Winter Red Streak

(synonym of Domine) ....... I09

English Winter Red Streak

(synonym of Wells) ........ 363

Eppes Sweet................ 103

Epse's Sweet............... 103

Equinetely ............... 88

Esopus ................. 120

Esopus Spitzemberg.......... I2I
Esopus Spitzenberg........... I2I

Esopus Spitzenberg (Nerv)..... I72

Esopus Spitzenburg...12, I5, 16, 17

I\&, 19, 24, I20

Esopus Spitzenburg........... I2I

Esopus Spitzcnburgh.......... I2I

Eтошан ................ 123

Etowal (synonym of Cooper

Market) ............. Ior

Etris ................. I23

Evening Party ............ 123

Ewalt ................... 124

Faldwalder .............. 125

FALIX ................. 125

Fallawater ........... I8, 32, I25

Fall de Vildes............. 125

Fallenwalder ............... 125

FAll PiPPiN.....12, I5, I6, 17, 18, 24

FALL PiPPin GROUP.......... 24

Fall Queen................ 88

Fall Queen of Kentucky....... 88

Fall Romanite............. 273

Fall Winesap.............. 89

FameUse....I5, 16, I7, 18, 19, 23, 25

FAMEUSE GRoup...........20, 25

FAMILY ................ I27

FARRIS .................. I 28

Faust's Rome Beauty.........290

Fay's Russet................ I64

Felch ................. 56

Femme de Menage........... 206

Ferdinand ............... I29

Ferris .................. I30

Fenilles $D^{\prime}$ Aucuba.......... 52

Filliken ............... I53

Fine Winter............. 373

Fink ................... 336

Fink's Secdling............ 336

Fish kil. ................ 32

Flanders Pippin............ 206

Flat Spitzenburg........... 345

Florence ................ I30

FLORY ................. I3I

Flory Bellfower............ I3I

Flory's Bellflower............ r3I

Flushing (synonym of Flushing

Spitzenburg) ........... 132 
Flushing (synonym of Newtown

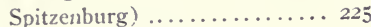

Flushing Spitzcnberg.......... 132

Flushing Spitzcnburg........ 132

Flushing Spitzenburg......... I 32 Flushing Spitzenburg (synonym of Roseau).............. 292

Flushing Spitzcnburgh....... 132

Forest .................. I3,

Fornwalder ................ 125

Forsythe's Seedling........... 227

Fowler ................... 3I I

FrakeR .................. I33

Fraker's Secdling........... I33

Frankfort Quccn............. 83

Frenchi PipPIN ..........24, 134

French Pippin (synonym of

Newark Pippin) ........... 223

French Russet............... 264

French Spitzenburg of Vt...... 292

Fuller .................. $31 \mathrm{I}$

Funkhouser............... 69

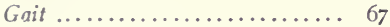

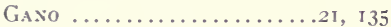

Gate..................... 67

Gay's Romanitc................ 255

Gelber Belleflcur............. $38 \mathrm{I}$

Gelber Fnglischer Scliönbluhen-

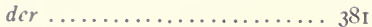

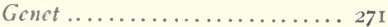

Geneton .................. $27 \mathrm{I}$

Geneva Pippin............... I 36

Geniton .................. $27 \mathrm{I}$

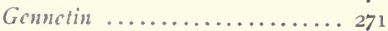

Genneting ............... $27 \mathrm{r}$

Gennetting ................. 27 I

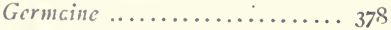

German Green............ 93

German Spitzenberg.......... 153

Gibbons Smokehousc.......... 312

GideoN SwEET .............4, I37

Gillet's Scedling............ 290

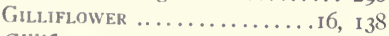

Gilliflower ................... 77

Gilpix ...............

GiNet ..................... $27 \mathrm{I}$

Givens ..................

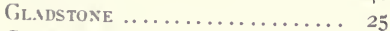

GlenLoc11 ............... 140
Golden Gray................ 328

Golden Medal .............. I 4 I

Golden Pippin............ I6, I4I

Golden Pippin (synonym of Belmont ) ................ 67

Golden Pappin (synonym of Ort-

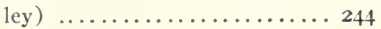

Gol.den RED............... I4 4

Golden Reinette............ I42

Golden Rennet.............. 142

Golden Russet.......17, I8, I43, 295

Golden Russet (synonym of Bullock) ................. 89

Golden Russet (synonym of Perry Russet)............. 257

Golden Russct, Amcrican....... 89

Golden Russet (not of N.Y.)... I64 Golden Russet of Mass.......... I64 Golden Russet of New England. I64 Golden Russet of N. Y....... I43 Golden Russet of Western New York .................. I43

Gold Medal................ I4

Goziden .................. 227

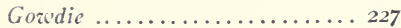

Graham's Red Warrior......... 227

Grand Duke Constantine..... 25

Grandmother's Apple......... 145

Granite Beacty ............ I 45

Gravenstfin ......12, I5, 17, 18

Gray Apple (synonym of McAfee $) \ldots \ldots \ldots \ldots \ldots \ldots \ldots \ldots$ Gray Apple (synonym of Pomme Grise ) ................26t

Gray Baldwin ................ 60

Grayhouse ................ 153

Gray Romanite (synonym of Greyhouse) ............ 153 Gray Ramanitc (synonym of

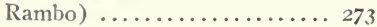

Gray's Kecper.................. 196

Greasy Pippin............... 244

Great Barbe................. I 45

Great Pearmain........................... 378

Grecn Bellflower.............. 244

Greening ...............145, 282

Green Mountain Pippin (synonym of Fallawater)....... 125 
Green Mountain Pippin (synoGreen Mountain Pippin (synonym of Virginia Greening)... $35^{2}$ Green Newtown...17, 18, 24, 145, I49 Green Newtown Pippin........ I 46 Green Neatown Pippin (synonym of Rhode Island Greening) ................ 282

Green Pippin.............. I6

GREen SweEt .............. I5

Green Siceet (synonym of Repka Malenka ) ...............232 Green Sweeting ............ I5 I Green Sweeting (synonym of Green Sweet)............ I5I

Greenville ............... I52

Green Winter Pearmain........ 378

Gree'n Winter Pippin.......... 146

Greyilouse ................ I5

Grimes ............ 8 , I'), 23, I53

Grimes Golden.............. I5t

Grimes Golden Pippin.......... I5t

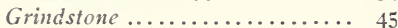

Grise .....................254

Gros Api Rouge.............. I8I

Gros Rambour d'Hicer.......... 256

Grosse Casselar Reinette........ II 4

Grosser Casselar Reinette....... II 4

Grosse Reinette d'Angleterre.... 93

Gul. Bellefleur................. $3^{8 \mathrm{I}}$

Hampshire Greening.......... 282

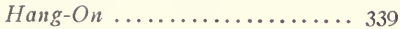

Hard Red.................. I I53

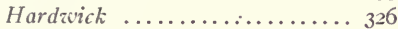

HaRgRove ................... I 55

Harrigan ................. 208

Haus Mütterchen............. 206

H.WLEY ................. 5 , 24

Hays .................... 373

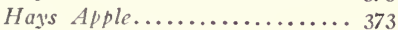

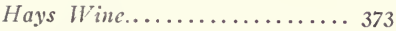

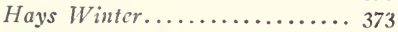

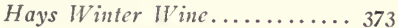

HaYwoOn ................... I55

HAZEN ................... I56

Heaster ..................... 158

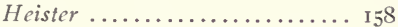

Helen .................. I 83

Hempstead ................ $32 \mathrm{I}$
PAGE.

Hendrick ............... 333

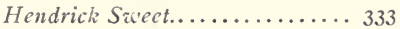

HenNiker .................. ${ }^{156}$

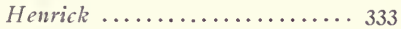

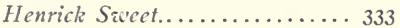

Henry Sweet.............. 333

Henshaw ................ 88

HEREFORDSHIRE ............. I 57

Herefordshire Beefing......... I57

Herefordshire Pcarmain........ 378

Herefordshire Red Streak...... 278

Hercfordshire Redstreak....... 278

Hertfordshire Pcarmain....... 378

Hibernat ................. 26

Hiester ................. I 58

Highland Beauty.......... I59, i 83

Hogan ................... 109

Holland Pippin (synonym of

Domine ) ............... 109

Holland Pippin (synonyn of

Holland Winter)........... I59

Holland's Red Winter......... 375

Holland Winter............. I59

Hollow Cored Pippin.......... 244

Hollow Core Pippin.......... 244

Hollow Crown Pearmain....... 373

Holmes ................. I6

Hol.mes SweEt.............. I6

Honey Greening............. 6 , I5 I

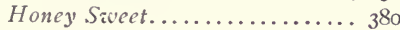

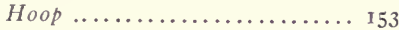

Hoopes .................. $\mathrm{I}_{53}$

Hoopes Pearmain............. I53

Hoops ................... 153

Hopsey ................... I53

Hopson ................... I53 $_{53}$

House .................. ${ }_{153}$

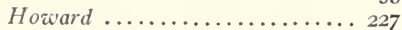

Howard's Swcet............ 54

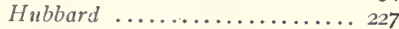

Hubbardston ........... 17, I8, I6r

Hubbardston Nonsuch (synonym of Hubbardston)........... I6I

Hubbardston Nonsuch (synonym

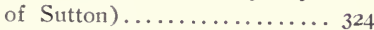

Hunt Russet. .............. I64

Hunt's Fine Green Pippin....... I46

Hunt's Green Newtow'n Pippin... I46

Huntsman .............. 18 , 65 
PAGE.

Huntsman's Favorite......... I65

Hyde King. ................ I66

Hyde's King (of the West).... I66

Illinois Greening.......................

Indian ................... 195

Indiana Jannetting.......... $27 \mathrm{I}$

Ingraham ............... I67

INGRAM $\ldots \ldots \ldots \ldots \ldots \ldots 24,167$

Ingram Seedling........... I67

Inman ................... 244

Isle of Wight Orange........ 202

Isle of Wight Pippin.......... 202

JACKSON ................. I68

Jackson (synonym of Amos).... 46

Jackson Red............... 227

Jackson Scedling............. I68

Jackson Winesap................ 3I I

Jacks Red................ I 35

Jacobs ...................... I69

JACoBs SweET. .............. I69

Jacobs Winter Sweet........... I69

James Rizer (synonym of Lim-

bertwig) ............... I93

James Rizer (synonym of Willow)

370

Janet ................... 27I

Janetting ................ $27 \mathrm{I}$

Januarea ................. 93

Jefferson Pippin...............27 I

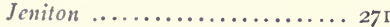

Jennett ................27

Jennette ................ $27 \mathrm{I}$

Jenniton ................ 27 ז

Jersey Black.............. 79

Jersey Greening (synonym of

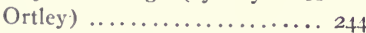

Jersey G̈reening (synonym of

Rhode Island Greening) ..... 282

Jersey SweEt .............. I2

Jewett Red.............. I9, I70

Jeziett's Fine Red............. 170

Jenvett's Red................ I70

Joe Berry.................. 225

Johnathin ............... I72

John May................. I6

Johnson ................. 278

Johnson's Fine Winter. ........ 385
PACR.

JoNATHAN.......17, I8, 24, 32, 172

Jonathan Buler............ I74

Jonathan of Buler........... I74

Jones Secdling.............. 43

Josic Moore................ 2 I9

KAIGHN ................. I 83

Kanada Reinctte............................. 94

Kanada-renett............... 93

Kansas ................. 175

Kansas Greening........... I75

Kansas KeEPER ............ 175

Kelley's Sweet.............. 219

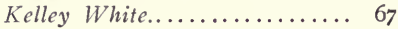

Kent Pippin............... I6

Kentucky Pippin............. 69

Kentucky Queen............. 88

Kentucky Red Streak......... 357

Kentucky Streak............. 69

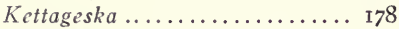

Keystone ................. I53

King (synonym of Buckingham) 88

King (synonym of Tompkins

King) $\ldots \ldots \ldots \ldots \ldots \ldots 176,345$

King (synonym of Twenty Ounce

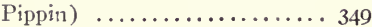

King Apple................ 345

King George the Third........ 84

King of Tompkins County..... 345

King Philip.............. 172

Kinnaird .............. I8, I76

Kinnaird's Chcice............ I76

Kinnaird's Favorite........... 176

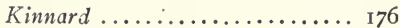

Kinnard's Choice........... I76

Kirkes Golden Reinette........ I42

KirkLAND .............. I I77

Kittageshee ............ I8, I78

Kleine Graue Reinette......... 96

Kleiner Api................ I8I

Kountz .................225

LACKER ................. I79

Lacquier .................. 179

Lac Victoria Seedling........... 188

Ladies Favorite of Tennessee... 88

Ladics Sweet.............. I84

Ladies' Srveet................ 333

Ladies Sweeting............ I84 
LADY ............. I5, I7, 32, I80

Lady Apple................ I8I

LADY Finger .............. 183

Lady Finger (synonym of

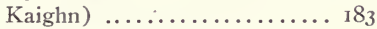

Lady Finger Pippin........... 183

LADY GROUP................ I8.2

Lady Henniker.............. 156

Lady Pippin................ 66

LAdy SeEdlings ............ I 83

Lady's Sweet................ I84

Lady's Srveeting............. $18_{4}$

LADY SwEET............... I8t

Lady Sweet (synonym of Sweet

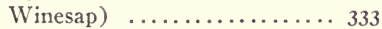

Lady Sweeting.............. 333

Lady Washington.............. 38I

Lambertwig ................ 193

LANDON .................... I85

Lane Albert............... 268

Lane Prince Albert............ 263

Lane's Prince Albert........... 268

Langford .................. I 86

LANKFORD ................ I8, 86

Lankford's Seedling............ I86

Lansinburg ................ I 88

LANSINGBURG .............. I87

Lansingburgh .............. 188

Lansingburg Pippin........... 188

Laquier .................. 179

LARGE LAdY ApPle.......... I82

Large Ncwtown Pippin......... I46

Large Rambo............... 273

Large Romanite............. 255

Large Striped Pearmain........ 196

Large Striped Winter Pearmain. 196

Large Winter Red............ 373

Large Yellow Newton Pippin... I46

Large Yellow Newtown Pippin. . 146

La Rue.................... $\sigma_{4}$

Late Baldwin.............. 56

Late Duchess ............. 25

LA VictoIre................ I 88

La Victoria Seedling.......... I 88

LAWver ................ I8, I89

Leanham ............... 227

Leather Apple of Turic......... 264

Lecker ................... I79

Leder .................... $26_{4}$
LeE Sweet.............. I9I

LEHIGH Greening............ 192

Lehigh Greening............ I34

Lexington Queen............ 88

Lille Api................. 181

LILLY OF KENT............ I93

Lily of Kent............... 193

Limber Twig............... 193

Limbertwig ............... 193

LiMBERTWIG (small or red)..... 193

LIMBERTWIG (large or green) .... 194

Lincoln Pippin............. 38I

Lineous Pippin.............. 38

Linnoeus Pippin............ 38

Litsey ................... 108

Little Pearmain.............. 89

Little Red Romanite (synonym of Gilpin)............. 138

Little Red Romanite (synonym of Romanite)............ 289

Little Repka................ 282

Little Seedling............. 282

Livre .................... 206

Lock's Favorite............. 36

Logan's Northern Pippin....... 213

Long Bois................ I8

LoNGFIEED ................. 26

Long Island Pippin.......... I6

Long IsLANd Russet (I)... .I7, I94

Long IsLANd Russet (II) ...... I95

Long Island Seek-No-Further... 130

Long Pippin............... 183

Long Stem of Pennsylvania... 196

Lopside .................. 15.3

Lop-sided Pearmain.......... 153

Lop-side Pearmain............ 153

Louise .................20, 25

LowELL ................ 24

Mabie Sweet .............. 24

McAfee ................... 196

McAfee Red................ 196

McAfee's Nonesuch........... 196

McAfec's Nonsuch ........... 196

McAfee's Red............... 196

McAffee .................. 197

McAffee's Nonesuch.......... 197

McClouds Family............ 127

McLouds Family............ 127 
PAGE.

MicIntosh .........I7, i3, 20, 25

Mackinlay ................. 197

McKinLey ................ I97

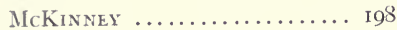

Magenta .................. 198

M.aiden Blush............ I7, I8

MAKEFIELd .............. 3I 2

Mala Carle ................ I99

Malcarle.................. 199

Mal Carle.................. 199

Male Carle................ 199

MALINDA ................. I99

Mamma Beam............... 67

Mamma Bean.............. 67

Mammoth Black Twig (synonym of Arkansas)............ 47

Mammoth Black Taig (synonym of Arkansas Black)..........

Mammoth Black Twig (synonym of Paragon) ............. 247

MAnchester ............... 200

Manks Codling............. 379

MANn ................... 20 I

Marietta Russct............. 293

Marietta Seek-No-Further..... 364

M.ırigold ..................202

Marigold Pippin............. 202

Marle Carle............... 199

Maroquin .................. 264

Martha ................ 3

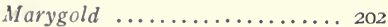

Mason Orange............. 204

Mason's Improved............ 204

Mason's Orange............. 204

Massachusetts Golden Russct.... I64

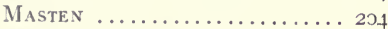

Masten's Secdling............. 204

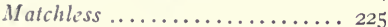

May ................. ${ }_{553}$

May Apple................. I 53

May Seek-No-Farther........... I53

May Seck-No-Further.......... I 53

Mcla Carla................ 199

Mela de Carlo................. I99

Mela di Carlo................ I99

Mela Januera................ 94

Melinda ................. 199

Melon ................. I5, 24, 204

Melon Apple............... 204
PAGE.

Melon de Norton............ 204

Melon, Norton............. 204

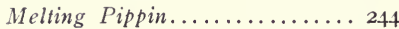

Menage .................. 206

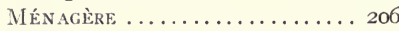

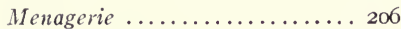

Mere de Menage.............. 206

Merit ................... 88

Merrill ................. 207

Merrill's ................ 207

Merrill's Apple............. 207

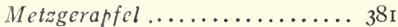

Metzger Calvill................38r

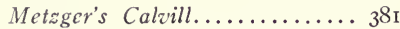

Michel Miller............... I58

Middle ................. 207

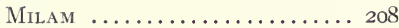

MILDEN .................. 209

Milding .................. 209

Millcreek .......................... 312

Millcreek Vandevere........... 31 2

Miller .................... 158

Milwaukee ..............25, 2 I I

Minister ................ 212

Minister Apple.............. $2 \mathrm{I} 2$

Minkler ............... I8, $2 \mathrm{I} 3$

Missing Link............. 2I

Missouri ................. 215

Missouri Janet...............27 I

Missouri Keeper............. 215

Missouri Orange............. 215

Missouri Pippin............ 18, 215

Missouri Pippin............. 215

Missouri Pippin (synonym of

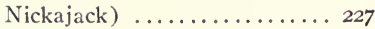

Missouri Red.............. 227

Missouri Superior............ 197

Mittle ................... 207

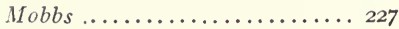

Monmouth ............... 216

Monmouth Pippin............217

Monroe Sweet.............. 24

Moon .................... $2 \mathrm{I} 8$

Moore's Late Sweet........... 219

Moore's Shanty............. 219

Moore's Swect............. 2 I9

Moore's Sweeting............ 219

Moore SweEt ............. 219

Moor's Sweeting............ 219 
PAGE.

Morris Red................. 324

Mother ................. 24

Mountain Pippin (synonym of

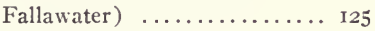

Mountain Pippin............ I46

Moyer .................... 220

Moyer Prise................ 220

Mumper Vandevere.......... $2 \mathrm{I} 3$

Ncisley's Winter............ 255

Neisley's Winter Penick....... 255

NeLson ................... $22 \mathrm{I}$

Nelson Siveet.............. $22 \mathrm{I}$

Ne Plus Ultra................. \$8

Nero ..................... 222

Neustadt's gelber Pepping...... I45

Never Fail................. $27 \mathrm{r}$

Neverfail ................. $2^{\prime} 7 \mathrm{\tau}$

Newark Pippin............. 223

Newark Sweeting............ 91

Newby .................. г г7

New England Golden Russet.... 16.4

New England Russet.......... I64

New England Seeknofurther... 364

New Greening............................

Newman ...............24, 224

Newman Seedling............ 224

Neav Missouri.............. I'

New Rhode Island Greening.... 33I

Newton's Pippin.............. I-16

Newton Spitzemberg.......... 225

Newton Spitzenburgh........ 225

Newton Yellow Pippin......... 146

Newtown Pippin...11, 15, 16, 19, 146

Newtown Spitzemberg........ 225

Newtoz'n Spitzenbergh........ 225

Newtown Spitzenburg...I5, 17, 225

Neztozen Spitzenburgh....... 225

New Water .................226

New York Greening........... 146

New York Pippin (synonym of

Ben Davis)................ 69

New York Pippin............ 146

Nickajack. ............... 227

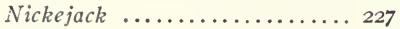

Nodhead .................. 170

Nonesuch (synonym of Red

Canada) .................276
Nonesuch (synonym of Hubbardston ) .............. I6r Nonpareille de Hubbardston.... I6I Nonsuch (synonym of Hubbardston) $\ldots \ldots \ldots \ldots \ldots \ldots \ldots \ldots \ldots$ I6I Nonsuch (synonym of Mc.Afee). 197 Nonsuch (synonym of Red Canada ) .............................. Normanton Wonder........... I12 North Carolina............. 227 Northern Spy..12, I5, 17, IS, 21, 24 37,229

Northern SPY GROUP......... 24

Northwestern Greening....24, 233 Northwestern Grecning....... 233 North West Greening........ 233 Norton's Melon............. 204 Norton Watermelon......... 204

Oaklang ................. 234

Oakland County Seek-No-Further .................. 234

Occident ................24, 235

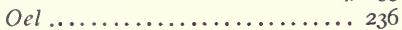

Oel Austin ..............24, 236

Ohio Favorite............. 244

Ohio Nonpareil ............. 98

Oldenburg...........17, 18, 25, 26

OlDENBL RGi GROUP............ 25

Old English Pearmain................... 378

Old Golden Pippin............ I4I

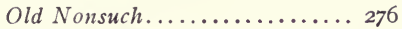

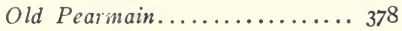

Olive ................... 237

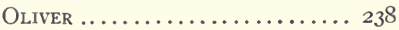

Oliver's Red............... 238

Olympi.t ..............24, 60, 239

Olympia Baldwin........... 239

Ontario ............... 21, 24, 240

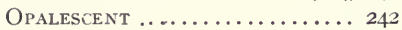

Orange Pippin............. 202

Orleans ................. I6

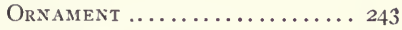

Ornament de Table.......... 243

Ornement de Table........... 243

Ortley .................. 244

Ortley Apple................ 244

Ortley Pippin.............. 244 
Ox-Eye (synonym of Buckingham $\ldots \ldots \ldots \ldots \ldots \ldots \ldots . .68$

$O x$ Eye (synonym of Newtown

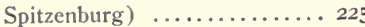

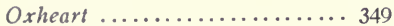

Ozark ................... 135

Palmer ..................... 246

Palmer Greening.............. 36

Palmer of N. Z............. 246

Paradise Winter.............. 380

Paradise Winter Sweet........ 380

Paragon .................24, 246

Paragon (synonym of Arkansas) 47

Pariser Rambour Reinctie...... 94

Park (synonym of McAfee).... I97

Park (synonym of Park Spice). 248

Park Apple................. 248

Parks Keeper............... 197

PARK SPICE ................ 248

PARLIN .................... 248

Parlin's Beauty.............. 248

Parmain d'Angletcre...................... 378

Parmain d'Hiver............. 378

Parmain-Pepping ............ 378

PARSON .................... 249

Parson's Swect.............. 249

Paternoster Apple............ II

Paterson's Swect.............. 54

Patterson's Sivect............ 54

Patterson Sivect.............. 54

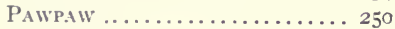

Pawpaw Seedling............. 250

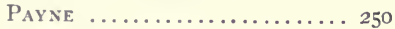

Payne Late Kecper........... 250

Payne's Keeper............. 250

Payton ................... 135

РеAсн ................... 25 I

Peach of Kentucky..........25I

Pearmain ................. 252

Pearmain (synonym of Winter Pearmain) ......................... 378

Pearmain d'Hiver........................ 378

Pearmain Hercfordshire........ 378

Peau ..................... 264

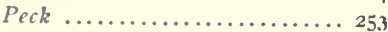

Pecker .................... 56

Pfek Pleasant......... 2, 24, 32, 253

Peck's Pleasant............. 253
PAGE.

Peewaukce.................. 258

Pelican ................... 255

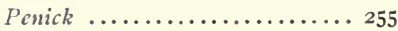

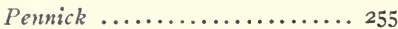

Pennock .................. 255

Pennock's Red Winter......... 255

Pennsyliania Cider............. 31 I

Pennsyliania Red-Streak....... 373

Pennsylvania Red Streak....... 373

Pepin de New-York.......... 69

Pepin d'Or................. I4I

Pepin Parmain d'Angleterre.... 378

Pepin Parmain d'Hiver......... 378

Peremenes ................ 379

Permaine ................. 379

Permein .................... 379

Perry Russet............... 256

Peter ................... 25

Petersburgh Pippin........... 146

Petit Api................. I8

Petit Api Rose.............. I8I

Petit Api Rouge............ I8I

Petit Apis................. I8I

Petite Reinctte Grise.......... 96

Pewaukee ..............25, $25^{8}$

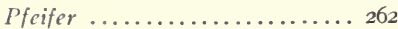

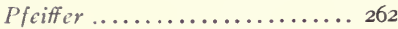

Pfund ..................... 206

Plitip Rick............... 172

Phoenix (synonym of Pennock). 255

Phoenix (synonym of Rome)... 290

Picard ................... 260

Picard's Reserve.............. 260

Pickard ................... 260

Pickard Reserve............ 260

Pickard's Reserve............. 260

PIfER ..................... 262

Pilliken .................. 153

Pim's Beauty of the West...... I25

Pineapple................. 257

Pineapple Russet............. 257

Pine's Beauty of the West...... 125

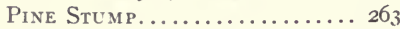

Piper .................... 262

Pippin ................... 263

Pippin (synonym of Newtown

Pippin) .............. 146

Pippin, Bullock............. 89

Pitzer Hill................ 269 
PAGE.

Platarchium 379

Polhemus 219

Pomme d'Api.............. I8r

Pomme d'Api Rouge........... I8I

Pomme d'Apis................ I8I

Pomme de Caen.............. 94

Pomme de Charles............ 199

Pomme de Cuir.............. 264

Pomme de Fer............... 292

Pomme de Laak............... II

Pomme de Transylvania........ 64

Pomme Finale.............. 199

Pomme Gree................. 264

Pomme Gris................. 264

Pomme Grise................ 264

Pomme Grise d'Or........... 328

Pomme Rose................ I8I

Pommeroy ................. I 84

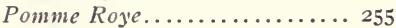

Pomone d'Apis............... I8I

Poplar Bluff................... 3I I

Popular Bluff................ 3I I

Porter .................... I 15

Portugal ..................... 94

Poughkeepsie Russet (synonym

of English Russet)......... I 8

Poughkeepsie Russet (synonym of Perry Russet)......... 257

Pound (synonym of Fallawater). 125

Pound (synonym of Nickajack). 227

Pound Sweet .............. 266

Pound Sweet (synonym of Moore

Sweet) ................219

Prager Reinette Franche de

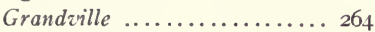

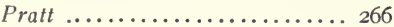

Pratt Sweet............... 266

Pride of Hudson............. 62

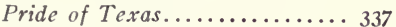

Pride of the Hudson.......... 62

Priestley .................. 267

Priestley's American........... 267

Priestly .................. 267

Prince Albert ............... 268

Prince Albert (Lane)......... 268

Princesse Noble............. 142

Prior's Late Red.............. 269

Prior's Red................ 269
PAGE.

Prolific Beauty ............. I6

Prolific Beauty (synonym of Pennock) ................. 255

Prolific Beauty (synonym of Blue Pearmain) ................ so

Pryor ..................... 269

Pryor Red.................. 269

Pryor's Pearmain............ 269

Pryor's Ked............... 269

Pumpkin Sweet.......... 66, I7, I8

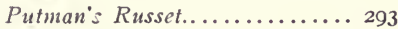

Putnam Russet............. 293

Putnam's Savewell........... 299

Quaker ......................32I

Queen ................... 88

Qucen of Haywood............ I55

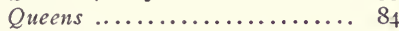

Quince .................. I7

Ralls .............18, 24, 270

RALLS GROUP .............. 24

Rall's Genet.................271

Ralls Janet................271

RАмво ............. I7, IS, 32, 273

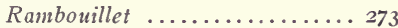

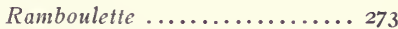

Ramboulrette .............. I09

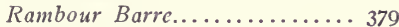

Raule Jannet...............271

Raule's Genet................27I

Raule's Janet.............. $27 \mathrm{I}$

Raule's Janett.............. $27 \mathrm{I}$

Raule's Janette.............. $27 \mathrm{I}$

Raule's Jannet................................

Raule's Jannette..............27I

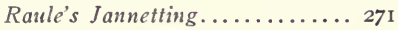

Raule's Jennetting...........27I

Raul's Gennetting............27I

Razule's Genet.............. 27I

Raccle's Janet.............. $27 \mathrm{I}$

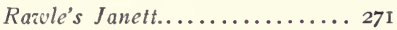

Rawle's Jannet............. $27 \mathrm{I}$

Raicle's Jennet.............. 271

Racile's Jenneting........... 27 I

Rawle's Jennette............. 27I

Razol's Janet............... $27 \mathrm{I}$

Reagan ................. I35

Red Astrachan...I5, I7, I8, 25, 26

Red Baldwin Pippin......... 56 
Red Ben Davis............. I35 Red Canada........5, 24, 37, 275 Red Canada of Ont........... 292

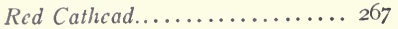
Red Check.............................. 217 Red Cheeked Pippin.......... 217 Red Cheek Pippin............ 217 Red Codlin................. I32 Red Doctor................. I07 Red Eiser.................. I 16 Red Everlasting............. I53

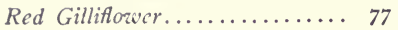
Red Gloria Mundi........... 88 Red Hazcl................... 227 Red Horse................. 88 Red Lady Finger............. I83 Red Limbertwig............. 193 Redling ................. Iо I

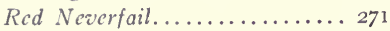

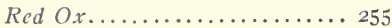
Red Pennock............... 255 Red Pippin (synonym of Ben Davis) Red Pippin (synonym of Nickajack) ............... 227 Red Pippin (synonym of

Streaked Pippin)......... 32 I Red Pound.................. 64 Red Rock................. I89 Red Romanite..............287 Red Romanite of Ohio......... I38 Red Russet................ 278 Red Russet (synonym of Pryor). 269

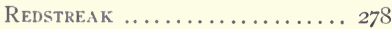
Red Streak................. 278 Red Swect Piptin........... 219 Red Sweet IVinesap............333 Red type of Westfield Seek-No-

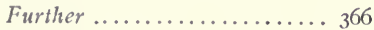

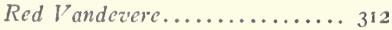

Red Warrior................ 227

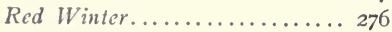

Red Winter Pearmain......... 183

Red Winter Pearmain ......... 279 Red Winter Pearmain (synonym

of Westfield Seek-No-Further) 364 Red Winter Pippin........... I8 3 Red Winter Swect............. 219 Reinette ................. 279
PAGE.

Reinette a feuille d'Acuba..... 52

Reinette Canada............. 94

Reinette Carpentin............ 96

Reinctte de Caen............. 94

Reinette de Canada........... 94

Reinette de Canada a'Cotes...... 94

Reinette de Caux............. II 4

Reinette de Darnetal.......... 264

Reinette de New York......... $\mathrm{I}_{4} 6$

Reinette d'Or............... II4

Reinette Dorée............. II4

Reinette du Canada.......... 94

Reinette du Canada $a^{\prime}$ Cortes.... 94

Reinette du Canada Blanche.... 94

Reinctte Grise............. 264

Reinette Grise Brownlces'...... 86

Reinette Grise de Darnetal..... 264

Reinette Grise Double......... 265

Reinette Grise de Grandville... 265

Reinette Grise d'Hizer........ 265

Reinette Grise Extra......... $26_{5}$

Rcinettc Grise Franchaise...... 264

Reinette Grosse de Angleterre... 94

Reinette Monstreuse de Canada.. 94

Reinette Pepin..............283

Reinette Pippin ............ 280

Reinette toute Grise .......... 265

Reinette Von Canada.......... 94

Reipka Mclenkaya.......... 282

Repka Malenka........... 28 I

Rhode Island.............. 282

Rhode Island Greening...12, 15, 16

I7, I8, I9, 24, 282

RHODE ISIAND Greening GROUP. . 24

Rhode Island Russet......... 257

Rhode Island Seek-No-Further.. I 30

Ribston PipPin ............. I7

Richardson's Red............ 66

Richfield Nonsuch............. 276

Rickmans Red.............. 227

RIDGE .................... 287

Ridged Pippin.............. 287

Ridge Pippin................ 287

Roa Yon................... $8_{4}$

Robinson ................... 316

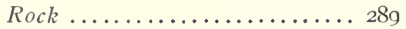

Rock Apple................. I 88

Rock PIIPIN .............. 288

Rock Remain...............27 I 


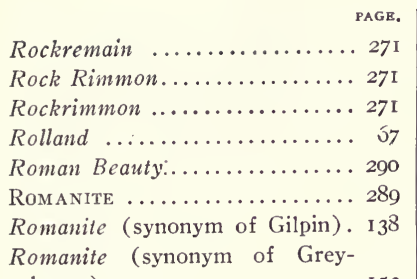
house) $\ldots \ldots \ldots \ldots \ldots \ldots \ldots$ I 53 Romanite (synonym of Pennock) ................ 255 Romanite (synonym of Rambo). 273 Romanite of the South....... 289 Romanite of the West......... 138 Romanite, South............ 289

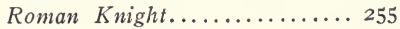
Roman Stem............... I7, 8

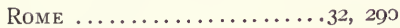
Rome Beauty.............. 290 Roseau .................. 292 Rose-COlored Lady Apple...... I 82

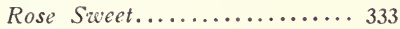
Rosseau ................. 292

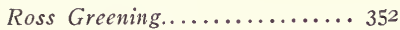
Rother Eiser.............. II6 Rother Eiserapfel............ I 6 Rouge de Pryor............. 269 Rouge Rayée (synonym of Eiser) II6 Rouge Rayée (synonym of Redstreak) 278

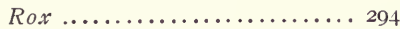
Roxbury.......15, 16, I7, I8, 23, 293 Roxbury Russet............ 293 Roxbury Russeting.......... 293

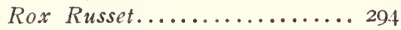
Royal Janette....................... 375 Royal Red of Kentucky........ 375

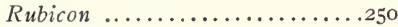

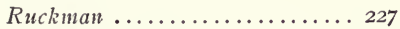

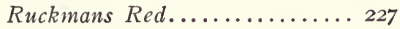

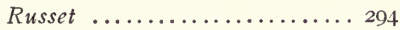
Russet BaLdwin............ 59 Russet, Boston or Roxbury..... 294 Russet, Golden .............. I43 Russet Pearmain............. I64 Russet Scek-No-Further...... 364 Russian Baldwin............ 295 Rutledge ................ 296
St. Heleria Russet........... 94

St. Lawrence ............. I7, 18 SALISBURY ................ 297 Salisbury Pippin............. 297 Salisbury Winter............ 297 SALOME ................24, 297 Savewell ................. 299

Scarlet Beauty............. 24

Scarlet CRanberry............ 299

Scarlet Pippin.............. 25

Schodack .................. 300

Schoolmocker ............... 30 I

Schoonmaker .............. 301

Schwere Apfel, Der.......... 326

ScotT ................... 301

Scott (synonym of Baker)..... 55

Scott's Red Winter........... 302

Scott's Winter............. 302

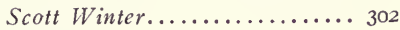

Scribner ........................ 303

Scribner's Spitzenberg......... 303

Scribner's Spitzenburgh....... 303

Scudamore's Crab............278

Scudamous Crab............. 278

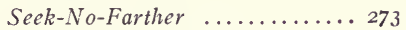

Secknofurther .............. 364

Seek-No-Further (synonym of Rambo) ..................273

Seek-No-Further .............. 303

Seek-No-Further of Delaware,

N. J., and Penn............ 273

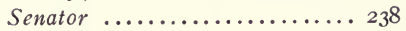

SHACKLEFoRd ........................ 304

Shackleford's Best.......... 304

SHANNON (I) ..................... 305

SHAN Non (II) ........... 306

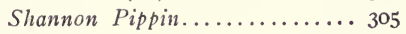

SHEDdAN .................. 306

Sheepnose (synonym of Bullock) 89

Sheepnose (synonym of Lady

Finger) ............... 183

SheEpNose ............... 307

Sheep Shire.............. I3 I

Sheep's Nose.............. 89

Sheep's Snout.............. 89

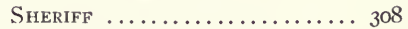

Shiawassee .............. 25

Shippens Russet............ 294

Shirley ................. 308 
Siberian Crab ............. I7

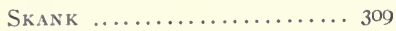

Sklanka ..................... $8_{\mathrm{r}}$

Sklanka Bogdanoff............ 8I

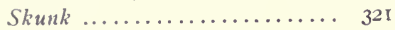

Sleight $\ldots \ldots \ldots \ldots \ldots \ldots \ldots \ldots . \ldots \ldots$ 3IO

Sleight's Lady Apple........... 310

Slight's Lady Apple........... 3І

Smith Cider................ 3 Io

Smith's .................. 3I I

Smith's Cider.............. 3II

SMOKEHOUSE .............. I5, 312

Smoke House.............. 312

Snorter ................. 197

Sol Carter................. 88

Sondergleichen von Hubbardston $16 \mathrm{I}$

Southern Romanite........... 289

Spice SweEt .............. 12

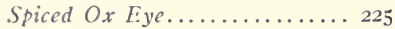

Spitzenberg ............... I2I

Spitzenberg Newtoz'n......... 225

Spitzenburg $\ldots \ldots \ldots \ldots \ldots \ldots . \cdots \cdots \cdot 3 \mathrm{I} 4$

Spitzenburgh (synonym of Eso-

pus Spitzenburg).......... I $2 \mathrm{I}$

Spitzenburgh (synonym of New-

town Spitzenburg).......... 225

Spitzenburgh Newtown....... 225

Spring Pippin............. 314

Springport ................ 314

Springport Pippin........... 314

Spy ..................229, 315

Staalclubs ................ 225

Stanard ................... 3I5

Stanard's Seedling............ 315

Stannard ........................ 315

Stannard's Seedling............. 315

Star Lady Apple............ I 82

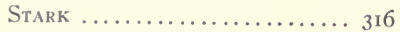

Starke Apple................ $3 \mathrm{I} 6$

Stayman ..................... 318

Stayman's Winesap........... 318

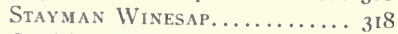

Stecle's Red................ 324

Steele's Red Winter (synonym of Baldwin) ............... 56

Steele's Red Winter (synonym of Red Canada)...

Steele's Red Winter (synonym of Sutton)
Steel's Red.............. 276

Stehly ................... 158

Steklianka Bogdanoff......... 8I

Sterling ............................ 319

Sterling Beauty..........45, 319

Stettin Pippin.............. II4

Stevenson Pippin............ 197

Stine ................... 197

Stone ................24, 320

Stone (synonym of American

Pippin) $\ldots \ldots \ldots \ldots \ldots \ldots \ldots, 45$

Stor Casseler Reinet........... II

Stor Kasselrenett ........... I14

Storr's Wine.............. I97

Stowe ................. $32 \mathrm{I}$

Stowe's Winter............. $32 \mathrm{I}$

Streaked Pippin ........... $32 \mathrm{I}$

Striped Gilliflower........... I6

Striped Pearmain............ 197

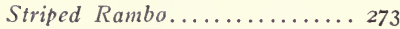

Striped Rhode Island Greening

(synonym of Domine)....... I09

Striped Rhode Island Greening

(synonym of Wells).................. 363

Striped Sweeting ............ 16

Striped Sweet Pippin......... 197

Striped Winter Pearmain....... 197

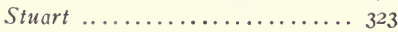

Stuart Golden............. 323

Stuart's Golden.............. 323

Stump, incorrectly........... 323

Sugar Barbel............... 6r

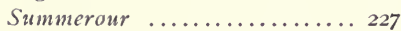

Sum Mer PiPPin ........... II

Sum Mer QueEN ............ I6

Summer RoSe............... 15

Summer Russet.................... 333

Sussex Scarlet Pcarmain....... 379

Sutton ...............32, 324

Sutton Bcauty (synonym of

Dumelow ) ............. II 2

Sutton Beauty (synonym of Sut-

ton) $\ldots \ldots \ldots \ldots \ldots \ldots \ldots \ldots \ldots \ldots \ldots \ldots, 324$

SWAar......... I5, I6, I7, I8, 326

Swaar Apple..................... 326

Swaysie Pomme Grisc......... 328

Swayzie ......................... 328

Swayzie Pomme Grise........ 328

SwazIE .................. 328 
Suarie Pomme Grise........ 328

Swazie's Pomme Gris......... 328

Swazy ................... 328

Swazy Pomme Gris........... 328

Sweet and Squr............ 329

Sweet Greening ........... I5I, 33I

Sweet King .............. 333

Sweet Maiden's Blush......... 91

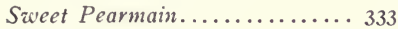

Sweet Pippin...............219

Sweet Rhode Island Greening... 33I

SweEt Russet.............. 333

Sweet Winesap ............ 333

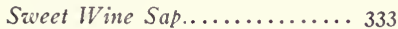

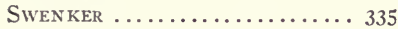

Sylvan Russet.............. 294

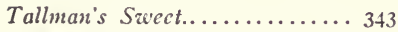

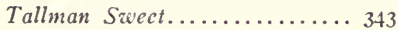

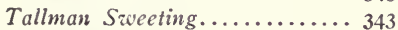

Talman's Swect............. 343

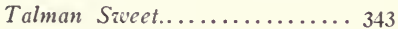

Talman's Sweeting.......... 343

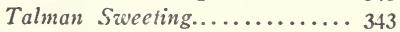

Teller...................... 206

Tenon Hills................. 67

Terry's Redstrcak........... 273

Tetofsky ...............25, 26

Tcwkesbury Blush........... 336

Tewkesbury Winter Blush .... 336

Tewksberry Winter Blush...... 336

Tezoksbcry Winter Blush....... 336

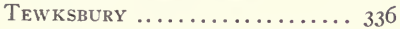

Tewksbury Blush............ 336

Tereksbury Winter Blush...... 336

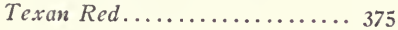

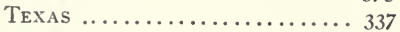

Thomas ................... 208

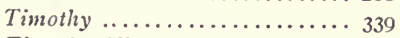

Timothy Titus Sort.......... 339

Titus ..................... 339

Titus (synonym of Titus Pippin) 339

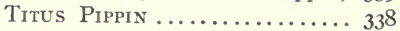

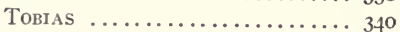

Tobias Apple................. 340

Tobias Black...........................

Tobias Pippin............................... 343

Tolman ..................... 343

Tolman Sweet........16, I7, I8, 343
PAGE.

Tolman Sweet........................ 343

Tolman's Sweeting...................... 343

Tolman Sweeting............. 343

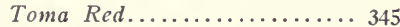

Tommy Red........................ 345

Tompkins County King....... 345

Tompkins King.......17, 18, I9, 345

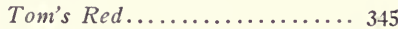

Tom Woodward Pippin........ 244

Treanham ................. 227

Trenham .................. 227

True Spitzenburgh........... I2I

Trumpington .............. 273

Tufts ................... 24

Tulpahocken ............... 125

Tulpehocken .............. I 25

Twenty Ounce ..........17, I8, 193

Twenty Ounce Pippin........ 349

Twitty's Paragon........... 247

Ulster Secdling............ I72

Valandingham ............. 197

Vandervere (synonym of Newtown Spitzenburg)......... 225

Vandervere (synonym of Smokehouse) .................. 312

Vandervere of New York...... 225

VANDEVERE ................ I8

Vandevere (synonym of Newtown Spitzenburg)......... 225

Vandcvere English........... 312

Vandevcre of New York....... 225

Van Dyme................ 244

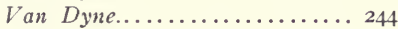

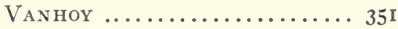

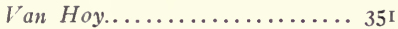

Van Hoy No Core............ 35I

Van Vlect................... I6r

VARICK ...................... 105

Verte de lile de Rhodes........ 283

$V$ erte de Rhode Island........ 283

Vickers .................. 186

VictoIRE, LA............... I 88

Victoria Pippin.............. 69

Victoria Red............... 69

Victoria SWEet .............. 24

Virginia Greening.......... 352 
V'irginia Pippin............ ${ }^{\text {PAGE. }}$ l'irginia Pippin (synonym of Virginia Greening?)....... $35^{2}$

WABASH 353

IVabash Bellflower........... 353

Wabash Red................ 353

Wabash Red Winter.......... 353

WAgENER ...........21, 24, 354

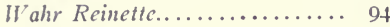

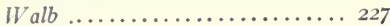

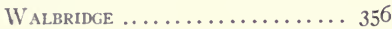

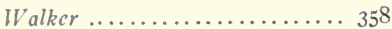

Walker Beauty ............ 358

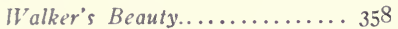

Walker's IVinter............. 358

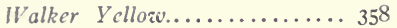

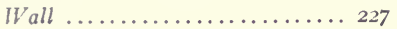

W Allace How ARD............ 359

IVallbridge ............... 357

IValtz Apple................ 253

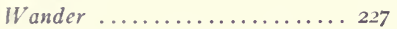

WANDERING SPY.............. 360

Warren Pippin (synonym of Ort-

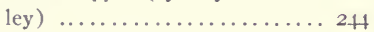

Warren Pippin (synonym of Yel-

low Bellflower) .......... 38r

Washington Royal.......... 36I

I"'atermelon ................ 204

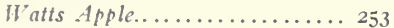

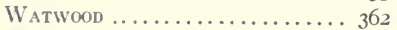

W'axen .................... 67

Waxen Apple................. 67

Wealthy .............17, 19, 25

WEALTHY GROUP............. 25

Weisser. Metzgerapfel.......... 381

Well Apple (synonym of Domine) $\ldots \ldots \ldots \ldots \ldots \ldots \ldots \ldots \ldots \ldots$

Well Apple (synonym of Titus

Pippin) ................................

IV'ellington ............... I 12

W'ellington's Reinette......... I12

IVel.ls .................... 363

Welis (synonym of Domine).... I09

II'ells Afple................ 363

IV csse Antillische Winterreinette 94

IVestchester Seek-No-Further. . I I30

Western Baldain (synonym of Babbitt)
Western Baldwin (synonym of

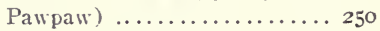

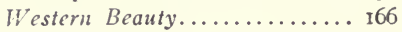

Westield .................. 364

Westfield Seek-No-Farther..... 364

IVEstField Seek-No-Further. .12, 16

I7, $18,32,364$

II estfield Seek-No-Further..... 364

WeSTFIELDSeek-No-Further; Red

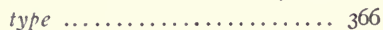

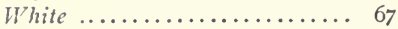

White Apple.............. 67

IVhite Astrachan........... 25

White Bellefteur............. 244

White Bellflower............. 244

White Crow............... 197

White Detroit.............. 244

White Pearmain ............ 367

IVhite Pippin ............24, 368

White Pippin (synonym of Can-

ada Reinette)............ 94

White Pippin (synonym of Ort-

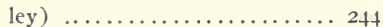

White Robinson..................... 380

Wiite SeEk-No-Further ...... 15

White Winter Pearmain....... 367

IVhite Zurdel............... 387

IVilcor's Winter............. 302

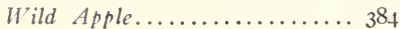

Williamson ............... 109

Willow ................ 370

IVillow Leaf................. 370

Willow Leaf Pippin............ 2.4

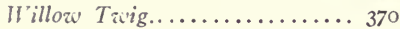

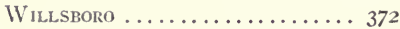

Windsor $\ldots \ldots \ldots \ldots \ldots \ldots \ldots .372$

IVindsor Chief.............. 372

Wine ................ I5, 373

Wine (synonym of Jonathan)... 172

Vine (synonym of Newtown

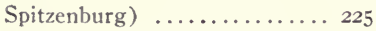

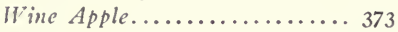

Winesap ...........17, 24, 374

WINESAP GROUP ............. 24

Winesap .................. 172

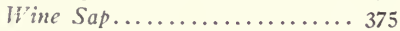

Winesap of Vt............ 292

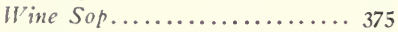

Wine Sweet.............. 380 
Winter BanANA............. 377

Winter Belle Bonne........... 67

Winter Blush (synonym of Fallawater)

Winter Blush (synonym of Rock

Pippin of Eastern New York). 288

Winter Genncting.............271

Winter Hog Island Sweet.... 378

Winter Horse.............................. 227

Winter Jannetting............27 I

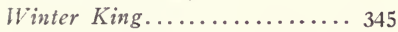

Winter Nonsuch........... 276

Winter Pcach................25

Winter Pearmain (synonym of

McAfee) ................ I97

Winter Pearmain (synonym of

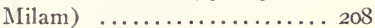

Winter Pearmain .............................. 378

Winter Pippin.............. 197

Winter Pippin of Geneva....... 136

Winter Queen.............. 88

Winter Queening............. 88

Winter Queen of Kentucky..... 88

Winter Rose............... 227

Winter Russet (synonym of

English Russet)........... I 8

Winter Russet (synonym of

Perry Russet)........... 257

Winter St. Lawrence......... 379

Winter Swcet Paradise......... 380

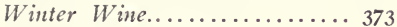

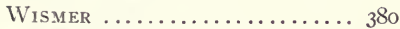

Wismer's Dessert............. 380

Wisner's Dessert........... 380

Wolf River..............20, 25

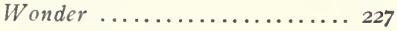

Woodman's Song............. 244
PAGE.

Woodpecker .......................... 56

Woodward's Pippin........... 244

Woolman's Long............ 244

Woolman's Long Pippin........ 244

Woolnary Long ............. 244

World's Wonder............. 227

Wyandotte ............... 196

Yeats ...................... $3 \mathrm{I} 6$

Yellow Bellefleur............. 38

Yellow Bellc Fleur........... 38

Yellow Belleflower........... 381

Yellow Bellflower...I5, 16, I7, I8 I9, 23, 381

Yellow Bellflower group..... 383

YeLLOW Forest.............. 384

Ycllow German Reinette....... I42

YelLow Harvest............. I2

Yellow Janett...............27I

Yellow Janette.............. 27 I

Yellow Newton's Pippin....... 146

Yellow Newtown.....17, I8, 24, I45

I 50,385

Yellow Newtown (synonym of

Canada Reinette)........... 94

Yellow Newtozn Pippin........ I46

Yellow Pippin (synonym of

Newark Pippin).......... 223

$Y$ cllow Pippin (synonym of Ort-

ley) ...................... 24

Yellow Transparent.........17, 25

Yopp's Favorite............18, I46

YoRk IMPERIAL........18, 19, 32, 385

York Pippin.............. 24

Zeeke .................. 197

ZURDEL ....................387 








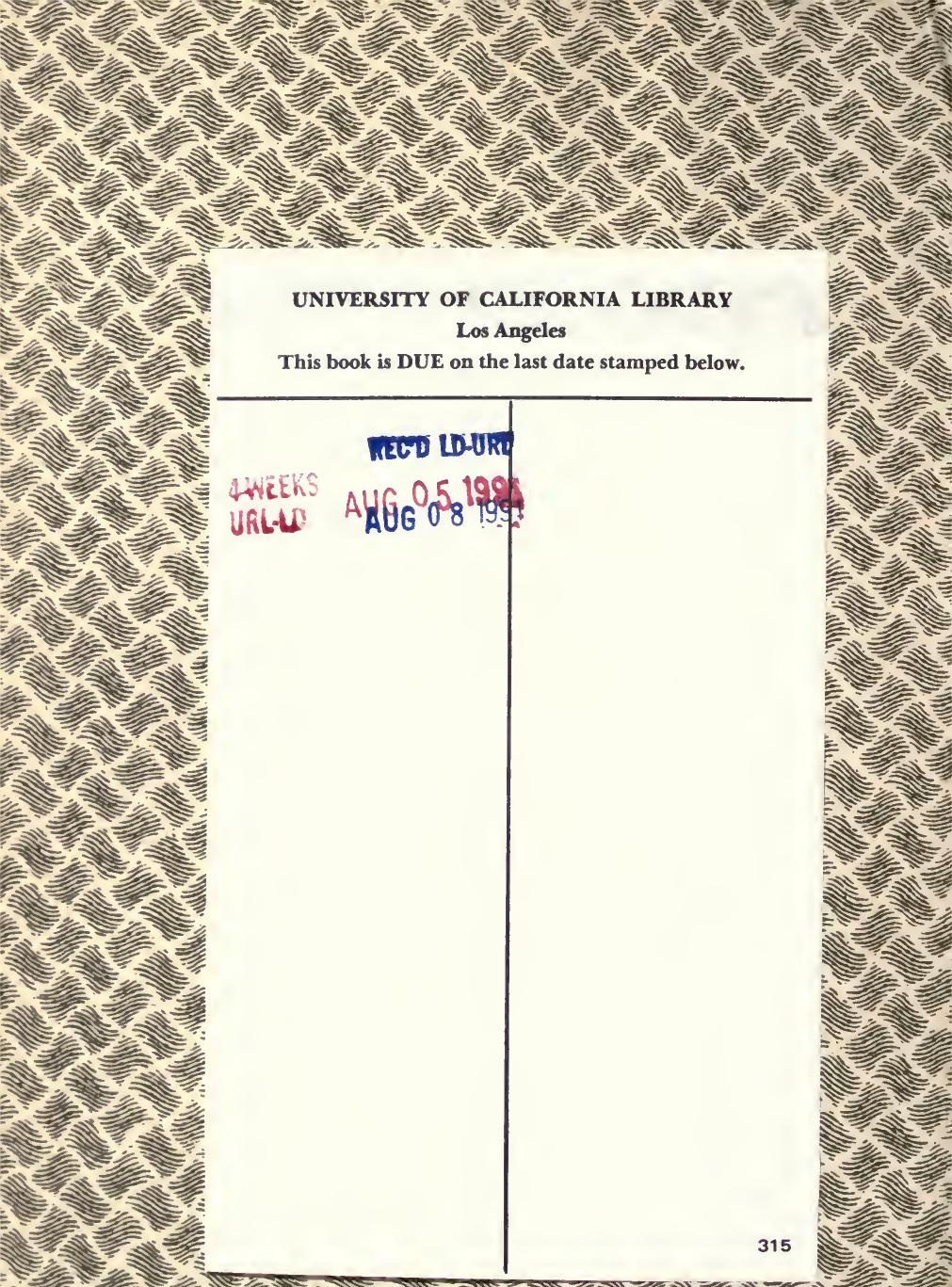





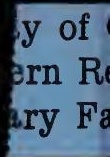

